\title{
CALIDAD DE LA DEMOCRACIA E INSTITUCIONES POLÍTICAS EN BOLIVIA ECUADOR Y PERÚ
}

\author{
Trabajo de Tesis presentado por \\ Simón Pachano
}

\author{
Para la obtención del título de \\ Doctor por la Universidad de Salamanca \\ Departamento de Derecho Público General \\ Área de Ciencia Política y de la Administración \\ Programa de Doctorado en Procesos Políticos Contemporáneos
}


Introducción 
Con el presente estudio pretendo alcanzar tres objetivos. El primero y que organiza al conjunto, es la identificación de los factores que determinan los grados de la calidad de la democracia en países que han vivido procesos recientes de democratización. El segundo objetivo se deriva del primero y apunta a contar con una visión de conjunto de los procesos vividos en Bolivia, Ecuador y Perú desde finales de la década y de 1970 y comienzos de la siguiente, cuanto se instauraron regímenes democráticos en cada uno de ellos. El tercero consiste en un debate conceptual acerca de la calidad de la democracia y de la clasificación de regímenes políticos, teniendo como referencia a los tres países estudiados. Los tres objetivos están estrechamente ligados tanto en términos de los temas que he abordado como en función de los conceptos y las perspectivas teóricas con que los he trabajado. Por ello, en términos generales el estudio puede ser calificado como un ejercicio de política comparada que toma como referencia a -y se inserta en- la teoría de la democracia.

La selección de la calidad de la democracia como problema de investigación responde a dos consideraciones básicas. En primer lugar, a que el mayor riesgo que enfrentan los regimen democráticos surgidos en la tercera ola de democratización no es el retorno a formas de autoritarismo, sino la conformación y permanencia de formas de democracia que se alejan de los estándares mínimos que debe mantener este tipo de régimen. Sin abandonar el campo de las democracias políticas, esos regímenes se transforman en algo diferente a las poliarquías que se esperaba obtener como resultado final. Para hacer frente a estas nuevas condiciones, dentro de la teoría de la democracia se ha desarrollado en los últimos años el análisis de la calidad de la democracia, y es allí donde se inserta este estudio. En segundo lugar, el análisis de la calidad de la democracia es claramente un campo teórico en construcción que se ha desarrollado fundamentalmente como un debate conceptual y no sobre la base del estudio de casos concretos. Ciertamente, los autores que se han ocupado de este tema han aplicado sus propuestas de medición y de evaluación a realidades específicas (generalmente a grandes conjuntos de países), pero solamente una vez que han desarrollado sus instrumentos teóricos y metodológicos. No ha habido el necesario diálogo entre el desarrollo teórico-conceptual y la realidad de uno o varios casos, de manera que se ha producido un divorcio entre ambos niveles y sobre todo se constata la existencia de un gran vacío en el análisis de situaciones concretas. Por ello, este estudio pretende ser un paso en la larga tarea de llenado de ese vacío. 
La selección de los tres países se explica por dos consideraciones básicas. La primera alude a la necesidad propia de las ciencias sociales en general y de la ciencia política en particular, de acudir al método comparativo como vía hacia la explicación y la comprobación. En este caso se ve reforzada esa necesidad por el carácter incipiente del desarrollo de la teoría de la calidad de la democracia y por la escasez de estudios aplicados. La segunda consideración hacer referencia a las característica de los tres países, esto es, a sus similitudes y sus diferencias en términos de procesos y de componentes del régimen y del sistema político, que hacen de ellos casos comparables y contrastables. Las similitudes en muchos de sus aspectos básicos permiten controlar de manera apreciable sus diferencias y por tanto detectar las causas de los procesos ocurridos en cada uno. Por consiguiente, ellos presentan una situación privilegiada para desarrollar un estudio comparativo, en el que es imprescindible controlar algunas variables para explicar los cambios que se manifiestan en otras.

El período analizado corresponde al que ha transcurrido desde la instauración de sus respectivos regímenes democráticos hasta el año 2008. Considerando que Ecuador inauguró su ordenamiento constitucional en 1979, Perú en 1980 y Bolivia en 1982, se puede considerar que se trata de un estudio que abarca las tres últimas décadas. Sin embargo, es necesario hacer dos puntualizaciones al respecto. La primera puede ser calificada como una precisión histórica y conceptual, ya que algunos hechos siembran dudas sobre la calificación de todo el período como democrático. El golpe de estado peruano de 1992, con la consecuente ruptura constitucional, es sin duda el más notorio de esos hechos, pero a este se pueden añadir también los derrocamientos de tres presidentes en Ecuador y uno en Bolivia. La segunda alude a la desigual disponibilidad de información para cada uno de los diversos temas tratados en el estudio. En este punto, la investigación choca con uno de los obstáculos propios de los tres países y de la mayoría de sus pares latinoamericanos, que es la falta de bases de datos y de series históricas sobre diversos aspectos, pero en especial de los temas de la ciencia política. Por ello, en muchos de los aspectos la información cubre solamente una parte pequeña de todo el período señalado. Esto ocurre incluso en aspectos tan básicos como los resultados electorales, que no están disponibles, con el nivel de desagregación necesario, en bases de datos oficiales y confiables, para los últimos años. 
El texto está organizado en cinco capítulos, cada uno de ellos divido en secciones. El primer capítulo trata sobre algunos aspectos teóricos y conceptuales del estudio de la democracia y de la calidad de la democracia. Junto a la revisión conceptual, en éste hago una revisión de los principales problemas que se deben enfrentar en el estudio de la democracia en países como Bolivia, Ecuador y Perú. Allí desarrollo un diálogo entre la realidad de los tres países y los conceptos propios de la teoría de la democracia, como un paso previo necesario para el tratamiento de la calidad de la democracia dentro de situaciones complejas como son las que se observan en los tres países. Una de las preocupaciones centrales de este capítulo es la relación entre la democracia y las diversas formas de ciudadanía, para lo que acudo a la revisión de algunos procesos previos entendidos como antecedentes históricos que marcan las situaciones posteriores. El interés está centrado también en el estado de derecho, entendido como requisito básico e insustituible de la democracia. A su vez, este tema -pero también la necesidad de comprender los múltiples niveles en que se desarrolla la acción política y por consiguiente en que se plasma la democracia- me lleva a realizar una disquisición conceptual sobre el sistema político y el régimen político. Finalmente, destaco la importancia de analizar la heterogeneidad social, cultural y política, vale decir el carácter plural de las sociedades de los tres países, que constituye un reto en la construcción de la democracia y por supuesto un desafío para su estudio.

El segundo capítulo trata sobre los procesos de transición a la democracia. Este se mueve en dos planos diferentes. Por un lado, revisa las características de las transiciones en los tres países, con énfasis en las especificidades de cada uno de ellos. Por otro lado, retoma algunos de los aspectos centrales del debate teórico que se desarrolló en torno al tema y que alimentó de manera importante a la teoría de la democracia. La revisión de estos dos niveles está guiada por la premisa que reconoce el carácter determinante de las transiciones para la evolución de los acontecimientos posteriores. De esta manera, las características de la transición -en términos de actores, instituciones y procesos-, definen un camino por el que se enrumban los países por lo menos hasta que se presente una nueva coyuntura crítica. Así mismo, este capítulo asume el debate sobre la consolidación de la democracia como un elemento básico para el análisis posterior de su calidad.

El tercer capítulo analiza algunos aspectos institucionales del sistema político de los tres países. En este plano sostengo que los diseños institucionales desempeñan un papel 
fundamental tanto para la instauración como para la consolidación de la democracia. Así mismo, a lo largo del capítulo destaco los efectos de los arreglos institucionales en la toma de decisiones así como en la formulación y aplicación de políticas. Los aspectos analizados son las relaciones entre los poderes ejecutivo y legislativo, los sistemas electorales, los sistemas de partidos y la distribución territorial del poder. La selección de estos aspectos institucionales se desprende de su condición de elementos centrales del sistema político y, en virtud de ello, del peso que tienen como condicionantes de las prácticas de los actores políticos. Por último, en este capítulo me permito una digresión acerca de los estudios de los sistemas electorales y los sistemas de partidos en los tres países, vale decir, del estado de la cuestión. Esto se justifica por la necesidad de establecer la base de conocimiento acumulado desde la que parte un estudio de esta naturaleza, pero tiene también un sentido de evaluación de los temas tratados por las ciencias sociales.

En el cuarto capítulo ingreso al tema de la calidas de la democracia. Con este fin, reviso los avances realizados en el ámbito conceptual y destaco su vinculación con los estudios de medición de la democracia y con la literatura que trata sobre los subtipos o formas disminuidas de democracia. Me guío por la consideración de que los tres son campos estrechamente ligados y que, por consiguiente, los avances realizados en cada uno de ellos aportan de uno u otro modo al análisis de las especificidades de las democracias. Mi interés es destacar los diversos aportes que se han hecho y valorar su utilidad para la investigación aplicada. Por ello, intento mantener siempre la relación entre el debate teórico y la situación de los tres países, bajo una modalidad en que éstos constituyen el referente concreto para la prueba y la validación de los conceptos que se han venido desarrollando desde las diversas perspectivas. Con este fin, selecciono a los que considero como los más importantes aportes teóricos acerca de la calidad de la democracia, lo que necesariamente establece un recorte una limitación del estudio. Mi intención en este campo es analizar los diversos componentes de cada uno de los acercamientos que existen al respecto y destacar las bondades y los problemas de su utilización. Mi conclusión general al respecto es que las propuestas de medición de la calidad de la democracia presentan aún muchos vacíos y que por tanto no son instrumentos directamente aplicables en la investigación comparativa.

El capítulo final contiene las conclusiones generales del estudio. Estas básicamente se refieren a tres aspectos fundamentales. Primero, al grado alcanzado por la calidad de la democracia en cada uno de los tres países. Segundo, a la manera en que los elementos 
institucionales han incidido sobre la calidad de la democracia. Tercero, a la posible incidencia de otros factores, como las relaciones particularistas y la presencia de poderosos actores con poder de veto. El elemento central de estas conclusiones es que el análisis de la calidad de la democracia demanda de arreglos metodológicos que incluyan variables operativas (como las institucionales y las que se refieren a los cálculos estratégicos de los actores, que trato en los capítulos previos). Sostengo que las perspectivas teóricas desarrolladas hasta el momento se mueven entre el extremo de un alto grado de generalidad de las dimensiones utilizadas y el extremo de los indicadores con los que se busca su medición o su evaluación. A partir de ello hago una propuesta de incorporación de las variables operativas, tomando como referencia el caso de los países estudiados. De cualquier manera y dado el nivel alcanzado por el desarrollo teórico así como el carácter exploratorio de mi investigación, mis conclusiones no pueden ser sino tentativas e inciertas. 
Agradecimientos 
Este trabajo me deja con una deuda impagable con muchas personas y con varias instituciones

La Facultad Latinoamericana de Ciencias Sociales, FLACSO, Sede Ecuador me dio el espacio académico ideal para el desarrollo intelectual y facilitó mi participación en el Programa Doctoral en que desarrollé el presente estudio. Adrián Bonilla, Director de FLACSO combinó las necesidades institucionales de fortalecimiento de la planta docente con el apoyo personal para una tarea que no dejó de causarle angustias

No pudo haber mejor lugar que los claustros históricos de la Universidad de Salamanca para concretar ese objetivo y para beneficiarme del conocimiento acumulado en una disciplina joven e incipiente en nuestros países. El Área de Ciencia Política y el Instituto de Iberoamérica fueron más que cálidos refugios en los duros inviernos salmantinos

En el desarrollo de la tesis me beneficié del conocimiento y el rigor académico de Manuel Alcántara, Catedrático del Área de Ciencia Política de la Universidad de Salamanca, quien al llevar la tutoría como un diálogo sin distancias y sin jerarquías convirtió en mito la renombrada austeridad castellana. No sería necesario destacar su conocimiento de la realidad latinoamericana y su solidez teórica como no fuera para sostener que este trabajo tendría una mayor cantidad de errores si no hubiera contado con su guía (los que quedan se deben a mi tozudez, que prefiero revestirla elegantemente con la alusión al carácter siempre inacabado del debate intelectual)

El empeño de Flavia Freidenberg se encuentra en el origen de mi participación en el Doctorado. Posiblemente fue la amistad que hemos cultivado a lo largo de interminables y saludables discusiones o su perseverancia en ponerle raíces a la ciencia política ecuatoriana, lo cierto es que me impulsó a algo que no estaba en mi hoja de ruta. Decir que ahora le agradezco no hace justicia al papel que ella ha jugado

Los colegas de FLACSO, Sede Ecuador, saben cuánto me he beneficiado de sus observaciones y sus cuestionamientos a la ortodoxia politológica. Sus reacciones y sugerencias a la presentación de avances parciales de este estudio me obligaron a reconsiderar aspectos que creía resueltos

Andrés Mejía y Francisco Sánchez se han encargado siempre de abrir puertas a los nuevos temas, sin perder la carga de ironía que se requiere para lidiar con una política que lucha por no tomarse en serio a sí misma

Una estadía de un semestre como Visiting Fellow en el Kellogg Institute fue una excelente vía para sondear en el sofisticado campo de la ciencia política norteamericana y para apreciar las diferencias con lo que podemos y debemos hacer en nuestros países. Los diálogos con Scott Mainwaring, Michael Coppedge y Guillermo O’Donnell fueron muy útiles para constatar que los puentes siguen siendo los instrumentos más útiles para unir las orillas

A Tere-María Sol no le puedo agradecer porque este trabajo es también de ella. Juntos hemos caminado en una aventura que nos ha unido, como para desmentir a quienes dicen que la política no lleva a acuerdos 
Capítulo I. Democracia, ciudadanía y estado 


\section{Resumen}

El presente capítulo aborda un conjunto de aspectos teóricos y conceptuales del estudio de la democracia y de la calidad de la democracia. Más que una revisión conceptual, este contiene un acercamiento a los principales problemas que se deben enfrentar cuando se estudian las experiencias concretas de países como Bolivia, Ecuador y Perú. Sus especificidades históricas, sociales, económicas, políticas e incluso culturales obligan a mantener un permanente diálogo entre la realidad y los conceptos propios de la teoría de la democracia. Esta reflexión es necesaria, como requisito indispensable, para el tratamiento de la calidad de la democracia dentro de situaciones de gran complejidad como son las que se observan en los tres países. El capítulo está dividido en seis secciones. La primera analiza la relación entre la democracia y las diversas formas de ciudadanía en constante interacción entre las propuestas conceptuales y la situación histórica de los tras países. La segunda se ocupa del estudio del estado de derecho, entendido como requisito básico e insustituible de la democracia. La tercera contiene un apunte conceptual acerca del sistema político y el régimen político, considerado como un paso necesario para el estudio de la democracia. La cuarta sección precisa el concepto de democracia con miras a su utilización en el análisis comparado. La quinta debate el tema de heterogeneidad social, cultural y política, que constituye un elemento de fundamental importancia para la construcción de la democracia en sociedades plurales como son las de los tres países estudiados. La última sección presenta las conclusiones.

\section{Inclusión, ciudadanía civil, ciudadanía política y ciudadanía social}

En América Latina, y en especial en los países andinos, es inevitable comenzar la reflexión sobre la calidad de la democracia con una alusión a la ciudadanía. El déficit que se aprecia históricamente en este aspecto condiciona de manera determinante las posibilidades de construcción de la democracia y, en consecuencia, determina el grado de ésta o su calidad. El reconocimiento de la ciudadanía plena, en lo civil, en lo político y en lo social es el cimiento que sostiene a la estructura democrática ya que ese reconocimiento expresa la vigencia de los derechos y las libertades que constituyen a la democracia como ordenamiento político ${ }^{1}$. Por ello, cualquier definición de democracia, aún la que pueda tipificarse como mínima y procedimental, toma como punto de partida

\footnotetext{
${ }^{1}$ La importancia de la condición ciudadana para la democracia es un asunto que merece mayor interés que el que ha recibido en el campo de la teoría política. Es más bien escasa su presencia en la reflexión contemporánea sobre la democracia. A manera de ilustración, en la ambiciosa obra de Sartori (1988) no se encuentra un capítulo específico dedicado la ciudadanía y apenas se lo toca de manera implícita al tratar temas como el individualismo y la libertad (Sartori, 1988: 351- 365) o la igualdad (Sartori, 1988: 410-443). Tratamientos explícitos de esta relación, desde la perspectiva de la teoría democrática, se encuentran en Przeworski (1998: 61-68), Nun (2002: 55-70), Zakaria (1998).
} 
a esos derechos y esas libertades ${ }^{2}$. Aunque sea de manera implícita, la ciudadanía está presente en el concepto básico de democracia.

Esta observación tiene mayor sentido cuando se hace referencia a países como Bolivia, Ecuador y Perú, que nacieron a la vida republicana bajo regímenes que no reconocían la condición ciudadana de la mayor parte de la población. Al contrario, constitucional y legalmente se establecieron las exclusiones en lo civil, en lo político y en lo social ${ }^{3}$. La exclusión jurídica de los indígenas -que para ese momento constituían la mayoría de la población en cada uno de los países- de las mujeres, de los iletrados y de los negros, así como de quienes no poseyeran patrimonio propio y que trabajaran en relación de dependencia, fue la base de las repúblicas oligárquicas que tuvieron vigencia por lo menos hasta mediados del siglo XX. La persistencia de un ordenamiento excluyente a lo largo de la mayor parte de la historia de estos países dio firmeza a opiniones que sostenían (si bien es cierto refiriéndose al caso peruano, pero que podrían ser extendidas a los otros) que "no ha existido un corte histórico desde el siglo XVI que haya significado un momento nuevo y diferente en su formación social" (Cotler, 1978:15, cursiva en el original $)^{4}$. En síntesis, los vacíos en el reconocimiento de la ciudadanía universal, en

\footnotetext{
${ }^{2}$ Definiciones como la de Schumpeter (1996), convertida en paradigma de las definiciones mínimas y procedimentales, se asientan en un conjunto de libertades, garantías y derechos que ponen en cuestión ese carácter mínimo. Como lo explica Lipset (1980: 41), después de haberse acogido a esa definición, ésta "implica cierto número de condiciones específicas: 1) una «fórmula política» o cuerpo de creencias que especifican qué instituciones - partidos políticos, una prensa libre, etc.- son legítimas (aceptadas por todos como adecuadas); 2) un conjunto de líderes políticos en funciones, y 3) uno o más conjuntos de líderes reconocidos que intentan obtener cargos". A lo largo de este capítulo desarrollaré este argumento que, como se verá tiene enorme incidencia no solamente en la construcción del concepto de democracia sino sobre todo en el análisis de su calidad.

${ }^{3}$ Las constituciones con que iniciaron su vida como estados independientes establecían requisitos muy rígidos (y en todas ellas muy similares) para acceder a los derechos de ciudadanía. La constitución boliviana del año 1826 (artículo 14) determinaba que se requería ser boliviano (es decir, haber nacido en territorio de ese país), ser casado o mayor de 20 años, saber leer y escribir y tener algún empleo, industria o profesar alguna ciencia o arte, sin sujeción a otro en clase de sirviente doméstico. La ecuatoriana de 1830 (artículo 12) reconocía como ciudadanos a los casados o mayores de 22 años, o a quienes tuvieran una propiedad raíz de determinado monto, o que ejercieran alguna profesión o industria útil sin sujeción a otro como sirviente doméstico o jornalero y que supieran leer y escribir. La de Perú de 1826 tenía como requisitos ser peruano, estar casado o ser mayor de 25 años, saber leer y escribir, tener algún empleo o industria o profesar alguna ciencia o arte sin sujeción a otro en clase de sirviente doméstico. Como se verá más adelante, varias de estas condiciones claramente limitantes se mantuvieron hasta mediados del siglo XX.

${ }^{4}$ Una visión ensayística sobre el mismo caso peruano destaca la condición de multitud -y no de ciudadanía- de la sociedad en la participación política (Basadre, 1980: 113 y siguientes). La ausencia del concepto de ciudadanía a lo largo de todo ese texto es una expresión de la inexistencia de esa condición en términos políticos y jurídicos, y no se la puede atribuir únicamente a la perspectiva analítica del autor. Véase también Klarén (2008: 255-297)
} 
todos sus niveles -civil, político y social-, obligan a tomar a este como el punto de partida del análisis.

La conformación de esos regímenes excluyentes obedeció a muchas causas, la mayor parte de ellas vigentes desde la sociedad colonial, que no cabe abordar aquí 5 . Interesa comprender los efectos jurídicos y políticos del reconocimiento limitado de la ciudadanía. A pesar de que constitucionalmente se estableció la igualdad ante la ley, en el mismo cuerpo constitucional se la dejó prácticamente sin efecto cuando se establecieron los requisitos para el ejercicio de la ciudadanía. Como se vio antes, ella estaba condicionada a la situación económica, el estado civil, la situación laboral y el grado de instrucción. Lo sorprendente es que esas condiciones se aplicaban no solamente a la ciudadanía política, como podría suponerse en el marco de un régimen de sufragio limitado, sino que se hacían extensivas también a la ciudadanía civil (y obviamente a la social, que ni siquiera se planteaba como posibilidad ${ }^{6}$. Por consiguiente, no sólo se restringía el régimen democrático, sino que se hacía lo mismo con el estado de derecho, ya que el reconocimiento como sujeto de derechos beneficiaba solamente a una minoría.

En este punto es necesario hacer una doble digresión conceptual: sobre el concepto de ciudadanía, por un lado, y sobre la relación entre la democracia y el estado de derecho, por otro lado. En el primer aspecto cabe retomar la división clásica de las tres formas de ciudadanía, civil, política y social, propuesta originalmente por Marshall (2007), para entender los diversos niveles en que se materializa el reconocimiento del individuo como sujeto de derechos. En esta perspectiva, la ciudadanía civil "se compone de los derechos necesarios para la libertad individual: libertad de la persona, de expresión, de pensamiento y religión, derecho a la propiedad y a establecer contratos válidos y derecho

${ }^{5}$ De la abundante literatura al respecto cabe destacar el enfoque de Todorov (1987: 158-159), que indaga sobre los orígenes de la concepción excluyente y la manera en que ésta condicionó el marco legal que se fue construyendo a lo largo del período colonial.

${ }^{6}$ Un minucioso análisis para el caso ecuatoriano se encuentra en Prieto (2004). A través de una disección de "los discursos políticos, científicos y periodísticos sobre los sujetos indígenas" (Prieto, 2004: 30), la autora ofrece una visión de conjunto de las condiciones reales de la ciudadanía desde fines del siglo XIX hasta mediados del siglo XX. Puede ser discutible, sin dejar de ser sugerente, la atribución del origen de la exclusión a una contradicción entre los deseos de igualdad jurídica de las élites y su profundo miedo social. "La suspicacia entre ese sector de la sociedad y las imágenes de una raza peculiar e inferior confluyen en (...) el 'liberalismo del temor'. Más aún, (...) el liberalismo del siglo veinte temprano en el Ecuador construyó un complejo de gobernabilidad que pospuso los derechos ciudadanos para los indígenas" (Prieto, 2004: 31). Este aplazamiento de los derechos parece haberse mantenido hasta mediados del siglo, cuando era fácil comprobar que las leyes vigentes obligaban a que la población "blanca" votara, mientras impedían que lo hicieran los "indios, cholos, montubios y negros” (Blanksten, 1951: 74). 
a la justicia (...) Las instituciones directamente relacionadas con los derechos civiles son los tribunales de justicia" (Marshall, 2007: 22-23). La ciudadanía política es "el derecho a participar en el ejercicio del poder político como miembro de un cuerpo investido de autoridad política, o como elector de sus miembros. Las instituciones correspondientes son el parlamento y las juntas del gobierno local" (Marshall, 2007: 23) ${ }^{7}$. La ciudadanía "social abarca todo el espectro, desde el derecho a la seguridad y a un mínimo bienestar económico al de compartir plenamente la herencia social y vivir la vida de un ser civilizado conforme a los estándares predominantes en la sociedad. Las instituciones directamente relacionadas son, en este caso, el sistema educativo y los servicios sociales" (Marshall, 2007: 23).

Como es ampliamente conocido, Marshall sugirió un desarrollo cronológico acumulativo de estos derechos, que se habrían ido definiendo en Europa (o, con mayor precisión, en el Reino Unido) a lo largo de los siglos XVIII, XIX y XX. Independientemente de que el reconocimiento de los derechos correspondientes no hubiera ocurrido dentro de esa secuencia, en la que cada tipo de ciudadanía se habría desarrollado en el orden mencionado, lo que importa aquí es la especificidad de cada uno de ellos y sus respectivos requisitos institucionales ${ }^{8}$. En este sentido, la ciudadanía civil se expresa en el estado de derecho, esto es, en el complejo entramado institucional que asegura la igualdad ante la ley, vale decir en el reconocimiento del individuo como un sujeto de derechos básicos ${ }^{9}$. Por su parte, la ciudadanía política se expresa en la democracia, entendida básicamente como el reconocimiento del individuo como sujeto de los derechos políticos de elegir y ser elegido. Finalmente, la ciudadanía social se expresa en el

\footnotetext{
${ }^{7}$ La omisión del órgano ejecutivo deja ver el sesgo británico en la propuesta de Marshall. Este constituye un espacio institucional de enorme importancia para el ejercicio pleno de la ciudadanía política en regímenes presidenciales como son los de los tres países analizados.

${ }^{8}$ Marshall advierte sobre los riesgos y las imprecisiones de esta cronología cuando sostiene que al "asignar a cada uno de los períodos formativos de los tres elementos de la ciudadanía a un siglo distinto (...) se solapaban de modo considerable los dos últimos" (Marshall, 2007: 31). Antes ya había dicho que hay "que tratar estos períodos con una razonable elasticidad, y hay cierto solapamiento evidente" (Marshall, 2007: 26).

${ }^{9}$ El tratamiento del estado de derecho podría llevarnos por los caminos de la filosofía política o de la doctrina jurídica, lo que significaría abandonar el campo de la ciencia política que es en el que pretendo moverme. Además, considero que no es necesario adentrarse en esos campos para sostener la argumentación sobre el reconocimiento de los derechos fundamentales y su relación con la democracia. Diversos acercamientos a este tema, desde la perspectiva de la ciencia política se encuentran en O'Donnell (1999; 2002), Diamond y Morlino (2005: xiv). Textos de mucha influencia en la filosofía del derecho y la ciencia política, en este tema, son los de Hamilton, Jay y Madison (1937: 47-62), Rawls (1996: 23-46) Bobbio (1987: 106 y siguientes; 1989: 17-20) y Arendt (2004: 188245).
} 
estado social de derecho o, con mayor precisión, en el estado de bienestar, que garantiza el reconocimiento del individuo como sujeto de los derechos sociales.

Con estos elementos cabe retornar a la realidad de los tres países, no solamente en el momento de su nacimiento como estados independientes, que he tomado como referencia inicial, sino a lo largo de su historia. Lo que interesa en este aspecto es identificar los cambios que se produjeron en términos del pleno reconocimiento de los derechos de ciudadanía en sus tres manifestaciones. Una primera constatación en este sentido es que, en términos de la formalidad jurídica, estos solamente se materializaron con la apertura de los actuales procesos democráticos, es decir, a fines de la década de los setenta y comienzos de la década de los ochenta del siglo XX. La eliminación de las exclusiones marcaron el quiebre con una larga historia de más de ciento cincuenta años. Si bien es cierto que paulatinamente se habían reducido e incluso eliminado los requisitos que hacían referencia a la condición económica, al estado civil y a la situación laboral, hasta ese momento se había mantenido el del grado de alfabetización ${ }^{10}$.

Una segunda constatación es la que alude al predominio de la ciudadanía política sobre las otras dos formas, y de manera especial sobre la civil. Dentro del ordenamiento constitucional y legal de cada uno de los países se reconocían los derechos de ciudadanía (bajo sus formas civil y política) para el conjunto de la población. Para esto se acudía a la fórmula de igualdad ante la ley y al reconocimiento del derecho a elegir y ser elegido, que invariablemente ocupaban un lugar de importancia en las disposiciones constitucionales. Sin embargo, como se vio antes, los requisitos que se establecían para "entrar en el goce" de esos derechos - como rezaban las constituciones- los limitaban significativamente. Las condiciones que se establecían para el ejercicio de los derechos políticos, esto es, para elegir y ser elegidos, se hacían extensivas a la esfera de los derechos civiles, comenzando por el acceso a la justicia y por la libertad de trabajo y contratación. La historia de los tres

\footnotetext{
${ }^{10}$ Como hitos del final de las repúblicas oligárquicas - con toda la dificultad que supone establecer fechas precisas para los procesos históricos- podrían colocarse a la Revolución Nacional de 1952 en Bolivia, el gobierno militar de Velasco Alvarado en Perú (1968-1975) y el gobierno militar de Rodríguez Lara en Ecuador (1972-1976). Sin embargo, en cada uno de los países se fueron eliminando paulatinamente algunas de las exclusiones sobre todo desde finales del siglo XIX y comienzos del XX (cuando en todos ellos se produjeron las revoluciones liberales), lo que obliga a mirarlo más bien como un proceso de largo plazo en el que se produjeron avances graduales, pero en el que también hubo retrocesos significativos en determinados momentos (especialmente bajo los gobiernos dictatoriales). Para una profundización en este tema, dentro de los procesos de transición a la democracia, véase el capítulo II.
} 
países a lo largo del siglo XX es rica en análisis y testimonios de esta situación ${ }^{11}$. Adicionalmente, a esta exclusión jurídica explícita se añadía la que se realizaba en la vida cotidiana, expresada bajo múltiples formas de discriminación que se constituyeron en prácticas rutinarias aceptadas por el conjunto de la población ${ }^{12}$. Las limitaciones establecidas para el ejercicio de la ciudadanía política se generalizaron a todo el ámbito de la condición ciudadana, lo que constituyó un obstáculo muy grande para la instauración no solamente de regímenes democráticos sino también de estados de derecho.

Esto nos conduce al segundo aspecto de la digresión conceptual, esto es, la relación entre la democracia y el estado de derecho. Este es un campo de fundamental importancia en el estudio de países como Bolivia, Ecuador y Perú, en los que las dificultades para establecer la primera se derivan en gran medida -junto a otros factores, por cierto- de la debilidad del último. La ausencia de un marco sólidamente definido de libertades, derechos y garantías es un factor que pesa decisivamente a la hora de constituir un régimen democrático ${ }^{13}$. Sin la igualdad jurídica que se expresa en el estado de derecho es absolutamente imposible instaurar un ordenamiento político que se asienta sobre la participación popular en la construcción del poder. La condición básica e insustituible para que esa participación sea efectiva y no solamente una ficción es precisamente la igualdad de condiciones en el plano de los derechos y las libertades civiles ${ }^{14}$. Eso fue

11 Véase, a manera ejemplo, Mariátegui (1975) Quintero y Silva (1990), Basadre (1980), Klarén (2008), Demélas (2003) Lavaud (1998), Linke (1962).

${ }^{12}$ La literatura -la novela, el cuento, la poesía- e incluso buena parte de las canciones populares de los tres países constituyen buenos referentes de la importancia de la marginación y de su percepción. Corrientes como el indigenismo, el costumbrismo y la novelística urbana indagaron en este campo con posibilidades que muchas veces le están negadas a la visión académica especializada. Al respecto véase Cueva (1969), Vich (2003), Ibarra (1992a; 1992b), Almaraz (1981). Por otra parte, la utilización de manera generalizada en los tres países del término indio como insulto o como peyorativo es una expresión de los contenidos más profundos de la discriminación y de la exclusión.

${ }^{13}$ Es relativamente escasa la producción académica sobre la relación entre democracia y estado de derecho. Aunque esa relación -O, cabría decir, ese condicionamiento mutuo- aparece implícitamente incluso en las definiciones mínimas o procedimentales de democracia (Schumpeter, 1996; Dahl, 1989; 1991), solamente en pocas ocasiones aparece de manera explícita (Linz, 1998; Linz y Stepan, 1996; O`Donnell, 2002; 1999). La condición actual de los regímenes democráticos como democracias liberales ha hecho perder hasta cierto punto las especificidades de ambos términos así como su particular trayectoria histórica (Bobbio, 1989: 45-48; 1997: 123-138). Los problemas que enfrentan las democracias latinoamericanas en el nivel de los derechos y las libertades ha actuado como incentivo para retomar el estudio del estado de derecho y sobre todo para reconocer su importancia en la construcción del régimen democrático (O`Donnell, 2002; Méndez, 2002). Un desarrollo de este tema se encuentra en la tercera sección del presente capítulo.

${ }^{14}$ Este rasgo fue destacado tempranamente por Tocqueville en el primer análisis empírico de una democracia (que a la vez, como todo estudio de esa naturaleza, permitió aportar elementos conceptuales y teóricos aún más allá de lo que seguramente pretendió el propio autor). Es ilustrativo al respecto su planteamiento acerca de la incidencia de la ley de sucesión sobre la igualdad, considerada esta última como la condición básica de la democracia en el plano político: "Es cierto que 
precisamente lo que no estuvo presente a lo largo de la historia de estos tres países, tanto por el efecto de las leyes e incluso de las disposiciones constitucionales como por otras formas de exclusión más sutiles pero no por ello menos dramáticas y efectivas en esa dirección.

Lo que interesa en este aspecto, por el momento, es indagar en las causas que llevaron a la instauración de regímenes que se asentaban sobre la ciudadanía limitada o de baja intensidad (Torres Rivas, 1991), no solamente en el nivel político -que es hasta cierto punto comprensible si se considera la casi total inexistencia de desarrollo de las ideas democráticas a nivel mundial en el momento en que ocurre la independencia de estos países y en general a lo largo del siglo XIX- sino en el ámbito civil. Una explicación puede encontrarse en la herencia histórica, tanto colonial como precolonial, especialmente en lo que se refiere a la organización de la economía y, dentro de ésta, a las formas de control y explotación de la mano de obra (fundamentalmente indígena). Por consiguiente, en términos generales se puede atribuir el mayor peso a los factores estructurales -económicos y sociales- que se expresan principalmente en la propiedad de la tierra y en las relaciones laborales (Quintero y Silva, 1990). La inexistencia de una ruptura clara con esa situación en el proceso independentista ha sido destacada no solo como una característica de los tres países sino también de la mayor parte del resto de América Latina (Halperin, 1970; Demélas, 2003; Klarén, 2008; Guerra, 1994; Cueva, 1988; Cotler, 1978). Esa ruptura debió esperar largo tiempo y, como he señalado antes, se fue produciendo por oleadas, especialmente a lo largo del siglo XX. Las revoluciones liberales (de fines del siglos XIX y comienzos del XX), los procesos de construcción de un entramado institucional -o modernización- del estado (entre las décadas de 1920 y de 1930) y las reformas agrarias (entre los cincuentas y comienzos de los setentas) son los hitos que marcaron esa trayectoria y que desplazan el análisis al tema de la construcción del estado nacional en cada uno de los países.

estas leyes pertenecen al orden civil, pero deberían estar situadas a la cabeza de todas las instituciones políticas, ya que influyen de un modo increíble en el estado social de los pueblos, del que las leyes políticas no son sino la expresión" (Tocqueville, 1985: T. 1, 48). Lo mismo se puede decir de las disposiciones legales que garantizan los derechos básicos, el acceso a la justicia, o la propiedad, entre otros. Véase también Arendt (2004: 225-229) y Kecskemeti (1994: 258) 
La construcción del estado nacional es un proceso que exige, en cualquier circunstancia, resolver el problema de la soberanía tanto hacia afuera como hacia adentro ${ }^{15}$. Hacia afuera, en el sentido de que debía insertarse en el mundo como un ente político que contara con las condiciones apropiadas para obtener el reconocimiento de la comunidad internacional. Hacia adentro, en tanto era necesario institucionalizar la autoridad estatal en términos políticos, jurídicos, económicos e incluso simbólicos. En la primera dimensión se debía materializar la soberanía del estado frente a sus pares en el contexto internacional, bajo lo que algunos autores denominan la externalización del poder (Oszlak, 1978: 12). En la segunda dimensión se requería definir la fuente última de la legitimidad del estado como instancia política que detenta el monopolio de la fuerza (Weber, 1972: 83; Tilly, 1992: 149-150; Skinner, 2003: 57) ${ }^{16}$. Después de alrededor de una década y media de luchas por la independencia y de la crisis de la metrópoli española, la dimensión externa no resultaba problemática (Halperin, 1970; Santana y Pérez, 1979). El problema fundamental se encontraba en la dimensión interna, donde se debía establecer la autoridad estatal $-\mathrm{o}$, dicho de otra manera, constituir el estado como único portador legítimo de la autoridad política-, por un lado, y definir el sujeto de la soberanía, por otro lado. La fórmula para lograr esos dos objetivos era una sola y se encontraba en el gobierno representativo, ya que por medio de este se podía identificar al pueblo o a la nación como el sujeto de la soberanía ${ }^{17}$. En el mismo acto y con el mismo instrumento

${ }^{15}$ El estudio de la construcción del estado nacional tuvo importancia en el pensamiento social y político latinoamericano hasta la década de los setenta del siglo XX. Preocupaciones generalizadas entre historiadores, sociólogos y juristas (todos ellos incursionando en el campo de lo político) fueron, por un lado, las especificidades de la formación de los estados nacionales latinoamericanos y, por otro lado, el carácter inacabado de ese proceso en la mayor parte de esos países (Lechner, 1988; Oszlak, 1978; Portantiero, 1984a; Cardoso, 1984; Cotler, 1978; Calderón, 1982). Posteriormente, como etapa final de este interés por el tema, se abrió un campo de estudio diferente con la implantación de las dictaduras en los países del Cono Sur, que se manifestó sobre todo en el tratamiento del denominado Estado burocrático autoritario (O`Donnell, 1979; Portantiero 1984b). La instauración de regímenes democráticos llevó la atención hacia otros temas (gobernabilidad, partidos políticos, relaciones entre poderes, órganos legislativos, gobiernos locales, etc.), lo que puede interpretarse como una expresión de la superación de la cuestión estatal.

16 Todo ello marca un paralelismo con el proceso que se desarrollaba en buena parte de los países europeos en ese momento dentro del proceso de sustitución de las monarquías absolutistas (Renan, 2000; Guerra, 1994: 40; Anderson, 2007; Hobsbawn, 1991), y no estaba exento de sus influencias así como de las que venían desde la reciente experiencia norteamericana (Dietrich, 1945).

${ }^{17} \mathrm{Al}$ parecer, históricamente en los tres países se tomaron como sinónimos para este efecto al pueblo y a la nación. En las constituciones se atribuye indistintamente la soberanía a cualquiera de ellos, como si fueran términos intercambiables. Así, las constituciones bolivianas de 1831, 1834, 1839, 1851,1861, 1868 y 1878 reconocen a la nación como la depositaria de la soberanía, en tanto que las de 1826, 1843, 1938, 1945, 1947 y 1967 reconocen al pueblo como el sujeto. En Ecuador la asignan a la nación las constituciones de 1843, 1851, 1869, 1878, 1884, 1897, 1906 y 1946, mientras que se la atribuyen al pueblo las de 1845, 1852, 1861, 1929, 1945, 1967, 1978 y 1998 (la de 1830, la primera de su historia, no contiene una definición al respecto). En Perú se asigna la soberanía a la nación en las constituciones de 1823, 1828, 1856, 1860, 1867 y 1920, en tanto que se la atribuye al pueblo en las 
era posible atribuirle al estado el carácter de resultado de una construcción social -su condición de producto de un contrato de sujeción, como sostenía el contractualismo- que era la condición imprescindible para su legitimación Sin embargo, el requisito básico para que esa fórmula arrojara los resultados esperados era la materialización de sus postulados básicos, esto es, su establecimiento en la realidad concreta. Se requería, por tanto, algo más que las disposiciones que se incluyeron indefectiblemente en sus respectivas constituciones. En otras palabras, dado que el gran obstáculo eran los factores mencionados antes $-\mathrm{y}$ sin que esto signifique caer en el determinismo estructural-, se puede sostener que era imprescindible que se produjera un cambio de estos para lograr avances en el plano de la construcción estatal ${ }^{18}$.

Si se toman como atributos mínimos del estado a la externalización de su poder, la capacidad de ejercer su control en todo el territorio nacional, la consolidación de su autoridad, la materialización en un entramado institucional dotado de efectividad para el cumplimento de sus funciones y la capacidad de convertirse en el elemento en que se materializa el sentimiento de pertenencia a la nación (Oszlak, 1978: 13), se puede concluir que en los tres países apenas se dieron pasos mínimos en cada uno de esos campos a lo largo de más de un siglo y medio ${ }^{19}$. Como sostuve antes, los estados pudieron

constituciones de 1826, 1933, 1979 y 1993 (mientras las de 1834 y 1839 no contienen una disposición al respecto). Por consiguiente, en los tres países no hay una secuencia histórica que pueda explicar el paso de una a otra concepción, lo que puede ser un indicador de la escasa importancia atribuida a la diferencia entre ambos conceptos o, más bien, de una cierta identidad entre ellos. Se puede suponer que la construcción de una nación equivalía a -o dependía de- la construcción de un pueblo, como ocurría en ese mismo momento en Europa (Renan, 2000). El pueblo o la nación, indistintamente, respondían adecuadamente a la pregunta básica de la comunidad imaginada que formula Anderson (2007: 89): ¿Por qué estamos aquí juntos?

${ }_{18}$ Un elemento de importancia para comprender las carencias de este proceso es la ausencia, en su fase inicial, de un proceso histórico de acumulación de demandas y reivindicaciones de libertades y derechos (en otras palabras, de construcción de ciudadanía) y el consecuente paso raudo y sorpresivo desde el régimen absolutista a uno que debía asentarse en la soberanía popular. El desencadenante de este paso no fue un elemento endógeno a esas sociedades tradicionales sino un hecho externo (incluso en términos geográficos), como fue la invasión de Napoleón a España. Esta fue "rechazada por la inmensa mayoría de los españoles e hispanoamericanos en nombre de valores que, en lo esencial, son los de una sociedad tradicional" (Guerra, 1994: 43). En el breve lapso de dos años (entre 1808 y 1810), "a causa de la desaparición del rey y para manifestar el rechazo al usurpador, la resistencia española y la lealtad americana solo podían recurrir a la soberanía de la nación, del reino, del pueblo, para legitimar su accionar" (Guerra, 1994: 44, las cursivas son mías). "Las juntas [de gobierno constituidas en los países latinoamericanos como reacción ante la invasión napoleónica] justificaron, pues, su existencia fundándose en el derecho natural (que autoriza a defenderse a toda comunidad atacada), y en los derechos antiguos del reino, nacidos de la relación pactista que fijaba los vínculos entre el rey y la nación" (Demélas, 2003: 132, cursiva en el original). Es, claramente, un proceso que no se asienta en sólidas bases históricas, lo que marcará indeleblemente su futuro.

19 Tilly (1992: 149-150) destaca las siguientes como actividades mínimas del estado: a) construir el estado (en el sentido de "atacar y vigilar a rivales y contrarios dentro del territorio reclamado por el 
tempranamente externalizar su poder, sin que ello signifique que no existieran retrocesos o incluso grandes vacíos ${ }^{20}$. El control de todo el territorio nacional y la construcción de un entramado institucional dejan aún en el momento actual un saldo deficitario si se toma como indicadores a la implantación de instituciones estatales que puedan encargarse efectivamente de la administración, la presencia del poder judicial en todas las circunscripciones administrativas, la existencia de infraestructura vial y de comunicaciones y la disponibilidad de servicios de educación, salud y de seguridad ciudadana. Se puede afirmar, por tanto, que persisten las zonas marrones, para utilizar la adecuada figura de O`Donnell (1993: 71). La consolidación del estado como elemento simbólico al que confluyen los sentimientos de pertenencia colectiva encontró también, e incluso encuentra hasta el momento actual, serias deficiencias ${ }^{21}$. En síntesis, la construcción del estado nacional ha sido un proceso azaroso, lleno de dificultades y aún inacabado.

A partir de esta constatación se abre otro campo de análisis, muy amplio y complejo, ya que es innegable que existe alguna relación entre este proceso y el de instauración del estado de derecho. Se trata de un tema que, precisamente por su amplitud y complejidad, exigiría abandonar el objeto central de esta sección y obligaría a desarrollar una reflexión teórica y conceptual diferente a la que se requiere para comprender los problemas de la ciudadanía en los tres países. Para evitar eso, basta con señalar que estado nacional y estado de derecho no son términos intercambiables, pero que existe una relación evidente entre los respectivos procesos de constitución. Se puede afirmar que la existencia de un estado nacional es un factor de enorme importancia para la instauración de un estado

Estado"; b) hacer la guerra (“atacar a los rivales fuera del territorio ya exigido por el Estado”); c) protección ("atacar y vigilar a los enemigos principales del gobernante, tanto fuera como dentro del territorio reclamado por el estado"); d) extracción ("extraer de la población subordinada los medios para construir el Estado, hacer la guerra y proteger"); e) arbitraje ("dirimir con autoridad las disputas entre los miembros de la población subordinada"; f) distribución ("intervención en el reparto de bienes entre los miembros de la población subordinada"); g) producción ("control de la creación y transformación de bienes y servicios entre los miembros de la población subordinada")

${ }^{20}$ Uno de esos vacíos se encuentra en la definición de los límites nacionales que, a pesar de ser un paso sustancial para la externalización del poder, fue un proceso inacabado en los tres países casi hasta fines del siglo XX. Perú y Bolivia definieron sus límites en 1842, después de una breve guerra. En la Guerra del Pacífico (1879-1884), en contra de Chile, Perú perdió parte de su territorio costero y Bolivia todo su litoral. Como consecuencia de la Guerra del Chaco (1932-1935) contra Paraguay, Bolivia perdió parte de su territorio oriental. Anteriormente, bajo la presidencia de Melgarejo (18641871), este país había cedido territorios a Brasil y Chile. Ecuador fijó sus límites con Colombia en 1904 y con Perú en 1998 (con este último país después de enfrentamientos bélicos en 1941, 1981 y 1995).

${ }^{21}$ Como se verá con detenimiento en los capítulos III y V, el estado nacional es cuestionado desde las reivindicaciones autonomistas y étnicas, especialmente en Bolivia y Ecuador. 
de derecho y que a la vez este retroalimenta a aquel en tanto los derechos y las garantías generan demandas de mayor presencia estatal efectiva. En ese sentido, el elemento clave viene a ser la correspondencia entre ambos procesos a lo largo de un determinado período, aunque posteriormente puedan seguir caminos divergentes ${ }^{22}$. Precisamente la ausencia de paralelismo y de contemporaneidad entre ambos procesos en el desarrollo histórico de Bolivia, Ecuador y Perú es uno de los elementos que explican las carencias y vacíos tanto en lo que se refiere al estado nacional como al estado de derecho.

En consecuencia, sin un estado nacional plenamente constituido y con un estado de derecho que no lograba superar la dimensión de algunas disposiciones constitucionales de carácter general, era prácticamente imposible que la ciudadanía pudiera tener vigencia en sus tres dimensiones básicas. Teniendo presente esta restricción cabe volver sobre el eje central de esta sección, esto es, sobre las posibilidades de construcción de regímenes democráticos en los tres países. Para ello es necesario reiterar, en primer lugar, que las restricciones a la ciudadanía civil establecieron una situación de exclusión de la mayor parte de la población en términos de protección de sus derechos básicos y de sus libertades, especialmente en lo que se refiere a la libertad de trabajo, al acceso a la justicia y al trato igualitario en los asuntos públicos. En segundo lugar, en el plano de la ciudadanía social apenas se dieron algunos pasos de importancia desde la tercera década del siglo XX, cuando en los tres países se sentaron las bases de los servicios públicos de educación, salud y seguridad social. Sin embargo, fue necesario esperar hasta finales del siglo para poder asegurar que se estaban logrando las metas de la universalización de estos servicios y la implantación de otros (como los de seguridad ciudadana), aunque siempre en niveles incipientes e insatisfactorios. En tercer lugar, y de manera hasta cierto punto diferente de -e incluso contraria a- las otras dos formas, la ciudadanía política

\footnotetext{
${ }^{22}$ Es importante subrayar la importancia de la simultaneidad de los procesos de formación ya que después de constituidos pueden seguir caminos diferentes. En efecto, un régimen autoritario puede instaurarse en un país que logró previamente constituir aceptablemente un estado de derecho sin que ello afecte al estado nacional, como ocurrió en Chile y Uruguay. En sentido contrario, con el transcurso del tiempo puede entrar en crisis el estado nacional sin que eso signifique la destrucción del estado de derecho, como ocurrió en la antigua Checoslovaquia (que en cuanto instauró su estado de derecho dio fin al estado nacional previamente existente). Por otra parte, es preciso destacar que "El término Estado nacional, lamentablemente, no por fuerza significa nación-estado, un Estado cuyos pobladores comparten una fuerte identidad lingüística, religiosa y simbólica" (Tilly, 1992: 21, cursiva en el original). Esto es muy importante en el análisis de las sociedades plurales o heterogéneas, que desplazan la reflexión al plano de los estados plurinacionales (que será tratado en la quinta sección de este capítulo y en los capítulos IV y V). La situación española de la actualidad puede ser ilustrativa en este sentido, ya que la reivindicación nacional-autonomista pone en cuestión a la nación-estado sin que ello afecte al estado nacional y al estado de derecho.
} 
convocó de mayor manera al debate público. La propia necesidad de legitimar al estado por medio de de su transformación en la expresión de la voluntad del pueblo o de la nación, obligaba a buscar los recursos y los procedimientos por los cuales pudiera hacerse efectiva esa condición. El tema de la representación se colocaba, de esta manera, en el centro de la preocupación de las elites políticas, aún por encima de sus propias convicciones que más bien se movían -y seguirían moviéndose durante largo tiempodentro de "una lógica patricia”(Guerra, 1994: 50) ${ }^{23}$.

La representación, esto es, la necesidad de dotarle al estado de la legitimidad popular debía realizarse en un medio adverso, caracterizado por las restricciones de las libertades civiles, por un lado, y por los temores a la acción directa de los sectores populares, por otro lado. De esta manera, esa legitimidad tenía pocas posibilidades de concretarse ya que al no caminar decididamente en la constitución de la ciudadanía, tanto civil como política, se hacía imposible contar con el sujeto que debía encarnar la soberanía a la que se aludía en los textos constitucionales. Al contrario de lo que ocurrió en otros países del continente -como Chile, Uruguay, Costa Rica y en menor medida Argentina-, pero de manera similar a lo que sucedió en la mayor parte de los restantes -especialmente de los centroamericanos-, en estos tres se cerró sistemáticamente el paso a la constitución plena de la ciudadanía. La igualdad ante la ley y el derecho a participar en la conformación del poder político fueron largamente postergados, e incluso no se puede decir que en la actualidad se los haya establecido plenamente ${ }^{24}$. De esta manera se dibujaba un círculo, ya que los vacíos en el proceso de construcción del estado nacional impedían avanzar en la

${ }^{23}$ Esta contradicción se hizo evidente en un momento tan temprano como es el Congreso de Angostura de 1819, cuando Simón Bolívar, el icono de la independencia americana, después de sostener que "solo la democracia (...) es susceptible de una absoluta libertad", advertía que "Poniendo restricciones justas y prudentes en las asambleas primarias y electorales, ponemos el primer dique a la licencia popular, evitando la concurrencia tumultuaria y ciega que en todos tiempos ha imprimido el desacierto en las elecciones y ha ligado por consiguiente, el desacierto a los Magistrados y a la marcha del Gobierno; pues este acto primordial es el acto generativo de la libertad o de la esclavitud de un pueblo" (www.ensayistas.org/antologia/XIXA/bolivar/bolivar2.htm); una versión algo diferente en la forma se encuentra en Dietrich (1945: 154). Fue una posición que mantuvo una vez lograda la independencia, cuando en 1824 propuso la presidencia vitalicia para el Perú y para Bolivia (Demélas, 2003: 320). Esta concepción restrictiva se expresó en la constitución grancolombiana de 1821, que en su artículo 10 señala que "El pueblo no ejercerá por sí mismo otras atribuciones de la soberanía que la de las elecciones primarias", unas elecciones que, por cierto, se realizaban bajo las restricciones señaladas antes. Manin (1998: 166) asegura que "el debate americano [se refiere a Norteamérica, SP] de 1878 fue, entonces la última ocasión en la que se consideró la posible presencia de rasgos aristocráticos en sistemas apoyados en elecciones libres de la elección". De acuerdo a las palabras de Bolívar y por lo señalado antes, no fue la última vez y más bien los sudamericanos -seguidores en buena medida de la revolución norteamericana- retomaron esa concepción.

${ }^{24}$ En la última sección de este capítulo trato con mayor detenimiento la situación actual de la ciudadanía en su forma civil, destacando su incidencia sobre la construcción de la democracia. 
constitución de la ciudadanía, a la vez que el carácter incipiente de ésta se transformaba en un obstáculo para aquel proceso.

En estas condiciones, resultó muy difícil -e incluso imposible por un largo tiempoestablecer regímenes democráticos. Las deficiencias en la configuración plena de la ciudadanía -expresadas sobre todo en las limitaciones de las libertades y los derechos básicos y en las restricciones al sufragio- se encontraban en la base de los regímenes que se conformaron en estos países a lo largo del siglo XX y que, aun cuando se asumiera un estándar retrospectivo, difícilmente podrían ser caracterizados como incluyentes y capaces de reconocer la condición ciudadana de todos los habitantes de cada país, mucho menos como democráticos $^{25}$. El reconocimiento parcial o limitado de la condición ciudadana fue el obstáculo central para que se pudieran sentar las bases de futuros regímenes democráticos. Desde esta perspectiva es posible afirmar que el fracaso de los reiterados intentos por establecer regímenes democráticos encuentra buena parte de su explicación en la ausencia de un proceso histórico de construcción de ciudadanía, con todo lo que ello implica ${ }^{26}$.

\section{Estado de derecho, condiciones y rendimientos de la democracia}

La reflexión sobre los problemas de construcción de la ciudadanía en los tres países, desarrollada en la sección anterior, tenía como objetivo abrir paso al debate sobre el concepto de democracia. Mi interés, como señalé inicialmente, no es repetir el largo recorrido por los textos de diversos autores, que ha sido hecho innumerables veces. Sin

\footnotetext{
${ }^{25}$ La necesidad de situarse en los estándares propios de cada período (la utilización de un estándar retrospectivo) para el análisis de la democracia ha sido propuesto por Mainwaring, Brinks y Pérez-Liñán (2001: 40) como una forma de evitar el anacronismo que se deriva de la aplicación de criterios contemporáneos a épocas anteriores. Los beneficios de este recurso, pero también la posibilidad de desembocar en el relativismo conceptual con su utilización, serán discutidos en la última sección de este capítulo.

${ }^{26} \mathrm{La}$ alusión a los antecedentes históricos se justifica plenamente ya que determinados hechos inciden de manera decisiva y determinante en todo el proceso posterior (lo que ha sido eficientemente desarrollado por la perspectiva de path dependence). En este sentido, tiene mucho sustento una suposición acerca de la influencia de la coyuntura crítica de la independencia sobre el proceso de definición del tipo de régimen en cada uno de los países. Como se ha señalado, para ese momento "La adopción del sistema democrático y republicano chocó con tres tipos de obstáculos: en el Perú, los partidarios de una monarquía moderada seguían siendo numerosos y gozaban del favor del Protector San Martín; tres años más tarde Bolívar, proclamado dictador mientras durase la guerra, pensó en establecer el principio de la presidencia vitalicia en Bolivia y en el Perú; en fin, en los tres estados [Bolivia, Ecuador y Perú, SP], los mismos republicanos se atemorizaban ante los riesgos acarreados por la adopción del régimen democrático" (Demélas, 2003: 315). Como lo han destacado varios autores, este temor no varió significativamente por lo menos a lo largo de los primeros cien años de la república (Prieto, 2004; Cotler, 1978; 1988; Lavaud, 1998; Demélas, 2003).
} 
negar la validez de un esfuerzo de esa naturaleza, considero conveniente restringir ese paso inevitable al mínimo posible y más bien hacer un ejercicio de enfrentamiento del concepto con la realidad de los países estudiados. Con este fin, es necesario trabajar en el ámbito del estado de derecho y de las libertades -abierto en la sección anterior-, en el campo de los requisitos sociales, económicos, culturales y políticos de la democracia y, finalmente, en el de los resultados de la democracia. Son tres campos de análisis diferentes, pero estrechamente ligados e incluso complementarios, que serán desarrollados en la presente sección.

Con este fin, es necesario tomar como punto de partida o como premisa básica a lo señalado en la sección anterior, en el sentido de que al colocar a las libertades individuales como elemento central del concepto de democracia se le da a este una dimensión que no tiene cuando se trabaja tanto con los conceptos mínimos como con los que incluyen aspectos sustantivos (como la igualdad social, la superación de la pobreza, entre otros $)^{27}$. Esto porque al estar esas libertades garantizadas por el estado de derecho - esto es, por un conjunto armónico de normas, disposiciones y procedimientosse alude no solamente a la plena vigencia de las garantías individuales, sino también al imperio de la ley. En ese sentido, al hacer referencia al estado de derecho se alude a la protección de los individuos como sujetos de derechos y libertades, pero también al gobierno de la ley por encima del gobierno de los hombres (Bobbio, 1985: 195-221). A su vez, como se ha visto en la sección anterior, el sometimiento del conjunto de la sociedad a la ley es el elemento básico de legitimación del orden político ${ }^{28}$.

$\mathrm{Al}$ tomar este punto de partida me alejo en alguna medida de la lógica expositiva de la mayor parte de los estudios al respecto, que toman como núcleo del concepto de

\footnotetext{
${ }^{27}$ Sobre las características de las definiciones mínimas, que pueden llegar a convertirse en subminimas y los riesgos que se desprenden de su utilización, véase Mainwaring, Brinks y Pérez-Liñán (2001). Ejemplos de estas definiciones se encuentran en Przeworski, cuando sostiene que "La democracia es un sistema en el cual algunos partidos pierden las elecciones" (1995: 14) y en Lipset, cuando afirma que la "democracia (en una sociedad compleja) es definida como un sistema político que da oportunidades constitucionales para el cambio de las autoridades gubernamentales" (1959: 71). Sin embargo, sería un error reducir a esas dos citas la construcción teórica que cada uno de esos autores hace sobre la democracia, ya que en sus respectivos trabajos se encuentra un tratamiento bastante más complejo al respecto.

${ }^{28}$ Una de las mejores aproximaciones a esas dos dimensiones del estado de derecho se encuentra en los Federalist Papers. Sus autores identifican a la protección de los derechos individuales y el gobierno de las leyes como los objetivos centrales del nuevo orden político. Las diferencias que ellos encuentran con la democracia clásica -que explican su negativa a calificar como democrático al régimen que en ese momento se creaba- radican no solamente en las que se derivan de las dimensiones de la sociedad como lo enfatizan en varias partes (Hamilton, Madison y Jay, 2000: 32-35), sino sobre todo en este aspecto del cual carecía la democracia griega (Hamilton, Madison y Jay, 2000: $33)$.
} 
democracia a los aspectos propios del régimen político y del sistema político ${ }^{29}$. Considero pertinente hacerlo de esta forma con el fin de comprender de mejor manera los problemas que encontraron los tres países en la construcción de ordenamientos democráticos, pero también por el peso que tiene el estado de derecho en la definición de este tipo de régimen. Como trataré de sustentar en esta sección, la competencia política, la dimensión de los derechos de sufragio, los procedimientos políticos, la capacidad de los gobernantes para ejercer sus funciones y la facultad de la ciudadanía para tomar cuentas a los mandatarios, entre otros elementos que han sido señalados como constitutivos del concepto de democracia, están necesaria e inevitablemente precedidos por la instauración del estado de derecho, esto es, por un régimen basado en el imperio de la ley ${ }^{30}$.

Una breve revisión de los conceptos de democracia permite comprobar esa afirmación. Así, la definición acuñada por Schumpeter en la década de 1940, que ha sido considerada como el arquetipo del concepto mínimo, no deja de apelar aunque sea implícitamente a la existencia del estado de derecho. En efecto, a la definición de democracia como un "sistema institucional, para llegar a las decisiones políticas, en el que los individuos adquieren el poder de decidir por medio de una lucha de competencia por el voto del pueblo" (Schumpeter, 1996: 343), antepone como condición que esta es posible por "la libre competencia por el voto libre" (Schumpeter, 1996: 345), que a su vez remite a la estrecha relación que debe existir "entre la democracia y la libertad individual" (Schumpeter, 1996: 346) ${ }^{31}$. Por consiguiente, el núcleo del concepto -la competencia por

${ }^{29} \mathrm{La}$ crítica a las perspectivas procedimentales ha destacado esa limitación del concepto a los componentes del régimen político y especialmente del sistema político, pero buscando exclusivamente añadir los aspectos sustantivos a la definición. Son excepcionales las críticas que llaman la atención sobre la necesidad de incluir al estado de derecho en la definición (O`Donnell, 2007; 2002; Bobbio, 1985). En la tercera sección del presente capítulo se encuentra un tratamiento de los conceptos de régimen y sistema político.

${ }^{30} \mathrm{La}$ alusión a la precedencia del estado de derecho debe ser entendida fundamentalmente en términos del orden jerárquico conceptual debido a que la democracia es imposible sin aquel orden jurídico. Pero también debe entenderse esa expresión en su sentido temporal ya que el establecimiento de las libertades y de los derechos es una condición indispensable para la instauración de un régimen democrático. Esto, que hasta cierto punto se ha perdido de vista porque cada vez atribuimos menor importancia al proceso histórico que condujo hasta las democracias existentes en el mundo, es sin duda un elemento que no puede ser soslayado en el análisis de países como los aquí tratados. Aportes como los de Moore (1973), Rueschemeyer, Huber y Stephens (1992), Held (2001) y Sartori (1988, especialmente el tomo II), que buscan situar a la democracia en una perspectiva histórica, requieren ser continuados a la luz de lo que se ha avanzado en este aspecto en el desarrollo conceptual sobre la democracia.

${ }^{31}$ Evidentemente, la traducción que he utilizado es defectuosa. En O`Donnell (2007: 25) se encuentra una traducción más adecuada, que establece que el método democrático es "el arreglo institucional 
el voto- no se agota en sí mismo o, dicho de otra manera, resulta insuficiente para denotar a la democracia, ya que remite obligadamente a un conjunto de condiciones sin las cuales aquella competencia sería insustancial. Esas condiciones -la libre competencia por el voto libre y, como requisito previo, la libertad individual- forman parte del concepto en tanto son propiedades o características indispensables para su identificación. Son propiedades de definición, no son propiedades variables, bipotéticas ${ }^{32}$. Las libertades y los derechos básicos constituyen un sine qua non de este concepto mínimo de democracia.

Algo similar se encuentra en el concepto de poliarquía de Dahl (1989; 1991), que puede ser considerado como una definición de la democracia en el plano estrictamente político. Pero, más allá de ese carácter restrictivo que se puede derivar de la definición de las poliarquías como "regímenes relativamente (pero no completamente) democráticos (...) sistemas sustancialmente liberalizados y popularizados, es decir, muy representativos a la vez que abiertos al debate público" (Dahl, 1989: 18), lo que importa son los requisitos que ellos deben tener para ser calificados de esa manera. Esos requisitos apuntan básicamente a las libertades y los derechos de los ciudadanos no solamente en el plano político sino también en el civil. En efecto, las condiciones que debe cumplir un régimen para que los ciudadanos puedan "formular las preferencias", "manifestar las preferencias" y "recibir igualdad de trato por parte del gobierno en la ponderación de las preferencias" (Dahl, 1989: 14), son las libertades y los derechos básicos de: a) asociación, b) expresión, c) voto, d) elegibilidad para el servicio público, e) competencia por el apoyo político, f) acceso a diversas fuentes de información, g) elecciones libres e imparciales, h) políticas derivadas de la voluntad popular (Dahl, 1989: 15) ${ }^{33}$. Se puede observar que, a pesar de girar en torno a las preferencias - esto es, a un elemento estrictamente políticoel eje central de este planteamiento no está constituido exclusivamente por los procedimientos políticos, sino por las libertades civiles y políticas que constituyen los

para arribar a decisiones políticas mediante el cual los individuos adquieren el poder de decisión mediante la lucha competitiva por sus votos"

32 Me acojo al concepto de definición mínima de Sartori (1992: 86), que señala que "Una definición es mínima cuando todas las propiedades o las características de una entidad que no son indispensables para su identificación se exponen como propiedades variables, hipotéticas, no como propiedades de definición. Esto equivale a decir que todo lo que cae fuera de una caracterización mínima queda para la verificación, que no se lo declara cierto por definición".

33 Posteriormente, Dahl reformuló en alguna medida este planteamiento cuando redujo a siete los requisitos: a) funcionarios electos, b) elecciones libres e imparciales, c) sufragio inclusivo, d) derecho a ocupar cargos públicos, e) libertad de expresión, f) variedad de fuentes de información, g) autonomía asociativa (1991: 268). Sin embargo, el núcleo se mantuvo en los mismos términos. Cabe destacar que, a pesar de la alusión a los funcionarios electos, a las elecciones libres y al sufragio inclusivo, en Dahl está ausente la competencia política que constituye el eje del concepto en Schumpeter. 
requisitos que "deben estar presentes para que sea posible clasificar a un régimen como poliárquico" (Dahl, 1991: 266) ${ }^{34}$. Por ello, una de las dos dimensiones teóricas de la democratización -junto a la participación- es la liberalización (Dahl, 1989: 14), que alude precisamente a la existencia de un marco de libertades y derechos como condición de la poliarquía $^{35}$.

En síntesis, es imposible pensar en la democracia contemporánea sin un estado de derecho, a la vez que no se puede concebir a éste fuera de un régimen democrático. Sin embargo, la relación entre ambos términos no es necesariamente armónica ni ha existido un desarrollo histórico conjunto de ellos. Solamente en los últimos tiempos (podría decirse desde la segunda posguerra) ambos han caminado conjuntamente, pero no siempre con la armonía que supone la afirmación sobre su relación recíproca. Más bien, siempre han existido tensiones, que se desprenden de las características específicas de cada uno de ellos y que pueden ser comprendidas cuando se observan sus respectivos procesos históricos y sus contenidos.

En este sentido, cabe señalar que los caminos seguidos por el estado de derecho y por la democracia fueron independientes e incluso no estuvieron exentos de roces y confrontaciones. Básicamente, como se lo ha señalado acertadamente, el estado de derecho busca limitar al poder, en tanto que la democracia busca repartirlo o distribuirlo (Bobbio, 1989: 8) ${ }^{36}$. La democracia, en su versión originaria, fue la expresión de la

${ }^{34}$ En términos históricos, el mismo Dahl (1991: 21-34) señala que la primera gran transformación democrática, consistió precisamente en la instauración de "sistemas en los cuales una cantidad sustancial de varones adultos libres tenían derecho a participar directamente, en calidad de ciudadanos, en el gobierno. Esta experiencia, y las ideas a ella asociadas, dieron origen a la visión de un nuevo sistema político en que un pueblo soberano no sólo estaba habilitado a autogobernarse sino que poseía todos los recursos e instituciones necesarios para ello" (Dahl, 1991: 21). El elemento central de esa nueva organización política de la sociedad fue, por tanto, el reconocimiento de lo que más adelante se conocería como los derechos de ciudadanía, aunque inicialmente estuvieran restringidos a los de carácter político. Esa evolución desde la concepción limitada marca la trayectoria de la democracia hasta su versión contemporánea, de manera que se justifica detenerse en ella.

${ }^{35}$ Es verdad que Dahl trata la liberalización como un atributo fundamentalmente político ya que destaca su forma de debate público (Dahl, 1989: 18), lo que se deriva de la diferencia que establece entre democracia y poliarquía o, dicho de otra manera, de la condición de esta última como democracia política. Sin embargo, esa concepción restrictiva se amplía cuando considera las secuencias históricas que llevan a regímenes democráticos (Dahl, 1989: 41-53).

${ }^{36} \mathrm{El}$ eje divisor entre la concepción liberal del estado de derecho y la de democracia consiste en que "con respecto a los diversos significados posibles de igualdad, el liberalismo y la democracia no coinciden, lo que entre otras cosas explica sus contraposición histórica durante un largo período" (Bobbio, 1989: 45). La igualdad propulsada por el liberalismo (estado de derecho) es la de carácter jurídico que coloca a todos los individuos en similares condiciones ante la ley, sobre la base del reconocimiento de sus derechos fundamentales, en tanto que la igualdad democrática es la que 
igualdad política de los ciudadanos, lo que necesaria e inevitablemente debía expresarse en la distribución del poder entre todos ellos. Dada la reducida magnitud de la sociedad ateniense en la que nació, esa distribución no presentaba mayores problemas ya que podía realizarse directamente, esto es, por medio de la participación directa de todos los ciudadanos en la definición de los asuntos políticos (Manin, 1998: 19-58; Sartori, 1988: 345-351; Held, 2001: 29-54). Sin embargo, en tanto las sociedades incrementaron su tamaño y se tornaron mucho más complejas en términos de sus relaciones sociales y de las actividades que se desarrollan en su interior, se fue haciendo cada vez más difícil mantener aquella forma de distribución directa (Sartori, 1999). No era posible que el conjunto de ciudadanos se hiciera cargo directamente de los asuntos políticos, pero no por ello podía la democracia renunciar a esa característica fundamental que es la distribución del poder. La representación fue el procedimiento utilizado, lo que significó ciertamente un cambio radical en las formas y en los procedimientos de la democracia, pero no constituyó una alteración de su esencia en el aspecto mencionado. No podía ser de otra manera, ya que la distribución del poder no es sino la expresión de la igualdad ciudadana o, para decirlo en el lenguaje utilizado en las páginas anteriores, es la condición básica para hacer efectivo el ejercicio de la ciudadanía política. Sin esa condición simplemente no puede existir democracia, ya sea en su forma directa o indirecta. En la primera se hace evidente y no necesita demostración alguna ya que cada uno de los individuos puede ejercer a plenitud su cuota de poder. En la segunda es menos visible, pero no por ello desaparece como característica básica de la democracia ${ }^{37}$. Por el contrario, al instaurar el voto como piedra angular y al reconocer el carácter estrictamente igualitario de éste, se puede afirmar que la democracia representativa ofrece aún mejores condiciones que la democracia directa para distribuir equitativamente el poder.

Otro elemento de fondo en la diferencia entre el estado de derecho y la democracia -o entre la limitación y la distribución del poder- es la concepción de libertad que contiene cada uno de ellos, planteada en términos clásicos como la diferencia entre la libertad de los antiguos y la libertad de los modernos (Constant, 1998). La primera "se componía de la participación activa y constante del poder colectivo [la segunda] debe componerse del

asegura similares condiciones para todos los individuos en la formación y el ejercicio del poder político. Otro eje divisor de similar importancia es, como se verá más adelante, el concepto de libertad que se expresa en cada uno de ellos.

${ }^{37}$ Llama la atención la escasa importancia que se ha dado a esta característica dentro del desarrollo de la teoría de la democracia a pesar de que es una de las similitudes más importantes entre democracia directa y democracia representativa. 
goce pacífico y de la independencia privada (...) El objeto de los antiguos era dividir el poder social entre todos los ciudadanos de una misma patria: esto era lo que llamaban libertad. El objeto de los modernos es la seguridad de sus goces privados; y ellos llaman libertad a las garantías concedidas por las instituciones de esos mismos goces" (Constant, 1998:139 $)^{38}$. Se trata, por tanto, de la contraposición entre dos concepciones de la libertad que, planteada en términos históricos, como lo hace Constant, no significa mayor problema ya que cada una de ellas correspondería a un momento determinado ${ }^{39}$. El problema de fondo se presenta cuando ambos tipos de libertades deben coexistir, que es el caso precisamente de las democracias contemporáneas que no pueden renunciar a ninguno de los dos. Cuando se sostiene que en la actualidad es imposible pensar en una democracia sin estado de derecho y en este sin aquella, se está planteando precisamente el problema de la vigencia de ambas libertades, la de los antiguos y la de los modernos, en el mismo momento y dentro del mismo ordenamiento jurídico y político.

Si se analiza la realidad de los tres países a la luz de estos elementos, se puede concluir que allí se encuentra una de las carencias más significativas a lo largo de su historia. En ninguno de ellos se establecieron las bases para lograr la igualdad ante la ley, garantizar los derechos básicos de las personas y establecer el gobierno de las leyes por encima del gobierno de los hombres ${ }^{40}$. Como se ha visto en la primera sección de este capítulo, las restricciones en torno a los derechos fueron explícitas durante largos períodos históricos, e incluso se mantuvieron vigentes cuando dejaron de constar en las constituciones y en las disposiciones legales. La organización del estado en su conjunto se estableció sobre la exclusión de amplios sectores de la población en términos de derechos, libertades y garantías, lo que constituyó el principal impedimento para establecer regímenes democráticos. Los diversos intentos por instaurar este tipo de regímenes estaban prácticamente condenados al fracaso en la medida en que no se los vinculaba con la construcción de estados de derecho en el pleno sentido de la palabra. El establecimiento

${ }^{38}$ En la concepción de la libertad de los modernos aparece claramente el espíritu de Locke que afirma que "la libertad natural del hombre consiste en no verse sometido a ningún otro poder superior sobre la tierra, y en no encontrarse bajo la voluntad y la autoridad legislativa de ningún otro hombre, no reconociendo otra ley para su conducta que la de la Naturaleza” (Locke, 1983: 36)

39 Bobbio (1985: 200) considera a esta identificación de dos momentos diferentes como "una transposición histórica arbitraria", pero concuerda con la necesidad de diferenciar los dos tipos de libertad. Así, reconoce que Constant "señaló, con una precisión desconocida hasta entonces, la diferencia entre las dos distintas maneras de entender la libertad en el lenguaje político, de modo que después de él la confusión resulta ya más difícil” (Bobbio, 1985: 201)

40 Esto se hace evidente en la posición que ocupan los tres países dentro de la clasificación de Freedom House (con todas las reservas que se debe tener ante esta medición, como se verá en el capítulo V). 
de la ciudadanía política -sujeta además a claras restricciones, como se ha visto antes- era absolutamente insuficiente y no podía tener algún futuro en tanto no contaba con los cimientos en los que debía asentarse. Ello explica en gran medida la serie de fracasos por instaurar regímenes democráticos que, en un lapso de menos de cuarenta años (desde la segunda guerra mundial hasta el inicio del actual período), incluye por lo menos cuatro intentos en Bolivia (1947, 1952, 1979 y 1980), cuatro en Ecuador (1945, 1946, 1948 y 1968) y dos en Perú (1945 y 1963) ${ }^{41}$.

La gran diferencia con el último intento, el que a finales de la década de 1970 y comienzos de la siguiente instauró los regímenes contemporáneos, se encuentra justamente en este aspecto. Al igual que en la mayoría de países de América Latina, en Bolivia, Ecuador y Perú se dio enorme importancia a la vigencia y el respeto a los derechos humanos, lo que implícita o explícitamente llevaba a la construcción de estados de derecho. La dolorosa experiencia de las dictaduras del Cono Sur y de Centroamérica fue asumida por el resto del continente y, casi sin excepción, se valoró la importancia de contar con un marco legal que pudiera proteger a los individuos. Ese fue el caso de Ecuador y Perú, cuyos gobiernos militares reformistas se diferenciaron claramente de aquellas dictaduras ( $\mathrm{y}$ de las que habían existido en su propia historia), en tanto que para Bolivia se trató de una experiencia propia. Como se verá en el siguiente capítulo, las transiciones a la democracia tuvieron mucho más de camino hacia el estado de derecho que hacía regímenes poliárquicos.

En síntesis, se puede afirmar que el estado de derecho debe incluirse entre los requisitos de la democracia. Los regímenes democráticos encontraron bases relativamente sólidas cuando junto a ellos se instauraron los estados de derecho. Más allá de la ciudadanía política, que había sido reconocida en varias ocasiones en cada uno de los países a lo largo de la historia reciente, la especificidad de esta nueva etapa se encontró en el establecimiento de la universalidad de los derechos civiles. Aún cuando estos no lograran materializarse plenamente, su sola alusión como base del nuevo ordenamiento jurídico y

\footnotetext{
${ }^{41}$ Ciertamente, esta es la explicación fundamental para comprender el fracaso de los anteriores intentos para establecer regímenes democráticos, pero no es la única. Junto a ella se encuentran factores como las condiciones económicas y sociales de la mayor parte de la población, que no permitían construir democracias con un sustento social amplio y sólido, lo que a su vez las hacía muy vulnerables a los enfrentamientos entre las élites y por tanto sujetas a los intereses de pequeños grupos. Así mismo se debe considerar el efecto de las prácticas políticas (especialmente el caudillismo y el militarismo imperantes en América Latina a lo largo de los siglos XIX y XX), que establecen relaciones verticales y despojan a la lucha política de sus contenidos esenciales. Estos aspectos adicionales serán tratados en el capítulo IV.
} 
político marcó una clara diferencia con las ocasiones anteriores y sobre todo fue uno de los factores de cambio de la orientación de los actores políticos con respecto a la democracia. La enunciación de los derechos se transformó a la vez en el marco dentro del que podía desarrollarse la democracia en tanto juego político, y en el objetivo a conseguir por medio de ella. Al estar ausente, en esa doble condición de garantía (aunque solo fuera potencial) de sus derechos y de objetivo posible de ser alcanzado, en las anteriores experiencias no se crearon los incentivos para que los actores sociales y políticos desarrollaran conductas democráticas, esto es, para que mantuvieran actitudes leales al ordenamiento jurídico y político. Por el contrario, la condición para alcanzar ese marco de derechos y libertades, en aquellas ocasiones, era el derrocamiento del ordenamiento existente, aún cuando éste se denominara democrático.

Obviamente, la existencia del estado de derecho no es suficiente para discutir el concepto de democracia a la luz de la experiencia de los tres países. Como he señalado al inicio de esta sección, junto a esa reflexión es necesario prestar atención a los requisitos sociales, económicos y políticos. Este, que constituye un ámbito de trabajo muy importante en la teoría de la democracia, es un campo en construcción y como tal se encuentra cruzado por intensos debates. El principal de estos elementos de confrontación es el de los elementos que se incluyen y los que se dejan fuera del paquete de requisitos ${ }^{42}$. Los trabajos pioneros en este campo tendían a colocar allí una gran cantidad de atributos o dimensiones, desde las de carácter estructural, como las económicas, hasta las de carácter cultural, como las religiosas, pasando por las históricas, sociales y políticas (Lipset, 1959; 1980; 1996; Moore, 1973). Sin embargo, el desarrollo de los estudios sobre democracia, por un lado, y sobre todo la multiplicación de regímenes de esta naturaleza en el mundo, por otro lado, obligaron revisar los planteamientos iniciales y en definitiva llevaron a evaluar de mejor manera el peso de cada una de las condiciones. Los estudios sobre democracia -muchos de ellos apoyados en sólidas bases de datos a nivel mundial, como los de Przeworski, Álvarez, Cheibub y Limongi (1996)- fueron afinando conceptos y echaron luz sobre los niveles de análisis en los que se debía trabajar con cada uno de

\footnotetext{
${ }^{42}$ En realidad, un debate previo a éste es el que trata sobre la existencia o inexistencia de condiciones para la democracia. Aunque en algún momento este debate pueda haber sido materia de foros académicos, como el que refiere Lipset (1959: 70), es poco probable que pueda tener espacio en la actualidad ya que existe acuerdo en que son necesarias ciertas condiciones mínimas. La controversia se encuentra en el carácter de esos requisitos y en el peso específico de cada uno.
} 
ellos, lo que abrió un campo mucho más amplio para la política comparada ${ }^{43}$. La generalización de la democracia, por su parte, puso en evidencia la amplia gama de características y especificidades de los regímenes que surgieron con la ola democratizadora (Linz, 1998: 231-234; Lijphart, 2000: 13-19; Collier y Levitsky, 1998: 137-159; Mainwaring y Pérez-Liñán, 2008: 14-59).

Entre las condiciones necesarias (ninguna de ellas suficiente por sí sola) se destacan el crecimiento económico y la economía de mercado (Lipset, 1980: 41-63; 1996: 52; Londregan y Poole, 1996: 1-30), una distribución del ingreso que no esté marcada por altos grados de desigualdad (Weffort, 1993: Nun, 2002: 83), un cierto nivel educativo con bajos niveles de analfabetismo (Dahl, 1991: 290; Lipset, 1959: 72), una tradición religiosa que sea compatible con la tolerancia (Toqueville, 1985), un grado apreciable de desarrollo institucional (Putnam, 1993) y una cultura política favorable al debate y al pluralismo (Lipset, 1996: 55-58). Por consiguiente, en términos generales se puede afirmar que desde los trabajos iniciales sobre este tema se hizo visible la tendencia a identificar una relación estrecha de la democracia con el proceso de modernización de la sociedad ${ }^{44}$. Aún cuando no se lo planteara en esos términos, es indudable que se establece aquella relación desde el momento en que las condiciones mencionadas son las que caracterizan a los procesos

\footnotetext{
${ }^{43} \mathrm{El}$ nivel de análisis en que se trate a la democracia es un tema que puede ser rastreado incluso hasta los primeros intentos de su caracterización como un régimen político. El ejercicio realizado por Schumpeter (1996) puede interpretarse como un intento para lograr un nivel de abstracción lo suficientemente general como para que pudieran caber en él las diversas manifestaciones democráticas que ya se hacían evidentes en su tiempo. Pero el debate al respecto tomó cuerpo solamente a partir de la década de los noventa del siglo XX, cuando se hizo evidente las múltiples formas de democracia que habían surgido en la ola democratizadora de la década anterior. Fue imprescindible, entonces, una mayor precisión conceptual y con ella la identificación de los múltiples niveles en que debe ser tratada la democracia (Collier y Levitsky, 1998; Linz y Stepan, 1996). El tema de los niveles de abstracción, en términos metodológicos, está tratado en Sarori (1970).

44 Por modernización se entiende aquí a la combinación que se produce entre desarrollo económico y el proceso de secularización de la sociedad. Este último "abarca tres rasgos principales: acción electiva basada en la decisión individual, la institucionalización o legitimación del cambio, la creciente diferenciación y especialización de roles, estatus e instituciones" (Germani, 1985: 26, cursiva en el original). Obviamente, se trata de un concepto muy discutible, como lo certifica la amplia literatura crítica que se produjo al respecto, especialmente en las décadas de los sesenta y setenta del siglo pasado (originada generalmente en la vertiente marxista). En términos sintéticos, se la puede entender como el camino hacia una sociedad caracterizada por "1) el predominio de normas universales, específicas y alcanzables; 2) alto grado de movilidad social (en general -pero no necesariamente- en sentido vertical); 3) un sistema ocupacional altamente desarrollado, independiente de otras estructuras sociales; 4) un sistema 'igualitario' de clases basado en pautas generalizadas de logros ocupacionales; 5) prevalencia de 'asociaciones' funcionalmente específicas de estructuras no adscriptivas” (Huntington, 1971: 286). Una visión de la importancia de la modernización para la democracia se encuentra en Putnam (1993: 83-86 y passim)
} 
de modernización ${ }^{45}$. De esta manera, la democracia ocupa el lugar de la variable dependiente y el proceso de modernización pasa a ser la variable independiente, lo que coloca sobre la mesa un problema de gran importancia para el análisis de realidades como la de los tres países estudiados ${ }^{46}$. En efecto, si la democracia es una consecuencia del proceso de modernización y si éste no ha ocurrido o solamente ha avanzado en una mínima expresión -como es el caso de estos países-, entonces serían extremadamente limitadas o incluso nulas las posibilidades de construirla. Se produciría de esta manera una situación sin solución posible o, peor aún, una realidad que únicamente admitiría soluciones no democráticas.

Frente a ello quedan dos posibilidades. La primera es aceptar aquella ausencia de alternativas como un hecho fatal, imposible de superar y adscribirse a las posiciones que sostienen la necesidad de gobiernos fuertes, dictaduras o despotismos desarrollistas como fase necesaria e inevitable en la ruta hacia la democracia. Obviamente, desde esta perspectiva no es posible realizar el más mínimo análisis de las democracias instauradas en países que no han vivido procesos de modernización, e incluso no es posible considerar como democráticos a los regímenes implantados en ellos. Sin embargo, la realidad es otra, ya que no se puede negar que esos regímenes tienen las características apropiadas para ser considerados como democráticos o por lo menos como semidemocráticos (Mainwaring, Brincks y Pérez-Liñán, 2001; Mainwaring y Pérez-Liñán, 2008), de manera que es necesario buscar una segunda posibilidad. Esta consiste en asumir la complejidad de los procesos históricos y con ella la relatividad de las condiciones planteadas para la instauración de los regímenes democráticos. Se llega así a una perspectiva que reconoce el carácter democrático (o semidemocrático) de estos regímenes sin dejar de reconocer el nivel insuficiente o incompleto de su modernización. Más que un juego de flexibilidad conceptual, esta opción debe ser vista como una

\footnotetext{
${ }^{45}$ En términos metodológicos y conceptuales, los orígenes más remotos de la reflexión sobre las condiciones que explican el surgimiento de un hecho social de gran trascendencia y enormes dimensiones se pueden encontrar en la explicación weberiana de la relación entre la ética protestante y el desarrollo del capitalismo (Weber, 1977). De ella -y en general del conjunto de la obra de Weber- se deriva también la teoría de la modernización que encuentra ciertas regularidades sociales y culturales en el desarrollo de las sociedades capitalistas. Aunque Toqueville (1985 [1835]) se adelantó cronológicamente en la identificación de ciertas condiciones sociales, económicas, políticas y culturales para un fenómeno social -en este caso la democracia-, es evidente que no le dio a su reflexión el nivel teórico conceptual que se encuentra en Weber.

${ }^{46}$ Una visión crítica a esta posición (expresada en la relación entre capitalismo y democracia) se encuentra en Rueschemeyer, Huber y Stephens (1992: 3), quienes sostienen que ella está cargada de muchos problemas que se desprenden de la tradición investigativa (cualitativa o cuantitativa) que se adopta para el análisis
} 
perspectiva que profundiza en la interrelación entre los procesos y que abre una ruta de comprensión de las democracias emergentes.

En este punto es necesario hacer una precisión conceptual, en tanto se deben diferenciar las condiciones que dieron lugar a las democracias en los tres países y las que pueden garantizar su permanencia. Una línea de análisis es la que indaga sobre las condiciones previas, a las que alude la literatura citada en las páginas anteriores, y otra bastante diferente es la que busca explicaciones para la durabilidad de la democracia (Przeworski, Álvarez, Cheibub y Limongi, 1996: 89-108; Mainwaring y Pérez-Liñán, 2004: 192-193; Putnam, 1993) o para su consolidación (Linz, 1987; Linz y Stepan, 1996: 29-50; Gunther, Nikiforos y Puhle, 1996: 119-128; O’Donnell, 1996: 5-27). Sobre el primer tema se hace imprescindible actualizar el debate a la luz de las nuevas democracias, tanto de América Latina como de Europa Oriental y de África. En todos esos casos se ha reducido a la mínima expresión la incidencia de los factores -mencionados en las páginas anterioresque constituyeron el eje de la explicación basada en los procesos de modernización. Pero, a la vez, en todos ellos se hizo presente un elemento que no fue considerado por la reflexión teórica previamente existente, que es el juego político específico que ocurrió en cada país y, dentro de este, los cálculos de los actores políticos y sociales. La literatura sobre las condiciones de la democracia destacó los elementos estructurales y culturales, pero dejó de lado el escenario político concreto en el que ocurrieron las transiciones a la democracia. Sin embargo, este vacío fue llenado por la literatura de la transición, que por medio de algunos de sus principales exponentes identificó el papel importante de los hechos políticos, así como de las posiciones y las negociaciones de los actores (O`Donnell y Schmitter, 1994; Cotler, 1988) ${ }^{47}$. Es conveniente, por tanto, integrar esas dos perspectivas para comprender de mejor manera la especificidad de las democracias en este tipo de países.

Desde este punto de vista -y en referencia a los tres países- se puede afirmar que pese a que Bolivia, Ecuador y Perú no contaban con todo el conjunto de las condiciones favorables para la democracia, hubo otros factores, relacionados con la realidad política, que la hicieron posible. En otras palabras, aunque cada uno de estos países apenas presentaba ciertos rasgos incipientes de modernización, la específica forma en que se

${ }^{47}$ El tratamiento de las transiciones a la democracia con referencia a los tres países se encuentra en el capítulo II. 
produjeron los hechos políticos hizo que se plasmara una situación que idealmente corresponde a etapas de plena concreción de aquella. Como se verá en el siguiente capítulo, las transiciones a la democracia tuvieron un carácter particular en cada caso y estuvieron claramente determinadas por las formas y las modalidades que asumió el desempeño de la política. Pero, el problema fundamental para lo que aquí interesa no es tanto el proceso que condujo hasta los regímenes poliárquicos actualmente existentes, sino los desafíos que se derivan para estos de la ausencia de los factores que deberían estar presentes previamente a su constitución como tales. En una palabra, el problema conceptual -y también político- se encuentra en el proceso de modernización como tarea pendiente para la democracia. En efecto, las democracias recientes de la mayor parte del globo, y entre ellas obviamente las de Bolivia, Ecuador y Perú, deben hacerse cargo de algo que en las democracias más antiguas, las de los países desarrollados, fue más bien una premisa.

Este carácter de premisa debe entenderse no sólo -ni principalmente- en el sentido temporal, sino en su sentido ontológico, esto es, en la condición propia de la democracia. Esto quiere decir que, a pesar de que las democracias recientes no fueron el resultado de un proceso de modernización, requieren de este para su permanencia y para su profundización. Dicho de otra manera, la experiencia de las democracias recientes demuestra que es posible el surgimiento de este tipo de régimen sin que se hayan cumplido en su totalidad las fases previas, pero a la vez dejan ver con claridad que no pueden ir más allá de un determinado punto si no son capaces de establecer a posteriori aquellas condiciones. Por ello, los procesos políticos, sociales y económicos vividos en los tres países desde la inauguración de los regímenes actuales pueden calificarse en general como una permanente búsqueda en ese sentido ${ }^{48}$. La lucha política, como se señaló al inicio del actual período democrático, expresa en buena medida aquella tensión (Cardoso, 1985: 141; Schmitter, 1985: 166).

\footnotetext{
48 Como se ha señalado recientemente, las luchas políticas electorales en estos países pueden interpretarse a la luz de esta búsqueda de modernización (con todas sus connotaciones) cuando se observa que las preferencias de una parte importante de la población están definidas por las carencias que existen en términos de su inclusión ciudadana, de la protección estatal y de la participación en las ventajas del desarrollo económico (Vergara, 2007:22). Aunque ese estudio hace referencia específicamente a la elección presidencial peruana de 2006, es posible hacerlo extensivo a la realidad de los tres países, incluso mucho más allá de los procesos electorales realizados recientemente. Para decirlo en otros términos, la modernización se ha convertido en el campo de conflicto en que se enfrentan proyectos alternativos (progresistas y conservadores), lo que ha llevado a muchos autores a referirse a varios proyectos políticos como expresiones de una modernización conservadora (que aparentemente sería un oxímoron).
} 
Por consiguiente, en buena parte de los países latinoamericanos se presenta una situación no contemplada dentro de la teoría de la democracia construida antes de la ola democratizadora en la que nacieron estos regímenes ${ }^{49}$. De esta manera, se puede sostener que en la relación entre modernización y democracia se altera "la secuencia, para decir con igual énfasis que (...) la democracia debía ser condición previa para la modernización" (Nun, 2000: 156). Es una inversión de la secuencia que abre paso al tercer tema planteado al inicio de esta sección, esto es, los rendimientos de la democracia (o, en términos más generales, del sistema político ${ }^{50}$. Si a estos se los entiende no solamente como los efectos sociales y económicos de la gestión de los gobiernos democráticos -que es el nivel en que generalmente se ha tratado este tema-, sino como la capacidad de los regímenes democráticos para construir sociedades incluyentes, entonces se puede hacer una evaluación más rigurosa de las democracias. La pregunta central alude, por consiguiente, a la capacidad de estos regímenes para cumplir con aquellas tareas que no fueron realizadas previamente o, si se quiere, para construir un orden asentado sobre las condiciones que aseguren la permanencia (y en lo posible la profundización y la consolidación) de la democracia.

Lo señalado tiene una doble connotación en términos teóricos y conceptuales, que obliga a una breve digresión. En primer lugar, al no restringir la evaluación a las variables económicas y sociales, se elimina -o por lo menos se reduce al mínimo- la visión instrumental de la democracia que la considera exclusivamente como un medio para alcanzar determinados fines (bienestar económico, servicios de educación y salud, oportunidades laborales, etc.). Este paso no deja de ser significativo si se piensa que uno de los riesgos de esa visión instrumental es que puede abrir la puerta a concepciones que

49 Sobre este tema llaman la atención Mainwaring y Pérez-Liñán (2004) cuando aluden al excepcionalismo latinoamericano. Sin embargo, lo autores se mantienen únicamente en el campo económico, tomando al nivel de desarrollo como única variable constitutiva de ese carácter excepcional. Una mirada más amplia, que abarque el conjunto del proceso de modernización, contribuirá sin duda a fortalecer aquel planteamiento.

${ }^{50} \mathrm{La}$ alusión a los rendimientos sociales y económicos del sistema político puede llevar la reflexión a la perspectiva sistémica, que ve a los ámbitos político, social y económico como subsistemas de un sistema más amplio, entre los que se establecen lazos bajo la forma de inputs y outputs (Habermas, 1975), lo que será abordado en la siguiente sección de este capítulo. Pero, también puede ser vista desde los propios conceptos mínimos de la democracia, que consideran a esta en términos estrictamente políticos y que debe arrojar resultados en términos de gestión de gobierno (Dahl, 1991). Así mismo, un acercamiento adicional es el que se encentra en la reflexión sobre gobernabilidad, que indaga sobre la capacidad del sistema político (democrático) para responder a las demandas y necesidades de la población (Alcántara, 1995; Camou, 1998; Flisfisch, 1983) 
minimizan la importancia del régimen democrático en sí mismo (y, en la práctica política concreta, a su erosión). En la medida en que los logros económicos y sociales son los parámetros de evaluación de la democracia, ésta se encuentra sometida a examen permanente no en tanto régimen político que asegura igualdad política y libertades -que materializa la condición ciudadana, para continuar con lo señalado a lo largo de este capítulo-, sino en tanto gestión de los gobiernos. La toma de cuentas, la accountability, se transforma en la evaluación del régimen en su conjunto, que es lo que ocurre generalmente con las críticas que se hacen desde la izquierda ${ }^{51}$. Pero, esto que resulta inevitable en la realidad de países como los estudiados, requiere un tratamiento muy cuidadoso en el plano teórico y conceptual, ya que puede conducir a la confusión de niveles de análisis, que a su vez puede desembocar en conclusiones equivocadas. Como se verá de inmediato, a partir de este punto se abre un debate de mucho interés acerca de la democracia y de su calidad, pero antes de entrar en ese aspecto es necesario dar un paso previo.

Este paso consiste en abordar la segunda connotación de este acercamiento. Se trata del carácter claramente normativo que tiene la evaluación de la democracia en los términos planteados aquí. Al abandonar la visión instrumental de la democracia y al considerarla a esta como un fin en sí misma, se está asumiendo sin lugar a dudas que ella expresa un valor que es válido per se, sin necesidad de aludir a sus resultados o a su desempeño en cualquier campo que se tome como parámetro de referencia ${ }^{52}$. Es, ciertamente, un concepto esencialista de democracia, que expresa su condición de ordenamiento político que posibilita la materialización de las libertades y los derechos ciudadanos (especialmente en sus formas civil y política). Si se considera a la democracia como un régimen político que establece un marco de libertades, garantías y derechos, no requiere de otros parámetros que estos para su evaluación.

\footnotetext{
${ }^{51}$ Los cuestionamientos desde la izquierda a la democracia realmente existente en los tres países tienen claramente ese signo. Su principal argumento apunta a los escasos avances logrados en la superación de la pobreza, en la distribución del ingreso, en la generación de empleo, en los servicios de educación y salud, entre otros. A partir de la identificación de esas carencias - muy ciertas y fáciles de comprobar- la crítica se enfila a la democracia como orden político. Por esa vía, la solución propuesta no puede ser otra que el cambio de régimen (Cordero, 2008).

52 “Clasificar un caso como 'democrático' o no, es no solamente un ejercicio académico. Esto tiene implicaciones morales, ya que hay consenso en la mayor parte del mundo contemporáneo en que, no importa lo que este concepto signifique, la democracia es la forma de gobierno normativamente preferible" (O`Donnell, 1999: 4).
} 
En síntesis, estos dos elementos -el abandono de la visión instrumental de la democracia y la aceptación de su carácter normativo- permiten abordar de mejor manera el debate mencionado antes acerca de los rendimientos de la democracia en países que presentan un proceso inacabado de modernización ${ }^{53}$. Los efectos sociales y económicos pasan a ser indicadores de un proceso más amplio que requiere ser impulsado y desarrollado por las democracias para mantenerse como tales. Pero, a la vez, esos efectos no pueden constituirse en la medida que señala la existencia o la inexistencia de democracia, ya que ellos constituyen el resultado de la gestión de los gobiernos y no de las características del régimen (Levine y Molina, 2007: 18). Se trata, por tanto de identificar adecuadamente el nivel de análisis, en términos teóricos y conceptuales, para evitar juicios erróneos como los que se encuentran en buena parte de las corrientes críticas de la democracia que ponen el énfasis únicamente en su capacidad para solucionar las necesidades inmediatas (De Souza, 2004: 127; Cueva, 1988) ${ }^{54}$.

Ciertamente, esta toma de posición puede aparecer como un contrasentido con respecto a lo que ocurre en la realidad, donde la democracia se pone en cuestión a diario precisamente a causa de sus resultados materiales. La pérdida de confianza en las instituciones democráticas y en general en la democracia como régimen político es un hecho que se deriva en gran medida de los bajos resultados de las políticas gubernamentales (Paramio, 1999: 82; Smith, 2005: 19-44; Pachano, 2007: 13-37). La población, los individuos de carne y hueso utilizan esos elementos como atajos cognitivos

\footnotetext{
${ }^{53}$ Esta afirmación sobre el carácter inacabado del proceso de modernización (y todo lo señalado al respecto en las páginas anteriores) puede ser interpretado como la expresión de otro concepto normativo (en este caso el de modernización). Es posible que así sea, ya que resulta casi estéril cualquier esfuerzo por despojar de esa connotación a conceptos que hacen referencia a procesos que son observados desde sus resultados (Huntington, 1971). Indudablemente, hay un componente teleológico del que es casi imposible escapar (por cierto, no es mi interés encontrar esa vía de escape). ${ }^{54}$ Ese tipo de críticas tiende a confundir los diversos niveles de análisis, especialmente en lo que se refiere a las condiciones en las que se desarrolla la democracia y los resultados que ella arroja en términos económicos y sociales. Así, se sostiene que "Actualmente hay, sin duda, una tendencia en muchos sectores de izquierda a considerar que la democracia es una categoría exclusivamente 'política', en el sentido más restringido del término, que en última instancia remite a cierto tipo de relación entre el Estado y la 'sociedad civil', relación caracterizada por la libertad de expresión, el pluripartidismo, la realización periódica de elecciones y la observancia de las normas prevista en los respectivos cuerpos legales. Reglas de juego que en si mismas me parecen positivas, pero con la salvedad de que nunca funcionan de manera indeterminada, o sea, con independencia de su inserción en cierta estructura más compleja que es la que les infunde una u otra 'orientación"' (Cueva, 1988: 12, cursivas en el original). Es obvio que en esas afirmaciones existe gran confusión entre los diversos niveles de análisis en la medida en que no se reconocen las diferencias entre los atributos del régimen y las características de la gestión de los gobiernos, así como entre las condiciones en que se desempeña el sistema político y los resultados que éste arroja (inputs y outputs). Al respecto véase la siguiente sección de este capítulo.
} 
para entregar, mantener o retirar su apoyo a una opción política y, más allá de ésta, en general al orden político. Es inevitable que eso suceda con más frecuencia o que existan mayores probabilidades de desencanto en los países latinoamericanos -y en general en los de menor desarrollo- a causa de los desafíos que se derivan de sus condiciones económicas, de las características de su inserción en el mercado mundial y de los bajos rendimientos de la gestión política de los gobiernos. Por ello no sorprende la abundancia de literatura que da cuenta de esos desafíos tanto en épocas de crisis -especialmente la de los años ochenta- como en momentos que podrían considerarse de relativa normalidad (Remmer, 1990; 1991; Torre, 1998; Abugatás, 1987; Garnier, 1994; Montúfar, 2000; Paramio, 2006; Stokes, 2002; BID, 2002; 2006; Araujo, 1998; Jácome, 2003). Dicho de otra manera, es inevitable que la democracia -como cualquier otro régimen político- sea evaluada de acuerdo a los resultados que son tangibles para la población, pero eso no justifica llevar esa reacción al nivel teórico y conceptual. A ese nivel le corresponde estudiarla y explicarla, pero no hacerla suya en términos de convertirla en un componente de la definición de democracia ${ }^{55}$. En síntesis, los resultados económicos y sociales no pueden tomarse como elementos que definen si un régimen es o no es democrático, de la misma manera que no pueden ser utilizados para definir si un régimen es o no autoritario. El tipo de régimen, en términos teóricos y conceptuales, no está determinado por sus resultados aunque, como se verá de inmediato, su permanencia y su estabilidad sí están condicionadas por estos.

En efecto, un tema muy diferente es el de la permanencia y la estabilidad de la democracia, que no puede ser confundido con su carácter o con sus contenidos. La capacidad de supervivencia de la democracia -como de cualquier ordenamiento políticoestá condicionada en gran medida por sus resultados tangibles y concretos $^{56}$. Pero, en lugar

\footnotetext{
${ }_{55}$ Cabe destacar que la evaluación basada en esos criterios puede tener un carácter positivo, como claramente ocurrió en Perú bajo Fujimori desde el momento en que exhortó "a la gente a aceptar [el] dolor como precio de una prosperidad posterior" (Stokes, 1997: 332) hasta cuando consolidó su modelo económico (Murakami, 2007: 243-249). Algo similar se puede decir de Bolivia, donde los logros de la estabilización económica dieron lugar a un consenso no solamente en torno a la orientación del modelo económico sino también sobre la democracia liberal como orden político (Romero, 1999: 14; Pachano, 2006: 20-23).

56 En gran medida pero no absolutamente, porque están también condicionadas por el carácter sustantivo de la democracia como condición básica e insustituible para el goce de las libertades y de los derechos. Esto es lo que explica, a manera de ejemplo, que una gran mayoría de la población (que se mantiene en alrededor de los dos tercios) de 17 países latinoamericanos exprese su rechazo a gobiernos autoritarios aún cuando estos pudieran potencialmente solucionar los problemas económicos (Latinobarómentro, varios años). Más allá de los reparos que se pueden hacer a la pregunta que da origen a esa respuesta (o precisamente por el carácter tendencioso de esta, que contrapone democracia
} 
de poner en cuestión el carácter democrático del régimen, lo que hace esto es colocar sobre la mesa el tema de la legitimidad. Como fue acertadamente planteado en un estudio seminal por Linz (1987: 42), esta última está estrechamente ligada a la eficacia y a la efectividad. De esta manera, una democracia aparece como legítima en primer lugar porque los ciudadanos consideran "que a pesar de sus limitaciones y fallos, las instituciones políticas existentes son mejores que otras que pudieron haber sido establecidas, y que por tanto pueden exigir obediencia" (Linz, 1987 38). Pero asume esa condición también por la eficacia, entendida como "la capacidad de un régimen para encontrar soluciones a problemas básicos (...) que son percibidas más como satisfactorias que como insatisfactorias por los ciudadanos conscientes" (Linz, 1987: 46) y por la efectividad, asumida como "la capacidad para poner realmente en práctica las medidas políticas formuladas, con el resultado deseado" (Linz, 1987: 49).

La propuesta de Linz puede ser tratada desde la perspectiva de los diversos orígenes que tiene la legitimidad, no tanto en términos de sus diversos tipos -a los que alude el autor acudiendo a los orígenes weberianos del concepto (Linz, 1987: 37)-, sino de acuerdo a los factores que le dan forma. En este sentido, con referencia a la democracia es posible identificar una legitimidad por origen, una legitimidad porprocedimientos y una legitimidad por resultados. La primera expresa el concepto propuesto por Linz, esto es, la aceptación de las instituciones políticas como las mejores entre la gama disponible. Esto es lo que le convierte a la democracia en "the only game in town" (Linz y Stepan, 1996: 30) ${ }^{57}$. Acudiendo a un lenguaje algo ampuloso se puede decir que se trata de la legitimidad emanada del contrato social o de los acuerdos básicos que dan forma al régimen político. Por consiguiente, se podrá asegurar que esa legitimidad es una realidad cuando existen acuerdos básicos acerca de la convivencia democrática, cuando no existen actores significativos que intenten cambiar las condiciones básicas del régimen o directamente sustituirlo por uno que no pueda ser calificado propiamente como democrático.

La legitimidad por procedimientos, por su parte, se sitúa en un nivel más concreto ya que no alude a los acuerdos constitutivos sino que se deriva de la manera en que opera la

a bienestar económico), es innegable que se trata de una evaluación positiva que se asienta en factores distintos a los económicos.

${ }^{57}$ Esta condición del único juego posible debe entenderse en el sentido más general del término, esto es, como la adscripción de la mayoría de los ciudadanos y los actores políticos a la democracia como orden político. Ese nivel no se ve afectado por la existencia de instituciones informales sobre la que llama la atención O`Donnell (1996: 19) para cuestionar la validez de este argumento. 
democracia. Sintéticamente se puede sostener que esta legitimidad expresa la relación entre los fines y los medios, en el entendido de que debe ser una relación directa y de mutuo condicionamiento. Los fines democráticos solamente se pueden obtener por medios democráticos, de manera que el resultado no depende única ni principalmente de las cualidades del fin. Los medios pasan a tener tanta importancia como los fines, hasta el punto de que se puede asegurar que la democracia consiste en el conjunto de estos más que en la obtención de determinados fines, como lo han puesto de relieve los diversos conceptos calificados como procedimentales (Schumpeter, 1996; Dahl, 1989; Przeworski, 1995; Lipset, 1980). La realidad de los países latinoamericanos y en especial de los tres estudiados confirma fehacientemente esta afirmación cuando se observa el efecto erosivo de acciones políticas efectistas, nula o escasamente apegadas a los procedimientos democráticos ${ }^{58}$. Se trata, por cierto, de unos medios que no se restringen a los procedimientos de selección de los cargos políticos, como son los sistemas electorales, ni a los que rigen a la toma de decisiones, sino también y sobre todo a los que aseguran la vigencia de las libertades y las garantías a lo largo de todo el proceso político. Este tipo de legitimidad alude, por consiguiente, a principios básicos que son constitutivos del concepto de democracia, como la competencia política, la autonomía de las autoridades elegidas y el respeto a las minorías (Dahl, 1989; O`Donnell, 1999; Linz y Stepan, 1996; Morlino, 2004). A diferencia del anterior tipo de legitimidad que se situaba en el nivel del régimen, este se encuentra en el nivel del sistema político, esto es, en las instituciones, los procedimientos, los actores y las prácticas políticas.

Finalmente, la legitimidad por resultados se obtiene a partir de los rendimientos que arroja el ejercicio del sistema político. A diferencia de lo planteado a lo largo de la presente sección, en el sentido de incluir en esos rendimientos a los aspectos de carácter más general, esta legitimidad tiende a surgir casi exclusivamente de los resultados económicos y sociales, esto es, de la evaluación que hacen los ciudadanos sobre la gestión del gobierno. Por consiguiente, se desarrolla en un nivel mucho más concreto que la anterior, ya que tiene como objeto a las instancias de gobierno (entendidas en su sentido más amplio, que incluye al Ejecutivo, al Legislativo y a las instancias subnacionales). Como se ha visto a lo largo de las páginas anteriores, este tipo de legitimidad tiene

\footnotetext{
${ }^{58}$ Los efectos erosivos de las constantes violaciones de los procedimientos democráticos en los tres países son analizados en los capítulos III y IV. Por el momento cabe recordar que varias de esas acciones (como el golpe de Fujimori en Perú y los derrocamientos de presidentes en Bolivia y Ecuador) se han justificado por sus fines económicos, sociales o políticos (o una combinación de todos ellos) y han contado con apoyo de amplios sectores de la población.
} 
enorme importancia en el desempeño concreto de los regímenes democráticos, ya que es el que se realiza diariamente y el que define las preferencias de los ciudadanos con respecto al menú de opciones políticas disponibles. En esas condiciones, aunque no trata directamente con elementos propios de la definición del régimen ni con las características del sistema, esa evaluación se convierte en elemento fundamental en el desempeño de las democracias. Cobra enorme fuerza, además, cuando rebasa el ámbito de las instancias de gobierno y se traslada hacia el nivel del sistema y del régimen en su conjunto, como ha ocurrido reiteradamente en los tres países estudiados. Como se verá con detenimiento en los capítulos III y IV, uno de los problemas centrales que han enfrentado las democracias de estos países es precisamente el de la transposición de niveles de la evaluación ciudadana. Pero, para comprender de mejor manera esta transposición y en general el problema de la legitimidad de la democracia, es necesario hacer una breve reflexión sobre los conceptos de régimen, sistema, gobierno y sociedad (o comunidad política), así como de sus interrelaciones.

\section{Régimen, sistema, gobierno y sociedad: un apunte conceptual}

Para comenzar, cabe destacar el escaso acuerdo que existe en torno a los conceptos de régimen y sistema, así como en menor medida de gobierno. Este desacuerdo es una expresión de la torre de Babel en que se ha encerrado la ciencia política, como la han calificado algunos autores (Sartori, Riggs y Teune, en Morlino, 1985: 14) y que en gran medida obliga a tomar una decisión más bien pragmática que rigurosamente conceptual. En efecto, como trataré de explicar en los párrafos que siguen, los contenidos y el uso de cada uno de estos conceptos dependen obviamente de la perspectiva teórica que se adopte al respecto, pero también se definen en gran medida por los objetivos que se persiguen. Pero, independiente y previamente a esa decisión existe un mínimo acuerdo generalmente implícito- acerca de la necesidad de diferenciar analíticamente los niveles mencionados (Alcántara, 1995: 52), fundamentalmente régimen, sistema y gobierno. Adicionalmente, es necesario incluir como cuarto elemento a la sociedad o, si se quiere, a la comunidad política.

Una segunda observación se refiere al origen teórico o epistemológico de esos conceptos. Cada uno de ellos viene no solamente de una específica corriente de pensamiento sino sobre todo de disciplinas claramente diferenciadas. El concepto de régimen es un 
producto de la reflexión jurídica y puede ser rastreado incluso hasta el antiguo debate sobre las formas de gobierno (Bobbio, 2000). Ya sea bajo la denominación de Estado o de régimen, en este nivel se ha incluido tradicionalmente al conjunto de normas y disposiciones que constituyen un ordenamiento jurídico. En la literatura jurídica del siglo XX (desde Jellinek a Kelsen) predomina el concepto de Estado, lo que encuentra su explicación en la necesidad de contar con el sustento material indispensable para que las normas jurídicas no aparezcan únicamente como una abstracción. Ese sustento viene a ser el Estado entendido como el ordenamiento jurídico pero también, al mismo tiempo, como una forma de organización social que toma forma concreta en instituciones y procedimientos específicos (Ozlak, 1978; Tilly, 1992). Esta interpretación -repensada desde la perspectiva de la ciencia política- es la que se encuentra cuando se alude, por ejemplo, a los tipos de régimen político (autoritario-democrático o, en otro plano, parlamentario-presidencial). Sin embargo, no se puede asegurar que exista consenso al respecto, como lo demuestra la utilización de régimen y gobierno como sinónimos o cuando dentro del sistema político se incluye el nivel de las normas.

\section{Gráfico $\mathbf{N}^{\circ} 1$ Interacciones del sistema político}

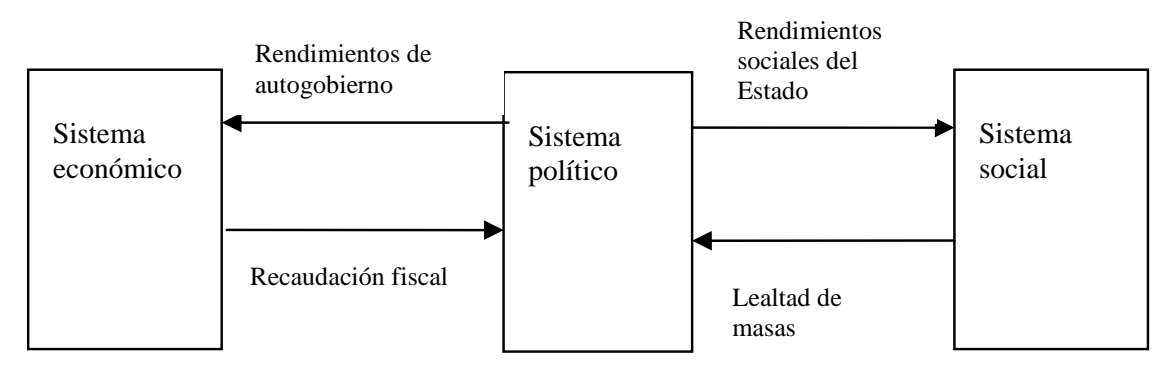

Fuente: Habermas, 1975: 20

Por su parte, el concepto de sistema ha sido desarrollado fundamentalmente por la perspectiva estructural-funcionalista dentro de varias disciplinas de las ciencias sociales, especialmente de la sociología y de la ciencia política (Young, 1993: 34-42). Derivado de la interpretación parsoniana, se ha impuesto el enfoque sistémico que reconoce múltiples niveles interrelacionados por influencias recíprocas (inputs y outputs). La formulación inicial en este sentido se la debe a Easton (1976; 1997), que sostiene que "puede denominarse sistema político a aquellas interacciones por medio de las cuales se asignan autoritativamente valores en una sociedad; esto es lo que lo distingue de otros sistemas de su medio" (Easton, 1997: 221). De esta manera, las características centrales del sistema 
político no serían sus elementos constitutivos o sus componentes, sino su función de asignar valores (que en esa visión eastoniana es la función de la política) y, a partir de ella, su ubicación central dentro de un sistema de sistemas. Por consiguiente, el sistema político gobierna al sistema económico y al sistema social, como lo expresa el gráfico número 1.

Este acercamiento a la definición del sistema político constituye un paso importante ya que permite la identificación de sus funciones dentro del conjunto de los sistemas de la sociedad $^{59}$. Así mismo, establece el carácter central del sistema político por su condición de ámbito en que se realiza la política, caracterizada a la vez por la asignación de valores o -en términos propios de la ciencia política- por la capacidad monopólica de ejercer el uso de la fuerza legítima. Esta capacidad, en términos de Easton, le otorga a la política su carácter especial y único, que a la vez se expresa en términos de poder y de gobierno. Sin embargo, esta definición deja sin solución dos problemas básicos que en el caso de cualquier estudio sobre la democracia tienen mucha importancia. Por un lado, no define claramente el nivel y las condiciones en que se produce esa asignación autoritativa de valores, de modo que con ella se puede aludir tanto la organización política gubernamental como a cualquier organización social (un sindicato, un club, una asociación) con respecto a sus integrantes. En todas ellas se puede encontrar aquella característica como función central, de modo que al definir de esa manera al sistema político se alude al género (poder) y no a la especie (política). Por otro lado, no ayuda a la identificación de los diversos niveles que constituyen al sistema político y en esa medida no permite diferenciarlo del régimen y del gobierno. Por el contrario, la noción de sistema político integra a todos ellos, y solamente los diferencia de "los otros sistemas de su medio" (Easton, 1997: 220). Ese medio -o ambiente- tiene una parte intrasocietal, que corresponde a los otros sistemas (no políticos) que pertenecen a la misma sociedad, y otra extrasocietal, que comprende los sistemas que están fuera de la sociedad dada (Easton, 1997: 221-222). Por tanto, en esta perspectiva, el sistema político se diferencia de los otros sistemas (económico, social, cultural) y de los que no forman parte de la sociedad en que está inmerso, pero no da cuenta de sus características ni de sus componentes específicos. En esta medida, resulta extremadamente amplio, no precisa claramente su

${ }^{59}$ Para mantener la tradición parsoniana -a la que Habermas (1975: 20-23) intenta combinar con la perspectiva marxista- se podría añadir el sistema cultural, que extrañamente este autor deja afuera. Cabe recordar el peso que tiene la cultura dentro de la construcción teórica de Parsons. El triple carácter de ésta (transmitida, aprendida y compartida) fundamenta en gran medida el concepto de socialización que a la vez constituye una de las piedras angulares del sistema social (Parsons, 1976: 25) 
objeto y en consecuencia no constituye un instrumento adecuado para la investigación aplicada $^{60}$.

Por último el concepto de gobierno es el que menos problemas presenta, aunque ello no significa que esté exento de imprecisiones. La principal de estas se encuentra en la asimilación de gobierno exclusivamente al órgano ejecutivo, sin incluir los demás ámbitos señalados antes o, para seguir con el lenguaje eastoniano, a todas las instancias encargadas de la asignación de valores ${ }^{61}$. Una segunda imprecisión, que está claramente en vías de superación, es la identificación entre gobierno y régimen. Esta tuvo vigencia durante mucho tiempo sobre todo en la literatura que hacía referencia a los diversos tipos de régimen bajo la denominación de formas de gobierno (Bobbio, 2000).

Más que una falta de acuerdo en torno a los conceptos, en realidad existe una indefinición conceptual derivada de la débil identificación de cada uno de los objetos de análisis. Una propuesta como la de Easton, que ha tenido gran influencia en la ciencia política contemporánea, integra bajo el mismo concepto a tres niveles o ámbitos que deben ser desagregados analíticamente. En primer lugar alude al ámbito en que se generan los valores y las creencias. En segundo lugar, dentro de ese mismo concepto incluye al espacio en que se desempeñan las instituciones, en que los actores desarrollan sus prácticas políticas y donde se toman las medidas de gobierno (se formulan y se aplican las políticas). En tercer lugar, también coloca allí al nivel en que se establecen las normas y regulaciones que definen lo que está permitido y lo que está prohibido, a la vez que determinan las modalidades y los procedimientos para la resolución de los conflictos. Son demasiados niveles y muy diferentes, de manera que al integrarlos a todos bajo un

${ }^{60} \mathrm{Al}$ respecto se ha señalado que "el sistema político es un concepto teórico sin referencia empírica inmediata, pero muy adaptable a ésta (...) [Es una ] Construcción teórica que (...) abarca la totalidad de elementos del sistema político: la comunidad política (la sociedad organizada), el régimen (el «Estado») y las autoridades (instituciones y agentes)" (Aguilera de Prat y Martínez, 2000: 15, cursiva en el original). Evidentemente, una definición de este tipo se acerca más al sistema social de Parsons que a un concepto específico de la esfera política. Algo similar se puede decir de los componentes del sistema político identificados por Huntington: “a) cultura, esto es, los valores, actitudes, orientaciones, mitos y creencias relevantes para la política y la dominación en una sociedad; b) estructura, esto es, las organizaciones formales a través de las cuales la sociedad toma las decisiones autoritativas, como partidos políticos, legislaturas, ejecutivos y burocracias; c) grupos, esto es, las formaciones sociales y económicas, formales e informales (...); d) liderazgo, esto es, los individuos que en los grupos y en las instituciones políticas ejercen mayor influencia que otros en la asignación de valores; e) las políticas, esto es, las pautas de actividad gubernamental concientemente diseñadas para la distribución de beneficios y sanciones en la sociedad" (Huntington, 1971: 316).

61 Como se verá más adelante, esta observación tiene mucho sentido cuando se alude a la gobernabilidad, que hace referencia al conjunto de esas instancias y no solamente al ejecutivo. 
concepto único se convierte a este en un instrumento poco adecuado para el análisis político de realidades concretas.

Varios autores han tratado de superar este indefinición conceptual por medio de la clasificación adecuada de los elementos que conforman el conjunto de niveles en que se desarrolla la acción política. Una formulación en ese sentido, planteada en torno al consenso necesario para la democracia, se encuentra en Sartori (1988: 121-126). El autor sostiene que respecto "de la teoría de la democracia hay que distinguir claramente al menos tres posibles objetos compartibles: a) valores fundamentales (tales como la libertad y la igualdad), que estructuran el sistema de creencias; b) reglas de juego o procedimientos; c) gobiernos y políticas gubernamentales específicas [que] pueden convertirse respectivamente, siguiendo a Easton, en tres niveles de consenso: a) consenso a nivel de comunidad, o consenso básico; b) consenso a nivel de régimen, o consenso procedimental; c) consenso a nivel de acción política, o «consenso político»" (Sartori, 1988: 122, cursiva en el original ${ }^{62}$. Lo importante de este planteamiento es que, por un lado, reconoce tres niveles diferenciados (aunque en un orden que debe ser revisado) y, por otro lado, identifica las funciones de cada uno de ellos. Por consiguiente, si es posible identificar esos niveles de consenso para la democracia, no hay razón para dejar de considerarlos como niveles de análisis claramente diferenciados para el estudio de la acción política.

Una conclusión relativamente similar se puede extraer de la formulación que hacen Linz y Stepan (1996) cuando analizan las condiciones necesarias para la consolidación democrática. Como se vio antes, estos autores sostienen que la consolidación se logra cuando la democracia se ha convertido en el único juego posible (the only game in town). Esta condición se logra, según los autores, también en tres niveles a los que denominan de comportamiento, actitudinales y constitucionales (Linz y Stepan, 1996: 30). Extrañamente, a pesar de identificar esas dimensiones, los autores no extraen las conclusiones que podrían derivarse de ello y más bien las tratan a todas estas bajo la perspectiva de la cultura y de las actitudes de las personas ${ }^{63}$. Pero, a pesar de ese error de

${ }^{62}$ Como se verá en la siguiente sección, Sartori sostiene una afirmación bastante cuestionable con referencia al consenso en el nivel de la comunidad.

${ }^{63}$ Los autores señalan que "en lo que se refiere a comportamientos, un régimen democrático se consolida en un territorio cuando ningún actor nacional, social, económico, político o institucional destina recursos importantes al intento de alcanzar sus objetivos creando un régimen no democrático o separándose del Estado. En lo que hace a las actitudes, un régimen democrático está consolidado cuando una gran mayoría de la opinión pública, incluso en medio de grandes problemas económicos y de una profunda insatisfacción con los funcionarios, mantiene la creencia de que los procedimientos e 
apreciación, lo que interesa es la identificación de esos niveles o dimensiones y las posibilidades que se derivan para el análisis político. Independientemente de las denominaciones que utilizan estos autores (que ciertamente no son adecuadas), es indudable que en este acercamiento se encuentra una pista para romper el carácter extremadamente abstracto y poco adecuado para la investigación aplicada que tiene el generalizado concepto eastoniano de sistema político.

Otro tipo de clasificación se desprende de la explicación del cambio político realizada por Morlino (1985). Este autor identifica también tres niveles, cuando sostiene que "parece plenamente válida la división general en tres partes: comunidad política, régimen y autoridad” (Morlino, 1985: 44). En la primera se encuentran “las personas o los grupos que son activos y pueden llegar a incidir en el sistema (...) También en este nivel tienen relieve las doctrinas, incluidas las de origen religioso, las ideologías, las creencias dominantes en la comunidad o, en todo caso, capaces de concitar grupos en torno a ellas. Finalmente, de la comunidad política pueden emerger (...) estructuras de conversión de las demandas [esto es] las estructuras intermedias, tales como los partidos políticos, los sindicatos (...) En el segundo nivel, el régimen, tienen relieve también las ideologías, los valores, los principios o las creencias, dominantes o en competencia, que influyen más específicamente en las reglas del juego o en los procedimientos y en las estructuras de autoridad (...) El tercer elemento del régimen son las estructuras de autoridad (Morlino, 1985: 44). Pese a su utilidad en términos taxonómicos, a esta clasificación se le puede reclamar la escasa delimitación de cada uno de los niveles y la ubicación de los componentes de un nivel en otro que no corresponde (por ejemplo, los partidos políticos y en general de las estructuras de intermediación dentro de la comunidad política). Es una clasificación que permite la identificación de varios niveles $-\mathrm{y}$ que en esa medida puede ser una guía para detectar cada uno de los ámbitos de estudio- pero no da cuenta de ellos adecuadamente.

Por su parte, en su revisión del concepto de gobernabilidad, Camou (2001) sostiene la necesidad de “distinguir los diferentes 'niveles' en que pueden presentarse las cuestiones de gobernabilidad" (Camou, 2001: 23). Los niveles a los que se refiere, siguiendo básicamente el modelo parsoniano, son el sistema económico (mercado), el sistema político administrativo (que incluye al Estado) y el sistema sociocultural (o sociedad civil)

instituciones democráticos constituyen el modo más apropiado de gobernar (...) En términos constitucionales, un régimen democrático está consolidado cuando las fuerzas gubernamentales y no gubernamentales se sujetan y habitúan a la resolución del conflicto dentro de los límites de las leyes, los procedimientos y las instituciones específicas" (Linz y Stepan, 1996: 31, cursiva en el original). 
(Camoun, 2001: 24). Este último nivel "combina los elementos propios del llamado sistema 'sociocultural' y del sistema 'comunitario"' (Camou, 2001: 24). El sistema político, por su parte, sería “el conjunto articulado de las creencias y valores (cultura), las fórmulas institucionales para la agregación de preferencias y toma de decisiones (tanto formales como informales, inscritas en el régimen, pero también fuera de él), y las prácticas y relaciones de poder efectivamente vigentes entre los actores políticos de una sociedad" (Camou, 2001: 25). Finalmente, el sistema económico o mercado sería "el conjunto articulado de 'actos de competencia e intercambio' controlados por el medio dinero y regulados por un régimen de propiedad, que cumple la función de 'asignar recursos y preferencias' según el principio de utilidad" (Camou, 2001: 25). Sin embargo, el autor incluye como elemento adicional al régimen político cuando sostiene que en el plano institucional se encuentran "las reglas y organizaciones del juego político que configuran 'fórmulas institucionales', es decir, mecanismos operacionales para la agregación de preferencias e intereses, y la toma de decisiones, uno de cuyos componentes centrales, al nivel más agregado, configura el régimen político" (Camou, 2001: 26). Se trata, por tanto de otra variación dentro del modelo de Easton, en la que se añade -innecesariamente, en mi opinión- al sistema económico.

También desde la preocupación por la gobernabilidad, Alcántara (1995) propone una clasificación en tres niveles diferenciados. Después de pasar revista a diversas corrientes explicativas, el autor sostiene que éstas "dejan un pozo lo suficientemente rico y atractivo que facilita la opción personal hacia un concepto concreto de sistema político (Alcántara, 1995: 54). Este estaría conformado, en primer lugar, por "los elementos institucionales (a cuya expresión formalizada aquí se la denomina régimen político) que representan los poderes políticos y sus reglas de interacción para consigo mismo y para con la sociedad, pero también a las normas, escritas o consuetudinarias, que hacen referencia a las formas de tenencia de la propiedad, a su transmisión, a su enajenación y a sus constricciones. En segundo término, los actores institucionalizados en que la sociedad se organiza ya sea de manera activa o pasiva, para transmitir sus demandas, influir y modificar en mayor o menor medida en las decisiones del gobierno. En tercer lugar, los valores de los individuos y de los grupos sociales que componen la sociedad en cuanto a la comprensión de la actividad política se refiere, derivados tanto de elementos estrictamente culturales como de experiencias históricas" (Alcántara, 1995: 54). Por 
consiguiente, son tres niveles diferentes que deben recibir también un tratamiento específico en términos analíticos.

A partir de esos acercamientos - de sus propuestas y de sus vacíos- es posible encontrar una vía para superar las limitaciones que se hacen evidentes en el concepto de sistema político. Esta ruta puede trazarse por medio de la identificación de los diversos niveles en que se realiza la política, definidos por el papel que desempeña cada uno de ellos y por sus componentes específicos. De esta manera, se puede identificar un primer nivel en que se construyen los valores, las creencias, las orientaciones y los mitos que dan forma a la política. Es el nivel básico de la sociedad, que incluso puede ser considerado en términos estrictos como pre-político ya que todas aquellas construcciones no son exclusivamente políticas y conviven con las creencias, orientaciones, etc. de cualquier signo. Es el ámbito de la sociedad o, si se quiere, de la comunidad política. Un segundo nivel es el de las prácticas políticas, de los actores y de las instituciones en que ellos se desempeñan. Por lo general este sigue pautas formalmente establecidas, pero pueden incluirse también las prácticas y las instituciones informales. Es el ámbito para el cual, por razones que señalaré más adelante, debe reservarse el término de sistema político. Un tercer nivel es el de las normas y las disposiciones que establecen los límites y los alcances de la acción política, que generalmente tiene un alto grado de formalización a través de las leyes, las normas y las disposiciones constitucionales. Es el campo del régimen político. En consecuencia, una conceptualización de este tipo lleva a identificar con claridad a la comunidad política, al sistema político y al régimen político. Los tres niveles están estrechamente relacionados por influencias mutuas (inputs y outputs), dentro de una constante interacción que produce cambios y modificaciones en cada uno de ellos como resultado de la acción de los otros. Sintéticamente en el gráfico número 2 se muestra la posición de cada uno de estos niveles y sus correspondientes interacciones. 


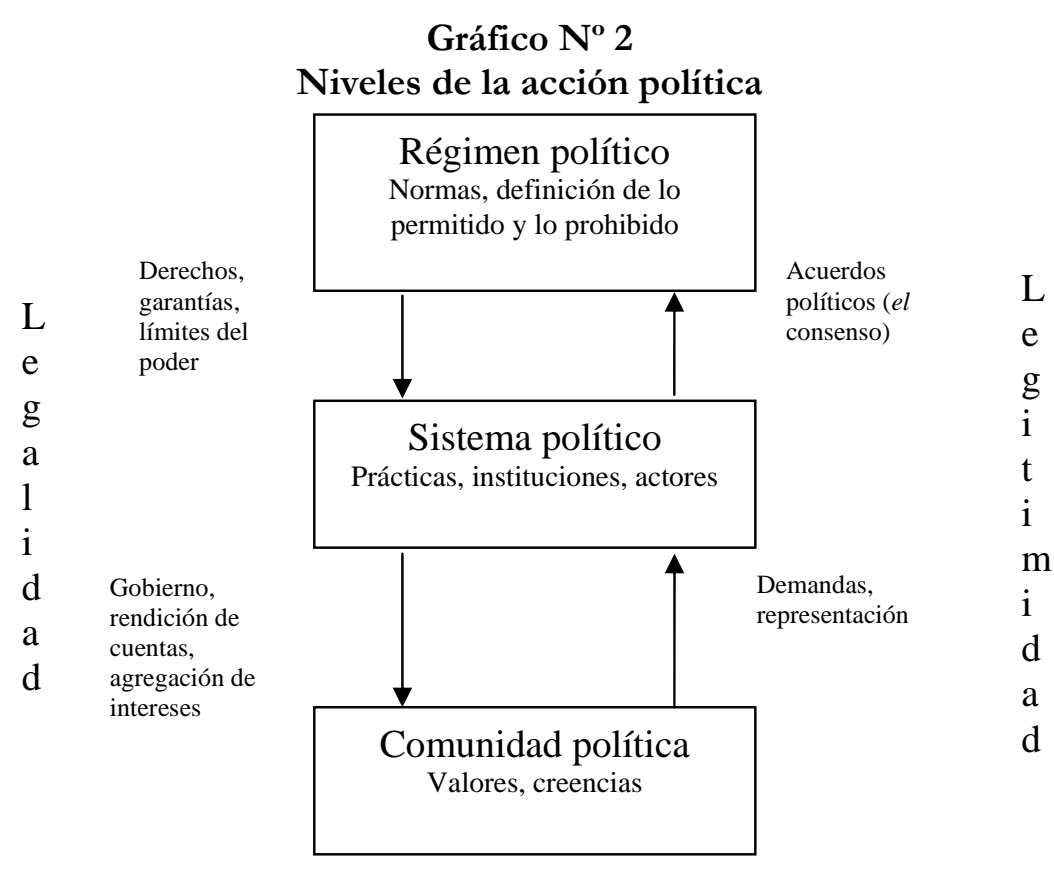

Elaboración: Simón Pachano

Esta clasificación ofrece, en primer lugar, la posibilidad de identificar claramente los niveles y, por tanto, de asignar a cada uno de ellos una denominación específica. Esta denominación es útil en tanto puede ser considerada como un concepto que expresa los contenidos y las funciones de cada uno de los niveles. De esta manera, además, cada uno de estos se diferencia de los demás sin las superposiciones que se presentan en algunas de las clasificaciones reseñadas antes. En segundo lugar, esta clasificación permite identificar las relaciones (los inputs y los outputs) que se establecen entre los diversos niveles, lo que por su parte facilita la interpretación de los flujos y de los obstáculos que se encuentran en esas interacciones. Por consiguiente, hace posible la identificación del lugar (por decirlo de alguna manera) en que se presentan los problemas y facilita la apreciación de su magnitud. En tercer lugar, al identificar esas relaciones establece un determinado orden o, si se quiere, demuestra un cierto grado jerárquico que debe seguir (en términos ideales) la política para mantener el equilibrio del conjunto e incluso para producir ordenadamente el cambio y evitar las rupturas que afectan a cada uno de los niveles o a todos ellos ${ }^{64}$. Por último, esta clasificación puede ser un buen instrumento para

${ }^{64}$ Como se verá en los capítulos III y IV, es muy importante la identificación de las relaciones que idealmente deben producirse entre los diversos niveles para comprender algunos de los problemas que han enfrentado los tres países en su historia reciente. Uno de los temas centrales en este sentido es la 
comprender los problemas de legitimidad que amenazan a los regímenes y a los sistemas políticos que, en el caso específico de los tres países estudiados, ha sido uno de los problemas más graves desde el retorno a los regímenes democráticos.

A diferencia de la formulación de Easton, que no permite diferenciar el sistema político de la totalidad del sistema social, esta clasificación lleva claramente a la identificación de un nivel estrictamente político, conformado por las instituciones, las prácticas y los actores políticos. Es, por tanto, el lugar en que se materializa la voluntad de los ciudadanos por medio de la representación y de la canalización de los intereses, donde se disputan los espacios políticos, se realizan los acuerdos, se toman las decisiones, se formulan las políticas y se procesan los conflictos. Por consiguiente, es en donde se genera la legitimidad por procedimientos, ya que todas aquellas prácticas y acciones deben guardar estrecha relación con los fines democráticos. Pero, a la vez, en la medida en que desde este nivel emanan las políticas y las decisiones de gobierno, viene a ser también el ámbito en que se genera la legitimidad por rendimientos o por resultados. El sistema político debe ofrecer respuestas a las necesidades y a las demandas de la población bajo la forma de acciones concretas.

En este nivel se hacen evidentes dos conflictos que la democracia debe resolver a cada paso y en cada momento. Primero, es necesario atender a la tensión entre eficiencia y eficacia, por un lado y procedimientos democráticos, por otro lado. Este conflicto se manifiesta fundamentalmente por la tentación a desarrollar practicas efectistas que permitan alcanzar objetivos concretos (económicos y sociales, principalmente) a cualquier costo y en el menor tiempo posible. La deficiente resolución de esta tensión puede desembocar en autoritarismos competitivos (Levitsky y Way, 2002) o en democracias delegativas (O’Donnell, 1992), que se justifican por la necesidad de dar respuesta a las necesidades sociales aún por encima -y a costa- de los procedimientos democráticos. Segundo, es preciso resolver el conflicto entre representación y acción de gobierno, en el sentido de que en el sistema político deben tener cabida todos los grupos sociales existentes en la sociedad, pero a la vez aquel debe gobernar a la sociedad. Con esto se

debilidad del output que va del sistema político a la comunidad política, que ha llevado a que con mucha frecuencia se ponga en cuestión el régimen político. Las constantes reformas constitucionales y la instalación de asambleas constituyentes dan cuenta cabal de ello. A pesar de esto, al considerar que el problema central de las democracias andinas es la crisis de representación, la mayor parte de diagnósticos -tanto académicos como políticos- han puesto énfasis en el output que va de la comunidad política al sistema político. 
abre el inmenso campo de la capacidad del sistema político para representar y agregar intereses asegurando la igualdad entre ellos (una igualdad que debe manifestarse tanto en la representación como en la gestión de gobierno) ${ }^{65}$. Este conflicto puede ser tratado desde la perspectiva de la gobernabilidad, entendida como la combinación entre "eficacia gubernamental y legitimidad social" (Camou, 1998: 37), como la capacidad del sistema político para dar respuesta a las demandas de la sociedad (Flisfisch, 1983:), como "el grado en que las relaciones entre los actores poderosos obedecen a unas fórmulas estables y adoptadas (Coppedge, 1996: 28), o como "la situación en que concurre un conjunto de condiciones favorables para la acción de gobierno, de carácter medioambiental o intrínsecas a éste" (Alcántara, 1995: 39). A pesar de sus diversas formulaciones, todas esas percepciones de la gobernabilidad aluden a este nivel y al problema mencionado.

Un elemento adicional que se desprende de esta clasificación es la ubicación y el papel del régimen político dentro de la democracia. El régimen incluye al "conjunto de pautas, explícitas o no, que determinan las formas y canales de acceso a los principales cargos de gobierno, las características de los actores admitidos y excluidos con respecto a ese acceso, y los recursos o estrategias que pueden emplear para ganar tal acceso" (O`Donnell y Schmitter, 1994: 118). Por tanto, el régimen da significación a los actores políticos y establece las diversas formas en que ellos pueden acceder a los cargos políticos, así como los procedimientos para ese acceso pero también para el procesamiento de los asuntos políticos. De esa manera, la mayor o menor apertura del régimen (expresada en términos de los actores incluidos pero también en cuanto al carácter y la viabilidad de sus procedimientos) determinará así mismo el mayor o menor grado de democracia. En ese sentido, el régimen adquiere su legitimidad en tanto es percibido como la expresión de un orden compartido por todos y válido para todos. Un régimen excluyente -ya sea en términos reales a causa de sus disposiciones normativas o en términos de percepción- tenderá siempre a presentarse como un orden ilegítimo o, por lo menos, dotado de escasa legitimidad. Dado su papel normativo sobre el sistema político y sobre la comunidad política, se trata de una legitimidad de origen. Utilizando la

${ }^{65} \mathrm{La}$ especificidad de la representación política, frente a la representación en el ámbito privado (como la que realiza un abogado en el campo jurídico), se hace evidente en este aspecto. Aunque ambas pueden ser descritas como la actuación de una o varias personas en representación de otra u otras, hay dos elementos básicos que las diferencian. Por una parte, en la representación privada se establece un mandato vinculante que no existe en la política. Por otra parte, en la privada no está presente la función de gobierno que caracteriza a la pública (Sartori, 1999: 257-277; Manin, 1998: 17; Przeworski, 1999: 231). 
metáfora del contrato, el régimen puede ser visto como el espacio en que aquel se materializa (específicamente bajo su forma de pactum subiectionis), incluso sin la intermediación del sistema político. Una vez constituido el régimen político generalmente por medio de la promulgación de una constitución- pasa a ser el parámetro de evaluación de la democracia en tanto orden político. Por consiguiente, la legitimidad de origen es compartida con la comunidad política, lo que se hace evidente cuando se presentan impugnaciones por su carácter excluyente ${ }^{66}$.

El último elemento que se puede desprender de esta clasificación es que por medio de ella se puede identificar con relativa claridad los inputs y los outputs que se establecen entre los diversos niveles. Los outputs de la sociedad se expresan fundamentalmente como demandas y como representación. Ambas tienen estrecha relación y se materializan en un mismo acto y por la misma vía o, dicho de otra manera, en democracia las demandas se transmiten por medio de la representación política ${ }^{67}$. Por su parte, la comunidad política recibe del sistema político rendimientos de gobierno bajo la forma de políticas, con lo que se hace posible la construcción de la legitimidad por rendimientos. La sociedad, las personas de carne y hueso pero también los grupos que ellas conforman, evalúan por el efecto de las políticas a las instancias del sistema político, de manera especial a sus representantes que en esa medida están sujetos a permanente escrutinio (de donde surge la accountability como otro output del sistema político hacia la comunidad política).

Desde el sistema político emanan acuerdos políticos que se dirigen hacia el régimen político, donde se transforman en normas. En realidad, en situaciones de normalidad en el sistema político se estructura el consenso político que garantiza la propia estabilidad del

\footnotetext{
${ }^{66} \mathrm{La}$ impugnación a la legitimidad del régimen desemboca generalmente en reformas constitucionales que tienden a hacerlo más inclusivo (por medio del reconocimiento de derechos de nuevos actores o de nuevos tipos de derechos para los actores ya dotados de significación). La definición del Estado como pluriétnico y multicultural -contenida en la constitución ecuatoriana de 1998-, con los correspondientes derechos colectivos que se desprenden de ella, es un ejemplo claro en ese sentido. La impugnación a la legitimidad de la comunidad política como asociación básica (que incluye ineludiblemente al régimen) tiene mayor profundidad y requiere de cambios en el tipo de régimen y en la organización del Estado. Un ejemplo en este sentido es la propuesta de Estado plurinacional de la manera en que aparece en la constitución boliviana aprobada en enero de 2009.

${ }^{67} \mathrm{La}$ introducción de formas de democracia directa (referendo, iniciativa legislativa, revocatoria de mandato e incluso presupuestos participativos) no alteran esta afirmación ya que son claramente complementarias al carácter representativo de la democracia contemporánea (Lissidini, 2008; Pachano, 2008). Únicamente las corrientes radicales que suponen una relación excluyente entre democracia representativa y participativa (De Souza, 2004) podrían sostener lo contrario.
} 
sistema y del régimen ${ }^{68}$. Por su parte, el sistema político recibe desde el régimen las normas y los procedimientos a los que se debe someter y que establecen lo permitido y lo prohibido. De esta manera, sus límites y sus alcances están determinados por el régimen, lo que quiere decir que también desde allí se da significación a los actores que pueden desempeñarse en el sistema político. En estos términos, el régimen define quiénes, cómo y dónde deben actuar, lo que es válido para las personas, los grupos y las instituciones que constituyen la política práctica.

Finalmente, todo este complejo entramado debe asentarse tanto sobre la legitimidad cuanto sobre la legalidad, entendidas como resultados pero también como insumos para el funcionamiento de todos y cada uno de sus niveles. Legitimidad y legalidad aparecen, en el ordenamiento democrático, no solamente como los pilares que sustentan a toda la estructura, sino también como elementos inseparables. Dadas las interrelaciones entre los tres niveles, es imposible que se pueda contar con una de ellas sin que esté presente la otra. En esa condición ninguna de ellas puede estar ausente y tampoco es posible sacrificar a la una por la otra ${ }^{69}$. Esta estrecha relación de mutuo sustento es un elemento básico sin el cual la democracia corre el riesgo de desmoronarse ${ }^{70}$.

${ }^{68}$ En situaciones de normalidad, esto es, desde el momento en que existe un régimen constituido y respetado por todos los actores. El paso previo, que corresponde a la constitución de ese orden (al contrato originario), puede haberse realizado con prescindencia del sistema político. Así mismo, la impugnación del orden existente puede dar lugar a la intervención directa de la sociedad en la construcción del nuevo. Desde Tocqueville en adelante, pasando por los Federalist Papers es muy rica la literatura que llama la atención sobre los riesgos y los peligros de situaciones de esta naturaleza (Elster, 1998: 66-70)

${ }^{69}$ Esta advertencia tiene mucho sentido en el caso de los tres países, Bolivia, Ecuador y Perú, donde frecuentemente, en función de una supuesta legitimidad (generalmente de resultados), se ha actuado en contra de la legalidad.

${ }^{70}$ Ciertamente, un acto político ilegal puede ser plenamente justificado por su legitimidad en situaciones excepcionales en las que, por ejemplo, se han afectado los derechos ciudadanos, no se han observado los procedimientos o en general han existido abusos del poder. En esos casos se ejerce legítimamente -aunque no fuera legalmente- el derecho a la resistencia. Sin embargo, si se ha llegado a ese punto quiere decir que previamente se han roto los principios y los procedimientos democráticos, de manera que no afecta a lo señalado acerca de la relación entre legalidad y legitimidad. En el fondo de este tema se encuentra el conflicto entre las concepciones de libertad del liberalismo y de la democracia. La primera considera a la libertad como "el derecho a hacer todo lo que las leyes permiten" (Montesquieu, 1989), en tanto que para la segunda la "libertad es la obediencia a la ley que uno se ha prescrito" (Rousseau, 1981: 102). Desde la perspectiva de Constant (1998), la primera corresponde a la libertad de los modernos, ya que se trata del goce de las libertades individuales, en tanto que la segunda sería la de los antiguos, debido a que la libertad equivale a la participación en el poder político. También se puede llegar al debate planteado por los comunitaristas dentro del liberalismo, en que precisamente se pone en cuestión el concepto de libertad (Riker, 1982: 3-19; Walzer, 1996: 47 y ss.). Anteriormente, la relación entre legalidad y legitimidad fue planteada con mucha precisión por Kant (1999: 83n) cuando sostuvo que la libertad es "la facultad de no obedecer ninguna ley exterior sino en tanto en cuanto he podido darle mi consentimiento". 
Antes de concluir con la descripción del sistema es necesaria una explicación sobre la ausencia -en esta clasificación- de varios elementos que se encuentran en algunas de las clasificaciones revisadas y, adicionalmente, encontrar una denominación para el conjunto una vez que la de sistema político ha pasado a connotar a una de las partes. Cabe comenzar por este último punto, en el que no se puede dejar de reconocer que la denominación del conjunto, al que la tradición derivada de Easton llamó sistema político, es bastante más compleja que la simple asignación de un nombre. Si se mantiene la perspectiva de la teoría de sistemas, se hace necesario denominar a ese conjunto como un sistema, con lo que se corre el riesgo de volver a adjetivarlo como político, con lo que se retornaría al punto de partida. Como se ha visto, esa denominación original resulta poco precisa cuando se trata de dar cuenta de sus componentes y, sobre todo, no es operativa. Tampoco cabe volver a la denominación parsoniana de sistema social, ya que la característica específica de este conjunto es la política y, por lo dicho, es una parte del sistema social. Quizás conviene abandonar el lenguaje (manteniendo la perspectiva de análisis) de la teoría de sistemas y acudir a un término más abarcador, como ordenamiento político. Este puede dar cuenta del conjunto, que a su vez forma parte del sistema social como un todo más amplio (como se muestra en el gráfico número 3).

Gráfico $\mathrm{N}^{\mathrm{o}} 3$

Componentes y relaciones del sistema social

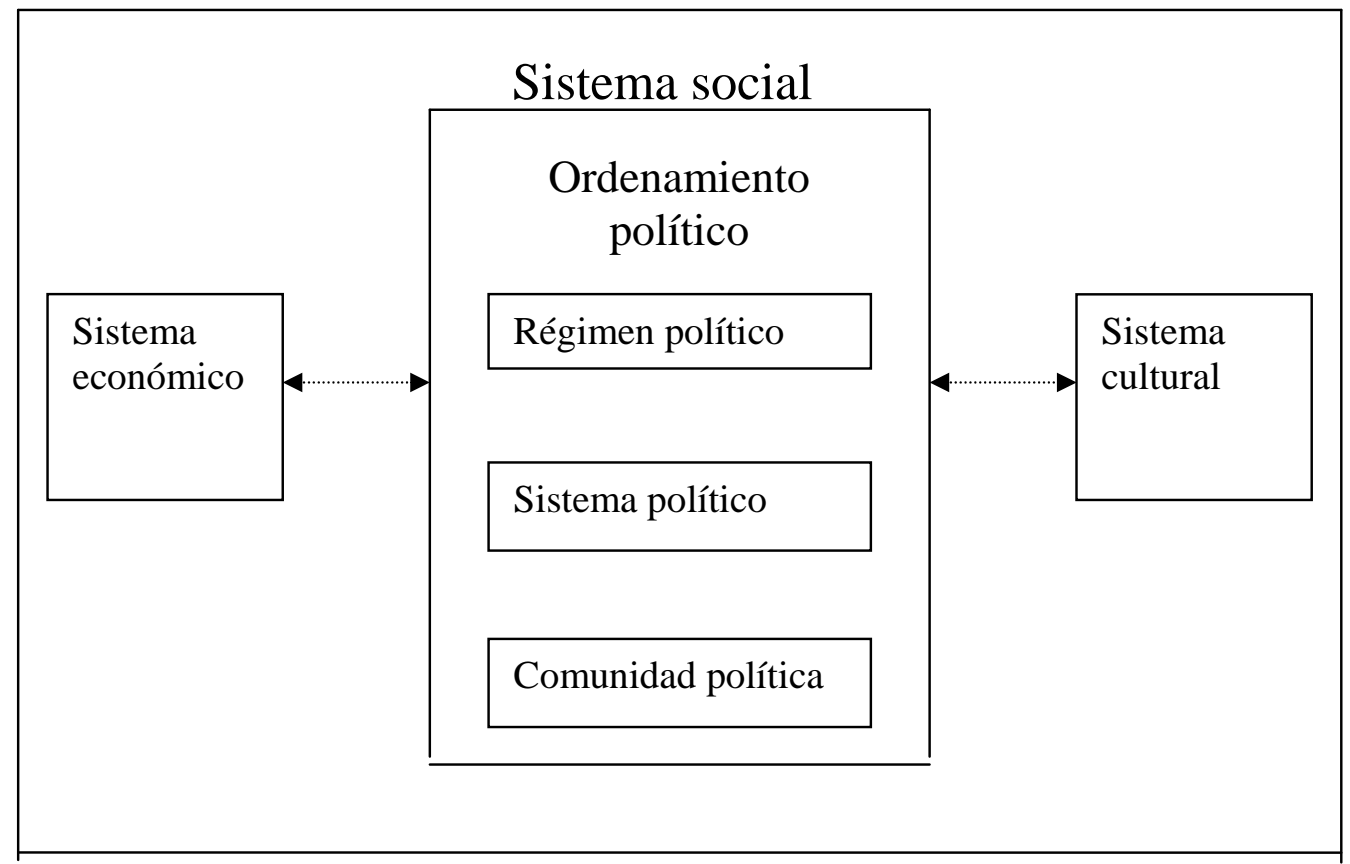

Elaboración: Simón Pachano 
Otra opción se encuentra en la utilización de régimen político para el conjunto, con la correspondiente sustitución de esa denominación para el nivel de las normas. Esta posibilidad tiene el atractivo que proviene del uso cotidiano de ese concepto que, en un nivel extremadamente general, designa las diferencias entre democracias y autoritarismos (como regímenes). Pero, a la vez choca con otro uso cotidiano del mismo término, el referido a las modalidades de división de poderes como parlamentario y presidencial (entendidos también como regímenes). Por el contrario, si se mantiene el concepto de régimen para el nivel de las normas se puede aludir indistintamente a sus diferencias en términos del carácter (democrático o autoritario) o de la organización de sus poderes (parlamentario o presidencial). Esto es así porque en la clasificación propuesta el régimen está definido por sus atributos normativos, y en esos términos puede ser, por ejemplo, democrático y al mismo tiempo parlamentario (e incluso pueden añadirse otros atributos que contribuyan a su denotación). Además, al aludir a la totalidad con el término régimen, sería necesario encontrar un sustituto para el nivel normativo, lo que constituye una tarea con pocas expectativas. Si se lo pasa a llamar normativo, como corresponde a su esencia, se eliminaría la posibilidad de aludir a él como un sustantivo. Por consiguiente, por lo menos mientras no se encuentre una mejor opción, parece adecuado mantener las denominaciones propuestas en la clasificación.

Por último, respecto a la ausencia de algunos elementos que aparecen en las clasificaciones citadas cabe hacer una precisión. En primer lugar, no es casual que en esta taxonomía no aparezcan los tres ámbitos heredados de la visión parsoniana, que son el sistema social, el sistema económico y el sistema cultural. Aunque ellos ocupan un lugar de mayor o menor importancia en las propuestas de los autores que derivan sus respectivas clasificaciones de Easton (Morlino, Alcántara, Camou), considero que es necesaria una aclaración conceptual respecto al sistema social y una apreciación acerca del lugar de los otros dos. Así, si se sigue la lógica de Parsons, que a su vez se encuentra en el origen de la propuesta de Easton, se debe aceptar que el concepto de sistema social abarca al conjunto de todos los sistemas (Parsons, 1976: 73-111). En consecuencia, es el sistema de sistemas, de modo que no cabe denominar de esa manera a uno de sus componentes. Más bien, el resto se encuentra dentro de éste (como se representa en el gráfico número 3). En cuanto a la ubicación de los otros dos -el sistema económico y el sistema cultural- se debe aceptar que, dentro de la organización política, ellos no tienen un papel de similar importancia a la que les corresponde a los elementos básicos (régimen 
político, sistema político y comunidad política). Ellos forman parte del sistema social, pero no del ordenamiento político (como también se ve en el gráfico número 3). Otra cosa muy distinta es que se relacionen con el conjunto del ordenamiento político y que se condicionen mutuamente (a través de inputs y outputs), como se veía parcialmente en el gráfico número 1.

\section{Concepto mínimo, concepto medio y concepto operativo de democracia}

Con estos elementos es posible volver al tema de la democracia y conviene retomarlo en el mismo punto en que quedó, el de la legitimidad. Para ello es preciso partir del componente básico, el de la sociedad, que existe como tal en la medida en que hay un acuerdo entre sus integrantes para constituirla. Sin ese acuerdo, ese pacto constitutivo (pactum societatis), no existe la sociedad como tal, esto es, como un grupo de personas que acuerdan vivir juntas dentro de un territorio determinado (Bobbio, 1997: 94). Pero, dentro del análisis de la política interesa no solamente ese acuerdo constitutivo, sino también un segundo pacto que lleva a la construcción y al reconocimiento de un poder político que rija sobre esa sociedad (pactum subiectionis). Este segundo paso es el que, en términos de Locke, conduce a la instauración de la sociedad política, ya que "siempre que cierto número de hombres se une en una sociedad renunciando cada uno de ellos al poder de ejecutar la ley natural, cediéndolo a la comunidad, entonces y sólo entonces se constituye una sociedad política o civil” (Locke, 1983: 69; véase también Arendt, 2004: 196; Gellner, 1998: 18) ${ }^{71}$. Cabe diferenciar, por consiguiente, a la sociedad como agrupación de personas de la sociedad como organización política (que, como se verá de inmediato, se materializa en el régimen político). En ambas facetas se presenta el problema de la legitimidad, esto es, de la aceptación de un orden (pre-político o político, respectivamente). Aunque para el análisis de la democracia tiene mayor relevancia la última -la de carácter estrictamente político-, no por ello se puede obviar el interés que debe concitar la primera, la sociedad como colectividad que decide vivir en conjunto.

Desde esta perspectiva, cuando se alude a la legitimidad en el nivel de la sociedad en realidad se está haciendo referencia a dos objetos diferentes. Por un lado, se encuentra la sociedad que requiere contar con la aquiescencia de sus integrantes para mantenerse como tal. Por otro lado, es claramente identificable la sociedad en tanto comunidad politica,

\footnotetext{
${ }^{71} \mathrm{El}$ concepto de sociedad civil que aparece en Locke difiere del que se ha vuelto de uso corriente en la actualidad. Este último se origina en la interpretación que hizo Gramsci de la versión marxista, que a su vez estaba tomada de Hegel. Al respecto, véase Tenzer (1991).
} 
esto es, en su condición de organización que define un orden, unas normas y unos procedimientos para procesar sus conflictos. Hay, en ambos casos, la referencia a una legitimidad de origen, esto es, la aceptación de un orden que proviene tanto del acuerdo de convivencia como del acuerdo de sujeción a un orden político. Si cualquiera de estos es puesto en cuestión, corre el riesgo de derrumbarse no solamente todo el orden político, sino de desaparecer la sociedad como tal $^{72}$. Por ello, y en general por la experiencia histórica de América Latina, África, los países de lo que fue la órbita soviética, Medio Oriente y parte de Asia, no es aceptable la afirmación de Sartori (1988: 122) acerca de la escasa importancia del consenso básico (o consenso a nivel de comunidad $^{73}$. Como se verá más adelante (en la última sección de este capítulo y en el capítulo IV), la democracia de los tres países debe enfrentar serios problemas en el nivel del consenso básico y, en consecuencia, muestra significativas carencias de legitimidad de origen.

Por otra parte, como se vio antes, la legitimidad en el nivel del sistema político alude básicamente a la que se establece por procedimientos, que debe ser entendida bajo tres formas diferentes. En primer lugar, se refiere a los resultados del sistema, entendido fundamentalmente en términos económicos y sociales o, dicho de otra manera, a los rendimientos de gobierno (en el sentido amplio señalado antes). En segundo lugar, es una legitimidad que se establece por la capacidad de representación del sistema político, esto es, por la posibilidad de que todos los ciudadanos vean canalizados y representados sus intereses en ese nivel. Por lo demás, ambas formas encuentran en la rendición de cuentas (accountability) un valioso e irrenunciable elemento de apoyo (Przeworski, 1999: 229; Peruzzotti y Smulovitz, 2002: 25-30). En tercer lugar, el propio sistema como tal

\footnotetext{
72 Sin ir al extremo de la experiencia yugoslava -caso paradigmático en los dos aspectos mencionados, se pueden detectar problemas de este tipo, aunque de menor magnitud, en los países estudiados. La sociedad en sí misma, bajo su expresión de la nación y del Estado, ha sido puesta en cuestión no solamente a lo largo de sus primeros años de historia republicana -aludidos en la primera sección de este capítulo-, sino incluso dentro del actual período democrático. Buena parte de los conflictos políticos y de las reformas que se han impulsado en Bolivia Ecuador y Perú en los últimos años se han originado en -y aluden a- la constitución de la nación y a la (re)definición del Estado.

${ }^{73} \mathrm{Al}$ referirse a los niveles de consenso, Sartori sostiene que "El primer objeto o nivel de consenso que podemos identificar como consenso básico- señala si una sociedad determinada comparte en su totalidad los mismos valores y fines valorativos. Cuando así ocurre, tenemos, según Almond, una «cultura política homogénea»" (Sartori, 1988: 122). Dado que las formas democráticas se superponen a las culturas políticas homogéneas y heterogéneas, continúa el autor, "No puede afirmarse que el consenso en el nivel de las creencias comunitarias sea una condición necesaria de la democracia" (Sartori, 1988: 122 cursiva en el original). La realidad de los tres países estudiados muestra lo contrario ya que la democracia aparece seriamente cuestionada precisamente en ese nivel de los valores básicos debido a que no existe acuerdo sobre temas tan fundamentales como la libertad y la igualdad a las que el propio Sartori identifica como constitutivas de este nivel.
} 
requiere de una legitimidad que está dada por el carácter de sus procedimientos, es decir, por el apego a las reglas del juego emanadas desde el régimen político. Este último sentido exige que la sociedad acepte los procedimientos democráticos como los más adecuados para la representación de sus intereses y para el procesamiento de las controversias políticas. Esta forma de legitimidad es la que se encuentra en permanente riesgo, ya que depende de los resultados, de su capacidad de representación y de agregación de intereses, y de los valores de la población acerca de la manera en que se procesan y resuelven los conflictos. Por consiguiente, se mueve permanentemente en un difícil equilibrio entre resultados, procedimientos y valores.

Una gran parte de los estudios sobre los procesos políticos en las democracias contemporáneas - especialmente en las de reciente aparición- se han concentrado en este nivel y en los problemas que se derivan precisamente de los tres elementos mencionados. Así, una vertiente de la política comparada y de los estudios de caso se preocupa de los rendimientos sociales y económicos de estas democracias (Linz, 1987; Helliwell, 1994; Nun, 2002; De Souza, 2004), lo que a su vez lleva la reflexión hacia temas como el de la gobernabilidad (Alcántara, 1995; Camou, 1998; Flisfisch, 1983; Mayorga, 1992; Mejía, 2002). La preocupación central de ese tipo de estudios es que los bajos rendimientos se traducen en obstáculos para el desempeño de los gobiernos y en general para el funcionamiento armónico del sistema político, lo que genera problemas de gobernabilidad $^{74}$. Otra vertiente se ha interesado en mayor medida por las condiciones de representación y de participación en las nuevas democracias (Manwaring, Bejarano y Pizarro, 2006; Przeworski, 1999; Manin, Przeworski y Stokes, 1999). El elemento central en este campo es la denominada crisis de representación, entendida sobre todo como la baja capacidad del sistema político para canalizar y agregar los intereses sociales, así como para ofrecer respuestas satisfactorias a todos ellos. En conjunto con el anterior o cada uno de ellos por separado, pueden llegar a configurar una situación en que la insatisfacción con los resultados o con las condiciones de representación alcance un nivel mayor y afecten al conjunto del sistema. Una tercera línea de análisis, que reconoce la importancia de los procedimientos, se ha desarrollado en mayor medida en los trabajos

\footnotetext{
${ }^{74}$ Las posiciones críticas (que propugnan una democracia radical o una democracia directa) toman a los rendimientos del sistema político como un componente del concepto de democracia. De esta manera, bajos resultados en lo económico y en lo social serían expresiones de ausencia de democracia (Cueva, 1988)
} 
teóricos y conceptuales, y solo en aspectos muy específicos ha ocupado un lugar en los estudios aplicados ${ }^{75}$.

Por último, sobre la legitimidad del régimen parece suficiente lo señalado en las páginas anteriores, aunque no resulta redundante reiterar que es en este ámbito donde se materializa el consenso que constituye la organización política de la sociedad (donde se expresa el pactum subiectionis). Por consiguiente, se trata de un consenso básico (similar al de la comunidad política), en el sentido de que sobre él se asienta el conjunto del ordenamiento político. De esta manera, los problemas de legitimidad que se presentan en este nivel ponen en riesgo a todo el ordenamiento político o, en otras palabras, se expresa como una crisis global que obliga a establecer un nuevo acuerdo básico.

Una vez identificados los niveles de consenso y sus respectivos problemas de legitimidad, es inevitable preguntarse por la connotación que tiene el concepto de democracia en cada uno así como en el conjunto de ellos. Como se vio antes, Sartori (1988) se ocupa de este tema desde la perspectiva del consenso necesario para la democracia, mientras Linz y Stepan (1996) lo hacen con el interés de detectar las condiciones requeridas para la consolidación de la democracia en cada uno de los niveles. Ambos acercamientos abren la puerta hacia una comprensión específica de la democracia en cada uno de los niveles, pasando del concepto general, que alude al conjunto, a nociones de carácter más operativo. En efecto, los estudios aplicados demandan mayor precisión que la que ofrece un concepto de alcance general, ya que no es extraño enfrentar situaciones en las que la democracia se ve afectada por problemas que se presentan solamente en uno de los niveles mientras los demás no mantienen las características que los definen como democráticos ${ }^{76}$. Al utilizar un concepto de alcance general se pierde la posibilidad de identificar esos problemas, con lo que se corre el riesgo de construir diagnósticos erróneos y de atribuir los problemas a un nivel que no corresponde.

\footnotetext{
${ }^{75}$ Los estudios en este campo se refieren fundamentalmente a las votaciones en los congresos y la disciplina partidista, a la utilización de determinadas facultades presidenciales como el poder de veto y de expedir decretos-ley, así como la utilización de recursos como la revocatoria del mandato o impeachment. Es notorio el vacío -o por lo menos la escasez de estudios- en aspectos fundamentales como la oposición desleal, el derrocamiento de presidentes y el surgimiento (y desarrollo) de organizaciones antidemocráticas y antisistema.

${ }^{76}$ El caso generalizado, y de mucha importancia en América Latina -en especial en los países analizados- es la inobservancia de los procedimientos democráticos (en el nivel del sistema político) mientras las disposiciones constitucionales y normativas (en el nivel del régimen) mantienen su carácter democrático. Esto es lo que deriva en los denominados autoritarismos competitivos (Levitsky y Way, 2002) y en las democracias delegativas (O’Donnell, 1992). Por el contrario, el déficit de democracia en el nivel del régimen puede instaurar democracias iliberales (Zakaria, 1998).
} 
Desde este punto de vista se hace más clara la connotación de los diversos conceptos de democracia de uso frecuente en la ciencia política. Así, a manera de ejemplo, es posible comprender que el concepto de Schumpeter hace relación al sistema político en tanto alude a la competencia por el voto, pero a la vez apunta también al régimen en la medida en que incluye como condiciones los derechos y libertades individuales (Schumpeter, 1996: 343-346). Lo mismo se puede afirmar respecto al concepto de poliarquía de Dahl, que coloca en el centro de la definición a los aspectos procedimentales, propios del sistema político, pero no deja de considerar los que se refieren al régimen cuando incluye los derechos y libertades como premisas básicas (Dahl, 1989: 18 y ss). La percepción de Bobbio, por el contrario, se centra en el régimen en la medida en que destaca los aspectos constitucionales y normativos de la democracia (Bobbio, 1985: 195-221), pero no deja de aludir a la importancia de los aspectos propios del sistema, especialmente cuando hace referencia al procedimiento para lograr la expresión de la mayoría ciudadana (Bobbio, 1985: 21) y cuando pasa revista a las promesas no cumplidas (Bobbio, 1985: 25$45)^{77}$.

La identificación de la democracia en cada uno de los niveles puede ser una buena vía para superar las críticas que se centran tanto en el carácter procedimental como en el normativo. Acusar de vicios procedimentales a la democracia (o a un concepto de ésta), puede tener sentido si con ello se alude al olvido de los otros niveles (lo que, dicho sea de paso y como se ha visto, no hace justicia a los conceptos que generalmente han sido descalificados por ese motivo). De igual manera, la crítica al carácter normativo es justificada en tanto la democracia o su concepto se refiera exclusivamente a las disposiciones formales, esto es, al nivel del régimen, pero no lo es si junto a ellas se encuentran elementos propios del sistema político (procedimientos, instituciones). Por último, esta diferenciación de niveles es un instrumento muy útil para el análisis de la calidad de la democracia y para sus mediciones, ya que permite identificar con claridad el nivel en que se la está evaluando o en el que se están desarrollando las mediciones.

Como una síntesis de lo señalado en esta sección, pero también como explicación final, se puede decir que cualquier concepto de democracia debe aludir diferenciadamente a

\footnotetext{
${ }_{77}$ Me resulta difícil identificar autores que hayan desarrollado un concepto de democracia referido al nivel de la sociedad. Por lo general, quienes trabajan en ese campo, usualmente por medio de encuestas y sondeos de opinión (Latinobarómetro, LAPOP, POLILAT), se manejan con conceptos implícitos que llegan a convertirse en supuestos más bien de carácter operativo. Las excepciones se encuentran en los acercamientos ya referidos de Sartori (1988) y Linz y Stepan (1996), cuando desagregan a su respectiva manera los niveles del ordenamiento político.
} 
cada uno de los niveles del ordenamiento político, pero a la vez debe referirse al todo ${ }^{78}$. La posibilidad de desplazarse entre ambos planos, el del todo y el de cada una de las partes, es imprescindible si se quiere contar con un concepto operativo y además útil para la evaluación de la calidad de la democracia.

\section{Democracia y heterogeneidad}

$\mathrm{Al}$ iniciar este capítulo sostuve que el estudio de la democracia (y de su calidad) en América Latina y en especial en los países andinos debe plantearse el tema de la ciudadanía como eje central. Varias de las razones fueron expuestas en la primera sección, pero no es posible cerrar esa reflexión sin aludir a los efectos de la heterogeneidad de las sociedades sobre la condición ciudadana y por tanto sobre la democracia. La existencia de sociedades heterogéneas o plurales, marcadas por cortes $-\mathrm{O}$ clivajes, en el lenguaje contemporáneo de las ciencias sociales- presenta un conjunto de retos muy difíciles de resolver para la democracia y para la teoría de la democracia.

Un punto de partida para esta reflexión se puede encontrar en la observación de Lijphart acerca de que "Una proposición bien establecida en la ciencia política es que es difícil lograr y mantener un gobierno democrático en una sociedad plural (...) La homogeneidad social y el consenso político son considerados como prerrequisitos o factores fuertemente conductivos a una democracia estable. De manera recíproca, las profundas divisiones sociales y diferencias políticas dentro de las sociedades plurales se deducen como responsables por la inestabilidad y derrumbamiento en las democracias" (Lijphart, 1989: 11). Lijphart opone a esa visión la posibilidad - en realidad la existencia concretade lo que él denomina democracias consociativas o consociacionales ${ }^{79}$. El autor define a éstas por medio de cuatro características: “un gobierno de la gran coalición de los líderes políticos de todos los sectores significativos de la sociedad plural (...) el veto mutuo o mando de la 'mayoría concurrente' (...) proporcionalidad como la norma principal de la representación política (...) y un alto grado de autonomía en cada sector para que arregle sus propios asuntos internos" (Lijphart, 1989: 39). Por tanto, las democracias

\footnotetext{
${ }^{78}$ Esta es una característica que, como se ha visto, se encuentra incluso en los conceptos considerados como mínimos, pero que por lo general más bien se la deja de lado en las críticas que ven en ellos sesgos específicos (como procedimentalismo o normativismo)

${ }^{79}$ La traducción consultada -bastante defectuosa, por cierto- utiliza los términos democracia unificadora o democracia unida para el original consociational democracy (Lijphart, 1989: 11n), lo que distorsiona el concepto de Lijphart ya que no dan cuenta del elemento consensual que destaca el autor y que constituye el núcleo de su concepto. A lo largo de este texto utilizaré indistintamente los términos consociacional o consociativa.
} 
consociativas se caracterizarían por un conjunto de elementos procedimientales que harían viable la convivencia democrática entre los componentes de las sociedades plurales. Pero, de hecho, detrás de esta proposición se encuentran dos supuestos que deben ser tratados antes de entrar en el campo de los procedimientos. Se trata, en primer lugar, de la constatación de la existencia de diferencias (sociales, económicas, culturales, entre otras) que marcan determinantemente a una sociedad, vale decir de la aceptación de su carácter plural y, en segundo lugar, de la instauración previa de un marco general que reconoce la igualdad de derechos y de oportunidades de los grupos sociales diferenciados. Por tanto, es necesario detenerse en estos dos elementos.

La existencia de diferencias es uno de los problemas más engorrosos con los que se enfrentan no solamente las democracias en el quehacer práctico, sino también la teoría democrática. En esta última existe una poderosa herencia de desconocimiento de las diferencias en función de la igualdad ciudadan ${ }^{80}$. Como se ha visto a lo largo de este capítulo, el elemento básico de la condición ciudadana es el reconocimiento de la igualdad (en lo civil, en lo político y en lo social), lo que se puede lograr únicamente si se dejan de lado los elementos que marcan las diferencias entre las personas. Dicho de otra manera, el logro de la igualdad ciudadana está condicionado al reconocimiento del individuo sin más atributos o características que su condición de ser humano que vive en una sociedad determinada. Es, sin duda, y cabe repetirlo, un paso enorme en la convivencia social y particularmente en la construcción de la democracia, hasta el punto de que se puede afirmar que sin esa condición es simplemente imposible alcanzar esta última. La eliminación de cualquier factor que establezca diferencias entre las personas, como el idioma, la religión, el color de la piel, el lugar de residencia, entre otros, es el elemento indispensable e insustituible para la construcción de un orden integrador. Sin embargo, la abstracción que se realiza en esa operación no elimina las diferencias en la realidad. Impide, eso sí, que éstas se expresen en las normas que rigen a la sociedad, es decir, que se trasladen al nivel del régimen político, y que marquen los procedimientos en el nivel del sistema político, pero no por ello dejan de existir.

\footnotetext{
80 Rousseau (1981), los autores de los Federalist Papers (2000), Mill, (1991) y, en alguna medida Tocqueville (1985) son los puntales de esa visión que asentaba la posibilidad de desarrollo de la democracia en la existencia de una sociedad homogénea o, por lo menos, en la que la igualdad ciudadana hubiera reducido la incidencia de estas. Es una visión que perduró bajo diversas formas hasta la década de los ochenta del siglo XX, cuando la democratización de países que encerraban sociedades heterogéneas planteó el problema en toda su dimensión.
} 
Precisamente ahí, en esa coexistencia de las diferencias existentes en la realidad y el principio básico de igualdad ciudadana, se encuentra uno de los mayores dilemas que deben resolver las democracias contemporáneas, especialmente las de países como los tres que son materia de interés en este trabajo. Este dilema consiste básicamente en optar exclusivamente por el carácter unificador de la ciudadanía universal o por el reconocimiento de las diferencias tanto en el régimen como en el sistema político. La respuesta que se dé a esta disyuntiva marcará profundamente el tipo de democracia y tendrá consecuencias en todos los niveles del ordenamiento político. Así mismo, tendrá profundas repercusiones en el aspecto teórico y conceptual, ya que se adentra en aspectos fundamentales y constitutivos del concepto de democracia (como la propia condición de igualdad ciudadana, el pluralismo y las condiciones de representación política).

El problema fundamental en este sentido es que, si la igualdad ciudadana es la condición básica sobre la que se erige la democracia, cualquier elemento que la altere o la modifique no sólo producirá cambios sustanciales en ella, sino que incluso podrá constituir su negación. Esta es la posición que se deriva de una visión estrictamente apegada a la concepción clásica de la democracia liberal, que no puede aceptar desviaciones en ese sentido. Una expresión clara de ella se encuentra en el alegato que hace Sartori (2001) frente al multiculturalismo y que, por la claridad de su planteamiento así como por la solidez de sus argumentos puede ser tomada como el arquetipo de esa posición. Sartori basa su argumentación en el pluralismo como elemento central de la sociedad abierta, vale decir de la sociedad democrática. Así, sostiene que "la sociedad abierta es, en esencia, la sociedad libre tal como la entiende el liberalismo (...) [y] es el pluralismo el que descifra mejor que cualquier otro concepto las creencias de valor y los mecanismos que han producido históricamente la sociedad libre y la ciudad liberal" (Sartori, 2001: 14-15). Pasa a ser básica, por tanto, la definición de pluralismo que, según el autor, debe distinguir "tres niveles de análisis (...): 1) pluralismo como creencia, 2) pluralismo social, y 3) pluralismo político" (Sartori, 2001: 31). El primer nivel se afianza en la tolerancia como principio básico y determina que "el pluralismo está obligado a respetar una multiplicidad cultural con la que se encuentra. Pero no está obligado a fabricarla" (Sartori, 2001: 32). En el segundo nivel, la noción de pluralismo no equivale a "cualquier diferenciación social (...) El pluralismo no es un mero y simple equivalente de la noción de 'complejidad estructural' (...) es un tipo específico de estructura social' (Sartori, 2001: 
34-35). El tercer nivel "indica una diversificación del poder (...) basada en una pluralidad de grupos que son, a la vez, independientes y no exclusivos" (Sartori, 2001: 35).

Dos aspectos deben ser destacados en la reflexión de Sartori. En primer lugar, la identificación de los niveles en que debe ser tratado el pluralismo que, como se verá más adelante, es fundamental para comprender los problemas que enfrentan las democracias en las sociedades plurales ${ }^{81}$. En segundo lugar, tiene mucha importancia la oposición que él destaca entre el pluralismo (de origen liberal y ligado a la tolerancia) y el multiculturalismo contemporáneo. Este último punto constituye el eje argumentativo de Sartori y es el que le lleva a negar la posibilidad de coexistencia de la democracia con el multiculturalismo. Su posición se asienta en la afirmación de que las sociedades fragmentadas no equivalen a sociedades pluralistas, ya que si bien el pluralismo postula una sociedad de asociaciones múltiples, estas deben ser "voluntarias (no obligatorias o dentro de las cuales se nace) y, en segundo lugar, no exclusivas, abiertas a afiliaciones múltiples" (Sartori, 2001: 39, cursivas en el original). De esta manera, la presencia de clivajes en la sociedad no sería un elemento que por sí solo pudiera llevar a la aceptación del multiculturalismo sino que, por el contrario, cerraría el paso al pluralismo. La única posibilidad para que esto no suceda $-\mathrm{y}$ por tanto que el pluralismo sea posible en una sociedad de esta naturaleza- se presentaría cuando "los cleavages, las líneas de división, se neutralizan y se frenan por múltiples afiliaciones (y también lealtades), mientras que ‘disfuncionan’ por así decirlo, cuando las líneas de fractura económico-sociales coinciden, sumándose y reforzándose unas a otras" (Sartori, 2001: 40, cursiva en el original).

A pesar de lo atractiva que resulta esta argumentación, tiene dos problemas que la debilitan y que la convierten en un discurso escasamente aplicable en las sociedades plurales contemporáneas. En primer lugar, en términos teóricos o conceptuales, Sartori se aferra a una de las dos interpretaciones posibles de la tolerancia y del pluralismo que se desprenden del liberalismo clásico. Cabe recordar en este sentido que "El liberalismo siempre ha tenido dos caras: de un lado, la tolerancia es la persecución de una forma de vida ideal; del otro, es la búsqueda de un compromiso de paz entre diferentes modos de vida. Según el primer punto de vista, las instituciones liberales se conciben como aplicaciones de principios universales. Según el segundo, son un medio para lograr la

\footnotetext{
${ }^{81}$ Cabe destacar que Sartori retoma en este texto los tres niveles de consenso que se encuentran en otros textos suyos, a los que me referí en la sección anterior.
} 
coexistencia pacífica. Para el primero, el liberalismo prescribe un régimen universal. Para el segundo, es un proyecto de coexistencia que puede emprenderse en muchos regímenes diferentes" (Gray, 2001: 12). Sin duda, Sartori adhiere a la primera interpretación, lo que le lleva a considerar la existencia un régimen universal como condición de la democracia y del pluralismo. De esta manera, cierra los ojos frente a la posibilidad de coexistencia de diversos modos de vida bajo un régimen democrático.

En segundo lugar, la propuesta de Sartori no es capaz de resolver el problema práctico que se presenta cuando los clivajes buscan expresión política en las sociedades fragmentadas o heterogéneas. El planteamiento de Sartori está formulado en términos normativos, lo que en sí mismo no es criticable si se considera a la democracia como un ideal a alcanzar, pero sostener que las asociaciones múltiples deben ser voluntarias y abiertas a afiliaciones múltiples no soluciona el problema cuando ellas no operan de esa manera en la realidad e incluso, cuando siendo voluntarias, las afiliaciones múltiples presentan demandas de carácter multicultural ${ }^{82}$. Si esas asociaciones múltiples o, para decirlo en los términos generalizados en el contexto latinoamericano actual, esas identidades existen y tienden a transformarse en expresiones políticas -como es el caso de los pueblos indígenas de Bolivia y Ecuador-, vale más tratar de comprender la complejidad del problema que sostener esa posición normativa.

Esa comprensión se inicia con la aceptación de la tensión existente entre el pluralismo y las manifestaciones de la heterogeneidad. La pregunta central, si se acepta que estas últimas existen y que no pueden ser negadas por medio de una afirmación de principios, es entonces cómo compatibilizar ambos términos. Una respuesta es la ofrecida por Lijphart que, como se vio al inicio de esta sección, consiste en el diseño de un conjunto de disposiciones procedimentales que llevan a la configuración de las democracias consociativas. Pero, previamente ha sido necesario aceptar la existencia de las diferencias

82 Antropólogos e historiadores han presentado un cúmulo de evidencias de la invención de la tradición, considerada como un recurso de diversos grupos sociales para establecer y afianzar su lugar en la sociedad (Hobsbawn, 1991; Thompson, 1979; Renan, 2000; Bauman, 2001). La reivindicación de los orígenes étnicos y lingüísticos, así como de los símbolos unificadores del grupo, es una de las expresiones más claras de esa invención. Lo importante es que, una vez inventados, pasan a formar parte de la tradición o, dicho de otra manera, llegan a tener los mismos efectos sociales que los componentes que se han desarrollado históricamente. Por consiguiente, en muchos casos de ellos no surgen asociaciones involuntarias, de esas que "se nos quedan "pegadas a la espalda", como dice Sartori $(2001$, 33) siguiendo a Wohlin, sino asociaciones voluntarias que hacen el camino inverso hacia una historia que se construye desde el presente. Por ello, en términos políticos resulta inútil el debate acerca de la veracidad de la tradición, como lo hace, a manera de ejemplo, Elorza (2005) con el euzkera cuando éste ya se ha convertido en parte de la reivindicación nacional vasca. 
no sólo como una realidad social y económica sino política, esto es, entenderlas como clivajes que tienen necesaria e inevitablemente una expresión política. Esa aceptación marca una diferencia sustancial con la comprensión que hace el liberalismo clásico. Este es intencionalmente ciego frente a las diferencias, las elimina por medio del reconocimiento de la ciudadanía universal. Por el contrario, la otra posición destaca las diferencias y las acepta como elementos que determinan o condicionan al régimen y al sistema político.

Esta aceptación ha sido planteada -desde la filosofía más que desde la ciencia políticacomo la política del reconocimiento (Taylor, 2001). Con ella se pretende que se reconozca "la identidad única de este individuo o de este grupo, el hecho de que es distinto de todos los demás" (Taylor, 2001: 61). Pero, al contrario de la interpretación que hacen algunos críticos, como el propio Sartori, este reconocimiento no equivale al abandono o a la sustitución del principio de la ciudadanía universal, es decir, el postulado básico del liberalismo, ya que este más bien constituye la base sobre la cual se erige el reconocimiento de la diferencia. Taylor es enfático en señalar esta condición, en el sentido de que "a esta exigencia [del reconocimiento] subyace el principio de igualdad universal" (Taylor, 2001: 61). Sin embargo, a este principio se le añade un elemento que, en términos estrictos de la lógica de la igualdad ciudadana, resulta ajeno e incluso contradictorio. El propio autor es consciente del conflicto que se genera cuando señala que "estos dos modos de política que comparten el concepto básico de igualdad de respeto entran en conflicto. Para el uno, el principio de respeto igualitario exige que tratemos a las personas en una forma ciega a la diferencia (...) Para el otro, hemos de reconocer y aun fomentar la particularidad. El reproche que el primero hace al segundo es, justamente, que viola el principio de no discriminación. El reproche que el segundo hace al primero es que niega la identidad cuando constriñe a las personas para introducirlas en un molde homogéneo que no les pertenece de suyo" (Taylor, 2001: 67).

El tema clave en todo esto es, entonces, "el desarrollo del concepto moderno de identidad [que] hizo surgir la política de la diferencia (Taylor, 2001: 60). En términos generales, el reconocimiento de las identidades como elementos determinantes de la política redefine la concepción predominante acerca de la ciudadanía universal y, en consecuencia, de la democracia. Pero es necesario prestar atención a la dimensión temporal y a los alcances de ese reconocimiento, ya que no son similares las 
consecuencias que se derivan de las medidas acotadas en el tiempo -bajo la forma de lo que se conoce como acción positiva o discriminación positiva- y las que se originan en medidas de carácter permanente. Las primeras pretenden "remediar años de discriminación y acercarse al tipo de sociedad que habría existido si hubiéramos observado la separación de Estado y etnicidad desde el principio" (Kymlicka, 1996: 17) ${ }^{83}$. Las otras se asientan en una concepción de "los derechos específicos de grupo [que] son necesarios para reconciliar diferencias culturales tradicionales más que para remediar discriminaciones históricas" (Kymlicka, 1996: 17). En consecuencia, las primeras atacan a problemas concretos que se consideran como obstáculos para que todas las personas se beneficien en similar grado de la condición de igualdad ciudadana, y en ellas se inscriben tanto algunas políticas internas de los países como varios instrumentos internacionales impulsados por organismos multilaterales (como Naciones Unidas). Las de carácter permanente, por el contrario, obligan a un rediseño del conjunto del ordenamiento político y social, hasta configurar el Estado multicultural. En éste, "una teoría de la justicia omniabarcadora incluirá tanto derechos universales, asignados a los individuos independientemente de su pertenencia de grupo, como determinados derechos diferenciados de grupo, es decir, un «estatus especial» para las culturas minoritarias" (Kymlicka, 1996: 19). En el fondo, entonces, esta posición se enmarca en la segunda de las caras del liberalismo, aquella que entiende a la tolerancia como un compromiso entre diferentes modos de vida (Gray, 2001).

El problema central a resolver en este aspecto es el de la compatibilidad entre la ciudadanía universal -que es, valga insistir, es la condición básica de la democracia- y las demandas que llevan a la constitución de ciudadanías múltiples o diferenciadas. Toda la reflexión que se realiza al amparo del liberalismo -como el constitucionalismo- o en paralelo a él -como la teoría de la democracia- tienen a la ciudadanía universal como piedra angular. Sin ella puede desplomarse todo el edificio, como lo advierte acertadamente Sartori (2001: 99-105) ${ }^{84}$. Eso es así, pero los defensores de la condición de la ciudadanía múltiple, como se ha visto, responderían con que ésta no anula a la

\footnotetext{
${ }^{83} \mathrm{La}$ observación de Kymlicka se concentra en el aspecto étnico, pero es aplicable a otros ámbitos (como el religioso o el lingüístico), como él mismo se encarga de demostrar a lo largo de su obra véase también Kymlicka y Norman, 1997).

${ }^{84} \mathrm{El}$ argumento de Sartori es que "El destino del 'ciudadano igual' no depende de la naturaleza nacional o no del Estado, sino de la estructura liberal-constitucional o no del Estado. Y, por consiguiente, si el ciudadano está hoy amenazado es porque el Estado que lo ha creado está amenazado. El ciudadano igual nace y vive con leyes iguales; y de la misma manera muere con leyes desiguales" (Sartori, 2001: 100).
} 
ciudadanía universal sino que la toma como el punto de partida y como el elemento básico e insustituible (Kymlicka y Norman, 1997: 25). En consecuencia, desde el punto de vista del liberalismo clásico no habría cabida para las ciudadanías múltiples, en tanto que desde la óptica del multiculturalismo serían perfectamente compatibles. Pero esta última afirmación por sí sola no es suficiente para despejar las dudas y ofrecer una respuesta adecuada al problema. Este solamente puede resolverse por medio de una indagación que se mueva paralelamente en dos niveles. Por un lado, debe desarrollar el debate teórico conceptual, lo que significaría en gran medida continuar el camino abierto por los autores citados en las líneas anteriores. Este debate debe llevar a determinar si con el reconocimiento de las ciudadanías múltiples se logra mantener lo esencial de la ciudadanía universal o si, por el contrario, eso constituye la negación de esta última. Por otro lado, el análisis no puede abstraerse de la realidad, vale decir, de las demandas realmente existentes. De poco o de nada serviría el debate teórico y conceptual si ellas se están presentando en el escenario político y están introduciendo el tema de la diversidad en los diferentes niveles del ordenamiento político.

El primer tema, esto es, la compatibilidad entre el principio básico de la ciudadanía universal y el reconocimiento de la ciudadanía múltiple, puede resolverse únicamente si se comprueba que esta última no afecta a aquel principio. En otros términos, cabe preguntarse si luego del reconocimiento de la ciudadanía múltiple o de cualquier forma de multiculturalismo se puede seguir considerando como democrático a un régimen político. Como se ha visto a lo largo de este capítulo, sin el reconocimiento de la ciudadanía universal no puede existir democracia ni Estado de derecho, lo que quiere decir que la negación o por lo menos la disminución de ella será motivo suficiente para dejar de calificar como tal a un régimen o para poner en duda esas condición. Por tanto, ahí está la clave para la respuesta a esa pregunta, pero evidentemente aún es insuficiente. Para responderla adecuadamente es necesario considerar previamente las diversas posibilidades de tratamiento de las diferencias que se ofrecen para un ordenamiento democrático.

Básicamente son tres las formas no violentas por las que se pueden procesar las diferencias ${ }^{85}$. La primera, que podría denominarse asimilación, consistiría en ceñirse

${ }^{85} \mathrm{El}$ énfasis en el carácter no violento se debe a que la todo el tratamiento realizado en este texto está centrado en un régimen democrático que, por definición, es la forma de procesar el conflicto sin 
estrictamente a la ciudadanía universal sin ningún grado de reconocimiento de las diferencias existentes en la realidad. Es la posición que defiende Sartori, pero que, como se ha visto, no abre los espacios necesarios para la canalización de las demandas de los grupos diferenciados. En el mejor de los casos, estas podrían encontrar respuesta en el campo de las políticas públicas, especialmente en el ámbito de la educación, donde podrían aplicarse formas de discriminación positiva que tenderían a reducir el peso de las inequidades que acompañan en la mayor parte de los casos a esas diferencias. Sin embargo, deja sin solución los problemas que se desprenden de las identidades (en el plano cultural, lingüístico, religioso o de cualquier tipo), que no tienen relación necesariamente con reivindicaciones de igualdad de oportunidades o similares. Es una vía que, pese al enorme avance que significa en la historia de la humanidad -y particularmente en países como los analizados, como se ha visto en la primera sección de este capítulo-, no logra apagar la bomba de tiempo que yace en las sociedades heterogéneas.

La segunda puede denominarse inclusión o integración, y consiste en el reconocimiento de las especificidades de la manera que lo plantean los multiculturalistas. En términos generales, esto quiere decir que en el nivel del régimen se han incluido las disposiciones que hacen posible el reconocimiento de las diferencias en términos de múltiples ciudadanías y que en el nivel del sistema político se cuenta con los instrumentos, las instituciones y los procedimientos necesarios y suficientes para que ellas puedan materializarse. Es, por tanto, algo bastante más complejo que un conjunto de procedimientos, ya que debe incluir previamente un cambio sustancial en el campo normativo. También es una concepción de mayor profundidad y alcance que las soluciones que se consiguen con las medidas de acción afirmativa o de discriminación positiva. Es aquí, en todo este conjunto, donde se demuestra la pertinencia de la pregunta formulada antes acerca de la compatibilidad entre estos arreglos y la ciudadanía universal y sobre la democracia.

La tercera forma no violenta para procesar las diferencias es la que podría tipificarse como autonomía. Es la más sencilla de todas -aunque también puede ser la más dolorosaya que consiste simplemente en resolver el problema de la heterogeneidad por medio de la separación física y jurídica de los grupos diferenciados. Literalmente, el problema se

acudir a la violencia. La reflexión sobre las formas de procesamiento de las diferencias está basada en Pachano (1993; 2003b; 2004b). 
resuelve de un solo tajo. Este se realiza cuando unos y otros llegan a la concusión de que es imposible convivir bajo un solo ordenamiento y se constituyen tanto estados como grupos diferenciados existen en el territorio. Por lo general se trata de reivindicaciones de carácter nacional, esto es, de grupos que se reivindican como una nacionalidad que pugna por alcanzar su propio ordenamiento jurídico bajo la forma de un Estado-nación. Es en sí misma la negación del multiculturalismo, aunque en muchas ocasiones sus propulsores hagan de éste su reivindicación central. A la vez, esta solución no merecería mayor atención dentro de una reflexión sobre la democracia y sobre su capacidad para procesar las diferencias, ya que en definitiva sería la expresión de la imposibilidad de lograr ese procesamiento. Sin embargo, cabe considerarla porque es una de las demandas que está presente en muchos países -entre ellos Bolivia- y por consiguiente plantea un desafío muy fuerte para sus democracias ${ }^{86}$.

De estas tres formas de procesar las diferencias, la segunda es la que corresponde al multiculturalismo y, en términos estrictos, la única que las asume y que busca una solución sin negarlas. Bajo distintas maneras, las otras dos están basadas en la negación de las diferencias. Por consiguiente, la búsqueda de respuesta a la pregunta acerca de la compatibilidad entre la igualdad ciudadana (y, de suyo, la democracia) y las ciudadanías múltiples solamente puede ser formulada a esta modalidad de resolución del conflicto. Dentro de ella, entonces, la respuesta es que sí se puede lograr esa compatibilidad siempre que se logre mantener dos premisas básicas. La primera es que el reconocimiento se refiera única y exclusivamente a las diferencias básicas de la sociedad, esto es, a los clivajes que la convierten en una sociedad heterogénea o, más claramente, que permiten referirse a ella en plural, como varias sociedades. Esto requiere contar no solamente con criterios claros al respecto, sino también con el acuerdo social -de las diversas sociedades y obviamente del conjunto de sus ciudadanos- sobre el carácter de esos cortes como elementos fundamentales de división. Por tanto obliga a poner un límite claro para otras diferencias que puedan considerarse menores y cuyo acceso al ámbito político, en condición de clivajes, podría afectar seriamente a todo el ordenamiento

\footnotetext{
${ }^{86}$ La autonomía, en los términos planteados aquí no debe confundirse con las autonomías regionales (provinciales, departamentales) que se han impulsado dentro de los procesos de descentralización en diversos países. Desafortunadamente estamos obligados a significar con la misma palabra a ambos fenómenos. Una alternativa para evitar esa confusión sería calificar como independencia a la decisión de una nación o de un grupo determinado que le lleva a conformar su propio Estado, pero eso es poco aconsejable por la carga histórica de este término. Lo mismo se puede decir de secesión, que implica una ruptura sin acuerdo. Por su parte, separación no da cuenta del proceso que lleva al resultado final y mucho menos de las características de este último.
} 
democrático ${ }^{87}$. La segunda es casi una perogrullada, ya se puede sostener que todo ello es posible siempre y cuando no se menoscabe la ciudadanía universal ni afecte a la esencia del pluralismo. Sin embargo, ese carácter redundante y estéril de la afirmación se supera cuando se considera que es necesario un acuerdo previo sobre la no inclusión -o la eliminación, en caso de que ya hubiera sido adoptada- de toda disposición que pueda producir esos efectos. Se podría argumentar, como crítica a esta afirmación, que ella hace descansar todo el problema en la voluntad de las personas. Eso es absolutamente cierto. Pero no se puede actuar de otra manera cuando existe una realidad que busca expresarse en esos términos y al mismo tiempo se busca como objetivo principal la preservación del ordenamiento democrático y de la(s) sociedad(es) como un todo. Es un pacto constitutivo que, a diferencia del clásico tratado por los contractualistas, no tiene a la superación de la guerra y del estado de naturaleza como elemento de cohesión, sino a la exclusión que pueda persistir a pesar de la vigencia de los derechos universales expresados en la igualdad ciudadana. Se trata, por consiguiente, de un pacto social que generalmente conduce al establecimiento de derechos colectivos que se suman a los derechos individuales, pero que deben estar subordinados a estos.

El problema más difícil de resolver es precisamente este último, que en términos sintéticos puede definirse como la jerarquización de los derechos. El cimiento y a la vez la argamasa de todo el pacto es la condición de elemento básico e insustituible asigna a los derechos individuales. Solamente después de ellos, o una vez que se encuentran plenamente asentados, podrán establecerse los derechos colectivos. De otra manera, la ciudadanía universal se verá seriamente afectada y con ello la democracia habrá perdido espacio. Esta secuencia, que incluso puede ser temporal, es determinante ya que ella marca la vigencia o la pérdida de la ciudadanía universal. Como se verá más adelante (especialmente en el capítulo IV), la alteración de ella genera incertidumbres, como las que se encuentran en Bolivia y Ecuador por las disposiciones constitucionales que ponen en el mismo nivel, sin orden jerárquico, a los derechos individuales y colectivos.

\footnotetext{
${ }^{87}$ En dos de los países estudiados se tuvo ejemplos recientes de los problemas que se derivan de la inclusión de diferencias secundarias o claramente arbitrarias como clivajes sobre los que se debe estructurar el régimen político y diseñar el sistema político. Así, en el debate constitucional en Bolivia se opuso a la demanda de autonomías regionales (un clivaje que define la organización social y el conflicto político) el reconocimiento de un alto número de "nacionalidades" que, sin ser tales, requerían de similares grados de autonomía, con lo que ambas tendían a anularse. En el debate constitucional ecuatoriano, por su parte, se incluyó al "pueblo montubio" -que no tiene rasgos identitarios que lo diferencien- en el mismo nivel que los pueblos y nacionalidades indígenas, con lo que se distorsionó el objetivo del reconocimiento de los derechos colectivos de estos últimos.
} 
Para finalizar, cabe hacer dos apuntes acerca de los desafíos que plantea la existencia de sociedades heterogéneas para la ciencia política y para la teoría de la democracia. En primer lugar, es innegable que la propuesta del multiculturalismo altera no solamente la concepción clásica de la democracia liberal sino que también amplía un campo que ha sido relativamente poco explorado por la ciencia política. Por lo general, ésta ha prestado atención a los clivajes en términos de factores que condicionan las preferencias de los electores y la conformación de los partidos y de los sistemas de partidos (Duverger, 1988; Lipset y Rokkan, 1967; Sartori, 1992; Dix, 1989). Se ha preocupado también de los efectos que tiene la combinación o el cruce de clivajes sobre la moderación del conflicto político (Lipset, 1980; Taylor y Rae, 1969). Se ha interesado en los resultados que se desprenden de la interrelación entre los clivajes y los arreglos institucionales, especialmente los de carácter electoral (Jones, 2004; Mozaffar et al., 2003). Así mismo, ha puesto énfasis en la medición del impacto de aquellas particularidades, especialmente las diferencias regionales, sobre los sistemas de partidos y sobre las estrategias electorales y organizativas de los partidos (Mainwaring y Jones, 2003; Pachano, 2004; 2008; Freindenberg y Alcántara, 2001). Finalmente, en menor medida la disciplina ha atendido a la transformación de los clivajes en ejes de la competencia política (Lijphart, 1969; 1989; Barry, 1975; Saideman et al., 2002; Zielinski, 2002). Pero, es casi inexistente la producción acerca del nuevo reto que plantea la política del multiculturalismo y que ha tomado cuerpo en países como los estudiados (particularmente en Bolivia y Ecuador). Aparte de la propuesta de la democracia consociativa de Lijphart, es difícil encontrar sustento teórico dentro de la ciencia política para comprender adecuadamente esta nueva situación ${ }^{88}$.

En segundo lugar, por lo señalado a lo largo de esta sección, se hace evidente la necesidad de incorporar la reflexión sobre las sociedades plurales o heterogéneas en la

${ }^{88}$ En gran medida, la ausencia de desarrollo teórico y conceptual ha impedido una adecuada comprensión de los procesos por los que atraviesan actualmente los países estudiados, particularmente Bolivia y Ecuador. Mientras se han ido robusteciendo y asumiendo protagonismo las fuerzas políticas que son portadoras de reivindicaciones particulares (y que, de una u otra manera, propugnan el multiculturalismo u otras formas de reconocimiento de la diversidad), la ciencia política no ha podido desprenderse de viejos moldes para su análisis. Una expresión de esta deficiencia es el reciclaje de conceptos como el de populismo, que sólo da cuenta parcial de los fenómenos que se viven en la actualidad. Así mismo, esta debilidad como disciplina la ha hecho dependiente en gran medida de conceptos propios de la antropología, como los de etnicidad, identidad, campos simbólicos, entre otros, que han sido asumidos sin la necesaria revisión crítica. Incluso, se puede afirmar que buena parte de la reflexión politológica tiene un sesgo antropológico en términos de la perspectiva de análisis adoptada. 
teoría de la democracia, y en particular en la rama que se preocupa por su calidad. Una teoría construida exclusivamente en torno a sociedades -verdadera o supuestamentehomogénea no resulta adecuada para comprender y explicar los logros y los vacíos que se presentan en los procesos democráticos que ocurren en las sociedades plurales. Es imprescindible, por consiguiente, un trabajo sostenido en el plano teórico y conceptual orientado a introducir toda la problemática que se deriva de la existencia de esas sociedades. No hacerlo o postergarlo podría equivaler a una suscripción tácita de la vieja visión que ve a la homogeneización como un requisito para la democracia, lo que significa a la vez postergarla indefinidamente o, más grave aún, negar la posibilidad de su construcción en estas sociedades.

\section{Conclusiones}

Con el presente capítulo he pretendido destacar los aspectos fundamentales que debe enfrentar la teoría de la democracia cuando es aplicada al estudio de países con un conjunto de características, como las que presentan Bolivia, Ecuador y Perú. El eje articulador de esta visión ha sido la condición ciudadana, entendida como el elemento básico sobre el que descansa todo el edificio democrático. Su tratamiento ha obligado a realizar un breve repaso de los principales antecedentes que marcaron los procesos en cada uno de los países, sin que ello encierre, ni de lejos, alguna pretensión de entrar en el monumental análisis histórico que aún está pendiente en los tres países y en general en el continente. Así mismo, la definición de ese eje articulador ha obligado a abrir una pequeña ventana hacia el amplio campo de las ciudadanías diversificadas o múltiples, que necesaria e inevitablemente se presentan como problema a resolver en las sociedades heterogéneas. Más que una conclusión, en este aspecto el texto ofrece un panorama de los problemas que deben ser enfrentados y apenas deja marcada una línea inicial por la que se puede transitar para el estudio de la democracia en sociedades complejas como son las de los países escogidos.

Como una forma de abrir el camino hacia el tema de la calidad de la democracia, en este capítulo he abordado brevemente algunos aspectos relativos al concepto de democracia. Fundamentalmente, me he detenido en la operatividad de los conceptos, tratando de demostrar que ésta se puede lograr por medio de la diferenciación clara de los niveles en que se trabaja. A la vez, esta reflexión me ha obligado a discutir las perspectivas teórico- 
metodológicas con las que se abordan usualmente a esos diversos niveles. A partir de esa discusión he formulado una propuesta de conceptualización de los niveles que permite identificar sus componentes y sus interrelaciones (inputs y outputs). Considero que la distinción entre régimen, sistema y comunidad, es un instrumento metodológico adecuado para el análisis de la política en sus diversas manifestaciones y, de manera especial, para el estudio de la democracia y de su calidad.

Vinculado a estos temas, he desarrollado algunos aspectos concernientes a la legitimidad de la democracia. Fundamentalmente, me he detenido en sus diversas manifestaciones, no precisamente en los tres tipos que han sido identificados dentro de la tradición weberiana (que son muy útiles para el análisis de otros fenómenos, como el populismo o el desempeño de la élites políticas) sino más bien atendiendo a sus causas y a los procesos por los cuales se va configurando (esto es, como legitimidad de origen, de procedimientos y de resultados). Mi interés en ese aspecto ha sido destacar la importancia de la legitimidad para el mantenimiento y la consolidación de la democracia, lo que inevitablemente repercute en su calidad.

En íntima relación con esto he aludido a los aspectos económicos y sociales, entendidos como: a) requisitos para la democracia, b) condiciones para su permanencia o consolidación, y c) sus rendimientos o resultados. He destacado la importancia de distinguir claramente como campos de estudio diferentes a cada uno de ellos. Sostengo que este es un paso necesario y decisivo para evitar los problemas que se derivan de la utilización de conceptos maximalistas de la democracia y para identificar adecuadamente los campos y niveles de análisis en que es necesario proceder a la hora de estudiar los procesos contemporáneos. Así mismo, esta diferenciación de niveles resulta imprescindible para el análisis de la calidad de la democracia, ya que es uno de los pasos que llevan a la definición de los parámetros con los que ella será evaluada.

La necesidad de poner atención en el estudio del Estado de derecho es un elemento que también he destacado a lo largo del capítulo. La relativamente escasa atención que ha le ha concedido la teoría de la democracia, así como su importancia para la construcción de regímenes y sistemas democráticos, justifican el amplio espacio que este tema ocupa en el presente texto. A la vez, ese tratamiento del Estado de derecho ha hecho evidente la pertinencia de volver la mirada sobre la construcción del estado nacional, entendido 
como un proceso de largo alcance que viene a ser ineludible en el estudio de países como los señalados. Las condiciones históricas en que se ha desarrollado el proceso de construcción de la democracia hacen imposible que se deje de considerar ese otro proceso que es el de construcción del Estado nacional. Buena parte de los problemas de las democracias en estos países provienen del carácter inacabado de este último proceso, de manera que es fundamental tomarlo en cuenta dentro del análisis. Por esta vía, además, he debido dirigir la mirada al proceso de modernización que, si bien lleva la reflexión a teorías que fueron ampliamente debatidas en América Latina -y que en gran medida se consideran superadas-, permite detectar algunas especificidades de las democracias de estos países.

Finalmente, cabe señalar que este capítulo constituye un intento de combinar el debate conceptual con el análisis de las condiciones concretas en que se desarrolla la democracia en Bolivia, Ecuador y Perú. Como señalé al inicio, no estaba orientado a la revisión exhaustiva de la teoría, sino al tratamiento de algunos aspectos que considero fundamentales para comprender los casos estudiados. Desde esta perspectiva, las reflexiones iniciadas aquí sirven de base para el análisis de los procesos de transición a la democracia en los tres países, que se desarrolla en el capítulo II. Así mismo, ellas constituyen la base para el tratamiento del desempeño concreto de las democracias y de la calidad de ésta, que se desarrolla en los capítulos IV y V, respectivamente. 
Capítulo II. Las transiciones a la democracia en Bolivia, Ecuador y Perú 


\section{Resumen}

El presente capítulo aborda los procesos de transición a la democracia en los tres países. La premisa básica de la que se parte es que las circunstancias en que se producen las transiciones y las características que éstas van asumiendo con el transcurso del tiempo condicionan la evolución posterior del sistema político. Por consiguiente, las posibilidades de consolidación de la democracia dependerán en gran medida de la manera en que se ha operado la transición $\mathrm{y}$, en consecuencia, cualquier indagación sobre la calidad de la democracia debe prestar atención a ese proceso. Como es obvio, no se trata de una relación unilineal ni de causalidad, sino de condicionamiento en varios niveles. El capítulo está dividido en cinco secciones. La primera se ocupa del carácter de las transiciones y busca detectar las especificidades de cada país en este aspecto. La segunda indaga en los efectos de la transición, entendiendo que ella señala un camino, marcado por los procesos políticos y las instituciones, por el que se enrumban los actores políticos. La tercera asume el debate sobre la consolidación de la democracia como un elemento básico para el análisis posterior de su calidad. La cuarta sección continúa el tratamiento de ese debate en el plano conceptual y en la última se consignan algunas conclusiones generales.

\section{Características de las transiciones}

Ecuador y Perú fueron pioneros en el proceso de transición a la democracia en América Latina ${ }^{1}$. En ambos casos se trató de transiciones diseñadas, controladas e implementadas por los gobiernos militares que en sus respectivas primeras etapas habían impulsado procesos de reforma social y económica. La segunda fase de cada uno de estos gobiernos se orientó prioritariamente al diseño de los procedimientos para la entrega del poder político a los civiles. Bolivia, por el contrario, siguió un camino tortuoso y caótico que no pudo ser conducido por los gobiernos salientes ni por las fuerzas de oposición.

A lo largo de la década de los setenta, Ecuador y Perú habían experimentado formas de reformismo militar en un marco de relativa estabilidad ${ }^{2}$. Aunque en ambos casos se produjo un cambio significativo dentro del respectivo gobierno militar, en un reemplazo de los duros por los blandos, para decirlo en los términos de O`Donnell y Schmitter (1994: 32 y siguientes), ninguno de esos cambios dentro de los gobiernos autoritarios puede

\footnotetext{
${ }^{1}$ República Dominicana fue el otro país que emprendió este proceso a finales de la década de los setenta, lo que no dejó de llamar la atención por las condiciones adversas que presentaban estos países para emprender en una tarea de este tipo (Conaghan y Espinal, 1990: 554).

${ }_{2}^{2}$ Aunque puede parecer contradictoria la calificación de estable para un régimen dictatorial, la azarosa historia de los países latinoamericanos -y en especial de los andinos- le da validez. No han sido una excepción sino más bien norma generalizada los golpes de Estado orientados al derrocamiento de gobiernos que a la vez fueron el producto de acciones similares, y no precisamente para instaurar un régimen diferente (constitucional, democrático), sino para continuar en el mismo camino.
} 
considerarse en términos estrictos como un cambio de régimen. En Bolivia, por el contrario, la inestabilidad y la diversidad de tipos de gobierno que se sucedieron desde 1964 eran la expresión de la ausencia de acuerdos básicos y/o de una fuerza política y social que pudiera imponerse sobre las demás. Al contrario de los otros dos países, donde fue efectiva la solución de fuerza, en éste no fue posible romper "el empate histórico entre las fuerzas centrales de la política del país, las FFAA y la COB” (Mayorga, 1991b: 23). En otros términos, por un conjunto de causas que no corresponde abordar aquí, en Bolivia no se pudo plasmar una dictadura exitosa, como pueden considerarse las de los otros dos países en términos de su efectividad en el logro de sus objetivos ${ }^{3}$.

El proceso de transición peruano se inició con el derrocamiento del general Juan Velasco Alvarado, en 1975, que marcó el final de la primera fase del régimen militar (Pease, 1980: 228 y ss.). Presionadas en buena medida por la crisis económica y por las demandas y protestas de diversas fuerzas sociales - muchas de ellas derivadas de las acciones desarrolladas desde el gobierno a lo largo de la primera fase- las Fuerzas Armadas consideraron que había llegado el momento de abandonar el proyecto reformista y para ello diseñaron un camino -contenido en el Plan Tupac Amaru, presentado a comienzos de 1977 (Planas, 2000: 143-144; Cotler, 1988: 243)- que habría de conducir hasta la entrega del poder político a los civiles. Ese camino se inició con la convocatoria a una Asamblea Constituyente (por medio del decreto 21949 de octubre de 1977) y la elección de sus integrantes en junio de 1978 (Tuesta, 1995: 38). Continuó, siempre bajo el control y la conducción de los militares, con la elaboración de la Constitución que permitiría establecer un ordenamiento democrático y que llevaría a la primera elección presidencial y parlamentaria, en mayo de 1980, doce años después del derrocamiento del último presidente civil y del cierre del Congreso.

Ecuador siguió un camino relativamente similar en algunos aspectos, en la medida en que el proceso de transición se inició también con el derrocamiento, en enero de 1976, de Guillermo Rodríguez Lara, el general que encabezó la fase reformista. Sin embargo, a

\footnotetext{
${ }^{3}$ En Perú, el gobierno de Juan Velasco Alvarado, surgido de un golpe en 1968, impulsó un proceso de reforma agraria (tardío con respecto al resto de países sudamericanos), nacionalizó el petróleo, tomó el control de los medios de comunicación y creó un sistema de movilización social orientado a consolidar el apoyo para el régimen (Pease, 1986; Cotler, 1988: 233). En Ecuador, el golpe se produjo en 1972, encabezado por Guillermo Rodríguez Lara (quien derrocó al gobierno de José M. Velasco, que había asumido todos los poderes en 1970). El gobierno militar expidió una segunda ley de reforma agraria (la primera fue de 1964) y apoyándose en la exportación petrolera propició la industrialización (Armijos y Flores, 1991; Jácome, 2003)
} 
diferencia de lo ocurrido en Perú y de lo que había sido usual en la historia ecuatoriana, el gobierno militar no convocó a asamblea constituyente. En su reemplazo diseñó el denominado Plan de Reestructuración Jurídica del Estado, que incluía un conjunto de acciones que desembocarían finalmente en la instalación del régimen democrático. Este plan fue anunciado en junio de 1976, y se inició de inmediato cuando el gobierno militar convocó a representantes de organizaciones sociales y políticas para recoger criterios y para hacer conocer su propuesta (Mills, 1983: 24). Posteriormente, una comisión se encargó de reformar la constitución de 1945, otra de redactar una nueva constitución y una tercera comisión elaboró las leyes de partidos y de elecciones (Mills, 1983: 25). En enero de 1978 se realizó un referendo, en el que fue escogida la nueva constitución y, finalmente, en julio del mismo año y en abril de 1979 se efectuaron las dos vueltas de la elección presidencial, dentro de la modalidad de ballotage introducida por primera vez en América Latina. En agosto de este último año se inició el mandato del primer presidente de esta nueva etapa constitucional, cuando habían transcurrido once años desde la posesión del último presidente civil elegido en las urnas (nueve de los cuales correspondieron a los tres gobiernos de facto: Velasco Ibarra, 1970-1972, Rodríguez Lara, 1972-1976 y Junta Militar, 1976-1979).

En Bolivia, por el contrario, la doble transición (Mayorga, 1991a: 209 y siguientes) fue el resultado de un largo proceso de erosión del régimen político instaurado desde $1964^{4}$. Los intentos de llevar adelante una transición controlada por el gobierno militar se encontraron con la resistencia de importantes sectores sociales y fracasaron definitivamente cuando la Corte Nacional Electoral debió anular las elecciones de julio de 1978 por su carácter fraudulento. Esto desembocó nuevos golpes de Estado y en la convocatoria a nuevas elecciones en 1979. Sin embargo, debido a la vigencia de la disposición constitucional que determina que si ninguno de los candidatos obtiene la mayoría absoluta en la elección ésta debe resolverse en el Congreso, fue este organismo

\footnotetext{
${ }^{4}$ Es posible establecer una continuidad del régimen desde el golpe de Estado de René Barrientos, en 1964, que dio fin a los gobiernos del MNR surgidos de la Revolución de 1952, hasta el retorno a la democracia en 1982. Los diversos intentos de bonapartismo y de instauración de gobiernos autoritarios fueron las características centrales de ese período. El gobierno de Hugo Banzer (19711978) que logró afianzarse por medio de una fuerte represión a las fuerzas de oposición (especialmente al sindicalismo minero) y del apoyo de sectores empresariales y de clase media (Lazarte, 1992: 67), fue el que más cerca estuvo de romper el empate entre la COB y las FFAA por medio de un régimen autoritario y represivo en lo político y desarrollista en lo económico (Mayorga, 1991a: 210). Como constantes en todo ese período, hasta el retorno a la democracia en 1982, se destacan la imposibilidad de conformar una arena política que permitiera el procesamiento de los conflictos y la ausencia de otros actores políticos distintos a los militares y a la poderosa central sindical. Estos fueron factores de importancia en la configuración de la transición.
} 
el que debió elegir al Presidente. Pero solamente pudo lograr un acuerdo para nombrar a un presidente interino por un año. Esto provocó un nuevo golpe de Estado en 1979, que a su vez desembocó en otra solución de compromiso cuando el Congreso volvió a elegir a otro presidente provisional (que, en este caso, fue la primera mujer en llegar a ese cargo), con el mandato de convocar a nuevas elecciones. Estas se realizaron en junio de 1980, pero de inmediato se produjo otro golpe militar que instauró una de las dictaduras más represivas de la historia boliviana, encabezada por Luis García Meza. Depuesta finalmente en 1982, con una nueva sucesión de golpes militares, se llegó a la entrega del gobierno a la coalición que había triunfado en las elecciones de 1980 (Lazarte, 1992: 67; Lazarte, 1993: 184; Mayorga, 1991a: 30; Laserna, 1992: 45 y 176).

Tiene interés destacar que mientras en Ecuador y Perú se elaboraron nuevas constituciones, la transición en Bolivia se efectuó dentro del marco de la constitución de 1966. Una interpretación formalista podría llevar a considerar a esto como el reflejo de los contenidos y de la orientación de los procesos en cada uno de los casos. Sin embargo, por ese camino se podría llegar a conclusiones erróneas, ya que se podría asumir que solamente en los dos primeros países se asistió claramente a un cambio de régimen, en tanto que lo ocurrido en Bolivia podría verse como un episodio más de la larga cadena de enfrentamientos que se venían produciendo por lo menos desde $1978^{5}$. Por el contrario, es posible afirmar que entre los tres países existen más similitudes que diferencias en este aspecto, ya que en todos ellos se estableció un nuevo tipo régimen. Se podría decir, siguiendo la línea de algunos autores de la época, que en los tres países se había resuelto el problema de la hegemonía y que en consecuencia el arbitraje militar o su presencia directa en la gestión estatal ya no tenían razón de ser (Pease, 1980; Laserna, 1992b; Cueva, 1980). Pero en realidad lo ocurrido parece ir más allá de lo que puede indicar esta afirmación, ya que en los tres países se abandonó el régimen imperante y se instauró uno que, hasta entonces, era desconocido para ellos ${ }^{6}$.

\footnotetext{
${ }^{5}$ La caída del gobierno de Hugo Banzer podría considerarse como el punto que marca el fin del régimen bonapartista militar instaurado en 1965, ya que en ese momento se hace evidente la pérdida de legitimidad de la conducción gubernamental por parte de las fuerzas armadas. Sin embargo, un análisis cuidadoso de los gobiernos que se sucedieron desde ese momento (1979) hasta la instauración del primer gobierno democrático (1982) demostraría que, independientemente de su ubicación política en el espectro izquierda-derecha, todos ellos fueron intentos fallidos de continuación o preservación de la misma línea.

${ }^{6}$ En realidad, esta afirmación debe ser matizada ya que en los tres países existieron experiencias previas de regímenes poliárquicos, como se podrá ver más adelante en este mismo capítulo y en el capítulo IV.
} 
En ese sentido, en los tres se asistió al desmontaje de un tipo de régimen y a la instauración, en su reemplazo, de un ordenamiento democrático. Por consiguiente, las diferencias entre ellos no se encuentran en el punto de llegada, que es lo que se desprendería de la visión formalista basada en la presencia o en la ausencia de una nueva constitución. En los tres casos se produjo efectivamente el cambio de régimen y la instauración de democracias o, para decirlo con mayor precisión, de poliarquías ${ }^{7}$. Pero eso no significa que no existieran diferencias, sino que a estas se las encuentra en otros niveles. Específicamente, ellas están en el tipo de régimen que existió previamente y en la manera en que fue desmontado. Por consiguiente, lo que varía entre ellos es el punto de partida y las acciones que llevaron al cambio. A su vez, esto obliga a identificar las diferencias existentes entre los actores políticos así como las posiciones que adoptaron ellos en relación al cambio de régimen.

En lo primero -en el tipo de régimen existente previamente- no caben dudas de las diferencias que se encuentran entre Bolivia y los otros dos países. Como se ha visto, estos últimos transitaron por un período de reformismo relativamente importante -tanto en términos de duración como en las acciones desarrolladas-, mientras que en Bolivia apenas se encuentran dos fugaces intentos de instauración de un gobierno de esa naturaleza ${ }^{8}$. Pero, la diferencia no está dada solamente por la orientación de los respectivos gobiernos -esto es, por su carácter reformista o no-, sino que junto a ella aparece también la mayor o menor capacidad para instaurar un régimen político propiamente dicho. En este sentido es indudable que los gobiernos militares de las décadas de los sesenta y setenta en Ecuador y Perú permitieron consolidar un tipo de régimen que -por falta de una mejor caracterización- puede ser calificado como lo que no era, esto es, como un régimen no oligárquico. En efecto, la característica central de los

\footnotetext{
${ }^{7}$ Dado el carácter eminentemente político y el énfasis en los derechos civiles de la población, parece más adecuado acudir al concepto de poliarquía de Robert Dahl que al más general de democracia (Dahl, 1989). Sin embargo, se puede advertir una contradicción en la terminología e incluso en los conceptos en tanto se alude a transición a la democracia y no a la poliarquía, o se trabaja con conceptos como régimen democrático y no necesariamente $-\mathrm{O}$ no siempre- con régimen poliárquico. Pero esta inconsistencia desaparece si se considera, comos se ha señalado en el capítulo anterior, que democracia y poliarquía -así como sus derivados y sus adjetivaciones- están entendidas aquí como términos intercambiables. Mientras no se señale lo contrario, con democracia y con régimen democrático se alude a la democracia política. Este tema será objeto de debate en el capítulo IV, al tratar el tema de la calidad de la democracia en los tres países.

${ }^{8}$ Los gobiernos de Obando, en 1969, y Juan José Torres, en 1970-1971, intentaron desarrollar una línea reformista relativamente similar a la que ya se observaba en Perú y a la que poco después se encontraría en Ecuador. Sin embargo, ambos no pasaron de ser intentos frustrados, incluso a pesar del apoyo popular -expresado en una fuerte y entusiasta movilización social- que tuvo el segundo (Lavaud, 1998; Calderón y Szmukler, 2000; Malloy 1992; Gamarra y Malloy, 1995).
} 
regímenes establecidos con los gobiernos militares fue la superación del viejo Estado oligárquico que había sido capaz de mantenerse aún después de las respectivas revoluciones liberales de fines del siglo XIX y comienzos del XX (Halperin, 1970: 207355; Rueschemeyer et al., 1992: 155-225; Pease, 1986: 17-21, Cotler, 1988: 228-233; Basadre, 1980; Cueva, 1980). Sin embargo, son regímenes que no llegan a cuajar -lo que obliga a esa clasificación por negación-, pero a la vez constituyen una ruptura con lo que existía anteriormente.

Bolivia no podía seguir ese camino debido a que la ruptura con el Estado oligárquico puede establecerse en la revolución de 1952 (Lavaud, 1998: 27-52; Zavaleta, 1990, 61-91; Whitehead, 1988: 81-85; Almaraz 1981). Los diversos gobiernos, tanto civiles como militares, que se sucedieron a partir de ella se enmarcaron dentro de un mismo tipo de régimen. La reforma agraria (la segunda de América Latina después de la mexicana), la nacionalización de los recursos naturales, en especial de la minería del estaño, el diseño de nuevas condiciones para el juego político -con la instauración del sufragio universal como elemento central, con la consecuente incorporación de la población indígena- y el papel central asignado a la organización social (sindical y campesina) pueden considerarse como las expresiones del fin del Estado oligárquico y de la instauración de un nuevo orden ${ }^{9}$.

En consecuencia -y esta es la característica del segundo nivel, el de las acciones que llevaron al cambio y las posiciones y los cálculos de los actores políticos- las tareas que se podían desarrollar en Ecuador y Perú diferían sustancialmente de las que se podían

${ }^{9}$ Es innegable el carácter impreciso del concepto de régimen oligárquico, lo que se hace mucho más evidente cuando se trata de una aproximación comparativa que requiere de una dimensión analítica y no solamente descriptiva. Sin embargo, dado que su utilización tiene raíces profundas en las ciencias sociales latinoamericanas y considerando que es necesario contar con una caracterización de la situación que prevaleció durante por lo menos un siglo y medio en los países estudiados, es pertinente acudir a él como un recurso más bien de carácter instrumental. Desde esta perspectiva, el régimen oligárquico se caracterizaría por aspectos propios de la organización económica (producción principalmente primaria -agrícola o minera-, control monopólico de los medios de producción o existencia de barreras al acceso a la propiedad de estos, uso extensivo de la fuerza de trabajo, escasa adopción de tecnología y de modernización del proceso productivo, baja diversificación, entre otros), por características de la sociedad (escasa movilidad, incluso con la presencia de obstáculos legales para que ésta se produzca, fuerte asociación entre grupos económicos y dominación social, exclusión basada en criterios sociales y étnicos y existencia de claras líneas de segmentación social) y finalmente por un tipo específico de organización política (exclusión de amplios sectores de la población durante un largo período mayoritarios- en la elección y en la toma de decisiones, baja observancia de la normas, formas no democráticas o claramente antidemocráticas). Una caracterización de este tipo, bastante generalizada en los estudios latinoamericanos entre los años sesenta y ochenta del siglo XX es la que hacen Pease (1986: 20 n), Zavaleta (1990: 161-203), Cueva (1980: 8) y, hasta cierto punto, Rueschemeyer et al (1992: 172-204). Una visión crítica se encuentra en Cardoso (1972: 237) 
impulsar en Bolivia. Los dos primeros países se enfrentaban al dilema de consolidar lo iniciado por las dictaduras militares reformistas -dotándole de un marco institucional en el que se pudieran expresar los diversos sectores sociales que recién adquirirían significación política- o retornar al pasado oligárquico. Bolivia debía establecer las condiciones para que las transformaciones realizadas desde 1952 tuvieran la expresión política necesaria para su plena realización o retroceder tres décadas en su historia con consecuencias sociales impredecibles ${ }^{10}$. Es decir, en los tres países se enfrentaba una coyuntura crítica, en tanto se trataba de situaciones cargadas de múltiples determinaciones que requieren soluciones de fondo y que determinan el posterior curso de los acontecimientos ${ }^{11}$. Pero el carácter de esas coyunturas o sus componentes y sus posibles rumbos de evolución eran sustancialmente diferentes en Bolivia con respecto a los otros dos países. Las características de las transiciones, esto es, el carácter conflictivo de la boliviana y los procesos más bien controlados en los otros dos países, expresan claramente esas condiciones diferentes y por consiguiente las opciones que podían escoger los actores políticos.

En este punto, cabe preguntarse por las causas que llevaron en los tres casos a escoger la opción que conducía al establecimiento de un régimen democrático, ya que, como se ha visto, era posible tomar el rumbo contrario o incluso perpetuar la situación existente. Una forma de responder a esta pregunta -que, por cierto, abre múltiples respuestas o puede derivar la atención hacia varios niveles (condiciones económicas, conflictividad social, contexto internacional, antecedentes históricos)- se encuentra precisamente en las decisiones tomadas por los actores sociales y políticos ${ }^{12}$. Para ello, para iniciar la

\footnotetext{
${ }^{10}$ Refiriéndose a las controversias de la fallida transición desarrollada entre 1977 y 1980, Whitehead (1988: 103) señala que "El más profundo problema que quedaba por resolver era el de qué partes del legado de la revolución de 1952 podrían revitalizarse o adaptarse para que proporcionaran apoyo a masivo y dirección a los futuros gobiernos de base popular. Tanto el carácter como la perdurabilidad de cualquier proceso de "democratización" dependerían del modo en que se respondiera a ese interrogante".

${ }^{11}$ El concepto de coyuntura crítica está tomado de la perspectiva de path dependence (Mahoney, 2001: 111-141; Pierson, 2000: 251 y ss.), sobre el que volveré más adelante en este mismo capítulo. Por el momento cabe destacar su pertinencia para el análisis de las transiciones en tanto permite comprender a estas como momentos determinantes de la evolución posterior de cada uno de los países.

12 Más que en justificaciones de carácter teórico o conceptual -que serían absolutamente pertinentes y válidas-, el respaldo de esta opción metodológica se encuentra en la respuesta que se puede dar a la pregunta básica acerca de las causas que produjeron una determinada orientación de los hechos (el tránsito hacia la democracia y no a otras formas de organización política) a pesar de que las condiciones estructurales no diferían significativamente de las que en ocasiones anteriores habían conducido a otros resultados (democracias inestables o gobiernos autoritarios). Este es el punto débil de las explicaciones estructurales (como las de Rueschemeyer et al, 1992) que hacen depender las
} 
indagación en este sentido, es necesario identificar previamente a esos actores y comprender las condiciones en que ellos se desempeñaban.

Un primer elemento en este sentido es que, amparados por las reformas introducidas por los regímenes militares, tanto en Ecuador como en Perú bajo habían surgido nuevos sectores sociales con sus respectivas demandas (Conaghan y Espinal, 1990: 564; Cotler, 1988). A ello contribuyeron los procesos de reforma agraria, de diversificación de la economía, de impulso a la industrialización y el fortalecimiento del papel del Estado en la economía (con múltiples efectos, entre los cuales no es despreciable la ampliación del cuerpo de funcionarios y de trabajadores del sector público). Eran grupos sociales que buscaban insertarse plenamente no sólo en el cuerpo social sino que de manera implícita o explícita demandaban presencia política ${ }^{13}$. Adicionalmente, las fuerzas armadas de ambos países habían pasado a ocupar el centro del espacio político y habían desplazado a los actores previamente existentes. La prohibición de los partidos políticos y en general de la acción política organizada, así como las restricciones a las actividades sindicales y gremiales dejaron a los militares en capacidad de controlar en términos casi absolutos todo el proceso, especialmente desde el momento en que se abrió la segunda fase que, como se ha visto, es cuando se operó la transición.

Dos efectos se derivaron de esta situación. En primer lugar, la alta capacidad de los militares para imponer sus condiciones y para definir con bastante precisión los pasos que habrían de seguirse. Esto es lo que ha llevado a considerar a las transiciones efectuadas en estos países como los casos más claros (junto a Brasil) de imposición (Karl, 1990: 9-10 ${ }^{14}$. En segundo lugar, y más importante, la escasa o nula presencia de actores

conductas de los autores de las condiciones socioeconómicas, sin considerar que durante la fase previa a la transición éstas tuvieron más bien el comportamiento de una constante.

13 Algunos autores coinciden en señalar que en Perú existió fuerte presión en este sentido por parte de diversos sectores sociales (O`Donnell y Schmitter, 1994: 38; Karl, 1990: 9; Mayorga, 1994: 29). Sin embargo, alguna evidencia lleva a pensar que esas acciones no tenían como meta el establecimiento de un régimen democrático sino que se dirigían prioritariamente a la satisfacción de intereses corporativos (Cotler, 1988: 252). La excepción puede encontrarse en la huelga general de julio de 1977 que incluyó entre sus demandas el retorno a la democracia (Mayorga, 1994).

14 Terry Lynn Karl (1990: 9) propone una tipología de transiciones basada en dos dimensiones: la fuerza relativa de los actores y las estrategias de transición. En la primera dimensión considera dos posibilidades: el ascenso de las elites o de las masas. En la segunda identifica estrategias de compromiso o de fuerza. Al cruzar estas dos dimensiones obtiene cuatro tipos de transición: por pacto (estrategia de compromiso con elites ascendentes); por reforma (estrategia de compromiso con masas ascendentes); por imposición (estrategia de fuerza con elites ascendentes); por revolución (estrategia de fuerza con masas ascendentes). Obviamente, la realidad siempre es reacia a mantenerse en las casillas 
políticos y sociales comprometidos con la transición y que pudieran asumir el papel de sujetos protagónicos de ella. La relación entre ambos hechos es evidente, ya que la centralidad y el predominio militar en el proceso no encontró un contrapeso en los actores civiles que tuvieron comportamientos fundamentalmente reactivos frente a las acciones desarrolladas por los primeros. Pero lo esencial en este aspecto es que allí se encuentra la explicación más sólida sobre el carácter de la transición en ambos países así como para la definición de las características de sus respectivas poliarquías en el período posterior. La ausencia de pactos en los procesos seguidos en los dos países, destacada por algunos autores (O`Donnell y Schmitter, 1994: 75; Karl, 1990: 11; O`Donnell, 1988: 18), se deriva precisamente de la ausencia de actores comprometidos con la transición y con capacidad para agregar las demandas de los diversos sectores sociales sobre la base de un alto grado de legitimidad. Los viejos actores estuvieron presentes durante ese período, pero carecían de la legitimidad necesaria para encabezar el proceso o por lo menos para negociar sus condiciones. Los nuevos estaban naciendo y eran aún demasiado débiles para ocupar el espacio requerido para convertirse en protagonistas ${ }^{15}$.

En Bolivia, por el contrario y como se ha visto, los mismos actores que coparon la escena política desde 1964 se mantuvieron a lo largo del período previo a la transición. El protagonismo de la Central Obrera Boliviana -que venía desde los primeros momentos de la revolución de 1952 (Lavaud, 1998: 33 y ss.)- encontró su único contrapeso en las Fuerzas Armadas que desde 1964 se transformaron en el otro actor central de la política. El empate aludido antes entre ellas fue la característica incluso de los momentos de mayor caos que precedieron a la transición. A esto contribuyó la debilidad de las organizaciones empresariales, que prácticamente desaparecieron con la revolución de 1952 y solamente alcanzaron una débil presencia -regionalmente diferenciada- desde 1971 (Laserna, 1996; Calderón y Smukler, 2000). También fue determinante la ausencia de otras organizaciones sociales fuera de la poderosa COB. A lo largo de todo el período, esta fue capaz de integrar en su seno y controlar no solamente a la totalidad de sectores asalariados y al campesinado, sino también a los sectores medios (como maestros y

de una tipología, de manera que siempre existen solapamientos, como se desprende de la observación del mismo autor con respecto al papel de la movilización social en el caso peruano (Karl, 1990).

${ }^{15}$ Este vacío de actores políticos se expresó en las primeras elecciones presidenciales y legislativas realizadas en ambos países. Sus resultados expresan una división de preferencias, sin ganadores absolutos, entre los viejos y los nuevos actores. Solamente en el segundo o tercer proceso electoral se hizo evidente el nuevo sistema de partidos que expresaba el nuevo mapa de actores políticos (Tuesta, 2005b, Tanaka, 1998; Grompone, 1996; Pachano, 2000). En el capítulo III, al abordar los sistemas de partidos, trataré con detenimiento este tema. 
empleados públicos). Estos grupos, que usualmente en otros países -como fue el caso de Ecuador y Perú- han canalizado sus demandas por medio de sus propias organizaciones, en Bolivia siempre lo hicieron dentro de aquella organización sindical (Lavaud, 1998: 172-176), lo que se tradujo en escasa autonomía que constituyó una limitación para su transformación en actores políticos. En esas condiciones, los partidos políticos tuvieron poco espacio para desarrollarse y, a pesar de que en los años inmediatamente anteriores a la transición habían cobrado alguna importancia (Romero, 1998: 19-26), su capacidad para agregar intereses era prácticamente nula.

Todo este conjunto de condiciones configuró -e hizo prácticamente inevitable- la situación caótica descrita al inicio de este capítulo. La polarización de las posiciones políticas y la débil constitución de actores políticos desembocaron finalmente en el bloqueo permanente. Cada uno de los dos sectores en pugna trató de romperlo por medio de la fuerza, pero con ello no se logró sino fortalecerlo ya que inevitablemente se configuraba una situación de ganadores y perdedores absolutos. Por tanto, constantemente se retornaba al punto de partida, pero siempre en condiciones más precarias y con menor margen de acción para los ya agotados actores centrales. En esta dirección, el punto más alto se alcanzó con la dictadura de García Meza, cuya vinculación con el narcotráfico constituyó un duro golpe para el reducido prestigio que aún tenían las Fuerzas Armadas ${ }^{16}$. Previamente, por su constante irrupción en el campo político habían llegado ya a una situación de legitimidad precaria, en la que cualquier intento de acceder nuevamente al poder, o de conservarlo en caso de haberlo hecho, solamente podía arrojar resultados negativos para ellas como institución ${ }^{17}$. Así, el propio interés institucional de preservación de la integridad de las Fuerzas Armadas creó el espacio

\footnotetext{
${ }^{16}$ La vinculación de García Meza con el narcotráfico fue fehacientemente comprobada y sirvió para que se convirtiera en el único dictador boliviano preso a pesar de la poca celeridad en el juicio (Barrios, 1994: 92; Whithead, 1988: passim).

${ }^{17}$ Se había llegado a "una degradación del poder militar. Hasta Natusch, a los oficiales que llegan al poder se los considera (...) como líderes legítimos; luego ya no sucede lo mismo, dado que los mejores se han quemado en el fuego del foro público, no restan sino los mediocres, artífices de una política, desde ya, dudosa en sí misma. A la larga, no les queda otro remedio que el de retirarse para dejar el poder en manos de los civiles, empujados por oficiales interesados en devolverle su honor a la Fuerzas Armadas, y en favor de la democracia o, por lo menos, del restablecimiento del régimen constitucional" (Lavaud, 1998: 117). Lazarte (1993: 185) coincide con esta apreciación cuando señala que "en ese borrascoso recorrido, el modelo militar se agotó completamente y cerró su ciclo", pero introduce una interpretación diferente cuando considera que "en estas condiciones el establecimiento de la democracia fue menos el resultado de un 'pacto de transición' que la imposición popular a una Fuerzas Armadas en proceso de desquiciamiento interno". Esta apreciación es acertada, pero cabría puntualizar que el agotamiento no se restringió a los militares sino al conjunto de un régimen que, reiterada e infructuosamente, había intentado romper con golpes militares el empate mencionado antes.
} 
apropiado para que se impusieran los sectores blandos de ellas, que actuaban movidos fundamentalmente por un objetivo de supervivencia institucional (Mayorga 1994: 37; Whitehead, 1988: 98-99).

Sin duda, el aspecto central a destacar a partir de esta breve descripción de los procesos de transición es el diferente papel desempeñado por los diversos grupos sociales y políticos en cada uno de los casos. Las posiciones que ellos adoptaron, las estrategias que definieron y que aplicaron, así como las demandas que canalizaron hacia los gobernantes autoritarios constituyeron en conjunto el elemento de mayor peso para la definición del rumbo seguido de ahí en adelante. De manera especial, la orientación de los actores durante el período de transición condicionó la posterior legitimidad del régimen democrático, lo que plantea la necesidad de identificarlos y de comprender su ubicación con respecto al nuevo régimen que, por acción u omisión, ellos habían contribuido a establecer. Pero, antes de entrar en ese campo, que es materia de la última sección del presente capítulo, es necesario mirar brevemente cuáles fueron los efectos de la transición en cada uno de los países.

\section{Los legados de la transición}

La pregunta por los efectos de la transición sobre la conformación del régimen democrático y sobre su desempeño posterior podría resultar ociosa si se considera la abundante bibliografía al respecto. Sin embargo, hay dos motivos para volver sobre ella en el marco del análisis sobre la calidad de la democracia en los tres países andinos. En primer lugar, el desarrollo posterior de los regímenes poliárquicos instaurados en cada uno de los países induce a suponer que muchas de las diferencias o especificidades que se encuentran actualmente se originan en aquel proceso. De este modo, se hace necesario buscar las especificidades de cada uno de ellos y, desde las perspectivas de análisis y desde los conceptos que se han construido al respecto, detectar los aspectos que pueden haber influido en el desarrollo democrático posterior. En segundo lugar, a pesar del importante número de trabajos que abordan el tema de las transiciones y de sus consecuencias, es escasa la investigación empírica acerca del impacto del tipo de transición en las características del régimen democrático. Aparte de las hipótesis formuladas en los trabajos clásicos o seminales, es muy poco lo que se ha avanzado en ese 
sentido por medio de estudios concretos ${ }^{18}$. Obviamente, no es mi interés llenar ese vacío, que no corresponde a los objetivos de este estudio, sino solamente encontrar algunas pistas que permitan una mejor comprensión de la evolución posterior.

En esta línea es importante centrar la atención en tres aspectos. En primer lugar, como un instrumento básico para evaluar los legados de la transición, es imprescindible preguntarse por la legitimidad de los regímenes militares tanto a lo largo de su ejercicio como en el momento de la entrega del poder a los civiles. Del grado de legitimidad alcanzado por ellos se desprenden muchos de los rasgos que posteriormente caracterizarán a las nacientes democracias. En segundo lugar, cualquier análisis de las condiciones en que opera el régimen democrático y sobre todo de su funcionamiento debe considerar los elementos básicos del diseño institucional. Aunque sea someramente, es necesario comprender las características y especificidades de aspectos como las relaciones entre los poderes del Estado, las facultades atribuidas a cada uno de ellos, las reglas de la competencia política y la distribución territorial del poder ${ }^{19}$. Finalmente, es necesario detectar las características de los actores políticos, de manera especial las condiciones establecidas para su constitución y para su desempeño.

En cuanto a lo primero, de lo señalado en las páginas anteriores se desprenden algunas conclusiones iniciales. La primera de éstas es que los regímenes de Ecuador y Perú gozaron de apreciable legitimidad (a lo largo de todo su ejercicio en el caso ecuatoriano, y por lo menos hasta los dos últimos años en el caso peruano). En este último, la crisis económica, desatada en buena medida por las propias acciones del gobierno militar en su primera fase (Cotler, 1988: 235), rompió el equilibrio que el régimen había logrado con una combinación de reformismo y movilización popular. La apropiación de "posiciones y soluciones revolucionarias propuestas en la década de 1930 por Haya de la Torre y el partido aprista" (Cotler, 1988: 230), además del desgaste de los partidos tradicionales y

${ }^{18}$ Es probable que en esto exista un condicionamiento temporal, en el sentido de que la mayor parte de estudios sobre las transiciones se realizó en el momento en que ellas ocurrían. Por ello, esos estudios estuvieron centralmente preocupados de la manera en que habían ocurrido los procesos, los elementos desencadenantes, las estrategias de los actores y las características del régimen resultante. Las transiciones como tales no se mantuvieron en la agenda de la investigación política por mucho tiempo -los estudios más recientes son de la primera mitad de la década de los noventa- y fueron rápidamente sustituidas por temas como la gobernabilidad o aspectos institucionales de las poliarquías (sistema de partidos, relaciones ejecutivo-legislativo, entre otros).

${ }^{19}$ Este tema será tratado con detenimiento en el capítulo III, pero es necesario abordarlo en el marco del estudio de las transiciones debido a la importancia que tienen los diseños institucionales en esos procesos. También es importante porque ellos son una pista para comprender por lo menos parcialmente muchas de las orientaciones que guiaron a los procesos de transición a la democracia. 
del apoyo de la izquierda (Planas 2000b), le permitieron aparecer como el legítimo portador de los intereses populares y a la vez como expresión de la nación en su conjunto. En Ecuador, la erosión de los partidos tradicionales -que se arrastraba ya para ese momento por largos treinta años- y especialmente el auge petrolero constituyeron las fuentes de legitimidad de las que se nutriría el régimen militar hasta la entrega del poder ${ }^{20}$.

Una segunda conclusión es, obviamente, la baja o inexistente legitimidad de los regímenes militares bolivianos inmediatamente anteriores a la transición. Al contrario de Barrientos, que trató de afianzarse por medio del pacto militar-campesino, y de los gobiernos de Ovando y Torres que buscaron el apoyo de los sectores populares organizados, especialmente de la poderosa COB, desde Banzer en adelante los gobiernos militares acudieron a la fuerza como el recurso básico para su implantación y para su estabilidad (Lavaud, 1998; Whitehead, 1988). Ninguno de ellos tuvo el apoyo de actores sociales y políticos significativos, ni pudieron neutralizar a la oposición. Por ello, el nivel de uso de la fuerza fue cada vez más alto hasta llegar a la utilización indiscriminada de la violencia como ocurrió en el gobierno de García Meza.

La diferencia entre los dos primeros países, por un lado y Bolivia, por otro lado, puede tener varias explicaciones, de las cuales cabe destacar dos. La primera es el papel desempeñado por los militares en cada uno de los casos. Como se ha visto, en Ecuador y Perú ellos actuaron como árbitros de última instancia, atribuyéndose el carácter de única institución con capacidad para resolver los conflictos estructurales que afectaban a los respectivos países. Elemento fundamental para ello fue la adopción de la ideología de la seguridad nacional, tanto como instrumento de interpretación de la realidad económica, social y política, así como en su calidad de instrumento apropiado para la conducción de la política interna y para el desempeño de la administración pública. En Bolivia no pudieron asumir ese papel arbitral debido a su condición de actores directos de la política. En esa condición ellos estaban impedidos de ponerse por encima de los conflictos y aparecer como los únicos encargados de solucionarlos. Por esa misma razón no podían utilizar la doctrina de la seguridad nacional sino para la represión, es decir, no

${ }^{20}$ Los partidos tradicionales en ese momento eran el Conservador y el Liberal, a los que podría sumarse también el Socialista. Los dos primeros fueron formados en las décadas finales del siglo XIX, en tanto que el último fue fundado en 1926 (Ayala: 1978). Junto a ellos había tenido destacada actuación Concentración de Fuerzas Populares, conformado en 1949 en torno a la figura de Carlos Guevara Moreno (Guerrero, 1994: 23). Como se verá en el capítulo III, la denominación de tradicionales se utilizó posteriormente también para los partidos que se consolidaron en el proceso de transición a la democracia, lo que puede llevar a confusiones. 
podían acudir a la interpretación de ella como un cuerpo de principios que les permitirían garantizar las condiciones de vida de la población.

La segunda explicación se encuentra en condiciones históricas de largo plazo, que definieron de diversa manera el papel y la apreciación de los militares en cada uno de los países. Si bien en los tres tuvieron una presencia constante en la política, tanto por medio de golpes militares como por el apoyo dictaduras civiles, el camino seguido no fue similar en todos ellos. Así, los militares ecuatorianos adoptaron tempranamente una posición corporativa que les permitió mantener alguna distancia con los sectores económica y políticamente dominantes y que por tanto les permitió asumir el papel de factor determinante en la arena política ${ }^{21}$. Su inicio se sitúa en el año 1925, cuando los oficiales de baja graduación protagonizaron un golpe de Estado que, por primera vez en la vida republicana, tenía un carácter estrictamente militar y no obedecía a un caudillo o a un grupo político o económico determinado (Maiguashca 1991; Paz y Miño, 2002). Posteriormente actuaron de manera similar en 1963 cuando un golpe efectuado por la cúpula de las Fuerzas Armadas terminó con el que hasta ese momento había sido el más largo período de estabilidad constitucional (en que se sucedieron cuatro gobiernos elegidos democráticamente desde 1948). La tercera experiencia de este tipo fue la de 1972, referida en las páginas anteriores. En todas esas ocasiones se definieron como gobiernos institucionales de las Fuerzas Armadas y encontraron en la situación de crisis generalizada (política, económica, social, institucional e incluso internacional en uno de los casos) la justificación para su irrupción en la política. No actuaron, como lo habían hecho en otros momentos, como el instrumento armado de un determinado sector, sino como el único actor con capacidad para poner orden en conflictos de larga duración (Fitch, 1977: 14-34). Independientemente de que esa afirmación hubiera sido cierta o no en su momento, lo importante es que se trató de una percepción aceptada por el conjunto de actores políticos y por la mayor parte de la población. Esto llevó a la construcción de una imagen de las Fuerzas Armadas como un factor fundamental para

\footnotetext{
${ }^{21}$ Se puede asegurar que esta orientación de los militares ecuatorianos tiene alguna relación con el origen social de sus integrantes que, con el proceso de profesionalización de las Fuerzas Armadas (especialmente desde la década de los treinta), fue cada vez menos elitista (Fitch, 1977: 16). Esto, junto a la identificación de un enemigo externo (sobre todo desde la derrota militar y la pérdida de territorio en 1941), propició la conformación de un sector militar nacionalista y desarrollista. Además, tuvo también mucho peso que su conformación como cuerpo profesional se produjo en la Revolución Liberal de inicios del siglo XX, lo que siempre les permitió a sus ideólogos reivindicar el carácter de componente fundamental (y fundacional) del Estado.
} 
lograr la estabilidad y el orden en un medio conflictivo ${ }^{22}$. Finalmente, esta percepción se robusteció por la adopción -y reinterpretación, como se ha visto antes- de la doctrina de seguridad nacional, que colocaba a este cuerpo como el garante del orden aún cuando éste se definiera como democrático.

Los militares peruanos no lograron el mismo grado de legitimidad alcanzado por los ecuatorianos, aunque durante sus dos últimos pasos por el gobierno hicieron serios esfuerzos en ese sentido (Cotler, 1988: 242). La instauración de las largas dictaduras militares personalistas de Leguía (1919-1930) y de Odría (1948-1956) fue la característica central del siglo XX (Tuesta, 1995: 32-35; Cotler, 1978: 183). La vinculación de los militares con los intereses de los grupos económicos dominantes fue un hecho indudable, alimentado en gran medida por el temor que suscitaba en unos y otros el avance de los sectores populares que encontraban en el naciente APRA una expresión política apropiada (Cotler, 1978: 246). Más adelante, en la década del sesenta, fueron los brotes guerrilleros y la presencia relativamente importante de una izquierda insurreccional los factores que ayudaron a la consolidación de aquellas posiciones dentro de las instituciones castrenses y que, en consecuencia, les impidieron actuar como un cuerpo externo a la política.

En Bolivia se produjo un quiebre cuando la revolución de 1952 prácticamente eliminó las Fuerzas Armadas y las sustituyó con las milicias populares (Lavaud, 1998). Sin embargo, no debió pasar mucho tiempo para que se las volviera a constituir -a diferencia de lo ocurrido en Costa Rica en 1948- y para que con ello retornara la presencia militar a la política. Ello fue posible, de alguna manera, porque en su refundación las fuerzas armadas fueron definidas como la expresión armada de la revolución triunfante. No eran simplemente el cuerpo armado del Estado, sino la expresión de una voluntad política específica que se había impuesto en un proceso revolucionario. Por ello, de ahí en adelante pudieron intervenir en el juego político como uno más de los actores, pero a la vez eso significó su obligación de someterse, como los otros actores políticos, al juicio de

\footnotetext{
22 Sin embargo, con excepción de la última intervención militar (1972-1979), ninguna de las anteriores pudo establecer las condiciones para garantizar algún grado de estabilidad política y desarrollo económico. La de 1925 abrió el período de mayor inestabilidad política del país, con la sucesión de 27 gobiernos entre ese año y 1948. La de 1963 pudo sostenerse precariamente por tres años e inauguró también un nuevo período de inestabilidad de casi una década en la que se sucedieron cinco gobiernos.
} 
la ciudadanía sobre la base de sus acciones políticas ${ }^{23}$. Quedaban así muy lejos de alcanzar aquella condición de árbitro de última instancia que habían logrado los militares ecuatorianos y hasta cierto punto los peruanos.

En síntesis, se puede sostener que existieron profundas diferencias en el grado de legitimidad que lograron los militares en cada caso. Es innegable que las fuerzas armadas de los tres países tuvieron una alta legitimidad de origen, otorgada en primer lugar por su condición de -reales o supuestas- herederas de las luchas por la independencia, ocurridas en todos ellos en las décadas de los diez y los veinte del siglo XIX. Más allá de los reparos que se pueden poner a esa condición, ya que en general no existió continuidad sino más bien ruptura con los ejércitos libertadores, lo que importa es que esa percepción se ha mantenido a lo largo de la historia y en esa medida ha constituido un factor determinante para su legitimación ${ }^{24}$. Pero, en segundo lugar, esa legitimidad de origen se fortaleció cuando, en diversos momentos, se produjo la renovación de las fuerzas armadas de cada uno de los países dentro de un proceso revolucionario. En Ecuador y Perú ocurrió dentro de las revoluciones liberales de inicios del siglo XX, en tanto que en Bolivia, aunque vivió un proceso relativamente similar en aquellos años, el verdadero cambio se produjo después de la revolución de $1952^{25}$. En consecuencia, los militares ecuatorianos y peruanos contaron con un tiempo suficientemente largo para rodear a esa legitimidad de origen del conjunto de creencias y mitos que son necesarios para afianzarla, en tanto que los militares bolivianos enfrentaron el proceso de transición cuando aún eran actores políticos de un proceso en marcha ${ }^{26}$. Los dos primeros países

\footnotetext{
${ }^{23}$ Algo similar ocurrió con lo militares ecuatorianos, ya que el ejército fue constituido como cuerpo profesional en la Revolución Liberal de comienzos del siglo XX. Hasta mediados de la década de los veinte actuaron como facciones al mando de caudillos.

${ }^{24}$ No se puede afirmar fehacientemente que exista continuidad entre los ejércitos que lucharon en las guerras de la independencia y las fuerzas armadas que se constituyeron en los países que surgieron de ese proceso (Haro, 1997). Por lo menos en los países andinos, no se conformaron de inmediato cuerpos armados profesionales, sujetos a estructuras jerárquicas, regidos por criterios meritocráticos y provenientes de una formación especializada. Para que esto ocurriera fue necesario esperar hasta las primeras décadas del siglo XX, cuando se fundaron los colegios militares y se estableció una carrera militar propiamente dicha.

${ }^{25}$ Durante la revolución liberal, Bolivia se vio envuelta en el conflicto entre federalistas y centralistas, que se manifestó incluso en enfrentamientos armados de grandes proporciones. Este fue un campo de conflicto que afectó directamente a las fuerzas armadas -que debían tomar partido por uno de los bandos- y que no estuvo presente en los otros dos países.

26 Otro factor de peso en la trayectoria de las fuerzas armadas bolivianas fue la guerra del Chaco, cuyos resultados prácticos y concretos distaban mucho del imaginario heroico que se construyó en torno a los militares (Almaraz, 1981; Lavaud, 1998). Por el contrario, la derrota militar ecuatoriana en la guerra con Perú en el año 1941 fue unánimemente atribuida a los políticos, en especial a quien ejercía la presidencia en ese momento, de modo que las fuerzas armadas quedaron a salvo de las críticas.
} 
estaban relativamente alejados de la etapa del caudillismo militar -que la vivieron durante la mayor parte de su vida independiente- mientras que Bolivia aún no lograba salir de ella.

Un segundo aspecto en este mismo plano es el que hace referencia a la legitimidad de resultados, esto es, a la capacidad de los regímenes militares para ofrecer rendimientos económicos, sociales y políticos que pudieran ser valorados positivamente por la población. Como se ha visto en las páginas precedentes, las primeras fases de los gobiernos militares de Perú y Ecuador impulsaron procesos de profundas transformaciones estructurales. Aunque los efectos económicos no fueron siempre exitosos -especialmente en el caso peruano en que hubo problemas serios en ese sentido (Cotler, 1988)-, en lo social, en lo político y en lo cultural sí se contó con una evaluación de signo positivo. Los gobiernos militares de ambos países realizaron transformaciones que fueron apreciadas positivamente por la población. Por el contrario, ninguno de los gobiernos bolivianos -tanto civiles como militares- pudo materializar mejores condiciones de vida para la población y por tanto tampoco logró aceptación por parte de ella. Incluso el gobierno de Hugo Banzer, que fue un intento de reformismo militar autoritario, fracasó en la obtención de logros económicos y sociales así como en el mejoramiento de la imagen de los militares. De esta manera, las fuerzas armadas peruanas y ecuatorianas contaron con cierta legitimidad de resultados, lo que les puso en condiciones bastante más favorables que a sus pares bolivianas para enfrentar no solamente el proceso de transición, sino para insertarse en la etapa que se abrió a partir de este. Dicho de otra manera, este se convirtió en uno de los factores que colocaron a los blandos en mejores condiciones en Ecuador y en Perú, con las consecuentes positivas para la transición.

En cuanto al segundo elemento, esto es, los diseños institucionales que se establecieron para el retorno a los regimenes constitucionales, se aprecian también diferencias entre los tres países. Estas diferencias se originaron en los procedimientos e instrumentos que se utilizaron para el retorno al ordenamiento constitucional. Como ya se ha visto, Perú escogió el camino tradicional de la asamblea constituyente, Ecuador utilizó un sustituto de ésta y Bolivia no hizo reformas constitucionales ni legales con este fin. Esto determinó que Ecuador y Perú comenzaran el nuevo período con nuevos marcos jurídico-políticos, mientras Bolivia debía hacerlo con la constitución expedida en 1967 y con el cuerpo legal correspondiente. Como se vio antes, esta diferencia inicial se derivó directamente de las 
características que tomó el proceso en cada uno de los casos y de las posiciones asumidas por los diversos actores políticos. Por ello, lo que interesa aquí no es regresar sobre ese tema, sino analizar someramente los principales contenidos de esos diseños con el fin de tener un primer acercamiento a las características de la arena política en la que debían desarrollarse de ahí en adelante los regímenes democráticos.

Un primer punto de importancia en este campo es el mantenimiento del presidencialismo en los tres países. En ninguno de ellos se buscó introducir cambios de fondo en el tipo de régimen que se había establecido desde su conformación como estados independientes y que, en virtud más de la tradición que de la evaluación del desempeño, llegó a adquirir carta de naturalización. La elección directa del presidente de la República, la doble condición de éste como jefe de Gobierno y jefe de Estado, y su preeminencia sobre los órganos legislativos fueron características heredadas que no sufrieron cambios significativos con respecto a los períodos anteriores de vigencia del orden constitucional. Las innovaciones más destacadas en este aspecto se produjeron en Ecuador y Perú con la introducción de la modalidad de doble vuelta (ballotage) para la elección presidencial. Con ello se buscaba darle mayor sustento al presidente elegido, en el entendido de que la mayoría absoluta que obtendría en la segunda vuelta permitiría alcanzar la estabilidad que había sido esquiva en las anteriores experiencias de gobiernos de origen electoral en ambos países ${ }^{27}$. En Bolivia se mantuvo la disposición que establecía la elección del presidente por mayoría absoluta, pero en lugar de acudir al recurso de la doble vuelta se dejaba la decisión final en el Congreso (lo que, como se verá, fue determinante en la definición de los hechos políticos posteriores).

Un segundo elemento en el plano institucional se encuentra en las relaciones entre el ejecutivo y el legislativo en cada uno de los países. En este aspecto los cambios más significativos se aprecian en Ecuador y en Perú, lo que es obvio a causa de la expedición de nuevas constituciones y en general por la conformación de nuevos órdenes políticos. Así, en Ecuador se estableció un órgano legislativo unicameral, rompiendo la tradición del bicameralismo que había predominado a lo largo de la mayor parte de su historia constitucional. Se suponía que de esta manera se contaría con mayor agilidad en el

${ }^{27}$ En Ecuador se introdujo la doble vuelta porque se suponía que la gran inestabilidad de la mayor parte del siglo XX se debía, por lo menos parcialmente, a la debilidad electoral de los presidentes (Mills, 1984). Sin embargo, no hay asidero para esa afirmación ya que los presidentes elegidos con menor votación pudieron terminar sus períodos al contrario de los que obtuvieron altas votaciones que no lograron hacerlo (Pachano, 2007a: 40). 
procesamiento de las leyes y en general en las actividades del Congreso (Hurtado, 1979). Sin embargo, esa cámara única estaba conformada por dos tipos de diputados, los que eran elegidos en distrito único nacional y los que provenían de cada una de las provincias, lo que generó algunas diferencias en la percepción de la representación de cada uno (Pachano, 2000; 2003) ${ }^{28}$. En Perú los cambios fueron más profundos ya que se introdujeron dos elementos nuevos en la relación entre el ejecutivo y el legislativo. Por un lado, la necesidad de que en determinadas situaciones específicas se someta el Consejo de Ministros y su presidente (uno de los ministros) a la confianza del congreso. Por otro lado, la facultad del presidente para disolver el congreso si este ha censurado o ha negado la confianza a dos consejos de ministros. Por tanto, se adoptaron elementos propios del régimen parlamentario, ajenos a la tradición peruana y de la mayor parte de países latinoamericanos.

Un tercer aspecto de importancia es el de los sistemas electorales. Los tres países entraron a la etapa democrática con sistemas de representación proporcional para la elección de los integrantes de sus respectivos órganos legislativos y de los miembros de las instancias subnacionales. Se puede suponer que la selección de estos sistemas en los casos de Perú y de Ecuador formó parte de la tendencia general hacia la inclusión y la apertura (cuya expresión fundamental fue el reconocimiento de los derechos políticos para la población analfabeta). Pero, también es probable que existiera una relación con el surgimiento de nuevos actores políticos, concretamente de partidos diferentes a los tradicionales, que precisaban de alicientes para su desarrollo. De esta manera, la adopción de sistemas proporcionales era coherente con los objetivos y con la tendencia general de la transición, aunque más adelante se mostrara como uno de los factores que alimentaron la ingobernabilidad (sobre todo en el caso ecuatoriano) ${ }^{29}$.

El punto central en todo este tema de los diseños institucionales radica en las condiciones establecidas en cada uno de los países para la constitución de actores políticos y para el desarrollo de las relaciones entre ellos. Como se ha visto, tanto en Ecuador como en Perú los militares pudieron conducir los procesos con relativa

\footnotetext{
${ }^{28}$ Un cambio formal en el congreso fue su denominación de Cámara de Representantes en lugar de Cámara de Diputados como había sido lo usual. Con las reformas de 1983 se volvió a esta denominación y para sus integrantes se retomó el tradicional nombre de diputados.

${ }^{29} \mathrm{La}$ fragmentación del sistema de partidos, estrechamente relacionada con el sistema electoral, ha sido uno de los factores centrales de la larga crisis de gobernabilidad en Ecuador. Este aspecto está tratado con detenimiento en el capítulo III.
} 
facilidad $^{30}$. Se puede asegurar, a partir de ello, que pudieron dar paso a un proceso de significación de actores políticos, expresado fundamentalmente en el papel que se atribuyó, dentro de la nueva institucionalidad, a los partidos políticos ${ }^{31}$. En ambos casos, con las respectivas particularidades, se les otorgó el monopolio de la representación, lo que obedecía en gran medida al intento de garantizar una transición ordenada y de establecer un régimen estable que pudiera procesar adecuadamente las demandas sociales (Tuesta, 1995: 40; Pachano, 1996; Echeverría, 1997, Mills, 1984). En Bolivia les correspondió también a los partidos ese papel central, pero ello ocurrió más como el resultado de la erosión de los actores centrales del período anterior que como el producto de un diseño previamente establecido. Es por ello que los partidos, a pesar de su debilidad, de la carencia de estructuras fuertes y de las superficiales raíces en la sociedad, pudieron ocupar el lugar central de la escena política de la transición en los tres países. Dicho de otra manera, en todos ellos se llegó a una situación relativamente similar en términos de la constitución de una democracia de partidos, pero los caminos que llevaron hacia ella fueron sustancialmente diferentes entre Ecuador y Perú, por un lado, y Bolivia, por otro lado.

El hecho sustancial en este sentido es que los partidos se convirtieron en los actores centrales de la política, y serían los que en adelante se harían cargo de la culminación del proceso de transición y de la consolidación de la democracia. Sin embargo, las condiciones para ello variaban significativamente entre los tres países, ya que cada uno de ellos presentaba antecedentes históricos muy particulares en términos del desempeño político y electoral de este tipo de organizaciones. Aunque en los tres países el origen de los partidos se remonta a la matriz liberal-conservadora de fines del siglo XIX (Romero, 1998; Tuesta, 1995a; 1995b; Ayala, 1978), la evolución siguió rumbos muy particulares en cada uno de ellos. Por consiguiente, además de las características propias de la transición, es necesario tomar en cuenta los antecedentes históricos de los actores centrales del proceso y las condiciones institucionales en que ellos debieron desempeñarse.

\footnotetext{
${ }^{30}$ De acuerdo a Nohlen (1994: 114), en estos países “en la redemocratización (...) las negociaciones entre el régimen y la oposición tuvieron sin duda un papel menos importante que en el caso de España, y no se podía hablar en absoluto de una 'transición pactada (...) la transición fue iniciada y también en gran parte controlada por los mismos militares tras cambios de poder intrarégimen”

${ }^{31}$ Es muy sugerente el acercamiento que hace Landi (1985), desde la perspectiva semiológica, del proceso de significación de los actores políticos. Esta muy bien podría ser complementada con $-\mathrm{y}$ apoyar a- la perspectiva que pone el énfasis en las decisiones estratégicas de los actores, que será tratada más adelante.
} 
Bolivia contaba con una historia de partidos débiles, que no habían logrado estructurar un sistema que perdurara en el tiempo y que pudiera hacerse cargo de la competencia política. La transición llegó cuando recién se estaba constituyendo la segunda generación de partidos, caracterizada por las propuestas de modernización formuladas por los principales partidos que la conformaban y por el enfrentamiento ideológico en la dimensión izquierda-derecha (Romero, 1998: 27-28; García, 2001). Además, ese incipiente sistema de partidos tenía como antecedente el fracaso que había significado la primera generación, correspondiente a la etapa revolucionaria iniciada en 1952, cuya característica central era la fuerte confrontación entre sus integrantes que dejaba poco margen para la conformación de un sistema de partidos regulado por pautas democráticas (Romero, 1998: 16-19). Es decir, se asentaba sobre bases muy frágiles que no garantizaban su estabilidad y el cumplimiento de las responsabilidades que se avecinaban. Adicionalmente, la rápida descomposición de este incipiente sistema llevó a la proliferación de partidos, la mayor parte de ellos agrupaciones minúsculas que no tenían capacidad de representación ni de agregación de intereses, pero que lograban participar en las negociaciones del momento (Gamarra, 1992: 23). Pero, las propias tareas del proceso de transición, así como el colapso del régimen asentado en el enfrentamiento entre la COB y las Fuerzas Armadas, tuvieron un efector reductor y concentrador de la representación, lo que se expresó en la conformación o el fortalecimiento de los partidos que ocuparían el centro de la escena política de ahí en adelante. El Movimiento Nacionalista Revolucionario (MNR), que había sufrido innumerables desmembraciones, Acción Democrática Nacionalista (ADN) y el Movimiento de Izquierda Revolucionaria (MIR) se transformaron así en los actores centrales del proceso, y habrían de mantener esa condición por lo menos hasta las elecciones del año $2002^{32}$.

Ecuador retornó a la democracia en una situación que planteaba más incógnitas que certezas, ya que los partidos tradicionales -conformados en las primeras décadas del siglo XX- se mantenían en la escena y la compartían con agrupaciones que se habían conformado pocos años antes o que estaban en proceso de estructuración (Mills, 1984). El Partido Liberal (PLE), el Partido Conservador (PC), formados en las últimas décadas

32 El MNR era el único de estos tres partidos formado antes del largo período dictatorial y de convulsiones abierto en 1971, y que por tanto tenía experiencia en la competencia electoral. Por el contrario, tanto el MIR como ADN eran partidos relativamente jóvenes, formados en la década de 1970 (1971 y 1979, respectivamente), por lo que no contaban con aquella experiencia. Adicionalmente, el MIR había nacido como una agrupación que buscaba instaurar un orden diferente a la democracia representativa y ADN buscaba explícitamente continuar la línea de la dictadura de Hugo Banzer (Romero, 1998: 22). 
del siglo XIX, y el Partido Socialista (PS), fundado en los años veinte, mantenían las estructuras que habían consolidado a lo largo del siglo XX (Ayala, 1978). Así mismo, Concentración de Fuerzas Populares (CFP), el Partido Social Cristiano (PSC) y el Partido Demócrata Cristiano (PDC), fundados en las décadas de los cincuenta y sesenta, aparecían como fuerzas políticas de importancia. A ellos se sumaron los partidos conformados en los últimos años, de manera especial Izquierda Democrática (ID) y el Partido Federación Nacional Velasquista (PNV) ${ }^{33}$. Por consiguiente, en ese momento no se podía identificar claramente las características del sistema de partidos que se haría cargo de la transición y sería necesario aguardar a los resultados de las elecciones para tener alguna claridad al respecto. No era posible, en esas condiciones, advertir la orientación que tendría ese conjunto actores políticos, mucho menos cuando varios de ellos -independientemente de su posición ideológica- cuestionaron el proceso impulsado por los militares y se abstuvieron de participar en la construcción de la nueva institucionalidad.

Perú siguió un proceso relativamente similar al de Ecuador, en tanto fueron los militares quienes se encargaron de dar significación a los actores políticos que de ahí en adelante ocuparían el centro de la escena política. Como en aquel otro caso, en el momento de retorno a la democracia convivieron partidos tradicionales y nuevas agrupaciones políticas. Entre los primeros se destacan el APRA (posteriormente Partido Aprista Peruano, PAP), fundado en 1931, el Partido Popular Cristiano, PCP, conformado en 1967, Acción Popular, AP, formado en 1957 y el Partido Comunista Peruano, PC, fundado en 1927 (Planas, 2000: 34-38; Tuesta, 1995: 97-104; Meléndez, 2007b: 216). Entre los movimientos y partidos jóvenes se cuenta una amplia gama de agrupaciones de izquierda (FOCEP, FENATRACA, UDP, DC y PSR), algunas de ellas surgidas como "hijos legítimos e ilegítimos del velasquismo" (Planas, 2000: 145-149). Se trataba, por tanto, de un sistema de partidos en conformación a partir del que había existido antes del gobierno militar y con la inclusión de los nuevos actores que iban surgiendo a lo largo del proceso. De esa manera, tampoco en este caso era posible anticipar la orientación que tendría este nuevo conjunto de actores políticos, más aún cuando en la primera elección presidencial triunfó uno de los partidos tradicionales, pero frente a un avance

33 Todos esos partidos, junto a los que se habían formado en los años inmediatamente anteriores, fueron convocados por el gobierno militar para integrar las comisiones encargadas de elaborar la Constitución y las leyes de elecciones y de partidos. El PDC cambió su denominación por Partido Democracia Popular-Unión Demócrata Cristiana (DP-UDC) al integrarse con una fracción del Partido Conservador (Pachano, 2007b). 
significativo de las nuevas fuerzas, sobre todo de la izquierda (lo que fue evidente en las elecciones legislativas).

Como conclusión de esta breve revisión de algunas características básicas de las transiciones se puede asegurar que, en términos generales, en los tres países se crearon condiciones apropiadas para el juego político. Evidentemente, esto se puede observar con más claridad en los casos de Ecuador y Perú, ya que hicieron su transición con nuevos ordenamientos jurídico-políticos. Por consiguiente, se hacía posible poner en práctica un ejercicio de ingeniería institucional que permitiera eliminar la exclusión política que había caracterizado históricamente a estos países -o por lo menos reducirla a niveles mínimos- y al mismo tiempo se podía incidir en el diseño institucional para favorecer a las nuevas fuerzas políticas y sociales que surgían al amparo de la nueva situación.

\section{3. ¿De la transición a la consolidación?}

A mediados de la década de los noventa se abrió un interesante debate sobre la fase posterior a la transición ${ }^{34}$. El eje de este enfrentamiento conceptual fue la noción de consolidación democrática o, con mayor precisión, el carácter de ésta como una etapa que debía seguir a la transición. No es este el lugar para profundizar en este tema, que por cierto resulta especialmente importante para el análisis de la calidad de la democracia $^{35}$. Lo que interesa aquí es más bien llevar esa preocupación a un campo más amplio y a la vez más concreto, que es el de la delimitación del período de transición en los tres países. Para decirlo de manera directa, cabe preguntarse hasta dónde duran las transiciones, por tanto, qué las caracteriza. Así mismo es necesario tener alguna referencia sobre los elementos que marcan su conclusión. Finalmente, es preciso anticipar lo que puede ocurrir una vez cumplido el período de transición, en donde surge precisamente el tema de la consolidación que fue el centro del debate mencionado. Pero,

\footnotetext{
${ }^{34} \mathrm{El}$ debate se inició con la publicación del artículo Otra institucionalización de Guillermo O’Donnell (que previamente fue presentado como ponencia a la conferencia "Consolidating Third Wave Democracies: Trends and Challenges", realizada en Taipei en agosto de 1995). En este cuestionaba el concepto de consolidación que se había generalizado entre los politólogos, aludiendo de manera particular al libro The Politics of Democratic Consolidation de Richard Gunther, Nikiforos Diamandouros y Hans-Jurgen Puhle. Estos tres autores aludidos respondieron con el artículo Las "ilusiones" de O Donnel: una réplica, que a su vez fue respondido por este autor con Ilusiones y errores conceptuales. Todos los artículos están recogidos en el número 2 de la revista La Política (1996, Paidós, Buenos Aires).

${ }^{35}$ En el capítulo I se encuentra un acercamiento parcial a este tema.
} 
antes de entrar en ese campo en el caso concreto de los tres países, es conveniente hacer una breve reflexión conceptual.

El punto de partida para esa reflexión se encuentra en la relación entre el tipo de transición (o de sus características) con el resultado final, esto es, con el tipo de régimen democrático que termina por conformarse. Existe acuerdo entre los autores que tratan el tema de las transiciones en que ese resultado final depende en gran medida de las características de aquella (Przeworski, 1995: 86; O’Donnell y Schmitter, 1994: 105-115; Karl, 1990: 9) ${ }^{36}$. Sin embargo, más allá de aludir a algunos aspectos generales, entre los que se destaca el papel fundamental de la transición en términos de la definición de las reglas de juego, no se encuentra un desarrollo teórico y metodológico que permita comprender a cabalidad el proceso.

Mi opinión, en este aspecto, es que un buen instrumento para lograr esa comprensión se puede encontrar en la perspectiva de path dependence. Esta permite ver los procesos en términos dinámicos (lo que, como se verá más adelante no es una tautología) y sobre todo ayuda a identificar los elementos que los conforman (Mahoney, 2001; Pierson, 2000; Page y Bednar, 2006). Así mismo, esta perspectiva pone atención en la incidencia de los factores estructurales pero también las decisiones estratégicas de los actores, de manera que se evitan los sesgos deterministas que se producen cuando al análisis se mueve solamente en uno de esos niveles.

$\mathrm{Al}$ situar el análisis en esta perspectiva se puede tomar a la transición como la coyuntura crítica (critical juncture) de la que se desprende un proceso que altera radicalmente el statu $q u 0^{37}$. Por consiguiente, hay un punto que marca un antes y un después en procesos de largo alcance y que, en el caso de los países estudiados, se lo puede situar en el momento en que se instala el primer gobierno democráticamente elegido ${ }^{38}$. Desde este punto de

\footnotetext{
36 Además de las características de la transición, también inciden sobre el resultado final las condiciones sociales del régimen autoritario, que es lo que he intentado poner de relieve en las secciones anteriores de este capítulo. Sin embargo, la alusión a estas condiciones no puede llevar a interpretaciones deterministas, en el sentido de que a determinadas características del punto de partida corresponden unas características específicas del punto de llegada, como hace notar acertadamente Przeworski (1995: 167).

${ }^{37}$ En general, sigo la formulación de path dependence de Pierson (2000) y de Mahoney (2001).

38 Se podría argumentar que en los casos de Ecuador y Perú esa coyuntura crítica podría situarse en la expedición de las respectivas constituciones, o incluso antes, en el inicio del Plan de Reestructuración Jurídica del Estado y del Plan Inca, respectivamente. Sin embargo, los avances y retrocesos que ocurrieron entre esos hechos y la posesión del primer presidente del nuevo período aconsejan tomar
} 
partida debería desprenderse una trayectoria de desarrollo caracterizada por la reproducción institucional, esto es, por comportamientos reiterativos de los actores que encuentran incentivos para actuar dentro de las nuevas normas. Tanto en Bolivia, por el carácter tortuoso costoso del proceso previo, como en Ecuador y Perú, por el carácter pactado de la instauración de la democracia, cualquier retorno a la situación anterior aparecía como poco deseable para los actores políticos significativos. Por el contrario, las nuevas condiciones ofrecían la posibilidad de contar con resultados crecientes (increasing returns) en los procesos de negociación económica, social y política. De esa manera, a pesar de los avances y retrocesos que se produjeron en esos años en cada uno de los países, se puede afirmar que se implantaron mecanismos relativamente estables de retroalimentación positiva (positive feedback), en el sentido de que las propias prácticas de los actores llevaban al fortalecimiento de las instituciones recientemente establecidas. El resultado final es lo que la teoría llama persistencia estructural (structural persistence), esto es, la reproducción de las pautas institucionales.

Si se observan los primeros años de desempeño de estas nuevas democracias se encuentra que la mayor parte de actores se ciñeron a las reglas del juego, incluidos quienes se opusieron a su implantación o de quienes fueron indiferentes ${ }^{39}$. La resolución de la coyuntura crítica de la transición había creado una institucionalidad que resultaba favorable para todos ellos ya que había eliminado las principales formas de exclusión que prevalecían en la situación anterior. Fundamentalmente, la instauración de regímenes poliárquicos sentó las bases para una negociación de tipo totalmente diferente a la que existía bajo los regímenes autoritarios. En términos generales, se había dado el paso inicial para abandonar la negociación corporativa que inevitablemente genera diferencias y que lleva al plano político las inequidades (en recursos políticos, pero también económicos y de otra naturaleza) que existen en la sociedad. Por lo menos en términos formales se habían instaurado tanto un campo de juego como unas reglas de las que

como referencia a este último. Además, el cambio de escena y de actores políticos ocurrió en términos reales en este último episodio. De cualquier manera, se trata de una referencia general que, como todos los hitos que se establecen en los procesos sociales, tiene fundamentalmente un carácter simbólico y orientador.

39 Posiblemente el caso emblemático en este sentido es el del ex dictador boliviano Hugo Banzer (y con él toda una corriente política), que se adscribió a ellas inmediatamente y que aceptó sucesivas derrotas en las contiendas presidenciales. Desde la perspectiva analizada $-\mathrm{y}$ sobre todo con la información que proporciona la propia realidad boliviana- habría suficientes motivos para sostener que no se trató de una conversión democrática apegada a principios, sino que se derivo de cuidadosos cálculos estratégicos. Lo mismo se podría asegurar en el caso ecuatoriano con personajes como el entonces dirigente empresarial León Fébres Cordero, opuesto al proceso de democratización pero finalmente beneficiario de éste. 
podían beneficiarse todos los actores sociales y políticos. La ausencia de intentos significativos de retorno a las formas autoritarias es un indicador claro de ello.

En los casos de Ecuador y Perú hubo dos factores que -a la manera de positive feedbackimpulsaron decisivamente esa vía. En primer lugar, en ambos se promulgaron nuevas constituciones y en general se diseñó una nueva institucionalidad política. Estas no solamente configuraron la nueva arena política en la que se podrían desempeñar con bastante libertad los actores políticos, sino que el propio proceso de elaboración de esa nueva normatividad jurídica y política fue un campo de negociación que permitió que cada uno de los actores encontrara algún tipo de beneficio en el resultado final. En segundo lugar, las transformaciones sociales y económicas impulsadas por los gobiernos militares dejaron establecida una tendencia de cambios que difícilmente podía ser revertida. Como se ha visto en las secciones anteriores, al amparo de esos cambios surgieron nuevas condiciones y nuevos actores que precisaban de significación política. Estos, aunque no jugaron necesariamente un papel activo en el retorno a la democracia, se transformaron en sus principales beneficiarios y por consiguiente en uno de sus pilares.

Bolivia no contó con esos cambios en el ordenamiento político, pero se había hecho evidente la imposibilidad de procesar los conflictos sociales y políticos dentro del modelo corporativo que había tenido vigencia durante más de una década y media. De manera similar a lo ocurrido en los otros dos países, se había configurado una coyuntura crítica que requería de nuevos instrumentos y de nuevas orientaciones de los actores políticos. La solución pasaba, tal como en Ecuador y Perú, por la conformación de un ámbito apropiado para la el procesamiento y la solución de los conflictos. La única posibilidad, después de haber comprobado reiteradamente que la solución autoritaria no tenía viabilidad para ninguno de los actores, era un régimen poliárquico que ofreciera similares condiciones a todos ellos. Para esto se acudió, como se ha visto antes, a la constitución de 1966. Al contrario de los otros dos países, aquí no se presentaron las condiciones apropiadas para entrar en un proceso de reforma constitucional o de elaboración de un nuevo marco jurídico y político. La dinámica de los hechos, el nivel al que había llegado el enfrentamiento y sobre todo la imposibilidad de que se constituyan actores hegemónicos, fueron obstáculos en ese sentido. 
En general, la coyuntura crítica de la transición abrió en los tres países un camino por el que transitarían posteriormente ${ }^{40}$. Los tres escogieron regímenes poliárquicos que fueron retroalimentándose con su propia marcha. Los elementos básicos de estos, como la realización de elecciones y el procesamiento de los conflictos con apego a las disposiciones legales fueron convirtiéndose en rutinas en cada uno de los países. Las prácticas contrarias a los procedimientos democráticos fueron perdiendo terreno y pasaron a convertirse en expresiones marginales, con la sola -y muy importanteexcepción del brote subversivo de Sendero Luminoso en Perú ${ }^{41}$.

Es en este punto donde se hace necesario volver a las dos preguntas formuladas antes, esto es, la limitación temporal del período de transición y el resultado final de ésta. En primera instancia, de lo dicho hasta el momento parecerían desprenderse dos conclusiones relativamente obvias. En primer lugar, que el período de transición en cada uno de los países habría concluido con la convocatoria a las siguientes elecciones presidenciales y parlamentarias o con algún hecho de similar importancia que pueda considerarse como un hito en ese sentido. En segundo lugar, que el resultado fueron regímenes poliárquicos que lograron implantarse relativamente bien y que pudieron satisfacer las demandas y las necesidades políticas de la mayor parte de los actores políticos. Sin embargo, aunque ambas afirmaciones contienen una dosis de verdad en tanto se apegan a lo que sucedió en la realidad, cada una de ellas debe ser matizada. Para hacerlo es necesario moverse tanto en el nivel de los hechos concretos acaecidos en cada país como en el conceptual.

En el primer nivel, es necesario pasar revista brevemente a las condiciones que rigieron durante los primeros años de funcionamiento de los nuevos regímenes. Un elemento central en este aspecto es la crisis económica que afectó a los tres países al igual que al resto América Latina (Torre, 1998; Garnier, 1994; BID, 2006). Si se toma como punto de

${ }^{40} \mathrm{El}$ punto de partida en los tres países viene a ser el mismo si se considera que las condiciones sociales, económicas y políticas colocaron a los actores frente a un rango de opciones definidas básicamente como el mantenimiento del statu quo o el cambio radical de éste. Como sostiene la teoría, la opción asumida frente a este punto clave de elección define la ruta posterior (Pierson, 2000: 251; Mahoney, 2001: 112;)

${ }^{41}$ Pero, aún en ese caso y sin desconocer la magnitud que alcanzó, se puede sostener que se trató de una experiencia marginal al conjunto de actores sociales y políticos peruanos. Su ubicación fuera $-\mathrm{y}$ en contra- del sistema político peruano (Degregori, 1996; 1990) fue absolutamente independiente del tipo de régimen establecido. Dicho de otra manera, la opción estratégica de Sendero Luminoso habría sido la misma bajo cualquier régimen. En este aspecto se puede encontrar alguna similitud con la persistencia de las FARC en Colombia, que al contrario de otros movimientos armados (como el M 19) optaron por la inserción democrática (Pizarro, 1989: 7 y siguientes). 
referencia al año 1982, cuando se produce el colapso de la deuda externa, con su manifestación más fuerte en México, se puede afirmar que la tarea central de las nuevas democracias pasa a ser la solución de los problemas económicos incluso por encima de las tareas políticas que aún estaban pendientes. Bolivia y Perú presentan en este sentido los problemas más agudos, expresados fundamentalmente en la hiperinflación y en la manifiesta incapacidad de los gobiernos para controlar efectivamente la economía (Laserna, 1992b; Gónzalez de Olarte, 1998). Ecuador sintió en menor medida los efectos de la crisis gracias a la inercia de la década de acelerado crecimiento que vivió al amparo de los altos precios del petróleo (Armijos y Flores, 1991). Pero, independientemente de las diferencias entre los tres, la evidencia que se configuró con el paso del tiempo fue que no se trataba de un desajuste pasajero que podría ser respondido y solucionado con las medidas de política económica aplicadas hasta entonces. Como en el resto de países latinoamericanos, se hacía necesario redefinir en su totalidad el modelo de desarrollo.

Esto llevó a lo que podría denominarse una doble transición, en el sentido de que a la de carácter político se añadía la que debía realizarse en el plano de la economía. De este modo, las acciones propias de la construcción de la democracia, básicamente las de liberalización y de democratización (O`Donnell y Schmitter, 1988: 20-23; Przeworski, 1995: 91-114), debían realizarse al mismo tiempo que las encaminadas a la reorientación de la economía en su conjunto. El problema central de la conjunción de estas tareas es que cada una de ellas impulsa los procesos en direcciones radicalmente diferentes. En efecto, las de liberalización y de democratización tienden a reducir el peso de las instituciones estatales en beneficio de la mayor presencia de la sociedad en la vida pública. Por el contrario, las de reorientación económica exigen una acción estatal decidida y reducen los espacios de la acción ciudadana ${ }^{42}$. Las primeras significan apertura hacia las diversas opiniones y tendencias, en tanto que las últimas requieren de sistemas políticos (relativa o totalmente) cerrados. Por consiguiente, cualquier análisis de la transición en estos países, así como en sus pares latinoamericanos, debe considerar cuidadosamente este aspecto.

\footnotetext{
${ }^{42}$ La última afirmación puede parecer contradictoria con la fórmula neoliberal de reducción del tamaño del Estado, y en efecto lo es si se atiende al resultado que se busca con la implantación de esas políticas. Pero no lo es si se considera el alto grado de intervención estatal que se requiere para lograrlo.
} 
En lo político esto llevó a la redefinición de los términos del conflicto distributivo o, dicho de otra manera, a la negociación de espacios dentro de las nuevas condiciones económicas. Tanto en Ecuador como en Perú los regímenes salientes habían dejado establecidas condiciones bastante claras en términos de la asignación de recursos entre los diversos sectores sociales ${ }^{43}$. Con bastante precisión se había definido la capacidad de respuesta institucional del sistema político, lo que expresaba un buen grado de acoplamiento entre las demandas de los actores y el entramado institucional y procedimental (Pachano, 1996: 37). La crisis marcó la obsolescencia de esa relación y de los correspondientes arreglos institucionales ya que, por un lado, estableció un cambio radical en las demandas (e incluso en las características de los actores sociales) y, por otro lado, redujo la capacidad del sistema político para atenderlas (tanto por la contracción de los recursos como por el desajuste frente al mismo cambio de demandas) ${ }^{44}$. Por consiguiente, se hacía imprescindible redefinir los términos de la relación entre los grupos sociales, no solamente en su calidad de sujetos económicos sino también en su papel de actores políticos. La redefinición de las reglas del juego económico exigía un paso similar en el plano político.

Este reto fue enfrentado de manera muy diversa en los tres países. En Perú se acudió a la salida autoritaria, expresada en el autogolpe de 1992. Previamente, desde su posesión en 1990, Fujimori llevó adelante un programa de cambio radical de la economía, con una orientación neoliberal totalmente opuesta a la que había pregonado en la campaña y que fue la razón de su triunfo (Stokes, 2002). Aunque no existe acuerdo entre los académicos sobre la causas del golpe de Fujimori, e incluso se duda sobre el peso de las de carácter económico, es innegable que estas se encuentran entre las más importantes ${ }^{45}$. De

\footnotetext{
${ }^{43}$ La Constitución ecuatoriana de 1978 era una clara expresión de esa orientación en tanto definía con precisión un modelo económico específico, caracterizado por la fuerte presencia estatal en la conducción económica, con el reconocimiento de áreas estratégicas de la economía y con una serie de elementos regulatorios sobre el mercado). Sin duda, era la expresión de la corriente predominante en ese momento y que fue adoptada por el gobierno militar (Hurtado, 2007).

${ }^{44}$ A los países latinoamericanos les sucedió lo que se podía leer en esos años en un graffiti en la ciudad de Quito: “Cuando tenía las respuestas me cambiaron las preguntas". Habiendo sido diseñados para una realidad específica, el cambio de ésta terminaba por convertirles en elementos de poca utilidad.

45 McClintock (1997: 56) duda de la importancia de los objetivos económicos en las motivaciones del golpe. Su argumento es que "ya estaba implementando los elementos principales de un programa económico neoliberal antes del autogolpe (y que) de hecho la reacción internacional en contra del autogolpe amenazó en lugar de facilitar, la implementación del programa neoliberal”. Creo que hay razones para no compartir esa afirmación cuando se observa la conflictividad social y política que caracterizó a los primeros veinte meses del gobierno fujimorista, que ponía en serio riesgo la aplicación de ese modelo (Conaghan, 2005: 28 y siguientes). Así mismo, la reacción internacional tuvo un carácter pasajero, centrada exclusivamente en la defensa de las instituciones democráticas y, si bien
} 
cualquier manera, el hecho es que la vía autoritaria permitió transitar de manera expedita hacia el nuevo esquema de desarrollo y aplicar sin mayores contratiempos el recetario neoliberal disponible en el momento. El significativo apoyo de la población fue un factor de importancia en ese sentido (McClintock, 1997: 54; Carrión, 1997: 296). Esto significó que al mismo tiempo se redujera significativamente el espacio político, con un retroceso evidente en el proceso de liberalización y de democratización. La instauración de un gobierno autoritario puso fin no solamente a la transición sino a la democracia en sí misma.

En Bolivia se configuró una salida que combinaba la forma consensual con algún grado de autoritarismo. Eran muy pocas las alternativas disponibles después de la debacle económica del primer gobierno democrático, el del presidente Hernán Siles. Las instituciones habían perdido casi absolutamente su capacidad no solamente para enfrentar la crisis sino en general para gobernar. Se había eliminado cualquier punto de referencia institucional que pudiera servir para establecer las condiciones que permitieran remontar la situación económica y al mismo tiempo mantener las reglas de participación y competencia democrática. La única posibilidad de solución estaba dada, en consecuencia, por un acuerdo de los actores significativos, que permitiera sentar las bases mínimas para el logro de aquellos objetivos (Laserna, 1992b; Mayorga, 1998). El primer paso se dio con el adelanto de las elecciones, que significaba básicamente apartar de la escena al gobierno de Siles y que implícitamente constituía un reconocimiento del fracaso del tipo de política incrementalista que se había impuesto desde el retorno a la democracia (Mayorga, 1998). El segundo paso fue el que dio con los acuerdos de 1995, en que se estableció un conjunto de reformas económicas y políticas que finalmente permitieron controlar la economía y dotarle de capacidad de respuesta al sistema político (Romero, 1999; Lazarte, 1993; Laserna, 1992; Mayorga, 2003). Paralelamente a este acuerdo, el gobierno -que había tomado la iniciativa en la convocatoria- tomó medidas drásticas en contra de los dirigentes sindicales que se oponían al plan económico propuesto, con lo que alejó el peligro de la desestabilización que caracterizó a su antecesor. El resultado fue lo que en adelante se conocería como la democracia pactada, que

inicialmente hubo alguna sanción económica (como el congelamiento de préstamos), pronto hubo más bien apoyo en ese sentido (Bowen, 2000: 118; Murakami, 2007: 258 y siguientes) Otras interpretaciones dan mayor peso al conflicto con el Congreso, que en gran medida giraba en torno a la orientación económica del gobierno (Kenney, 1997: 77; Murakami, 2007: 243 y siguientes). Aparte de estas interpretaciones, hay autores que destacan la importancia de la guerra en contra de la subversión de Sendero Luminoso (Degregori, 2000: 40-41) 
pudo funcionar con relativa facilidad durante los siguientes dieciocho años (Pachano, 2006: 17).

En Ecuador se configuró una situación radicalmente diferente a la de ambos países, ya que no hubo consensos sobre la orientación que debía tomar la economía y tampoco hubo la imposición de un modelo específico por vía autoritaria ${ }^{46}$. Desde el año 1981, este país se movió permanentemente entre los intentos de ajuste realizados por los sucesivos gobiernos (cada uno de ellos de diferente tendencia política) y el retroceso en las medidas tomadas (Pachano, 2007: 13-37). Los bloqueos -ya sea por vía de las instituciones formales como de las informales- fue la característica central de todo el período. La debilidad de los gobiernos, expresada sobre todo en su carácter minoritario en el Congreso, y la presencia de poderosos grupos corporativos llevaron a la conformación de una arena política en la que el conflicto distributivo se definía por la capacidad de presión de cada uno de los grupos antes que por la voluntad de la mayoría ciudadana o por las decisiones gubernamentales. Se constituyó, de esta manera, un sistema con muy baja capacidad de procesamiento del conflicto y por tanto con serios vacíos en términos de sus resultados económicos y sociales. La solución -si así se la puede llamar- se encontró en las prácticas clientelares que, como cualquier forma de particularismo, tendían a profundizar las diferencias de acceso de los diversos grupos a los recursos y a la vez tendían a erosionar las instituciones ${ }^{47}$.

En síntesis, se puede afirmar que en Perú cuando se podía decir que se habían cumplido -o estaban por cumplirse- las principales tareas de la transición se produjo el quiebre de la democracia. A pesar del carácter autoritario del régimen establecido, lo que ocurrió no fue exactamente un retorno al pasado, a las dictaduras militares, sino la instauración de un autoritarismo competitivo, esto es, de un régimen que tiene su origen en las elecciones pero que gobierna al margen -y en contra- de los procedimientos democráticos y que antes que una forma disminuida de democracia viene a ser una forma disminuida de

${ }^{46} \mathrm{El}$ intento más cercano a este tipo de salida se encontró en los dos primeros años del gobierno de Febres Cordero (1984-1988), pero la oposición de diversos sectores le obligó a retroceder (Pachano, 2007: 20-21)

47 Aparentemente, este círculo se habría roto con las acciones desplegadas por el gobierno de Rafael Correa (posesionado en enero de 2007). Es probable que así sea en lo que se refiere a la posibilidad de aplicar una política económica específica (en este caso de signo radicalmente contrario a la neoliberal que pretendieron instaurar los gobiernos anteriores). Sin embargo, en lo político no se advierten cambios de similar magnitud, y más bien se puede comprobar la profundización de las prácticas clientelares y de las formas corporativas de acceso a los recursos. Desafortunadamente no se cuenta aún con estudios al respecto. 
autoritarismo (Levitsky y Way, 2002: 52). De este modo, el régimen poliárquico inaugurado en 1980 tuvo una vida corta, de apenas diez años en los que se sucedieron tres presidentes, y fue necesario esperar una década para reiniciar la transición. En Bolivia, por el contrario, se logró completar con relativo éxito las tareas propias de la transición, si por éstas se entiende al funcionamiento pleno de los procedimientos poliárquicos y la adecuación de los procedimientos institucionales a esa nueva situación (lo que en efecto de produjo con las reformas de 1985). En Ecuador, por su parte, se hace muy difícil identificar un hito que marque el fin de la transición ya que no hubo un momento específico que defina la consolidación de los procedimientos democráticos o, como en el caso peruano, que exprese con claridad su ruptura ${ }^{48}$. Se podría afirmar que la transición se cumplió en tanto esos procedimientos se volvieron rutinarios y fueron aceptados por el conjunto de actores sociales y políticos, pero de ello no se desprende que el resultado fuera la consolidación. Fue más bien un típico caso de informalización institucional y de estructuración de una democracia delegativa (O’Donnell, 1992).

Con estos elementos es posible pasar al segundo nivel, esto es, al de los conceptos válidos para un análisis de este tipo. Para iniciar esta reflexión cabe señalar que la literatura sobre la transición a la democracia en los países latinoamericanos, generada en la década de los ochenta, se abocó fundamentalmente al tratamiento de los temas estrictamente políticos. Los efectos de las dictaduras en el Cono Sur y del derrumbamiento de los regímenes oligárquicos en Centroamérica -con su secuela de guerras civiles-, abrieron paso a una reflexión esencialmente política, muy diferente del tipo de pensamiento concentrado en la economía, que había predominado hasta entonces $^{49}$. La instauración de regímenes autoritarios que buscaban un reordenamiento integral del Estado, en los años setenta, llevó a dar los primeros pasos en la nueva

\footnotetext{
48 Soy conciente de los riesgos que se desprenden de la utilización de la noción de consolidación para referirse a la situación posterior a la transición, como ha hecho notar acertadamente O`Donnell (1996c). Pero, como se puede ver, la alusión que hago es exclusivamente a los procedimientos democráticos no a la democracia en tanto régimen.

${ }^{49}$ Durante largo tiempo imperó en todo el continente una visión que establecía una separación tajante entre economía y política o que, por lo menos, era indiferente a esta última. Una expresión muy clara de esta posición se encuentra en la abundante literatura de la denominada teoría de la dependencia, que tenía débil o nula relación con la escasa reflexión que en ese momento se hacía sobre lo político. De manera especial, no se planteaba como problema a resolver el del tipo de régimen (democrático o autoritario), de modo que la ruptura de la condición de dependencia no tenía relación con las condiciones políticas. Solamente se aludía en un plano muy general a la estructura de clases que era necesaria para ese fin. Llama la atención, por ejemplo, que en una obra de tanta importancia como la de Cardoso y Faletto (1971: 102-129) no se incluya una reflexión al respecto, especialmente al abordar el tema del populismo y del Estado desarrollista.
} 
perspectiva de análisis ${ }^{50}$. Poco tiempo después, las tareas propias de la transición, referidas no solamente a la construcción de las instituciones democráticas, sino también a la instauración del Estado de derecho, demandaron un nuevo tipo de pensamiento de contenido político, en el que, al contrario del que había predominado anteriormente, lo económico pasaba a segundo plano.

Temas como la capacidad de las instituciones para procesar las demandas $-\mathrm{y}$, de esa manera, lograr como objetivos básicos la satisfacción de las necesidades de la población y la estabilidad de la democracia- o las condiciones para establecer acuerdos sociales y políticos, dentro de la perspectiva de la concertación social, fueron ganando espacio en la reflexión de las ciencias sociales. Al mismo tiempo, se iba dando mayor importancia al estudio de los actores sociales y políticos, en contraposición a la visión de los grandes procesos que había caracterizado al pensamiento de los años previos ${ }^{51}$. En gran medida, este cambio de orientación de la perspectiva de análisis se produjo por la incidencia de las demandas provenientes de diversos sectores sociales. Buena parte de éstas tenían contenidos eminentemente políticos, referidos sobre todo a la búsqueda de participación en la toma de decisiones y a la instauración de un marco de derechos y libertades. Si anteriormente las reivindicaciones se dirigían principalmente a la obtención de mejores condiciones en la asignación de los recursos, bajo la forma de un conflicto distributivo (Garnier: 1994), en la nueva situación se habían incorporado las dimensiones propiamente políticas. Por ello, si algo caracterizó a las transiciones fue la instalación de lo político en el centro del debate. Las reivindicaciones asociadas a derechos humanos, representación, libertades y participación, entre otras, expresaban claramente la nueva orientación. En consecuencia, de ahí en adelante sería necesario poner atención en los actores políticos que tuvieran la capacidad de interpretar, expresar y agregar esas demandas, procesarlas desde las instancias de toma de decisiones y materializarlas en forma de políticas ${ }^{52}$.

\footnotetext{
${ }^{50}$ Las mejores expresiones de esta nueva orientación se encuentran en los texto de O’Donnell (1993; 2000) sobre el Estado burocrático-autoritario y en los de Lechner sobre la crisis del Estado (1988).

$51 \mathrm{O}$, para decirlo en palabras de uno de los autores de ese momento, comenzaba a ponerse más atención en los combatientes -y en sus propuestas- que en las grandes batallas.

${ }^{52}$ Esto tuvo su correlato en las ciencias sociales cuando pusieron en primer plano de su preocupación a temas estrictamente políticos, como partidos, congresos, representación, participación, gobernabilidad, y cuando sustituyeron los grandes relatos por el análisis de procesos concretos asentado en la investigación directa.
} 
Pero, al mismo tiempo, el agotamiento del modelo económico planteó nuevos desafíos a la política y al pensamiento. La crisis de los ochenta -sin duda su expresión más evidente- hizo volver la mirada nuevamente hacia la economía, pero en esta ocasión ya no en los términos restringidos que se planteaban en torno al conflicto distributivo, sino como la necesidad de redefinir en su totalidad el modelo de desarrollo. Por consiguiente, a las tareas propias de la transición se añadió la relacionada a la redefinición del modelo económico, lo que debía tener necesariamente su correlato en el nivel de las ciencias sociales. Se constituyó así el marco adecuado para la reflexión sobre la relación entre política, sociedad y economía, que vendría a ser la característica del pensamiento latinoamericano sobre la transición a la democracia. Era el momento para dejar atrás la vieja separación entre el pensamiento económico y el pensamiento político (que, por lo demás y como se ha visto antes, este último no recibía mayor atención). Las nuevas condiciones, caracterizadas por la necesidad de instaurar un régimen que resultaba extraño para la mayor parte de países del continente, necesitaban de cuidadosos procesos de diseño institucional y de negociación política para establecer las condiciones que le otorgaran estabilidad y legitimidad. Adicionalmente, dado que en la mayor parte de países se encontraban en retirada las expresiones corporativas que habían predominado en épocas anteriores (con las excepciones señalas antes, entre las que destaca el caso de Ecuador), al tiempo que los actores sociales históricos iban cediendo su lugar a los denominados nuevos movimientos sociales caracterizados por su orientación hacia temas puntuales que los alejaban de la lucha por el poder político (Evers, 1985; Calderón, 1995), se hacía más necesaria una reflexión que lograra integrar los tres niveles señalados ${ }^{53}$. Implícita o explícitamente, las nuevas perspectivas reconocían una relación de mutuo condicionamiento entre el régimen político y las condiciones económicas y sociales.

A pesar de las condiciones favorables para el desarrollo de esa nueva perspectiva de análisis y de comprensión de los problemas del continente, las urgencias por encontrar respuestas a la reformulación del modelo económico llevaron nuevamente a una ruptura, especialmente por la búsqueda de lograr altos grados de autonomía para la economía (y consecuentemente para el pensamiento económico). Se fue imponiendo así la percepción

\footnotetext{
${ }^{53}$ En las transiciones, hay "un viraje desde el movimiento nacional-popular hacia el movimiento democrático (...) Con ello, el movimiento social gana en términos estratégicos, pero se paga el precio de la subordinación de las demandas particulares a las metas políticas. A la vez, esto otorga el liderazgo a los actores políticos" (Garretón, 1997: 26, cursivas en el original)
} 
de ésta como un espacio eminentemente técnico, que debía ser tratado -en términos prácticos pero también en el nivel del pensamiento- aisladamente sin el contagio de la política. La presencia dominante de tecnócratas en los espacios de toma de decisiones tuvo su expresión en los reiterados intentos de presentar al pensamiento económico -y a su aplicación práctica- como un espacio de reflexión que no solamente podía, sino que debía aislarse de cualquier consideración política e incluso social ${ }^{54}$. El predominio de las concepciones neoliberales se asentó precisamente sobre esas premisas, sin que existiera durante un largo período una visión alternativa con la fuerza necesaria para retomar los elementos positivos que se presentaron al inicio de esa etapa. Es evidente, como queda demostrado a la luz del tiempo transcurrido, que esa fue una vía de empobrecimiento, de la que solamente se ha comenzado a salir en años muy recientes.

En ese contexto resulta alentador un debate como el mencionado al inicio de la presente sección, ya que apunta directamente al núcleo de la transición y, desde este, a las características de la democracia (O`Donnell, 1996b; 1996c; Gunther, Nikiforos y Puhle, 1996). Lo esencial es que permite comprender los múltiples caminos que se abren a partir de la transición y, además de llamar la atención sobre el riesgo de dejarse atrapar por la tentación teleológica, pone énfasis en el rigor del manejo conceptual. De este último aspecto es importante rescatar las nociones de consolidación y de institucionalización, que son los elementos básicos de ese debate. Ambos están marcados con grandes signos de interrogación, aunque en cada caso las causas sean distintas.

En cuanto a la consolidación, las preguntas centrales son qué se consolida y, antes de eso, qué significa en sí misma la consolidación de la democracia. O`Donnell advierte sobre el carácter polisémico del término (O`Donnell, 1996c: 12), pero sobre todo cuestiona las posiciones que sostienen que "la poliarquía, o la democracia política, está 'consolidada': si existe la expectativa de que se mantendrán en un futuro indefinido elecciones limpias, competitivas y regulares y si esta expectativa es compartida por la mayoría de los actores políticos y la opinión pública, si múltiples actores invierten estratégicamente sus recursos suponiendo la continuidad de las elecciones y de las autoridades electas, y si las libertades contextuales son razonablemente respetadas, entonces ceteris paribus, es probable que la poliarquía subsista" (O`Donnell, 1996c: 11). La crítica central de este autor radica en la

\footnotetext{
${ }^{54}$ Es interesante el análisis comparativo de Conaghan, Malloy y Abugatas (1990) sobre la incidencia de los grupos de tecnócratas en la definición de las políticas económicas en Bolivia, Ecuador y Perú, y especialmente los intentos de preservar a estos del contagio de la política.
} 
aplicación del término consolidación "a algo que es probable, aunque no seguro, que persista” (O`Donnell, 1996c: 12) y, apuntando al fondo del asunto, señala que el problema es que no existe un acuerdo sobre los elementos constitutivos de la consolidación (O`Donnell, 1996c, 27). Esta ausencia se debe, en gran medida, al mencionado sesgo teleológico, que lleva a considerar como indicador básico de la consolidación a la vigencia de las instituciones formales de las poliarquías. Por medio de un ejercicio deductivo se trasladan acríticamente ciertas características de las viejas poliarquías del "cuadrante noroccidental del planeta” (O`Donnell, 1996c: 16).

Por su parte, los autores criticados por O`Donnell argumentan sobre la necesidad de contar con concepto como el de consolidación ya que con este se alude a "la estabilización, rutinización, institucionalización y legitimación de pautas de conducta políticamente relevantes” (Gunther, Diamandouros y Puhle, 1996: 120). Básicamente, los autores consideran "consolidad un régimen democrático cuando todos los grupos políticamente relevantes reconocen que sus instituciones políticas básicas son el marco legítimo para la competencia política y se adhieren a las reglas del juego democráticas" (Gunther, Diamandouros y Puhle, 1996, 120). En este sentido, se adscriben a la formulación de Linz y Stepan de democracia consolidada como "un régimen político en el que la democracia como un complejo sistema de instituciones, reglas, incentivos y desincentivos, se ha convertido, por decirlo de alguna manera, en the only game in town (Linz y Stepan, 1996: 30) $)^{55}$.

No es este el lugar para entrar a fondo en estos temas, pero si es necesario hacer una breve referencia a ellos en relación con los casos estudiados ${ }^{56}$. El problema de las nuevas poliarquías - entre ellas las de los tres países analizados- es que tienden a consolidar prácticas y procedimientos que no se corresponden exactamente con los que están definidos formalmente. Este es precisamente el eje de la crítica de O`Donnell, que abre paso a su llamado de atención sobre las instituciones informales que se establecen en las nuevas poliarquías. En términos estrictos, se institucionalizan otros elementos que no constan en la lista de chequeo de las poliarquías, vale decir entre los que se reconocen como

${ }^{55}$ Linz y Stepan (1996: 31) identifican res niveles en los que se debe manifestar la condición de la democracia como the only game in town: en los comportamientos, en las actitudes y en lo constitucional. Considero que es más apropiado identificar esos niveles como el de la sociedad (con sus valores y orientaciones) el de las prácticas política (o sistema político) y el de las normas (o del régimen político), como está desarrollado en el capítulo I.

${ }^{56}$ Un tratamiento más detallado de estos temas se encuentra en los capítulos I y V. 
sus elementos constitutivos, y por supuesto tampoco guardan coherencia con sus propias disposiciones. La construcción de la democracia política o de la poliarquía como un tipo ideal choca directamente con la realidad de los países en que se establece, con las prácticas que predominan y con las opciones que toman los actores políticos. Por consiguiente, hay razones para las dudas de O`Donnell acerca del carácter consolidado de estas poliarquías.

Como se vio antes, en el momento inicial de los regímenes democráticos, en los tres países estaban presentes los elementos básicos que caracterizan a las poliarquías. En todos ellos tenían vigencia las disposiciones que garantizaban la libertad de asociación, la libertad de expresión, la libertad de voto, la elegibilidad para el servicio público, el derecho a la competencia política, la libertad y diversidad de las fuentes de información, las elecciones libres e imparciales y, en buena medida aunque no absolutamente, la garantía de que la política de los gobiernos dependa del voto ciudadano y no de poderes que se sitúan por encima de éste ${ }^{57}$. Es decir, en mayor o en menor medida, cumplían con los requisitos de la poliarquía propuestos por Robert Dahl (1989: 15; 1991: 280-281). Dicho de otra manera, se podía afirmar que en todos ellos se habían establecido regímenes basados en la "libertad legal para formular y proclamar alternativas políticas en una sociedad con las libertades de asociación, de expresión y otras básicas de la persona que hagan posible una competencia libre y no violenta entre líderes, con una revalidación periódica del derecho para gobernar, con la inclusión de todos los cargos políticos efectivos en el proceso democrático y que permita la participación de todos los miembros de la comunidad política, cualquiera que fuesen sus preferencias políticas, siempre que se expresen pacíficamente" (Linz, 1998: 226).

Por consiguiente, una visión general basada exclusivamente en las disposiciones constitucionales y legales llevaría a asegurar que en los tres países se establecieron con relativo éxito regímenes poliárquicos. Sin embargo, un breve vistazo a su desempeño permite detectar un conjunto de elementos que distorsionan ese carácter. De manera especial, la vigencia de prácticas (convertidas en verdaderas instituciones) como el clientelismo y el corporativismo, tiende a erosionar algunos de los elementos constitutivos de las definiciones mencionadas. La lista de chequeo de la poliarquía no puede

${ }^{57} \mathrm{La}$ salvedad hecha en el último aspecto se debe fundamentalmente a las prerrogativas que se reservaron las fuerzas armadas ecuatorianas y en alguna medida también las peruanas. 
ser completada en su totalidad cuando se comprueba que esas prácticas han invadido en su totalidad al sistema político y que, de esa manera, rompen con varios de los principios básicos sobre los que se asienta -o debe asentarse- la poliarquía ${ }^{58}$. Estas han desarrollado profundas raíces en los tres países, hasta convertirse en parte de sus sistemas políticos en un ejercicio de adaptación mutua. Las democracias de estos países se han visto obligadas a convivir con ellas, a integrarlas en sus procedimientos, aunque para ello se deba acudir a la informalización institucional.

Pero no es únicamente la presencia de estas instituciones informales lo que pone en cuestión al carácter de las poliarquías en los tres países. Se pueden citar por lo menos cinco causas adicionales en esa línea. Primera, en algunos casos no se ha cumplido con el requisito de limpieza en los procesos electorales. En Perú en las elecciones presidenciales del año 2000 se comprobó que desde las esferas gubernamentales se había manipulado el proceso y los resultados (Degregori y Meléndez, 2007: 95). En Bolivia se aprobó un texto constitucional sin respetar los procedimientos establecidos para ello. En Ecuador se realizó un referéndum al margen de las disposiciones constitucionales y legales. Segunda, los gobiernos surgidos a partir de procesos electorales encontraron a lo largo de determinados momentos escaso espacio para desarrollar sus actividades, no sólo por las condiciones económicas que han estrechado el margen de acción, sino por la presencia de poderosos actores con poder de veto (Pachano, 2007a: 23). Tercera, en Perú y Ecuador en diversos momentos las fuerzas armadas entraron a la arena política, ya sea como actores directos o como árbitros de última instancia. Cuarta, dos gobiernos de Bolivia y tres de Ecuador no pudieron concluir los períodos para los que fueron elegidos, mientras uno en Perú rompió el orden constitucional para instaurar su propio régimen dictatorial. Quinta, aún sin prestar atención a los reclamos generalmente infundados sobre restricciones a los derechos políticos, se puede afirmar que en los tres los países diversos gobiernos han hecho uso de prácticas autoritarias para someter a la oposición y para amedrentar a los medios de comunicación, perseguir a periodistas y a líderes de opinión. En definitiva, es poco probable que todos ellos logren rebasar sin problemas el umbral de esa definición mínima de democracia política o de poliarquía. En unos más

${ }^{58}$ En esta afirmación hay, sin duda, un fuerte componente normativo ya que implícitamente considera que la poliarquía debe cumplir con condiciones previamente establecidas. Este es un resultado inevitable cuando se acude a tipos ideales o incluso a conceptos que buscan tener validez universal, como es precisamente el de democracia política o poliarquía. Si a estos se les quita uno o varios de sus componentes básicos se eliminaría la posibilidad de comparación y se llegaría a un relativismo que alimentaría la confusión conceptual (al respecto véase Collier y Levistsky, 1996). Me ocupo de esto en los capítulos I y V. 
que en otros -pero en general en todos ellos- se puede encontrar deficiencias en por lo menos uno de sus componentes.

Un hecho que no se puede dejar de destacar en estos acontecimientos es la actitud de apoyo por parte de la ciudadanía y de los actores que disponen del poder suficiente para inclinar la balanza en uno u otro sentido. En efecto, la disolución del Congreso efectuada por Alberto Fujimori recibió el apoyo de la mayoría abrumadora de la ciudadanía peruana (Cotler y Grompone, 2000; Tanaka 1998), lo que le permitió arremeter contra los partidos y establecer una democracia plebiscitaria asentada en formas clientelares y en un discurso antipolítico. La destitución inconstitucional de los presidentes Bucaram, Mahuad y Gutiérrez se produjo como el corolario de masivas manifestaciones populares (o de sectores medios urbanos, en el último caso) en contra de sus gobiernos (Pachano, 2007a). En este caso quien encabezó el segundo golpe de Estado triunfó en las elecciones dos años después. ${ }^{59}$.

Si se considera que la conducta de los actores constituye uno de los pilares básicos de la democracia, la tendencia brevemente reseñada no ofrece un panorama alentador para el futuro de la democracia en los tres países ${ }^{60}$. Se obtienen conclusiones contrarias a la corriente que predominó en los primeros años de la transición al tomar como referencia ya no solamente a las actitudes contemplativas sino incluso de apoyo de amplios sectores de la población a acciones en contra de la democracia. Es evidente que se asiste a un debilitamiento de los valores que acompañaron a las transiciones y que fueron factores fundamentales para alejar el peligro del autoritarismo y del retorno a las formas dictatoriales, así como para eliminar la inestabilidad que caracterizó a los tres países durante casi cuatro quintas partes del siglo veinte. Frente a esto es posible afirmar que ha predominado el pragmatismo de los resultados por encima de la valoración de los procedimientos democráticos. La legitimidad de resultados ha sustituido a la legitimidad de origen y a la legitimidad de procedimientos, lo que explica en gran medida la amplia divulgación de las prácticas particularistas señaladas antes.

\footnotetext{
${ }^{59}$ Las cifras del Latinobarómetro demuestran el cambio de actitud de la población en cuanto a la preferencia de un régimen democrático frente a un régimen autoritario. Más allá del aspecto cuantitativo que reflejan las encuestas, la actitud hacia la democracia debe ser vista también en términos de la capacidad de incidencia que tienen los diversos sectores sociales. La actitud de las elites y de los militares es obviamente fundamental en este sentido.

${ }^{60} \mathrm{La}$ conducta de los actores ha sido destacada como uno de los componentes fundamentales de la democracia en países en desarrollo, junto al crecimiento económico, a las instituciones y a los valores democráticos. Véase Przeworski, 1991, Mainwaring, 1992.
} 
Una realidad de esta naturaleza puede dar lugar a explicaciones basadas en las condiciones económicas y sociales de amplios sectores de la población. En términos concretos, se puede aludir a una relación entre pobreza y desafección con la democracia. Pero, aunque existen argumentos fuertes para sostener esa percepción, al considerarla en toda su complejidad se introducen matices que tienden a alterar el carácter lineal y determinista que está presente en esa formulación. En esta dirección, es necesario considerar el peso de factores que pueden llevar a colocar en segundo plano los valores y procedimientos democráticos, especialmente en lo que hace relación a la vigencia de libertades y derechos. Las condiciones económicas y sociales de un alto porcentaje de la población de los tres países significan no solamente privación de los recursos materiales sino también serias deficiencias en la posibilidad de ejercer a plenitud sus derechos (Méndez, 2002: 33). En general, la exclusión económica y social está fuertemente asociada a la exclusión jurídica ${ }^{61}$.

Pero, esa explicación es válida para explicar las orientaciones de los grupos sociales que por vivir en condiciones de pobreza e indigencia podrían tener otras prioridades (e incluso podrían encontrar razones poderosas para desconfiar de la democracia), no resulta adecuada para esclarecer la conducta de otros sectores, como facciones de las elites empresariales y organizaciones sociales que no agrupan a los más pobres. Para estos casos es necesario buscar explicaciones en un campo diferente al de las condiciones estructurales, ya que no es allí en donde se incuban sus orientaciones de desafección con la democracia. El nivel en que se debe indagar es el de la racionalidad política por la cual se guían aquellos actores, esto es, por los cálculos de costos y beneficios que ellos efectúan para tomar esas orientaciones.

En este sentido, es posible proponer una ecuación entre las condiciones de pobreza y de necesidades insatisfechas, que generan una población ávida de soluciones inmediatas, por

\footnotetext{
${ }^{61}$ Es importante señalar que las condiciones económicas y sociales, en especial la pobreza y la desigualdad en el ingreso, no fueron obstáculos para que en los tres países se produjeran acuerdos políticos en torno a objetivos de preservación y fortalecimiento de la democracia. Como se ha hecho notar, ninguno de ellos mostraba indicadores económicos y sociales mejores que los del resto de países del continente, lo que quiere decir que para establecer las bases consensuales de la democracia no fue necesario resolver previamente los problemas económicos y sociales (Mainwaring, 1992). Por períodos no despreciables, fueron acuerdos bastante fructíferos en términos de ofrecer condiciones adecuadas para la representación y para garantizar la estabilidad (como lo expresa claramente el caso boliviano con sus dieciocho años de estabilidad política y económica).
} 
un lado y, por otro lado, las conductas de las dirigencias políticas que, en aras del pragmatismo, responden a esas demandas con ofertas que inevitablemente rebasan los marcos del manejo económico y por tanto la capacidad del régimen para procesarlas. La magnitud de las necesidades de población y la búsqueda de réditos electorales por parte de los dirigentes políticos se juntan para impulsar prácticas clientelares de corto plazo que derivan en comportamientos antidemocráticos ${ }^{62}$. La necesidad de arrojar resultados inmediatos le otorga al clientelismo carta de naturalización en el conjunto del sistema político y ya no sólo en determinados partidos o líderes en particular. Todos los partidos y en general las organizaciones políticas se ven impulsados a entrar en la lógica clientelar como garantía de supervivencia y de obtención de logros electorales. De esa manera se debilitan los acuerdos básicos que, por definición, exigen supeditar los intereses de partido y de grupo a los objetivos de la construcción y de la consolidación democrática.

Aunque en determinadas coyunturas ha predominado la racionalidad derivada de metas de largo plazo, se debe precisar que esto no ha ocurrido en todos los países y que aún aquellos que siguieron esa ruta ahora parecen dirigirse en sentido contrario. Bolivia a partir de 1985 constituyó la excepción entre los tres países, pero aún en ese caso se cerró el ciclo de esa orientación de los actores ${ }^{63}$. En todos ellos se ha llegado a niveles agudos de fragmentación de la representación política, han tomado fuerza los líderes y las organizaciones asentadas en prácticas clientelares y se han roto los acuerdos básicos que sostenían a la democracia. Aún más, Perú y Ecuador encontraron muchos obstáculos para introducir una lógica de acción orientada al fortalecimiento democrático, ya que el conjunto de actores políticos y sociales se guió siempre por el cálculo de corto plazo y por la obtención de beneficios para determinados grupos de presión. Incluso es interesante comprobar que en Perú una rígida política económica de orientación liberal tuvo como contrapartida comportamientos clientelares de corto plazo, demostrando con ello que no hay incompatibilidad entre ambas, que la correspondencia entre economía y política puede ser inexistente y que los factores explicativos de esas percepciones, orientaciones y actitudes no se encuentran en el nivel económico (Conaghan, 2005).

${ }^{62}$ Un acercamiento a fondo de esta relación, sobre la base del análisis empírico de una situación específica se encuentra en Auyero (2004). El autor destaca la complejidad de las relaciones clientelares, que no se reducen a la utilización política de las carencias de los pobres.

${ }^{63}$ Romero (1999: 49-85) destaca la importancia que tuvieron para la estabilidad política boliviana los acuerdos logrados aspectos de tanta importancia como la democracia, la economía de mercado y el multiculturalismo. Sin duda esos acuerdos se rompieron a partir de las elecciones del año 2002 (Pachano, 2006: 26) 
De esta situación se desprende un conjunto de dudas acerca de la capacidad del régimen democrático para sobrevivir con actores sociales y políticos que desarrollan conductas opuestas a sus principios básicos. Obviamente, esas orientaciones van estrechando el margen en que el propio régimen puede desplegar su capacidad de consolidación. La generalización de prácticas particularistas y de instituciones informales reduce paulatinamente esa capacidad y marca unos límites para la ampliación y la profundización de las poliarquías. Así, y de acuerdo a los acontecimientos que se han producido en los últimos años, se puede afirmar que por lo menos dos de los tres países (Bolivia y Ecuador) están muy próximos a alcanzar esos límites o incluso ya los han rebasado ${ }^{64}$. Por ello, tiene vigencia la interrogante acerca del tipo de régimen que se estaría conformando en esos países andinos.

Como se ha visto antes, la reducción de la capacidad de respuesta de las instituciones a las necesidades de la población provocó la obsolescencia de los sistemas políticos vigentes desde la instauración de las poliarquías. La crisis del Estado, a la que se ha hecho constante referencia a lo largo de la historia reciente de América Latina y en particular de los tres países andinos aquí analizados, expresa precisamente esa pérdida de vigencia y de legitimidad de las instituciones. A ello debe sumarse el efecto erosivo de las prácticas particularistas y de la informalización de la política. La respuesta en los tres casos países fue la reforma integral de sus constituciones por medio de asambleas constituyente ${ }^{65}$. Si bien es cierto que cada una de ellas obedeció a circunstancias propias de cada país, no deja de ser un fenómeno común e incluso refleja la presencia de nuevos actores en la escena política ${ }^{66}$. Pero, a pesar de las diferencias, lo cierto es que los intentos de

64 Este texto se escribe cuando en ambos países se están desarrollando sendos procesos constitucionales. En los dos se instalaron asambleas constituyentes dirigidas a establecer un nuevo marco jurídico y político, en lo que constituye el reconocimiento de la desaparición del que tuvo vigencia desde el retorno al régimen democrático.

${ }^{65}$ Que en el caso ecuatoriano llegan a dos en un lapso de diez años. La primera asamblea se instaló en 1997, después del derrocamiento del presidente Bucaram, a pesar de que formalmente el Congreso y las instancias correspondientes (como el Tribunal Constitucional) dictaminaron que no se había roto la constitución vigente. La segunda se instaló en 2007, como el resultado de una propuesta de reforma integral por parte de una agrupación política constituida pocos meses antes.

${ }^{66}$ En realidad, Perú marca la diferencia en este aspecto ya que la instalación de una constituyente fue la consecuencia del autogolpe, en tanto que en Bolivia y Ecuador se originaron en las demandas de determinados grupos políticos que veían en ellas una posibilidad de reestructuración integran del sistema político. Por ello también la enorme diferencia en términos de objetivos de la reforma constitucional peruana en relación a la de los otros dos países. En Perú no se buscó la ampliación de la capacidad de inclusión del sistema político, sino más bien la desarticulación del sistema de partidos previamente existente (Tanaka, 1998). Aunque también se encontraban de por medio los problemas de violencia política, la generación de condiciones para la pacificación fue sólo un componente marginal ya que el gobierno había escogido la vía militar como solución para el conflicto. Más bien, la 
reestructuración global de los sistemas políticos son claros indicadores del debilitamiento -o incluso de la desaparición- del conjunto de normas y procedimientos que se habían establecido en cada uno de los países y que pudieron sustentar la transición con todas las tareas que le son consustanciales. Pero, en sentido contrario a lo que se esperaba obtener como resultado de estos procesos, ello no han desembocado en cambios sustanciales en términos de fortalecimiento (y consolidación) de la democracia. Aunque es muy pronto para hacer una afirmación fuerte y sustentada en este sentido en los casos de Bolivia y Ecuador, hay muchos indicios que apuntan hacia nuevas formas de debilitamiento de las poliarquías. ${ }^{67}$.

Por otra parte, un elemento de importancia para comprender el tipo de poliarquías que se han conformado o que están por conformarse, es que buena parte de las reformas fueron emprendidas fundamentalmente por la presión de sectores sociales y políticos específicos, de modo que estuvieron fuertemente marcadas por las determinaciones coyunturales. Muchas de ellas respondieron a las necesidades del momento, y no al establecimiento de un nuevo ordenamiento sobre bases estables y duraderas. Incluso buena parte de esas reformas ha tomado como punto de partida y como eje conductor la crítica a la democracia como régimen político, dentro de una visión que recuerda el debate de los años de la Guerra Fría. Así, en lugar de fortalecer las instituciones de la democracia representativa, de otorgarles mayor capacidad de representación y de vincularlas con mecanismos adecuados de participación, se ayudó a su erosión al alimentar la desconfianza de la población en ellas. Entre las instituciones más golpeadas por esta tendencia se encuentran los partidos políticos y los congresos, que han sido el objeto directo de la orientación adversa de las reformas hacia su condición de actores centrales de la representación política.

reforma fue realizada como una manera de ceder a la presión internacional y de otorgar reconocimiento jurídico al pronunciamiento anticonstitucional que el gobierno había realizado el año anterior. El objetivo era ofrecer los sustentos jurídicos para el régimen surgido de aquella acción, lo que llevaba más bien a estrechar los márgenes del juego político. Su viabilidad estuvo asegurada por la crisis generalizada de los partidos políticos, por el incremento de los niveles de desconfianza de la población y por el apoyo a la solución militar del enfrentamiento interno.

${ }^{67}$ Los intentos de sustitución de la democracia representativa por una nunca bien definida democracia participativa e incluso directa están acompañados en ambos países por un profundo rechazo a la institucionalidad poliárquica propiamente dicha. El cuestionamiento a las formas de representación (con los partidos políticos en el centro de esa crítica) va acompañado de concepciones mucho más graves, como las que tienden a reducir la importancia de la ciudadanía individual en aras de las formas colectivas. La posibilidad de la implantación de democracias corporativas es algo más que eso, que una mera posibilidad, hasta llegar a ser prácticamente una evidencia en ambos países. 
De esta manera, el conjunto de problemas reseñado está conduciendo a democracias débiles en términos de representación y de participación ciudadana, con ciudadanos poco comprometidos con los valores democráticos e incluso adversos a ellos, y con instituciones agobiadas por sus propios elementos constitutivos. Resulta evidente que las democracias de los tres países, pero de manera especial las de Bolivia y Ecuador, están lejos de consolidarse en términos de la conformación de instituciones sólidas que garanticen el procesamiento de las demandas y del conflicto político así como la responsabilidad de los mandatarios ante los electores. Por ello, aún sin compartir las visiones catastrofistas y pesimistas que hablan de la ausencia de democracia, sí es posible sostener que se están configurando regímenes amorfos que ponen en riesgo los principios y valores básicos de la democracia, frente a lo cual los propios actores asumen actitudes hostiles que socavan los cimientos de ésta ${ }^{68}$.

\section{Una digresión sobre las perspectivas académicas}

Para concluir, cabe destacar que el conjunto de problemas reseñados en las páginas precedentes ha sido objeto de diversos acercamientos desde el ámbito académico. Además de la preocupación por las reformas en sí mismas, con el interés en procesos de más largo aliento se los ha tratado desde las perspectivas de la gobernabilidad y la representación. En conjunto han constituido campos de análisis sobre los cuales se ha debatido larga y profundamente para explicar los problemas que han debido enfrentar los respectivos sistemas políticos. Las diversas formas en que se ha entendido a estos dos conceptos tienen mucha importancia para comprender cuáles han sido las percepciones de los problemas de la democracia en los tres países y en general en América Latina así como para entender la orientación de las soluciones que se han aplicado. Sin el ánimo de entrar en profundidad en estos campos, cabe señalar solamente algunos aspectos centrales y que guardan relación con el tema central tratado en este texto.

En primer lugar, se puede observar que varios estudios coinciden en que existe una relación directa entre el deterioro de las condiciones de vida de la población, la baja capacidad del sistema político para enfrentar esos problemas y la pérdida de confianza de

\footnotetext{
${ }^{68} \mathrm{La}$ calificación como regímenes amorfos es una alusión a la combinación de elementos propios de la poliarquía (elecciones, gobiernos elegidos, instituciones representativas, entre otros) con formas ajenas a ésta (como las prácticas particularistas, pero también formas institucionales que pueden socavar los cimientos de la democracia).
} 
la población (Flisfisch, 1983, Camou, 1998; Ansaldi, 1991, Alcántara, 1995). De una manera sintética, esa relación constituye el corazón del concepto de gobernabilidad en su versión latinoamericana. Una revisión de la utilización de este concepto permite asegurar que entre esos autores hay acuerdo sobre la relación causa-efecto que se produce entre condiciones económicas y sociales, por un lado, y limitaciones institucionales, por otro lado (Camou, 1998) ${ }^{69}$. Esta percepción ha dado origen a dos interpretaciones bastante diferentes en términos de las explicaciones a las que se acude y de las conclusiones a las que se llega. Una corriente la ha entendido como la baja capacidad de los gobiernos y en general del sistema político para ofrecer respuestas a las demandas de la sociedad, mientras desde otra perspectiva se considera que las explicaciones se encuentran en el nivel de la sociedad, especialmente en las formas de exclusión socioeconómica que prevalecen en ella. Como es obvio, de cada una de ellas se desprenden diferencias no solamente en términos de explicaciones sino también de propuestas de soluciones.

Desde la primera perspectiva, la sobrecarga de demandas sociales, que constituía el eje del concepto original de crisis de gobernabilidad -o ingobernabilidad- y que ponía énfasis en la conducta de los actores sociales, ha sido sustituida por el concepto de capacidad de respuesta gubernamental. Con ello se desplaza el interés hacia el ámbito institucional o más precisamente hacia la relación entre las demandas sociales y las instituciones. $\mathrm{Al}$ poner el acento en este terreno se expresa implícita o explícitamente mayor preocupación por el perfeccionamiento de la democracia. En ese sentido, tiene una connotación claramente progresista y orienta su crítica más bien hacia la insuficiencia de democracia. Los problemas de gobernabilidad se producirían, según este acercamiento, por deficiencias del sistema político, por tanto las soluciones deberían encontrarse en el mejoramiento de los diseños institucionales, elevación de la capacidad de respuesta a las demandas sociales y perfeccionamiento de los procedimientos democráticos.

\footnotetext{
${ }^{69}$ El concepto de gobernabilidad utilizado en América Latina difiere significativamente del planteado originalmente en la ciencia política norteamericana. En éste, los problemas de gobernabilidad eran vistos casi exclusivamente como el incremento ilimitado de las demandas sociales, que a su vez se derivaban de las respuestas positivas que va ofreciendo continuamente la democracia (Huntington, 1980). De este modo, a cada respuesta satisfactoria que ofrece el régimen democrático le seguiría una elevación del número y el nivel de las demandas sociales. La necesidad de poner límites a las demandas y a la propia capacidad de respuesta del sistema político es la conclusión lógica a la que se llega por esa vía, lo que hacía de esta perspectiva una posición claramente conservadora en términos de la ampliación, la profundización y el grado de inclusión del régimen. Hasta cierto punto, la crítica de esa posición se dirigía al exceso de democracia. El concepto generalizado en América Latina apunta en el sentido contrario, esto es, a las debilidades de la democracia.
} 
La otra perspectiva, aquella que considera que los problemas de gobernabilidad provienen de las exclusiones sociales, devuelve el problema al nivel de la sociedad, pero de una manera diferente a la de la formulación original. Aunque coincide con ésta en que las demandas sociales tienden a incrementarse, no atribuye esta situación a las respuestas positivas que entregaría la democracia, sino más bien a causas estructurales y a la baja capacidad del sistema político para procesarlas. Es decir, a la insuficiencia de democracia y no a su exceso. Según esta perspectiva, los problemas de gobernabilidad pueden evitarse o controlarse solamente en la medida en que se resuelvan previamente las diferencias e inequidades sociales ${ }^{70}$. Obviamente, una perspectiva de este tipo supedita la democracia a las condiciones económicas y sociales, lo que llevaría simplemente a aceptar que ésta es imposible en países, como los estudiados, donde los niveles de pobreza afectan a proporciones muy grandes de la población. Sin embargo se trata de una posición teórica que ha alcanzado gran peso político y en esa medida debe ser tomada en cuenta. Sobre todo es importante hacerlo porque de ella se desprenden muchas de las posiciones que impugnan a democracia como régimen factible para los países andinos.

Las consecuencias disímiles de cada una de las posiciones acerca de la gobernabilidad se expresan en la que se podría considerar como una nueva edición del debate entre institucionalismo y estructuralismo. Así, la primera perspectiva pone el énfasis en los cambios institucionales necesarios para perfeccionar la democracia, en tanto que la segunda se adentra en los resultados económicos y sociales ${ }^{71}$. La escasa claridad en cuanto a diferenciar una y otra ha desembocado en una visión confusa que lleva a atribuir a la democracia los problemas estructurales y que busca resolverlos por medio de reformas institucionales. Dado que éstas no pueden incidir inmediatamente en ese terreno, de manera inevitable se alimenta la insatisfacción con los rendimientos de las instituciones y en general con la democracia. Se alimenta de esa manera a las tendencias

\footnotetext{
${ }^{70}$ Es evidente que esta posición supera ampliamente el nivel estrictamente político del régimen y del sistema político, ya que hace establece la interacción de estos con el nivel estructural. Su énfasis está en los rendimientos del sistema político, lo que puede llevar en sus versiones más extremas a cierta indiferencia con respecto al régimen, es decir, puede ir más allá de la vigencia de la democracia.

${ }^{71}$ Llama la atención que quienes sostienen la segunda posición han sido los más entusiastas partidarios de las reformas constitucionales como mecanismo de solución de los problemas. De una manera que no resulta clara al considerar solamente este nivel de análisis, han desplazado las soluciones a un campo que no identifican como prioritario ni como el ámbito en donde se generan y se manifiestan los problemas.
} 
contrarias a las instituciones democráticas -con los partidos y los congresos en lugar destacado- y en general a las orientaciones antipolíticas ${ }^{72}$.

A la vez, en íntima relación con la preocupación por la gobernabilidad, los medios académicos latinoamericanos -y en particular los de los tres países analizados- han expresado su preocupación por los aspectos relacionados con el segundo de los temas señalados, el de la representación (Mainwaring, Bejarano y Pizarro, 2006; Lazarte, 1998). Principalmente se destacan los pobres resultados de la gestión de los gobiernos, el bajo desempeño de los partidos políticos en su función de representación, así como el carácter relativamente estrecho de las instituciones políticas, señalando que tanto aquellos como éstas no dan cabida a los intereses del conjunto de sectores que conforman la sociedad. Se sostiene que de esa manera se ha ido estableciendo una democracia excluyente y elitista que requiere de cambios profundos como condición para sobrevivir. En el contenido de esos cambios existen menos acuerdos, ya que se abre una amplia gama que va desde quienes sostienen que ellos deberían operarse en el nivel de la representación, con el fin de conseguir que las instituciones y los partidos tengan mayor grado de representatividad, hasta quienes sugieren la instauración de una democracia directa y deliberativa que sustituya la representación por la participación. Por tanto, nuevamente se abre la gama de posiciones entre dos puntos extremos. El primero sostiene la necesidad y la posibilidad- de introducir reformas en el ámbito institucional con el fin de dotar al sistema político de mayor representatividad. Su supuesto básico es que los arreglos institucionales tienen incidencia decisiva sobre las prácticas de los actores y por tanto las modificaciones que se realicen en el primer nivel tendrán su expresión en este último. El segundo niega implícita o explícitamente la efectividad de las reformas institucionales y sugiere más bien que aquellos arreglos no tendrán mayor significación mientras no se sustituya en su totalidad la concepción de régimen representativo. El problema, desde esta perspectiva, se desplazaría hacia el tipo de régimen y no a las formas específicas que éste adopta en cada caso particular ${ }^{73}$.

\footnotetext{
${ }^{72}$ En el capítulo III se trata este tema en referencia a las instituciones democráticas, con especial énfasis en los partidos y en los órganos legislativos.

73 Aunque tiene menos sustento teórico y conceptual que el primero, e incluso a pesar de que aparece como una posición carente de viabilidad práctica, este último punto de vista ha cobrado importancia en los últimos años dado que se ha convertido en uno de los elementos centrales de la agenda política especialmente en Bolivia y Ecuador. Inicialmente fue patrimonio del discurso de líderes y movimientos que provienen desde fuera del ámbito institucional de la política, pero con el pasar del tiempo se ha transformado en uno de los temas básicos del debate y ha penetrado incluso en sectores
} 
A pesar de estas diferencias las dos posiciones aluden a problemas de relación entre el sistema político y la sociedad. Ambas encuentran en esos problemas las causas de la insatisfacción ciudadana con la democracia. El primero se enfoca en las condiciones de la representación de la sociedad en el sistema político, en tanto que el segundo -en especial en sus versiones más radicales- busca la eliminación de cualquier diferencia entre sociedad y sistema político. Sin embargo, ambos reconocen la existencia de una demanda de participación, a la que le atribuyen tanta importancia que vendría a ser la causa del desencanto con el régimen ${ }^{74}$. No obstante, en el fondo se encuentran concepciones totalmente diferentes de la democracia. Es decir, al igual que lo que ocurre con las perspectivas que analizan la gobernabilidad, ambas rebasan el nivel original del planteamiento -en este caso el de la representación- y replantean el problema de la democracia en sí mismo. Incluso es posible señalar que en realidad más que un debate acerca de la representación (y de la participación) es una reflexión sobre la democracia en lo que tiene que ver a su relación con la ciudadanía ${ }^{75}$.

Por esa vía se ha llegado a establecer una separación profunda y amplia entre representación y participación. Se los ha transformado en conceptos antitéticos que a su vez dan forma a conceptos de democracia también enfrentados. La posibilidad de llegar a puntos de acuerdo se aleja en la medida en que a la representación se le vacía de su contenido participativo y en que a la participación se la considera como algo factible de ser realizado sin ningún componente de representación. Además, al colocarlos en orillas opuestas se olvida de que toda forma representativa tiene un componente de

que inicialmente sostenían la primera posición. Los procesos constitucionales que llevan adelante esos dos países están influidos muy fuertemente por esa visión.

${ }^{74}$ Es una afirmación que debe ser sometida a discusión, ya que no es posible identificar una relación clara de causa a efecto entre los dos elementos, esto es, representación (o limitaciones en la representación y en la participación) e insatisfacción con el régimen. En efecto, no existe mayor asidero para sostener que la ciudadanía exija mejores condiciones de representación de participación, como sí existe para afirmar que espera mejores rendimientos del sistema político. En gran medida, esta visión tiene mucho de profecía autocumplida, ya que ha creado una idea que al generalizarse entre la población se ha convertido en parte de la agenda política. Sin embargo, un simple ejercicio de análisis comparativo demuestra que en situaciones de satisfacción de las demandas socioeconómicas no se presenta esa supuesta demanda de participación.

${ }^{75}$ Las ya aludidas reformas constitucionales realizadas por medio de las asambleas constituyentes son excelentes indicadores del grado que ha alcanzado este debate en los medios políticos andinos. En todas ellas se han incluido artículos alusivos a la participación. Incluso en algunos casos se ha llegado a denominar expresamente como democracia participativa al régimen establecido por esas constituciones, a pesar de que en realidad se trata por lo general de la introducción de mecanismos de democracia directa o semidirecta que forman parte consustancial del régimen representativo y que en algunos casos (como el ecuatoriano) ya estaban vigentes antes de los cambios constitucionales. 
participación (Manin, Przeworski y Stokes, 1999b: 1), cuyo peso depende precisamente de la mayor o menor apertura y capacidad de inclusión del sistema, pero que no puede materializarse aisladamente. Desde esa perspectiva resulta evidente que, como ha sucedido con el tema de la gobernabilidad, tampoco éste ha sido planteado en su verdadera dimensión y por esa razón se ha transformado en el origen de posiciones diametralmente opuestas.

El aspecto positivo que se puede rescatar de esta confrontación es que coloca a la canalización de demandas y la agregación de intereses, dos de los temas fundamentales de la democracia, en el centro del debate. En efecto, al aludir a representación y a participación se hace referencia necesariamente a la capacidad del sistema político para establecer la relación entre la sociedad y el Estado o, más concretamente, entre aquella y las instancias de toma de decisiones (Manin, Przeworski y Stokes, 1999a; Sartori, 1999a; 1999b). Por tanto, lleva el análisis a las condiciones en que se establece esa relación y sobre todo a los mecanismos y procedimientos establecidos para su materialización. Esto quiere decir que el análisis se desplaza al nivel institucional, independientemente del tipo de democracia o del mayor o menor énfasis que se ponga en la representación o en la participación.

En consecuencia, se puede afirmar que el debate teórico y también el político sobre las democracias latinoamericanas y en particular de los tres países se han desarrollado en torno a dos temas que se entrecruzan. Por un lado, el de la gobernabilidad, en el que se enfrentan las posiciones estructuralistas con las institucionalistas. Por otro lado, el del carácter del régimen democrático, en el que se ha puesto sobre la mesa la dicotomía participación-representación. Ambos giran en torno a insuficiencias de la democracia, ya sea en términos de su capacidad para responder a las demandas de la sociedad, o bien en términos de ofrecer condiciones adecuadas para la expresión de los diversos sectores sociales. Se puede decir, por tanto, que ambos confluyen en el debate sobre la democracia realmente existente, esto es, sobre los resultados (económicos y sociales) del funcionamiento del régimen democrático más que sobre sus bases conceptuales y su sustento teórico $^{76}$. En el fondo del asunto se encuentra la insatisfacción con los

${ }^{76}$ Es verdad que buena parte de los participacionistas cuestionan las bases conceptuales y teóricas de la democracia (representativa), pero también es cierto que sus propuestas no han sido formuladas con el sustento teórico necesario para que sean consideradas como modelos alternativos viables. Por ello, su 
rendimientos del sistema político, independientemente del tipo de régimen. El problema es que la democracia crea expectativas que rebasan largamente su condición de régimen político, lo que ha llevado a atribuir los problemas a una de las condiciones de éste, bajo la percepción de crisis de representatividad.

Finalmente, llama la atención la escasa atención que se ha dado en todo este debate a la vigencia del Estado de derecho. Como se ha visto, la mayor parte de la reflexión académica y de la agenda política ha girado en torno a aspectos propios del sistema político y de las condiciones estructurales en que éste se desarrolla. Se puede decir, aludiendo a la diferenciación clásica de la ciudadanía (Marshall, 2007), que ha habido gran preocupación por su forma política y por su forma social, pero que ha estado prácticamente ausente el interés por la forma civil. Las libertades y los derechos propios de este nivel, expresados en el Estado de derecho más que en la democracia entendida como régimen político, han ocupado apenas un lugar secundario tanto en el campo académico como en el de la política práctica. Seguramente ha influido en ello el escaso peso que tuvo la lucha por los derechos civiles en el proceso de transición. Con excepción de Bolivia, donde la demanda por la vigencia de los derechos humanos fue uno de los factores centrales de la transición (en lo que se establece algún grado de similitud con las transiciones del Cono Sur que tuvieron a esa reivindicación como su eje), en general estos fueron supeditados a los de carácter económico y político. Incluso llama la atención que en los actuales procesos constituyentes se ponga mucho más énfasis en la inclusión política que, como se ha visto, fue bastante satisfactoria con la instauración de las nuevas poliarquías, y que por el contrario no se preste mayor atención a esos otros aspectos ${ }^{77}$.

\section{Conclusiones}

La utilidad del presente capítulo para el análisis de la calidad de la democracia en los tres países se desprende fundamentalmente de tres elementos que han sido destacados a lo largo de éste. En primer lugar, la revisión de las especificidades -y también de las similitudes- de las transiciones permite comprender las bases sobre las que se asientan las

campo de expresión privilegiado ha sido el de la política práctica, mientras que ha sido muy pobre su incidencia en los medios académicos.

${ }^{77} \mathrm{La}$ diferencia y la relación entre democracia y Estado de derecho están tratadas en los capítulos I, IV y V. 
poliarquías construidas en cada uno de ellos. En este sentido, las transiciones marcan la coyuntura crítica de la que se desprenden en gran medida los aspectos constitutivos de las democracias políticas de los tres países. Obviamente, no existe un determinismo en ese sentido, pero sí se dibuja una ruta que expresa a lo largo de todo el período los elementos constitutivos iniciales.

En segundo lugar, la descripción y el análisis de los procesos de transición han permitido comprender el juego de fuerzas que se estableció en ellos, esto es, las estrategias y los cálculos de los actores políticos. Más allá de la definición de los términos o de las reglas del juego, vale decir de las normas constitucionales y legales, las transiciones tienen enorme importancia por su carácter de períodos iniciales de la acción política de los actores. La manera en que ellas se configuran, es decir, el tipo de transición depende tanto de las reglas formales como de las prácticas y orientaciones de los actores. Así mismo, esas prácticas y esas orientaciones tienen tanta influencia hacia adelante como la que se reconoce a las reglas. De la misma manera, las prácticas configuran conductas de los actores que posteriormente pueden identificarse como pautas que se interiorizan como formas de cultura política y que generan comportamientos rutinarios.

En tercer lugar, la revisión de los principales problemas y temas de las transiciones en los tres países llevan a confirmar que el interés se ha centrado fundamentalmente en los aspectos políticos y sociales, con fuerte déficit en la construcción del Estado de derecho. También este es un aspecto determinante para el tipo de democracia que se puede construir de ahí en adelante, ya que constituye una limitación muy seria para el establecimiento de regímenes propiamente poliárquicos.

En síntesis, el estudio de las transiciones es un elemento fundamental para el análisis de la calidad de la democracia. Sin una referencia a ese período, a sus características e incluso a sus avances y retrocesos, es imposible adentrarse en toda su complejidad en el campo teórico y empírico que plantea el estudio de la calidad de la democracia. Por ello, el presente capítulo debe ser comprendido como la indagación sobre el conjunto de antecedentes que llevaron a la configuración de las poliarquías en cada uno de los países. 
Capítulo III. Instituciones y procesos políticos 


\section{Resumen}

Este capítulo analiza algunos aspectos institucionales del sistema político de los tres países. La reflexión está guiada por la importancia de los diseños institucionales para la democracia (tanto para su establecimiento como para su consolidación). Así mismo, a lo largo del capítulo se destacan los efectos de los arreglos institucionales en la toma de decisiones así como en la formulación y aplicación de políticas. Los aspectos analizados para este fin son las relaciones entre los poderes ejecutivo y legislativo, los sistemas electorales, los sistemas de partidos y la distribución territorial del poder. La selección de estos cuatro campos institucionales se desprende de su carácter de elementos centrales del sistema político y, en virtud de ello, del peso que tienen como condicionantes de las prácticas de los actores políticos. Siguiendo la selección de estos elementos institucionales, el capítulo está organizado en cinco secciones, precedidas por una introducción. La primera trata el tema de las relaciones entre los poderes. La segunda aborda los sistemas electorales y los sistemas de partidos de manera conjunta. La tercera abre un paréntesis en el análisis de los tres países para realizar una breve reflexión conceptual sobre el estudio de los sistemas electorales y los sistemas de partidos. La cuarta, de carácter más exploratorio que las otras debido a la escasez de estudios al respecto, aborda la distribución territorial del poder. Finalmente, el capítulo se cierra con una sección de conclusiones generales.

\section{Introducción}

Dos premisas y un objetivo guían al presente capítulo. La primera premisa sostiene que los arreglos institucionales condicionan las prácticas y las conductas de los actores políticos, a la vez que reciben la influencia de esas prácticas y esas acciones en una fluida interacción. Esta premisa se desprende en buena medida de los avances logrados en el campo del denominado nuevo institucionalismo, que supera el estudio puramente formal de las instituciones por medio del análisis de las interacciones entre éstas y las prácticas de los actores (Peters, 2003: 33-41; March y Olsen, 1984: 738-740; Colomer, 2001: 4-5). Las decisiones estratégicas de los actores políticos se enmarcan en unas instituciones previamente existentes -están constreñidas por éstas (Crawford y Ostrom, 1995: 582583)-, pero a la vez tienden a cambiarlas en función de sus intereses específicos ${ }^{1}$. Desde esta perspectiva, entonces, las instituciones constituyen un marco que condiciona las estrategias de los actores políticos, pero a la vez son constantemente modificadas por las

\footnotetext{
1 Refiriéndose a los sistemas electorales - una de las instituciones básicas del sistema político-, Colomer sostiene que la elección de estos es importante porque "producen graves consecuencias políticas, especialmente sobre el número de partidos políticos y la composición de las asambleas y los gobiernos. Sin embargo, los sistemas electorales -como otras instituciones políticas- son también una consecuencia de los partidos políticos, las asambleas y los gobiernos previamente existentes, cada uno de los cuales tiende a preferir aquellas fórmulas y procedimientos institucionales que puedan consolidar, reforzar o aumentar su poder relativo" (Colomer, 2004: 25).
} 
acciones de estos. En ese sentido, las instituciones marcan el campo en que se desenvuelve la política, pero a la vez son la expresión de ella. Los actores buscan modificar a las instituciones de acuerdo a sus respectivos intereses, con lo que se genera una tensión constante entre estabilidad y cambio ${ }^{2}$.

La segunda premisa sostiene que la calidad de la democracia depende en gran medida de los arreglos institucionales, tanto en el nivel del régimen como del sistema político ${ }^{3}$. Aunque la calidad de la democracia está condicionada por un conjunto más amplio de factores, entre los que se cuentan las prácticas de los actores y los efectos no esperados de coyunturas históricas que viven las sociedades, es innegable que el diseño institucional constituye el elemento determinante en tanto establece el marco para la acción política. No se trata de las instituciones en el sentido amplio del término, que las considera como regularidades del comportamiento que se van implantando en una sociedad, sino del diseño del entramado institucional del régimen y del sistema político. Por consiguiente, la premisa apunta hacia la formalidad institucional y no a las instituciones en ese sentido amplio que lleva a considerarlas tanto en su aspecto formal como en el informal ${ }^{4}$. La noción de diseño institucional da cuenta de ello y establece la diferencia con las instituciones, que pueden ser entendidas en ese sentido más amplio.

El objetivo se desprende de ambas premisas y apunta al análisis comparado de los componentes institucionales fundamentales de los sistemas políticos de los tres países. Más que de una descripción, se trata de una taxonomía de los elementos básicos del sistema político y de la identificación de las especificidades de su funcionamiento en cada uno de los países. Con esto busco identificar los principales factores institucionales que dieron origen a $-\mathrm{O}$ que contribuyeron a que se presentaran- los problemas de representación y de gobernabilidad que afectaron a los tres países desde las transiciones a la democracia.

${ }^{2} \mathrm{El}$ análisis de la estabilidad y el cambio en las sociedades no es un campo privativo de la ciencia política. El interés por el tema en esta disciplina estuvo antecedido por el desarrollo que se logró en la sociología y de la antropología. Textos fundacionales de éstas, como los de Durkheim y Mauss, tenían entre sus objetivos centrales la explicación de las condiciones que llevan a la estabilidad de las sociedades así como los que producen el cambio.

${ }^{3}$ Cada una de estas premisas podría formulares como una hipótesis y, en consecuencia, abriría por sí misma un amplio campo de investigación y análisis. Sin embargo, los avances logrados por la ciencia política en el estudio de las instituciones hace posible su tratamiento como hechos que no requieren demostración sino que más bien organizan el análisis hacia adelante (Thelen, 1999).

${ }^{4}$ Como se verá más adelante, los aportes sobre las instituciones informales son muy importantes para comprender el desempeño de la política en países como los estudiados. Sin embargo, el reconocimiento de su peso y de su importancia no invalidan la premisa planteada. 
La reflexión que desarrollo en el presente capítulo se restringe a cuatro grandes conjuntos institucionales que pueden considerarse como centrales o básicos del sistema político. Estos son la relación entre los poderes del Estado (especialmente entre el Ejecutivo y el Legislativo), el sistema electoral, el sistema de partidos, y la distribución territorial del poder. Por consiguiente, dejo de lado otros conjuntos que pueden tener mucha importancia en el estudio de la democracia (y de su calidad), como el poder Judicial, el ámbito de la vigilancia constitucional, el de la seguridad y la defensa (incluidas las instituciones armadas) y el de las relaciones internacionales. Todos ellos son campos de fundamental importancia, que ciertamente ejercen influencia sobre las condiciones en que se desarrolla la democracia, pero no de la manera directa y con la fuerza que lo hacen los cuatro elementos seleccionados ${ }^{5}$.

\section{Las relaciones Ejecutivo-Legislativo}

Bolivia Ecuador y Perú forman parte de la larga tradición de regímenes presidenciales propia de América Latina. En ninguno de los tres países se han impulsado cambios en este aspecto y, por el contrario, las sucesivas reformas constitucionales y políticas se han orientado a profundizar el presidencialismo (Tanaka, 2002; 2003; Mainwaring y Shugart, 2002). Como se verá a lo largo de esta sección, ese carácter del régimen puede considerarse como el origen de muchos de los problemas de gobernabilidad y de representación que debió enfrentar cada uno de los países, especialmente por los bajos incentivos que ofrece para la conformación de coaliciones de gobierno. Incluso los diseños institucionales contenidos en las nuevas constituciones de Bolivia y Ecuador que, entre otros objetivos, buscaban superar los problemas de gobernabilidad- apuntan a fortalecer a los ejecutivos en desmedro de los órganos legislativos, de manera que es altamente probable que la tendencia se mantenga e incluso que se profundice hacia el futuro.

Para sustentar estas apreciaciones es necesario pasar revista a lo sucedido en cada uno de los países desde la implantación del régimen democrático, poniendo atención a las

\footnotetext{
${ }^{5}$ Una razón adicional para seleccionar esos elementos del sistema político es la importancia que se les atribuye en las mediciones de calidad de la democracia. Como se verá en el capítulo IV, la mayor parte de enfoques al respecto los toman como factores centrales o como parámetros de medición, en tanto que son escasos los acercamientos que incluyen a los otros componentes.
} 
relaciones Ejecutivo-Legislativo, especialmente en su papel de incentivo (o desincentivo) para la formación de coaliciones de gobierno ${ }^{6}$. Pero, previamente a entrar en ese campo es necesario diferenciar a las coaliciones electorales de las coaliciones de gobierno, ya que no solamente constituyen fenómenos diferentes sino que -de manera fundamental para el tema de esta sección- cada una de ellas puede encontrar incentivos específicos en el diseño institucional. Dicho de otra manera, hay incentivos institucionales específicos para la conformación de coaliciones electorales, que difieren de los incentivos para la conformación de coaliciones de gobierno. Por tanto, aunque se puede considerar como altamente probable que los incentivos para la formación de coaliciones de gobierno al mismo tiempo impulsen la formación de coaliciones electorales (ya que los actores políticos actuarían electoralmente en función de la conformación del futuro gobierno), no se puede afirmar que siempre será así, ya que aquellos incentivos pueden aparecer como una segunda instancia, prácticamente independiente de la fase electoral. Así mismo, aunque se puede considerar como altamente probable que los incentivos para la formación de coaliciones electorales impulsen también la formación de coaliciones de gobierno (debido a que tiende a producir gobiernos multipartidistas), no se puede esperar que siempre ocurra así ya que la preservación de la coalición depende en gran medida de la fuerza de cada partido en el Legislativo.

Con estas precisiones es posible analizar la forma específica que asumieron las relaciones Ejecutivo-Legislativo en cada uno de los países y observar las consecuencias que se desprendieron de ellas. Así, como he señalado al inicio de esta sección, aunque los tres países mantuvieron el carácter presidencial de sus regímenes, hay ciertas diferencias que deben ser desatacadas y que aportan explicaciones desde la perspectiva comparativa. En este sentido, el caso más singular es el de Bolivia, que ha sido calificado como semipresidencialismo/semi-parlamentarismo (Verdesoto, 2005: 14) presidencialismo parlamentarizado (Mayorga, 2003: 104; García, 2001: 35), presidencialismo atenuado (Mayorga, 1992: 53) o presidencialismo bibrido (Gamarra, 1992: 27) ${ }^{7}$. La elección del presidente de la República por parte del Congreso, en caso de que no existiera un ganador absoluto en la votación directa, es el factor central que lleva a esas definiciones. Según esas interpretaciones, de

${ }^{6}$ Llama la atención el escaso número de estudios acerca del tipo de régimen y de las relaciones Ejecutivo-Legislativo. Esa baja preocupación académica por el tema puede tomarse como expresión de la ausencia de debate político al respecto. En ninguno de los tres países - a pesar de que en todos ellos se expidieron nuevas constituciones por medio de asambleas constituyentes- se ha debatido en profundidad la posibilidad de instaurar un régimen parlamentario o de moverse en el amplio campo que existe entre los dos polos, esto es, en los semipresidencialismos y semiparlamentarismos.

${ }^{7} \mathrm{El}$ análisis del caso boliviano está basado en Pachano (2006). 
este arreglo institucional se derivarían varios efectos positivos. En primer lugar, se harían imprescindibles los acuerdos no solamente para elegir al presidente (coaliciones electorales) sino también para el ejercicio gubernamental (coaliciones gubernamentales) ${ }^{8}$. En segundo lugar, esa misma necesidad de contar con los votos de otro u otros partidos para la elección en el Congreso y sobre todo para formar gobierno, tendría un efecto moderador de la competencia política. En tercer lugar, las coaliciones establecidas de esa manera permitirían superar en buena medida los problemas de legitimidad dual propios del presidencialismo. Finalmente, ese tipo de elección tendría un efecto reductor del número de partidos al limitar el campo de acción de los partidos pequeños en tanto su éxito y sus posibilidades dependen no solamente de los resultados de la elección presidencial sino fundamentalmente de la legislativa (Mayorga, 2004; García, 2001) ${ }^{9}$. Finalmente, todo ello llevaría a la conformación de tendencias centrípetas que acercarían las posiciones de los principales partidos y, por tanto, se produciría la continuidad en las políticas.

La explicación es, sin duda, muy atractiva y sugerente. Su validez se refuerza cuando un análisis comparativo con otros países del continente demuestra que, ante condiciones económicas, sociales y políticas similares, estos no pudieron constituir gobiernos que contaran con apoyo en el congreso y que dispusieran del espacio necesario para la formulación de políticas de largo alcance. En algunos de esos países los gobiernos debieron acudir a medidas desesperadas, generalmente de corte clientelar, para apenas lograr su supervivencia, como lo ilustra el caso de Ecuador (Mejía, 2004; Pachano, 2001). Otros países debieron optar por la vía autoritaria, cuya mejor expresión es el proceso desarrollado en Perú entre 1992 y 2001 (Tanaka y Marcus-Delgado, 2001; Cotler y Grompone, 1995; Grompone y Mejía, 1995). Algunos países encontraron la fórmula en las viejas prácticas del populismo caudillista, con la experiencia venezolana a la cabeza

\footnotetext{
${ }^{8} \mathrm{Al}$ referirse a las primeras experiencias de elección de presidentes del período democrático, Gamarra señala que "para las relaciones entre los poderes del Estado y los partidos políticos, la elección del Presidente por parte del Congreso Nacional es un aspecto crítico pues en un sistema multipartidista sugiere a todo partido que coaliciones entre dos o más partidos serán absolutamente necesarias para el próximo período presidencial. La colaboración entre partidos es extremadamente importante. En 1989, los políticos bolivianos parecían haber logrado un equilibrio que no se hubiera alcanzado con un sistema puramente presidencial, especialmente con un presidente elegido por una segunda vuelta" (Gamarra, 1992: 32). Sin embargo, el mismo autor hace notar la insuficiencia de esa explicación en condiciones donde impera el patronaje, vale decir el clientelismo (Gamarra, 1992: 36).

${ }^{9}$ Este último aspecto se hizo más evidente desde la aplicación de las reformas de 1994, ya que se limitó la elección dentro del Congreso a los dos candidatos con mayor votación en lugar de los tres primeros como era hasta ese momento. Es decir, se incrementó la exigencia sobre los partidos, lo que significaba menos posibilidades para los más pequeños.
} 
(Carrasquero, Maingon y Welsh, 2001; Penfold, 2001; Kornblith, 2004; Molina, 2003a; 2003b).

Sin embargo, hay tres razones muy importantes para hacer una revisión de esta explicación. En primer lugar, una razón de carácter fáctico es que la estabilidad política se terminó con la caída del presidente Sánchez de Lozada, en octubre de 2003, el sistema de partidos se pulverizó, los acuerdos políticos dejaron de constituir el elemento central de la política y se rompieron los acuerdos básicos acerca de la economía y de la democracia. Por tanto, es posible suponer que existieron otros factores, más fuertes que aquel elemento del diseño institucional, que determinaron su neutralización y finalmente lo transformaron en algo ineficaz en términos de causa de los resultados positivos mencionados. En segundo lugar, existe una razón de carácter teórico y conceptual, que alude a la necesidad de diferenciar con claridad entre dos tipos de efectos de esa modalidad de elección presidencial: los que se manifiestan en la estabilidad política y los que se pueden observar en la continuidad de las políticas (o, si se quiere, en los consensos sobre las orientaciones económicas, sociales, etc.). La tercera razón es también de carácter metodológico-conceptual, y consiste en un llamado de atención sobre la ausencia de otros componentes del sistema político en el análisis que se ha realizado hasta el momento.

Una primera hipótesis que quiero plantear al respecto es que los resultados políticos positivos que se obtuvieron en Bolivia dependieron en buena medida de la disposición constitucional señalada, pero que ella habría sido estéril sin la presencia de otros elementos propios del diseño institucional del sistema político, pero también sin los específicos cálculos estratégicos de los actores políticos. Una segunda hipótesis es que, a pesar de haber sido factores fundamentales para lograr la estabilidad política, esos componentes institucionales son insuficientes para explicar la tendencia centrípeta que se expresaría en la continuidad de las políticas económicas. Finalmente, sostengo que, a pesar de que operaron adecuadamente mientras se pudo mantener la hegemonía de tres partidos, dentro de un bipartidismo sui generis, aquellos arreglos institucionales se transformaron en obstáculos para la inclusión de nuevas demandas en la agenda política $^{10}$.

${ }^{10} \mathrm{El}$ sistema multipartidista moderado que giraba en torno a "una estructura de tríada partidista (MNR, MIR, ADN)" (Mayorga, 2004: 29, cursivas en el original) fue más bien un bipartidismo ya que desde 1989 en adelante dos de los partidos (ADN y MIR) actuaron como un solo frente (el Acuerdo 
La primera hipótesis puede sustentarse en el recuento del conjunto de hechos que antecedieron al derrocamiento del presidente Sánchez de Lozada y a la elección de Evo Morales como presidente de la República en diciembre de 2005, que marcan el fin de la democracia pactada y, en consecuencia, de los efectos virtuosos de los arreglos institucionales ${ }^{11}$. En este sentido, en primer lugar, es preciso reconocer que las manifestaciones iniciales de agotamiento del modelo de democracia pactada, que se hicieron evidentes en las elecciones del año 2002, tuvieron su antecedente en la práctica del último de los gobiernos que surgieron de los acuerdos políticos. En efecto, el gobierno encabezado inicialmente por Hugo Banzer (1997-2001) y después por su vicepresidente Jorge Quiroga (2001-2002) desvirtuó totalmente aquella modalidad de gestión política cuando conformó lo que se denominó la megacoalición. En esta participaron, además de los dos partidos que formaron la alianza electoral triunfadora (ADN y MIR), los partidos populistas que habían irrumpido en el escenario político desde fines de la década de los ochenta (CONDEPA y UCS), así como otro partido de igual signo conformado poco tiempo antes (NFR). La presencia de estas organizaciones marcó tres diferencias notorias con las pautas que habían regido para la conformación de los gobiernos anteriores. Por una parte, era la primera vez que había un alto número de partidos, lo que obligaba a ampliar y profundizar el prebendalismo propio del modelo. Por otra parte, trasladaba al interior del gobierno buena parte de las disputas, especialmente las que tenían como objetivo la captación de recursos económicos y políticos ${ }^{12}$. Finalmente, su propia condición de partidos claramente clientelares y personalistas tendía a arraigar las prácticas de ese tipo y a dejar en segundo plano los acuerdos programáticos. Todos esos elementos determinaron el comienzo del fin de la lógica que se había establecido desde 1985. Simplemente, ésta no podía seguir existiendo dentro de esas condiciones.

Patriótico) que tenía como contendor al otro partido significativo (MNR). Los partidos más pequeños quedaban prácticamente excluidos o debían integrarse en una de las coaliciones (de preferencia en la gobernante).

${ }^{11}$ Entre esos hechos se destacan las movilizaciones populares del año 2000 en Cochabamba (la guerra del agua) y las de febrero de 2003 en La Paz. Aunque tuvieron un fuerte contenido reivindicativo, las motivaciones últimas de esta acción colectiva deben buscarse en el ámbito político. Un intento de análisis en este sentido se encuentra en Prada (2004) que, en un plano más discursivo que analítico, sostiene que ellas constituyeron la expresión del agotamiento del modelo neoliberal y la eclosión de un modelo alternativo. En términos más concretos, es evidente que ellas se enmarcaron en la corriente crítica que iba tomando cuerpo conforme se iban agotando los recursos de la democracia pactada.

${ }^{12}$ En la práctica, el único partido que quedó fuera de la coalición fue el MNR, que de esa manera podía ocupar cómodamente el lugar de la oposición frente al que aparecía como un acuerdo orientado exclusivamente a la satisfacción de intereses prebendalistas. 
Cabe destacar que el primer acuerdo político que tuvo resultados positivos en la capacidad de toma de decisiones fue el Pacto por la Democracia. Este se estableció en 1985 entre el partido de gobierno (MNR) y el principal partido de la oposición (ADN) con el objetivo de apoyar la iniciativa gubernamental denominada Nueva Política Económica (NEP). Este pacto no tuvo como objetivo la elección del presidente, ya que se produjo después de que ésta se había realizado en el Congreso ${ }^{13}$. Así mismo, no fue un acuerdo de cogobierno o de participación en la administración gubernamental, sino más bien de establecimiento y preservación de una orientación de política económica, lo que incluía por cierto el compromiso del gobierno en funciones para hacer posible la alternabilidad con el partido de oposición (Gamarra, 1992: 29). En otras palabras, este primer acuerdo entre dos partidos tuvo un carácter predominantemente ideológicoprogramático -no prebendalista- y no estuvo determinado de manera alguna por la modalidad de elección del presidente en el Congreso.

El segundo gobierno, elegido en 1989, fue el que inauguró la lógica de alianzas de gobierno propiamente dichas ${ }^{14}$. El Acuerdo Patriótico, suscrito por el MIR y ADN, tuvo por consiguiente la forma de pacto parlamentario y de coalición gobernante, lo que marcó una diferencia sustancial con la modalidad establecida en el gobierno inmediatamente anterior ${ }^{15}$. Adicionalmente, este entendimiento incluyó ya no la alternación entre los dos partidos involucrados en él, sino la continuidad bajo la forma de una alianza de carácter permanente entre los dos partidos, lo que se manifestó en la siguiente elección (1993) a la que acudieron bajo la cobertura del mismo Acuerdo

\footnotetext{
${ }^{13}$ Hugo Banzer con ADN obtuvo el primer lugar en las elecciones de 1985, con el 33,2\% de los votos, seguido por Víctor Paz Estensoro del MNR, con el 30,7\%. El MIR (que obtuvo el 10,3\%) y otros grupos de izquierda se unieron al MNR y eligieron a Víctor Paz.

14 Aunque, también los dos presidentes elegidos antes de 1989 requirieron del mecanismo establecido en la Constitución -debido a la ausencia de mayoría absoluta en la elección directa-, ninguno de ellos fue el producto de un pacto establecido específicamente para la elección en el congreso. La alianza que llevó al gobierno a Hernán Siles, en 1982, se había conformado como coalición electoral entre el MNRI y el MIR, para participar en las elecciones de 1980 (que fueron desconocidas por el golpe militar de García Meza). Por tanto, no fue un acuerdo establecido dentro del Congreso para la elección o nominación del presidente. La elección de Víctor Paz, como se ha visto, fue el producto de un acuerdo parlamentario, pero no dio como fruto una coalición gobernante. En este aspecto se ve claramente la diferencia entre las coaliciones electorales, las que se forman para la elección o nominación en el Congreso y las de gobierno, como lo hace Gamarra (1992: 26)

${ }^{15}$ En 1989, Gonzalo Sánchez de Lozada (MNR) triunfó en las urnas (con el 25,8\% de los votos), pero la formación del Acuerdo Patriótico determinó la nominación congresal de Jaime Paz (que, con el 22,0\%, había ocupado el tercer lugar, debajo del 25,4\% de Hugo Banzer). Al presentar la candidatura de Sánchez de Lozada, el MNR había roto su compromiso de apoyar a ADN, lo que fue un factor de importancia para empujar a este partido a la alianza con el MIR.
} 
Patriótico. Por consiguiente, las diferencias entre ambas experiencias radican no solamente en los acuerdos que constituyeron a los gobiernos, sino sobre todo en la manera en que manejaron las relaciones dentro de cada gobierno y entre estos y los partidos de la oposición. Como he señalado antes, el factor fundamental para la constitución del gobierno de Víctor Paz Estensoro fue el acuerdo con el MIR (y otros grupos minoritarios) para la elección, lo que abrió paso a una negociación permanente por cargos y prebendas dentro del gobierno (Ardaya y Verdesoto, 1994; Mayorga, 1998). Pero el elemento central para su gestión gubernamental -y el que explica su capacidad para formular y sostener políticas- fue el Pacto por la Democracia con ADN, el principal partido de la oposición. Este fue el factor que le otorgó amplio espacio para la gestión, especialmente en la definición de la política económica. Por el contrario, en el gobierno de Jaime Paz Zamora el mismo acuerdo legislativo estructurado para la elección del presidente se mantuvo como coalición gubernamental, lo que en la práctica llevó a la exclusión de la oposición. Por consiguiente, entre uno y otro se perdió el factor más importante que se puede desprender de la modalidad de elección en el Congreso, esto es, la posibilidad de obtener un compromiso por parte de la oposición. En síntesis, el gobierno del Acuerdo Patriótico abrió las puertas para la implantación de una modalidad en que la oposición quedaba excluida y por tanto los consensos se reducían a la coalición gobernante. De esta manera se iniciaba el retorno de los aspectos más negativos del presidencialismo $^{16}$. Con ello se fue debilitando el impulso hacia los consensos, que era precisamente el principal resultado que se podía derivar del mecanismo de elección presidencial en el Congreso. La posibilidad de establecer gobiernos de consenso quedó anulada desde el momento en que la elección congresal se convirtió en un dispositivo para excluir a la oposición y para lograr apoyos que entrañaban altos costos políticos y programáticos.

\footnotetext{
${ }^{16}$ En adelante se mantuvo esta característica. Así, para la elección en el congreso, el tercer gobierno (1993-1997) recibió el respaldo de los partidos populistas (CONDEPA y UCS) y de la única agrupación de izquierda que tuvo alguna importancia electoral (MBL). Los mismos partidos pasaron a formar parte de la coalición gubernamental, lo que se tradujo en una cómoda mayoría legislativa (Romero, 1999: 46; Mayorga, F, 2001: 172). Pero al mismo tiempo, esto significó la exclusión de la oposición de similar manera a lo que había hecho el gobierno anterior. La modalidad introducida por el gobierno del Acuerdo Patriótico se había implantado en la gestión presidencial boliviana, y lo había hecho bajo la lógica de un bipartidismo que sin embargo amparaba a varios partidos en su interior. Esta fue la modalidad que llegó a su máxima expresión en el gobierno de Hugo Bánzer (elegido en 1997), expresada en la ausencia de acuerdos con el principal partido de la oposición, la inclusión en el gobierno de los partidos pequeños con el fin de lograr apoyo legislativo (tanto para la elección presidencial como para la gestión gubernamental) y la consolidación de las prácticas clientelares y prebendalistas como mecanismo de preservación de esos acuerdos (Mayorga, F, 2001: 174; Lazarte, 1992: 79)
} 
La importancia atribuida a esta modalidad de elección se basa también en su efecto positivo en términos de facilitar los consensos porque exige establecer coaliciones dentro del congreso y estas pueden convertirse en acuerdos de gobierno. Pero la explicación va más allá y alude -aunque más bien de manera indirecta- al efecto moderador que tendría la disposición constitucional en la relación entre el gobierno y la oposición y al papel que a esta le cabe en la obtención de la estabilidad como resultado final. Esa alusión indirecta se encuentra en el supuesto básico que está detrás, y es que en la medida en que se hace necesaria la conformación de coaliciones para la elección presidencial en el congreso -y eventualmente para gobernar-, los actores políticos tenderían a bajar el nivel de los enfrentamientos y a reducir la distancia entre ellos. Es decir, se conformaría una tendencia centrípeta que facilitaría los entendimientos entre el gobierno y la oposición.

Sin embargo, la breve revisión realizada antes permite ver que ese segundo efecto solamente se produjo en el período 1985-1989, mientras que en el anterior y en los cuatro siguientes se formaron coaliciones de gobierno que excluyeron a la oposición. En consecuencia, lo ocurrido en cinco de los seis gobiernos demuestra que no se produjo el que se suponía sería el efecto central de ese elemento del diseño institucional. Se puede sostener, ciertamente, que el resultado evidente del procedimiento de selección presidencial fue la conformación de alianzas legislativas-gubernamentales, lo que no deja de ser un elemento altamente positivo dentro de la historia de inestabilidad que caracterizó anteriormente a Bolivia, pero eso no supone necesariamente el acercamiento entre el gobierno y la oposición. Por tanto, no es un elemento suficiente para explicar la tendencia centrípeta del sistema, especialmente en lo que se refiere a la toma de posiciones acerca de los temas fundamentales del país. Esto quiere decir que es necesario buscar otras causas para explicar los consensos en torno a la democracia y a la economía de mercado que caracterizaron a la mayor parte del período, ya que es verdad que la forma de elección del presidente tuvo efectos moderadores (que se expresaron en la conformación de coaliciones), pero nada asegura que estos no hayan sido puramente instrumentales.

Entre esas causas adicionales se pueden identificar dos elementos adicionales del diseño institucional que han sido muy poco estudiadas por los académicos que se han ocupado de este caso. En primer lugar, considero que se debe dar mayor importancia al voto 
único presidencial-legislativo, que ha tenido varios efectos sobre el sistema de partidos, sobre las estrategias de los diversos actores políticos (partidos, movimientos y agrupaciones ciudadanas) y sobre las conductas de los electores. En términos generales, éste ha actuado como reductor del número de partidos y puede ser considerado como un factor tan importante como la modalidad de elección presidencial para impulsar la conformación de coaliciones. El hecho fundamental es que, dada la integración entre el voto presidencial y el legislativo, la posibilidad de obtener escaños legislativos se ha visto fuertemente limitada para los partidos que no presentan candidato presidencial, lo que puede inducir a escoger entre tres estrategias alternativas. Primera, la presentación de candidatos presidenciales propios para lograr un efecto de arrastre de las listas de senadores y diputados. Segunda, la participación en coaliciones electorales que aseguren un determinado número de escaños y algún grado de participación en el gobierno. Tercera, la presentación de candidatos únicamente para el congreso, dentro de un cálculo de costo-beneficio realizado a partir de la evaluación de su propia fuerza.

De acuerdo a las cifras electorales se puede sostener que predominó la primera opción, esto es, la participación de todos los partidos en las elecciones presidenciales, ya que siempre se presentó un alto número de candidatos (con una media de 12,3 para todo el período $)^{17}$. La estrategia que está detrás de esta alta participación electoral queda en evidencia cuando se observa que la distribución de la votación entre los candidatos tendió a concentrase en los partidos que ocuparon los tres primeros lugares, mientras los demás obtuvieron porcentajes significativamente bajos. Es decir, la mayor parte de los partidos habría visto a la elección presidencial como el mecanismo que les permitiría obtener los votos necesarios para contar con algunos escaños legislativos, lo que se posibilitaría por la utilización de una fórmula proporcional en la asignación de estos últimos. Así, con votaciones relativamente pequeñas podrían alcanzar una representación nada despreciable en el congreso, sin que interese en mayor medida el resultado de la elección presidencial. ${ }^{18}$. Esto hizo que la segunda estrategia, la formación de coaliciones para conformar las listas de diputados y senadores, fuera utilizada como un recurso

${ }^{17}$ El número de candidatos presidenciales fue de 13 en 1980, 17 en 1985, 9 en 1989, 14 en 1993, 10 en 1997 y 11 en 2002. Comparativamente, en Ecuador la media para el período 1979-2002 es de 9,1 y en Perú, para el período 1980-2000 es de 10,8.

${ }^{18}$ Esto se refleja en el numero efectivo de partidos en las elecciones presidenciales que, si bien alcanza una cifra relativamente alta (4,8 para el período completo), al compararla con la media del número absoluto de candidatos $(12,3)$ se demuestra que la mayor parte de los partidos no tuvieron significación en la elección presidencial y que acudieron a ella a pesar de sus propias limitaciones en ese campo. 
adicional y supeditado al anterior, mientras que la tercera -participación en elecciones legislativas sin candidato presidencial- apenas ocupó un lugar marginal. De esta manera el voto único ayudó a la conformación del sistema tripartito al que ha aludido constantemente la literatura académica (o bipartidista, en los términos que he señalado antes), una de cuyas características era ciertamente la cercanía entre sus integrantes. En estas condiciones, los tres partidos significativos (MNR, ADN y MIR) estaban prácticamente obligados a reducir las distancias entre ellos como una garantía de estabilidad del sistema que los favorecía, pero a la vez a integrar a las otras fuerzas que podrían poner en riesgo su predominio ${ }^{19}$.

En segundo lugar, sostengo que también es necesario prestar mayor atención a la existencia de la barrera de representación del 3\% para las elecciones de diputados en circunscripciones plurinominales (Mayorga, 2005: 3). En este aspecto también se debe atender al efecto sobre los cálculos estratégicos de los actores, ya que una disposición de esa naturaleza les obliga a desarrollar acciones orientadas a superar esa barrera. Inevitablemente, deben optar por conformar partidos de alcance nacional, lo que puede hacerse por medio de la constitución de un partido nuevo o, más bien, por la reagrupación de organizaciones pequeñas y dispersas o, finalmente, por la integración de las que recién nacían en otras ya existentes. Esta última es la que parece haber predominado a lo largo del período, hasta la elección del año $2002^{20}$. En ese año cambió radicalmente el panorama cuando surgió una cuarta fuerza (el MAS) y prácticamente desapareció uno de los tres partidos significativos (ADN) ${ }^{21}$. Mientras ello no sucedió, el sistema pudo funcionar sobre la base de los tres partidos y de las coaliciones que establecían entre ellos y con los otros partidos. Para ello fue decisiva la existencia de la barrera de representación, ya que actuaba como un mecanismo disuasivo para las nuevas organizaciones y por tanto de protección de quienes ya estaban dentro del sistema. Se conformó así un esquema que solamente podía ser desmontado por la presencia de un

${ }^{19}$ En gran medida, esto es lo que explica la doble característica de inclusión-exclusión del sistema, ya que por un lado aseguraba el predominio de aquellos partidos en el ámbito del ejecutivo, mientras por otro lado abría la participación de los demás en la arena legislativa y solamente como compañeros de segundo orden en el gobierno.

${ }^{20}$ Hay muchos ejemplos al respecto, pero quizás el más llamativo por la evolución posterior de los acontecimientos es el de la alianza de los campesinos productores de coca, encabezados por Evo Morales, con Izquierda Unida en las elecciones de 1989, que constituyó un acuerdo beneficioso para los dos integrantes (Tanaka, 2003: 96).

${ }^{21}$ Ciertamente, a lo largo del período hubo indicios de que el sistema asentado sobre el trípode partidos podría alterarse por la entrada de otras agrupaciones, especialmente cuando surgieron CONDEPA y UCS, pero como se ha visto estas agrupaciones fueron rápidamente integradas en las coaliciones y, además, nunca lograron rebasar su condición de organizaciones de base regional. 
nuevo partido que tuviera fuerza a nivel nacional, como en efecto ocurrió cuando surgió el MAS.

Lo dicho lleva a pensar que es probable que estos dos elementos del diseño institucional, junto a la modalidad de elección del presidente, hayan jugado un papel importancia para que se produzca el acercamiento entre los partidos. Sin embargo, aunque pueden dar pistas sobre el origen de la tendencia centrípeta, los tres factores institucionales no son suficientes para explicar en su totalidad los acuerdos alcanzados sobre los aspectos fundamentales. En otras palabras, es probable que sin ellos no se hubiera dibujado esa tendencia, pero a la vez es posible sustentar que esta no se debió solamente a ellos. La explicación puede ser mucho más compleja, pero dentro de ella con seguridad les cabe un lugar de primera importancia a estos elementos institucionales ${ }^{22}$.

El caso ecuatoriano es bastante diferente, ya que la mayor parte de componentes del diseño institucional actuaron como incentivos para el enfrentamiento entre el Ejecutivo y el Legislativo. La pugna de poderes estuvo presente a lo largo de veintiséis años desde el inicio del período democrático. Ninguno de los gobiernos constituidos entre 1979 y 2007 logró la mayoría en el Congreso, pero este hecho por sí mismo no explica el enfrentamiento permanente ya que podía haber sido superado mediante la conformación de alianzas de gobierno ${ }^{23}$. Así, la formación de gobiernos de minoría fue una constante y ha sido destacada como una de las características centrales del sistema político ecuatoriano (Conaghan, 1995; Barczak, 2001; Mejía, 2002; Pachano, 2006a; 2007). Desde 1979, cuando se inició el actual período constitucional, ningún partido ha obtenido la mayoría de los escaños en el congreso y solamente cuatro de los nueve presidentes que han surgido de elecciones han contado con la primera bancada legislativa. Además, la fragmentación de la representación legislativa ha sido una constante, como lo demuestra el alto número de listas que han obtenido escaños en cada una de las elecciones. Por la importancia que tiene para la conformación de coaliciones legislativas -tanto de apoyo al

\footnotetext{
22 Un acercamiento de ese tipo se encuentra, con diversos matices, en Tanaka (2003), Mayorga (2004, 2005), Conaghan (1996), Conaghan, Malloy y Abugatás (1990) y Ardaya y Verdesoto (1994), pero aún esta pendiente un análisis que se proponga como objetivo encontrar los elementos que expliquen la política de consensos.

${ }_{23}$ Pongo en 2007 la fecha final de este período debido a que en ese año el gobierno (presidido por Rafael Correa) rompió la lógica del enfrentamiento-negociación que se había impuesto como tendencia y prácticamente disolvió el Congreso. Para ello recurrió a acciones inconstitucionales, de manera que no se la puede considerar como una solución dentro de las que estaban disponibles en el marco del ordenamiento democrático (Pachano, 2009).
} 
gobierno como de oposición-, el análisis se ha concentrado en las elecciones de diputados y en la conformación del congreso, en tanto que han recibido menor atención los aspectos ligados a la elección presidencial y a la conformación del ejecutivo.

La conflictiva relación entre ambos poderes se hace evidente sobre todo en la dificultad para establecer acuerdos estables de largo o mediano alcance en torno a las políticas económicas y sociales ${ }^{24}$. A pesar de los reiterados intentos de sucesivos gobiernos por implantar un conjunto de reglas para la economía, no fue posible obtener los resultados esperados. La constante reiteración en los intentos por introducir esas políticas demuestra el carácter inacabado del proceso y sugiere centrar la atención en los factores que impidieron alcanzar los acuerdos ${ }^{25}$. Básicamente, en esta parte me interesa destacar algunos elementos que hacen referencia a la combinación entre el diseño institucional y las decisiones estratégicas de los actores, ya que de allí se pueden desprender explicaciones más consistentes que las que se obtienen desde otras perspectivas.

Todos los presidentes del período, independientemente de sus respectivas posiciones políticas, invariablemente adoptaron duras medidas al inicio de sus respectivos períodos pero siempre dieron marcha atrás hasta terminar, en la mayor parte de los casos, en formas de populismo económico (Conaghan, Malloy y Abugatás, 1990, Thoumi y Grindle, 1992). Como he señalado antes, todos los intentos de aplicación de políticas económicas tuvieron similar orientación pero se encontraron con la oposición generalizada, entre ellos la de quienes a su vez trataron de impulsar medidas de esa naturaleza cuando les correspondió la conducción gubernamental. Así, el primer gobierno de esta etapa (1979-1984) se encontró con la oposición de todas las fuerzas políticas representadas en el Congreso cuando intentó impulsar un plan de reformas. La aplicación de políticas de ajuste y austeridad, entendidas por el gobierno como las medidas adecuadas para enfrentar la crisis de inicios de la década de 1980, fue resistida

\footnotetext{
${ }^{24}$ El tratamiento del caso ecuatoriano en este aspecto está basado en Pachano (2007)

25 Cabe destacar el carácter secundario que tiene para este análisis el contenido o la orientación de las políticas, ya que lo que importa realmente es la ausencia de consensos en torno a ellas. Generalmente se ha visto el problema únicamente como rechazo a la receta neoliberal del Consenso de Washington, pero lo mismo puede decirse de la ausencia de acuerdos en torno a las políticas de otro signo. Por consiguiente, más que un enfrentamiento de dos concepciones claramente definidas, a lo largo del período se observó un constante bloqueo incluso por parte de quienes apoyaban el tipo de política que intentaba impulsar el gobierno del momento. Los diversos actores sociales y políticos cambiaban repetidamente de posición, de modo que no se puede asegurar, como lo han hecho algunos autores (Acosta, 2000; Schuldt, 1994; Salgado, 2001), que los problemas fueron la expresión de la oposición a las políticas de corte neoliberal que intentaron aplicar algunos de los gobiernos.
} 
por todos los actores políticos y sociales. Desde ahí en adelante se hizo evidente la baja disposición de esos actores para cambiar las condiciones vigentes -el statu quo- ya que eso introducía elementos de incertidumbre en tanto podía verse afectada su posición en la asignación de recursos. La vigencia de un modelo rentista, instaurado desde el auge petrolero de la década de 1970, y el diseño institucional que alimentaba la pugna entre los poderes, pueden identificarse como los elementos que tuvieron un peso decisivo en esas conductas.

Por ello, los gobiernos que se sucedieron posteriormente vieron repetirse, con sus respectivas particularidades, esa situación. Febres Cordero (1984-1988), que se había opuesto al programa de ajuste de su antecesor, impulsó medidas similares durante los dos primeros años de su gestión, pero debió dar marcha atrás en los dos últimos hasta terminar con los peores indicadores económicos de todo el período (Pachano, 2007: 2022). Sus intentos iniciales estuvieron basados en buena medida en la utilización de la facultad constitucional del presidente para enviar proyectos de urgencia económica que deben ser tratados por el Congreso en un plazo perentorio, esto es, acudió al poder de veto, una atribución presente en varios regímenes presidenciales (Shugart y Carey, 1992: 140-142). La utilización de este recurso -especialmente en la forma arbitraria que lo hizo cuando envió simultáneamente varios decretos con el fin de que el congreso no dispusiera del tiempo suficiente para tratarlos- era un indicador de la propia debilidad del gobierno y de las dificultades para llegar a acuerdos ${ }^{26}$.

Pero, incluso un gobierno que contó inicialmente con una mayoría favorable en el congreso -gracias a la formación de una coalición con otro partido-, como fue el de Rodrigo Borja (1988-1992), no pudo aplicar un programa que fuera más allá de las medidas de carácter coyuntural. El abandono de sus propuestas de campaña, que provocó el alejamiento de sus propios partidarios, y los cálculos estratégicos para las elecciones de medio período llevaron a la ruptura de la alianza con el consecuente debilitamiento del gobierno ${ }^{27}$. Posiblemente, el factor de mayor importancia para la determinación del rumbo que finalmente tomó la conducción económica fue la tortuosa

${ }^{26}$ Aunque los partidos que confluían en algunas votaciones en el apoyo al gobierno representaban el $42.2 \%$ del total de diputados, nunca llegaron a constituir una coalición estable. Los partidos claramente gubernamentales (PSC y PL) significaban menos de la quinta parte del total del congreso.

${ }^{27} \mathrm{La}$ elección de medio período, en que se renovaba aproximadamente el 85\% de los integrantes del congreso, fue introducida en las reformas constitucionales realizadas en 1983 y se constituyó en un elemento de incertidumbre e inestabilidad a lo largo del período, más aún cuando estaba vigente la prohibición de reelección inmediata de los diputados. Esta elección intermedia fue abolida en 1998. 
relación entre el gobierno y su partido. El divorcio entre las propuestas de campaña y las acciones del gobierno establecieron una gran distancia con el partido que esperaba otra orientación en el manejo de la economía y de las políticas sociales ${ }^{28}$. En esas condiciones era muy estrecho el margen que tenía el gobierno para enfrentar los vetos y los bloqueos de los diversos actores sociales y políticos.

La situación se agravó para los siguientes gobiernos, que no contaron con mayorías en el congreso y que tuvieron serias dificultades para constituir coaliciones. Así, el gobierno de Durán Ballén (1992-1996) acudió a la entrega de cargos en el sector público (patronage) y de recursos para obras o para fines personales (pork) como procedimientos básicos para sostener su política económica (Mejía, 2002). Esto indujo a la desafiliación de diputados de diversos partidos, que pasaron a conformar un bloque de independientes, con los que el gobierno pudo aprobar algunas reformas y leyes durante los dos primeros años de su gestión. Sin embargo, las elecciones medio período significaron también en esta ocasión un revés para el gobierno que terminó absolutamente debilitado ${ }^{29}$.

El nivel que alcanzaron los bloqueos en el gobierno de Durán Ballén marcó el inicio de un período de inestabilidad política que se alargó por lo menos hasta el año 2008. La renuncia forzada de su vicepresidente -quien en la práctica ejercía el mando del gobierno- fue el precedente para la defenestración de los tres presidentes que fueron elegidos posteriormente. Marcó también el inicio de la aplicación de la sucesión

\footnotetext{
${ }^{28}$ Stokes (2001: 112), que aborda brevemente el caso ecuatoriano sostiene que la debilidad de los partidos explica el cambio de política de los gobiernos con respecto a las ofertas de campaña. Sin embargo, la explicación no parece adecuada para el gobierno de Rodrigo Borja, ya que su partido, Izquierda Democrática, en ese momento contaba con mejor organización, mayor número de afiliados y la primera preferencia electoral a nivel nacional. Quizás la referencia habría que hacerla a la debilidad del sistema de partidos como un todo, lo que probablemente reduciría los efectos positivos de la fortaleza de un solo partido. Otro tipo de explicación, seguramente más persuasiva, pondría énfasis en la ausencia de interés del presidente y de los miembros de su gabinete por cambiar la orientación del propio partido. Un ejemplo caso muy claro en sentido contrario (esto es, de impulsar el cambio de orientación del partido desde la gestión del gobierno) se encuentra en el primer gobierno de Felipe González, en España, en que el propio presidente del gobierno asumió la tarea de demostrar al partido la necesidad y la validez de posiciones económicas y políticas distintas a las que había mantenido hasta entonces (Maravall, 2003: 13-70). Por el contrario, el discurso del presidente ecuatoriano se mantenía en sus posiciones opuestas a las reformas que aplicaba su propio equipo de gobierno.

${ }^{29}$ El gobierno intentó una salida a esta situación por medio de una reforma política, para la cual convocó a dos plebiscitos (en 1994 y 1995). A pesar de que seis de sus siete propuestas fueron aprobadas en el primero (y negadas las 11 del segundo), no pudo romper el bloqueo establecido por el conjunto de actores. Su debilidad alcanzó el punto más alto cuando el vicepresidente debió renunciar a causa de denuncias de corrupción que no fueron procesadas dentro de lo establecido por la constitución.
} 
constitucional como solución a los golpes de Estado, en un ejercicio de estiramiento institucional que mantuvo el orden jurídico más como una ficción que como una realidad.

Así, el siguiente mandatario elegido para el período 1996-2000, Abdalá Bucaram, apenas pudo permanecer ciento veinte días en el cargo, a pesar de los esfuerzos que hizo -por medio de las ya habituales prácticas de pork y patronage- para darle bases políticas a su gobierno. Así mismo, el siguiente gobernante, Jamil Mahuad, que debía ejercer el cargo entre 1998 y 2002, fue derrocado por un golpe militar -apoyado por el movimiento indígena- en enero de 2000. Aunque inicialmente se asentó sobre una poderosa coalición (conformada por su partido, Democracia Popular, y por el Partido Social Cristiano, que sumaban el 51,3\% de los escaños), nunca contó con las condiciones adecuadas para llevar adelante una política de largo plazo. Además, la manera en que encaró la crisis financiera del año 1999, sin duda la mayor de la historia ecuatoriana, alejó a sus aliados que veían el peligro de un desgaste con miras a las próximas elecciones ${ }^{30}$. Finalmente, el gobierno elegido en 2002, que debía ejercer hasta 2006, fue derrocado en el año 2005 después de que se alejara de los sectores que posibilitaron su triunfo y aplicara un programa económico de corte neoliberal. El apoyo de sectores empresariales no fue suficiente para llenar el vacío político que se hizo evidente a lo largo del período de gobierno en las cambiantes alianzas que conformó. Las mayorías móviles, como pasaron a llamarse (Gerlach, 2003: 127), aportaban apenas el apoyo necesario para aprobar una ley o una reforma determinada, siempre sobre la base de negociaciones específicas que distaban mucho de constituir una base estable ${ }^{31}$.

\footnotetext{
${ }^{30}$ Las medidas más controvertidas del gobierno fueron la declaración de un feriado bancario de una semana, la congelación de los depósitos bancarios (el corralito, como se lo llamó en Argentina) y la entrega de recursos a varios bancos que se encontraban al borde la quiebra, la mayor parte de ellos por manejos fraudulentos de sus propietarios o directivos protegidos por la permisiva Ley de Instituciones Financieras que había sido aprobada en 1994 durante el gobierno de Sixto Durán (Jácome, 2003: 4; Gerlach, 2003: 129). Lo sorprendente es que sus propios aliados empujaron la adopción de esas medidas (y de otras, como la sustitución del impuesto a la renta por un gravamen a las transacciones bancarias que tuvo efectos nefastos para la economía), pero jamás estuvieron dispuestos a hacerse cargo de las consecuencias que inevitablemente tendrían.

${ }^{31}$ En diciembre de 2004, el gobierno acudió a una maniobra desesperada cuando, por medio de una alianza heterogénea que logró conformar en el Congreso, destituyó inconstitucionalmente a los miembros de la Corte Suprema de Justicia, a los integrantes del Tribunal Constitucional y a los del Tribunal Supremo Electoral. Se trataba claramente de un golpe de Estado que, al ser resistido fundamentalmente por la población en las calles (pero también por la oposición política y por los medios de comunicación), abrió las puertas a la caída del gobierno. Esta se produjo cuatro meses más tarde.
} 
En términos generales, la experiencia ecuatoriana es la muestra de un sistema político asentado en un diseño institucional que alienta la fragmentación y que no ofrece alicientes para la cooperación. Adicionalmente, esas condiciones institucionales promueven el juego político de corto plazo que gira en torno a la obtención de resultados inmediatos y estrictamente delimitados para cada grupo social. De allí se desprenden las prácticas particularistas, como el clientelismo y el corporativismo (bajo diversas formas de representación directa de intereses particulares), que caracterizan a la política ecuatoriana. Además, es un sistema político con bajísima capacidad de agregar intereses, en el que interviene un alto número de veto players y que debe satisfacer cada una de las múltiples demandas sin posibilidad de englobarlas dentro de políticas de alcance general $^{32}$. El cambio - parcial, por cierto, ya que está asentado en las mismas prácticas clientelares y particularistas- solamente ha comenzado a hacerse evidente desde la instauración de un gobierno dispuesto a imponer su voluntad (en una modalidad de decisionismo schmidtiano) y por tanto a romper la lógica de la negociación con el resto de fuerzas políticas y sociales ${ }^{33}$.

El caso de Perú guarda ciertas similitudes con el de Ecuador, ya que el diseño institucional amparaba una relación conflictiva entre los dos poderes, pero se diferenció claramente de éste cuando se acudió a la ruptura constitucional como solución al problema (en lugar del estiramiento institucional que caracterizó a la política ecuatoriana). En efecto, sin desconocer el resto de factores que pueden explicar el autogolpe de Alberto Fujimori en abril de 1992, puede tomarse como un resultado del tipo de relación que se había establecido, desde 1980, entre el Ejecutivo y el Legislativo ${ }^{34}$. En este sentido, el golpe marcó no solamente un punto de ruptura de los acuerdos de la transición, sino que

\footnotetext{
32 Un acercamiento válido para el caso ecuatoriano es el que centra la atención en los jugadores con poder de veto (veto players), tanto institucionales como no institucionales (Tsbellis, 2000; 2002; Andrews y Montinola, 2004). Este ha sido explorado por Mejía et al (2004) y por Pachano (2007).

${ }^{33} \mathrm{El}$ agotamiento del modelo previamente vigente, en términos de haber alcanzado sus límites y también de erosión de los partidos políticos como sus actores centrales, fue también un factor fundamental para el triunfo de la opción política liderada por Rafael Correa. Los altos niveles de apoyo que ha mantenido a lo largo de su gestión y que se han expresado en sucesivas contiendas electorales, se iniciaron cuando el Presidente demostró su voluntad de enfrentarse directamente a los partidos y en general a los actores con poder de veto, incluidos quienes fueron sus aliados en la elección que le llevó a la presidencia (Pachano, 2009).

34 Las explicaciones del golpe aluden fundamentalmente a los problemas de gobernabilidad producidos por la pérdida de control de la economía (Cotler, 2000: 28), la amenaza de la insurrección de Sendero Luminoso (Bowen, 2000: 79-102), el colapso de los partidos (Degregori, 2000: 34), la debilidad del aparato estatal (Grompone, 2000: 80) y la deslegitimación de la democracia que llegó hasta la percepción de su fracaso (McClintock, 1997: 56). La incidencia de los factores institucionales ha sido destacada por Kenney (1997)
} 
instauró una nueva relación (de desequilibrio) entre los dos poderes. Se trataba, por cierto de unos acuerdos implícitos que siempre llevaron la situación hasta sus límites extremos, dentro de una práctica de bloqueos bastante similar a la que se observó en Ecuador.

En efecto, ninguno de los tres primeros gobiernos del período pudo obtener la mayoría en el Congreso y a la vez éste se caracterizó por la fragmentación (con una media de 14,5 partidos con representación y de 4,4 en términos de número efectivo). Por consiguiente, los gobiernos estuvieron obligados a fatigosas negociaciones para estructurar las mayorías que les permitirían aprobar leyes y llevar adelante sus programas de gobierno (Planas, 2000: 97; Crabtree, 2005: 232-278). Fueron gobiernos bastante débiles en lo político, a pesar de que el diseño constitucional instaurado desde 1980 llevaba a la conformación de un Ejecutivo que podía ser calificado como medianamente fuerte ${ }^{35}$. Por consiguiente, se abría una brecha entre la debilidad política del presidente (originada en la fragmentación del sistema de partidos) y la relativa fortaleza que le ofrecía el diseño constitucional.

Esta situación obligó a los presidentes, en cuanto pudieran hacerlo, a acudir a las facultades constitucionales que los colocaban en posición de ventaja con respecto al Congreso. Era una manera de no hipotecar sus políticas a unas alianzas que no controlaban y que, dado el número de sus componentes así como la diversidad de intereses que agrupaban, solamente podían ofrecer incertidumbre. Por ello, las dos vías de expedición de decretos fueron ampliamente utilizadas por los gobiernos de Belaunde (1980-1985), que la utilizó en 667 ocasiones y de García (1985-1990), que elevó el número hasta 1033 (Kenney, 1997: 79). De esa manera podían gobernar al margen del

\footnotetext{
${ }^{35}$ La calificación como medianamente fuerte está basada en la clasificación de Shugart y Carey (1997: 155), en torno a los poderes legislativos y no legislativos del Presidente. Los primeros incluyen las facultades de veto total, veto parcial, decreto, exclusividad en la iniciativa legislativa y en la propuesta de referéndum (Shugart y Carey, 1997: 149-152). Los no legislativos consisten en las atribuciones para formar gabinete, para destituir a sus integrantes y para disolver al Legislativo, así como (en términos negativos para el Ejecutivo) el grado en que la asamblea puede censurar al Presidente y a los ministros del gabinete (Shugart y Carey, 1997: 152-154). En el caso peruano, esas facultades se manifestaban de manera especial en el numeral 20 del artículo 211 de la Constitución, que le permitía al presidente "dictar medidas extraordinarias en materia económica y financiera, cuando así lo requiere el interés nacional y con cargo a dar cuenta al Congreso". También en el numeral 10 del mismo artículo, que contribuía a reforzar esas facultades cuando establecía que podrá "dictar decretos legislativos con fuerza de ley, previa delegación de facultades del Congreso y con cargo a dar cuenta a éste". Así mismo, de acuerdo al artículo 231 podía decretar el estado de emergencia sin consultar al congreso. Adicionalmente, de acuerdo al artículo 227 el presidente tenía la capacidad de disolver la Cámara de Diputados cuando "ésta ha censurado o negado la confianza a tres Consejos de Ministros".
} 
Congreso, sin que ello signifique que se hubiera eliminado el riesgo de conformación de una mayoría opositora que habría hecho fracasar incluso esos procedimientos.

Por otra parte, los presidentes peruanos nunca pudieron utilizar la facultad constitucional que les permitía disolver la Cámara de Diputados. Dos factores impidieron la aplicación de ese procedimiento. En primer lugar, era muy poco probable que la Cámara censurara o vetara por tres ocasiones seguidas al Consejo de Ministros -aunque un presidente la buscara intencionalmente-, ya que con ello provocaría su disolución. En segundo lugar, en un marco de volatilidad y de fragmentación bastante altas, los presidentes, incluyendo a Fujimori (incluso, él más que cualquiera de los otros), no podían tener la certeza de conseguir como resultado mejores condiciones que las vigentes, esto es, una mayoría en la elección que se desprendería de aquel acto.

El descontrol de la economía, evidente desde la segunda mitad del gobierno de Alan García y el asedio de Sendero Luminoso y el MRTA, configuraron una situación tremendamente grave. La inflación llegó a 2.775\% y 7.650\% en 1989 y 1990, respectivamente, mientras el PIB cayó en -8,4, -11,6 y -5,4 en 1988, 1889 y 1990, respectivamente (González de Olarte, 1998: 14). Alrededor del 45\% del territorio había sido declarado en emergencia por la subversión y el número de atentados llegó a 11.937 en el período de gobierno de Alan García, con 1.228 desaparecidos durante el período de Fernando Belaunde, 1.628 en el de García y 1.023 en el de Fujimori (Tamayo, 2003: 97). Por consiguiente, era un escenario que exigía soluciones inmediatas, y que constituyó la justificación esgrimida por Fujimori para su autogolpe de abril de 1992.

A diferencia de Ecuador, que mantuvo el enfrentamiento entre el Ejecutivo y el Legislativo hasta mediados de la primera década del siglo XXI, en Perú se rompió el diseño establecido en la transición y se dio paso a un gobierno autoritario que concentró todos los poderes (Stokes, 2002; Murakami, 2007; Conhaghan, 2005). En consecuencia, no se acudió a una solución dentro del ordenamiento democrático, aunque se buscará su legitimación por medio de la instalación de un Congreso Constituyente y la expedición de una nueva Constitución. En ese sentido, Perú constituye la expresión más aguda del 
enfrentamiento entre los dos poderes y de la contradicción entre las facultades constitucionales y la debilidad política de los presidentes ${ }^{36}$.

En un balance general se puede sostener que, a pesar de las diferencias en los arreglos institucionales, en los tres países se han manifestado con mucha fuerza los conflictos entre los poderes que son característicos del presidencialismo. Como se ha sostenido reiteradamente este tipo de régimen genera por lo menos cuatro problemas que son de difícil solución ${ }^{37}$. En primer lugar, se produce una legitimidad dual ya que tanto el presidente como los integrantes del órgano legislativo pueden apelar a su carácter de representantes de la voluntad popular. En segundo lugar, presenta una rigidez, derivada de la vigencia de períodos fijos para el mandato presidencial y legislativo, que dificulta significativamente el procesamiento de las crisis políticas (que generalmente terminan por convertirse en crisis del régimen, como lo ilustran los sucesivos episodios acaecidos en los tres países). En tercer lugar, establece una separación tan profunda entre los poderes que hace muy difícil la cooperación entre ellos. Finalmente, instaura una lógica de sumacero o de ganador absoluto, especialmente en la elección del presidente de la República, que tiende a obstaculizar las alianzas de gobierno y genera problemas de gobernabilidad.

El diseño institucional boliviano fue el más adecuado de los tres países para superar en buena medida algunos de estos problemas, sobre todo por sus incentivos a la formación de coaliciones de gobierno, a la reducción de las distancias políticas y a la orientación centrípeta de la política. Sin embargo, todo ello descansaba solamente en los elementos institucionales señalados antes (la elección del presidente en el congreso, el umbral de representación y el voto único por presidente y congreso), sin que el resto de componentes del sistema político mantuvieran coherencia con ellos, de manera que padecía de debilidad congénita. Por su parte, los otros dos países contenían muchos elementos que tendían a profundizar los problemas del presidencialismo sin ninguno que tendiera a atenuarlos. En consecuencia, en Bolivia y sobre todo en Ecuador y Perú, las relaciones entre los poderes del Estado fueron siempre conflictivas, produjeron múltiples problemas de gobernabilidad e impidieron contar con democracias que tuvieran

\footnotetext{
${ }^{36}$ Ecuador siguió un camino relativamente similar - en tanto se acudió a la fuerza- cuando el Congreso fue prácticamente cerrado por el presidente Correa con el apoyo del Tribunal Supremo Electoral, en 2007, pero no tomó la forma de golpe de estado abierto (operó el mencionado estiramiento institucional)

${ }^{37}$ Los problemas del presidencialismo -o sus peligros- han sido destacados por Linz (1993; 1996), Linz y Valenzuela (1994), Pérez Liñán (2003; 2005) y Sartori (1996). Visiones críticas se encuentran en Mainwaring y Shugart (1994; 2002), Nohlen, (1993).
} 
capacidad para procesar las demandas sociales y para canalizar el conflicto político. La solución, en los tres países -aunque bajo diversas formas en cada uno de ellos-, fue algún tipo de ruptura del régimen, que sin embargo no llevó a la superación del presidencialismo sino más bien a su profundización.

Perú acudió al golpe de Estado, que en sí mismo significó la eliminación de uno de los dos poderes y el predominio absoluto del otro, pero que además en el largo plazo -por medio de la nueva Constitución- consagró el desequilibrio entre ellos cuando fortaleció al Ejecutivo. En Bolivia y Ecuador se llegó a una situación relativamente similar pero por medio de la acción de gobiernos caudillistas que, asentados en un gran apoyo electoral, impulsaron procesos de transformación constitucional dirigidos a fortalecer el poder presidencial. En ninguno de los tres casos se buscó superar los problemas de fondo propios del régimen presidencial. Por el contrario, a estos se los enfrentó con la profundización de ese carácter, lo que puede traer consecuencias en el medio y en el largo plazos, sobre todo cuando se dibuje nuevamente la situación de fragmentación y de atomización que fue la constante a lo largo del período ${ }^{38}$. En síntesis, el balance en términos de la relación entre los poderes no es positivo en los tres países y tampoco muestra indicios de cambios que permitan superar esa condición. Es un factor que ha afectado -y que afectará, por cierto- a la democracia y su desempeño.

\section{Sistemas electorales y sistemas de partidos}

El segundo componente institucional de importancia para la calidad de la democracia de cada uno de los países es el que está conformado por los sistemas electorales y los sistemas de partidos. Como se verá a lo largo de esta sección, hay varias razones de peso para tratarlos en conjunto, lo que no equivale a desconocer las particularidades de cada uno. El énfasis, sin embargo, está puesto en los sistemas de partidos, ya que considero que en ellos se encuentran muchas de las claves para comprender el juego político

\footnotetext{
${ }^{38}$ Los procesos políticos que viven tanto Bolivia como Ecuador dependen casi en su totalidad de la presencia del fuerte liderazgo presidencial de Evo Morales y Rafael Correa, respectivamente. La ausencia de un partido político que pueda dar continuidad a su gestión, la inexistencia de otros liderazgos de su misma tendencia que puedan tomar la posta y el escaso o nulo interés puesto en la institucionalización (a pesar de la expedición de nuevas constituciones), llevan a sugerir esa dependencia del proceso con respecto al caudillo. Son formas de bonapartismo que en gran medida reproducen situaciones vividas en esos mismos países y en gran parte de América Latina (Ibarra, 2008; Pachano, 2009). Perú tiene serías posibilidades de formar parte de esta corriente, como quedó claro en las últimas elecciones presidenciales (Vergara, 2007).
} 
desarrollado en los tres países y sobre todo para entender las características de sus ordenamientos políticos. De manera especial, la reflexión desarrollada en esta sección se guía por la búsqueda de respuestas acerca de la capacidad que tuvieron los partidos políticos de los tres países para cumplir con sus funciones básicas, especialmente para conducir los procesos políticos de las respectivas sociedades. Sostengo que el análisis del sistema de partidos ofrece la perspectiva adecuada para comprender los problemas de representación casi con independencia de las características internas de cada uno de sus integrantes.

Tanto la evolución reciente de los sistemas de partidos, así como el resultado final (entendido por éste a la situación actual) pueden llevar a asegurar que en cada uno de los tres se conformó una situación particular. En efecto, mientras en Bolivia se conformaba un sistema de partidos de "pluralismo moderado" (Mayorga, 2005: 3) o de "multipartidismo limitado" (Ardaya, 2003: 11) y en Ecuador era posible identificar uno de pluralismo polarizado (Freidenberg, 2000a; Mejía, 2002), en Perú en cambio fue prácticamente imposible que el sistema de partidos constituido en la transición contara con una mínima estabilidad, lo que llevó tempranamente a su desaparición (Tanaka, 2005; Tuesta, 1995b; Grompone, 1995). Así mismo, y como consecuencia de esas condiciones, en Bolivia y Ecuador se materializaron condiciones más adecuadas para la inclusión institucional de los sectores tradicionalmente excluidos, mientras que en Perú se impuso una relación clientelar directa -ajena a cualquier forma de institucionalizaciónentre las instancias de poder y aquellos sectores ${ }^{39}$.

Es inevitable, por consiguiente, preguntarse por los factores que llevaron a esas configuraciones de los sistemas de partidos y a esos resultados totalmente diferentes, sobre todo si se considera que los tres países presentan algunas similitudes en otros aspectos. En efecto, en términos generales se puede decir que en lo estructural no se encuentran diferencias significativas que permitan tomarlas como los elementos causales de las características específicas de los sistemas de partidos en cada caso. Incluso la heterogeneidad regional de cada país (que será tratada en la tercera sección del siguiente

${ }^{39}$ Esto no quiere decir que el clientelismo no tuviera fuerte presencia en los otros dos países, en especial en Ecuador, sino que en estos tuvo una dimensión institucional que no existió en Perú. Al respecto son muy ilustrativas las explicaciones del fujimorismo como fenómeno político de manipulación de los sectores populares por medio de una relación directa que no solamente prescindía sino que eliminaba cualquier intermediación partidista (Grompone, 1996; Degregori, 2000; Cotler, 2000). Por el contrario, el clientelismo ha tenido expresión partidista en Bolivia (CONDEPA y UCS) y en Ecuador (PRE, PRIAN y hasta cierto punto PSC). 
capítulo) aparece más como un elemento común que como una especificidad de alguno de ellos. Aún más, cuando se compara a estos tres países con los dos del norte andino -y sobre todo cuando se lo hace con otros de América Latina, como los del Cono Sur- es posible agruparlos en un bloque relativamente homogéneo. De manera que las explicaciones para las diferencias hay que buscarlas en otros niveles, para lo cual se hace necesario recapitular brevemente sobre lo ocurrido con los sistemas de partidos en cada uno de los países.

Cabe volver, entonces, a la caracterización que se ha hecho de ellos y que es generalmente aceptada dentro de la ciencia política. Por un lado se encuentra Bolivia, con un sistema de pluralismo moderado que logró funcionar establemente durante un período bastante largo ${ }^{40}$. Este sistema constituyó lo que se ha denominado como la "tercera generación de partidos" (Romero, 1998). Sin embargo, en las elecciones presidenciales y legislativas del año 2002 se observaron signos de cambio, cuando uno de los partidos tradicionales (ADN) prácticamente desapareció y los otros dos (MNR y MIR) debieron compartir el espacio con dos partidos surgidos muy poco tiempo antes (MAS y NFR) ${ }^{41}$. Finalmente, ese sistema dejó de existir en las elecciones del año 2005, cuando solamente uno de los tres partidos centrales (MNR) siguió presente pero reducido a una mínima expresión. Por otro lado, en Ecuador se conformó uno de pluralismo polarizado, caracterizado por el alto número de partidos que entran en la competencia y que pueden obtener puestos en los diversos niveles de elección

${ }^{40}$ Por casi dos décadas (desde 1985 hasta 2003) tuvo vigencia el sistema basado en tres partidos centrales (MNR, MIR y ADN). Este es un período muy largo para un país que anteriormente se había caracterizado por la alta inestabilidad de sus gobiernos y, en consecuencia, por las enormes dificultades para que los partidos se estabilizaran amparados en la competencia electoral. La presencia de nuevos partidos, especialmente de corte populista (CONDEPA y UCS), que pudo haber sido un elemento de desestabilización o de ruptura del sistema, no fue significativa y nunca constituyó una amenaza.

${ }^{41}$ En las presidenciales, el MNR obtuvo el $22,46 \%$ de los votos, seguido muy cerca por el MAS y por NFR que obtuvieron el 20,94\% y el 20,91\%, respectivamente. El MIR, otro de los puntales del sistema ocupó el cuarto lugar con el 16,77\%. ADN apenas llegó al 3,40\% (Payne et al, 2003). Con respecto a las elecciones anteriores, de 1997, entre los partidos tradicionales sólo el MNR incrementó su votación (de 18,20\%), mientras el MIR logró mantener la misma proporción que obtuvo cuatro años antes (de 16,77\%) y ADN vio reducirse la suya a menos de la séptima parte de la que le había permitido ganar las elecciones de aquel año $(22,26 \%)$. De los dos partidos populistas, CONDEPA prácticamente desapareció (en gran medida por la ruptura que dio origen a NFR) y apenas alcanzó el 0,37\%, lo que significó una pérdida de casi el $98 \%$ de los votos que había obtenido en la elección previa, y UCS redujo su votación a la tercera parte. Por consiguiente, se puede asegurar que la gran votación del MAS, que en las siguientes elecciones ganaría la presidencia, se explica originalmente por la transferencia desde los partidos populistas y seguramente en menor medida de ADN. Un análisis bastante detallado de los cambios ocurridos en la elección de 2002 se encuentra en Bohrt y Chávez, (2002). 
(especialmente en el Congreso Nacional), y por la amplia brecha ideológica que separa a sus componentes. Pero, a pesar de esas características que pueden considerarse poco favorables para la consolidación del sistema, cuatro partidos (PSC, ID, PRE y DP) lograron algún grado de estabilidad en términos de respaldo electoral. No obstante, este ordenamiento mostró signos de agotamiento desde las elecciones de 2002, entre los que se destaca la reducción de la proporción de votos que obtenían en conjunto y su reclusión a espacios regionales muy delimitados ${ }^{42}$. Por último, cuando parecía que en Perú se conformaría también un sistema de pluralismo polarizado, este entró tempranamente en crisis y desapareció ${ }^{43}$. A pesar de los esfuerzos que han realizado los partidos que han logrado sobrevivir, hasta el momento ha sido imposible reestructurar un sistema que ofrezca condiciones institucionales adecuadas para la representación y canalización de intereses. Por el contrario, el contexto político peruano está copado por figuras individuales y por organizaciones de vida efímera, que apenas pueden cumplir con la participación en una contienda electoral ${ }^{44}$.

Ninguna de estas características puede ser imputada a los factores de orden estructural que predominaron a lo largo del período. El telón de fondo en el que se desarrollaron las acciones fue bastante similar en todos los países y estuvo determinado por la crisis económica. Las diferencias se encuentran en la manera en que cada uno de ellos la enfrentó, esto es, en las decisiones políticas adoptadas, que a su vez estuvieron condicionadas por los márgenes de acción que establecían los respectivos diseños institucionales. Los desafíos eran muy similares para todos ellos y consistían básicamente en encontrar nuevos rumbos para la economía que, sobre todo en los casos de Bolivia y

\footnotetext{
${ }^{42}$ Entre 1978 y 2002, esos cuatro partidos obtuvieron el 65,6\% de los escaños legislativos. En 1998, en el punto más alto de su presencia, ellos llegaron a contar con el 84,6\% de los escaños, en tanto que en el año 2002 esa proporción se redujo al $62,0 \%$. Esa pérdida se produjo sobre todo por la caída de la DP, desde el 28,5\% al 5,0\% y del PRE, desde el 19,5\% hasta el 15,0\%. En las presidenciales del año 2002, los candidatos de las cuatro organizaciones apenas sumaron el 38,0\%, mientras en 1998 habían alcanzado el $77,8 \%$ y a lo largo del período habían mantenido un promedio de alrededor del $65 \%$. Sin embargo, ninguno de estos partidos ha logrado un segundo triunfo en las presidenciales, lo que configura una situación muy particular en tanto ninguno de los partidos más votados ha logrado captar más de una vez la presidencia de la República.

${ }^{43}$ En la elección de 1978, el 88,5\% de los votos fue captado por los partidos que aparecían como la base del sistema que comenzaba a conformarse (AP, PPC, APRA e IU). En las sucesivas elecciones, hasta 1990, superaron el 90\%. Como se ha hecho notar (Tanaka, 2001: 71 y ss) el colapso del sistema se hizo evidente con posterioridad al autogolpe de Fujimori de abril de 1992, sin que se pueda sostener que ocurrió la relación inversa, esto es, que el golpe se produjo por la debilidad de los partidos.

${ }^{44}$ No se han hecho evidentes los efectos de la Ley de Partidos Políticos, expedida en 2002, orientada a estructurar un sistema de partidos, tanto por medio de la renovación de los existentes como por la creación de otros.
} 
Perú, se hallaba al borde del colapso. A mediados de los ochenta ambos países vivieron procesos hiperinflacionarios que exigían medidas inmediatas. En Bolivia, en 1985, se llegó a un acuerdo político que abarcó tanto la definición del modelo económico como las características del sistema político (Romero, 1999; Lazarte, 1993; Laserna, 1992; Mayorga, 2003). A pesar de ser fuertemente cuestionados por la sociedad (Calderón, 1988: 195), los partidos políticos lograron ponerse a la cabeza del proceso de redefinición de la economía. En términos concretos esto se presentó como el control de la hiperinflación, lo que a la larga fue uno de los factores fundamentales para que los partidos recuperaran su legitimidad. En Perú, por el contrario, los partidos políticos no tuvieron ni la voluntad ni la capacidad para hacer frente a esas condiciones con medidas que podían ser impopulares. Debió ser un personaje ajeno a ellos, un outsider, el que se encargara de esa tarea, obviamente sin recurrir a los acuerdos y a los consensos que se observaron en Bolivia ${ }^{45}$. En Ecuador, por su parte, la crisis no se presentó de la misma manera que en los otros dos países, de manera que durante mucho tiempo los partidos que ejercieron el gobierno y que predominaron en el congreso pudieron eludir el tema mientras buscaban mantener los niveles de apoyo electoral por medio de prácticas clientelares (Mejía et al, 2004; Pachano, 2006a). Al desentenderse de la definición del modelo económico y al dejarlo más bien en manos de tecnócratas trataron de eludir los costos políticos, a pesar de que en largo plazo se verían perjudicados por el deterioro de las condiciones de vida de la población (Conaghan, Malloy y Abugatás, 1990; Schuldt, 1994).

Los resultados de la gestión del sistema político fueron, por tanto, radicalmente diferentes en cada uno de los países y desembocaron en resultados también diferentes en lo que hace relación al sistema de partidos y a su funcionamiento. En Bolivia se crearon las condiciones (en realidad, las crearon los mismos partidos) para diseñar un sistema político que pudiera hacerse cargo de las nuevas condiciones económicas que se habían establecido por medio de los acuerdos de 1985. Precisamente, la inclusión del tema político en esos acuerdos es la clave de la permanencia y la estabilidad del sistema de partidos que surgió a partir de ellos. En Perú, en cambio, con el autogolpe de Fujimori se

${ }^{45}$ Cabría hacer un símil entre el gobierno de la UDP, con Hernán Siles, en Bolivia, y el del APRA, con Alan García, en Perú. Ambos nacieron con gran apoyo popular y tuvieron orientaciones de política económica bastante similares. Así mismo, ninguno de ellos pudo cambiar el rumbo en el momento en que era necesario hacerlo. En Bolivia, sin embargo, los partidos políticos (incluido el MIR, uno de los que conformó la UDP y en consecuencia el gobierno de Hernán Siles) pudieron establecer el acuerdo político mencionado, que permitió superar la situación sin llegar al suicidio de los partidos, en tanto que en Perú ocurrió esta última situación. 
instauró un régimen de autoritarismo competitivo, en los términos de Levitsky y Way (2002: 52), que buscó -y obtuvo- una legitimidad de resultados en sustitución de la legitimidad de origen que le era ajena. Adicionalmente, la oportunidad que se presentó con la instauración de una asamblea (denominada Congreso Constituyente Democrático) para elaborar una nueva constitución, no fue aprovechada por los partidos de oposición, que prefirieron abstenerse y dejaron así el campo libre para la instauración del nuevo régimen (Tanaka, 2001: 82). En Ecuador, al adoptar la lógica clientelar los partidos se insertaron en un juego de corto plazo que requería de resultados inmediatos, tangibles y claramente dirigidos a sectores específicos de la población. Por esa vía se llegó a la corporativización de la política, a la representación directa de intereses específicos y a la reducción de los partidos a espacios regionales muy acotados.

Además de los desafíos económicos, durante todo ese período estuvo presente en los tres países la demanda de mayor inclusión en el sistema político institucional. De manera especial, ésta fue planteada por los pueblos indígenas, por organizaciones sociales urbanas de diverso tipo y por las agrupaciones de mujeres, lo que corrió también por un camino diferente en cada caso ${ }^{46}$. El mayor cuestionamiento a las condiciones de inclusión que ofrecía el sistema político se originó en los movimientos de carácter étnico-cultural. En Ecuador encontró tempranamente su materialización institucional, cuando a mediados de la década de los noventa se conformó un partido de esta orientación (MUPP-NP). Así mismo, en Bolivia, que contaba con algunos antecedentes de organización política indígena por medio de los movimientos kataristas, se constituyó a finales de esa década un partido de esa naturaleza (MIP) y, más adelante, otro que a pesar de haberse originado más bien como la expresión de sectores campesinos que no tenían un discurso étnico, fue adoptando estas posiciones (MAS). Por el contrario, en Perú no se ha producido un hecho similar y más bien el tema étnico ha estado casi ausente de la escena política (Van Cott, 2000b) ${ }^{47}$. En los dos primeros países, los movimientos de origen étnico se integraron rápida y eficientemente en el sistema político, lo que se

\footnotetext{
46 Únicamente en el caso de las mujeres se encuentra una misma medida básica -el establecimiento de cuotas de representación- que sin embargo ha arrojado resultados diferentes en cada uno de ellos a causa de la incidencia de factores propios del sistema electoral, como el tipo de representación y el tamaño de las circunscripciones (Sample, 2005; 125). Sin embargo, en los tres países se ha producido el incremento de la proporción de mujeres en las instancias de representación, en especial en los órganos legislativos.

${ }^{47}$ Este tema se manifestó tardía y parcialmente en la campaña electoral del año 2006, pero no como expresión de un movimiento social que hubiera acumulado fuerzas, como en los otros dos países, sino como la propuesta mesiánica y fundamentalista de Ollanta Humala, un candidato de orientación ultranacionalista de derecha (Vergara, 2007).
} 
expresó en una importante presencia en las instancias de representación y, en ambos casos, por el triunfo en las elecciones presidenciales (en el año 2002 en Ecuador y 2005 en Bolivia, en ambos casos dentro de alianzas más amplias, que incluyeron a otros sectores $)^{48}$.

Finalmente, por consideraciones de diversa naturaleza, en los tres países se produjo la apertura de los sistemas políticos. Esta se expresó en las reformas legales y constitucionales que tendieron a flexibilizar las condiciones establecidas para la participación electoral, que he mencionado en la sección anterior. Dentro de éstas, en Bolivia se estableció la figura de los diputados uninominales, que buscaba una mayor cercanía e identificación entre el representante y el elector (Mayorga, 1999: 11; Bohrt y Chávez, 2002: 87; Ardaya, 2003; Zegada, 1998: 45; Tuesta, 2005). Más adelante se abrió la posibilidad de que las organizaciones sociales de cualquier tipo pudieran participar en las mismas condiciones que los partidos políticos en los procesos electorales. En Ecuador se instauró -al parecer, accidentalmente- un sistema de votación personalizada en listas abiertas (panachage), que alteró las condiciones de la representación y que sobre todo exigió nuevas estrategias por parte de los partidos ${ }^{49}$. Previamente se había abierto la posibilidad de participación de organizaciones no partidistas en condiciones más favorables que las que se reconocen para los partidos. En Perú se produjo una primera flexibilización bajo el gobierno de Fujimori, que buscaba claramente debilitar a los partidos políticos por medio de la apertura a las organizaciones de diversa naturaleza, lo que llevó a que asociaciones de vecinos e incluso organizaciones fantasmas pudieran obtener escaños legislativos. Más adelante, se ha buscado establecer algunas normas que tiendan a regularizar esta situación, especialmente por medio de la ya mencionada Ley de Partidos Políticos.

Las consecuencias de estos cambios se ven claramente en la desaparición de los sistemas de partidos de Bolivia, Ecuador y Perú. El sistema peruano colapsó después del autogolpe de Fujimori, el de Bolivia fue extinguiéndose desde las elecciones del año 2002

\footnotetext{
${ }^{48}$ La presencia de estos partidos en las instancias de representación debería ser confrontada a la proporción de población indígena en cada uno de los países. Por el momento es imposible establecer esa relación, ya que no se cuenta con información confiable al respecto. La única excepción es Ecuador, donde el censo del año 2001 la estableció en el 6,8\% de la población nacional, pero que ha sido sometida a múltiples cuestionamientos por parte de las organizaciones indígenas.

$49 \mathrm{Al}$ parecer, la intención de la reforma, sometida a referéndum en el año 1997, fue la instauración de un sistema de voto preferencial, pero por la forma en que estuvo hecha la pregunta derivó en el sistema mencionado. Se trataría, por tanto, de un efecto no buscado o accidental (Pachano, 1998).
} 
y el de Ecuador, después de una lenta y larga agonía, siguió un camino similar especialmente desde las elecciones del año 2006. Frente a esto es necesario, por consiguiente, plantearse nuevamente la pregunta acerca de los factores que llevaron a que se materializaran situaciones tan diferentes dentro de contextos que, como he señalado antes, muestran más semejanzas que diferencias. Mi propuesta al respecto, como ya la he anticipado, es que las explicaciones se encuentran en los propios elementos del diseño institucional, que se mostraron inadecuados para enfrentar los problemas de representación y de gobernabilidad.

Para comprender las características de los procesos que llevaron a ese desenlace en los tres países, es útil mirarlos a través del prisma que ofrece el concepto de institucionalización del sistema de partidos (Mainwaring y Scully, 1995: 4 y ss.). Este hace posible evaluar algunos de los componentes básicos de cada sistema y destacar sus especificidades y permite comprender algunos de los elementos fundamentales de los procesos vividos en cada caso, esto es, las causas que los llevaron por caminos tan diferentes. Para ello cabe señalar que la noción de sistema de partidos institucionalizado toma como punto de partida el concepto más general de institucionalización, que "se refiere a un proceso por el cual una práctica o una organización llega a establecerse y a ser ampliamente conocida, si no universalmente aceptada. Los actores desarrollan sus expectativas, sus orientaciones y su comportamiento basados en la premisa de que esta práctica u organización prevalecerá en el futuro" (Mainwaring y Scully, 1995: 4). La estabilidad y la legitimidad pasan a ser, entonces, los elementos centrales de esta definición.

Desde esta perspectiva, un sistema de partidos institucionalizado debe cumplir con cuatro condiciones básicas. En primer lugar, es necesario que exista estabilidad en las reglas del juego y en la naturaleza de la competencia interpartidista. En segundo lugar, los principales partidos deben tener raíces fuertes en la sociedad, expresadas en el respaldo electoral relativamente estable, así como en cierto grado de solidez en su posición ideológica y en sus propuestas. En tercer lugar, requiere que los principales actores políticos y sociales otorguen legitimidad a los procesos electorales y a los partidos, lo que a la vez determina que los partidos se conviertan en los actores claves para el acceso al poder. Finalmente, los partidos no deben subordinarse a intereses de grupos de presión y de liderazgos fuertes (Mainwaring y Scully, 1995: 5). Si se analiza a los sistemas de 
partidos de Bolivia, Ecuador y Perú a través de estas cuatro condiciones, se pueden identificar algunas de las particularidades de cada uno de ellos.

Así, se puede asegurar que en Bolivia estuvieron presentes durante por lo menos doce años (desde 1985 hasta 1997) esas cuatro condiciones en conjunto. Las reglas de la competencia entre los partidos tuvieron relativa estabilidad hasta las reformas de 1995, en que se introdujo la figura de los diputados uninominales (elegidos por primera ocasión en 1997). Los partidos demostraron tener arraigo fuerte en la sociedad, expresado en la estabilidad de su votación y en niveles relativamente bajos de volatilidad, por lo menos hasta las elecciones del año 2002 en que se observaron los primeros síntomas de la descomposición del sistema de partidos. Así mismo, por lo menos hasta ese mismo momento se podía asegurar que los procesos electorales y los partidos en sí mismos gozaban de legitimidad, en la medida en que los grupos que los impugnaban no tenían mayor peso en las definiciones políticas y constituían más bien sectores marginales en términos de su incidencia sobre la orientación de los procesos ${ }^{50}$. Por último, a pesar del peso de fuertes liderazgos personales dentro de los partidos, se podía asegurar que estos habían logrado un grado considerable de independencia de grupos de presión y de poderes externos a ellos.

En Perú, por el contrario, en todo el período transcurrido desde el retorno a la constitucionalidad en 1980 no han estado presentes al mismo tiempo esas cuatro condiciones. Las leyes electorales establecidas sobre la base de la Constitución de 1979 fueron cambiadas radicalmente en 1993 (por el Congreso Constituyente Democrático), especialmente por el paso del congreso bicameral al unicameral y por la instauración de la circunscripción única nacional para elegir a los diputados ${ }^{51}$. Los partidos perdieron sus lazos con la sociedad a partir del golpe de abril de 1992 y no han sido capaces de retomarlos y menos aún de fortalecerlos. Así mismo, los procesos electorales perdieron

${ }^{50}$ Es interesante, en este aspecto, la apreciación de Romero sobre los ejes de consensos en Bolivia desde 1985. Tomando el planteamiento de Keeler acerca de las "ventanas de reformas", sostiene que en Bolivia fue posible establecer consensos de amplia base social a causa del mandato electoral (vale decir, de su legitimidad) y por la gravedad de la crisis. Esto habría hecho posibles los consensos sobre la democracia como régimen político, la economía de mercado y el multiculturalismo (Romero, 1999: 49 y ss). Cabría introducir algunos matices acerca del consenso sobre el último eje, pero eso no invalida la argumentación en general.

${ }^{51}$ De un congreso integrado por 240 escaños (180 diputados y 60 senadores), se lo redujo a 120 en una sola cámara. La circunscripción nacional única se venía utilizando desde 1979 para la elección de senadores, como una forma transitoria hasta que concluyera el proceso de regionalización en que deberían ser elegidos por circunscripciones regionales, pero ese proceso fue interrumpido por el autogolpe de Fujimori (Tuesta, 2005: 153). 
su legitimidad dentro de un régimen que apostaba a la estrategia de la consolidación por resultados (mediante prácticas clientelares) y no por su origen democrático. Finalmente, la casi total ausencia de partidos durante la mayor parte del período hace innecesario considerar si ellos estuvieron sometidos a intereses de grupos de poder o de líderes omnipotentes.

Ecuador presenta en estos aspectos una situación heterogénea, ya que tampoco han estado presentes las cuatro condiciones, pero a diferencia de Perú se mantuvieron algunos de los rasgos constitutivos de ellas. Las reglas electorales han sido alteradas prácticamente para cada nueva elección, lo que impide hablar de estabilidad en las normas. Los partidos no han mantenido lazos relativamente fuertes con la sociedad, lo que se expresa en altos índices de volatilidad, pero han sido capaces de contar con electorados cautivos por medio de prácticas clientelares y por su reducción a espacios provinciales. Aunque los procesos electorales no han sido cuestionados en su condición de mecanismos de acceso a las instancias de poder y tampoco en su ejecución, los principales actores sociales han recurrido a otras prácticas para resolver los problemas políticos (entre las cuales se cuentan los derrocamientos de tres presidentes de la República sin atenerse a las disposiciones constitucionales y legales). Finalmente, el carácter corporativo de la política ecuatoriana transformó a los partidos (o a buena parte de ellos) en apéndices de grupos de presión.

Por tanto, en una primera aproximación es posible asegurar que en Bolivia existió un sistema de partidos medianamente institucionalizado durante un período relativamente largo, mientras en Ecuador se mantuvo un sistema incipiente (inchoate) y en Perú colapsó un sistema que podía ser calificado también de incipiente y que no ha podido renacer después de haberse pulverizado, por lo que puede ser calificado de fallido. Para desarrollar esta argumentación considero necesario tratar cada una de las condiciones mencionadas dentro de una perspectiva comparativa, y tratar de establecer así una visión de conjunto de los procesos vividos en los tres países ${ }^{52}$.

La estabilidad de las reglas electorales parece ser un elemento determinante en la permanencia del sistema boliviano, en tanto que es un elemento que no se encuentra en

52 Por razones de ausencia de información no me ocuparé de la cuarta condición (la dependencia de liderazgos fuertes y de grupos de presión). Es una materia que queda pendiente para próximas investigaciones. 
los casos de Perú y Ecuador. Ella otorgó un alto grado de certidumbre a los partidos y en general a los actores políticos bolivianos, que pudieron definir estrategias para plazos relativamente largos y, de esa manera, desarrollar prácticas que les aseguraron continuidad y permanencia. Por el contrario, el constante cambio de las normas, que caracterizó al proceso ecuatoriano, colocó a los partidos en un entorno de incertidumbre que alimentó las prácticas de corto plazo y la búsqueda de resultados inmediatos. En Perú, las normas que constituyeron el sistema electoral desde 1993 fueron diseñadas precisamente para erosionar la fuerza electoral de los partidos, de manera que más allá de su permanencia, siempre iban a arrojar resultados adversos para la institucionalización del sistema de partidos.

Es probable, dentro de esta perspectiva, que un cambio de tanta profundidad en las reglas del juego electoral y de las condiciones de la representación, como fue la instauración de la figura de los diputados uninominales, deba considerarse como uno de los factores fundamentales para la erosión del sistema de partidos de Bolivia ${ }^{53}$. Esta disposición cambió la composición del congreso al establecer que más de la mitad de los integrantes de la cámara baja (68 de 130) ya no fueran elegidos por listas sino en distritos uninominales. Era inevitable que una medida de esta naturaleza tuviera efectos de mucha importancia en la relación de los electores con sus representantes y por supuesto con los partidos $^{54}$. Con su aplicación tomaron cuerpo los problemas que ya fueron previstos por algunos autores en el momento mismo de su instauración (Romero, 2002: 254; Mayorga, 1999: 42) y que ocasionaron la resistencia de los partidos (Ardaya, 2003: 36; Zegada, 1998: 47 y ss). Es verdad que sus aspectos negativos no se expresaron con claridad en las primeras ocasiones en que se votó por este tipo de diputados, pero estos se hicieron evidentes en la medida en que se iba transformando en una rutina sobre la cual podían construirse las estrategias de los diversos actores y de los electores. A la personalización de la representación y a la pérdida de importancia de los partidos se debe añadir el efecto

\footnotetext{
${ }^{53}$ Es verdad que se introdujeron reformas en 1986, 1990 y 1993 (Ardaya, 2003: 12), pero fueron más bien ajustes que no alteraron sustancialmente las reglas del juego político como sí lo hizo la creación de los diputados uninominales.

${ }^{54} \mathrm{La}$ mayor parte de estudios al respecto coinciden en destacar la importancia de estos cambios en las condiciones de la representación, especialmente por el grado de personalización, por la posibilidad de contar con el voto cruzado, por la denominada territorialización de la política y por el cambio de concepción en la noción misma de representación (Ardaya, 2003; Mayorga, 2005; Bohrt, 2002; Romero, 2002; Zegada, 1998). Al decir de Mayorga, R (2005: 11), con ella se pasó de la representación política a la representación "descriptiva", en tanto que Zegada (1998: 73) advierte una superposición entre la representación social y la representación política, que genera conductas de carácter instrumental.
} 
de territorialización de la representación y de la política nacional, entendido como la creación de un mandato vinculante y como la introducción de los problemas locales en el escenario nacional ${ }^{55}$. Adicionalmente, la figura de los diputados uninominales se constituyó en un elemento de fricción con los municipios dentro del proceso de descentralización había comenzado en esos mismos años por medio de la Ley de Participación Popular.

Así mismo, la inestabilidad de las reglas electorales puede ser uno de los factores que sirven para explicar el carácter incipiente del sistema ecuatoriano de partidos. El cambio constante de éstas dibujó un horizonte de incertidumbre, con la consecuente imposibilidad de definir estrategias de largo alcance y, sobre todo, de anticipar con algún grado de confianza los resultados. Pero, posiblemente el efecto de mayor peso en este sentido es que a la larga se fue estructurando un cuerpo normativo heterogéneo y lleno de contradicciones. Los objetivos iniciales -que aparentemente apuntaban al fortalecimiento de los partidos políticos- se fueron desdibujando por la introducción de reformas que respondían a los intereses del momento y que no expresaban una visión de largo alcance acerca de las condiciones que debían establecerse para lograr adecuada representación y aceptables niveles de gobernabilidad ${ }^{56}$. Entre esas reformas, las de mayor impacto fueron las que permitieron la participación de organizaciones distintas a los partidos (mal llamadas de independientes), bajo condiciones mucho menos exigentes que las establecidas para los partidos. En fin, más allá de estos aspectos puntuales, la ausencia de un cuerpo normativo estable se convirtió en un obstáculo para que los actores

\footnotetext{
${ }^{55} \mathrm{El}$ diputado uninominal pasó a convertirse en un gestor de servicios públicos municipales, como lo fueron durante un largo período los diputados ecuatorianos, hasta que en 1997 se suprimieron las denominadas partidas de interés provincial, que ellos manejaban. Como fue señalado en su momento, en Bolivia con la elección de diputados uninominales "se ha producido una suerte de 'confusión' del discurso propiamente político, relacionado con la elección nacional, con un discurso municipalista orientado a la satisfacción de las necesidades urbanas o básicas de la población” (Zegada, 1998: 48). Así mismo, "Tanto los uninominales de distritos urbanos como los de distritos rurales asumieron su rol como concejales municipales o en todo caso como articuladores o gestores de la política local colocando en un segundo plano su rol legislativo y fiscalizador en la política nacional" (Mayorga, 1999: 20). Es ilustrativa la declaración de un diputado boliviano: "como candidato, inicialmente me resistí a entrar en la oferta municipal, pero luego, para asegurar mi elección, no tuve más remedio que sumarme a lo que hacían otros candidatos y comencé a ofertar, como si mi elección fuera para alcalde" (Ardaya, 2003: 37).

${ }^{56}$ En realidad, el diseño inicial era en sí mismo contradictorio, ya que por un lado apuntaba a fortalecer a los partidos políticos con medidas como el monopolio de la representación, mientras que por otro lado los debilitaba con disposiciones como la utilización de una fórmula de representación altamente proporcional, la inexistencia de barreras de representación, la utilización de la doble vuelta para la elección presidencial, la prohibición de alianzas y de reelección de los diputados (Pachano, 2003; Mejía, 2003; Freidenberg, 2000a)
} 
políticos y los ciudadanos pudieran establecer pautas de conducta relativamente estables $^{57}$.

En Perú, como he señalado, el problema central en el aspecto normativo-institucional se encuentra parcialmente en su inestabilidad, pero también en su orientación. El cambio en la composición del congreso (de bicameral a unicameral), así como el paso la introducción de la circunscripción única nacional para la elección de sus integrantes y la desproporción entre votos y escaños que se derivó de ésta, plantearon problemas muy fuertes de adaptación para los actores políticos, en especial para los partidos (Tuesta, 2005: 156). Inevitablemente, debían desarrollar estrategias sustancialmente diferentes a las que habían venido desplegando, ya que las condiciones institucionales así lo exigían. Por su parte, la adopción del voto preferencial para la elección de diputados contribuyó al debilitamiento de los partidos, tanto por el desplazamiento a un segundo plano de las adscripciones partidistas, como por la competencia entre candidatos de una misma lista y también por su carácter de incentivo para incorporar a caudillos locales en las listas de los partidos. Adicionalmente, la alta proporcionalidad derivada de la combinación entre la circunscripción nacional única y la fórmula D’Hondt de asignación de escaños, se constituyó en un incentivo para la presencia de partidos en el escenario nacional ${ }^{58}$. La legislación del régimen autoritario buscaba claramente eliminar la intermediación de los partidos políticos y favorecer a los outsiders y a grupos de efímera vida que podían ayudar a sustentar al régimen (Tuesta, 2005: 170; Grompone, 1995: 28; Marcus-Delgado, 2001: 18).

La mayor o menor capacidad de los partidos para echar raíces fuertes y estables en la sociedad también ha sido uno de los elementos básicos para la definición de las características de cada uno de los sistemas y, en consecuencia, para establecer sus diferencias. La relativa estabilidad y consolidación del sistema boliviano se asienta en gran medida en este factor, ya que los partidos contaron durante un tiempo bastante largo con

\footnotetext{
${ }^{57}$ Por la "reiterada introducción de nuevas disposiciones - pero también por la ausencia de objetivos claros- se ha configurado una institucionalidad incoherente" (Pachano, 2003: 208). Esta ha incidido negativamente no solamente sobre los partidos y el sistema de partidos, sino sobre la eficiencia, eficacia y calidad de la democracia (esto es, sobre la gobernabilidad). Así mismo, ha llevado a la informalización de la política, expresada en el establecimiento de rutinas que se realizan al margen de los procedimientos establecidos. Finalmente, ha sido un factor fundamental en la pérdida de confianza en las instituciones del sistema político y en general en el régimen democrático (Pachano, 2003: 209)

${ }^{58}$ Entre 1980 y 1990 hubo un máximo de 6 partidos con representación en la Cámara de Diputados, en tanto que en el año 2001 llegó a 13 (Tuesta, 2005: 165 y 169).
} 
gran capacidad para expresar los intereses y canalizar las demandas de la sociedad. La definición de la agenda política estuvo a cargo de los partidos que, por lo demás, se mostraron receptivos a las demandas provenientes de sectores que no contaban con representación política directa o que se expresaban por medio de organizaciones sociales y de formas de acción colectiva que no tomaban forma política. Esto se expresó en la definición de los ejes de consenso mencionados antes, que permitieron constituir gobiernos de coalición y mantener políticas de largo alcance ${ }^{59}$. El respaldo electoral logrado por los partidos mayoritarios, aún después de haber llevado adelante gestiones gubernamentales en las que tomaron medidas económicas impopulares, es un buen indicador en ese sentido. Por el contrario, en Perú los partidos perdieron los lazos con la sociedad en la medida en que se apartaron no solamente de los intereses específicos que los vincularon en algún momento (generalmente en su origen), sino que fueron incapaces de adoptar posiciones frente a los temas fundamentales del país (Conhaghan, Malloy y Abugatás, 1990). En Ecuador, como he señalado antes, las relaciones se establecieron por medio de redes clientelares que terminaron por revertirse en contra de los propios partidos, ya que éstas los colocaban ante la necesidad de entregar resultados inmediatos y concretos. La imposibilidad de definir políticas de largo alcance en estos últimos dos países -al contrario de Bolivia- puede ser una pista de importancia en este sentido.

Es probable que las diferencias en este aspecto tengan un punto de partida muy importante en la forma en que cada uno de los países enfrentó los problemas derivados de la crisis de comienzos de los ochenta. En Bolivia, en el año 1985, se logró un consenso no solamente en el campo económico sino también en el político, que tuvo como efecto la estabilidad de los años siguientes. Esta se manifestó tanto en el plano de las políticas que adoptaron sucesivos gobiernos, como la continuidad del régimen constitucional. En ambos niveles se trató de transformaciones sustanciales tanto con respecto a su propia historia (caracterizada por la inestabilidad política y por la discontinuidad en la orientación de las decisiones de los gobiernos), como en relación a la mayor parte de países del continente y obviamente en referencia a los del área andina. Lo importante de este consenso, para el tema aquí tratado, es que fue realizado por los partidos políticos y que contó con amplio apoyo de la sociedad. De esta manera, los

\footnotetext{
${ }^{59}$ Como se vio en la primera sección, un factor de mucha importancia en la materialización de los gobiernos de coalición y en la estabilidad de políticas, sobre el que está de acuerdo la mayor parte de autores, fueron los elementos institucionales que forzaron a acuerdos partidistas de conformación de gobiernos (Lazarte, 1998b; Gamarra 1992, Mayorga, 2003; Toranzo; 2000).
} 
partidos asumieron directamente la conducción del proceso de reorientación de la economía, lo que no ocurrió en los otros dos países. En efecto, el régimen autoritario peruano encabezó la redefinición de la economía, con prescindencia de los partidos, lo que significó que los efectos positivos de ese proceso (como el control de la inflación) pudieran ser atribuidos más bien al carácter antipolítico de ese régimen (Marcus-Delgado, 2001: 16). Mientras tanto, debido a la existencia de determinadas condiciones que hacían posible soslayar la crisis económica sin enfrentarla directamente y por tanto sin reorientarla, en Ecuador los partidos pudieron evadir el tema. Inevitablemente, por este camino la crisis llegó a convertirse en una constante que tendría efectos tremendamente negativos en el largo plazo pero que en el corto plazo -con prácticas clientelares de por medio- permitían obtener réditos para los partidos (Mejía et al, 2004; Pachano, 2007).

Es importante destacar que tanto en Bolivia como en Perú se aplicaron políticas que se enmarcaban en la entonces dominante orientación neoliberal, mientras que en Ecuador hubo varios intentos de caminar en esa dirección pero siempre se produjeron retrocesos que terminaron en formas híbridas que no pueden ser identificadas como partes de aquel modelo (Toumi y Grindlee, 1995; Pachano, 2006; Mejía et al, 2004). En los dos primeros países existió apoyo relativo a esta orientación económica. En Bolivia se expresó en la sucesiva elección de gobernantes que explícitamente la adoptaron como base de su campaña y de su gestión de gobierno. En Perú se manifestó en los altos índices de aprobación que mantuvo Fujimori durante su largo período en la presidencia. Temas de gran sensibilidad, como el control de la inflación y la instauración de condiciones que permitían algún grado de certidumbre en la situación económica del futuro inmediato, se encuentran en la base de esa conducta social. Los procesos de profundo deterioro de las condiciones de vida y la incertidumbre incluso acerca de lo más inmediato, generaron un ambiente propicio, que tendió a dejar en un segundo plano los demás componentes de estas políticas -muchos de ellos de efectos negativos para la misma población que las apoyaba-, lo que facilitó su implantación ${ }^{60}$.

\footnotetext{
${ }^{60} \mathrm{El}$ apoyo social no es la única paradoja en este campo. Lo es también la actitud de quienes adoptaron las políticas en cada uno de los países. Víctor Paz Estensoro y el MNR no expresaban precisamente una posición favorable al neoliberalismo y, así mismo, es conocida de sobra la contradicción entre la posición en campaña y la posición en el gobierno que mostró Fujimori. Es probable que en ambos casos haya sido determinante el interés por mantener el orden institucional o, dicho de otra manera, de evitar el colapso del Estado, aunque cada uno de ellos lo haya hecho de una manera radicalmente distinta. Acercamientos en este sentido se encuentran en Torre (1998: 24 y ss) y en Stokes (2001).
} 
Independientemente del contenido de esas políticas, que no es del caso analizar aquí, lo cierto es que en los dos casos la conducción de la economía se transformó en uno de los factores centrales -si no el fundamental- para el apoyo con el que contaron los gobiernos y para la legitimación del régimen político. En Bolivia fueron los partidos, en tanto que en Perú fue un régimen autoritario, pero en ambos casos quienes se encargaron de tomar las decisiones y de aplicarlas lograron altos grados de apoyo ${ }^{61}$. Por el contrario, al no haberse producido algún tipo de acuerdo y al no existir una reorientación clara de la economía (en cualquier sentido, no necesariamente en la dirección predominante), en Ecuador todos los actores políticos sufrieron rápido desgaste, y con ellos la institucionalidad política ${ }^{62}$. Al contrario de la experiencia boliviana, donde algunos elementos institucionales impulsaron los acuerdos, el diseño institucional del sistema político ecuatoriano no ayudó a la construcción de consensos y más bien se puede decir que los obstaculizó.

Ya sea por los resultados del manejo de la economía o por otras razones, los partidos de cada uno de los países muestran grandes diferencias en términos de su desempeño electoral. Si se considera que una de las facetas del acto de votación es la evaluación o calificación de la acción de los partidos (Downs, 1956; Przeworski, 1999; Maravall, 2003), entonces la mayor o menor estabilidad de la votación de un partido puede tomarse como un indicador del grado de aceptación que éste tiene en la sociedad. Por ello, es sin duda una de las mejores pistas para acercarse al tema de las raíces sociales de los partidos y de legitimidad alcanzada por estos. A la vez, el grado de estabilidad de la votación de cada partido es uno de los elementos definitorios de los sistemas de partidos, ya que expresa la permanencia o por el contrario la inestabilidad de las organizaciones que lo conforman.

\footnotetext{
${ }^{61}$ Es necesario aclarar que, a pesar de la relativa semejanza entre Bolivia y Perú, existen profundas diferencias cuando se los considera desde la perspectiva de la democracia que es, en estricto sentido, la única que se puede adoptar para tratar el tema de la legitimidad. Puede resultar un contrasentido hablar de legitimidad de un régimen autoritario ya que por definición en el marco de este no existen procedimientos ni instancias de construcción de esa legitimidad. Por ello, la utilización del concepto de autoritarismo competitivo -al que he aludido antes- puede ser de mucha utilidad para comprender el caso peruano. En este plano, la diferencia fundamental se plantea entre el consenso (Bolivia) y la imposición (Perú) de las políticas

62 Tres datos pueden tomarse como indicadores del desgaste de los actores políticos ecuatorianos. Primero, la pérdida de popularidad de los gobiernos apenas transcurridos los dos o tres primeros meses de su gestión, registrada por las diversas encuestas que hacen el seguimiento (Informe Confidencial, Perfiles de Opinión, Cedatos). Segundo, el derrocamiento de tres presidentes cuando ellos perdieron el apoyo popular. Tercero, ningún partido y ninguna agrupación de cualquier naturaleza pudo llegar más de una vez a la presidencia de la República a lo largo del período, con excepción de la reelección inmediata de Rafael Correa, que se produjo en condiciones sustancialmente diferentes a las que rigieron para todo el período.
} 
La regularidad de la votación de los partidos puede ser apreciada por medio del índice de volatilidad, que mide la variación de la proporción de votos o escaños obtenidos por cada partido dentro del total ${ }^{63}$. De acuerdo a este índice, el sistema de partidos boliviano contó con los más bajos índices de volatilidad a lo largo del período, en tanto que el peruano se encuentra en el extremo opuesto y el ecuatoriano ocupa un lugar intermedio (como se puede apreciar en el cuadro número 1). Esto guarda mucha coherencia con las características de cada uno de los sistemas de partidos señaladas a lo largo del presente texto, esto es, con la presencia relativamente sostenida a través del tiempo de los partidos bolivianos, con la desaparición de los partidos iniciales y el permanente surgimiento de nuevas organizaciones en Perú y con la gran fragmentación del sistema ecuatoriano. Todos estos factores se expresan en diferencias significativas, que van desde una volatilidad media de 20,7 en Bolivia, hasta una de 70,1 en Perú, lo que indica un comportamiento radicalmente diferente de los sistemas de partidos en cada uno de los países. Se puede afirmar, por consiguiente, que los partidos bolivianos desarrollaron mayor capacidad para mantener el apoyo de sus electores, mientras que los partidos peruanos prácticamente no pudieron hacerlo y los ecuatorianos apenas han lograron mantenerlo en niveles bastante pobres.

Este mismo índice puede ser mirado desde la óptica de los electores, esto es, como un indicador del grado de adscripción que ellos desarrollan a cada uno de los partidos que conforman el respectivo sistema. Desde esta perspectiva, se puede sostener que en Perú y en Ecuador ellos no establecieron lazos fuertes y estables con los partidos, como si parece haber ocurrido en Bolivia durante un largo período ${ }^{64}$. Las causas para estas diferencias pueden ser múltiples, pero seguramente la más importante es la señalada antes acerca de la manera en que se enfrentó la crisis económica en cada uno de los países. La baja volatilidad de los partidos bolivianos puede ser la expresión de los consensos alcanzados en ese aspecto, en tanto que los altos niveles observados en Perú pueden explicarse por el carácter marcadamente antipolítico del régimen que llevó adelante la

\footnotetext{
${ }^{63}$ Para la medición de la volatilidad se utiliza generalmente el índice de Pedesen, consistente en la diferencia de los valores absolutos de la proporción de votos o de puestos ganados o perdidos por cada partido entre dos elecciones. Este se expresa en la fórmula VT $=\Sigma\left(\left|\mathrm{P}_{1}-\mathrm{P}_{2}\right|\right) / 2$, donde $\mathrm{P}_{1}$ es la proporción de votos (o de escaños) en la elección inicial y $\mathrm{P}_{2}$ es la proporción en la segunda votación. La escala se mueve entre 0 y 100 (a valores más altos mayor volatilidad).

${ }^{64}$ Es evidente la contraposición que existe entre los electores "flotantes" que destaca Conaghan (1984) en el caso ecuatoriano y los consensos que identifica Romero (1999) en el caso boliviano.
} 
reorientación económica, así como los niveles relativamente altos de Ecuador pueden deberse a la inconsistencia de los partidos ecuatorianos en este campo. Por tanto, los altos niveles de volatilidad en estos dos últimos casos expresaría no solamente la baja capacidad de los partidos para profundizar sus raíces en la sociedad, sino también la insatisfacción de los electores con el desempeño de los partidos.

La regularidad se expresa en términos concretos en la permanencia de cada uno de los partidos a lo largo de diversas contiendas electorales y, dentro de esto, en la proporción de votos que obtiene. Por ello es importante observar el desempeño histórico de cada partido, esto es, la votación que logra en cada elección pero también -y como paso previo- su presencia o ausencia en sucesivas elecciones. En este sentido se observan también profundas diferencias entre los tres países, como se desprende de las cifras contenidas en los cuadros $2 \mathrm{a}, 2 \mathrm{~b}$ y $2 \mathrm{c}$.

En Bolivia se aprecia una mayor capacidad de permanencia de los partidos más votados (MNR, ADN, MIR), con bastante regularidad en las proporciones que obtuvo cada uno de ellos a lo largo del tiempo. Adicionalmente, los tres partidos estuvieron siempre presentes en los primeros lugares hasta las elecciones del año $2002^{65}$. En ese año prácticamente desapareció uno de ellos (ADN), con lo que se inició el descalabro del sistema en su conjunto, que llegaría posteriormente, en la elección del año 2005. En Ecuador la permanencia de cuatro partidos (PSC, PRE, ID y DP) estuvo acompañada de fuertes variaciones en la votación de cada uno de ellos, en especial de ID y DP. En la elección del año 2002 se produjo un quiebre significativo de esa tendencia, ya que los cuatro partidos vieron reducirse significativamente sus respectivas proporciones de votos y por consiguiente cambió también la composición de los primeros lugares. Dos agrupaciones relativamente nuevas desplazaron a los partidos que tradicionalmente habían ocupado los primeros lugares, con lo que aparentemente se inició un proceso de renovación del sistema de partidos, pero que no logró continuar más allá de las elecciones del año 2006. De ahí en adelante, tanto los partidos tradicionales como los dos nuevos cedieron su espacio a una sola fuerza política constituida en torno al liderazgo personal de Rafael Correa. En Perú, la desaparición casi total de los partidos que iniciaron el período impide hablar de cualquier grado de regularidad, especialmente a

${ }^{65}$ En el año 1993 ADN y MIR formaron la alianza Acuerdo Patriótico (AP) que, al haber ocupado el segundo lugar, no se altera la afirmación acerca de la regularidad. 
partir de la elección de 1990. Como he señalado antes, la característica central en este caso es la baja permanencia de los partidos, lo que se comprueba con estas cifras.

Un aspecto de importancia, vinculado a la volatilidad y a la regularidad de la votación de los partidos, es la proporción de votos que obtienen quienes ocupan los primeros lugares. Independientemente de las etiquetas de los partidos que llegan a esos puestos, cabe atender a las proporciones de cada uno de ellos, ya que este constituye un indicador de la concentración o de la dispersión de la votación. En este plano, en las cifras de los mismos cuadros $2 \mathrm{a}, 2 \mathrm{~b}$ y $2 \mathrm{c}$, se observa algo que aparentemente es contradictorio con lo que he venido sosteniendo y con la tendencia que marcan los indicadores tratados antes, especialmente por lo que ha ocurrido en Perú. En efecto, allí se encuentran las más altas votaciones de los ganadores (con una sola excepción el primero obtuvo siempre más del $40 \%$ ) y grados de concentración extremadamente altos entre los dos primeros partidos (que solamente en una ocasión se sitúan por debajo del 70\% y llegan hasta casi la totalidad de los votos en la última elección). Esto se expresa en la media de votación obtenida por el ganador (49,5\%) y de los dos primeros (78,5\%) a lo largo del período. Por el contrario, en Bolivia se observan cifras más bajas, con promedios de 30,6\% y de $55,2 \%$ para el ganador y para la suma de los dos primeros lugares, respectivamente. Además, en este caso se observa un descenso de esas proporciones a partir de la elección de 1997. Por su parte, en Ecuador se encuentran las proporciones más bajas, con promedios de $28,0 \%$ para el ganador y $51,4 \%$ para los dos primeros. Su punto más bajo, que es también el menor de los tres países, se encuentra en la elección del año 2002, en la que el primero apenas obtuvo la quinta parte de los votos y la suma de los primeros no llegó al 40\% (para superar levemente el 50\% es necesario añadir el tercer partido).

De acuerdo a los niveles de volatilidad y a la regularidad de la votación se podría esperar que en Bolivia estuvieran los mayores grados de concentración de la votación en los primeros candidatos y que en Perú se encontraran los más bajos. Eso no es así debido a dos factores, que inciden en cada uno de los casos. En primer lugar, el grado de polarización política que existe en cada uno de los países lleva a que los votos se distribuyan de manera específica en torno a un eje ideológico o de cualquier otra naturaleza $^{66}$. De acuerdo a esta perspectiva, los bajos porcentajes observados en Bolivia

${ }^{66}$ Hago referencia a un eje ideológico en el sentido amplio que lo toma la teoría espacial de la política (Downs, 1957; Colomer, 2001Przeworski, 1995), entendido como los temas (o issues) que marcan las diferencias de posiciones de los actores políticos y de los electores. Puede ser el eje izquierda-derecha, 
se derivarían de una competencia centrípeta, en la que los partidos centrales del sistema no presentaban grandes diferencias, lo que llevaría a que los electores pudieran escoger indistintamente a uno de ellos sin que se altere significativamente su posición dentro del espectro ideológico. Mientras que los de Perú expresarían una competencia centrífuga, en la que se presentan amplias y profundas brechas entre los partidos, de modo que los electores tenderían a colocarse en posiciones extremas del eje ideológico. Pero se podría sostener que esta explicación choca, por un lado, con los índices de volatilidad de cada uno de los países (que muestran bajos niveles en Bolivia y altos en Perú), y por otro lado con las cifras de Ecuador que debería aparecer en una posición más cercana a la de Perú que a la de Bolivia. Ello no esa así ya que los grados de volatilidad del sistema de partidos no expresan necesariamente -ni van asociados con- un determinado grado de concentración de la votación. Esto quiere decir que se puede encontrar una combinación de baja volatilidad con baja concentración de la votación en los primeros lugares, como ocurre en Bolivia, así como alta volatilidad con alta concentración como ocurre en Perú. Así mismo, es probable una situación en la que exista alta volatilidad y baja concentración, como se observa en Ecuador.

En segundo lugar, cabe considerar como elemento previo el grado de afinidad de los electores con los partidos, que a su vez se expresa en su regularidad en términos de votación. Como he señalado antes, éste depende de un amplio conjunto de factores, entre los que se cuentan algunos que son propios del sistema electoral (como el tipo de voto -único o múltiple-, la forma de presentación de la candidatura, el tamaño y número de las circunscripciones, entre otros) así como los que hacen referencia al desempeño de los partidos y por tanto al papel evaluador del voto de los electores. En Bolivia parece que se produjo la confluencia de un elemento propio del diseño del sistema político, como es la utilización del voto único para elegir presidente e integrantes del congreso, con algún aspecto relacionado con el desempeño político, que en este caso es claramente la capacidad de los partidos para asumir la conducción económica ${ }^{67}$. En Perú, por el contrario, los electores no habrían encontrado incentivos institucionales para canalizar sus votos en uno u otro sentido y, al mismo tiempo, no reconocerían en los partidos

pero también pueden incorporarse otras dimensiones que definen las posiciones en diversos momentos. El tema económico puede constituir uno de esos ejes (que, por lo demás, puede ser analizado también desde la perspectiva ideológica del espectro izquierda-derecha). Un análisis de las posiciones de los electores en dos dimensiones, para el caso peruano, se encuentra en Vergara (2007)

${ }^{67}$ Nuevamente cabe aludir a los ámbitos de consenso que han sido destacados por varios autores, y que tienen como eje el desempeño económico (Romero, 1998; 1999; Lazarte, 1998a). 
algún aspecto positivo en términos económicos y sociales, que sí lo encontrarían, en cambio, en un personaje ajeno a ellos, un outsider, que condujo el proceso de estabilización de la economía (Tanaka, 2001; Grompone, 2005). De esta manera, las preferencias electorales de los electores peruanos se habrían definido más bien en contra de los partidos, sin que existieran contrapesos institucionales que los llevaran a moderar esas posiciones. En Ecuador se presentaría una situación relativamente similar a la de Perú en términos institucionales -en tanto no se encuentran incentivos para la concentración del voto de los electores- pero diferente en términos políticos ya que no existe algún actor que por sus rendimientos en la conducción gubernamental lograra concentrar la votación (Pachano, 2005; Mejía et al, 2004).

Estas diferencias se expresan también en el número de partidos que conforman el sistema de cada uno de los países. Un primer acercamiento se logra con las cifras del cuadro número 3 , en el que constan todos los partidos que presentaron candidatos en cada una de las elecciones presidenciales en los respectivos países. Aparte de las variaciones que se observan a lo largo del período en cada país y que no expresan alguna regularidad (excepto una leve tendencia al descenso en Bolivia), es importante destacar que en términos generales los tres países se mantienen alrededor de un punto medio relativamente similar, entre 9,1 y 11,7, partidos en promedio, con una desviación estándar de 1,3. Es difícil asegurar si se trata de un número alto o bajo, ya que no se cuenta con parámetros al respecto, pero sí se puede decir que en tanto más alta sea la cifra de partidos que se presentan a elecciones presidenciales, más evidente será la fragmentación del sistema ${ }^{68}$. Pero, independientemente de esa relación, es importante destacar que en los tres países parecen existir incentivos para la participación en las elecciones presidenciales y que en ninguno de ellos opera una fórmula reductora del número de partidos, como podría ser en el caso de Bolivia la sustitución de la segunda vuelta por la elección en el congreso. Así, el carácter multiplicador del número de candidatos que tiene

\footnotetext{
${ }^{68}$ Se podría tomar como parámetro al umbral que establece Sartori para definir al pluralismo extremo, que es "en torno a cinco (o seis)" (Sartori, 1992: 165, cursiva en el original). Sin embargo, como el propio autor lo señala, este es un "artefacto operacional" (Sartori, 1992: 164) que debe estar siempre acompañado de la evaluación del peso de cada partido para la conformación de alianzas o para el chantaje (Sartori, 1992: 154-155). Este último aspecto hace poco adecuado el criterio para elecciones presidenciales en las que se puede prescindir de las alianzas sin ningún riesgo, lo que ocurre claramente en Ecuador y Perú. Solamente en Bolivia se podría aplicar hasta cierto punto ese parámetro, ya que las alianzas (o, en su defecto, los chantajes) eran necesarias para la conformación del gobierno por la inexistencia del mecanismo de la doble vuelta. En estricto sentido, la propuesta de Sartori se refiere a los partidos en las elecciones legislativas y parece fuertemente influido por la realidad de los regímenes parlamentarios o semiparlamentarios.
} 
la utilización de la doble vuelta (Pérez-Liñán, 2002; Jones, 1994; 1999) parece funcionar en Ecuador y Perú, pero su ausencia en Bolivia no se manifiesta en el efecto contrario seguramente a causa de la incidencia de factores de otra naturaleza.

Pero, la percepción de similitud entres los tres sistemas cambia cuando se trabaja con el número efectivo de partidos y se encuentra una situación bastante coherente con la que se apreciaba desde el punto de vista de la concentración de la votación ${ }^{69}$. De acuerdo a este indicador, Bolivia y Ecuador han contado en promedio con un número efectivo de partidos relativamente similar, de 4,8 y 5,2, respectivamente, en tanto que Perú presenta un número significativamente más bajo, de 2,9, como se puede apreciar en el cuadro número 4. Nuevamente cabe aludir aquí a la incidencia de los diversos grados de polarización, que son los que pueden explicar esas diferencias. La alta polarización en Perú determina que un indicador como éste, que es sensible al peso proporcional de los partidos, se sitúe en niveles bajos ya que se reduce la incidencia de los partidos pequeños. Por el contrario, en Bolivia y Ecuador se encuentra un número efectivo más alto debido a la menor concentración de la votación en los partidos que obtienen mayor votación y, por tanto, el indicador refleja el peso relativamente mayor de los partidos menos votados.

Finalmente, otro indicador que ofrece una visión de las diferencias entre los tres países es la fragmentación del sistema de partidos, esto es, del grado en que el sistema se encuentra seccionado o distribuido internamente ${ }^{70}$. Como se puede observar en el cuadro número 5, Bolivia y Ecuador presentan índices prácticamente idénticos $(0,79$ y 0,80 , respectivamente), mientras Perú se sitúa muy por debajo de las cifras de esos países (con un índice de fragmentación de 0,64). Se puede asegurar que la fragmentación tiene estrecha relación con el grado de concentración de la votación ya que en ambos casos se considera el número de partidos pero se lo pondera por el peso electoral de cada uno de ellos. Por ello, no debe sorprender que en Bolivia se encuentre un grado relativamente alto de fragmentación, ya que los partidos que ocupan los primeros lugares obtienen

${ }^{69} \mathrm{El}$ número efectivo de partidos es un índice que permite apreciar las diferencias que existen entre varios sistemas (o en un mismo sistema a lo largo del tiempo) por la cantidad y el peso electoral de los partidos que los conforman. Por consiguiente, este indicador es sensible al número de los partidos, pero también a la proporción de votos (o de escaños) que obtiene cada uno de ellos. En el análisis de los tres países he utilizado el índice de Laakso y Taagepera, expresado en la fórmula $1 / \sum \mathrm{p}^{2}$, en donde $\sum \mathrm{p}^{2}$ es la suma absoluta de los cuadrados de las proporciones de votos o de escaños obtenidos por los partidos.

${ }^{70} \mathrm{El}$ índice de fragmentación de Rae (1971) se expresa en la fórmula $\mathrm{F}=1-\left(\sum \mathrm{t}^{2}\right)$, donde $\sum \mathrm{t}^{2}$ es la suma de los cuadrados de los porcentajes de la votación de cada partido. Sus valores oscilan entre 0 y 1 , correspondiendo la mayor fragmentación a los valores más altos. 
bajas proporciones de la votación global. El caso de Ecuador es exactamente el mismo, aunque en otros aspectos difieren sustancialmente los dos sistemas. El de Perú guarda también coherencia con lo que se observó en términos de concentración, lo que lo convierte en el sistema con menor grado de fragmentación de los tres. Cabe reiterar que los grados de concentración y de fragmentación no han incidido en la volatilidad y que más bien pueden encontrarse sistemas con alta fragmentación y baja volatilidad (Bolivia), al mismo tiempo que sistemas con altos grados en ambos indicadores (Ecuador) y también una combinación entre baja fragmentación y alta volatilidad (Perú). Nuevamente cabe acudir aquí a explicaciones basadas en la polarización del sistema de partidos y en las estrategias que desarrollan los partidos en las contiendas electorales.

El análisis de los indicadores utilizados (volatilidad, concentración y número efectivo de partidos) lleva a sostener que, en relación a las elecciones presidenciales, los tres sistemas presentan más diferencias que similitudes y que entre ellos pueden formar pares en unos indicadores pero pueden aparecer totalmente distanciados en otros. Así mismo, es posible señalar que los diversos elementos constitutivos del sistema electoral influyen decisivamente en la conformación de los sistemas de partidos, pero que tienen también importancia aspectos de otra naturaleza, como el rendimiento económico y social del sistema político. Finalmente, es claro que todos esos aspectos se manifiestan bajo la forma de diversos grados de polarización, que a su vez se convierte en la variable explicativa más significativa de las características de cada uno de ellos.

Así, en Bolivia se constituyó un sistema que, a pesar de revelar altos índices de fragmentación y bajos de concentración de la votación, mantuvo baja volatilidad y alta estabilidad en términos de las tendencias políticas que accedieron al gobierno, lo que se expresó en bajos grados de polarización. Como he señalado reiteradamente, esta situación tendió a cambiar desde las elecciones de 1997, en que se redujo la concentración, se incrementaron tanto el número efectivo de partidos como la fragmentación. En Ecuador se constituyó un sistema caracterizado por altos índices de volatilidad y de fragmentación, con un número efectivo de partidos también alto y con baja concentración de la votación, con altos niveles de polarización como su manifestación obvia. En Perú se conformó un sistema que presentaba indicadores muy altos de concentración y de volatilidad, pero también bajo número efectivo de partidos y baja fragmentación, dentro de un marco de polarización aguda. 
Una apreciación diferente de los sistemas de partidos de cada país se obtiene cuando se toma como referencia a las elecciones legislativas ${ }^{71}$. Dado que las elecciones presidenciales están orientadas por estrategias que privilegian la captación del principal cargo de elección y no necesariamente por la búsqueda de consolidación de los partidos (lo que las reviste de mayor grado de personalización), no constituyen el mejor indicador de la situación de los partidos. Por el contrario, en las elecciones legislativas se expresan de mejor manera las estrategias orientadas al fortalecimiento partidista en términos electorales y a la captación de mayores espacios en el sistema político. Es una diferencia que se deriva de los elementos constitutivos del régimen presidencial y que es imposible dejar de considerarla en un análisis como el presente que pretende destacar las características básicas de los sistemas de partidos en tres regímenes de esta naturaleza.

Una primera aproximación se obtiene con el índice de volatilidad, que muestra un comportamiento radicalmente diferente al que se observó en las elecciones presidenciales en cada uno de los países, como se puede ver en el cuadro número 6. Bolivia es el único de los tres países en que este indicador es más alto en las elecciones legislativas que en las presidenciales (48,7 frente a 20,9, respectivamente, es decir, más del doble). Esto hablaría de un voto dividido entre ambos tipos de elecciones, lo que resulta sorprendente ya que es el único país en que se utiliza una sola papeleta para la elección presidencial y legislativa. La única posibilidad para romper esa regla -y por tanto para producir esa gran diferencia entre ambos tipos de elección- es la presentación de candidatos únicamente al congreso y no a la presidencia, de manera que la alta volatilidad en las legislativas se explicaría por la presencia de esos partidos que no compiten en las presidenciales.

Perú y Ecuador, por el contrario, muestran volatilidades más bajas en las legislativas que en las presidenciales. En el primer caso se puede suponer que la polarización, que ha caracterizado a las contiendas presidenciales, no se manifestado en las legislativas ya que a lo largo de la mayor parte del período éstas perdían relativamente su importancia debido a la centralidad absoluta del ejecutivo. Así mismo, es probable que haya influido

\footnotetext{
${ }^{71}$ Con el fin de medir de manera adecuada y precisa la fuerza de los partidos, en el caso de los dos países que cuentan o han contado con congresos bicamerales (Bolivia a lo largo de todo el período y Perú hasta 1990), entiendo por elecciones legislativas a las de la cámara baja (Cámara de Diputados), sin considerar a los senados. Por esa misma razón tampoco he incluido las elecciones de diputados uninominales en Bolivia ni a los diputados nacionales de Ecuador (vigentes, en número de 12, hasta las elecciones de 1998.
} 
la utilización del distrito único nacional para la elección de diputados, que obliga a los partidos a desarrollar estrategias diferentes a las que son necesarias para la elección presidencial. En el caso ecuatoriano es posible atribuir esas diferencias a un alto grado de personalización de la política -que llevaría a la alta volatilidad en las presidenciales-, a la reducción de los partidos a espacios subnacionales y a la relativa consolidación de cuatro partidos a lo largo del período (Pachano, 2006).

La concentración de la votación, por el contrario, varía mucho menos en cada uno de los países y, en consecuencia, mantiene las diferencias que se observaban entre ellos en el análisis de las elecciones presidenciales. Lo que llama la atención en este caso es la baja proporción de votación que obtienen tanto los partidos que ocupan el primer lugar como la suma de los dos primeros (como se puede ver en los cuadros 7 a y $7 \mathrm{~b}$ ). Tanto en Bolivia como en Ecuador se mantienen en proporciones bastante cercanas a las de las elecciones presidenciales, pero en Perú se sitúan por debajo de éstas. De cualquier manera, por medio de este indicador se manifiesta claramente la debilidad de los partidos en los tres países. Los que han ocupado el primer lugar han obtenido alrededor de la tercera parte de los votos, con la excepción de dos elecciones peruanas en las que han conseguido la mayoría absoluta (sin embargo, por lo menos una de ellas, la de 1995, deja mucha dudas en cuanto a su limpieza). El caso extremo se encuentra en Ecuador, donde la suma de los partidos que han ocupado los dos primeros lugares apenas alcanza una media inferior al 40\%. Pero también llama la atención el caso de Bolivia, en donde queda claro que la estabilidad y la alternabilidad en el ejercicio del gobierno se ha producido entre partidos relativamente pequeños. Se trata, por tanto, en los tres países, de sistemas de partidos que a causa de su débil respaldo electoral ofrecen escasas posibilidades de conseguir mayorías legislativas. De esta manera, se vuelve también una tarea muy difícil la estructuración de gobiernos de mayoría, especialmente cuando no existen los mecanismos institucionales que incentiven la conformación de coaliciones. La excepción en este aspecto es sin duda Bolivia, donde el mecanismo de elección presidencial en el Congreso ha permitido superar en alguna medida esta debilidad.

Cambios más visibles se encuentran en el número de partidos que se presentan a la contienda legislativa y que -con la excepción de Bolivia en que se mantiene en el mismo nivel que en las presidenciales- es significativamente más alto (como se puede ver en el cuadro número 8). En Perú el número se eleva de una media de 10,8 a una de 14,5, en 
tanto que en Ecuador se incrementa de una media de 9 a una de 27. Es probable que la explicación para el caso boliviano se encuentre en las escasas posibilidades de triunfo que tienen los partidos que no presentan candidatura presidencial, de modo que el voto único para presidente y legisladores aparece como un desincentivo para la multiplicación de partidos en las elecciones legislativas. En Perú la elevación esta dada sobre todo por las elecciones del año 1995, que fueron realizadas bajo unas normas de apertura irrestricta del sistema en lo que fue una estrategia clara de debilitamiento de los partidos políticos. En Ecuador siempre hubo más incentivos para la presentación de listas al congreso, pero tuvo un aliciente adicional desde las elecciones de 1996 en que se abrió la posibilidad de participación para las organizaciones de independientes y sobre todo desde el año 1998 en que se utilizó el sistema de votación personalizado en listas abiertas (panachage), lo que desembocó en un total de 69 listas que presentaron candidatos a las elecciones legislativas del año $2002^{72}$. En los tres casos, es evidente que este es un resultado de la utilización de fórmulas de representación proporcional, que aseguran la obtención de puestos con bajas votaciones.

El número efectivo de partidos refleja también esta situación. Como se puede observar en el cuadro número 9, en Bolivia se mantiene un número muy similar al que aparecía en las elecciones presidenciales (4,8 y 4,9, respectivamente), mientras en Perú se incrementa de 2,9 a 4,4 y en Ecuador de 5,2 a 8,0. Cabe destacar que la comparación de este indicador con el anterior permite apreciar la fortaleza o la debilidad de los partidos, ya que la medición del número efectivo es sensible al peso electoral que ellos tienen. Por consiguiente, una diferencia significativa entre ambos demuestra que la mayor parte de los partidos o listas que presentan candidatos a las elecciones obtienen muy bajo respaldo electoral. Por ello, se puede afirmar que en Perú y sobre todo en Ecuador una gran parte de los partidos que compiten en las elecciones legislativas no tiene significación electoral

Finalmente, la fragmentación del sistema de partidos alcanza en los tres países niveles relativamente similares a los que se observaron en las elecciones presidenciales (como se puede apreciar en el cuadro número 10. En Bolivia no se encuentra alguna variación entre ambos tipos de elecciones, en tanto que en Ecuador hay un incremento de siete

\footnotetext{
${ }^{72}$ No todas las listas son partidos en sentido estricto ya que, por un lado, muchas son organizaciones de independientes que se forman exclusivamente para esa elección y que desaparecen de inmediato independientemente del resultado. Por otro lado, son alianzas que los partidos realizan en el nivel provincial incluso con otros que en el nacional se presentan como competidores.
} 
puntos que no resulta significativo dentro de los niveles alcanzados por este indicador ( 0,80 en las presidenciales). En Perú, por el contrario, se encuentra un nivel bastante más alto, de once puntos, que tiene significación frente al nivel alcanzado en las presidenciales (0,64 frente a 0,75 de las legislativas). De cualquier manera, se puede afirmar que son sistemas altamente fragmentados, tanto en las elecciones presidenciales como en las legislativas.

Los partidos políticos ocupan un lugar central en esas dos arenas políticas. Como he señalado antes, ellos deben desempeñar las funciones básicas relacionadas con la representación y con la participación. Independientemente de las diferencias que pueden existir entre esas dos dimensiones, así como de la diversidad de actores que entran en escena en cada una de ellas, hay un conjunto de funciones que deben ser desarrolladas por ellos, tanto para establecer las relaciones entre la sociedad y el Estado como para hacer posible el gobierno desde el sistema político ${ }^{73}$. De manera sintética, esas funciones son: canalización de demandas y de intereses; elaboración de propuestas para presentarlas a la sociedad; definición de programas de gobierno; conformación y administración de gobiernos; construcción de alternativas de oposición; reclutamiento y formación de los dirigentes políticos; resolución de conflictos; agregación de intereses y representación de la sociedad, entre otros (Alcántara, 2004; Sartori, 1992, Ware, 2004). De éstas, la canalización de demandas y la agregación de intereses son exclusivas de los partidos y resultan prácticamente indelegables a otras organizaciones sociales. Así también, a diferencia de los movimientos sociales y de los grupos de presión, los partidos son las únicas organizaciones que pueden cumplir todas ellas al mismo tiempo.

Este es el marco que se debe considerar cuando se alude a problemas que han sido objeto de constante controversia en los últimos años. Uno de los más importantes de estos es el que se ha denominado crisis de representación. La percepción general, en este sentido, es que los partidos han tenido durante largos períodos el monopolio de la acción política pero no han sido capaces de ofrecer condiciones adecuadas para la representación y la canalización de intereses (Rojas y Suazo, 1996; Tapia, 2000; Grompone, 1995; 2005, Quintero, 2002; 2005; Planas, 1997; 2000; Adrianzén, 1992;

\footnotetext{
${ }^{73}$ Nuevamente cabe aludir aquí a la identificación de los niveles de la acción política, desarrollados en el capítulo I. Si se asume que el sistema político es el elemento central que organiza a los otros sistemas (económico y social-cultural) y que establece un conjunto de relaciones con la comunidad política y con el régimen político, entonces el sistema político concentra la participación y la representación de la sociedad, pero a la vez debe gobernarla.
} 
Cotler, 2000; Lynch, 1999; Pease, 1999). Sin embargo, en ese tipo de afirmaciones existen cuatro elementos que deben ser sometidos a debate.

En primer lugar, ellas reducen todo el problema a dos de las funciones señaladas antes (representación y canalización de intereses). Al olvidar el resto dejan fuera del análisis algunos aspectos fundamentales, como el ejercicio gubernamental, los rendimientos económicos y sociales de las políticas, la efectividad de la toma de decisiones y los elementos de contexto que intervienen en esos procesos. De esta manera, toda la complejidad del problema se reduce a un solo aspecto, que no es necesariamente el más importante dentro del contexto general de los países latinoamericanos. Al partir de un marco tan estrecho, el análisis no puede desarrollarse en toda su amplitud potencial.

En segundo lugar, asumen que la reivindicación de mejor representación o de mayor participación es la premisa básica y el elemento explicativo final de la insatisfacción ciudadana. Sin embargo, como he señalado antes, no existen indicadores adecuados que permitan comprobar esta afirmación ${ }^{74}$. Más bien, todo parece indicar que los sistemas políticos andinos -junto a buena parte del resto de países latinoamericanos- han vivido procesos muy importantes de apertura en los últimos años. Las reformas políticas aludidas al inicio de esta sección, muchas de las cuales incluyeron cambios en el nivel constitucional que a la vez significaron profundas transformaciones del régimen, se hicieron en su mayoría para ofrecer mejores condiciones de representación. Por lo general, éstas se orientaron explícitamente a permitir la entrada de nuevos actores en la escena política de cada uno de los países, y en la mayor parte de los casos lo lograron ${ }^{75}$. Si es así, el problema no tendría su explicación en los obstáculos a la participación y en la mala representación, sino en la forma en que se produjo la apertura, especialmente en la escasa adecuación de las instituciones para canalizar ese proceso.

En tercer lugar, se establece una relación causal unidireccional, que se origina en los partidos (en la que estos aparecen como la variable independiente), sin considerar que al mismo tiempo se produce el movimiento contrario, esto es, que el contexto en que se

\footnotetext{
${ }^{74}$ La mayor parte de sondeos de opinión -como las mediciones del Latinobarómetro, que ofrecen una visión comparativa y que podrían tomarse como fuentes para la comprobación de esta afirmaciónotorgan lugar prominente a la insatisfacción con las condiciones económicas y sociales. Esto quiere decir que la mayor parte de las demandas apunta hacia los rendimientos del sistema político y no necesariamente a sus condiciones de representatividad.

${ }^{75}$ Incluso las reformas de Fujimori, en Perú, que tenían otra orientación, sirvieron de puerta de entrada para nuevos sectores sociales y políticos (Grompone, 1996)
} 
desempeñan produce efectos sobre los partidos (donde ellos son la variable dependiente). Esto lleva a perder de vista todos los elementos externos que convergen como condicionantes del desempeño de los partidos (Ware, 2004; Panebianco, 1990) ${ }^{76}$. Al reducir todo el conjunto de problemas a una relación unidireccional se hace prácticamente imposible comprender los movimientos de interacción y, en consecuencia, se amplía el campo para los errores.

Por último -pero en primer lugar de importancia- se utiliza un criterio estrecho de representación, que no diferencia entre la de carácter político y la de carácter social, de modo que atribuye a la primera características que pertenecen a la segunda ${ }^{77}$. Por definición a los partidos les corresponde asumir la representación política, lo que quiere decir que deben mantener distancia con los intereses de sectores delimitados de la sociedad con el fin de disponer de los grados de autonomía necesarios para cumplir con el conjunto de las funciones que deben desempeñar en el marco de un régimen democrático. $\mathrm{Al}$ atribuirles condiciones propias de la representación social, a los partidos se les exige representar directamente segmentos aislados de la sociedad, lo que constituye la negación de su condición de organizaciones políticas y, en términos prácticos, puede conducir a su aislamiento con respecto a los sectores que no forman parte de su base social específica ${ }^{78}$. Todo ello contribuye a su desgaste ya que se crean expectativas de satisfacción inmediata de demandas concretas que, por la coexistencia de múltiples intereses y por las condiciones en que opera la representación política, no pueden ser respondidas positivamente. Desde esta perspectiva, los problemas no se derivarían de vacíos en la representación sino que serían el resultado de una concepción diferente (y equivocada) de ésta. Al difundirse entre la sociedad, esa concepción aplica a los partidos

\footnotetext{
${ }^{76}$ Llama la atención que, a pesar del predominio de esta visión centrada en los partidos, no se cuente sino con pocos estudios sobre sus condiciones internas, su estructura, su organización y sus procedimientos de selección de líderes y de candidatos. La mayor parte de estudios se ha concentrado en los sistemas de partidos y en el desempeño de ellos en las contiendas electorales. Con ello se pierde de vista también la incidencia de muchos elementos internos de los propios partidos. Excepciones a esta visión se encuentran en Alcántara y Freidenberg (2003), Alcántara (2004), Freidenberg (2004) y en el conjunto de artículos incluidos en Roncagliolo y Meléndez (2007).

${ }^{77} \mathrm{La}$ representación social se caracteriza por expresar directamente los intereses de grupos sociales delimitados, bajo la forma de mandatos vinculantes y revocables automáticamente. La representación política busca agregar los intereses diversos para construir el interés general (inexistente en sí mismo pero posible de ser construido a partir del proceso de agregación), lo que se traduce en mandatos no vinculantes y en el alto grado de autonomía de este nivel de representación (Sartori, 1999a: 258)

${ }^{78}$ Los partidos de origen étnico enfrentan un dilema muy difícil de resolver precisamente a causa de su vinculación de origen con sectores delimitados de la sociedad. En su condición inicial de movimientos sociales, ellos eran los portadores de las demandas de esos sectores, mientras que en tanto partidos deben responder a las demandas globales y construir propuestas para el conjunto de la sociedad (Van Cott, 2003; 2004; Yashar, 2005; Cordero, 2008).
} 
los criterios de evaluación de desempeño que son válidos para las organizaciones sociales (sindicales, gremiales, territoriales). En este sentido, no es una percepción abstracta sino una visión generalizada de la cual depende la legitimidad de los partidos.

Este aspecto es crucial para comprender la situación y los desafíos que enfrentan los partidos en los países andinos, ya que demuestra que la situación es bastante más compleja que lo que se puede expresar al aludir a crisis de representación. Como señalé antes, es posible sostener que la insatisfacción con los partidos se origina en el deterioro de las condiciones de vida de amplios sectores de la población de los países andinos (esto es, en los rendimientos del sistema político). En la medida en que los partidos han ocupado el lugar central en la conducción de los gobiernos, ellos aparecen como los principales responsables de la orientación de las políticas que han conducido a esos resultados negativos. Sin embargo, esto no puede ser explicado con la alusión a los vacíos de representación -o puede serlo solamente de manera indirecta y por medio de un largo conjunto de interacciones-, sino más bien como problemas de gestión. Conceptos como eficiencia, eficacia y capacidad de toma de decisiones y de ejecución de políticas deben ocupar el lugar que actualmente se le ha asignado al de representación.

En este punto es necesario volver sobre lo señalado antes, acerca de las reformas que han realizado los cinco países en las últimas dos décadas, que de una u otra manera se han orientado hacia la apertura del sistema político. Como lo han sostenido varios autores (Mayorga, 2004, Tanaka, 2002b; 2003; Pachano, 2006a; 2007; Sánchez y Freidenberg, 1998; Freidenberg, 2006), se han logrado mayores y mejores niveles de inclusión, sobre todo por medio del reconocimiento de los sectores tradicionalmente excluidos como sujetos de derecho político, así como por arreglos institucionales que han establecido mejores condiciones de acceso de esos sectores y de las minorías a las instancias de toma de decisiones. El surgimiento y la presencia significativa de los partidos de origen étnico en Ecuador y Bolivia, así como el reemplazo de los partidos tradicionales por nuevas fuerzas en Perú y Venezuela se inscriben en esa tendencia. Igualmente da cuenta de ella la renovación de las elites políticas que en grados diferentes ha ocurrido en los cinco países, pero que en todos ellos ha sido uno de los fenómenos destacados ${ }^{79}$.

\footnotetext{
${ }^{79} \mathrm{La}$ importancia de los procesos políticos locales está directamente asociada a estos fenómenos. Como lo comprueban varios estudios, muchas veces la observación del nivel nacional impide comprender a cabalidad las nuevas formas de participación política, las nuevas condiciones de representación y el peso de los sectores que llevan a la renovación de la arena política (Blanes, 2001)
} 
La apertura del sistema político, especialmente de la manera en que se efectuó, dio lugar a tres problemas que aluden -ellos sí- a la representación y a la participación. En primer lugar, la mayor parte de arreglos institucionales se han orientado hacia fórmulas proporcionales de asignación de puestos en las elecciones (especialmente en los órganos legislativos), y han impulsado procesos de reforma del Estado, entre los que destaca la descentralización administrativa y política ${ }^{80}$. En conjunto, ambas vías han elevado la presencia política electoral de minorías y han ayudado a la constitución de nuevos actores políticos (Tanaka, 2002a; Mayorga, 2003; Pachano, 2001). Por tanto, se ha ampliado el espectro de la representación por medio de la participación de mayor número de actores y por la multiplicación de los polos de decisión. Pero, a la vez, por esas mismas vías se ha contribuido a la fragmentación de la representación, tanto desde la perspectiva de las instancias nacionales -concretamente los órganos legislativos- como en las entidades locales. La expresión de esto en el ámbito del sistema de partidos es el incremento del número de sus componentes, mientras que en el plano electoral se manifiesta como altos niveles de volatilidad del voto (Mainwaring y Scully, 1995). Ambos aspectos han sido perjudiciales para la consolidación de los sistemas de partidos.

En segundo lugar, en los tres países se despojó a los partidos del monopolio de la representación política que habían mantenido durante varias décadas. Las reformas introducidas flexibilizaron la participación electoral, bajo modalidades específicas en cada uno de ellos, pero todas tendientes a ofrecer espacio a los independientes o no afiliados y a las organizaciones ciudadanas que en algunos casos han contado con mayores facilidades que los partidos (como ocurrió claramente en Ecuador y Perú, pero también hasta cierto punto en Bolivia desde las reformas del año 2004). De esta manera, los partidos debieron insertarse en unas condiciones de competencia que les resultaban claramente desfavorables.

En tercer lugar, la apertura de sistemas políticos oligárquicos significó inevitablemente que la arena política debía procesar un número mayor de demandas, con los consecuentes problemas de gobernabilidad que se han señalado antes. Pero además del

80 Colomer (2004: 31-41) sostiene que la instauración de sistemas electorales basados en la representación proporcional es una tendencia dominante en un alto número de países y que obedece a la búsqueda de mayor apertura del sistema de partidos. Ese análisis debe complementarse con el de los resultados que tiene esa apertura en términos de la fragmentación y en un plano más general de la gobernabilidad. 
aspecto cuantitativo es necesario considerar que la apertura ha colocado en la arena política múltiples clivajes anteriormente desconocidos o por lo menos sin expresión en ese nivel. Reivindicaciones étnicas, regionales y las que acompañan a nuevos tipos de sujetos sociales (como las de los productores de coca en Bolivia) han tomado carta de naturalización en el sistema político junto a las que existían previamente. En términos de representación -especialmente en su dimensión electoral- esto plantea un dilema en torno a las preferencias de las personas, ya que al coexistir varias de ellas no sólo en el mismo momento sino incluso en el mismo individuo se establece un conflicto por la prioridad en el momento de la decisión. Cuál de ellas es la que define la orientación de los electores, por un lado, y qué respuestas se ofrecen desde los niveles de toma de decisiones, por otro lado, es el dilema. A la vez, están en juego las posibilidades que existen para agregar aquellas preferencias en una sola orientación y no producir efectos centrífugos ${ }^{81}$. Dicho de otra manera, los electores pueden señalar una orientación determinada en torno a un tema, pero otra orientación muy diferente en torno a otro tema, así como pueden manifestarse direcciones distintas en el voto para las instancias nacionales y en el que se asigna para los ámbitos locales.

Los partidos de los países andinos han debido enfrentar esas consecuencias de la apertura de los sistemas políticos por medio de la adaptación, pero en ese proceso han sufrido erosión y desgaste. A pesar de que al finalizar la década de 1980 los cinco países mostraban sistemas de partidos en proceso de consolidación, diez años después todos ellos atravesaban por problemas de desestructuración. Los problemas descritos en la presente sección han incidido determinantemente en ese sentido y han contribuido a conformar lo que equivocadamente se ha denominado crisis de representación o falta de representatividad de los partidos y de las instancias políticas. La enumeración de la serie de factores que han confluido y los procesos que se han abierto a partir de ellos demuestran que el tema es bastante más complejo que lo que se puede expresar con esa afirmación.

\section{El estudio de los partidos, de los sistemas de partidos y de los sistemas electorales: una digresión sobre los casos estudiados}

\footnotetext{
${ }^{81}$ No es este el lugar para desarrollar todas las consecuencias que se pueden derivar de esta situación, pero cabe destacar el escaso interés que se le ha otorgado en los estudios sobre América Latina y de manera especial en la Región Andina. La coexistencia de múltiples clivajes invita a profundizar en este aspecto (un desarrollo del modelo de análisis se encuentra en Colomer, 2001 y en Paramio, 1999).
} 
Los temas abordados en la sección anterior se enmarcan en un campo de análisis que ha mostrado apreciable desarrollo en las últimas décadas. La sistematización de los estudios realizados al respecto da cuenta de una producción sustentada tanto en la evidencia empírica como en la acumulación teórica y conceptual ${ }^{82}$. Invariablemente, en todos ellos se destacan los avances logrados en la descripción y en la identificación de los fenómenos estudiados, pero sobre todo se pone especial énfasis en la construcción teórica y conceptual que resulta cada vez más sólida en la medida en que se asienta en tres componentes básicos del conocimiento científico: el carácter acumulativo, la solidez conceptual y la validación empírica. Así, desde los estudios fundacionales de Michels, Ostrogorsky y de las propuestas de Weber, hasta las sofisticadas mediciones actuales, pasando por la piedra angular colocada por Duverger, se ha acumulado gran cantidad de evidencia acerca de las características de los partidos y de los sistemas de partidos, que ha permitido establecer regularidades bajo la forma de leyes cientificas. Sobre ellas se han construido conceptos que han dado forma a múltiples perspectivas de análisis que, pese a sus discrepancias en términos de factores explicativos y de relaciones causales, conforman un horizonte teórico relativamente sólido ${ }^{83}$. Adicionalmente, en este momento ya se cuenta con un acervo de estudios empíricos que es suficientemente amplio para poder poner a prueba esos conceptos y esas relaciones causales.

Dentro de esta perspectiva, hay cuatro temas de carácter metodológico sobre los que se han realizado enormes avances y que interesan destacar en el presente estudio ya que son de enorme valor en el acercamiento a los casos de Bolivia, Ecuador y Perú. En primer lugar, la diferencia que, en términos de niveles de objeto de estudio y de niveles de análisis, se plantea entre partidos, sistemas de partidos y sistemas electorales. Aunque se

\footnotetext{
82 Son muy numerosos los textos que sistematizan los estudios acerca de partidos y sistemas de partidos. Algunos de ellos están citados a lo largo de este capítulo, lo que me exime de presentar una lista que jamás podrá ser exhaustiva, pero cabe destacar los de Alcántara (2004), Alcántara y Freidenberg (2003), Gunther y Diamond (2003), Sartori (1992), Ware (2004) y Maiwaring y Scully (1995), que constituyen referencias obligadas para un estudio de este tema.

${ }^{83}$ Me refiero a las perspectivas sociológica, institucional y competitiva, que destaca Ware (2004: 3539), que no establecen lo que podría considerarse como una ruptura epistemológica, sino que forman parte de un mismo cuerpo teórico. Incluso, me atrevo a sostener que, con escasas excepciones que vienen más bien de posiciones casi fundamentalistas, la mayor parte de autores que enfrentan el tema de partidos y de sistemas de partidos combinan adecuadamente las tres perspectivas mencionadas. Un ejemplo en este sentido es el de Mainwaring y Scully (1995), que aunque tiene su asidero principal en la perspectiva institucional no deja de considerar la incidencia de los factores sociales y de la competencia electoral como elementos explicativos del comportamiento de los partidos y de la estructura de los sistemas de partidos.
} 
encuentran tan estrechamente relacionados que es hasta cierto punto difícil comprender a uno de ellos sin acudir a los otros dos, cualquier acercamiento a la realidad empírica debe reconocer desde el inicio los límites entre cada uno de ellos. El estudio de los partidos demanda un tipo de acercamiento y de información diferente al que se hace necesario cuando se aborda el tema de los sistemas de partidos y, a la vez, éste difiere de los requerimientos que tiene el análisis de los sistemas electorales. Esto, que parece un lugar común, es sin embargo un punto de inicio muy necesario para evitar que en el camino se presenten confusiones que serán difíciles si no imposibles de controlar en el transcurso del estudio. La condición previa, en este sentido, es acudir desde el inicio a la clara diferenciación del objeto de estudio, el nivel de análisis y las variables intervinientes ${ }^{84}$. De esta manera se puede llegar a considerar que los tres elementos (partidos, sistema de partidos y sistema electoral) son los componentes o los subsistemas de un sistema de sistemas.

En segundo lugar, desde los primeros estudios se ha reconocido la importancia de la relación entre sistema electoral y sistema de partidos. A partir de la formulación original de Duverger (1988), a esta relación se le otorgó el carácter de ley, en el sentido de expresar una relación causal cargada de regularidad, en la que el sistema electoral aparece como la variable independiente, vale decir la causa, y el sistema de partidos como la variable dependiente, esto es, como el resultado. Son de sobra conocidas las dos formulaciones que Duverger hace al respecto, en términos de que la utilización de la fórmula de mayoría en una sola vuelta tiende a constituir sistemas bipartidistas y que la utilización de fórmulas proporcionales o de fórmula mayoritaria en dos vueltas tiende a conformar sistemas multipartidistas ${ }^{85}$. Más allá de las críticas que se puedan hacer a la universalidad de estas leyes y a la dirección de la relación, como lo hace Colomer (2004: 26) cuando propone colocar aquellas leyes cabeza abajo, está ampliamente demostrado que la interacción entre ambos sistemas es demasiado fuerte como para soslayarla o ignorarla ${ }^{86}$.

\footnotetext{
${ }^{84}$ Es muy rico el debate metodológico en la ciencia política en estos aspectos, especialmente el que se ha generado en torno al método comparativo (Caïs, 2002; Lijphart, 1971; Ragin, 1987; Sartori, 1970; 1999; Collier, 1999)

${ }^{85}$ Duverger plantea que la relación mencionada "Puede esquematizarse en la fórmula siguiente: el escrutinio mayoritario de una sola vuelta tiende al dualismo de los partidos" (1988: 245, cursiva en el original) y "por lo contrario, el escrutinio mayoritario de dos vueltas o la representación proporcional tienden al multipartidismo" (1988: 266, cursiva en el original).

${ }^{86} \mathrm{La}$ propia crítica de Colomer, que busca invertir la relación en tanto sostiene que son los partidos los que escogen los sistemas electorales, no constituye una negación del planteamiento original de
} 
En tercer lugar, derivado en parte de esa relación e independientemente de la perspectiva que se adopte (sociológica, institucional o competitiva), el análisis no puede dejar de considerar como uno de los elementos centrales a la dimensión institucional. La alusión a partidos, sistemas de partidos y sistemas electorales es en sí misma una referencia a instituciones, esto es, a normas, a procedimientos y a rutinas previamente establecidas. La dimensión institucional se hace más evidente si se pasa de la simple alusión a la profundización en el estudio de cualquiera de ellos. Aún cuando el objetivo se relacione con la búsqueda de los orígenes históricos de los partidos o con sus raíces sociales, en algún momento se volverá imprescindible abordar cada uno de estos temas o los tres en su conjunto en tanto instituciones que están sujetas a determinadas regularidades. Desde la instalación definitiva de los partidos como los elementos centrales de la representación política se han ido definiendo normas y procedimientos para regular su desempeño, de manera que están muy lejanos los tiempos en que los partidos podían ser vistos como asociaciones informales que carecían de estructuras estables y en general de organización ${ }^{87}$. Así mismo, los sistemas de partidos contemporáneos ya no pueden ser tomados como el resultado no buscado de la competencia electoral -como pudo ocurrir en los años iniciales de la política de partidos-, sino que son en realidad el fruto de intenciones y decisiones tomadas en torno a objetivos específicos. Mucho más clara resulta esta aseveración cuando se trata de sistemas electorales, que bien pueden ser definidos como diseños institucionales intencionalmente orientados a fines claramente determinados.

Por último, debido a una serie de elementos de carácter metodológico, pero también por la propia diversidad de los objetos de análisis, el estudio de estos temas está prácticamente obligado a recurrir a métodos que puedan dar cuenta tanto de las

Duverger. Más bien su propuesta puede ser complementaria, ya que se centra en el proceso de selección del sistema electoral por parte de los partidos sin que eso signifique una negación de los efectos que éste tiene una vez que ha sido puesto en práctica. Aún más, de acuerdo a los resultados del estudio comparativo que él realiza, la tendencia dominante en los países analizados es la selección de sistemas electorales basados en fórmulas proporcionales porque son los que ofrecen mayores posibilidades de entrada a nuevas fuerzas (Colomer, 2003: 40 y 2004: 31 y ss.) y por tanto -como lo había dicho Duverger- el resultado final es la constitución de sistemas pluripartidistas.

${ }^{87}$ Tanto Duverger (1988), como Sartori (1992) y Ware (2004) destacan el carácter informal de los partidos hasta mediados del siglo XIX. Su condición de organizaciones informales estaba estrechamente relacionada con el carácter excluyente y elitista de los sistemas políticos. Los avances en la democratización, en especial la expansión del sufragio universal, fueron elementos determinantes en la transformación de los partidos en instituciones basadas en una organización estable y sujeta a reglas que crecientemente se fueron haciendo explícitas. 
especificidades como de las diferencias y que a la vez permitan poner a prueba conceptos y teorías. Como se ha insistido frecuentemente, para satisfacer esas condiciones en las ciencias sociales se hace necesario acudir al método estadístico o al comparativo (Lijphart, 1971; Collier, 1999: 56). Eso es precisamente lo que se ha hecho con los estudios de estos temas y es lo que se ha traducido en significativos avances en este campo. Por consiguiente, al adoptar la perspectiva comparada y al apoyarse en métodos estadísticos se busca contar con un fuerte sustento para las aseveraciones y sobre todo para las relaciones entre las diversas variables incorporadas en el estudio. Como ocurre con todos los temas de las ciencias sociales, en las explicaciones acerca de los comportamientos de los partidos, así como de las características de los sistemas de partidos y de los sistemas electorales siempre están presentes múltiples variables, de manera que se hace necesario acudir a perspectivas de análisis que puedan dar cuenta de esa multiplicidad y de su interacción.

Sin embargo, los estudios de partidos, de sistemas de partidos y de sistemas electorales en América Latina (y de manera particular en los tres países estudiados) no se han asentado firmemente en esos cuatro componentes metodológicos. En primer lugar, son aún escasos los estudios sobre estos temas ${ }^{88}$. Es verdad que en años recientes se ha generalizado el interés acerca de ellos, pero todavía quedan muchas áreas por explorar y muchas preguntas por responder. Incluso no se dispone de explicaciones satisfactorias para aspectos de tanta importancia como el colapso de los sistemas de partidos en algunos países y el avance de las tendencias antipolíticas que inevitablemente afectan a los partidos ${ }^{89}$. En segundo lugar, la mayor parte de los estudios se centran en un solo país, lo que deja fuera a los efectos positivos que se pueden conseguir con la perspectiva comparada. Son muy pocos los estudios que abordan dos o más países y que pretenden buscar determinadas regularidades que puedan entregar pistas más seguras para la interpretación ${ }^{90}$.

${ }^{88}$ A pesar de esos vacíos, hay valiosas contribuciones hechas en varias revistas especializadas. Cabe destacar entre ellas a América Latina Hoy (Universidad de Salamanca), Política y Gobierno (CIDE, México), Revista Paraguaya de Sociología, Cuadernos del CLAEH (Uruguay) y Revista de Ciencia Política (Chile).

${ }^{89}$ Se han dado pasos de importancia en estos aspectos, como los que se encuentran en Mayorga (1998 y 2005), Tanaka (2001, 2005a y 2005b), Degregori (2000), Planas (1997 y 2000), Tuesta (1995 y 1997 y 2005), Freidenberg (2000 y 2006), Freidenberg y Alcántara (2001), Roncagliolo y Meléndez (2007) Romero (1998 y 2003), Pachano (2007a, 2007b y 2007c), pero aún son insuficientes para comprenderlos adecuadamente.

${ }^{90}$ Las excepciones más claras en este sentido se encuentran en el gran aporte del estudio conducido por Alcántara y Freidenberg (2001), en los trabajos que ha desarrollado IDEA Internacional y en los 
Aunque los países andinos no se alejan de la tendencia general descrita en la sección anterior, es satisfactorio comprobar que aproximadamente desde el inicio del siglo se aprecian ciertos signos de cambio. El interés por los estudios de estos temas, así como la adopción de la perspectiva comparativa han comenzado a ser parte de la agenda de investigación de varios académicos y de centros de investigación en ciencia política. Así mismo, se advierte un saludable interés por la investigación empírica, asentada no solamente en información previamente existente, como las bases de datos electorales, sino también en la que se recoge específicamente para satisfacer los objetivos de aquellos estudios $^{91}$. Estos avances -que, por cierto, no son suficientes para dejar de señalar los vacíos y las debilidades de la investigación política en estos campos- permiten hacer un breve recuento de los principales temas que se han abordado y de las perspectivas que han predominado.

En primer lugar, si se adopta un criterio estrictamente numérico, se puede asegurar que en los tres países se han realizado avances muy disímiles en estos campos ${ }^{92}$. De un total de 121 textos recopilados, 53 tratan sobre sistemas de partidos, 28 sobre sistemas electorales, 17 sobre partidos y 23 pueden considerase mixtos en tanto tratan varios de esos temas conjuntamente. En Bolivia se encuentra el mayor número de libros y artículos (46 en total), conformados principalmente por análisis de sistema de partidos boliviano (con 19 textos) $)^{93}$. En cambio, son pocos los estudios comparativos desarrollados por

estudios de Dieter Nohlen sobre sistemas electorales (Nohlen, 1993; 1995; Nohlen et al, 2005). Así mismo se encuentran importantes acercamientos en Alcántara (2004), Tuesta (1999 y 2005a), Aguinaga (2005), Zovatto (2005), Pérez-Liñán (2002), Rodríguez y Pizarro (2005) y en los estudios de académicos norteamericanos como Mainwaring y Scully (1995), Snyder y Samuels (2001), Dix (1989), entre otros.

91 Nuevamente cabe destacar el trabajo del equipo de la Universidad de Salamanca (Alcántara y Freidenberg, 2001) y recientemente la investigación impulsada por IDEA, que ha incursionado en los partidos por dentro (Roncagliolo y Meléndez, 2007). Acercamientos comparativos en torno a estos países se encuentran en Tanaka (2005a y 2005b), Tuesta (2005), Aguinaga (2005), Zovatto (2005), Freidenberg (2005) y Pachano (2005a).

${ }^{92}$ Esta apreciación numérica se refiere tanto a las publicaciones de circulación internacional, como a los libros y artículos que solamente están disponibles en bibliotecas y librerías en cada uno de los tres países. En el trabajo de campo de esta investigación he destinado un gran esfuerzo a la recolección del material bibliográfico, ya que la mayor parte de la producción de cada país solamente se encuentra dentro de sus fronteras. Estoy plenamente conciente de que es imposible considerarlo como un recuento exhaustivo, pero sí se lo puede tomar como una muestra relativamente representativa.

${ }^{93}$ Una fuente muy importante para el seguimiento y análisis de los procesos electorales es la revista Opiniones y Análisis, lo que demuestra la importancia de una publicación periódica para el desarrollo del trabajo académico. Por otra parte, la Corte Nacional Electoral impulsó la difusión de las cifras electorales y de análisis al respecto, lo que encuentra su parangón en la actividad que comenzó a 
académicos bolivianos o en los que se incluya a Bolivia dentro de estudios comparados. En Ecuador y Perú la cantidad de textos es significativamente menor (con 28 y 23, respectivamente) y predominan también los estudios de sistemas de partidos (12 y 10), seguidos por los de elecciones y sistemas electorales ( 9 y 7 ), por los de partidos ( 7 y 1$)$ y por los mixtos ( 1 y 6 ). Llama la atención el bajo número de estudios sobre partidos en Perú, esto es, sobre aspectos que hacen relación a su organización, a la vida interna, a los arreglos políticos, a la toma decisiones, entre otros, lo que puede obedecer a la ausencia de ellos en la escena política durante más de una década. Tampoco es el fuerte de estos países la comparación, aunque en Perú se advierte el nacimiento de una tendencia en ese sentido $^{94}$. Perú es, entre los tres, el país que muestra un menor número de estudios en el conjunto de temas.

En parte es posible explicarse estas diferencias cuantitativas por las propias características de los sistemas de partidos y de las contiendas electorales en cada uno de los países. Se puede suponer que la consolidación de un sistema multipartidista moderado, que a su vez expresaba el consenso en torna a la democracia como régimen político y por consiguiente la legitimidad alcanzada por la competencia política, fueron incentivos de importancia para el estudio de estos temas en Bolivia. Por el contrario, el colapso del sistema de partidos y la pérdida de legitimidad de los procesos electorales pueden haber influido en el escaso interés que despertaron en Perú durante más de una década. Sin embargo, la forma en que se produjo la restauración de la democracia, con alta participación social y política que requería de formas organizativas estables e institucionalizadas, puede haber influido decisivamente para que la atención de los académicos se dirija a estos temas. En el caso de Ecuador se puede suponer que el predominio de las relaciones clientelares -que tienden a colocar a los partidos en un segundo plano a pesar de que son utilizados como instrumentos- se expresó en el mundo académico en algo cercano a la indiferencia. Además, dentro de este ámbito no son pocas las voces que constantemente cuestionan la validez de los procesos electorales como

desarrollar la Oficina Nacional de Procesos Electorales, ONPE, de Perú (especialmente con la publicación de su revista Elecciones). Ecuador es el país que menos avances muestra en este ámbito. ${ }_{94}$ Los primeros avances en este sentido son los que viene realizando Martín Tanaka, quien ha abordado temas transversales a los cinco países integrantes de la Comunidad Andina de Naciones. También cabe destacar los esfuerzos iniciales que está haciendo el grupo de académicos de Ciencia Política de la Pontificia Universidad Católica del Perú, en Lima. Además de estos deben tomarse en cuenta las investigaciones que viene desarrollando Ágora Democrática, conjuntamente con Idea Internacional, que al tener su sede en Lima logra una mayor incidencia entre la comunidad académica peruana. 
mecanismos de expresión y de canalización de las demandas ciudadanas, así como a los partidos en tanto instituciones básicas para la representación.

También es posible encontrar explicaciones en la evolución previa de las ciencias sociales en cada uno de los países, esto es, en la herencia de la que se han nutrido quienes desarrollan actualmente sus actividades en la ciencia política. En este plano es posible afirmar que Perú contó con un desarrollo más temprano, especialmente en las décadas de 1970 y 1980, cuando existió una producción considerable de estudios en diversos campos, entre los que se destacó el de los estudios políticos (junto al de la historia, que ocupó un lugar destacado) ${ }^{95}$. Este proceso se vio afectado en alguna medida por las condiciones adversas del régimen fujimorista, pero constituyó una base relativamente sólida para el posterior resurgimiento. Bolivia, por su parte, contó con una trayectoria de ensayismo centrada sobre todo en la búsqueda de explicaciones de la revolución de 1952. La necesidad de comprender el tipo de Estado que había nacido a partir de aquel proceso y la capacidad (o incapacidad) de éste para lograr la inclusión de los sectores populares predominó durante varias décadas ${ }^{96}$. Finalmente, Ecuador fue también heredero de una tradición ensayística que, sin embargo, tuvo rupturas que significaron largos períodos de silencio. Durante las décadas de 1970 y de 1980 se produjeron los primeros intentos de explicar la política desde las ciencias sociales, pero se puede afirmar que es solamente desde la década de 1990 cuando se comienza a trabajar -de manera muy incipiente, por cierto- en el campo específico de la ciencia política ${ }^{97}$.

\footnotetext{
95 Me refiero, fundamental pero no exclusivamente, a los trabajos de Aníbal Quijano, Julio Cotler, Henry Pease, Rolando Ames, Alberto Flores, que abrieron líneas de investigación en el campo de la política. Así mismo, ha sido de mucha importancia para la constitución de un conocimiento acumulativo la permanencia de entidades de investigación como el Instituto de Estudios Peruanos, que ha mantenido a la reflexión sobre lo político como una de sus prioridades.

${ }_{96}^{6}$ Se destacan en este caso los trabajos de Jaime Almaraz Paz, Augusto Céspedes y, ya como un paso inicial dentro de las ciencias sociales, los de René Zavaleta. Desde la década de los ochenta se cuenta con la producción de autores como Fernando Calderón, Jorge Lazarte, René Mayorga y Carlos Toranzo que, conjuntamente con investigadores bolivianos y extranjeros (como Jean Perre Lavuad y James Malloy), sentaron las bases para el desarrollo posterior.

${ }_{97}$ Durante las décadas de 1910 y de 1920 se produjeron ensayos de gran valor en torno al tema del concertaje, que implícita o explícitamente abordaban el campo político desde la perspectiva de la construcción del Estado-nación. Sin embargo, por lo menos hasta la década de 1970 no se puede identificar algún aporte sustantivo en el campo político. Los trabajos de Agustín Cueva y de Osvaldo Hurtado constituyen una ruptura de ese silencio y a la vez el inicio de la reflexión desde las ciencias sociales. Los aportes de Rafael Quintero y Juan Maiguashca se destacan en esos años iniciales. Una nueva perspectiva, inserta ya en la ciencia política, se inicia a mediados de la década de 1980 con el trabajo de Amparo Menéndez sobre el clientelismo..
} 
Un factor explicativo adicional se encuentra en el grado de profesionalización de la ciencia política en cada uno de los países. En Bolivia se instauró una carrera de esa disciplina en el año 1983 y existen dos programas de maestría (Varnoux, 2005: 92, 96), en tanto que en Perú recién se la estableció en el año 2005 y cuenta también con una maestría (Tanaka, 2005: 227) y en Ecuador han existido tres programas que no han tenido regularidad y mantiene en funcionamiento una maestría y un doctorado en ciencias sociales con especialización en ciencia política (Mejía, Freidenberg y Pachano, 2005: 156). En todos los casos se cuenta con especializaciones en ciencia política dentro de las escuelas de sociología, lo que explica el escaso desarrollo autónomo de la disciplina y la gran influencia de la visión sociológica (y también antropológica). Se trata, por tanto de un campo relativamente nuevo en los tres países, que no ha podido aún adquirir su identidad y que no ha logrado institucionalizarse debido a que "sus integrantes no comparten similares técnicas metodológicas ni tampoco una literatura común” (Mejía, Freidenberg y Pachano, 2005: 156).

Los resultados de este bajo grado de desarrollo de la ciencia política se hacen evidentes en los estudios sobre partidos, sistemas de partidos y sistemas electorales (y muchos más en los estudios sobre la relación entre poderes del estado, tratada en la primera sección de este capítulo) que, como he señalado antes, son relativamente recientes en los tres países. En buena parte de ellos se advierte alguna influencia de las perspectivas de análisis predominantes en la ciencia política contemporánea. Por consiguiente, una alta proporción de los estudios ha adoptado una perspectiva cercana al institucionalismo y ha dado también mucha importancia a las conductas de los actores. Acogiendo la clasificación de Ware (2004: 35 y ss.), se puede asegurar que la mayoría de autores se ha encaminado tanto por el enfoque institucional como por el de la competencia (que al decir del mismo autor son variantes de una misma perspectiva), mientras ha tendido a relegar a segundo plano el enfoque sociológico. Esto constituye hasta cierto punto una ruptura con la visión que se generalizó en las décadas anteriores, caracterizada precisamente por el predominio de un enfoque sociológico-estructural que prestaba escasa atención a las instituciones y a los actores. Pero lo es solamente hasta cierto punto, ya que aún conserva alguna fuerza el enfoque que considera a los partidos (a sus posiciones y a sus comportamientos) como el resultado directo y casi mecánico de las condiciones sociales. De manera especial en Ecuador se tiende a explicar las acciones y conductas de los actores políticos, así como los resultados de los procesos electorales, a 
partir de los clivajes sociales o por derivación directa de las condiciones estructurales (Quintero, 2002; 2005). Así mismo, aún ocupan un campo muy amplio las explicaciones culturalistas, más cercanas a la antropología que a la ciencia política, que no prestan atención al desarrollo disciplinario que se ha producido en las últimas décadas y enfrentan estos temas sin un criterio de conocimiento acumulativo (Bustamante, 2000).

A pesar de todo ello, se pueden identificar algunos resultados positivos. Esta, que podría considerarse como una nueva generación de estudios políticos, ha hecho posible que actualmente se disponga de mejor y más abundante conocimiento sobre los partidos, los sistemas de partidos y los sistemas electorales de cada uno de los países. La mayor parte de autores se han orientado por el estudio de caso, concentrándose en uno solo de los países. Pero, dentro de las limitaciones de una disciplina que está dando sus pasos iniciales, también es factible encontrar estudios transversales de partidos (Alcántara y Freidenberg, 2003), análisis comparativos de sistemas de partidos (Payne et al, 2003, Sample y Zovatto, 2005; Pachano, 2005a; 2005b;) y de los sistemas electorales (Aguinaga, 2005; Tuesta, 1999; 2005a; 2005b). Así mismo, se cuenta con estudios acerca del financiamiento de los partidos y de la política en general (Payne et al, 2003; Griner y Zovatto, 2004) y sobre el surgimiento de partidos de origen étnico (Van Cott, 2000; 2003; 2004; Collins, 2001; Sánchez y Freidenberg, 1998; Cordero, 2008). Sin embargo, hay temas que no han recibido mayor atención en términos comparativos, como el comportamiento electoral de la población (Zovatto, 2005) y la participación de las mujeres en la política (Sample, 2005).

A pesar de los avances realizados, no se dispone de estudios comparativos de temas sumamente importantes y que han tenido fuerte impacto en el desarrollo político de los tres países, como la evolución de los sistemas de partidos. Se puede conocer con cierto detalle lo que ha ocurrido en este aspecto en cada uno de los países, pero aún está pendiente un estudio comparativo que pueda identificar las causas de la conformación de sistemas muy diferentes y sobre todo de la distinta evolución que ellos han tenido. Un estudio de este tipo permitiría conocer las similitudes y las diferencias, de modo que se podría contar con explicaciones más precisas que las que se pueden extraer del estudio de caso. En este plano no solamente se han formulado explicaciones adecuadamente sustentadas en cada uno de los países, sino que además se han desarrollado interesantes debates al respecto (Tanaka, 2001; Gamarra, 1992; Mayorga, 1992), pero están pendientes 
los estudios que, al abarcar varios países y diversas etapas históricas, puedan contribuir a sustentar con mayor firmeza aquellos planteamientos. Lo mismo se puede decir de otros temas, como la organización interna de los partidos y el desarrollo de los procesos electorales.

Cualquier estudio comparativo debe tratar no solamente con las semejanzas, sino también con las diferencias que existen entre las unidades sujetas al análisis. El objetivo de este tipo de estudios consiste precisamente en explicar unas y otras, con el fin de identificar los factores determinantes de ellas. Es ampliamente aceptada la perspectiva que sostiene que "La comparación es un método de control de nuestras generalizaciones" (Sartori, 1999a: 29), vale decir, que es posible identificar las variables que, en condiciones relativamente parecidas, producen resultados similares o diferentes. De ahí la importancia de destacar las diferencias y no restringirse únicamente a las semejanzas. De ahí también la importancia del tratamiento de este tema para el análisis de la calidad de la democracia que, como se verá en el capítulo IV, lo incluye como uno de los componentes básicos en su medición y en su evaluación.

Dentro de esta visión es importante destacar que los arreglos que se establecen en el nivel de las instituciones y de los procedimientos determinan las estrategias de los actores y por tanto delimitan el espacio para los resultados. En el campo específico de los partidos y sistemas de partidos es ampliamente conocida la influencia de esta perspectiva, especialmente desde ya citada formulación original de Duverger (1988: 245 y ss.). A partir de ese punto se ha avanzado significativamente en este campo, no sólo en términos conceptuales sino sobre todo en el estudio empírico ${ }^{98}$. Dentro de ese desarrollo teórico y conceptual, uno de los hallazgos más importantes es el que hace relación a los condicionamientos institucionales de las estrategias de los actores ${ }^{99}$. Al encontrarse condicionadas esas estrategias por las regulaciones institucionales, éstas pasan a convertirse también en objeto de la confrontación política, lo que se expresa claramente en las propuestas de cambio de los diseños existentes y su reemplazo por formas que satisfagan los intereses de los sectores que se sienten excluido o que buscan contar con

${ }^{98}$ Existe abundante literatura al respecto, de manera que cualquier intento de citarla corre el riesgo de dejar fuera no solo una buena parte de ella sino contribuciones de mucha importancia. Sin embargo, cabe destacar los aportes hechos en este campo por Shugart y Taagepera (1989), Lijphart (1994; 2000), Nohlen, 1995), Sartori (1996), Alcántara (2004), Gunther, Montero y Linz (2002) y Colomer (2001)

${ }^{99}$ Este se nutre parcialmente de las propuestas originadas en el planteamiento de Anthony Downs sobre los cálculos estratégicos de los actores, siempre delimitados por las restricciones institucionales (Downs, 1957). 
mejores condiciones (Colomer, 2004). La disputa por las reglas electorales, que ha predominado en la arena política de los tres países por lo menos durante los últimos quince años, es la mejor expresión de la importancia que los propios actores le asignan al nivel institucional, lo que se justifica plenamente en tanto es el que determina las reglas de juego y condiciona en gran medida los resultados.

Como cierre de esta breve digresión, considero conveniente explicar la importancia atribuida a los partidos, los sistemas de partidos y los procesos electorales en el presente capítulo. Es notorio el mayor espacio asignado a este tema, en referencia a las relaciones entre los poderes del Estado, tratado en la primera sección, lo que se explica fundamentalmente porque las relaciones entre el ejecutivo y el legislativo están sujetas a menores variaciones que los sistemas electorales y los sistemas de partidos. Las primeras están fuertemente determinadas por el carácter presidencial del régimen de los tres países, lo que marca límites más estrechos y por consiguiente deja un espacio relativamente reducido para las variaciones. De acuerdo a las características de ese tipo de régimen cabe esperar que sean relaciones tensas, cargadas de conflictos y sujetas a múltiples obstáculos difíciles de erradicar por medio de arreglos institucionales (Linz, 1993; 1996; Linz y Valenzuela, 1994; Sartori, 1996; Mainwaring y Shugart, 1997; 2002; Conaghan, 1994). En términos generales, las relaciones entre los poderes dentro de un determinado tipo de régimen (en este caso el presidencial que rige en los tres países) presentan menos elementos variables que los que se derivan de los sistemas de partidos y los sistemas electorales ${ }^{100}$.

El espacio asignado a los partidos se explica también por la incidencia que tiene su desempeño a lo largo del tiempo sobre la calidad de la democracia. Al constituir los partidos uno de los elementos centrales de la representación política, lo que ocurra con ellos será determinante para definir las características y las especificidades de la democracia. Su consolidación -o, por el contrario, su debilitamiento- como instancias de agregación de intereses y como correas de transmisión de las demandas ciudadanas, definirá en gran medida lo que ocurra en el conjunto del sistema político. Desde esa

100 Esto no significa relegar a un segundo plano las diferencias que existen en el plano de las relaciones entre el ejecutivo y el legislativo. Es indiscutible el efecto que tuvieron a lo largo del período las dos características que marcan la diferencia entre Bolivia y los otros dos países, esto es, la elección del presidente en el congreso y el voto único para presidente y una parte del congreso. Como se vio en la primera sección, a partir de ellas se pueden explicar muchas de las conductas y de las prácticas políticas que caracterizaron a la política boliviana. Sin embargo, ellas no llevan a la configuración de un tipo de régimen sustancialmente diferente al de los otros. 
perspectiva, el colapso de los sistemas de partidos en los tres países, reseñado en este capitulo, es uno de los elementos explicativos de las condiciones de sus respectivas democracias.

\section{Distribución territorial del poder}

La distribución territorial del poder político - un aspecto que incide en la calidad de la democracia- es de reciente interés para la ciencia política. Por consiguiente, es poco lo que se ha avanzado en términos de la reflexión teórica y conceptual, especialmente si se lo compara con los dos temas tratados en las secciones anteriores. Por lo general, se lo ha abordado, indirectamente, desde la perspectiva de la descentralización o por los estudios de la distribución de la votación de los partidos a lo largo del territorio nacional. Los estudios sobre descentralización (realizados en mayor número con objetivos de planificación que con fines académicos), se han preocupado fundamentalmente de la formulación y la gestión de políticas públicas, relegando a un segundo plano el juego político, las relaciones de poder y en general las estructuras políticas que se conforman en los niveles subnacionales.

Los estudios sobre la distribución territorial de la votación, por su parte, se han concentrado en el desempeño de los partidos en los procesos electorales, de modo que han llevado a destacar las diferencias de votación a lo largo del espacio nacional Jones y Maiwaring, 2003; Pachano, 2004b), la relación entre el número de electores y el número de escaños, bajo el concepto de desproporción (malapportionment) (Snyder y Samuels, 2001), la incidencia de los componentes del sistema electoral en el desempeño de los partidos en el nivel local (Morgenstern y Swindle, 2005) y la relación entre el nivel nacional y el local en el desempeño de los partidos (Freidenberg y Alcántara, 2001; Anckar, 2000; Park, 2003; Snyder y Samuels, 2001; Morgenstern y Swidle, 2005). Todos estos temas estuvieron precedidos por los aportes de trabajos que buscaron detectar la influencia de la magnitud y el número de circunscripciones electorales sobre el comportamiento de los partidos y sobre los resultados de las elecciones (Duverger, 1988; Taagepera y Grofman, 2003; Park 2003; Nohlen, 1995; Sartori, 1992).

En la presente sección me mantendré básicamente en el marco de esta última corriente, lo que significa que restringiré el análisis básicamente al desempeño de los partidos en los 
procesos electorales. Pero, a la vez exploraré la conformación de sistemas subnacionales de partidos, que es sin duda un tema novedoso y escasamente trabajado. Mi interés en estos dos aspectos se deriva de la incidencia que la implantación territorial y el desempeño de los partidos en los niveles subnacionales pueden tener sobre la democracia. Mi hipótesis al respecto es que el desempeño uniforme de un partido en términos territoriales produce condiciones positivas de representación ya que se constituye en un incentivo para su definición como partido nacional y, derivado de ello, es también un estímulo para la agregación de intereses. En otras palabras, un partido que obtiene su votación en el conjunto del territorio nacional sin mayores distorsiones con respecto a la distribución de la población, tiende a construir su agenda con los temas de carácter nacional, sin restringirse a los de localidades específicas. Por el contrario, la distribución territorialmente dispar de la votación de un partido tiende a transformarlo en una organización de arraigo local, con propensión a representar intereses específicos.

Para desarrollar esta perspectiva es necesario señalar que existe votación uniformemente distribuida en el espacio nacional cuando la proporción que obtiene en cada espacio subnacional no se aleja significativamente de la proporción que ese espacio representa en el total nacional. Así, si un determinado espacio subnacional (una provincia, un departamento o cualquier unidad con la que se trabaje) acoge al $X \%$ del electorado nacional, cada partido político deberá obtener en ese espacio aproximadamente el $X \%$ de su propia votación nacional ${ }^{101}$. Obviamente, por un conjunto de factores sociales, económicos, políticos e institucionales, es poco probable que exista perfecta coincidencia entre ambos términos. El análisis comparado demuestra que siempre se encuentran distorsiones, que se expresan en diferencias entre la distribución de la votación de los partidos y la distribución de la población o del electorado nacional (Jones y Maiwaring, 2003). De esa manera, se constituyen bastiones electorales, entendidos como los espacios en que un partido obtiene una proporción de su votación nacional significativamente más alta que la proporción de la población de ese espacio sobre el total nacional.

La conformación de bastiones pone sobre la mesa tres temas de importancia para el desempeño de los partidos y en general para las condiciones en que se desarrolla la política en el nivel nacional. En primer lugar, un partido que cuente con uno o más

101 Este supuesto me llevó a la construcción del Índice de Distribución Territorial, IDT, un instrumento para medir la distribución territorial de la votación, que explicaré y utilizaré más adelante. 
bastiones inevitablemente -por simple lógica aritmética- obtendrá en otros espacios proporciones de su votación menores a la proporción de la población de estos. Por tanto, tenderá a sobrerepresentar a unos espacios y a subrepresentar a otros, lo que puede llevar a privilegiar los intereses de los primeros en menoscabo de los últimos ${ }^{102}$. En segundo lugar -de la misma manera que ocurre en el campo militar, del cual viene la noción de bastión-, éste puede constituirse en una fortaleza en la que predomina un partido, sin que a ella puedan acceder otros partidos. Pero, cabe aclarar que esto se cumple solamente en el caso de partidos que cuentan con altas proporciones de votación tanto en ese espacio subnacional como en el nivel nacional, mientras que un partido pequeño puede obtener una alta proporción de su votación en un espacio subnacional sin que éste actúe como una fortaleza a la que no pueden acceder los otros. En consecuencia, en este último caso no existe un bastión en la acepción original (militar) del término. En tercer lugar, las distorsiones de la votación con respecto a la distribución de la población nacional marcan diferencias y a la vez establecen relaciones complejas entre el juego político nacional y el subnacional. Un resultado de esto es la vinculación, que he venido señalando, de los partidos con intereses de espacios subnacionales claramente definidos, lo que transforma a estos intereses en factores de importancia en el juego político nacional. Un segundo resultado es la instauración de juegos políticos propios o específicos en esos niveles subnacionales o, dicho de otra manera la conformación de múltiples arenas políticas diferenciadas de la nacional, lo que se expresa en la conformación de sistemas subnacionales de partidos y demuestra la importancia de su estudio. Un tercer resultado es la compleja relación que se establece entre el juego nacional y los diversos juegos subnacionales, que obliga al desarrollo de estrategias múltiples por parte de los partidos y que introduce una serie de dimensiones que deben ser consideradas en el análisis del desempeño de la política.

Con estos elementos cabe dar unos pasos hacia atrás y preguntarse por las causas de la distribución irregular de la votación de los partidos en términos territoriales y, por tanto, de la conformación de bastiones y de sistemas subnacionales de partidos. La primera causa es la existencia de espacios subnacionales claramente diferenciados en términos

102 Obviamente, esa relación podrá ser alterada de acuerdo a la estrategia que defina el partido. Si privilegia la consolidación de sus bastiones se mantendrá esa situación de fortaleza en unos lugares y de debilidad en otros. Por el contrario, si la estrategia está orientada a la penetración en los espacios en que es débil, se verá obligado a hacerse cargo de los intereses de específicos de estos o a impulsar propuestas de alcance nacional que puedan recibir apoyo en unos y otros. Como se verá más adelante, la consolidación de bastiones tiende a imponerse ya que es altamente satisfactoria en términos de costo-beneficio. 
económicos, sociales y culturales, que pueden constituirse como sociedades regionales (Pachano, 2006). Por tanto, las diferencias en la distribución de la votación serían la expresión política de un clivaje territorial. Sin embargo, la existencia de esos clivajes presentes en la mayor parte de países del mundo- no siempre encuentra su expresión política en la votación diferenciada de los partidos o en otras manifestaciones. Para que esas características territoriales se manifiesten políticamente debe concurrir una serie de elementos estructurales e históricos que, finalmente, llevan al surgimiento de identidades regionales o locales (Lijphart, 1969; 1989; Lipset y Rokhan, 1967; Dix, 1989; Jones, 2004; Zielinski, 2002) ${ }^{103}$.

Pero, además de esos factores es posible que la traducción de los clivajes en expresiones políticas se deba al diseño institucional del sistema político, que constituye la segunda causa que considero necesario destacar. En efecto, es probable que en muchos casos la relación se plantee de manera inversa, esto es, que los componentes del sistema político determinen la expresión de los factores estructurales y que no sean estos los que condicionen a aquellos. De esta manera, se puede sostener que "si no identificamos primero las estructuras políticas -y en particular la estructuración de los partidos- es probable que olvidemos la pregunta crucial: “¿Cómo es posible que unas estructuras socioeconómicas similares no se traducen [traduzcan, SP] en sistemas de partidos similares?" (Sartori, 1992: 227, cursiva en el original). Por tanto, en muchos casos los clivajes tenderían a tomar forma política por el efecto de los diseños institucionales y, así mismo, estos podrían evitar -o por lo menos minimizar- la traducción de los clivajes en expresiones políticas.

La realidad de cada uno de los tres países estudiados presenta especificidades en estos aspectos. La existencia de partidos que distribuyen de manera heterogénea su votación en el respectivo territorio nacional es una de las características de los sistemas de partidos de Bolivia y Ecuador (Romero, 2003; Freidenberg y Alcántara, 2001a; Pachano, 2004a), pero

103 Lipset y Rokhan (1967: 112) sostienen que los clivajes no se traducen automáticamente en posiciones de los partidos, sino que "el punto crucial en la discusión de la traducción de los clivajes estructurales en los sistemas de partidos depende de los costos y beneficios de las alianzas y coaliciones". Considero que, siendo acertada parcialmente, es una visión muy estrecha, ya que a pesar de que siempre se debe subrayar la ausencia de cualquier traducción automática de los clivajes en el plano político -como lo he sostenido antes-, la alusión exclusiva a los costos y beneficios de las alianzas no permite dar cuenta de toda la complejidad del problema. Un análisis más profundo de la expresión de los clivajes en el plano político se encuentra en la reflexión de Lijphart (1969; 1989; 2000) sobre las sociedades plurales y la democracia consociativa o consociacional, que abordé en el capítulo I. 
no aparece de la misma manera en Perú (Vergara, 2007). Para seguir con la reflexión anterior, se puede sostener que la causa de esta diferencia se encuentra, por un lado, en la existencia de clivajes territoriales en los dos primeros países y su ausencia en el último o, por otro lado, en los diferentes diseños institucionales vigentes en cada uno de ellos.

Para valorar el peso de la primera causa es necesario considerar brevemente que en los tres países se han conformado históricamente sociedades regionales claramente diferenciadas, pero en Perú éstas no encuentran la expresión política que tienen en Bolivia y Ecuador ${ }^{104}$. Los espacios subnacionales peruanos están eclipsados por el enorme peso que tiene la ciudad de Lima en términos económicos y demográficos. Allí se asienta el 28\% de la población total peruana (Murakami, 2007: 72) y se genera más del $35 \%$ del PIB. Esto no tiene parangón con lo que ocurre en los otros dos países, donde existe una multipolaridad, con ciudades y regiones que mantienen cierto equilibrio poblacional y económico (La Paz, Santa Cruz y Cochabamba, en Bolivia, Quito, Guayaquil y Cuenca, en Ecuador). Por consiguiente, hay una base estructural diferente, que lleva a la conformación de espacios socioeconómicos, culturales y políticos claramente diferenciados dentro de Bolivia y Ecuador. En Perú, a pesar de las enormes diferencias regionales (Murakami, 2007), no se han conformado sociedades regionales que puedan incidir significativa y persistentemente en la política.

El peso de la segunda causa o explicación se puede encontrar en gran medida en ciertas características del sistema electoral. Durante la mayor parte del período estudiado, en Perú se utilizó una circunscripción única nacional para la elección de los integrantes del Congreso, lo que constituyó un desincentivo para la conformación de partidos de base local para competir en la arena nacional. Bolivia y Ecuador utilizaron a sus unidades político-administrativas (departamentos y provincias, respectivamente) como circunscripciones electorales, lo que fue un estímulo para cultivar las bases territoriales de los partidos. En ambos países se generalizó la noción del diputado como representante territorial, a la que aludí en la sección anterior, lo que llevó al fortalecimiento de los lazos con su localidad de origen, en tanto que el diseño peruano abría muy poco espacio para esta figura. Adicionalmente, ésta se fortaleció en Bolivia con la incorporación de los

104 Como he mencionado antes, las sociedades regionales son espacios en los que se estructuran relaciones económicas específicas, se establecen tejidos sociales particulares, se construyen pautas culturales y de comportamiento distintas a las del resto del país, se instauran mecanismos propios de legitimación de la acción social y política y se constituyen estructuras de poder también característicos de ellas (Pachano, 1985; Maiguashca, 1988). 
diputados uninominales y en Ecuador con la posibilidad de presentar candidaturas apenas con el respaldo de firmas recogidas en la circunscripción de elección.

Por otra parte, en el mismo campo institucional, en Bolivia y Ecuador se impulsaron procesos de descentralización que fortalecieron a las instancias políticas subnacionales, en tanto que en Perú hubo retrocesos en ese sentido. En efecto, Ecuador es heredero de una larga historia de municipios y consejos provinciales elegidos por votación popular (los primeros desde fines del siglo XIX y los últimos desde mediados del siglo XX) y dotados de autonomía administrativa y económica. En Bolivia se inició un proceso bastante ambicioso con la promulgación de la ley de participación popular, en 1993, que continuó con la elección de prefectos desde 2006. En Perú, por el contrario, durante el período autoritario de Fujimori se retrocedió en los intentos de descentralización y de regionalización que se habían iniciado en el gobierno de Alan García. Se eliminaron las elecciones directas en el nivel regional que recientemente había sido instaurado y se sometió económica y administrativamente a los municipios.

De esta manera, Perú aparece como un caso muy diferente al de los otros dos países en los dos niveles identificados como causantes de la traducción de los clivajes en el plano político. Es posible sostener que la ausencia de lo regional en la política peruana se derive de la combinación de ambas causas, que se potenciarían mutuamente. La debilidad de las sociedades regionales se vería agudizada por los elementos propios del diseño institucional, especialmente por los que corresponden al sistema electoral como los que definen la estructura política administrativa de los niveles subnacionales. Esa misma relación, pero a la inversa, se encontraría en Bolivia y Ecuador, donde la existencia de fuertes y diferenciadas sociedades regionales se fortalece con algunos elementos del diseño institucional, especialmente -pero no exclusivamente- del sistema electoral.

El peso de lo regional en Bolivia y Ecuador $-\mathrm{y}$, por cierto, sus diferencias- se hace evidente cuando se analizan los dos aspectos que he venido mencionando, esto es, la distribución territorial de la votación de los partidos y la conformación de sistemas subnacionales de partidos ${ }^{105}$. Mi interés, como lo he venido señalando, es destacar la

105 La exclusión de Perú en el siguiente análisis obedece a las razones expresadas en los párrafos precedentes, pero también a la inexistencia de diputados elegidos en alguna circunscripción subnacional en casi la totalidad del período considerado. Solamente desde el año 2006 se ha eliminado 
importancia de la distribución territorial de la votación de los partidos como elemento determinante de su comportamiento, para lo cual me sirvo del Índice de Distribución Territorial, IDT, como herramienta de medición ${ }^{106}$. Para ello he tomado las elecciones de diputados realizadas en cada uno de los dos países en el año 2002. La selección de este tipo de elección -y no las presidenciales o las municipales- obedece a que son las que expresan de mejor manera la votación del partido, en tanto que en las otras inciden en mayor medida las características individuales de los candidatos y están orientadas por temas (issues) generalmente diferentes a los que definen a los partidos. Para el caso boliviano, que cuenta con dos cámaras y con un sistema mixto por el cual se elige a diputados uninominales y plurinominales de manera separada, he tomado solamente a los diputados de esta última en la cámara baja. Hago mío el supuesto de que esta última es una votación que se define en mayor grado por las propuestas del partido y por las adscripciones a éste, en tanto la votación de los uninominales está fuertemente influida por la persona del candidato (Romero, 2005; Mayorga, 2004; Ardaya, 2003).

Como he señalado antes, ambos países utilizan la división político-administrativa para establecer las circunscripciones electorales, lo que determina que el número de estas sea relativamente grande en Ecuador, con 22, y más bien pequeño en Bolivia, con 9. Esto marca una diferencia importante, debido a la incidencia del número de circunscripciones en la medición final de la distribución territorial de la votación. En los cuadros números 11a y 11b se observa la distribución de las circunscripciones electorales en cada uno de los países, con sus respectivos tamaños de población. Así mismo, se ve que, a pesar del menor número de unidades subnacionales, el rango (la diferencia entre los extremos) es mayor en Bolivia, pero también es más alta la media de tamaño de las circunscripciones.

la circunscripción única nacional y se ha utilizado (hasta ahora por una sola ocasión) a los departamentos como circunscripciones electorales.

${ }^{106} \mathrm{El}$ índice se expresa como IDT $=\left(\Sigma\left|\mathrm{P}_{\mathrm{n}}-\mathrm{V}_{\mathrm{n}}\right|\right) / 2$, donde $\mathrm{P}_{\mathrm{n}}$ es el peso de la provincia en el padrón electoral y $\mathrm{V}_{\mathrm{p}_{\mathrm{n}}}$ es el peso de la votación provincial sobre la votación nacional del partido. Por consiguiente, mide las distancias de la votación de cada partido con respecto a la proporción de votantes de cada unidad subnacional (expresadas en las diferencias absolutas). El IDT se expresa en una escala de 0 a 100, en que 0 constituye la mejor distribución, como corresponde a la medición de una brecha (Pachano, 2004: 86). Este índice lo desarrollé fundamentalmente durante una estadía como Visiting Fellow en el Kellogg Institute de la Universidad de Notre Dame. Fueron muy valiosos los comentarios de Scot Mainwaring y de Andrés Mejía a las primeras versiones. De acuerdo a la información de que dispongo, solamente se ha construido un instrumento para medir la distribución territorial de la votación de los partidos políticos en los términos que se será tratada aquí. Se trata del indice de nacionalización (PNS, Party Nacionalization Score) de Mainwaring y Jones (2004: 142), que utiliza el coeficiente de Gini invertido. Considero que ambos son compatibles y su uso conjunto puede ser beneficioso para la investigación. 
Entre los dos elementos -el número y el tamaño medio- existe mutua interacción. El reducido número de circunscripciones, como ocurre en Bolivia, se convierte en un imperativo para que los partidos presenten candidatos en todas o en la mayor parte de ellas. No hacerlo equivaldría a reducir significativamente las posibilidades de obtener una buena votación a nivel nacional, ya que la ausencia en una sola circunscripción tiene un peso mayor que cuando el número de circunscripciones es alto. A esto contribuye la mayor magnitud de la media del tamaño de las circunscripciones, ya que expresa la importancia de cada una de ellas en el total nacional. Por consiguiente, entre ambos anulan las posibles interpretaciones que se pudieran desprender del rango muy amplio. En ese sentido, la dispersión es menor en el caso boliviano, a pesar de que la varianza sea significativamente más alta.

Un siguiente elemento a considerar es el número de partidos o de listas que se presentaron a la elección y el número de unidades en que lo hicieron. Este constituye un indicador de la importancia que le asignan los partidos a cada una de las unidades, así como del grado de implantación de los partidos en el territorio nacional. Los cuadros números 12a y 12b ofrecen una visión de cada uno de los países, de la que se desprende que en Bolivia hay una alta proporción de partidos (50\%) que presentan candidatos en todos los departamentos. En el otro extremo, solamente dos partidos de un total de 18 (esto es, el 11,1\%) presentaron candidatos en un solo departamento. Por el contrario, en Ecuador solamente un partido (equivalente al 4,2\%) presentó candidatos en todas las provincias, mientras siete $(29,2 \%)$ presentaron candidatos en una sola provincia. En promedio, cada partido boliviano presentó candidatos en 6,4 departamentos de un total de 9 , es decir, en el $71 \%$ de las posibilidades disponibles, en tanto que cada partido ecuatoriano presentó en 8,5 provincias que equivalen al 38,8\% del total. Este constituye ya un antecedente para obtener diferencias sustanciales en la distribución territorial del sistema de partidos en su conjunto.

Se puede sostener, por consiguiente, que el número de circunscripciones influye en estos resultados. La mayor cantidad de unidades subnacionales existente en Ecuador podría encontrarse en la base de ese comportamiento de los partidos, ya que estos pueden tomarla como un incentivo para presentarse solamente en algunas de ellas. Un simple cálculo de costo-beneficio puede llevar a que un partido deje de lado provincias de escasa población o a las que constituyen bastiones de otros partidos. Dado que pueden 
recuperar esa votación con relativa facilidad en otras unidades, no se transforma en un problema insubsanable. Por el contrario, en Bolivia conllevaría mucho riesgo abandonar cualquiera de los departamentos, talvez con la sola excepción del Beni que aporta con menos del 1\% de la votación nacional. En Ecuador hay siete provincias que están en esa condición, de manera que los partidos tienen más amplitud para la selección de las provincias en que pueden dejar de presentar candidatos, si con ello obtienen beneficios que justifiquen los costos de la ausencia. Como se verá más adelante, esto incide de manera indirecta en la desproporción de la distribución territorial.

Al observar la media del IDT de cada país (cuadros 13a y 13b), que puede considerarse como una medición de la distribución global del sistema de partidos, se puede observar claramente la diferencia entre los dos países. En Bolivia se sitúa en 44,43 mientras en Ecuador llega a 71,18. Así mismo, la dimensión de las brechas de cada partido expresa claramente las diferencias entre los dos países. Es evidente que los partidos bolivianos distribuyen su votación de manera más uniforme, lo que puede obedecer a las causas anotadas pero también puede tener relación con el número de partidos y con otros componentes del sistema electoral. Las facilidades de entrada a la contienda electoral que ofrece el sistema ecuatoriano pueden incidir en esa dirección, especialmente porque las agrupaciones de independientes -a diferencia de los partidos reconocidos legalmente como tales- no están obligadas a conformar listas nacionales para participar en las elecciones legislativas. Este es un aliciente para la multiplicación de listas restringidas a una provincia o a un pequeño número de ellas. Así se explica el alto número de listas que obtienen su representación exclusivamente en una provincia. Por otra parte, esas brechas pueden explicarse también por la flexibilidad que existe para la conformación de alianzas en los niveles subnacionales. Como he señalado en la sección anterior, estas pueden establecerse de manera totalmente autónoma de lo que sucede en el nivel nacional, lo que quiere decir que un partido puede formar una alianza diferente en cada una de las provincias (lo que se hace evidente en el cuadro 13b, en que un mismo partido aparece como parte de diversas coaliciones) ${ }^{107}$. De esta manera se multiplica el número de listas y

107 Es cierto que en algunos casos es posible considerar a esas listas como una expresión del partido que las ampara, pero en la mayoría de las ocasiones no se lo puede hacer por tres razones. Primera, porque para definir a qué partido se la puede asignar sería necesario contar con un criterio general esto es, aplicable a todos los casos-, lo que resulta prácticamente imposible por el carácter pragmático y no ideológico de las alianzas. Segunda, por el grado de autonomía que adquieren en la propia contienda electoral. Tercera, por su posterior desempeño relativamente autónomo en el congreso 
de partidos, y a la vez se distorsiona en mayor grado distribución territorial de la votación.

Finalmente, es probable que las brechas guarden relación con la forma de presentación de las listas y el tipo de voto. El sistema de listas abiertas y voto personalizado, utilizado en Ecuador, ofrece más posibilidades para opciones individuales que el de listas cerradas, utilizado en Bolivia. Las listas abiertas constituyen una invitación para la participación de un alto número competidores, ya que es posible obtener buenos resultados con los votos individuales. Esto deriva en el debilitamiento de los partidos por vía de la multiplicación de actores políticos, y en la reducción de un buen número de listas a espacios subnacionales muy específicos, que son los únicos lugares en donde pueden obtener puestos. La existencia de los diputados uninominales en Bolivia vendría a evitar este problema, ya que el fenómeno de la personalización y de la fragmentación se encauza de esa manera y puede ser controlado por las propias normas de la votación establecida para ese nivel.

Como he venido señalando, la forma en que los partidos distribuyen territorialmente su votación es uno de los elementos que determinan la orientación de sus políticas y definen también en gran medida su capacidad para agregar las demandas de la población. Un partido que logra una mejor implantación en todo el territorio dispondrá de mejores condiciones para formular políticas de alcance nacional y para tomar distancia con grupos económicos y sociales que puedan influir directamente en su orientación. Por el contrario, un partido que concentra su votación en una circunscripción determinada o en un número reducido de ellas encontrará siempre mayores obstáculos para alejarse de la influencia de los grupos que tienen peso político en esos espacios. Así, las posibilidades de unos y otros para formular políticas -y aplicarlas una vez llegados a las diversas instancias de gobierno- varían considerablemente. Desde esta perspectiva y de acuerdo a las cifras que arroja la aplicación del IDT, es posible suponer que buena parte de las diferencias en el comportamiento de los partidos en los dos países se explica por su implantación territorial. No es, obviamente el factor único, pero sí un elemento que tiene enorme peso en la definición de las orientaciones y de las pautas de conducta de los partidos y en general de los actores políticos. Basta considerar al respecto que resulta imposible comprender los procesos políticos ecuatorianos sin acudir a las diferencias regionales como variable explicativa, lo que incluso se manifiesta claramente en la 
estructuración de las candidaturas para la presidencia y la vicepresidencia de la República ${ }^{108}$. Por el contrario, a pesar de que en Bolivia se ha incrementado la demanda de autonomía regional de los departamentos de Santa Cruz, Tarija, Beni y Pando, hasta el momento las diferencias regionales no se han traducido en brechas de la magnitud que alcanzan en Ecuador y mucho menos en la conformación de bastiones electorales. Más allá de las distorsiones que podrían considerarse como naturales o propias de cualquier país, ellas no han alcanzado la dimensión de factor explicativo como sí lo han hecho en el caso ecuatoriano. Los grados sustancialmente diferentes alcanzados por el IDT en cada uno de los países expresan precisamente esas realidades diversas.

Estas diferencias entre los dos países se hacen evidentes también cuando se ve que varios de los partidos ecuatorianos más votados y con mayor trayectoria obtienen una alta proporción de su votación en una sola provincia, lo que no ocurre en Bolivia. En efecto, el PSC, el partido más votado durante quince años (1987-2002), obtuvo más de tres cuartas partes del total de sus votos $(78,5 \%)$ en la provincia de Guayas en la elección legislativa del año 2002. En esa misma elección, Izquierda Democrática, otro partido que ocupó el primer lugar durante ocho años (1984-1992) concentró su votación en Pichincha, donde estuvieron dos tercios de sus electores $(66,0)$. El PRIAN, que pasó a ocupar el primer lugar precisamente en la elección del año 2002, obtuvo también alrededor de dos tercios de su votación en la provincia de Guayas (64,6\%) y el PRE, un partido que ocupó los primeros lugares desde 1986, consiguió también entre la mitad y un tercio de sus votos nacionales $(60,0 \%)$ en la misma provincia ${ }^{109}$. Por el contrario, en Bolivia los partidos que han predominado en la escena política distribuyeron más armónicamente su votación. Así, la mayor concentración del MNR fue en el departamento de Santa Cruz, donde obtuvo el 39,8\% de su votación nacional. ADN, que para ese año vio reducirse significativamente su votación, obtuvo menos de un tercio de sus votos $(30,1 \%)$ en el departamento de La Paz. La mayor distorsión en la distribución territorial la tuvo el MIR, cuya votación se concentro en un 50,8\% en el departamento de La Paz. Sin embargo, los partidos pequeños o los que habían entrado en declive, como CONDEPA y UCS, sí tuvieron altos índices de concentración en un solo

\footnotetext{
108 Las diferencias entre la costa y la sierra -e incluso entre las ciudades de Quito y Guayaquil- marcan profundamente a la política ecuatoriana (Freidenberg y Alcántara 2001a). Invariablemente, el binomio para la elección de presidente y vicepresidente (en papeleta única e indivisible) se conforma por un candidato de la una región para el un cargo y uno de la otra región para el otro cargo

${ }^{109}$ Las brechas se hacen evidentes cuando se considera que las provincias de Guayas y Pichincha acogen al $26,1 \%$ y al $19,4 \%$ de los votantes ecuatorianos.
} 
departamento (el primero con el 79,7\% en La Paz y segundo con el 55,6\% en Santa Cruz $)^{110}$.

Esto quiere decir que el juego político ecuatoriano giró en torno a partidos que tenían un anclaje regional o provincial muy fuerte, mientras que en Bolivia este fue un factor de menor peso y que afectó sobre todo a los partidos más pequeños. Si bien en ambos países tiene mucha importancia el factor regional, en Ecuador éste asume la condición de elemento determinante para el juego político -y por consiguiente para el análisis-, mientras que en Bolivia tiene un carácter más bien secundario o por lo menos subordinado a otros aspectos y condicionantes. Esto se manifiesta con claridad en la conformación de los gabinetes gubernamentales, en las alianzas dentro del congreso y en general en las negociaciones políticas. En Ecuador es imposible prescindir de estas consideraciones, mientras que en Bolivia tiene importancia pero no llega a adquirir el peso que se observa dentro de la política ecuatoriana. Es probable -y esta sería una hipótesis a comprobar en futuros estudios- que la explicación de la orientación totalmente diferente que ha tenido la formación de coaliciones y la toma de decisiones en cada uno de los países se encuentra en buena parte en este factor, especialmente en la conformación de sistemas de partidos claramente regionalizados. La alta capacidad que mostró el sistema boliviano a lo largo de dieciocho años (1985-2003) para formular políticas de alcance nacional y la baja capacidad del sistema ecuatoriano en ese mismo sentido, pueden tener fuerte relación con las determinaciones regionales que condicionan a los partidos políticos.

Esta realidad se hace más evidente cuando se analizan los sistemas subnacionales de partidos. Cabe destacar, que los estudios sobre sistemas de partidos se han concentrado fundamentalmente en el nivel nacional. Desde los inicios de los estudios contemporáneos sobre partidos y sistemas de de partidos (Duverger, 1988) hasta los que en la actualidad pueden considerarse como clásicos y constituyen referencia obligada (Sartori, 1992; Ware, 2004; Panebianco, 1990), han prestado poca atención a la conformación de sistemas en los niveles subnacionales. Incluso los conceptos desarrollados al respecto (como los de Sartori, que han tenido gran influencia en estudios posteriores) se mantienen en ese nivel sin atender a las particularidades de los espacios subnacionales.

110 En los departamentos de La Paz y Santa Cruz se asienta el 31,4\% y el 23,6\%, respectivamente de la población electoral boliviana. Por tanto, en el caso del MNR y ADN las brechas son insignificantes. 
Las escasas excepciones (Morgenstern Swindle, 2005) confirman esa tendencia, pero aún en esos casos no tratan el tema de los sistemas de partidos que se conforman en los niveles locales. De esta manera, se considera a los sistemas nacionales de partidos como un todo único y -de modo más implícito que explícito- como algo homogéneo. No se ha puesto atención a las diferencias y particularidades internas, esto es, a la conformación de sistemas subnacionales, con lo que se ha desperdiciado una valiosa fuente de información con las consecuentes explicaciones.

En países que muestran una gran diversidad territorial, como los tras analizados aquí, es necesario acompañar el análisis del nivel nacional con el de los niveles subnacionales. Dicho de otra manera, la cabal comprensión de las especificidades de situaciones de alta heterogeneidad hace imprescindible desplazarse en términos espaciales desde el ámbito nacional hacia los espacios más pequeños que lo conforman. Es un desplazamiento que se puede efectuar con los conceptos elaborados para el nivel nacional, lo que en este caso concreto quiere decir que así como se ha trasladado el concepto de partido hacia el nivel subnacional (por ejemplo al hablar de partidos locales), es también posible aplicar el concepto de sistema de partidos en estos ámbitos ${ }^{111}$. Para ello, considero apropiado utilizar la clasificación de los sistemas de partidos propuesta por Sartori, que ha sido objeto de amplia difusión y que es sin duda muy útil para el análisis. En una superación de la formulación original de Duverger, que clasificaba a los sistemas de partidos en unipartidistas, bipartidistas y pluripartidistas, Sartori identifica siete clases al desagregar los unipartidistas en tres categorías y a los pluripartidistas también en tres (Sartori, 1992: 158). De esta manera, clasifica a los sistemas de partidos en: a) de partido único; b) de partido hegemónico; c) de partido predominante; d) bipartidista; e) de pluralismo limitado; f) de pluralismo extremo; g) de atomización. Como lo señala el propio autor, la primera clase (que corresponde al universo del unipartidismo) se constituye cuando un sólo partido monopoliza el poder político y no se permite la existencia de otros (Sartori, 1992: 160). La segunda (que también forma parte del mismo universo) aparece cuando se permite la existencia de otros solamente como "satélites" o subordinados del partido hegemónico (Sartori, 1992, 161). Por consiguiente, son dos clases que no interesan en el

111 Desde una óptica que no considero necesario desarrollar aquí, para otros acercamientos puede ser útil diferenciar entre sistemas subnacionales de partidos y sistemas de partidos subnacionales. Los primeros aludirían en general a los sistemas que se conforman en los niveles subnacionales con todos los partidos políticos, independientemente de su origen y de su base electoral, mientras los otros solamente considerarían a los partidos de origen y/o base electoral subnacional. 
presente análisis ya que las normas vigentes en Bolivia, Ecuador y Perú no pueden dar lugar a esas condiciones. Por tanto, la clasificación se reduce a los otros cinco.

Un desafío de la investigación empírica es hacer operativa esa clasificación, lo que significa establecer criterios adecuados para la identificación de cada una de esas clases de sistemas. En la formulación original, esos criterios son el numérico y el ideológico (Sartori, 1992: 158-162), pero al trabajar en el nivel subnacional -por lo menos en los tres países y seguramente en la mayor parte de los latinoamericanos- surge como obstáculo la ausencia de información acerca de la dimensión ideológica. Para el nivel nacional se cuenta con estudios (como los del Proyecto de Elites Políticas de la Universidad de Salamanca) acerca de la posición de los partidos en un eje espacial, pero esas referencias no pueden tomarse como válidas en su totalidad para los espacios subnacionales. La existencia de las sociedades regionales, con su expresión identitaria y con la construcción de formas culturales específicas, impiden hacer esa traslación automáticamente. Por ello, considero que para estos niveles resulta conveniente moverse exclusivamente con el criterio numérico. Pero, dado que se sacrifica la dimensión ideológica, y para que la clasificación sea operativa, es necesario añadir algunos elementos a los establecidos por Sartori. Fundamentalmente, es necesario establecer límites superiores e inferiores a cada una de las clases.

De acuerdo a la definición de cada una de las clases, considero apropiado establecer los límites que se observan en el cuadro número 14. Estos límites permiten identificar con claridad a cada una sin que lleguen a superponerse entre ellas. Por tanto, antes que una determinación arbitraria de límites, es una manera de hacer operativos a los conceptos que se han visto sustraídos de una parte esencial, como es la dimensión ideológica. Obviamente, pueden ponerse en cuestión los límites establecidos para cada una de ellas, aunque es muy probable que una propuesta alternativa se mantenga dentro de unos rangos relativamente cercanos a estos. Lo importante de esta demarcación entre las clases es que permite asignar un criterio excluyente para cada una de ellas, lo que quiere decir que resulta improbable que un caso se encuentre en dos clases a la vez. Finalmente, cabe reiterar que esta clasificación no resulta útil para analizar las distancias entre los partidos o la polarización a la que ésta puede dar lugar, ni para comprender algunos aspectos que están estrechamente relacionados con la distancia ideológica, como la formación de alianzas (o, al contrario, la imposibilidad de establecerlas). 
Caben algunas explicaciones sobre los criterios y los límites asignados a la clasificación. En primer lugar, todas las clases (excepto las dos últimas, de pluralismo extremo y de atomización) están sujetas a más de una condición. De esta manera, consideran los límites inferior y superior de la votación y la distancia entre las votaciones de los partidos. De esta manera se cumple el carácter excluyente de cada una de las clases, sin que se puedan presentar casos de duda en la asignación de la clasificación en cada caso. En segundo lugar, aunque de acuerdo a la definición de Sartori, el sistema de partido predominante se caracteriza por "una configuración del poder en que un partido gobierna solo, sin estar sujeto a la alternación, siempre que continúe obteniendo, electoralmente, una mayoría absoluta" (Sartori, 1992: 161), en un régimen presidencial, en el que el ganador se lleva todo (Linz, 1993), se puede dejar de lado el requisito de la mayoría absoluta ${ }^{112}$. La combinación del umbral del 40\% con una distancia de diez puntos porcentuales con su inmediato seguidor parece una condición adecuada para calificarlo de esa manera, ya que se cumple la condición de una distribución unimodal (Sartori, 1992: 162) y además en esas condiciones un partido puede gobernar solo con los recursos políticos que le proporciona el régimen presidencial ${ }^{113}$. Finalmente, en las dos últimas clases no es necesario incluir un segundo criterio, además de la votación acumulada por los partidos, debido a que ésta por sí sola es capaz de expresar la realidad de esos sistemas.

Tomado como referencia a las elecciones legislativas del año 2002, que es cuando se hizo evidente el proceso de cambios que vivían los sistemas de partidos de ambos países, se pueden apreciar algunos aspectos de importancia. En primer lugar, en el nivel nacional se configuró en cada uno de ellos un sistema de pluralismo extremo. En Bolivia esto significó un cambio con respecto al pluralismo limitado que predominó a lo largo del período (Mayorga, 1999: 3; Ardaya, 2003: 11). En Ecuador, por el contrario, significó la profundización del sistema que se había conformado desde el inicio del período

112 Es importante destacar que la definición de Sartori tiene un carácter diacrónico, ya que alude a la alternación y a la obtención a la mayoría absoluta en más de una elección. Considero que en condiciones de alta volatilidad no resulta útil esa perspectiva porque el sistema nacional y los sistemas subnacionales cambian significativamente entre elecciones.

113 En algunos países latinoamericanos se ha establecido, dentro de la modalidad del ballotage, la asignación del triunfo al candidato que cumpla precisamente esas dos condiciones (por lo menos $40 \%$ de los votos y una distancia mínima de diez puntos) en la primera vuelta. En Nicaragua se redujo a $35 \%$ el umbral y a 5\% la diferencia, pero se trata de una decisión motivada por cálculos coyunturales más que por criterios relativos a la profundización de la democracia o a la consolidación del sistema de partidos (Martí, 2008: 299; Cuarezma y Cabistán, 2008: 721). 
democrático (Pachano, 2007b). En segundo lugar, dentro del sistema boliviano se hizo evidente una cerrada competencia por los primeros lugares, mientras en Ecuador la competencia se produjo solamente a partir del segundo lugar. Por último, en Bolivia se mantuvieron en los tres primeros puestos los partidos que habían predominado a lo largo del período (MNR, MIR y ADN), en tanto que en Ecuador se advirtió ya el debilitamiento de ese tipo de partidos y el inicio de su sustitución por los que emergían a causa de la crisis de estos ${ }^{114}$.

En los niveles subnacionales se conformó solo un sistema de partido predominante en cada país (como se puede ver en los cuadros 15a y 15b). En Bolivia estuvo asentado en Pando, el departamento menos poblado, y en Ecuador ocurrió en Guayas, la provincia más poblada, lo que marca una diferencia notable. En Bolivia hubo dos sistemas bipartidistas, equivalentes al 22,2\% del total de departamentos, y en Ecuador en hubo este tipo de sistema en cuatro provincias, equivalentes al 18.2\%. En Bolivia no hubo casos de pluralismo limitado, mientras en Ecuador se presentó en dos provincias (9,1\% del total). La mayor parte de sistemas en ambos países fueron de pluralismo extremo, con seis departamentos en Bolivia y quince provincias en Ecuador, equivalente al 66,7 y al 68,2, respectivamente. Por tanto, en ambos países predominó en proporciones similares este último tipo de sistema. Obviamente, tratándose de un corte estático en el tiempo, no se puede asegurar que exista alguna relación con la crisis del sistema de partidos que ya se vivía en esos momentos, pero sí es posible sostener que hay claras diferencias con la conformación del sistema nacional de partidos. Esto puede tomarse como un indicador de la complejidad del juego político en este tipo de sociedades plurales.

Por último, es importante destacar que las cifras electorales en los niveles subnacionales pueden dar pistas importantes acerca del comportamiento general de los partidos. Sobre todo, permiten ver de mejor manera el declive de los partidos centrales de cada uno de los sistemas nacionales, que he tratado en la sección anterior. Así, en Ecuador el Partido Social Cristiano, que hasta esa elección se mantuvo como el partido más votado en el nivel nacional, solamente pudo ocupar el primer lugar en siete provincias, el segundo lugar en cinco y se situó por debajo del quinto lugar en nueve provincias. El partido

${ }^{114} \mathrm{La}$ crisis de los partidos centrales de los respectivos sistemas fue mucho más evidente en la elección presidencial, realizada conjuntamente con la legislativa, en ambos países. En Bolivia dos partidos recientemente conformados ocuparon el segundo y el tercer lugar, mientras en Ecuador ese tipo de partidos ocupó desde el primero hasta el tercero, inclusive (los partidos tradicionales más votados sólo pudieron ocupar los lugares cuarto, quinto y sexto). 
Izquierda Democrática alcanzó el primer lugar solamente en dos provincias, el segundo lugar en un número similar, el tercero en cinco y llegó por debajo del quinto puesto en cinco provincias. El Partido Roldosista Ecuatoriano logró el primer lugar en dos provincias, el segundo en tres, el tercero en cinco y estuvo por debajo del quinto puesto en diez provincias. El partido Democracia Popular-Unión Demócrata Cristiana obtuvo solamente un primer puesto, dos segundos, tres terceros, tres cuartos y en once provincias estuvo por debajo del octavo lugar. En conjunto, estos resultados abonan la percepción de la crisis del sistema de partidos, que habría de concretarse en las siguientes elecciones (2006), cuando esos partidos prácticamente desaparecieron del escenario político nacional y subnacional.

Para Bolivia, en cambio, la votación de los partidos en los niveles subnacionales no expresó claramente el quiebre del sistema de partidos que, sin embargo, se hacía evidente en la elección presidencial realizada conjuntamente a la legislativa. Por el contrario, en esta última los partidos centrales del sistema lograron mantener en gran medida los primeros lugares, sin que se pueda apreciar un peligro inminente de desplazamiento por parte de otras fuerzas. En efecto, Movimiento Nacionalista Revolucionario ocupó el primer lugar en cuatro departamentos, el segundo lugar en otros cuatro y el tercer lugar en uno solo. Acción Democrática Nacionalista, el partido que tuvo el más bajo desempeño y que inició el movimiento descendente, logró el primer lugar solamente en dos departamentos, el segundo lugar en otros dos, el tercer lugar en uno y el cuarto lugar en cuatro departamentos. El Movimiento de Izquierda Revolucionario obtuvo el primer lugar solamente en $\mathrm{n}$ departamento, el segundo en otro, el tercero en cinco departamentos, el cuarto en uno y el sexto en uno. Finalmente, Al contrario de lo que ocurrió en Ecuador, donde otros partidos diferentes a los cuatro principales ocuparon el primer lugar en diez provincias y el segundo lugar en trece provincias, en Bolivia ningún partido fuera de los tres centrales pudo ocupar el primer lugar y solamente uno logró el segundo en un departamento.

El cierre de esta breve revisión de algunos aspectos propios de la distribución territorial del poder se sintetiza en una pregunta acerca de la manera en que ellos inciden sobre la democracia. Esta es una pregunta que no estoy en capacidad de responder con la información y los insumos disponibles en este momento. Como he señalado a lo largo de esta sección, esta perspectiva de análisis se encuentra en sus momentos iniciales, de manera que no existe el desarrollo conceptual ni la base empírica que se requieren para 
avanzar significativamente en las explicaciones al respecto. Por ello, como una manera de cubrir parcialmente ese vacío, a lo largo del texto he formulado algunas hipótesis y he propuesto algunas explicaciones sobre los efectos que se pueden desprender de cada uno de los temas tratados. En especial, he puesto mucho énfasis en la incidencia que pueden tener los diseños institucionales sobre los resultados finales, lo que constituye un intento de superar el nivel del análisis estrictamente estructural en el análisis de las sociedades que presentan fuertes clivajes territoriales. Como lo ilustran los casos de los tres países, las características que toma el juego político dependen en gran medida de los arreglos institucionales aplicados en cada caso. Incluso en Perú, que no ha sido parte del análisis por las razones presentadas, se puede asegurar que elementos propios del diseño institucional (la utilización de una circunscripción única nacional y el débil o casi inexistente proceso de descentralización) determinaron la ausencia de lo regional como factor definitorio de la política.

\section{Conclusiones}

La principal conclusión que se puede extraer del presente capítulo es la ratificación del carácter complejo (o abigarrado, para usar el calificativo que tuvo amplia difusión en Bolivia) de la institucionalidad en los tres países ${ }^{115}$. Las dificultades propias de las sociedades plurales o heterogéneas se han visto potenciadas por los diseños institucionales que enmarcan a la relación entre los poderes del estado, a los partidos políticos, a los procesos electorales y a los espacios subnacionales. La instauración de regímenes fuertemente presidencialistas, con claro desequilibrio de funciones (por consiguiente, sin un buen sistema de controles y balances), la utilización de sistemas electorales que han llevado a sus límites extremos el principio de la representación proporcional, la permisividad para la entrada de actores en la escena política nacional y la poca importancia política asignada a las dimensiones subnacionales, han sido factores de importancia para esa potenciación de los conflictos. Sin desconocer la importancia de los factores estructurales en la configuración de los problemas de gobernabilidad y de representación, es innegable el peso que han tenido sobre estos los componentes institucionales.

115 Abigarrado fue un término frecuentemente utilizado para describir la situación política boliviana, especialmente la complejidad de su sistema político y las prácticas de unos actores poco apegados a la observancia de las normas. René Zavaleta lo introdujo en el análisis político (Zavaleta, 1990: 44). Como sinónimo de heterogéneo (estrictamente multicolor) puede ser un adjetivo útil para calificar la realidad de los tres países. 
Los reiterativos problemas de gobernabilidad, las dificultades de los partidos políticos para cumplir su función de representación y de agregación de intereses, el colapso final del sistema de partidos y la sobrecarga de demandas en los órganos del nivel nacional por la debilidad de las entidades subnacionales, se explican en gran medida por las características institucionales de cada uno de los países. Tres elementos centrales se destacan en este plano, y son los que han guiado la estructura de este capítulo. En primer lugar, en los tres países se establecieron regímenes presidenciales que afectaron seriamente al principio del balance y control de poderes. Aún en el caso boliviano, que ha sido tomado como el menos presidencialista de los tres, se hizo evidente aquel desequilibrio. De esta manera, en todos ellos se buscó dar efectividad al ejecutivo, con el costo del debilitamiento del legislativo. En segundo lugar, con las respectivas particularidades, se establecieron condiciones muy favorables para el surgimiento y la constitución de partidos políticos, pero a la vez -y por ese mismo carácter- muy propicias para la fragmentación. A pesar de que se constituyeron sistemas de partidos relativamente estables - con la clara excepción de Perú a partir del golpe de abril de 1992, las condiciones institucionales fueron en general adversas para que ellos lograran grados apreciables de institucionalización. En tercer lugar, la realidad evidente de sociedades divididas, heterogéneas, con fuertes clivajes territoriales, no tuvo su correlato en el nivel institucional. En general, se las trató como a sociedades homogéneas, sin atender a la necesidad de contar con los arreglos institucionales que permitieran la expresión de esa diversidad sin afectar a la unidad del conjunto.

Entre estos tres elementos se estableció un complejo proceso de interacciones y de mutuos condicionamientos, que tendió a expresarse en el funcionamiento defectuoso de los respectivos sistemas políticos y en sucesivas crisis políticas que requirieron en muchos casos de acciones realizadas al margen de la institucionalidad vigente. Así, el desequilibrio en la relación entre los poderes se nutrió adicionalmente de los débiles sistemas de partidos y de los defectuosos diseños de los sistemas electorales. De esa manera, las presidencias constitucionalmente fuertes adolecieron de una debilidad política que trató de ser contrastada con fatigosas -y muchas veces frustradas- negociaciones con múltiples actores o con acciones autoritarias. A la vez, la baja capacidad de procesamiento del conflicto político en los niveles subnacionales produjo la sobrecarga de demandas en el nivel nacional. Finalmente, los tres factores en su conjunto propiciaron la difusión de las 
prácticas particularistas -especialmente del clientelismo y del corporativismo-, que debilitaron a los partidos y en general a las instituciones democráticas (en una relación expresada en el gráfico 1). La sustitución de los ciudadanos por los clientes y de los partidos por actores con poder de veto fueron los resultados más visibles y más negativos de esa institucionalidad.

Frente a ello, en los tres países se introdujeron con mucha frecuencia reformas constitucionales y en cada uno de ellos -aunque en situaciones diferentes- se acudió a los procesos constituyentes para establecer un nuevo diseño político. Los resultados fueron diversos en los tres casos. En Perú se instaló el Congreso Constituyente Democrático como una manera de dotar de legitimidad al régimen autoritario instaurado por el golpe de estado de 1992, de modo que el producto final debía responder necesariamente a esa orientación. Por ello, cuando éste concluyó fue necesario iniciar un proceso de desmontaje que aún no ha concluido. Bolivia y Ecuador, lo hicieron como parte de procesos de carácter fundacional, que guardan ciertas semejanzas entre ellos pero que tienen también profundas diferencias. En el primer caso se colocó al tema étnico como eje del nuevo ordenamiento, mientras en el segundo se puso énfasis en los derechos, dentro de una visión garantista (que incluyó a la naturaleza que fue reconocida como sujeto de derechos). Sin embargo, la reciente realización de los cambios en estos dos últimos países impide hacer un balance basado en la aplicación de esos principios.

El elemento común a las reformas impulsadas en los tres países es el mantenimiento, e incluso la profundización, de los elementos mencionados antes. En ninguno de ellos se ha matizado el fuerte presidencialismo ni se ha buscado un mejor equilibrio entre los poderes del estado. Por el contrario, tanto el modelo autoritario peruano como la centralidad de líderes fuertes en los procesos de Bolivia y Ecuador, desembocaron en diseños de presidencialismos más fuertes y de legislativos disminuidos. Similares razones, además de una particular comprensión de la democracia participativa en Bolivia y Ecuador, relegó a un segundo plano a los partidos políticos. La conformación de sistemas de partidos en los que se asiente el juego político y a través de los que se canalice la participación y la representación de la sociedad no ha ocupado un lugar de importancia en las agendas de reformas de los tres países. Finalmente, las mismas causas se pueden encontrar en la concentración de las facultades y las atribuciones políticas en el gobierno central, en detrimento de los niveles subnacionales. 
En síntesis, todo el conjunto de evidencias obtenido a lo largo de treinta años de desempeño de los sistemas políticos no ha sido suficiente para emprender en un cambio de fondo. Por el contrario, se ha insistido reiteradamente en profundizar los elementos del diseño institucional que, de una u otra manera, han sido factores determinantes para los problemas de gobernabilidad y de representación. Son sistemas políticos que sin duda han logrado grandes avances en la inclusión, especialmente de los sectores que históricamente estuvieron excluidos de las instancias de poder político. Pero son al mismo tiempo sistemas con baja capacidad de procesamiento del conflicto político y de la conducción de las instancias gubernamentales en todos los niveles. A pesar de que han resuelto en buena medida los problemas de representación, no han sido apropiados para hacer lo mismo con los problemas de gobernabilidad. Tampoco han sido idóneos para alcanzar su legitimidad en los tres niveles señalados en el capítulo I, esto es, como legitimidad de origen, legitimidad de procedimientos y legitimidad de resultados. Las tres han sido constantemente impugnadas por ciudadanía, ya sea por su acción (cuando ha contribuido a desestabilizar a los gobiernos legalmente constituidos, como ocurrió en Ecuador en tres ocasiones y en Bolivia en una) o por su indiferencia (cuando ha sido permisiva con acciones de fuerza, como fue el golpe peruano de 1992).

Desde esta perspectiva cabe volver a lo que ocurrió en el pasado inmediato. En Bolivia la democracia pactada se asentó sobre los acuerdos políticos y los procedimientos utilizados en la selección de autoridades y en la toma de decisiones, en tanto que, por constricciones de carácter estructural pero también por las propias limitaciones del modelo, no pudo asentarse sobre los resultados económicos y sociales. Por consiguiente, el sistema político contó con legitimidad de origen y de procedimientos pero no de resultados. En Ecuador los bloqueos políticos y el predominio de prácticas particularistas (clientelismo y corporativismo) hicieron imposible la definición de un rumbo claro en lo económico y en lo social. Fue un camino lleno de avances y retrocesos en diversas direcciones, con constantes violaciones a las reglas de procesamiento de la política (entre las que se incluyen tres golpes de estado), que se tradujeron en bajos rendimientos económicos y sociales. Por consiguiente, es un caso de débil legitimidad de origen y ausencia de legitimidad de procedimientos y de resultados. En Perú, el régimen autoritario apostó a una reforma económica que, al mostrarse como la manera eficiente de enfrentar la hiperinflación y de retomar el control de la economía, logró apoyo mayoritario entre la 
población. Fue claramente un caso de legitimidad de resultados sin legitimidad de origen y de procedimientos.

En el momento actual es posible asegurar que los tres países mantienen tareas pendientes en lo que hace a la legitimidad de sus sistemas políticos. Bolivia y Ecuador requieren establecer las bases sobre las que se pueda construir un sistema político que exprese las orientaciones de los diversos sectores sociales y que a la vez tenga capacidad para procesar las demandas de cada uno de ellos. Es decir, deben emprender al mismo tiempo en la construcción de la legitimidad de origen y de la legitimidad de procedimientos, que fueron las que desaparecieron junto con los viejos sistemas políticos, y que son las que permitirán alcanzar la legitimidad de resultados. La posibilidad de hacerlo exige algún tipo de acuerdo político, que a su vez requiere de actores constituidos y con capacidad de representación pero también de agregación de intereses. 


\section{Cuadros y gráficos}

\section{Cuadro $\mathbf{N}^{\circ} 1$}

Volatilidad agregada según país (elecciones presidenciales)

\begin{tabular}{|l|r|l|r|l|r|}
\hline \multicolumn{2}{|c|}{ BOLIVIA $^{(1)}$} & \multicolumn{3}{c|}{ ECUADOR $^{(2)}$} & \multicolumn{2}{c|}{ PERU' $^{(3)}$} \\
\hline $1980-85$ & 43,0 & $1978-84$ & 39,5 & $1980-85$ & 50,0 \\
\hline $1985-89$ & 7,1 & $1984-88$ & 39,8 & $1985-90$ & 68,0 \\
\hline $1989-93$ & 19,6 & $1988-92$ & 49,8 & $1990-95$ & 65,4 \\
\hline $1993-97$ & 20,4 & $1992-96$ & 45,2 & $1995-00$ & 97,1 \\
\hline $1997-02$ & 13,3 & $1996-98$ & 35,5 & & \\
\hline & & $1998-02$ & 74,1 & & 70,1 \\
\hline Promedio & 20,7 & Promedio & 47,3 & Promedio & \\
\hline
\end{tabular}

Elaboración propia. Fuentes: (1) Romero (2003) y Fundemos (1998); (2) Tribunal Supremo Electoral (varios años); (3) Payne et al (2003)

\section{Cuadro $\mathrm{N}^{\circ} 2 \mathrm{a}$}

Bolivia: votación según partidos, elecciones presidenciales

\begin{tabular}{|l|l|l|l|l|l|l|l|l|l|l|l|l|l|}
\hline \multicolumn{2}{|c|}{1979} & \multicolumn{3}{c|}{1980} & \multicolumn{2}{c|}{1985} & \multicolumn{2}{c|}{1993} & \multicolumn{2}{c|}{1997} & \multicolumn{2}{c|}{2002} \\
\hline Partido & $\%$ & Partido & $\%$ & Partido & $\%$ & Partido & $\%$ & Partido & $\%$ & Partido & $\%$ & Partido & $\%$ \\
\hline UDP & 36.0 & UDP & 38.7 & ADN & 33.2 & MNR & 25.8 & MNR & 35.6 & ADN & 22.3 & MNR & 22.5 \\
\hline MNR & 35.9 & MNR & 20.1 & MNR & 30.7 & ADN & 25.4 & AP & 21.1 & MNR & 18.2 & MAS & 20.9 \\
\hline ADN & 14.9 & ADN & 16.8 & MIR & 10.3 & MIR & 22.0 & CONDEPA & 14.3 & CONDEPA & 17.2 & NFR & 20.9 \\
\hline PS-1 & 4.8 & PS-1 & 8.7 & MNRI & 5.5 & CONDEPA & 12.3 & UCS & 13.8 & MIR & 16.8 & MIR & 16.3 \\
\hline APIN & 4.1 & FDR & 3.0 & MNRV & 4.9 & IU & 8.1 & MBL & 5.4 & UCS & 16.1 & MIP & 6.1 \\
\hline MITKA & 1.9 & PARA & 2.8 & PS-1 & 2.6 & PS-1 & 2.8 & ARBOL & 1.9 & IU & 3.7 & UCS & 5.5 \\
\hline PUB & 1.3 & MNRU & 1.9 & FPU & 2.6 & MRTKL & 1.6 & ASD & 1.8 & MBL & 3.1 & ADN & 3.4 \\
\hline VO & 1.1 & FSB & 1.6 & MRTKL & 2.1 & FULKA & 1.2 & VR-9 & 1.3 & VSB & 1.4 & L y J & 2.7 \\
\hline & & PRIN & 1.3 & PDC & 1.6 & MIN & 0.7 & FSB & 1.3 & EJE & 0.8 & PS & 0.7 \\
\hline & & AFIN MNR & 1.3 & FSB & 1.3 & & & EJE & 1.1 & PDB & 0.5 & MCC & 0.6 \\
\hline & & MITKA 1 & 1.3 & MRTK & 0.9 & & & IU & 1.0 & & & CONDEPA & 0.4 \\
\hline & & PUB & 1.2 & ACP & 0.9 & & & MKN & 0.8 & & & & \\
\hline & & MITKA & 1.2 & MNRI-1 & 0.8 & & & INDEPEND. & 0.5 & & & & \\
\hline & & & & IU & 0.7 & & & MFD & 0.4 & & & & \\
\hline & & & & AUR & 0.6 & & & & & & & & \\
\hline & & & & FNP & 0.6 & & & & & & & & \\
\hline
\end{tabular}

Elaboración propia. Fuentes: Payne et al (2003); Fundemos (1998); Romero (2003) 
Cuadro $\mathbf{N}^{\circ} 2 b$

Ecuador: votación según partidos, elecciones presidenciales

\begin{tabular}{|c|c|c|c|c|c|c|c|c|c|c|c|c|c|}
\hline \multicolumn{2}{|c|}{1979} & \multicolumn{2}{|c|}{1984} & \multicolumn{2}{|c|}{1988} & \multicolumn{2}{|c|}{1992} & \multicolumn{2}{|c|}{1996} & \multicolumn{2}{|c|}{1998} & \multicolumn{2}{|c|}{2002} \\
\hline Partido & $\%$ & Partido & $\%$ & Partido & $\%$ & Partido & $\%$ & Partido & $\%$ & Partido & $\%$ & Partido & $\%$ \\
\hline CFP & 27.7 & ID & 28.7 & ID & 24.7 & PUR & 31.9 & PSC & 27.2 & $\mathrm{DP}$ & 34.9 & PSP-PK & 20.7 \\
\hline PSC & 23.9 & PSC & 27.2 & PRE & 17.7 & PSC & 25.0 & PRE & 26.3 & PRE & 26.6 & PRIAN & 17.4 \\
\hline PLRE & 22.7 & CFP & 13.5 & PSC & 14.7 & PRE & 21.9 & $\mathrm{PK}$ & 20.6 & ID & 16.1 & LISTA 40 & 15.4 \\
\hline ID & 12.0 & MPD & 7.4 & APRE & 12.5 & ID & 8.5 & $\mathrm{DP}$ & 13.5 & $\mathrm{PK}$ & 14.7 & ID & 14.0 \\
\hline FRA & 9.0 & FRA & 6.8 & $\mathrm{DP}$ & 11.5 & APRE & 3.2 & APRE & 4.9 & MIRA & 5.1 & PSC & 12.1 \\
\hline \multirow[t]{7}{*}{ FADI } & 4.7 & PD & 6.6 & CFP & 7.8 & PSE & 2.6 & PLRE & 3.0 & MPD & 2.6 & PRE & 11.9 \\
\hline & & $\mathrm{DP}$ & 4.7 & MPD & 5.0 & $\mathrm{DP}$ & 1.9 & MPD & 2.4 & & & INDEPEND. 1 & 3.7 \\
\hline & & FADI & 4.3 & FRA & 3.3 & MPD & 1.9 & UCI & 1.2 & & & INDEPEND.2 & 1.7 \\
\hline & & PSE & 0.8 & PLRE & 1.6 & CFP & 1.4 & LISTA 20 & 0.9 & & & PL & 1.2 \\
\hline & & & & $\mathrm{PR}$ & 1.2 & PLRE & 0.9 & ID & 0.0 & & & MPS & 1.1 \\
\hline & & & & & & FADI & 0.5 & & & & & INDEPEND.3 & 0.9 \\
\hline & & & & & & PAB & 0.3 & & & & & & \\
\hline
\end{tabular}

Elaboración propia. Fuentes: Tribunal Supremo Electoral (varios años)

Cuadro $\mathbf{N}^{\circ} 2 \mathrm{c}$

Perú: votación según partidos, elecciones presidenciales

\begin{tabular}{|c|c|c|c|c|c|c|c|c|c|}
\hline \multicolumn{2}{|c|}{1980} & \multicolumn{2}{|c|}{1985} & \multicolumn{2}{|l|}{1990} & \multicolumn{2}{|l|}{1995} & \multicolumn{2}{|l|}{2000} \\
\hline Partido & $\%$ & Partido & $\%$ & Partido & $\%$ & Partido & $\%$ & Partido & $\%$ \\
\hline $\mathrm{AP}$ & 46.49 & APRA & 53.10 & FREDEMO & 32.57 & CAMBIO 90 & 64.42 & Perú al 2000 & 51.02 \\
\hline APRA & 28.19 & $\mathrm{IU}$ & 24.69 & CAMBIO 90 & 29.09 & UPP & 21.81 & Perú Posible & 41.16 \\
\hline PPC & 9.92 & CODE & 11.90 & APRA & 22.50 & APRA & 4.11 & Somos Perú & 3.07 \\
\hline PRT & 4.17 & $\mathrm{AP}$ & 7.25 & $\mathrm{IU}$ & 8.20 & CODE & 3.24 & Solidaridad Nacional & 1.84 \\
\hline IU & 3.03 & FNTC & 1.41 & IS & 4.74 & Movimiento Civico Nacional Obras & 2.58 & APRA & 1.41 \\
\hline UDP & 2.55 & FDUN & 0.84 & FNTC & 1.30 & $\mathrm{AP}$ & 1.64 & FREPAP & 0.73 \\
\hline FNTC & 2.12 & PAN & 0.41 & FREPAP & 1.11 & FREPAP & 0.77 & $\mathrm{AP}$ & 0.43 \\
\hline FOCEP & 1.58 & PST & 0.24 & UNO & 0.33 & $\mathrm{IU}$ & 0.57 & UPP & 0.34 \\
\hline $\mathrm{UN}$ & 0.47 & M7J & 0.16 & UD & 0.14 & Perú al 20005 & 0.34 & & \\
\hline OPRP & 0.46 & & & & & Nuevo Perú & 0.13 & & \\
\hline APS & 0.30 & & & & & PRP & 0.12 & & \\
\hline MDP & 0.26 & & & & & Alternativa Perú Puma & 0.09 & & \\
\hline PAIS & 0.24 & & & & & Paz y Desarrollo & 0.09 & & \\
\hline PSP & 0.23 & & & & & Reconciliación Nacional & 0.07 & & \\
\hline
\end{tabular}

Elaboración propia. Fuente: Payne et al (2003) 
Cuadro $\mathbf{N}^{\circ} 3$

Número de partidos en elecciones presidenciales, según país

\begin{tabular}{|c|c|c|c|c|c|}
\hline \multicolumn{2}{|c|}{ BOLIVIA } & \multicolumn{2}{|c|}{ ECUADOR } & \multicolumn{2}{|c|}{ PERÚ } \\
\hline Año & Número & Año & Número & Año & Número \\
\hline 1979 & 8 & 1978 & 6 & 1980 & 14 \\
\hline 1980 & 13 & 1984 & 9 & 1985 & 9 \\
\hline 1985 & 16 & 1988 & 10 & 1990 & 9 \\
\hline 1989 & 9 & 1992 & 12 & 1995 & 14 \\
\hline 1993 & 14 & 1996 & 9 & 2000 & 8 \\
\hline 1997 & 10 & 1998 & 6 & & \\
\hline 2002 & 11 & 2002 & 11 & & \\
\hline Media & 11.6 & Media & 9.0 & Media & 10.8 \\
\hline
\end{tabular}

Elaboración propia. Fuentes: Romero (2003); Fundemos (1998); Tribunal Supremo Electoral (varios años); Payne et al (2003)

\section{Cuadro $\mathrm{N}^{\circ} 4$}

Número efectivo de partidos en elecciones presidenciales, según país

\begin{tabular}{|l|r|l|r|l|r|}
\hline \multicolumn{2}{|c|}{ BOLIVIA } & \multicolumn{3}{c|}{ ECUADOR } & \multicolumn{3}{c|}{ PERÚ } \\
\hline Año & Núm. Efect. & Año & Núm. Efect. & Año & Núm. Efect. \\
\hline 1979 & 3.5 & 1978 & 4.8 & 1980 & 3.2 \\
\hline 1980 & 4.4 & 1984 & 5.2 & 1985 & 2.8 \\
\hline 1985 & 4.5 & 1988 & 6.5 & 1990 & 4.0 \\
\hline 1989 & 4.9 & 1992 & 4.5 & 1995 & 2.1 \\
\hline 1993 & 4.7 & 1996 & 4.8 & 2000 & 2.3 \\
\hline 1997 & 5.9 & 1998 & 4.1 & & \\
\hline 2002 & 5.8 & 2002 & 6.8 & & \\
\hline & & & & & \\
\hline Media & 4.8 & Media & 5.2 & Media & 2.9 \\
\hline
\end{tabular}

Elaboración propia. Fuentes: Romero (2003); Fundemos (1998); Tribunal Supremo Electoral (varios años); Payne et al (2003)

\section{Cuadro $\mathrm{N}^{\circ} 5$}

Fragmentación del sistema de partidos en elecciones presidenciales, según país

\begin{tabular}{|c|c|c|c|c|c|}
\hline \multicolumn{2}{|c|}{ BOLIVIA } & \multicolumn{2}{|c|}{ ECUADOR } & \multicolumn{2}{|c|}{ PERÚ } \\
\hline Año & Fragmentación & Año & Fragmentación & Año & Fragmentación \\
\hline 1979 & 0.71 & 1978 & 0.79 & 1980 & 0.69 \\
\hline 1980 & 0.77 & 1984 & 0.81 & 1985 & 0.64 \\
\hline 1985 & 0.78 & 1988 & 0.85 & 1990 & 0.75 \\
\hline 1989 & 0.80 & 1992 & 0.78 & 1995 & 0.53 \\
\hline 1993 & 0.79 & 1996 & 0.79 & 2000 & 0.57 \\
\hline 1997 & 0.83 & 1998 & 0.76 & & \\
\hline 2002 & 0.83 & 2002 & 0.85 & & \\
\hline Media & 0.79 & Media & 0.80 & Media & 0.64 \\
\hline
\end{tabular}

Elaboración propia. Fuentes: Romero (2003); Fundemos (1998); Tribunal Supremo Electoral (varios años); Payne et al (2003) 
Cuadro $\mathbf{N}^{\circ} 6$

Volatilidad agregada en elecciones legislativas, según país

\begin{tabular}{|l|r|r|r|r|r|}
\hline \multicolumn{2}{|c|}{ BOLIVIA } & \multicolumn{2}{c|}{ ECUADOR } & \multicolumn{2}{c|}{ PERÚ } \\
\hline \multicolumn{1}{|c|}{ Año } & Volat. & \multicolumn{1}{c|}{ Año } & Volat. & Año & Volat. \\
\hline $1980-85:$ & 57.5 & $1979-84$ & 16.0 & $1980-85$ & $1985-90$ \\
\hline $1985-89:$ & 30.8 & $1984-86$ & 19.9 & $1990-95$ & 61.6 \\
\hline $1989-93:$ & 59.7 & $1986-88$ & 22.0 & $1995-00$ & 74.0 \\
\hline $1993-97:$ & 47.0 & $1988-90$ & 20.6 & $2000-01$ & 83.5 \\
\hline & & $1990-92$ & 15.7 & & 59.6 \\
\hline & & $1992-94$ & 27.3 & & \\
\hline & & $1994-96$ & 36.1 & & \\
\hline & & $1996-98$ & 46.2 & & \\
\hline & & $1998-02$ & & & \\
\hline
\end{tabular}

Elaboración propia. Fuentes: Romero (2003); Fundemos1998); Tribunal Supremo Electoral (varios años); Payne et al (2003)

Cuadro $\mathrm{N}^{\mathrm{o}} 7 \mathrm{a}$

Votación del primer partido en elecciones legislativas, según país

\begin{tabular}{|l|r|r|r|r|r|}
\hline \multicolumn{2}{|c|}{ BOLIVIA } & \multicolumn{2}{c|}{ ECUADOR } & \multicolumn{2}{c|}{ PERÚ } \\
\hline \multicolumn{1}{|c|}{ Año } & Votación $\%$ & \multicolumn{2}{c|}{ Año } & Votación $\%$ & Votación \% \\
\hline 1980 & 38.74 & 1979 & 31.73 & 1980 & 38.92 \\
\hline 1985 & 32.83 & 1984 & 20.01 & 1985 & 50.09 \\
\hline 1990 & 25.65 & 1986 & 14.48 & 1990 & 30.08 \\
\hline 1993 & 35.55 & 1988 & 22.62 & 1995 & 52.10 \\
\hline 1997 & 22.26 & 1990 & 24.46 & 2000 & 42.16 \\
\hline & & 1992 & 23.13 & 2001 & 26.30 \\
\hline & 1994 & 26.36 & & \\
\hline & & 1996 & 27.89 & & \\
\hline & & 2002 & 24.11 & & \\
\hline & & & 26.44 & & \\
\hline
\end{tabular}

Elaboración propia. Fuentes: Romero (2003); Fundemos (1998); Tribunal Supremo Electoral (varios años); Payne et al (2003) 
Cuadro 7b

Votación de los dos primeros partidos en elecciones legislativas, según país

\begin{tabular}{|l|r|l|r|r|r|}
\hline \multicolumn{2}{|c|}{ BOLIVIA } & \multicolumn{2}{c|}{ ECUADOR } & \multicolumn{2}{c|}{ PERÚ } \\
\hline \multicolumn{1}{|c|}{ Año } & Votación $\%$ & \multicolumn{2}{c|}{ Año } & Votación $\%$ & \multicolumn{2}{c|}{ Año } & 65.43 \\
\hline 1980 & 58.89 & 1979 & 46.53 & 1980 & 74.53 \\
\hline 1985 & 63.19 & 1984 & 31.46 & 1985 & 55.08 \\
\hline 1990 & 50.88 & 1986 & 27.10 & 1990 & 66.10 \\
\hline 1993 & 56.61 & 1988 & 38.95 & 1995 & 65.40 \\
\hline 1997 & 40.46 & 1990 & 39.27 & 2000 & 46.01 \\
\hline & & 1992 & 39.03 & 2001 & \\
\hline & & 1994 & 43.14 & & \\
\hline & & 1996 & 49.21 & & \\
\hline & & 2002 & 44.36 & & \\
\hline & & & 40.30 & & \\
\hline
\end{tabular}

Elaboración propia. Fuentes: Romero (2003); Fundemos (1998); Tribunal Supremo Electoral (varios años); Payne et al (2003)

\section{Cuadro $\mathbf{N}^{\circ} 8$}

Número de partidos en elecciones legislativas, según país

\begin{tabular}{|l|r|r|r|r|r|}
\hline \multicolumn{2}{|c|}{ BOLIVIA } & \multicolumn{3}{c|}{ ECUADOR } & \multicolumn{3}{c|}{ PERÚ } \\
\hline \multicolumn{1}{|c|}{ Año } & Número & \multicolumn{1}{|c|}{ Año } & Número \\
\hline 1980 & 13 & 1978 & 12 & 1980 & 16 \\
\hline 1985 & 13 & 1984 & 17 & 1985 & 12 \\
\hline 1990 & 10 & 1986 & 16 & 1990 & 16 \\
\hline 1993 & 12 & 1988 & 16 & 1995 & 20 \\
\hline 1997 & 10 & 1990 & 15 & 2000 & 10 \\
\hline & 1992 & 17 & 2001 & 13 \\
\hline & 1994 & 27 & & \\
\hline & & 1996 & 64 & & \\
\hline & & 1998 & 69 & & \\
\hline & 2002 & & & 14.5 \\
\hline
\end{tabular}

Elaboración propia. Fuentes: Romero (2003); Fundemos (1998); Tribunal Supremo Electoral (varios años); Payne et al (2003) 
Cuadro $\mathbf{N}^{\circ} 9$

Número efectivo de partidos en elecciones legislativas, según país

\begin{tabular}{|l|r|r|r|r|r|}
\hline \multicolumn{2}{|c|}{ BOLIVIA } & \multicolumn{3}{c|}{ ECUADOR } & \multicolumn{2}{c|}{ PERÚ } \\
\hline \multicolumn{1}{|c|}{ Año } & Núm. Efect & \multicolumn{1}{c|}{ Año } & Núm. Efect & Año & Núm. Efect \\
\hline 1980 & 4.4 & 1978 & 6.4 & 1980 & 4.2 \\
\hline 1985 & 4.5 & 1984 & 10.3 & 1985 & 3.0 \\
\hline 1990 & 5.0 & 1986 & 11.4 & 1990 & 5.0 \\
\hline 1993 & 4.7 & 1988 & 8.2 & 1995 & 3.3 \\
\hline 1997 & 5.9 & 1990 & 7.9 & 2000 & 4.0 \\
\hline & & 1992 & 7.8 & 2001 & 6.6 \\
\hline & & 1994 & 7.5 & & \\
\hline & & 1996 & 6.4 & & \\
\hline & & 1998 & 6.7 & & \\
\hline & & 2002 & 7.8 & & \\
\hline
\end{tabular}

Elaboración propia. Fuentes: Romero (2003); Fundemos (1998); Tribunal Supremo Electoral (varios años); Payne et al (2003)

\section{Cuadro $\mathrm{N}^{\mathbf{0}} 10$}

Fragmentación del sistema de partidos en elecciones legislativas, según país

\begin{tabular}{|c|c|c|c|c|c|}
\hline \multicolumn{2}{|c|}{ BOLIVIA } & \multicolumn{2}{|c|}{ ECUADOR } & \multicolumn{2}{|c|}{ PERÚ } \\
\hline Año & Fragmentación & Año & Fragmentación & Año & Fragmentación \\
\hline 1980 & 0.77 & 1978 & 0.84 & 1980 & 0.76 \\
\hline 1985 & 0.78 & 1984 & 0.90 & 1985 & 0.67 \\
\hline 1990 & 0.80 & 1986 & 0.91 & 1990 & 0.80 \\
\hline 1993 & 0.79 & 1988 & 0.88 & 1995 & 0.70 \\
\hline 1997 & 0.83 & 1990 & 0.87 & 2000 & 0.75 \\
\hline & & 1992 & 0.87 & 2001 & 0.85 \\
\hline & & 1994 & 0.87 & & \\
\hline & & 1996 & 0.84 & & \\
\hline & & 1998 & 0.85 & & \\
\hline & & 2002 & 0.87 & & \\
\hline Media & 0.79 & Media & 0.87 & Media & 0.75 \\
\hline
\end{tabular}

Elaboración propia. Fuentes: Romero (2003); Fundemos (1998); Tribunal Supremo Electoral (varios años); Payne et al (2003) 
Cuadro $\mathbf{N}^{\circ} 11 \mathrm{a}$

Bolivia: número y tamaño de las circunscripciones

\begin{tabular}{|l|r|r|}
\hline \multicolumn{3}{|c|}{ Bolivia } \\
\hline \multicolumn{1}{|c|}{ Departamento } & \multicolumn{2}{c|}{ Votantes } \\
\hline Pando & 21,969 & 0.61 \\
\hline Beni & 147,187 & 4.12 \\
\hline Tarija & 168,118 & 4.70 \\
\hline Oruro & 177,618 & 4.97 \\
\hline Chuquisaca & 220,044 & 6.16 \\
\hline Potosí & 277,707 & 7.77 \\
\hline Cochabamba & 595,406 & 16.66 \\
\hline Santa Cruz & 843,849 & 23.61 \\
\hline La Paz & $1,121,836$ & 31.39 \\
\hline TOTAL & $3,573,734$ & 100.00 \\
\hline Rango & & 30.78 \\
\hline Media & & 11.11 \\
\hline
\end{tabular}

Cuadro $\mathbf{N}^{\circ} 11 b$

Ecuador: número y tamaño de las circunscripciones

\begin{tabular}{|l|r|r|}
\hline \multicolumn{3}{|c|}{ Ecuador } \\
\hline PALovincia & \multicolumn{2}{|c|}{ Votantes } \\
\hline PASTAZA & 10,398 & 0.13 \\
\hline ORELLANA & 36,307 & 0.45 \\
\hline NAPO & 42,641 & 0.52 \\
\hline ZAMORA & 44,984 & 0.55 \\
\hline MORONA & 46,457 & 0.57 \\
\hline SUCUMBÍOS & 67,707 & 0.83 \\
\hline CARCHI & 75,053 & 0.92 \\
\hline BOLÍVAR & 109,885 & 1.35 \\
\hline CAÑAR & 127,802 & 1.57 \\
\hline COTOPAXI & 158,995 & 1.95 \\
\hline IMBABURA & 239,834 & 2.94 \\
\hline ESMERALDAS & 240,104 & 2.94 \\
\hline LOJA & 249,445 & 3.06 \\
\hline CHIMBORAZO & 285,837 & 3.50 \\
\hline TUNGURAHUA & 298,822 & 3.66 \\
\hline EL ORO & 324,419 & 3.98 \\
\hline AZUAY & 356,170 & 4.37 \\
\hline LOS RÍOS & 420,363 & 5.15 \\
\hline MANABÍ & 432,558 & 5.30 \\
\hline PICHINCHA & 871,154 & 10.68 \\
\hline GUAYAS & $1,585,512$ & 19.44 \\
\hline TOTAL & $2,131,978$ & 26.14 \\
\hline RangO & $\mathbf{8 , 1 5 6 , 4 2 5}$ & 100.00 \\
\hline Media & & 26.01 \\
\hline OUI & 370747 & 4.55 \\
\hline
\end{tabular}

Elaboración propia. Fuente: Tribunal Supremo Electoral del Ecuador 
Cuadro $\mathrm{N}^{\circ} 12 \mathrm{a}$

Bolivia: número de circunscripciones en que los partidos presentaron candidatos

\begin{tabular}{|l|r|c|}
\hline \multicolumn{3}{|c|}{ Bolivia } \\
\hline \multicolumn{1}{|c|}{ Partido } & $\begin{array}{c}\text { No circunscripciones } \\
\text { en que presentó } \\
\text { candidaturas }\end{array}$ & \multicolumn{1}{c|}{} \\
\hline ADN & 9 & 100.0 \\
\hline CONDEPA & 9 & 100.0 \\
\hline FRI & 9 & 100.0 \\
\hline FSB & 9 & 100.0 \\
\hline KDN & 9 & 100.0 \\
\hline MASU & 9 & 100.0 \\
\hline MIR & 9 & 100.0 \\
\hline MRTKL & 9 & 100.0 \\
\hline MSM & 9 & 100.0 \\
\hline MBL & 7 & 77.8 \\
\hline MNR & 7 & 77.8 \\
\hline MPP & 5 & 55.6 \\
\hline NFR & 4 & 44.4 \\
\hline PCB & 3 & 33.3 \\
\hline PDC & 3 & 33.3 \\
\hline UCS & 3 & 33.3 \\
\hline PS & 1 & 11.1 \\
\hline VR9 & 1 & 11.1 \\
\hline
\end{tabular}

Elaboración propia. Fuente: Corte Electoral de Bolivia 
Cuadro $\mathbf{N}^{\circ} 12 b$

Ecuador: número de circunscripciones en que los partidos presentaron candidatos

\begin{tabular}{|c|c|c|}
\hline \multicolumn{3}{|c|}{ Ecuador } \\
\hline Partido & $\begin{array}{l}\mathrm{N}^{\circ} \text { de circunscripciones en } \\
\text { que presentó candidaturas }\end{array}$ & $\%$ \\
\hline PRIAN & 22 & 100.0 \\
\hline PL & 20 & 90.9 \\
\hline PRE & 18 & 81.8 \\
\hline PSC & 18 & 81.8 \\
\hline ID & 17 & 77.3 \\
\hline DP-UDC & 16 & 72.7 \\
\hline MPD & 15 & 68.2 \\
\hline MPS & 14 & 63.6 \\
\hline CFP & 12 & 54.5 \\
\hline PS-FA & 12 & 54.5 \\
\hline MUPP-NP & 10 & 45.5 \\
\hline PSP/MUPP-NP & 7 & 31.8 \\
\hline PSP & 6 & 27.3 \\
\hline MPD /PS-FA & 3 & 13.6 \\
\hline $\mathrm{PSC} / \mathrm{AN}$ & 3 & 13.6 \\
\hline PSP/MPD & 3 & 13.6 \\
\hline PS-FA /MUPP-NP & 2 & 9.1 \\
\hline AN /PS-FA /DP-UDC & 1 & 4.5 \\
\hline ID /DP-UDC & 1 & 4.5 \\
\hline ID /MCNP & 1 & 4.5 \\
\hline ID/MIRE & 1 & 4.5 \\
\hline MIP & 1 & 4.5 \\
\hline MUPP-NP /MCNP & 1 & 4.5 \\
\hline TD & 1 & 4.5 \\
\hline
\end{tabular}

Elaboración propia. Fuente: Tribunal Supremo Electoral del Ecuador 
Cuadro $\mathbf{N}^{\circ} 13 \mathrm{a}$

Bolivia: IDT por partidos

Elección de diputados, 2002

\begin{tabular}{|l|r|}
\hline ADN & 10,01 \\
\hline MIR & 18,71 \\
\hline MNR & 18,74 \\
\hline MASU & 25,70 \\
\hline MBL & 26,20 \\
\hline UCS & 34,01 \\
\hline FRI & 34,25 \\
\hline MSM & 40,87 \\
\hline FSB & 42,39 \\
\hline PS & 45,88 \\
\hline NFR & 48,04 \\
\hline CONDEPA & 51,14 \\
\hline VR9 & 54,61 \\
\hline PDC & 55,02 \\
\hline KDN & 57,48 \\
\hline MPP & 68,61 \\
\hline PCB & 73,06 \\
\hline MRTKL & 95,03 \\
\hline \multicolumn{2}{|l}{} \\
\hline MEDIA & 44,43 \\
\hline Elaboración propia
\end{tabular}


Ecuador: IDT por partidos

Elección de diputados, 2002

Cuadro $\mathrm{N}^{\circ} 14$

Criterios de clasificación partidos

\begin{tabular}{|l|r|}
\hline MPD & 34,23 \\
\hline CFP & 35,90 \\
\hline MPS & 36,99 \\
\hline PRE & 37,25 \\
\hline PRIAN & 38,47 \\
\hline MUPP-NP & 38,47 \\
\hline DP-UDC & 40,97 \\
\hline PS-FA & 42,52 \\
\hline ID & 48,14 \\
\hline PSC & 53,37 \\
\hline PL & 58,50 \\
\hline PSP/MUPP-NP & 84,95 \\
\hline PSP & 90,10 \\
\hline MPD/PS-FA & 91,55 \\
\hline PSP/MPD & 92,53 \\
\hline PSC/AN & 92,77 \\
\hline ID/MIRE & 96,50 \\
\hline TD & 98,65 \\
\hline MUPP-NP/MCNP & 99,08 \\
\hline ID/DP-UDC & 99,17 \\
\hline PS-FA/MUPP-NP & 99,43 \\
\hline ID/MCNP & 99,48 \\
\hline AN/PS-FA/UDP- & 99,48 \\
\hline DC & 99,87 \\
\hline MIP & 71,18 \\
\hline & \\
\hline MEDIA & \\
\hline
\end{tabular}

Elaboración propia

de los sistemas de

\begin{tabular}{|l|l|}
\hline \multicolumn{1}{|c|}{ Tipo de sistema } & \multicolumn{1}{|c|}{ Criterios (según porcentaje de votación) } \\
\hline De partido predominante & $\begin{array}{l}\text { Primer partido más del } 40 \% \text { y distancia de } 10 \text { puntos con el } \\
\text { siguiente partido }\end{array}$ \\
\hline Bipartidista & $\begin{array}{l}\text { Dos primeros partidos más del } 50 \% \text { y distancia de } 5 \text { puntos } \\
\text { con el siguiente partido }\end{array}$ \\
\hline Pluralismo limitado & $\begin{array}{l}\text { Tres primeros partidos menos del } 66 \% \text { y distancia de } 5 \\
\text { puntos con el siguiente partido }\end{array}$ \\
\hline Pluralismo extremo & Cuatro primeros partidos menos del $75 \%$ \\
\hline De atomización & Cinco primeros partidos menos del $66 \%$ \\
\hline
\end{tabular}




\section{Cuadro $\mathbf{N}^{\circ} 15 \mathrm{a}$}

Bolivia: sistemas subnacionales de partidos (elección legislativa 2002)

\begin{tabular}{|l|l|}
\hline $\begin{array}{l}\text { De partido } \\
\text { predominante }\end{array}$ & Pando \\
\hline Bipartidista & Beni, Santa Cruz \\
\hline Pluralismo limitado & $\begin{array}{l}\text { Chuquisaca, Cochabamba, La Paz, Oruro, Potosi (en el limite de } \\
\text { atomizacion), Tarija }\end{array}$ \\
\hline Pluralismo extremo & \\
\hline De atomizacion & \\
\hline
\end{tabular}

Elaboración propia

\section{Cuadro $N^{\circ} 15 b$}

Ecuador: sistemas subnacionales de partidos (elección legislativa 2002)

\begin{tabular}{|l|l|}
\hline $\begin{array}{l}\text { De partido } \\
\text { predominante }\end{array}$ & Guayas \\
\hline Bipartidista & Esmeraldas, Los Rios, Zamora, Galapagos \\
\hline $\begin{array}{l}\text { Pluralismo } \\
\text { limitado }\end{array}$ & Orellana, Napo \\
\hline $\begin{array}{l}\text { Pluralismo } \\
\text { extremo }\end{array}$ & $\begin{array}{l}\text { Carchi, Imbabura, Pichincha, Cotopaxi, Tungurahua, Bolivar, Chimborazo, } \\
\text { Cañar, Azuay, Loja, Manabi, El Oro, Sucumbios, Pastaza, Morona }\end{array}$ \\
\hline $\begin{array}{l}\text { De } \\
\text { atomizacion }\end{array}$ & \\
\hline
\end{tabular}

Elaboración propia

\section{Gráfico $\mathbf{N}^{\mathbf{0}} 1$}

\section{Relación entre los componentes del sistema político}

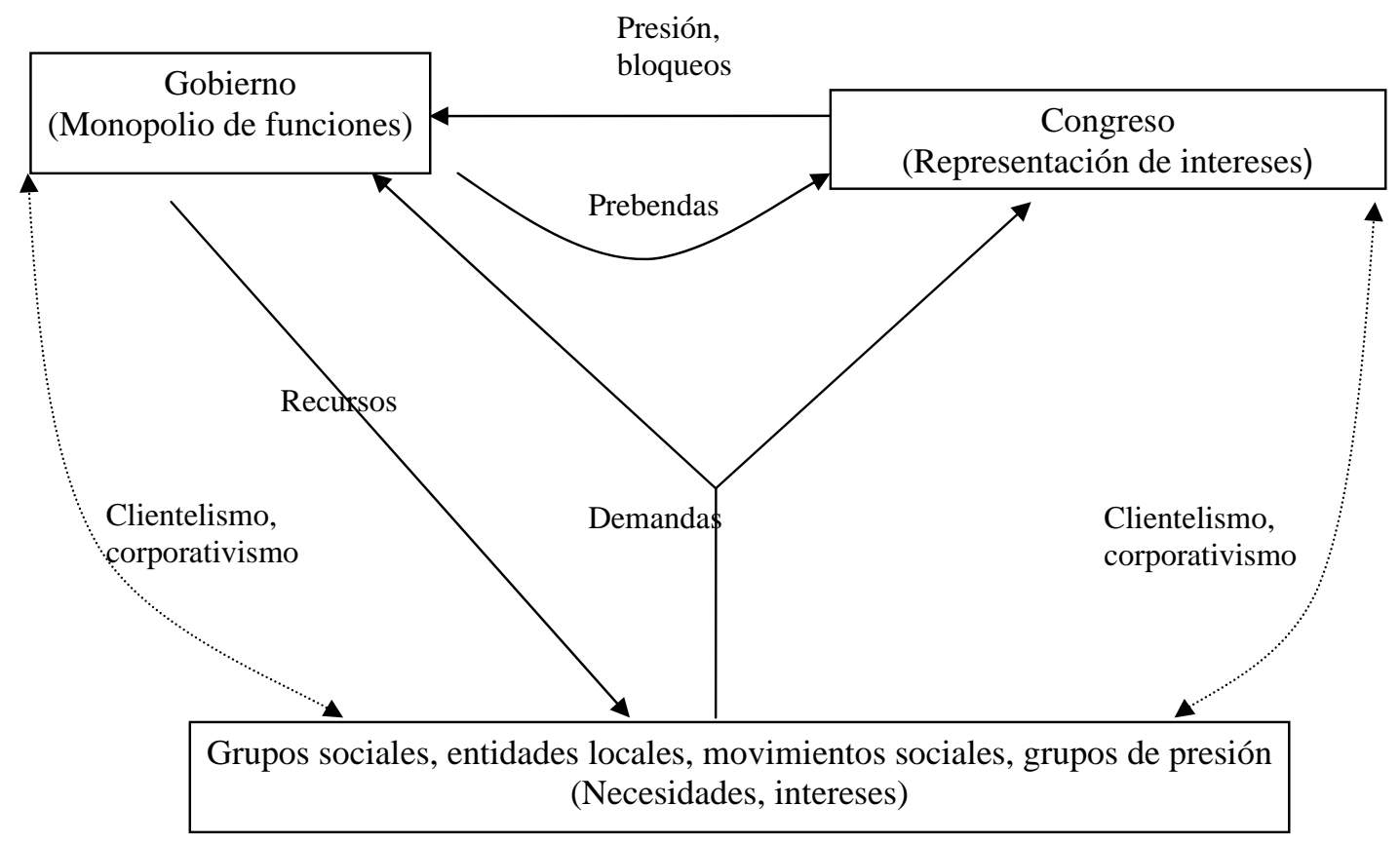


Capítulo IV. La calidad de la democracia 


\section{Resumen}

En el presente capítulo reviso los avances realizados en el ámbito conceptual de la calidad de la democracia. Destaco su vinculación con los estudios de medición de la democracia y con la literatura que trata sobre los subtipos o formas disminuidas de democracia. Mi interés es valorar los avances obtenidos en cada uno de ellos, considerados como campos complementarios, cuyo tratamiento conjunto puede aportar significativamente al mejor conocimiento de las especificidades de las democracias. El capítulo se inicia con una breve introducción y está dividido en cuatro secciones. En la primera sección abordo los subtipos de regímenes o democracias disminuidas, con la intención de identificar los aportes realizados en ese campo y su utilidad para los estudios de la calidad de la democracia. En la segunda sección reviso brevemente algunos aportes realizados desde la perspectiva de la medición de la democracia. Mi interés es destacar las líneas generales por las que se ha orientado ese tipo de reflexión, que constituye un elemento de apoyo a los estudios de la calidad. En la tercera sección destaco algunos aspectos teóricos y conceptuales básicos de la calidad de la democracia. Con ello busco identificar los elementos que han servido para la construcción teórica y conceptual. En la cuarta sección paso revista a diversos estudios sobre la calidad de la democracia, que en mi opinión constituyen los principales aportes conceptuales en este ámbito. Hago una revisión de ellos a la luz de los tres países estudiados, destacando sus aportes y sus vacíos. Mi intención en este campo es analizar los diversos componentes de cada uno de los acercamientos que existen al respecto y destacar las bondades y los problemas de su utilización. Mi planteamiento central al respecto es que ninguna de las propuestas de medición de la calidad de la democracia puede ser aplicada en su totalidad en la investigación comparativa y que es necesario combinar varias de ellas para el análisis empírico. En la última sección presento las conclusiones generales del capítulo.

\section{Introducción}

Si se quisiera calificar a los regímenes políticos de Bolivia, Ecuador y Perú en el momento actual, se diría que en los tres se verifica en grado variable la lista de chequeo de la poliarquía, de la democracia política o de cualquiera de las definiciones mínimas o procedimentales de democracia. En todos ellos se cumplen, en alguna medida, los requisitos usualmente reconocidos de la democracia: se celebran elecciones para elegir a los mandatarios; éstas se mantienen generalmente dentro de los parámetros que sirven para calificarlas de limpias y libres; no hay serias restricciones legales ni institucionales para la participación política de la población adulta; existe un marco relativamente aceptable de libertades civiles; hay pluralismo en la opinión expresada en los medios; generalmente -con las excepciones de rigor- los gobiernos actúan dentro de los marcos establecidos constitucional y legalmente; y, finalmente, los ciudadanos tienen a su alcance los recursos 
y los medios para controlar a los políticos. Por tanto, si se tratara de diferenciar solamente entre autoritarismo y democracia, se podría afirmar que los tres países se sitúan en el terreno de esta última.

He destacado que aquellas condiciones se cumplen en grado variable o en alguna medida. Esto quiere decir que no siempre están presentes todos los elementos al mismo tiempo y además que, aún en los casos en que han concurrido todos, varios de ellos no lo han hecho en la plenitud de sus condiciones o en su grado óptimo. A manera de ejemplo, en algunos casos la celebración de elecciones ha cumplido con los requisitos que exige la limpieza de los procesos, pero no han sido libres o no han existido las garantías para que se materialice el pluralismo de opinión mediante el acceso equitativo a los medios de comunicación. Así mismo, en muchos casos se han violado los derechos de la oposición o de determinados sectores sociales específicos, poniendo en seria duda la vigencia de las libertades políticas y de la igualdad de oportunidades. De la misma manera, a lo largo de todo el período se han producido exclusiones de individuos y grupos sociales específicos, ha existido acceso inequitativo a la justicia, se ha contaminado a ésta con la política (politización de la justicia y judicialización de la política), entre otros hechos que constituyen evidencias de la debilidad del estado de derecho, considerado siempre como un requisito básico del régimen democrático.

La constatación de estas distorsiones con respecto al tipo ideal de democracia plantea la necesidad de impulsar una reflexión detenida sobre el carácter de los regímenes de los tres países. Aunque dentro de una perspectiva dicotómica, que solamente reconoce autoritarismos y democracias, los tres pueden ser ubicados principalmente en el campo de las democracias, aquellas distorsiones obligan a un análisis centrado en las especificidades ${ }^{1}$. Dicho de otra manera, desde la perspectiva dicotómica los tres deberían ser calificados como democracias porque no son autoritarismos. Pero con ello se avanzaría muy poco en la identificación y clasificación de sus respectivos regímenes. En una visión más detallada, como es la comparación que desarrollo aquí, se hace necesario considerar los aspectos particulares que definen la especificidad de cada uno de ellos. Se

\footnotetext{
${ }^{1}$ La perspectiva dicotómica tiene su expresión más acabada y sólida en la clasificación Álvarez et al. (1996: 3 y ss.). Como se verá más adelante, esta tiene gran valor heurístico para el análisis comparado de grandes muestras de países, pero es insuficiente cuando se analiza un número reducido de casos donde la identificación de las especificidades es el elemento central. Esta es una expresión clara de la diferencia, dentro del método comparativo, entre estudios con un "N pequeño” y un “N grande” (Lijphart, 1971: 685-691; Collier, 1999: 52).
} 
precisa, para esto, acudir a perspectivas más complejas que den cuenta del grado variable en cada uno de sus atributos al que me he referido.

Una de esas perspectivas es la que se ha ido desarrollando en torno a la calidad de la democracia. Este es un tema de interés reciente en la ciencia política, por tanto es un campo conceptual en proceso de construcción. Después de la preocupación por las transiciones (que he analizado en el capítulo II), en el ámbito académico se hizo evidente la necesidad de poner atención en las diferencias del grado de avance de las democracias, en particular en el proceso de afianzamiento sus diversos atributos ${ }^{2}$. La generalización de regímenes que cumplen con los requisitos básicos de la democracia política (o de la poliarquía) y/o con los del Estado de derecho, junto a la diversidad de grado que presentaba cada uno de los atributos, puso de manifiesto las diferencias sustanciales que existen entre ellos (Munck, 2009: 38). Esta evidencia de las diferencias entre y dentro de regímenes democráticos llevó a la formulación de preguntas sobre las características y las consecuencias de ellas ${ }^{3}$. Fundamentalmente, puso en cuestión la visión dicotómica que solamente reconocía la existencia de regímenes autoritarios y democráticos ${ }^{4}$. La investigación comparada demostró fehacientemente la existencia de una amplia gama de regímenes entre esos dos extremos o tipos puros. En gran medida esta perspectiva de análisis se fue estructurando a partir de la constatación de desviaciones con respecto a algún modelo normativo de democracia. Esta línea de pensamiento llevó a la adjetivación de la democracia, en la que los términos que se añadían al concepto expresaban el grado o el

\footnotetext{
${ }^{2}$ Estoy consciente de que, después de lo señalado en el capítulo II acerca de los problemas derivados del uso del concepto de consolidación, la alusión al afianzamiento de los atributos de la democracia puede interpretarse como un eufemismo para evitar aquel tema engorroso. En realidad, este recurso se debe a la necesidad de marcar una diferencia con aquella perspectiva debido a su sesgo mecanicista, en especial por su tendencia a considerar que, una vez alcanzado un determinado nivel, las democracias prácticamente no estarían sujetas a retrocesos. Los procesos vividos en muchos países del mundo, entre ellos los tres estudiados, demuestra que ello no es así. Como se verá en este capítulo, algunos de los problemas que enfrentan las democracias contemporáneas son los avances y retrocesos en los diversos atributos de la democracia, lo que en muchos de los casos lleva a verdaderos cambios de régimen.

${ }^{3}$ Las causas de las diferencias entre regímenes democráticos han recibido menor atención en la literatura especializada que las características y las consecuencias. Como se verá a lo largo de este capítulo, la mayor parte de autores se han abocado a la explicación de las particularidades y de sus efectos sobre la democracia, mientras han dejado de lado la búsqueda de los orígenes de esas diferencias.

${ }^{4}$ Este debate estuvo antecedido -y en gran medida acompañado- por el que se desarrolló en torno al concepto de democracia, en términos de sus atributos, su carácter normativo, su capacidad operacional y los niveles en que se realiza el análisis. Visiones de conjunto al respecto se encuentran en Schmitter y Karl (1996), Collier y Levitsky (1998), Held (2001), Lijphart (2002)
} 
tipo de desviación con respecto al modelo o tipo ideal (Schmitter y Karl, 1996; Collier y Levitsky, 1998).

Era prácticamente inevitable que este tipo de reflexión abriera el campo de la medición de la democracia. Una consecuencia lógica del trabajo sobre las diferencias entre regímenes democráticos era la necesidad de valorarlas, de contar con criterios e instrumentos que permitieran establecer la magnitud de esas diferencias. Así mismo, la alusión a desviaciones con respecto a un modelo debía desembocar en la búsqueda de parámetros que dieran cuenta de las características y el peso de esas desviaciones. Por ello, desde ambas preguntas se han construido propuestas de medición que buscan, por un lado, identificar los grados en que la democracia ha avanzado o retrocedido en determinados aspectos en una visión comparativa de diversos casos o, por otro lado, dimensionar el grado en que un caso en particuar se diferencia de un modelo ideal definido previamente. Por tanto, se abrió un campo que, en términos estrictos y para evitar problemas de carácter conceptual y metodológico, siempre debe ser considerado como la expresión de una de las dos interrogantes señaladas.

En parte como desarrollo de ese campo de medición de la democracia, pero también como producto de un proceso autónomo, en los medios académicos surgió la preocupación por la calidad de la democracia. Tanto las diferencias entre regímenes así como la mayor o menor distancia con un modelo ideal pueden ser interpretadas desde la perspectiva de la calidad, esto es, de sus propiedades y sus características, ya sea en referencia a otras democracias o bien en relación a una construcción conceptual. Por consiguiente, al utilizar la noción de calidad el análisis tiende a apreciar a la democracia como igual, mejor o peor que otras o que el tipo ideal construido o seleccionado, de manera que siempre será necesario establecer una gradación. Si esta es cuantitativa o cualitativa es un tema secundario, que se desprende de los objetivos de cada investigación en particular, pero que no afecta a los aspectos de fondo. Lo importante es comprender que el estudio de la calidad de la democracia supone una escala construida con un conjunto de criterios que se consideran básicos para el régimen democrático.

A partir de estas consideraciones es procedente desarrollar el análisis de la calidad de la democracia en los tres países. Mi objetivo es moverme en el campo o perspectiva que he reseñado, de modo que tomaré como referencia un concepto básico de democracia -un 
tipo ideal-, que en gran medida lo he planteado en el capítulo I, y a la vez desarrollaré un análisis comparado entre algunos componentes de los sistemas y regímenes políticos de los tres países. Para ello, y de la misma manera que lo he hecho en los capítulos anteriores, me moveré entre el análisis de los tres países y el debate teórico conceptual que se ha desarrollado al respecto en los últimos años. Pero, antes de entrar en el campo específico de la calidad de la democracia, revisaré brevemente dos corrientes de reflexión que, en mi opinión, son claramente complementarias con ella. Me refiero a los aportes que se han realizado acerca de los subtipos de régimen o democracias disminuidas, por un lado y de la medición de la democracia, por otro lado.

\section{Tipologías de democracia o democracias disminuidas ${ }^{5}$}

Considero necesario reiterar que un paso básico para el surgimiento del interés en la calidad de la democracia fue la constatación de la existencia de una variedad de regímenes que se situaban entre los tipos puros de autoritarismo y democracia. Esta constatación dio paso a diversos tipos de acercamientos o de perspectivas de análisis, que a la vez se expresaron en nuevos conceptos. Desde una de estas perspectivas de análisis se detectó la existencia de regímenes que, al conservar y combinar algunas características de los dos tipos extremos (autoritarismos y democracias), pueden ser considerados como regimenes bíbridos (Diamond, 2002: 25; Morlino, 2004: 10; Diamond y Morlino, 2005: xiv). Desde otro punto de vista, se propuso una clasificación tricotómica, en la que en medio de los dos extremos se encuentra un tipo al que se ha denominado régimen semidemocrático (Mainwaring, Brincks y Pérez-Liñán, 2001: 38; Mainwaring y Pérez-Liñán, 2008: 18) ${ }^{6}$. En otros acercamientos se acudió a la construcción de conceptos que buscaban destacar las características de determinados casos dentro de esas clasificaciones complejas, como las democracias delegativas (O’Donnell, 1992: 5), las democracias iliberales (Zakaria, 1998: 1), los

\footnotetext{
${ }^{5}$ Con todos los riesgos de considerarlo como un atentado contra el rigor conceptual, utilizo indistintamente las denominaciones de democracias disminuidas, subtipos de democracia y tipos de régimen. Con esos términos me refiero a las diversas formas que se sitúan entre la democracia y el autoritarismo.

${ }^{6}$ La clasificación de Álvarez et al. (1996), aludida antes, es rebatida directamente por Mainwaring, Brinks y Pérez-Liñán (2001: 38) porque no reconoce a los regímenes intermedios, esto es, a los que no se sitúan en uno de los dos extremos del continuum autoritarismo-democracia. Sin embargo, se debe reconocer que los primeros dejan abierta la puerta a la existencia de otros tipos cuando señalan que "Aunque distinguimos diferentes tipos de democracia y de dictadura, la clasificación básica es dicotómica” (Álvarez et al., 1996: 4). El problema se encuentra, como he sostenido antes (nota 1 del presente capítulo), cuando se trata de identificar el grado que alcanza cada uno de los atributos de la democracia en cada situación particular.
} 
autoritarismos competitivos (Levitsky y Way, 2002: 52) y los regimenes electorales autoritarios (Schedler, 2002: 36). Por tanto, desde diversas ópticas se aceptó que las diferencias dentro de los regímenes democráticos planteaban problemas teóricos que debían ser resueltos por medio de la construcción de conceptos adecuados a esas realidades. De una manera esquemática se puede ubicar a estas propuestas en una representación espacial como la del gráfico $\mathrm{N}^{\circ} 1$.

Gráfico $\mathbf{N}^{\circ} 1$

Ubicación de los regímenes

\begin{tabular}{|c|c|c|c|}
\hline \multirow[t]{6}{*}{$\begin{array}{l}\text { Régimen } \\
\text { autoritario }\end{array}$} & & & $\begin{array}{l}\text { Régimen } \\
\text { democrático }\end{array}$ \\
\hline & & $\begin{array}{l}\text { Regímenes } \\
\text { semidemocráticos } \\
\text { (Mainwaring, Brinks y } \\
\text { Pérez-Liñán, 2001) }\end{array}$ & \\
\hline & $\begin{array}{l}\text { Autoritarismo } \\
\text { competitivo } \\
\text { (Levitsky y } \\
\text { Way, 2002) }\end{array}$ & $\begin{array}{l}\text { Democracias } \\
\text { delegativas } \\
\text { (O’Donnell, 1992) }\end{array}$ & \\
\hline & \multicolumn{2}{|c|}{$\begin{array}{l}\text { Regímenes electorales } \\
\text { autoritarios (Schedler, } \\
\text { nnno }\end{array}$} & \\
\hline & \multicolumn{2}{|c|}{$\begin{array}{l}\text { Democracias iliberales } \\
\text { (Zakaria, 1998) }\end{array}$} & \\
\hline & \multicolumn{2}{|c|}{$\begin{array}{l}\text { Regímenes híbridos (Diamond y Morlino, } \\
\text { 2005) }\end{array}$} & \\
\hline
\end{tabular}

Fuentes: Mainwaring, Brinks y Pérez-Liñán (2001); Levitsky y Way (2002); O’Donnell (1992); Schedler (2002); Zakaria (1998); Diamond y Morlino (2005); Diamond (2002). Elaboración: S. Pachano

Varios elementos se desprenden de estos primeros acercamientos. En primer lugar, existe un acuerdo sobre la heterogeneidad de los regímenes políticos, aún dentro de cada uno de los tipos. Por consiguiente, es posible identificar diversos tipos de democracia como también de autoritarismo. En segundo lugar, hay un amplio espacio entre ambos términos que puede ser ocupado por regímenes en los que predominan los componentes democráticos o por otros en los que imperan los componentes autoritarios. De cualquier manera, sea que se sitúen hacia el lado del autoritarismo o hacia el lado de la democracia, todos esos tipos de régimen comparten el carácter híbrido. Todos ellos son combinaciones en los que entran en diversas dosis los ingredientes de cada uno de los 
tipos básicos. Son, desde esa perspectiva, formas adjetivadas o disminuidas de autoritarismo y de democracia, respectivamente ${ }^{7}$.

En tercer lugar, debido a los diversos parámetros con se construye cada uno de estos acercamientos, no se los puede considerar necesariamente como excluyentes sino que pueden ser más bien complementarios. Finalmente, todos estos acercamientos parten de un mismo tronco, que es el reconocimiento de la existencia de un régimen democrático, ya sea como un hecho empírico o como una construcción teórica. Ninguno de ellos incluso los que analizan a los regímenes que se sitúan en el espacio del autoritarismoconstituye una forma de negación de la democracia. Por el contrario, todos ellos buscan explicar los elementos que señalan el grado de alejamiento de la democracia o que han devenido en déficit en algunos de sus aspectos, de modo que se mantienen dentro del horizonte de la teoría de la democracia y son parte de ella ${ }^{8}$. Con estos elementos cabe analizar brevemente a cada uno de ellos.

Considero conveniente comenzar por la clasificación que identifica a los regimenes semidemocráticos como una categoría intermedia entre la democracia y el autoritarismo (Maiwaring, Binks y Pérez Liñán, 2001). El planteamiento central de sus autores se resume en que "las clasificaciones dicotómicas son insuficientemente sensibles a las

${ }^{7}$ El autoritarismo competitivo de Levitsky y Way (2002) y los regímenes electorales autoritarios de Schedler (2000) se encontrarían en algún punto situado entre el centro de la línea continúa y el extremo del autoritarismo puro. La democracia delegativa de O`Donnell (1997), las democracias iliberales de Zakaria (1998) y los regímenes semidemocráticos de Mainwaring, Brinks y PérezLiñán (2002) se encontrarían en un punto situado entre el centro y la democracia pura. Los regímenes híbridos de Diamond (2002), Morlino (2004) y Diamond y Morlino (2005) se encontrarían en cualquier punto a lo largo de esa línea, ya sea equidistante a los dos extremos o desplazado hacia uno de ellos.

${ }^{8}$ Este último punto debe ser subrayado cuando se analiza a los países latinoamericanos y de manera especial cuando se hace referencia a su pensamiento político, ya que la relativa fuerza de una visión claramente antidemocrática -en la política y en la academia- hizo que la mayor parte de críticas a la democracia fueran formas de negación de ésta en tanto régimen político y mucho más en tanto ideal a alcanzar. La fuerte herencia del marxismo en una orilla y la debilidad del liberalismo en la otra orilla, dejaron escaso espacio para el surgimiento de un sólido pensamiento democrático. El éxito que aún mantienen divulgadores como Eduardo Galeano y Carlos Montaner, que en realidad podrían ser considerados como caricaturistas de las posiciones que defienden, es una expresión de la fuerza de esas visiones. Fuera de la experiencia del pequeño conjunto de países al que me he referido en capítulos anteriores -Costa Rica, Chile y Uruguay-, la democracia como ideal político y como eje del pensamiento académico recién tomó cuerpo a partir de los efectos de las última ola dictatorial, e incluso en algunos países, como Ecuador y en alguna medida Perú, solamente cuando ya se iniciaron las respectivas transiciones. Por ello parece demasiado optimista afirmar que "En todas partes se han abandonado discretamente los adjetivos vagos como 'popular', 'guiada', 'burguesa' y 'formal', para calificar a la 'democracia' (Schmitter y Karl, 1996: 37). La democracia de estos países sigue cargada de adjetivos, muchos de ellos descalificativos. 
variaciones del régimen debido a que muchos regímenes caen en una zona intermedia. Una clasificación ordinal -democracia, semidemocracia y no democracia o autoritarismocaptura de mejor manera las variaciones significativas de los regímenes" (Maiwaring, Binks y Pérez Liñán, 2001: 38). El cuestionamiento a la perspectiva dicotómica, que solamente reconoce la existencia de regímenes democráticos y autoritarios, se basa en el concepto de democracia que utilizan los autores y que busca alejarse tanto de las definiciones no procedimentales como de las que identifican como procedimentales subminimas ${ }^{9}$. Como una manera de superar las limitaciones de ambas definiciones proponen una clasificación procedimental basada en cuatro atributos centrales, que son básicamente los propuestos por Dahl para la poliarquía ${ }^{10}$. La ausencia de cualquiera de ellos elimina la posibilidad de considerar como democrático a un régimen ya que "esta definición supera el test de ser mínima y completa si a) los cuatro criterios son necesariamente componentes de la democracia, sin los cuales un régimen no debería ser considerado como democrático, y b) ninguna otra característica es necesaria para definir a la democracia” (Maiwaring, Binks y Pérez Liñán, 2001: 41).

De esta manera los regímenes semidemocráticos se caracterizan por "la presencia de elementos autoritarios en los regímenes competitivos (...) La existencia de instituciones electorales no excluye la presencia de restricciones autoritarias en el uso de esas instituciones" (Maiwaring, Binks y Pérez Liñán, 2001: 52). Por consiguiente, el elemento diferenciador es la vigencia de los derechos y las libertades y la observación de los procedimientos democráticos. Por ello, "la realización de elecciones libres y limpias no es garantía de los otros tres criterios de definición de la democracia; tampoco la ausencia o malfuncionamiento de estas instituciones hace a todos los casos igualmente autoritarios" (Maiwaring, Binks y Pérez Liñán, 2001: 52). Por el contrario, se encuentran diferencias de grados -regímenes que se sitúan en una "zona gris" (Maiwaring, Binks y Pérez Liñán, 2001: 52)- que, en opinión de los autores, hacen necesaria la clasificación tricotómica.

\footnotetext{
${ }^{9}$ Entre los conceptos de democracia procedimentales submínimos incluyen las de Schumpeter (1996) y de Przeworski (1991).

${ }^{10}$ Los cuatro elementos son: 1 ) elecciones libres, limpias y competitivas para el legislativo y el ejecutivo; 2) inclusión electoral de toda la población adulta; 3) protección de las libertades civiles y de los derechos políticos; 4) gobernantes con capacidad real para gobernar y sometimiento de los militares al control civil (Maiwaring, Binks y Pérez Liñán, 2001: 38). Señalan además, para sostener el carácter procedimental de su definición que ésta "no dice nada acerca de la accountability, de los defectos en el estado de derecho excepto aquellos que inciden sobre los derechos civiles y políticos, y de las manifestaciones de 'decretismo'. Añadir estos criterios que no son inherentes a la naturaleza de la democracia lleva a una definición no mínima” (Maiwaring, Binks y Pérez Liñán, 2001: 41)
} 
Dos observaciones son necesarias acerca de esta propuesta. En primer lugar, de la misma manera que varios de los otros autores analizados, trabajan con un concepto mínimo y procedimental de democracia, pero -también al igual que los otros- no dejan de incluir en éste los aspectos sustantivos. En realidad, la amplia zona gris que ellos destacan está conformada por la ausencia de aquellos atributos y no solamente por el carácter electoral del régimen. En segundo lugar, en el amplio espacio que se encuentra entre el autoritarismo y la democracia, los autores identifican exclusivamente un subtipo de democracia disminuida. En gran medida, esto se debe a que la propuesta está construida como una alternativa a la clasificación dicotómica, aquella que reconoce solamente a los regímenes extremos o puros $^{11}$. Sin embargo, la investigación comparativa demuestra que ese espacio puede ser ocupado por regímenes que de diferencian en diversos aspectos y en diversos grados. Si se considera que los cuatro criterios de clasificación que destacan los autores pueden presentarse también en diversos grados, entonces se debe aceptar que es posible que puedan combinarse en múltiples formas. En consecuencia, la referencia a los regímenes semidemocráticos siempre debería ser hecha en plural, esto es, se debería aceptar que no se trata de un solo tipo de régimen sino que bajo esa denominación pueden encontrarse diversos tipos, lo que se aprecia espacialmente en el gráfico 2.

\section{Gráfico $\mathbf{N}^{\circ} 2$}

\section{Ubicación de los regímenes semidemocráticos}

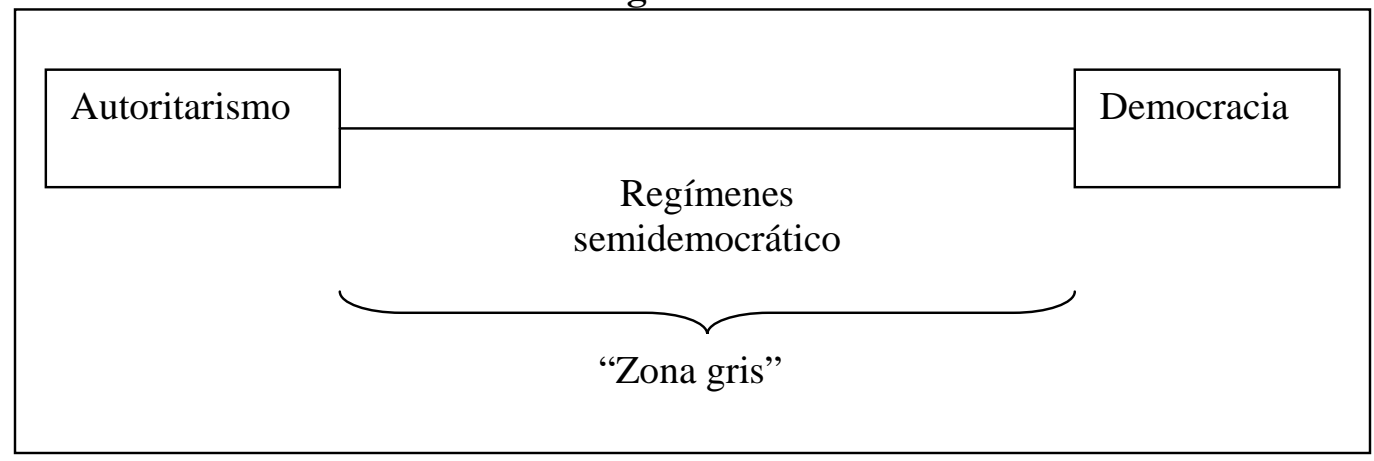

Fuente: Mainwaring, Brinks y Pérez-Liñán (2001). Elaboración: S. Pachano

En la aplicación de sus criterios a diecinueve países de América Latina, los autores incluyen a los tres países estudiados aquí. Bolivia y Ecuador aparecen como países

\footnotetext{
${ }^{11}$ Los autores toman como expresión de la clasificación dicotómica fundamentalmente a Álvarez et al. (1996) y a Przeworki et al. (2000). Adicionalmente como ya he señalado, cuestionan las definiciones de Schumpeter (1996) y Przeworki (1991), por el carácter submínimo, pero también la de Bollen (1991), por su carácter no procedimental.
} 
democráticos en los años 1982-1999 y 1979-1999, respectivamente, en tanto que Perú tiene esa calidad en 1980-1982, semidemocrático en 1983-1984, democrático en 19851987, semidemocrático en 1988-1991, autoritario en 1992-1994 y semidemocrático en 1995-1999 (Maiwaring, Binks y Pérez Liñán, 2001: 49). Estos resultados muestran los alcances y los límites de esta clasificación. Por una parte, es relativamente sensible a los cambios que se producen en los principales indicadores que la sustentan, como se observa en las diversas ubicaciones que se le asigna a Perú a partir del golpe de estado de 1992. Pero, por otra parte, debido a que estas variaciones están asentadas fundamentalmente en la realización de elecciones competitivas (Maiwaring, Binks y Pérez Liñán, 2001: 50), no puede expresar otras formas de desplazamiento desde el régimen democrático hacia el autoritarismo. El ejercicio autoritario del gobierno, como ocurrió en Ecuador en el período 1984-1988 y en Bolivia en 1985, no son recogidos debido a las limitaciones que establecen los criterios de la clasificación. Los propios autores son conscientes de esta limitación cuando señalan que se podría clasificar a las "semidemocracias en varias subcategorías, pero en todos aquellos casos tienen lugar elecciones razonablemente libres y competitivas, mientras son afectados otros elementos de la democracia" (Maiwaring, Binks y Pérez Liñán, 2001: 50). El problema, en mi opinión, es que a pesar de haber incluido inicialmente un conjunto de atributos en la clasificación, en el momento de se aplicación se le otorga el papel fundamental a uno solo de ellos (las elecciones razonablemente competitivas y libres) ${ }^{12}$.

La segunda clasificación trata sobre las democracias delegativas, definidas como regímenes que "no son democracias consolidadas o institucionalizadas, pero pueden ser duraderas [y que no presentan] amenazas inminentes de una regresión autoritaria abierta, pero tampoco vislumbran avances en dirección a una representatividad institucionalizada" (O’Donnell, 1992: 6, cursiva en el original). El origen de estos regímenes se encuentra en el fracaso de la que el autor denomina "segunda transición", que corresponde al paso "de un gobierno democráticamente electo hacia un régimen democrático o, lo que es equivalente, hacia una democracia institucionalizada, consolidada" (O’Donnell, 1992: 7, cursiva en el original). El parámetro que determina "el resultado de la segunda transición es el suceso

\footnotetext{
${ }^{12}$ Aún restringiéndose a ese atributo, la ubicación de los países no sería exactamente la que presentan los autores. Las elecciones peruanas en todo el período de Fujimori estuvieron cargadas de sospechas sobre la limpieza, la libertad y las garantías para la oposición (Cotler, 2000; Tuesta, 1999; Conaghan, 2005). Las elecciones ecuatorianas de medio período del año 1986 tuvieron también serias irregularidades (Pachano, 2000).
} 
[éxito] o fracaso en la construcción de un conjunto de instituciones democráticas que se convierten en importantes puntos decisorios en el flujo del poder político" (O’Donnell, 1992: 7). Este fracaso en la construcción de las instituciones democráticas establece como premisa básica que el ganador de "una elección está autorizado a gobernar en el país como le parezca conveniente y, en la medida en que las relaciones de poder lo permitan, hasta el final de su mandato" (O’Donnell, 1992: 10). De esta manera, el presidente pasa a ser "la encarnación de la nación, el principal fiador del interés nacional, lo cual cabe a él definir" (O’Donnell, 1992: 10). Finalmente, las “otras instituciones -como el Congreso y el Poder Judicial- son incomodidades que acompañan las ventajas internas e internacionales de ser un presidente democráticamente electo. La idea de obligatoriedad de rendir cuentas (accountability) a esas instituciones, o a otras organizaciones privadas o semiprivadas, aparece como un impedimento innecesario a la plena autoridad que el presidente recibió la delegación de ejercer”' (O’Donnell, 1992: 11, cursiva en el original).

Gráfico $\mathbf{N}^{\circ} 3$

Ubicación de las democracias delegativas

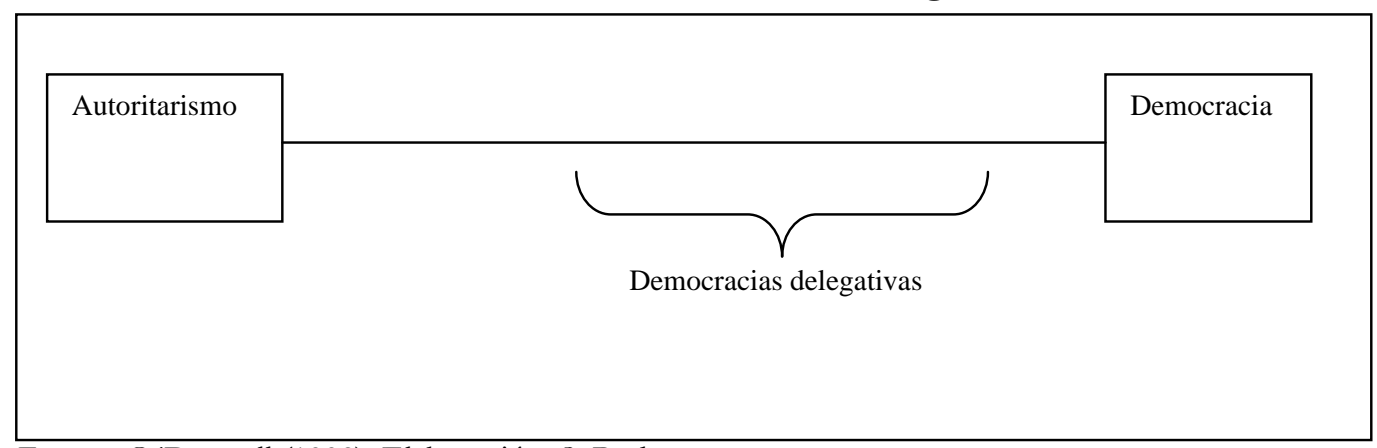

Fuente: O’Donnell (1992). Elaboración: S. Pachano

El énfasis del análisis está puesto en los regímenes donde los presidentes gobiernan al margen de los procedimientos de accountability horizontal y vertical. Esto marca la diferencia entre los regímenes de delegación representativa (es decir, las democracias liberales o representativas) y "aquellos en que el elemento delegativo es fuertemente predominante" (O’Donnell, 1992: 12). La única forma de control desde la ciudadanía al gobierno, en las democracias delegativas, serían las elecciones que solamente tienen un carácter retrospectivo y no funcionan como un mecanismo de control durante la gestión. Por otra parte, éstas se caracterizan por la generalización de prácticas políticas como el clientelismo y otras formas de particularismo, que establecen una relación directa entre el mandatario y los electores dentro de una perspectiva plebiscitaria (O’Donnell, 1992: 18). 
Un último aspecto a destacar es que, a pesar de que son democracias escasamente institucionalizadas en el aspecto formal, no lo son en el aspecto informal y tampoco se trata de regímenes efímeros (O’Donnell, 1992: 13).

Me parece importante destacar tres aspectos de este enfoque. En primer lugar, las democracias delegativas se alejan de la democracia en términos de las características que asume el ejercicio de la presidencia. El elemento fundamental en este sentido es la ausencia de accountability y, por tanto, la pérdida o la reducción de la posibilidad de control a los políticos por parte de la ciudadanía. En este sentido, se los puede considerar como regímenes verticales, que pueden dirigirse hacia formas autoritarias y que llevan a las prácticas particularistas y plebiscitarias a su máxima expresión. En segundo lugar, cabe destacar que, aunque las instituciones y el proceso de institucionalización desempeñan un papel de importancia en la construcción conceptual de este tipo de régimen, buena parte de la reflexión del autor está basada en la manera en que los gobiernos enfrentaron la crisis económica o, se puede decir, en la efectividad de sus políticas ${ }^{13}$. Por consiguiente, se podría interpretar que, más que un tipo de régimen, es un tipo de gobierno, lo que reduciría la riqueza explicativa del propio concepto. Finalmente, muchos de los elementos que el autor destaca como componentes de este tipo de régimen han sido los que tradicionalmente se han utilizado para caracterizar al populismo ${ }^{14}$. Por consiguiente, no queda claramente establecido su estatus como un concepto alternativo en este aspecto.

El autor no realiza el ejercicio de aplicación de su propuesta a la realidad de cada uno de los países latinoamericanos, aunque señala algunas pistas generales que permiten extraer

${ }^{13}$ El resultado de la segunda transición "está fundamentalmente condicionado por la políticas públicas y por las estrategias políticas de varios agentes que incorporen el reconocimiento de un interés superior común en la tarea de construcción institucional democrática (...) [Las democracias delegativas] no alcanzaron progreso institucional ni eficacia gubernamental en el enfrentamiento de sus respectivas crisis sociales y económicas" (O’Donnell, 1992:7)

${ }^{14}$ Una crítica en este sentido se encuentra en Peruzzotti (2001). Este autor se pregunta "Si la democracia delegativa parece ser un aggiornamento de las tradiciones populistas, ¿cuál es entonces la fuente de sus diferencias?” (Peruzzotti, 2001: 137). La respuesta se encontraría, según este autor, en el contexto de crisis en que emergen estos regímenes, que se caracteriza por la “subinstitucionalización” (underinstitutionalisation) y la crisis económica y política. Sin embargo, en mi opinión eso no zanja el problema con respecto al populismo, ya que buena parte de la explicación del populismo se asienta precisamente en la crisis o en la manera en que se la buscar resolver (Laclau, 2007; De la Torre, 2008; De la Torre y Peruzzotti, 2008) y, como se ha visto, O’Donnell atribuye el surgimiento de la democracia delegativa al contexto de crisis y a la manera en que los gobiernos la enfrentan. La similitud entre la noción de democracias delegativas y democracias populistas se encuentra también en Morlino (2004: 11) 
conclusiones generales para los tres países estudiados. Así, afirma que en "las democratizaciones contemporáneas, solamente Uruguay y Chile están consiguiendo escapar de los círculos infernales [de la democracia delegativa]" (O’Donnell, 1992: 18). En consecuencia, el resto de países, entre ellos sin duda Bolivia, Ecuador y Perú, caerían inevitablemente en alguna forma de democracia delegativa, sobre todo a causa de la inexistencia de una tradición de instituciones y prácticas democráticas (que si existiría en los casos excepcionales de Uruguay y Chile). Si esto es así, la noción de democracia delegativa constituiría un apropiado recurso para calificar el tipo de régimen que se ha instaurado en la mayor parte de países, pero no resultaría útil para identificar las particularidades de cada uno. Además, aplicando los criterios básicos de esta noción, se podría sostener que Bolivia dejó de ser una democracia delegativa entre 1986 y 2003, cuando logró mantener políticas económicas y sociales de largo alcance y no hubo espacio para los liderazgos plebiscitarios. Lo mismo podría decirse de Ecuador entre los años 1988 y 1996 (bajo los gobiernos de Rodrigo Borja y Sixto Durán Ballén) e incluso entre 1998 y 2000 (durante el gobierno de Jamil Mahuad, que sin embargo terminó arrastrado por la peor crisis económica de su historia). En definitiva, se puede afirmar que la noción de democracia delegativa tiene básicamente un carácter descriptivo, en tanto es muy útil para identificar determinados rasgos generales, pero que no permite identificar con precisión las especificidades de cada caso.

La tercera propuesta de clasificación es la que identifica al autoritarismo competitivo como una forma disminuida del autoritarismo y no de la democracia (Levitsky y Way, 2002: 52). No son regímenes que se desplazan hacia la democracia, como esperaba la transitología, sino hacia el autoritarismo. Aunque "las instituciones democráticas formales son ampliamente vistas como los principales medios para obtener y ejercer el poder político, los gobernantes violan esas reglas tan a menudo y tan ampliamente que el régimen fracasa en alcanzar los estándares mínimos convencionales de la democracia (Levitsky y Way, 2002: 52 ${ }^{15}$. Por tanto, al contrario de otras formas -como las democracias delegativas o los autoritarismos electorales a las que aluden explícitamente los autores

\footnotetext{
${ }^{15}$ Estos estándares -vale decir el concepto mínimo de democracia que sirve de referencia- se sintetizan en cuatro criterios: "1) Los ejecutivos y los legislativos son escogidos a través de elecciones abiertas, libres y limpias; 2) virtualmente, todos los adultos tienen derecho al voto; 3 ) los derechos políticos y las libertades civiles, incluyendo la libertad de prensa, la libertad de asociación y la libertad para criticar al gobierno sin represalias, son protegidas ampliamente; y 4) las autoridades electas disponen de real autoridad para gobernar y no están sujetas al control tutelar de líderes militares o eclesiásticos (Levitsky y Way, 2002: 53).
} 
(Levitsky y Way, 2002: 53)-, que buscan siempre mantener la fachada democrática, estos regímenes se basan en la violación abierta o en la manipulación de las reglas de la democracia. Eso es lo que lleva a que se sitúen más cerca del autoritarismo que de la democracia (que en su representación espacial ocuparía un amplio espacio, como se aprecia en el gráfico 4). Sin embargo, existe una débil línea que separa a estos regímenes del autoritarismo puro, y es la que se establece por medio de lo que los autores identifican como cuatro arenas de confrontación. Estas arenas (electoral, legislativa, judicial y medios de comunicación) constituyen los espacios en los que la oposición puede plantear sus desafíos y llegar potencialmente a sustituir al régimen o democratizarlo en alguna medida (Levitsky y Way, 2002: 54).

\section{Gráfico $\mathrm{N}^{\circ} 4$}

\section{Ubicación de los autoritarismos competitivos}

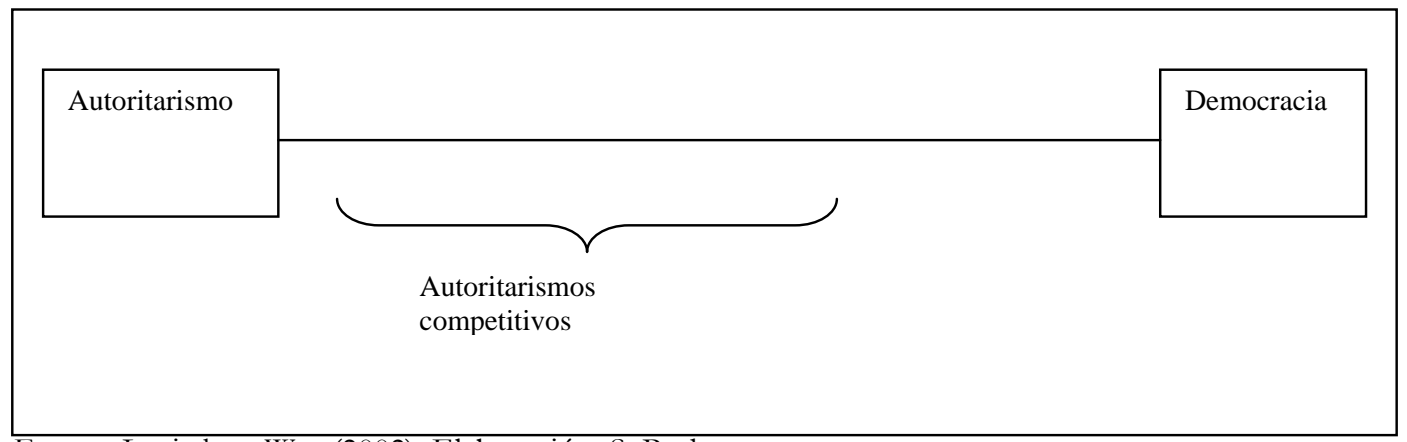

Fuente: Levitsky y Way (2002). Elaboración: S. Pachano

Tres elementos se destacan de esta propuesta. En primer lugar, Esta caracterización llama la atención sobre las posibilidades de un desplazamiento hacia las formas autoritarias y no hacia las formas democráticas. La ruptura con el paradigma de la transición -en palabras de Carothers, a quien citan los autores (Levitsky y Way, 2002: 63)- es más pronunciada en esta perspectiva que en la de las democracias delegativas. La posibilidad de involución hacia formas autoritarias es un hecho concreto, como se vio en el caso peruano durante la década de Fujimori, que toman precisamente como uno de los ejemplos de este tipo de régimen (Levitsky y Way, 2002: 61). En segundo lugar, la existencia de la débil línea que separa a éstos de los regímenes autoritarios ofrece un espacio no solamente para el juego político (restringido) de las fuerzas de oposición, sino que por esa misma razón plantea desafíos conceptuales en términos de la posible evolución de este tipo de régimen. De manera especial, se hace necesario contar con el instrumental teórico adecuado para comprender las posibilidades reales de abandono de esa situación. Es probable que una 
respuesta a esta inquietud se encuentre en la actualización de la teoría de las transiciones, ya que precisamente se haría necesaria una nueva transición (algo similar a la segunda transición a la que alude la propuesta de las democracias delegativas), lo que obligaría a afinar el análisis hasta establecer los límites que tendría esa transición $y$, consecuentemente, a encontrar el punto en que se podría considerar que han dejado de ser autoritarismos competitivos y han pasado a formar parte de otras formas de democracia desminuida. En tercer lugar, la denominación escogida y los atributos que destacan los autores llevan a considerar a estos regímenes más como formas de autoritarismo que de democracia. Por consiguiente, se plantea un desafío para su clasificación dentro de los regímenes democráticos, especialmente cuando se trata de la medición o de la evaluación de su calidad. Efectivamente, eso es así si se considera que su carácter sustantivo es el autoritarismo y la democracia es solamente una adjetivación (reducida, por lo demás a una de sus expresiones, la competencia electoral).

La utilidad de esta noción, para el análisis de los tres países estudiados, se hace evidente cuando permite comprender las características del régimen vigente en Perú entre 1992 y 2000. Los autores señalan que este es un caso paradigmático de autoritarismo competitivo y a la vez dejan abierta la posibilidad o la duda de incluir también a Venezuela (Levitsky y Way, 2002: 61). Esa duda se puede hacer extensiva a Bolivia y Ecuador, que a partir de los recientes procesos constituyentes están instaurando regímenes que pueden ser incluidos en esa categoría. En estos se encuentran algunos elementos que son componentes básicos del autoritarismo competitivo, como la manipulación electoral (por medio de la asignación selectiva y excluyente de la publicidad oficial o el abuso de esta publicidad), la utilización del cobro de impuestos como arma política, el fomento de conflictos entre actores económicos y sociales, la promulgación de leyes restrictivas a los medios, entre otros (Levitsky y Way, 2002: 58). En consecuencia, la noción de autoritarismo competitivo puede ser un instrumento adecuado para la calificación de situaciones en las que se han perdido los principales atributos de la democracia -especialmente en lo que se refiere a los derechos tanto civiles como políticos- y apenas subsisten los procesos electorales despojados de sus condiciones básicas.

La cuarta propuesta es la de las democracias iliberales (Zakaria, 1998), entendidas como regímenes que mantienen las libertades políticas -básicamente las elecciones- pero 
irrespetan las libertades cívicas. La clave de este tipo de régimen se encuentra en la defectuosa combinación entre estado de derecho y democracia o entre liberalismo y democracia. Las democracias contemporáneas "han encarnado, al mismo tiempo, la democracia y el liberalismo constitucional. Por tanto, es difícil imaginarlos separadamente, ya sea en la forma de democracia iliberal o de autocracia liberal" (Zakaria, 1998: 6). Sin embargo, la evolución reciente de algunos países recientemente democratizados demuestra que es posible esa separación, de modo que el "liberalismo constitucional nos ha llevado a la democracia, pero la democracia no parece traer consigo el liberalismo constitucional" (Zakaria, 1998: 7).

\section{Gráfico $\mathrm{N}^{\circ} 5$}

\section{Ubicación de las democracias iliberales}

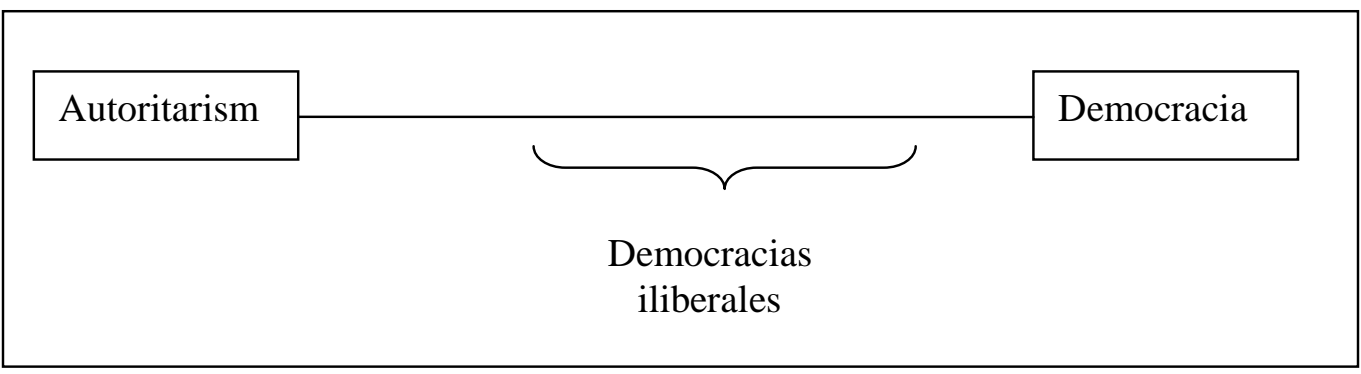

Fuente: Zakaria (1998). Elaboración: S. Pachano

A diferencia de las otras propuestas reseñadas, el autor no desarrolla los elementos que constituyen a la democracia iliberal como un tipo de régimen. Su planteamiento se mantiene en un nivel extremadamente general, pero no se puede negar el valor de este enfoque en cuanto llama la atención sobre la tensión entre democracia y estado de derecho y, de manera especial, sobre la posibilidad de que esa tensión puede no ser resuelta adecuadamente. Como he destacado en el capítulo I, este es uno de los problemas que enfrentan muchos países latinoamericanos y, de manera especial, los tres que son objeto de este estudio, pero a pesar de ello ha recibido muy poca atención tanto desde la academia como desde la política. La debilidad del estado de derecho o, en otras palabras, el carácter iliberal de sus democracias, es uno de los problemas más serios que enfrentan en la actualidad estos países.

Considero que son necesarias dos observaciones acerca de este enfoque. En primer lugar, del mismo modo que las demás clasificaciones, el aspecto que determina la existencia de estos regímenes es la ausencia (o la mínima expresión) de los derechos y las libertades. 
Los elementos procedimentales son componentes esenciales de la democracia, pero en este caso aparecen como insuficientes para considerar como tal a un régimen. En segundo lugar, también de manera similar a algunas de las otras clasificaciones, ésta identifica un solo tipo de democracia disminuida, lo que, junto al grado de generalidad que he señalado, impide comprender claramente en dónde se ubica con relación a ambos polos. No resulta claro si las democracias iliberales se encuentran más cerca de la democracia o del autoritarismo, ni en qué condiciones se podría asegurar que han dejado de ser iliberales para convertirse en democracias completas o, en el caso contrario, en autoritarismos puros.

En su aplicación práctica a los tres países, el concepto de democracia iliberal resulta útil ya que refleja acertadamente la situación caracterizada por las carencias en la construcción del estado de derecho. Las deficiencias en la vigencia de los derechos civiles, los obstáculos en el acceso de amplios grupos sociales a la justicia, la manipulación de ésta desde las instancias políticas (politización de la justicia) y su utilización para zanjar los problemas políticos (judicialización de la política), son hechos generalizados en todos ellos. En consecuencia -y a pesar de los avances logrados con respecto a épocas anteriores en que se intentó establecer regímenes democráticos-, los actuales ordenamientos constitucionales de Bolivia, Ecuador y Perú pueden ser calificados como democracias iliberales. Dicho de otra manera, el concepto tiene utilidad para reflejar las características centrales de uno de los aspectos básicos de la democracia. Sin embargo, sus límites son evidentes, ya que no toma en consideración el resto de atributos de la democracia, lo que no debe ser olvidado a la hora de utilizarlo en el análisis concreto ${ }^{16}$.

La quinta propuesta de clasificación es la que identifica a los regímenes electorales autoritarios o autoritarismos electorales (Schedler, 2002; 2006), que se encuentran en una "zona nebulosa entre la democracia liberal y el autoritarismo cerrado" (Schedler, 2002: 37). Pero, a diferencia de la zona gris de los regímenes semidemocráticos, en este caso particular esa zona nebulosa se configura no tanto en relación a la democracia liberal y al autoritarismo, sino fundamentalmente con referencia a la que el autor denomina democracia electoral. Para llegar a este punto, identifica como tipos intermedios entre la democracia y el autoritarismo a la democracia electoral y al autoritarismo electoral (Schedler,

\footnotetext{
${ }^{16}$ Esta limitación del concepto de democracia iliberal es la misma que se encuentra en la medición de las libertades de Freddom House y hasta cierto punto de Polity IV. En estricto sentido, son más bien mediciones el estado de derecho que de la democracia.
} 
2002: 47). Por tanto, son cuatro tipos de régimen, que en una representación espacial ocuparían los lugares que se observan en el gráfico 6. Por consiguiente, el paso más importante en la caracterización del autoritarismo electoral es la identificación de los rasgos que le diferencian del autoritarismo cerrado, por un lado (hacia la izquierda en el gráfico), y de la democracia electoral, por otro lado (hacia la derecha). Desde esta perspectiva, los autoritarismos electorales son regímenes que "mantienen las elecciones, toleran algún pluralismo y la competencia interpartidista, pero al mismo tiempo violan las normas democráticas mínimas, tan severa y sistemáticamente que no tiene sentido clasificarlas como democracias. Estos regímenes electorales no constituyen formas limitadas, deficientes o distorsionadas de democracia. Ellos son especies de régimen autoritario" (Schedler, 2002: 36). Por tanto, siendo parte de los regímenes autoritarios, se diferencian de estos en la vigencia de las elecciones, no en los aspectos sustantivos de vigencia y respeto a los derechos y a las libertades.

\section{Gráfico $\mathrm{N}^{\circ} 6$}

Ubicación de los autoritarismos electorales

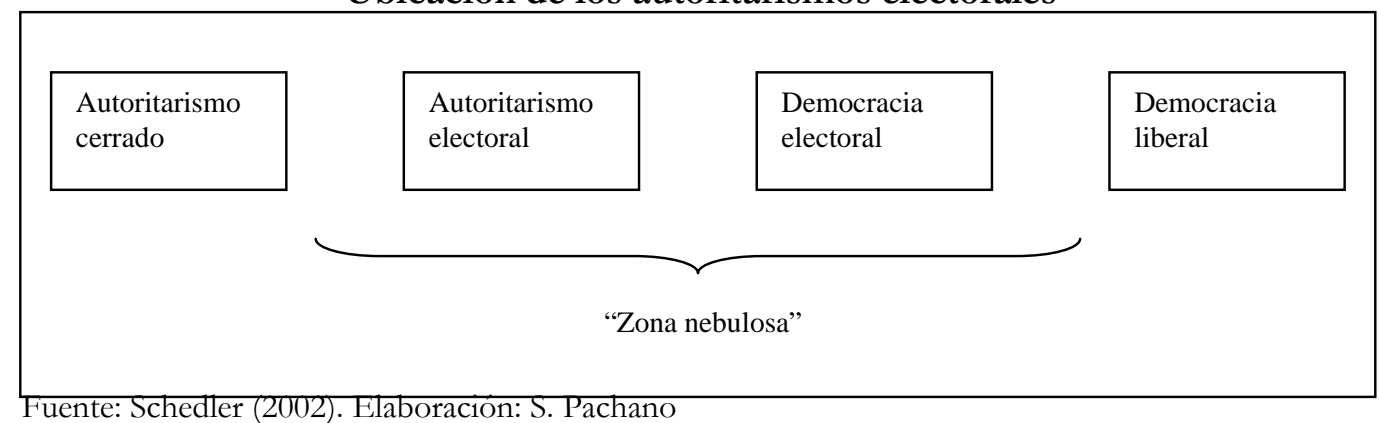

Fuente: Schedler (2002). Elaboración: S. Pachano

El otro límite, el que los separa de las democracias electorales, se establece por el carácter de las elecciones. En las democracias electorales, "la competencia política cumple con las normas democráticas mínimas; en el autoritarismo electoral ellas no están presentes" (Schedler, 2002: 38). A la vez, las democracias electorales se diferencian de las democracias liberales en que mientras éstas "van más allá de los mínimos electorales, las democracias electorales no lo hacen. Éstas se arreglan para 'obtener elecciones rectas', pero fallan en institucionalizar otras dimensiones vitales del constitucionalismo democrático, como el estado de derecho, la accountability política, la integridad burocrática y la deliberación pública" (Schedler, 2002: 37). En consecuencia, aunque el eje de la distinción de estos regímenes se encuentra en las elecciones (de ahí el adjetivo electoral para el autoritarismo), no se restringe a la realización o a la ausencia de ellas, sino al 
conjunto de condiciones -a algún grado de vigencia de los aspectos sustantivos- que se requieren para considerarlas democráticas.

$\mathrm{Al}$ respecto me parece pertinente hacer cuatro consideraciones. En primer lugar, es necesario destacar que, de la misma manera que la propuesta del autoritarismo competitivo, este tipo alude a regímenes que se sitúan en el campo del autoritarismo y no de la democracia. Por tanto, no se los puede considerar como formas disminuidas de democracia, lo que constituye un elemento de importancia a la hora de emprender en análisis de medición y calidad. Sin embargo, identifica también un subtipo de democracia (la democracia electoral), lo que otorga mayor precisión a la clasificación. En segundo lugar, es sugerente la diferencia que establece entre el autoritarismo electoral y las democracias electorales (estas sí consideradas como formas disminuidas de la democracia liberal) y, a la vez, entre éstas y la democracia liberal. Son diferencias de grado en los aspectos esenciales de vigencia de las libertades y de los derechos, vale decir, del estado de derecho. Esa diferencia exige mayor precisión y cuidado en el análisis, pero a la vez hace más viable la identificación de cada uno de esos regímenes. La definición de los umbrales que los separan pasa a convertirse en el elemento central en la investigación empírica, con todas las dificultades que ello supone pero a la vez con los beneficios que se pueden obtener de una clasificación más detallada. En tercer lugar, aunque las elecciones aparecen como el elemento que los califica y que los diferencia de los autoritarismos cerrados, es conveniente destacar que la diferenciación con la democracia (tanto con su vecina inmediata, la democracia electoral, como con la más lejana democracia liberal), no está basada en la existencia o en la ausencia de elecciones, sino en las condiciones de ésta. Por tanto, el análisis no se reduce a la existencia o ausencia de esa dimensión, sino al conjunto de condiciones que se integra en el concepto. Por último, es importante observar que más que la identificación de un tipo de régimen, este enfoque proporciona una clasificación de varios tipos. En este sentido, se acerca más a la perspectiva de los regímenes híbridos, desarrollada por Diamond y Morlino, que a las de los otros autores considerados, ya que se guía por la identificación de un continumm entre la democracia y el autoritarismo. Como se verá más adelante, esto tiene mucha importancia para la medición y la evaluación de la calidad de la democracia.

Un ejercicio de aplicación de esta clasificación a los tres países es útil para comprender algunas de sus características. Así, se puede asegurar que, durante la mayor parte del 
período, en los tres países predominaron las democracias electorales, esto es, regímenes en que la competencia política cumplía con las normas mínimas, pero en un contexto que presentaba muchos vacíos en los aspectos relacionados con las libertades y los derechos. El caso especial, según los criterios de esta clasificación, se encontraría en Perú, que vivió un período de autoritarismo cerrado, entre el golpe de abril de 1992 y la instalación del Congreso Constituyente Democrático en enero de 1993, y uno de autoritarismo electoral, entre esta última fecha y noviembre de 1990, en que se produce la renuncia de Fujimori y se inicia la segunda transición (en que se volvería a la democracia electoral). Aparte de este caso, en los otros dos países no se identifican situaciones que configuren autoritarismos cerrados ni autoritarismos electorales, aunque existen amplias probabilidades de que los procesos que se viven en Bolivia y Ecuador deriven hacia esta última forma.

El último tipo de régimen es el de los regimenes híbridos, que abarca un amplio espectro en la medida en que esos regímenes "combinan elementos democráticos y autoritarios" (Diamond, 2002: 23) ${ }^{17}$. Por tanto, se trata de regímenes que pueden situarse en cualquier punto entre ambos polos, manteniendo siempre algunos de los componentes mínimos de la democracia. Pero, más allá de esa visión básica, y al igual que el resto de tipos considerados aquí, su definición toma como punto de partida los vacíos o las ausencias, ya que se establece en contraposición a la democracia ${ }^{18}$. Así, se sostiene que "el análisis de una buena democracia no debe incluir solamente a las democracias electorales, esto es, regímenes híbridos cuyas fallas en asegurar un mínimo nivel de derechos civiles los mantienen entonces debajo del umbral mínimo requerido para ser clasificados como estrictamente democráticos" (Morlino, 2004: 10, cursiva en el original). En general, dentro de este tipo se incluyen "las democracias defectuosas [que] son también la 'contraparte' de las buenas democracias. En efecto (...) las democracias excluyentes, las democracias dominantes, las democracias iliberales y las democracias delegativas son en sí mismas híbridos institucionales" (Morlino, 2004: 11, cursiva en el original). "Todos estos

${ }^{17}$ El uso del término híbrido para calificar a las nuevas democracias -concretamente a las de América Central- se originó en Karl (1995). Con esa denominación llamaba la atención sobre los regímenes que, a pesar de contar con elecciones competitivas y multipartidistas, se violaban los derechos humanos y mantenían el tutelaje por parte de los militares.

${ }^{18}$ En términos estrictos se debería decir que estos regímenes se definen también en relación con los autoritarismos, ya que no son "ni claramente democráticos ni convencionalmente autoritarios" (Diamond, 2002: 25). Sin embargo, como he señalado antes, toda la elaboración conceptual al respecto forma parte de la teoría de la democracia y por tanto se definen en relación a este tipo de régimen, lo que a su vez expresa el carácter normativo de esta reflexión. 
regímenes carecen de una arena de competencia suficientemente abierta, libre y limpia para que el partido gobernante pueda ser fácilmente depuesto del poder si no obtiene el apoyo de una mayoría del electorado. Aunque la victoria de la oposición no es imposible en un régimen híbrido, esta requiere de un nivel de movilización, unidad, habilidad y heroísmo mayor que el que se requeriría en una democracia” (Diamond, 2002: 24).

Esta definición de los regímenes híbridos se completa -en la propuesta de Diamond- con una clasificación de estos de acuerdo a varios criterios. Primero, sugiere medir separadamente a las democracias electorales y a las democracias iliberales (Diamond, 2002: 25), ya que cada una de ellas presenta características específicas que se sitúan en niveles de análisis diferentes. Para decirlo en los términos utilizados en el capítulo I, las primeras se definen de acuerdo a la ciudadanía política, mientras para las últimas se toma como referencia a la ciudadanía civil. Segundo, dentro de los regímenes no democráticos el autor diferencia entre los que permiten algún tipo de competencia electoral multipartidista y los que son políticamente cerrados (Diamond, 2002: 25). Finalmente, dentro de los regímenes electorales autoritarios separa a los autoritarismos competitivos de los hegemónicos. De esta manera, el autor establece cinco clases (y una residual). Estas son la democracia liberal, la democracia electoral, los regímenes ambiguos (la clase residual), los autoritarismos competitivos, los autoritarismos electorales hegemónicos y los autoritarismos políticamente cerrados (Diamond, 2004: 26). Estas clases se situarían espacialmente de la manera que se ve en el gráfico 7. 


\section{Gráfico $\mathrm{N}^{\mathrm{o}} 7$ \\ Ubicación de los regímenes híbridos}

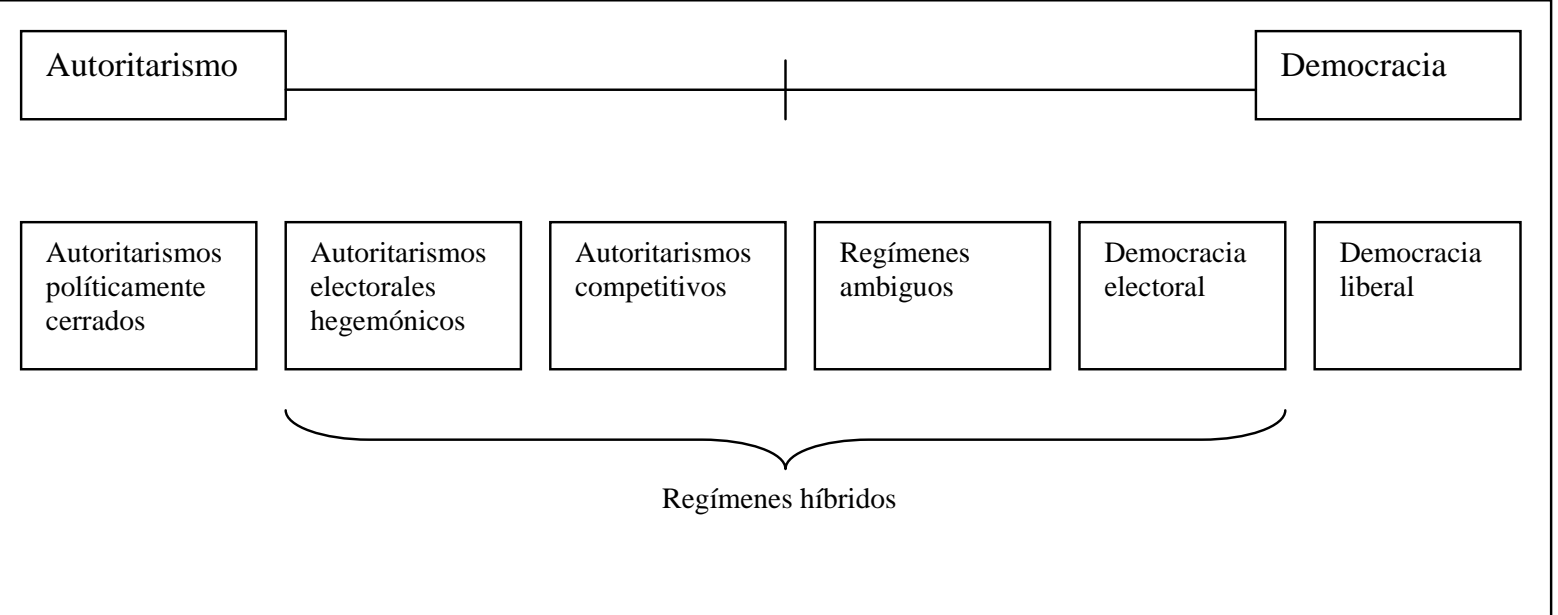

Fuente: Diamond (2002). Elaboración: S. Pachano

Cuatro aspectos se destacan en esta clasificación. En primer lugar, ella está guiada por la combinación de la competencia electoral y la vigencia de los derechos y las libertades como criterios básicos, pero el carácter democrático o no de la primera depende del grado de cumplimiento de la segunda. En efecto, el mayor o menor grado de democracia de uno de esos regímenes no está dado por la realización de elecciones -e incluso no solamente por la limpieza de éstas-, sino por la vigencia de los derechos y las libertades, que son los elementos que definen el carácter de esas elecciones. Por ello, no es posible verla exclusivamente como una clasificación de las democracias electorales ${ }^{19}$. En segundo lugar, incorpora algunas de las propuestas realizadas por otros autores, como los autoritarismos competitivos (Levitsky y Way, 2002) y los regimenes electorales autoritarios (Schedler, 2002). De esta manera, se convierte en una propuesta de integración de las perspectivas que se han concentrado en un sólo tipo de régimen o que han identificado un número reducido de ellos (como es el caso de Schedler), lo que indudablemente constituye un avance en términos de la clasificación. En tercer lugar, su elemento central

\footnotetext{
${ }^{19}$ El riesgo de tomarla como una clasificación basada en el criterio electoral se encuentra en una definición submínima de régimen democrático que aparece cuando Diamond sostiene que "Los regímenes se consideran democráticos si tienen elecciones libres, limpias y abiertas para todas las posiciones del poder político (...) Adicionalmente a las puntuaciones de Freedom House, tres tipos de datos se extraen de mi clasificación de regímenes no democráticos: el porcentaje de escaños legislativos en poder del partido gobernante, el porcentaje de votos obtenidos por el candidato presidencial del partido gobernante y los años que el presidente en ejercicio ha permanecido continuamente en el poder” (Diamond, 2002: 29). Por tanto, parecería que reduce la importancia de la vigencia de los derechos y las libertades. Sin embargo, la alusión a las puntuaciones de Freedom House señalan en la otra dirección, ya que se refieren a los derechos y las libertades.
} 
radica en la búsqueda de la "gama de grises" (Diamond, 2002: 33), para superar la visión en blanco y negro que resulta de la consideración exclusiva de los tipos extremos (e incluso de un solo tipo intermedio). De esta manera se abre la posibilidad de encontrar múltiples regímenes que pueden diferenciarse entre ellos por el grado en que presentan uno o más atributos de la democracia. Por último, cabe anotar que esta clasificación deja un vacío cuando, en lugar de definir con la misma precisión que el resto de categorías, atribuye a una de ellas un carácter residual y una denominación extremadamente general, como es la de regímenes ambiguos. Pero, a pesar de ello, constituye la visión más acabada y compleja de los subtipos de régimen, ya que permite identificar con mayor precisión cada una de las diversas posibilidades de conformación de regímenes.

En su aplicación a Bolivia, Ecuador y Perú, esta clasificación permitiría en primer lugar, ubicar a Perú en el casillero de los autoritarismos políticamente cerrados (durante la dictadura de Fujimori) y en el de los autoritarismos competitivos entre 1993 y 2000. En segundo lugar, lo novedoso de esta perspectiva es que, aparte de ese período en que Perú constituye una excepción, los tres países se ubicarían durante la mayor parte del tiempo alternativamente en el casillero de las democracias electorales y en de los regímenes ambiguos $^{20}$. En este último se incluiría a Bolivia en el año 1995, Ecuador en el período 1984-1988, a Perú en la fase posterior a la renuncia de Fujimori y, posiblemente, a Ecuador y Bolivia en la actualidad.

Después de esta revisión general de las propuestas reseñadas es necesario formular algunas conclusiones que tienen utilidad para el tratamiento de la medición y la calidad de la democracia. En primer lugar, como he venido reiterando, todas las clasificaciones o las propuestas de identificación de subtipos de democracia o de autoritarismo parten de una definición mínima de democracia. Implícita o explícitamente, la mayor parte de esos enfoques toman como referencia al concepto de poliarquía de Dahl (1989; 1991). Por tanto, utilizan una definición procedimental de la democracia que no deja fuera de sus elementos constitutivos a la vigencia del estado de derecho, pero que no incluye los elementos estructurales socioeconómicos, como equidad o distribución del ingreso. La selección de este concepto mínimo se explica fundamentalmente porque, como se vio en

\footnotetext{
${ }^{20}$ A pesar del vacío señalado antes con respecto a la categoría de regímenes ambiguos, ella permite detectar las especificidades de los regímenes que van perdiendo las características de las democracias electorales pero que no pueden ser ubicados en uno de los casilleros de los autoritarismos. Son regímenes que se sitúan en la frontera entre la democracia electoral y el autoritarismo (Diamond, 2002: 27).
} 
el capítulo I, la definición del tipo de régimen -cualquiera que sea éste- no puede incluir elementos que corresponden al ejercicio del gobierno o a las políticas públicas. El buen desempeño de un régimen autoritario no lo convierte en democracia, como tampoco ésta se transforma en autoritarismo cuando en su ejercicio arroja resultados negativos. Como se verá más adelante, en este último caso se transforma en una democracia de baja calidad en términos de sus rendimientos, e incluso puede afrontar problemas de legitimidad (de resultados) pero no por ello cambia en cuanto a régimen. Son otros los elementos que determinan el cambio de régimen. Desde esta perspectiva, la utilización del concepto mínimo alude de manera especial a la legitimidad de origen y de procedimientos, que -de manera más implícita que explícita- son las que marcan los límites de cada uno de los subtipos con la democracia. La pérdida o la disminución de esas formas de legitimidad se encuentran en la construcción conceptual de los enfoques revisados.

Adicionalmente, la selección del concepto mínimo tiene una explicación operativa o metodológica. Cabe destacar que el interés de los diversos enfoques reseñados puede ser la clasificación de diversos subtipos, la identificación de un subtipo en particular o la medición de la democracia. Por tanto, para alcanzar cualquiera de esos tres objetivos es imprescindible contar con un concepto operativo que pueda expresarse en dimensiones, variables e indicadores. Con ello se pretende evitar los riesgos de estiramiento conceptual y de incremento de la diferenciación, que se derivan de las estrategias de ascenso y descenso en la escala de generalidad de un concepto (Sartori, 1970; Collier y Levitsky, 1998). Como se desprende de la revisión de las diversas propuestas, uno de los problemas básicos que se debe enfrentar en la clasificación de regímenes y/o en la identificación de un tipo de régimen es la delimitación. Los límites que separan a cada una de las clases están determinados por conjuntos de atributos que deben estar claramente enunciados y que, así mismo, deben ser observables en la realidad. Para ello, es necesario considerar que, como cualquier otra teoría, la de la democracia - de la que, como he venido insistiendo, forma parte la reflexión sobre estos regímenes específicos- exige una coherencia interna que a su vez está dada por la definición precisa de conceptos que hagan posible la investigación empírica ${ }^{21}$.

\footnotetext{
${ }^{21}$ La relación entre la teoría (de alcance medio) y la investigación empírica se manifiesta en que "En las ciencias sociales, una teoría es una especulación razonada y precisa sobre la respuesta que cabe dar a la pregunta de una investigación, e incluye una declaración de por qué tal respuesta es correcta (...) para asegurarse de que una teoría es falsable, hay que elegir una que pueda generar
} 
Como una crítica a este último argumento, se puede sostener que las necesidades operativas no deberían sacrificar al contenido, esto es, que la democracia no puede ser reducida a esa mínima expresión únicamente por conveniencia práctica. Esa observación tendría validez solamente si el carácter mínimo y operativo del concepto violara el principio de inclusión exhaustiva de todas las propiedades del objeto de estudio (la democracia). Dicho de otra manera, y repitiendo lo que señalé en el capítulo I, caería en aquella desviación si dejara fuera algunas propiedades de definición (Sartori, 1992: 86). De la revisión realizada, se puede asegurar que las seis propuestas cumplen con ese principio. Todas ellas definen como pilares de su concepto a los elementos procedimentales de la democracia, pero no por ello abandonan aspectos de fondo o de contenido que son también propiedades de definición de ella, como la vigencia de las libertades civiles y políticas o, en general, la vigencia del estado de derecho. A pesar de ser definiciones procedimentales no reducen la democracia a las elecciones. Por consiguiente, al utilizar un concepto mínimo no sacrifican el contenido de la democracia.

En segundo lugar, aunque todas esas clasificaciones destacan a los componentes del régimen y del sistema político como los elementos en los que se expresa cada una de las formas disminuidas, ellos no aparecen en todos los enfoques como los elementos constitutivos de cada una de esas formas. Dicho de otra manera, todos los autores revisados en las páginas anteriores consideran que las formas disminuidas se hacen evidentes por las carencias en aspectos como la vigencia de las libertades básicas o la limpieza de las elecciones, pero en algunos casos esas carencias provienen de aspectos propios del régimen (de su diseño institucional, de sus pautas de procedimiento), mientras que en otros se originan en las acciones de los gobernantes. En el fondo, esto lleva a preguntarse por las causas que provocaron el alejamiento de la democracia y por consiguiente a la constitución de cada uno de los diversos subtipos. En términos generales, se puede sostener que las respuestas de los autores aluden, por un lado, a aspectos propios de la conformación de los regímenes (vale decir a características estructurales derivadas de su diseño institucional) y, por otro lado, a acciones o prácticas de los gobernantes. Por tanto, en el primer caso se trataría de características constitutivas de los regímenes

tantas consecuencias observables como sea posible (King, Keohane y Verba, 2005: 29-30, cursiva en el original). La apelación a las consecuencias observables se relaciona con lo que he señalado acerca de la necesidad de hacer operativa a la teoría por medio de dimensiones, variables e indicadores. 
políticos y, en esa condición, plantearían problemas muy difíciles de resolver cuando se busque superarlas. Por el contrario, en el segundo caso bastaría -en términos muy simplistas- con un cambio de gobierno para alterar la situación vigente ${ }^{22}$. Pero, aunque será de mucha importancia en el análisis de los tres países, no considero necesario entrar en ese tema en este momento ya que sería un ejercicio poco fructífero en términos conceptuales y teóricos dado que la identificación de las causas no consta entre las preocupaciones de los autores revisados y, en consecuencia, cualquier esfuerzo en ese sentido constituiría un estiramiento de las propuestas originales ${ }^{23}$.

En cambio, sí considero necesario destacar que cuando se hace referencia a cualquiera de estos tipos disminuidos de democracia se está aludiendo a sus características, tanto en el nivel del régimen político como del sistema político, en los términos que propuse en el capítulo I. Por consiguiente, independientemente de las causas que hubieran provocado el surgimiento de un tipo disminuido de democracia, sus características deben expresarse como elementos constitutivos de éste. Esas características no deben ser solamente elementos de expresión, como los he denominado antes, sino elementos constitutivos o, siguiendo nuevamente a Sartori (1992), propiedades de definición. Esto quiere decir que cualquiera de los regímenes híbridos, una democracia delegativa, un autoritarismo electoral, una democracia iliberal, un régimen semidemocrático o un autoritarismo competitivo pueden ser calificados de esa manera en virtud de sus respectivos atributos y no solamente por el ejercicio del gobierno o por las políticas específicas de un determinado momento. De esta manera, si se encuentra un régimen democrático en que un gobierno se desempeña autoritariamente o que no cumple con todas las condiciones que se han establecido en el concepto mínimo de democracia, no convierte automáticamente al régimen en no democrático bajo cualquiera de las formas mencionadas. Será, ciertamente, un gobierno autoritario que actúa dentro de un régimen democrático (y que, en esa condición, incluso

\footnotetext{
${ }^{22} \mathrm{El}$ problema puede presentarse de manera mucho más compleja cuando se acude a la segunda explicación, ya que las prácticas de los gobernantes pueden convertirse en formas ampliamente aceptadas por el conjunto de los actores políticos y de la sociedad en general, hasta transformarse en pautas culturales de acción política. En ese caso prácticamente no tendrían importancia los aspectos estructurales del régimen y la solución de los problemas sería aún más difícil que en el otro caso.

${ }^{23}$ Sin que exista claridad al respecto, en los enfoques de las democracias delegativas ( $\mathrm{O}$ 'Donnell, 1992) y de las democracias iliberales (Zakaria, 1998) se puede apreciar un cierto sesgo en el sentido de atribuir la definición del tipo a las acciones de los gobernantes y no a las características de su diseño y de su estructura. En cambio, las propuestas de Schedler (2002), Diamond (2002), Diamond y Morlino (2004; 2005), Morlino (2004; 2007) y Mainwaring, Brinks y Pérez-Liñán (2001) parecen aludir a causas propias del régimen. De cualquier manera, como lo he señalado antes, ninguno de los autores se interesa en ofrecer explicaciones acerca de las causas.
} 
podría presentar diversos grados de autoritarismo), pero no se podrá trasladar directamente esa condición al régimen.

A partir de esta consideración se hacen evidentes dos problemas para la investigación empírica. El primero consiste en la necesidad de detectar con precisión los límites que separan al régimen del gobierno (o más bien al ejercicio de este último). Para ello será necesario definir previamente y con absoluta claridad los elementos constitutivos del régimen y también los del gobierno. El segundo se desprende de la posibilidad de encontrar la situación contraria a la señalada, esto es, que exista un gobierno democrático dentro de un régimen autoritario ${ }^{24}$. En este caso, además de contar con los mismos instrumentos metodológicos y conceptuales señalados antes, el tema central a dilucidar se referirá a los efectos que podría producir la acción del gobierno sobre el tipo de régimen. No se debe descartar, al respecto, que el ejercicio autoritario del gobierno puede dejar huellas negativas en la democracia hasta llegar a afectarla en sus atributos fundamentales ${ }^{25}$.

En tercer lugar, hay una diferencia clara entre los enfoques que reconocen un continuo que va desde el autoritarismo hacia la democracia y los que únicamente identifican un subtipo entre ambos polos. Como se ha visto (con el apoyo de los gráficos), la propuesta de regímenes híbridos (Diamond, 2002; Diamond y Morlino, 2004) y la de autoritarismos electorales (Schedler, 2002) proponen explícitamente clasificaciones dentro de un continuo entre ambos términos extremos. En efecto, en la clasificación de Diamond y Morlino, entre los autoritarismos políticamente cerrados y las democracias liberales se encuentran dos subtipos de autoritarismo (el autoritarismo electoral hegemónico y el autoritarismo competitivo) un subtipo indefinido (los regímenes ambiguos) y un subtipo de democracia (la democracia electoral), definidos por el grado en que contienen los diversos atributos clasificatorios. En la clasificación de Schedler del autoritarismo

\footnotetext{
${ }^{24} \mathrm{El}$ caso no es solamente hipotético. Los gobiernos peruanos posteriores a Fujimori pueden ser un ejemplo de ello, ya que se mantuvieron -y en gran medida aún se mantiene- dentro de un subtipo de autoritarismo establecido por la Constitución de 1992. Otro caso similar, fuera de los tres países estudiados, es el de los gobiernos chilenos posteriores a la dictadura, que debieron gobernar con la Constitución y las leyes del período autoritario, hasta que las reformas constitucionales del año 2005 eliminaron los denominados enclaves autoritarios.

${ }^{25}$ El caso más claro en los tres países se presenta con el gobierno de Febres Cordero en Ecuador (1984-1988), que a partir del ejercicio autoritario del gobierno devino en un tipo de democracia disminuida que, como he señalado antes, puede ocupar el casillero de los autoritarismos competitivos, en la clasificación de Levitsky y Way, o de los regímenes ambiguos, en la de Diamond y Morlino.
} 
electoral, entre el autoritarismo cerrado y la democracia liberal se encuentra un subtipo de autoritarismo (el autoritarismo electoral) y un subtipo de democracia (la democracia electoral), definidos también por el grado alcanzado en sus diversos componentes. Por consiguiente, en ambas propuestas pueden constituirse varios regímenes entre los dos polos, lo que lleva a considerarlas como clasificaciones continuas.

Por el contrario, las otras clasificaciones identifican a un solo tipo de régimen que, de acuerdo a sus atributos o a sus características, se encuentran en algún punto más cercano al autoritarismo, a la democracia o equidistante de ambos extremos. Así, el autoritarismo competitivo de Levitsky y Way estaría más cerca del autoritarismo puro que de la democracia, en tanto que la democracia delegativa de O’Donnell ocuparía un lugar más cercano a esta última. Los regímenes semidemocráticos de Mainwaring, Brinks y PérezLiñán se encontrarían en un punto equidistante a ambos extremos. De cualquier manera, al identificar solamente a un tipo de régimen que ocuparía un lugar entre esos puntos, estas clasificaciones plantean un problema más complejo que las anteriores ya que no permiten establecer con relativa claridad cuál es ese punto en que se sitúa cada uno de los regímenes identificados como formas disminuidas de la democracia (o del autoritarismo). Así, al calificar a un régimen como democracia delegativa, autoritarismo competitivo o semidemocrático, se lo puede situar en un amplio espacio entre ambos extremos, lo que introduce gran imprecisión en la clasificación. De hecho, en la medida en que puede situarse en múltiples puntos, un mismo tipo de esos regímenes podría tener tantas diferencias en sus atributos que podría ser considerado como varios tipos diferentes. Esto se evita con la clasificación continua, que establece con mayor precisión las diversas posibilidades que se encuentran a lo largo de la línea que corre entre los dos polos.

Por último, considero que a pesar de las diferencias entre estos enfoques, no existen diferencias sustanciales entre ellos. Como he señalado antes, todos ellos parten de conceptos bastante similares de democracia y apuntan en la misma dirección cuando buscan determinar las carencias que los constituyen como regímenes específicos. Básicamente, todos reconocen que estos cumplen con los procedimientos fundamentales -concretamente con la realización de elecciones para la selección de los principales cargos políticos- y que la principal carencia se encuentra en el plano de las libertades y los derechos. Por consiguiente, es posible tratarlos como derivaciones de un solo cuerpo conceptual, y en esa medida es posible adoptar una posición ecléctica que, sin 
considerarlos opuestos o excluyentes sino más bien complementarios, puede tomar a cada uno de ellos como la expresión de una situación específica. Pero, para ello es necesario considerar los niveles de generalidad y de agregación de cada una de las clasificaciones, identificando en primer lugar a las más generales -y por tanto más incluyentes- e introduciendo en ellas las que aluden solamente a situaciones específicas.

Desde esta perspectiva, es evidente que la clasificación más general y más incluyente es la de los regímenes híbridos (Diamond, 2002; Diamond y Morlino, 2005; Morlino, 2004). Sin duda, es la que reconoce una mayor cantidad de subtipos, por consiguiente la que registra de mejor manera los diversos grados que pueden diferenciar a los regímenes. Además, como los propios autores lo destacan, incluye a varios de los tipos que aparecen en las otras clasificaciones. En ella se identifican subtipos como los autoritarismos electorales, los autoritarismos competitivos y las democracias electorales que aparecen (no solamente con las mismas denominaciones sino con similares atributos) en las clasificaciones de Schedler y de Levitsky y Way. Pero también es posible incluir en ella a las democracias iliberales de Zakaria (1998) y a las democracias delegativas de O’Donnell (1992), ya que dentro de los regímenes híbridos se encuentran regímenes que presentan características bastante similares a las que destacan estos autores.

\section{Medición de la democracia}

La identificación de diversos tipos de régimen es no solamente un fin en sí mismo -por el valor que tiene para la investigación empírica-, sino que es también un medio para llegar a la medición de la democracia y a la evaluación de su calidad. Sin embargo, la revisión de la literatura académica permite asegurar que no se ha desarrollado la reflexión de conjunto de los tres temas (tipo de régimen, medición y calidad). La mayor parte de los autores considerados en la sección anterior dirigen su esfuerzo fundamentalmente a la identificación de los subtipos de democracia y solo una minoría lo hace como parte de su preocupación por la calidad de la democracia (en realidad, en términos explícitos, solamente Diamond y Morlino vinculan ambos temas). Por otra parte, quienes se han ocupado de la medición de la democracia no siempre han tenido como objetivo el análisis de su calidad ni la identificación de subtipos. Así mismo, quienes han tratado los temas de calidad, en muchas ocasiones han obviado los problemas de medición y han mostrado escaso interés en la identificación de los subtipos. En definitiva, la relación 
entre los tres ámbitos es una tarea que debe ser realizada. Sobre ella volveré en la tercera sección del presente capítulo, cuando me ocupe de los problemas de la investigación sobre la calidad de la democracia, pero para ello es necesario pasar revista previamente al campo de su medición.

Un primer punto al respecto es que se trata de un tema que está siendo abandonado por la investigación académica. Después de un primer momento de auge, durante la década de 1980 y parte de la de 1990, el interés fue decayendo mientras ganaban espacio los estudios sobre calidad de la democracia. Los trabajos de Bollen (1980; 1990), Bollen y Grandjean (1981), Bollen y Paxton (2000), Elkins (2000) y en menor medida de Coppedge 1990), tenían como objetivo central la construcción de un procedimiento de medición más que la explicación de las características de regímenes políticos concretos. A pesar de que en algunos casos hacían referencia a algún país o utilizaban alguna base de datos de un gran número de casos, eran fundamentalmente textos de carácter metodológico ${ }^{26}$. Adicionalmente, estos estudios buscaban construir índices que pudieran sintetizar la medición de las diversas variables consideradas. En ese contexto, el debate que se desarrolló a partir de estos enfoques fue extremadamente metodológico y cargado de tecnicismos que finalmente aportaban poco a la comprensión de los aspectos de fondo. El perfeccionismo estadístico que guió a varios de los estudios terminó por hacer perder de vista el fondo del asunto, que debía ser la explicación de las características de las democracias reales o concretas.

Un segundo punto acerca de este tipo de estudios, estrechamente relacionado con el primero, es que ineludiblemente debía resolver el problema de los parámetros y los instrumentos de la medición. Este es un paso imprescindible en la medición de cualquier objeto o fenómeno, de manera que no se lo puede obviar cuando se intenta medir la democracia. Esto significa, por un lado, delimitar el objeto de estudio y, por otro lado, seleccionar los instrumentos de medición. Aunque es evidente que el objeto de estudio es la democracia, se hacía necesario establecer claramente el concepto con el que se podría

\footnotetext{
${ }^{26}$ A manera de ejemplo, Bollen (1981: 653) hace referencia a la aplicación de su método a 113 países, pero no se interesa en presentar los resultados obtenidos. Algo similar se encuentra en Bollen y Paxton (2000: 75), que presentan una tabla comparativa de 81 países exclusivamente para demostrar la correlación entre las variables utilizadas y no para explicar las características de los casos y sus diferencias. En términos estrictos, no son estudios sobre la democracia, sino sobre los métodos de medición de la democracia.
} 
$\operatorname{trabajar}^{27}$. Es decir, nuevamente se presentaba la necesidad de contar con un concepto operativo. Siendo la misma exigencia que debieron enfrentar quienes buscaban identificar los subtipos de democracia, la respuesta fue también similar y por tanto se acudió a un concepto mínimo y procedimental de democracia. La mayor parte de autores tomaron como punto de partida la definición de poliarquía de Dahl o la de Schumpeter (Bollen y Paxton, 2000: 58; Coppedge, 1990: 51 ${ }^{28}$. Este supera de manera óptima los problemas de barreras infranqueables que presentan los conceptos maximalistas -es decir, de ausencia de referentes empíricos que puedan cumplir todas las condiciones- y las de inclusión indiscriminada de los conceptos minimalistas ${ }^{29}$. Por ello, se acudió a conceptos que limitaban considerablemente el objeto de estudio, como el que sostiene que "la democracia política es el grado en el cual el poder político de las élites es minimizado por las no-elites" (Bollen, 1990: 9).

Una vez definido el objeto de estudio, se hacía imprescindible descomponer el concepto en sus respectivas dimensiones y variables. Éste es en sí mismo un campo de debate, ya que define el procedimiento de la medición. Los resultados de ésta dependen en gran medida de la manera en que se resuelva este problema, ya que por medio de las dimensiones y las variables se establecen las condiciones para la comparación -que es uno de los procedimientos básicos en este ejercicio- y para el establecimiento de los grados con que se presenta cada atributo de la democracia. En uno de los primeros intentos, se seleccionó a la soberanía popular y a las libertades políticas como las dimensiones de la democracia (Bollen y Grandjean, 1981: 652). A su vez, la soberanía popular -

\footnotetext{
${ }^{27}$ De inmediato volveré sobre el problema del objeto de estudio, que es bastante más complejo que lo que se puede entender al afirmar que éste es la democracia.

${ }^{28}$ El uso del concepto de poliarquía se justifica, según Coppedge (1990: 52) porque ésta al igual que la democracia es una cualidad de un sistema político, "pero a diferencia de la democracia (al menos como es usualmente concebida), la poliarquía es también una dimensión. Hay grados de poliarquía en una gama que va desde la poliarquía total hasta la ausencia de poliarquía. Aquellos que están buscando una medida que les permita hacer comparaciones entre estados pueden por tanto encontrar una medición de poliarquía específica, que les dice más acerca de los diversos grados o del fracaso en alcanzar la poliarquía completa que sobre la democracia”

${ }^{29}$ En su clasificación de los regímenes políticos, Álvarez et al. (1996) destacan la utilidad de un concepto basado exclusivamente en la competencia electoral, que ellos reconocen como minimalista (Álvarez et al., 1996: 20). No deja de ser sugerente su negativa a introducir atributos que "son demasiado importantes para ser resueltos por medio de una definición prescriptiva" (Álvarez et al., 1996: 18). Sin embargo, el uso de un concepto minimalista como el que proponen los autores es tan amplio que no resulta útil para fines como los de la medición y la evaluación de la calidad. El caso contrario, de definición maximalista -y por consiguiente escasamente operativa- es la de Freedom House, que incluye derechos económicos, desigualdades y derechos de propiedad, entre otros. Como se verá más adelante, éste último deriva en un concepto subjetivo y por tanto de poca utilidad para el análisis concreto.
} 
entendida como la capacidad de control de los ciudadanos hacia las élites- debía desagregarse en variables como elecciones libres, amplio derecho al voto, igual peso del voto y procesos electorales limpios. Las libertades políticas, por su parte, se desagregaban en las instituciones por medio de las cuales los ciudadanos pueden influir en las decisiones de las elites, incluyendo la libertad de palabra, la prensa libre y la libertad para hacer oposición (Bollen y Grandjean, 1981: 652). En general, se fue generando un cierto acuerdo en torno a la utilización dimensiones como competencia para la elección de los cargos del ejecutivo y el legislativo, participación política, libertades políticas, soberanía popular y vigencia de los derechos políticos y civiles (Bollen, 1990; Bollen y Grandjean, 1981; Coppedge y Reinicke, 1990; Munck y Verkuilen, 2002).

Un tercer punto que se destaca en estos estudios es la preferencia por la medición cuantitativa (Bollen, 1990; Bollen y Paxton, 2000). La búsqueda de índices que pudieran sintetizar el conjunto de dimensiones y variables sometidas a medición, fue un gran aliciente para desarrollar ese tipo de acercamiento. Fruto de ello son los diversos índices que se mantienen en las mediciones periódicas de la democracia, como las de Freedom House y de Polity IV o el índice de democracia electoral (IDE) diseñado específicamente para el estudio del Programa de Naciones Unidas para el Desarrollo (PNUD, 2004). Sin embargo, la construcción de estos índices lleva inevitablemente a recortar o a reducir los componentes de la democracia - en aras de tornarlos operativos- y tiene una alta carga de subjetividad que es prácticamente imposible de evitar. La ponderación de cada una de las variables -un paso estrictamente necesario para la construcción de cualquier índice- está cargada de arbitrariedad, especialmente cuando se trata de sintetizar su peso en un valor específico. Así, por ejemplo, pueden existir argumentos igualmente válidos para otorgar mayor peso a las elecciones limpias que a la libertad de expresión, que para sostener lo contrario (y lo mismo podría afirmarse de cualquier otro par de variables que se someta a ponderación). La asignación de valor en gran medida expresa los valores del investigador. Adicionalmente, la medición cuantitativa no garantiza que se supere la subjetividad si la recolección de datos se ha hecho de una manera en que predominan los criterios de determinadas personas. Es lo que sucede con el índice de Freedom House, que expresa la opinión de expertos acerca de cada una de las variables.

Un cuarto punto importante en la medición de la democracia, que aparece en cualquier ejercicio de esta naturaleza, es la relación de causalidad que se establece entre las diversas 
variables seleccionadas. En términos generales, en todos estos estudios la variable dependiente es la democracia y las variables independientes son los diversos atributos que se asignan al concepto básico y operativo con el que se trabaja. Sin embargo, en este aspecto se presentan tres problemas de importancia. En primer lugar, al afirmar que ese objeto es la democracia en sí misma -y no su calidad o su grado dentro de algún criteriose corre el riesgo de mantener el estudio en niveles de abstracción tan altos que no permiten un acercamiento concreto al tema estudiado. En segundo lugar, precisamente por ese nivel de generalidad, ese tipo de estudios tiene un alto riesgo de confundir entre el estudio de los atributos de la democracia como régimen ya constituido y las condiciones para el surgimiento de éste. En tercer lugar, la tendencia a buscar causalidades -que está más presente en estos estudios que en los de carácter cualitativoabre mayores probabilidades para que se presenten problemas de endogeneidad, esto es, de explicaciones basadas en interrelaciones mutuas entre variables que pueden tomar alternativamente la condición de causa o de efecto.

Finalmente, tanto en este tipo de estudios como en los de calidad de la democracia, existe una diferencia significativa entre los arreglos metodológicos y los instrumentos que se deben utilizar para el trabajo con un caso, con varios casos y con muchos casos. El problema del tipo de estudio, ya sea de caso, comparativo o estadístico, define en gran medida las variables a usar y la selección de los respectivos indicadores. Como se ha señalado reiteradamente (Collier y Mahon, 1993; Collier, 1999; Lijphart, 1971; Ragin, 1987; Caïs, 1997), las estrategias de investigación son muy diferentes en cada uno de estos estudios $^{30}$. Las posibilidades de profundización en el tratamiento de una variable determinada, que ofrece el estudio de caso y la capacidad de comparación entre muchas variables, que ofrecen los estudios comparativos y estadísticos, son ventajas que deben evaluarse de acuerdo a los fines que se persiguen y que, por tanto, deben adecuarse a la estrategia de investigación.

Para concluir, es necesario volver sobre el relativo acuerdo que existe entre los autores en cuanto a la selección de las variables fundamentales en este tipo de estudios, al que me referí antes. Acudo para esto a dos propuestas. En primer lugar, a la de Coppedge y

\footnotetext{
${ }^{30}$ La literatura metodológica ha puesto mucho énfasis en las diversas estrategias que se deben seguir en cada tipo de estudio. La diferencia entre los estudios de un caso, de algunos casos y de muchos casos no es solamente un problema de tamaño, sino de metodología. La adecuación de los indicadores, las variables y las dimensiones al $\mathrm{N}$ (el número de casos), es uno de los temas claves de debate en el ámbito metodológico de las ciencias sociales (Collier, 1999).
} 
Renicke (1990: 53-55) que contiene las siguientes variables: a) elecciones libres y limpias; b) libertad de asociación; c) libertad de expresión; d) disponibilidad de fuentes alternativas de información; e) derecho al voto. En segundo lugar, a la clasificación hecha por Munck y Verkuilen (2002: 10) que, al recoger nueve propuestas diferentes tiene un carácter más comprehensivo. Ellos destacan las siguientes variables centrales: a) competencia por los cargos; b) participación; c) inclusión y competencia; d) coerción; e) libertades políticas; f) soberanía popular; g) competencia electoral; h) derechos políticos y derechos civiles; i) limitaciones al poder ejecutivo ${ }^{31}$. En definitiva, como he señalado antes, hay un acuerdo básico en la selección de las variables, lo que guarda coherencia con el concepto mínimo y procedimental que sirve de base para todo el análisis.

Finalmente, la medición de la democracia como ámbito teórico y metodológico, fue un predecesor de importancia para el análisis de la calidad de la democracia. Aunque son dos campos de estudio diferentes, es evidente la relación complementaria que existe entre ambos, especialmente en los estudios cuantitativos que buscan construir índices de calidad. Sin embargo, esa estrecha relación no significa que uno de los dos campos se disuelva en el otro o que constituyan un solo ámbito de estudio. Más bien, es necesario tomar a la medición de la democracia como un posible subsidiario -no indispensablepara el estudio de la calidad. Desde esa perspectiva, el ámbito de la calidad de la democracia puede incluir al de la medición y por tanto es bastante más amplio que éste. Como se verá en la siguiente sección, el estudio de la calidad puede requerir de la medición, pero puede también prescindir de ella sin que eso afecte a sus resultados.

\section{La calidad de la democracia como instrumento analítico}

En efecto, la calidad de la democracia es un campo de estudio bastante más complejo que el de la medición ya que exige contar con criterios claros acerca de la calidad y no solamente de la democracia en sí misma. Como se ha visto a lo largo de este capítulo, los atributos de la democracia -aquellos que pueden servir para su medición- pueden sintetizarse en un número relativamente pequeño de variables. Pero, al considerar la calidad, se introducen inevitablemente juicios que deben expresarse en una escala de gradación. Como ha sido subrayado, la referencia a calidad supone contar con criterios

\footnotetext{
${ }^{31}$ Los autores considerados por Munck y Verkuilen son Álvarez et al. (1996), Arat (1991), Bollen (1980), Coppedge y Reinicke (1991), Freedom House a través de Ryan (1994), Gasiorowski (1996), Hadenius (1992), Polity IV, a través de Marshall y Jaggers (2001) y Vanhanen (2000).
} 
que puedan determinar si una democracia es buena o mejor (Diamond y Morlino, 2004: 21). Por consiguiente, además de la definición de democracia, es imprescindible contar con una definición clara de calidad.

Cabe comenzar, entonces, por la definición de calidad que, hay que señalarlo, no ha sido de gran preocupación por parte de los autores que tratan el tema. Entre los escasos aportes al respecto se encuentra la definición trasladada desde la economía (o, en términos más precisos, desde la industria y el comercio), que reconoce tres niveles. En primer lugar el de los procedimientos, en que la calidad es "el resultado de un proceso exacto, controlado, llevado adelante de acuerdo a métodos y procedimientos precisos" (Diamond y Morlino, 2004: 21). En segundo lugar, el nivel de los contenidos, en el que la calidad es "inherente a las características estructurales del producto, como el diseño, los materiales y el funcionamiento” (Diamond y Morlino, 2004: 21). En tercer lugar el de los resultados, en que la calidad "de un producto está indirectamente indicada por el grado de satisfacción con él, independientemente de cómo es producido o de su contenido" (Diamond y Morlino, 2004: 22).

Considero que, además de identificar los diversos niveles en que puede ser analizada la calidad, estos criterios son muy útiles para el estudio de la democracia. Así, en el nivel de los procedimientos significaría analizar las modalidades de selección de los gobernantes (en especial, pero no exclusivamente, los procesos electorales), la elaboración de las leyes (o, en términos más correctos, del marco jurídico general que rige a un ordenamiento político), la toma de decisiones en los diversos niveles de elaboración de las políticas, las condiciones existentes para el procesamiento de los conflictos y la vigencia de las condiciones para el control de los políticos por parte de los ciudadanos (accountability vertical). En el nivel de los contenidos se incluiría el diseño institucional -partiendo desde el tipo de régimen-, el carácter de las normas y la división y el equilibrio de poderes (el sistema de balances y controles) y las limitaciones institucionales al ejercicio del poder (accountability horizontal). En el nivel de los resultados sería necesario abordar temas como la satisfacción de las personas con el funcionamiento de la democracia, pero también los efectos e impactos de las políticas públicas. En síntesis, estos tres niveles de análisis de la calidad aluden a los tipos de legitimidad de la democracia (por origen, por procedimientos y por resultados), destacados en el capítulo I, que a su vez hacen 
referencia a los pactos constitutivos, a la operación de la democracia y a sus rendimientos.

Una vez explicitado el concepto de calidad, es necesario destacar que en el estudio de la democracia se pueden aplicar mediciones de carácter objetivo y de carácter subjetivo. La primera utiliza información "como las estadísticas de participación electoral (...), la composición de los cuerpos legislativos (...) o el derecho al voto en un sistema político (...) La otra tradición confía en el juicio de expertos quienes definen los índices de la posición de un país en aspectos de la democracia liberal, como la limpieza de las elecciones, la libertad de prensa o las libertades de los grupos políticos" (Bollen y Paxton, 2000: 60). A esta última se debe añadir también la medición que se hace sobre la base de la opinión de personas que no son consideradas como expertas en los temas tratados, y que se obtiene fundamentalmente de la aplicación de encuestas acerca de temas propios de la democracia como la vigencia de las libertades, el apoyo a las instituciones políticas, la satisfacción con el desempeño de éstas, con las acciones de los políticos y con la orientación y el efecto de las políticas públicas.

Cada uno de los tipos de medición arroja sus propios resultados y tiene su utilidad específica. Las mediciones subjetivas -tanto las que recogen el parecer de expertos como las que acuden a la opinión de la ciudadanía- pueden ser muy valiosas para valorar los grados de legitimidad de un régimen y la satisfacción con el desempeño de la democracia en un momento determinado. Por su parte, las mediciones objetivas pueden ser un excelente instrumento para conocer las condiciones de la democracia con relativa independencia de la opinión de expertos o de los ciudadanos. Por consiguiente, cada una de ellas no mide un objeto diferente, sino que son modalidades sustancialmente diferentes de medir el mismo objeto. Los enfoques subjetivos expresan los valores de algún grupo de personas -que pueden ser los expertos o una muestra poblacional- acerca de la democracia. Es posible que en ellos se haga explícito el concepto de democracia que utilizan esas personas, pero también es posible realizar la medición prescindiendo de él ${ }^{32}$.

\footnotetext{
${ }^{32}$ En la medición por medio de la opinión de expertos es casi inevitable hacer explícito el concepto de democracia que se quiere someter a prueba, en tanto que hay mayor campo para prescindir de éste cuando se la efectúa por medio de la opinión de los ciudadanos. Por ello, este último tipo de medición genera un alto grado de incertidumbre, especialmente cuando las opiniones sobre las preferencias hacia la democracia o su satisfacción con ella no van acompañadas de algún tipo de indagación sobre la concepción de democracia que utiliza cada uno de los ciudadanos consultados.
} 
Las mediciones objetivas, por su parte, abordan a la democracia a través de un conjunto de variables, derivadas a su vez de un concepto claramente explicitado. Ante ello se podría argumentar que éstas expresan los valores del investigador, que es claramente quien selecciona $-\mathrm{y}$, eventualmente, pondera- las variables, lo que introduciría una carga de subjetividad en este tipo de medición. Pero, este sesgo se elimina precisamente por el planteamiento explícito del concepto que, como condición sine qua non, debe ser el producto del conocimiento acumulado y, en consecuencia, aceptado por la comunidad académica $^{33}$. Este requisito se cumple a medias cuando se recaba la opinión de expertos y muy difícilmente cuando se acude a los ciudadanos.

Por otra parte, estos dos tipos de medición pueden aplicarse en cualquiera de los niveles de análisis de la calidad, pero se puede advertir que existen diversos grados de compatibilidad en las múltiples combinaciones que se pueden establecer. Así, la calidad en los procedimientos se evalúa de mejor manera por medio de la medición objetiva ya que se toma como unidad de análisis a los procesos desarrollados en el marco de la acción política, esto es, a hechos acaecidos durante un tiempo determinado. En cambio, cuando se evalúa la calidad por los resultados generalmente tiene amplio campo la medición subjetiva, ya que en buena medida se busca conocer la satisfacción de las personas con la democracia. Sin embargo, en este ámbito se aplica también la medición objetiva, de manera especial cuando se busca evaluar el impacto de las políticas públicas. El análisis de la calidad en los contenidos arroja mejores resultados cuando se utiliza alguna medición objetiva, ya que sus unidades son las normas, las instituciones, la formulación y aplicación de las políticas, entre otras. Finalmente, en necesario tomar en consideración que al aplicar mediciones subjetivas a la calidad en los contenidos y en los procedimientos - como lo hacen diversos estudios, como Latinobarómetro y Lapop, que consultan la opinión de las personas sobre aspectos sustantivos de la democracia- existe siempre una fuerte influencia de los resultados de la gestión política. Inevitablemente, las personas consultadas en las encuestas están influidas por sus propias condiciones materiales, a lo que debe sumarse lo que he señalado antes acerca del peso de los valores

\footnotetext{
${ }^{33}$ El carácter explícito y aceptado en la comunidad académica como criterio de validez del concepto es ciertamente una condición mínima, pero suficiente para eliminar los rasgos de subjetividad (en este punto me remito a lo tratado en el capítulo I acerca de la construcción del concepto de democracia).
} 
y por consiguiente de la dificultad de controlar el concepto de democracia con el que cada persona emite su juicio ${ }^{34}$.

En este punto me parece necesario volver sobre lo dicho antes acerca de que la calidad de la democracia es un campo conceptual en construcción. Este es aún más joven que el de la medición, reseñado en la sección anterior, y por ello no se lo puede identificar aún como un espacio teórico-conceptual, esto es, como una teoría de alcance medio. Aunque existen varios puntos de acuerdo entre los autores que trabajan en el tema, aun quedan muchos por explorar. Entre los aspectos sobre los que existen acuerdos se destaca la utilización de un concepto mínimo y procedimental de democracia como punto de partida para el análisis (Lijphart, 2000; Munck y Verkuilen, 2002; Munck, 2009; Altman y Pérez-Liñán, 2002; Diamond y Morlino, 2005b; Morlino, 2004; Beetham, 2004; 2005; Levine y Molina, 2007; Schmitter, 2005). Por lo general, de la misma manera que lo hacen quienes se ocupan de la medición de la democracia, la mayor parte de los autores utilizan el concepto de poliarquía de Robert Dahl o se sitúan muy cerca de éste. En consecuencia, la reflexión sobre la calidad de la democracia hace referencia fundamental pero no exclusivamente al ámbito político. Con escasas excepciones (Rueschemeyer, 2005; Lijphart, 2000), esa reflexión no alude a los aspectos económicos o sociales, tanto en términos de condiciones que favorecen la constitución de regímenes democráticos como en su carácter de resultados de la gestión de ellos ${ }^{35}$. Se establece así una separación tajante entre los procesos políticos de selección y control de los gobiernos por parte de los ciudadanos y la gestión de esos gobiernos. Por ello se afirma que "la calidad de la democracia depende del funcionamiento de los procesos mediante los cuales la población

\footnotetext{
${ }^{34}$ Es innegable la superioridad de la medición objetiva sobre la subjetiva. La posibilidad de controlar los conceptos - partiendo del concepto básico de democracia- es un elemento decisivo en este sentido. Sin embargo, la medición subjetiva puede ser muy útil cuando se tratan determinados temas, como la legitimidad y el grado de apoyo a la democracia. También es útil cuando se trabaja con ciertas variables propias de la democracia (y del estudio de su calidad), como la participación, en que puede ser importante la opinión/explicación de las personas sobre la decisión de participar o no. Por ello, el ideal de medición se encuentra en la combinación de ambos tipos, aunque siempre mantendrá su preeminencia la de carácter objetivo.

${ }^{35}$ Como he señalado reiteradamente en el capítulo I, la consideración de los factores sociales, económicos, políticos, culturales e internacionales como condiciones para el surgimiento de la democracia constituye un campo de análisis específico (Lipset, 1959, 1996; Moore, 1973; Linz, 1998; Huber, Rueschemeyer y Stephens, 1993), muy diferente a la visión de estos como condiciones para la durabilidad de las democracias (Przeworski, Álvarez, Cheibub y Limongi, 1996; Linz, 1987; Karl, 2000) y también de las que los ve como resultados de la gestión política (Przeworski, 1991). Son tres campos de análisis que no deben ser confundidos entre ellos y tampoco con la calidad de la democracia.
} 
selecciona y controla [a] sus gobernantes, no de la eficacia del gobierno en la solución de los problemas del país" (Levine y Molina, 2007: 18-19) ${ }^{36}$.

Considero que este punto de partida abre el debate sobre dos temas de fundamental importancia en el estudio de la calidad de la democracia, en particular en países como los estudiados. El primero de ellos es el carácter mínimo del concepto de democracia o, dicho de otra manera, el recorte que hace entre lo que queda dentro y lo que queda fuera. Hasta dónde es mínimo, qué incluye y qué excluye, son las preguntas que no se pueden soslayar como paso previo a la utilización del concepto. La calidad de la democracia o, más bien, lo que entendamos por ella, estará en función directa de la magnitud que asignemos a ese mínimo. El segundo tema es la relación entre los atributos de la democracia política o poliarquía con las prácticas políticas, con la gestión gubernamental y en general con los elementos señalados antes (económicos, sociales, etc.). El problema central en este nivel alude a los efectos que pueden derivarse de esa relación, ya que resulta inevitable que muchos de los factores mencionados incidan directamente sobre las condiciones de la democracia. Aunque hayamos definido previamente un concepto mínimo de democracia -en el que no se incluyen esos elementos-, siempre será necesario considerar las relaciones que se establece con ellos o la influencia que estos tienen sobre los aspectos constitutivos de esa misma democracia mínima.

En este aspecto es necesario llamar la atención sobre dos temas. En primer lugar, reiterando lo señalado en el capítulo I, se debe aceptar que aún definiciones tan acotadas como la de Schumpeter (1996) o la de poliarquía de Dahl (1989; 1991), que generalmente han sido consideradas como formas estrictamente electorales de democracia, incluyen un número tan alto de condiciones que llevan a poner en duda el carácter mínimo del concepto (O`Donnell, 1999; Nun, 2002). Dentro de esas condiciones ocupan un lugar destacado las libertades y los derechos que deben amparar a los individuos para que puedan ejercer a plena capacidad la decisión política. En general, esos tipos de definiciones incluyen a diversos niveles, que no se reducen al político-electoral, sin los cuales este último no tendría validez como método para expresar la voluntad de los ciudadanos. Así, la definición de Schumpeter de la democracia como un "sistema institucional, para llegar a las decisiones políticas, en el que los individuos adquieren el

\footnotetext{
${ }^{36}$ Esta afirmación de Levine y Molina niega implícitamente la posibilidad de medir la calidad de la democracia en los resultados.
} 
poder de decidir por medio de una lucha de competencia por el voto del pueblo" (Schumpeter, 1996: 343), está supeditada a que sea "la libre competencia por el voto libre" (Schumpeter, 1996: 345) y a la relación "entre la democracia y la libertad individual" (Schumpeter, 1996: 346). Por consiguiente, el concepto desborda el ámbito estrictamente político y se adentra en el terreno de las libertades civiles o del estado de derecho. Lo mismo se puede sostener acerca del concepto de Dahl, cuando por lo menos tres de sus ocho garantías institucionales son realmente libertades civiles, no estrictamente políticas (1989: 15) ${ }^{37}$. En consecuencia, la característica mínima del concepto se ve rebasada en la propia definición, lo que significa que al indagar sobre la calidad de la democracia se hace necesario superar el ámbito de lo electoral y sus procedimientos. Si la democracia es "un método para llegar a las decisiones políticas" (Schumpeter, 1996: 343) o para "responder a las preferencias de sus ciudadanos, sin establecer diferencias entre ellos" (Dahl, 1989: 13), lo es solamente porque se asienta en un conjunto de libertades, garantías y derechos que son parte indisoluble de ella.

En segundo lugar, a partir de esas mismas definiciones acotadas se puede establecer que los individuos requieren contar con determinadas condiciones materiales para acceder a y disfrutar plenamente de- esos derechos y esas libertades (Rueschemeyer, Huber y Stephens, 1992; O`Donnell, 1999; Nun, 2002; PNUD, 2004). La pobreza y las diversas formas de discriminación social son obstáculos en ese sentido y condicionan severamente la estabilidad y la durabilidad de las democracias (Álvarez et al., 1996; Przeworski, 1998). Aún si se toma como referencia únicamente a la decisión electoral -esto es, al aspecto estrictamente procedimental, que otorga el carácter mínimo a la definición- se hace imposible soslayar la incidencia de esos factores. Pero, en términos teóricos y conceptuales, el problema no está en reconocer esa incidencia sino en determinar el lugar que ellos ocupan tanto en la definición de democracia como en la de su calidad. En una visión extremadamente resumida se puede asegurar que ellos no son elementos constitutivos del concepto de democracia pero sí son factores condicionantes ${ }^{38}$. Para decirlo en otras palabras, no se los puede considerar como las variables que definen a la

\footnotetext{
${ }^{37}$ Me refiero a las libertades de asociación y de expresión y a la diversidad de fuentes de información.

${ }^{38}$ Es clara la diferencia entre el lugar que ocupan en el concepto de democracia los factores estructurales mencionados y el que les corresponde a los atributos del estado de derecho. Como he señalado antes, siguiendo a Sartori (1992: 86), estos últimos son propiedades de definición, no solamente variables hipotéticas. Es decir, hacen parte del concepto, en tanto que los factores estructurales no tienen esa condición.
} 
democracia, pero sí como variables intervinientes en el proceso de su constitución así como en su permanencia. Por ello - por su peso en la conformación y en la duración de un régimen democrático- es inevitable considerarlos como elementos propios del concepto de calidad de la democracia, aunque no lo sean del concepto de democracia. De esta manera, a pesar de que el concepto de calidad de la democracia se deriva directamente del concepto de democracia, se hace evidente que en el primero deben considerarse elementos que no se encuentran en el último. Esto es estrictamente lógico en términos conceptuales ya que con cada uno de ellos se está aludiendo a unidades de análisis diferentes y que se sitúan en niveles también diferentes.

En efecto, una vía posible para el tratamiento adecuado de la calidad de la democracia se encuentra en la diferencia que se debe hacer entre ambos conceptos. Es una diferencia que radica fundamentalmente en la unidad de análisis con la que trabaja cada uno de ellos. El concepto de democracia tiene como unidad de análisis al conjunto formado por el régimen y el sistema político. El concepto de calidad de la democracia trabaja con una unidad de análisis más amplia, que incluye a los dos señalados pero que no se circunscribe a ellos, ya que incorpora elementos propios del otro nivel (el de la comunidad política) y sobre todo porque se preocupa del desempeño de la democracia. Aspectos como "respuesta a la voluntad popular, responsabilidad y soberanía" (Levine y Molina, 2007: 17), “accountability vertical, responsabilidad (...) accountability horizontal (...) transparencia" (Diamond y Morlino, 2005: x) no son elementos constitutivos del concepto de democracia, pero sí lo son del concepto de calidad de la democracia.

Abundando en esta diferencia, se debe señalar que el concepto de democracia es estático, mientras el de calidad es dinámico (o, si se quiere utilizar un anglicismo, performativo). El primero se refiere a un conjunto de variables o atributos que constituyen una realidad específica y que, como he señalado antes, puede tener diversos grados dentro de una gama relativamente amplia de regímenes que se sitúan en el continum autoritarismodemocracia (los diversos tipos de regímenes identificados por los autores reseñados antes). El concepto de calidad alude también a esas variables o atributos pero, además de poner el énfasis en su comportamiento, los rebasa en la medida en que se preocupa también del desempeño de otros elementos que no forman parte del concepto de democracia. 
Es conveniente destacar que dentro del propio concepto de democracia -sin necesidad de aludir a su calidad- es posible identificar diversos grados, en una escala que mide los avances en las variables fundamentales que caracterizan al régimen. Así, sin entrar en el campo de la calidad de la democracia, es posible evaluar el proceso de democratización. Para ello se puede acudir a instrumentos como los dos ejes sugeridos por Dahl (1989: 18), esto es, la liberalización (entendida como la ampliación y profundización de las libertades) y la participación (como ampliación y profundización de los derechos políticos) ${ }^{39}$. Cabe reiterar que en este caso no se alude necesariamente a la calidad de la democracia, ya que se trata de una indagación en el tipo de régimen, en la línea que se desplaza desde el autoritarismo hasta la democracia. La calidad de la democracia, por su parte, reconoce a ese nivel como uno de sus campos de análisis - de manera que también puede ocuparse de los avances logrados en la liberalización y en la participación- pero su interés se centra en la medición de las variables que califican a un régimen como democrático. Pretende evaluar a la democracia no solamente en contraposición al régimen autoritario, sino en relación a sí misma, a su propio concepto. Por ello tiene enorme importancia la definición inicial de democracia. En última instancia, la medición de la calidad dependerá de los atributos con los que se ha construido el concepto de democracia o, para decirlo en los términos usados antes, de la magnitud que asignemos a la definición mínima. Esto, a su vez, exige un trabajo en dos niveles. Por un lado es necesario identificar la distancia que establece con el régimen autoritario y, por otro lado, es preciso conocer el grado alcanzado por cada uno de sus atributos. De esta manera, la calidad de la democracia mide a la democracia en dos dimensiones relacionadas pero diferentes.

Aún a riesgo de ser redundante, creo que es necesario subrayar que a partir de esta consideración se abren dos campos de análisis diferentes pero íntimamente relacionados. El primero es el de los procesos de democratización, en que los elementos fundamentales, para seguir con la propuesta de Dahl, son los avances en la liberalización y la participación. Este es el que mide la distancia con el régimen autoritario. El segundo es el análisis de la calidad de la democracia, en que el eje se encuentra en los atributos de la democracia. En este se busca medir a la democracia en relación consigo misma o al

\footnotetext{
${ }^{39}$ Como se ha visto en el capítulo II, esos dos ejes fueron retomados, con bastante acierto desde mi punto de vista, como parámetros para el análisis de las transiciones a la democracia (O`Donnell y Schmitter, 1994: 19-30). En esos casos no se estaba analizando la calidad de la democracia -mal podría habérselo hecho si aún no existía-, sino los avances hacia la constitución de ella como ordenamiento político.
} 
grado de materialización de los atributos propios de su concepto. Obviamente, ambas perspectivas se pueden $-\mathrm{y}$ se deben- integrar en un solo análisis, sobre todo cuando se trata de estudiar casos de procesos de democratización que pueden ser calificados de incompletos o de frustrados ${ }^{40}$. También se deben fundir ambas cuando se requiere analizar los retrocesos autoritarios, en que la pérdida de los atributos de la democracia llega a un punto que exige un nuevo proceso de democratización, esto es, de recuperación de las libertades y de la participación ${ }^{41}$. De esta manera, se enlaza el estudio de la calidad de la democracia con el del tipo de régimen, revisado al inicio de este capítulo.

En este punto -y abordando el análisis de los tres países- es necesario volver nuevamente sobre el problema del concepto, sus dimensiones y sus variables. Siguiendo lo señalado antes, en el sentido de marcar los límites de lo mínimo, es necesario definir lo que queda dentro y lo que queda fuera, lo que va a ser objeto de medición y lo que no se va a considerar como indicador de la calidad de la democracia. Con ello se abren múltiples posibilidades, que están dadas por las diversas perspectivas teóricas que se han ido construyendo en torno a este concepto. Así, las democracias de Bolivia, Ecuador y Perú podrán analizarse desde la perspectiva de los procedimientos, los contenidos y los resultados (Morlino, 2004: 11; Diamond y Morlino, 2004: 21), desde la decisión electoral, la participación, la respuesta a la voluntad popular, la responsabilidad y la soberanía

\footnotetext{
${ }^{40}$ La constante apelación, en las ciencias sociales de los tres países estudiados, al carácter incompleto de la constitución del estado nacional se ha trasladado también al tema de la democracia (Menéndez, 1991; Calderón, 1995, Cotler, 1988; Schmitter y Karl, 1996). Así, las democracias débiles o disminuidas de estos países serían el producto de procesos incompletos de democratización. En esos casos, el análisis de la democracia y en especial de su calidad, debe ser muy precisos en considerar la herencia histórica y, en términos de Morlino (2007: 3) evaluar cuidadosamente la relevancia de las tradiciones autoritarias. A la vez, esto enlaza el tema con la perspectiva de path dependence, reseñada en el capítulo II (Mahoney, 2001; Pierson, 2000; Page y Bednar, 2006). Esta destaca la constitución de una trayectoria de desarrollo que, por medio de incentivos propios, lleva a la reproducción institucional por vía de los cálculos que hacen los actores políticos acerca de los costos y los beneficios que obtienen al actuar dentro de las condiciones que establece el régimen, en este caso el de carácter autoritario. Esta puede ser una buena vía de análisis de la reproducción y persistencia de los regímenes autoritarios y también de las democracias disminuidas.

${ }^{41}$ Como se ha visto en la revisión de las propuestas de estudio de las democracias disminuidas, en la primera sección de este capítulo, se pueden identificar regímenes que estrictamente son formas de autoritarismo más que de democracia -como los autoritarismos electorales hegemónicos de Diamond (2002) y los autoritarismos electorales de Schedler (2002)-, lo que significa que han perdido la mayor parte de los atributos democráticos (en realidad, conservan solamente la realización de elecciones, pero despojadas de los requisitos de libertad y limpieza). Es evidente que en esos casos se hace necesario un nuevo proceso de democratización, la segunda transición a la que aluden algunos de los autores citados. Perú, con el retroceso autoritario producido por el fujimorismo, es el caso paradigmático de esta situación en el estudio de los tres países.
} 
(Levine y Molina, 2007: 17), desde los derechos civiles, la participación y la competencia efectiva (Altman y Pérez-Liñán, 2002: 85) o desde la libertad de expresión, la libertad de organización, el pluralismo y las elecciones libres (Coppedge y Reinicke, 1990: 51). De cualquier manera, es probable que la conclusión se acerque mucho a las que ya se encuentran en algunos trabajos comparativos, que ubican a estos países en lugares relativamente bajos del ranking de calidad de la democracia (Levine y Molina, 2007: 3940; Altman y Pérez-Liñán, 2002: 92). Pero, antes de seguir por ese camino es necesario revisar brevemente los aportes más destacados sobre la calidad de la democracia.

\section{El desafío del estudio de la calidad de la democracia}

Algunas referencias a la calidad de la democracia se encuentran tempranamente en Lijphart (1969), orientadas exclusivamente a los arreglos institucionales que hacen posible la expresión de los múltiples clivajes en las sociedades plurales ${ }^{42}$. También se encuentran algunos anticipos del tema en autores como Sartori (1988), Bobbio (1985), Dahl (1991), Linz (1987; 1998), Przeworski (1995; 1998), Huntington (1980) y Schmitter y Karl (1996), Held (2001), Smith (2005), que tratan aspectos que podrían considerarse como los ejes conceptuales básicos de la democracia. Así mismo, se pueden encontrar preocupaciones al respecto en autores como Putnam (1993), Alcántara (1995) y O’Donnell (1996), que analizan aspectos específicos del desempeño de las democracias. En general, el tratamiento actual de la calidad de la democracia -que, como he señalado reiteradamente, constituye en sí mismo un cuerpo teórico específico- viene precedido de un gran conjunto de aportes realizados desde diversas perspectivas y múltiples intereses teóricos. Es, sin duda, uno de los resultados del proceso de democratización correspondiente a la denominada tercera ola (Huntington, 1991: 579) que, al constituirse como un proceso mundial, estableció las condiciones para el desarrollo del estudio comparativo de la democracia en múltiples aspectos. En otras palabras, la vigencia de regímenes democráticos en un gran número de países puso sobre la mesa problemas y desafíos desconocidos hasta entonces, que obligaron a desarrollar perspectivas de análisis y

\footnotetext{
${ }^{42}$ La perspectiva de Lijphart, aún en sus textos más recientes (Lijphart, 2000: 257-278) difiere sustancialmente de la corriente que desarrolla el tema de la calidad de la democracia. En términos estrictos, este autor no forma parte de la teoría que se ha ido construyendo en los últimos quince años, fundamentalmente porque no tiene como eje central al grado en que un régimen se aleja del tipo ideal de democracia o que pierde algunos atributos que la caracterizan. Pero está evidentemente emparentada con ella en la medida en que indaga en las condiciones institucionales que le permiten desempeñarse de la mejor manera posible.
} 
conceptos adecuados ${ }^{43}$. A la vez encontró a la ciencia política dotada de un buen arsenal conceptual que se había ido construyendo desde algunas décadas antes ${ }^{44}$.

Estas condiciones permitieron que se fueran sentando las bases para construir el concepto de calidad de la democracia. Sin embargo, se trata de una empresa compleja ya que es uno de esos "conceptos multifacéticos que sería imposible definir y describir en un artículo" (Coppedge, 2001: 1). Adicionalmente, por las razones señaladas en varias oportunidades en las páginas anteriores -especialmente por tratarse de un tema relativamente nuevo-, no se cuenta con un cuerpo conceptual plenamente establecido y compartido por la comunidad académica. Los acercamientos existentes hasta el momento constituyen tentativas de formulación de teoría al respecto. Fundamentalmente, son esfuerzos orientados a la construcción de perspectivas de análisis, en las que los elementos centrales son las definiciones de los conceptos, conjuntamente a la identificación de las variables que deben ser consideradas para su medición -o para su evaluación, si es el caso- y de los respectivos indicadores de cada una de éstas.

Para entrar en ese campo considero apropiado concentrar el análisis en las propuestas que han tenido mayor acogida en la comunidad académica (especialmente la latinoamericana) y que, además, son las que intentan construir perspectivas metodológicas integrales para el estudio de este tema. Por ello, en la presente sección me ocuparé de tres propuestas que han sido ampliamente utilizadas por algunos de los autores que han construido indicadores o que han propuesto procedimientos de

\footnotetext{
${ }^{43}$ Entre esas perspectivas y esos conceptos, además de la calidad de la democracia, se encuentran los de consolidación, institucionalización y gobernabilidad. Cabe recordar que antes de esos debates tenía gran importancia explicar las características de los regímenes autoritarios (Linz, 1987; 1998) y los propios procesos de transición, a los que he hecho referencia en el capítulo II.

${ }^{44}$ Si se quisiera fijar un hito de inicio de los estudios contemporáneos sobre la democracia y sus problemas, podría escogerse el año 1942, cuando se publica la primera edición de Capitalismo, socialismo y democracia de Schumpeter. Esto a pesar de que, a decir del autor en el prólogo a aquella edición, su interés no era la democracia sino el socialismo, pero "El problema de la democracia se ha abierto paso al lugar que ahora ocupa en este libro porque me ha resultado imposible exponer mis puntos de vista sobre la relación entre el orden socialista de la sociedad y el método democrático de gobierno sin un análisis más bien minucioso de este último” (Schumpeter, 1996: 15). Su reflexión sobre la democracia resulta más sorprendente cuando se considera que para él se trataba de un moribundo, ya que su obra está dirigida a "demostrar que inevitablemente surgirá una forma socialista de sociedad de la descomposición igualmente inevitable de la sociedad capitalista” (Schumpeter, 1996: 16) y el socialismo que tenía al frente no era el democrático sino el totalitario propio del modelo soviético Por otra parte, en el inicio de la tercera ola ya se contaba con textos de fundamental importancia como La poliarquía de Robert Dahl, cuya primera edición es de 1971, y An Economic Theory of Democracy de Anthony Downs, publicada en 1957.
} 
medición o evaluación. Las tres propuestas son las de Altman y Pérez-Liñán (2002), de Levine y Molina (2007) y de Diamond y Morlino, contenida en Diamond (2002), Diamond y Morlino (2004; 2005) y Morlino $(2004 ; 2007)^{45}$.

En la primera de estas propuestas, Altman y Pérez-Liñán sostienen que "Por calidad de la democracia se entiende el grado que ha alcanzado realmente una determinada poliarquía su potencial como régimen político. El supuesto que subyace a esta visión es que la poliarquía es una condición necesaria, aunque no suficiente, para una alta calidad de la democracia” (Altman y Pérez-Liñán, 2002: 86). En otros términos, según estos autores, los análisis de la calidad de la democracia deben asumir que existe una poliarquía, esto es, que se ha cumplido previamente el proceso de democratización o de transición desde un gobierno autoritario. Por ello, desde esa perspectiva se sostiene que "Cuando comparamos la calidad de la democracia entre países no estamos comparando cuál de los países es más democrático (...) Más bien, estamos analizando en cuáles países se desempeña mejor la democracia dados algunos estándares normativos" (Altman y PérezLiñán, 2002: 87).

A partir de estos elementos y siguiendo a Robert Dahl y a Kim Quaile Hill, los autores proponen tres dimensiones para el análisis de la calidad de la democracia: derechos civiles, participación efectiva y competencia efectiva (Altman y Pérez-Liñán, 2002: 88-89). Cada una de estas dimensiones se expresa a través de sus respectivas variables. Así, los derechos civiles se manifiestan en un conjunto de condiciones institucionales que permiten la participación y la oposición a la élite gobernante. Para su medición los autores acuden a la medición de Freedom House (Altman y Pérez-Liñán, 2002: 88). La participación efectiva se expresa en el derecho a participar en las decisiones políticas, pero también en el cumplimiento real de este derecho. Para su medición acuden a la participación electoral,

\footnotetext{
${ }^{45}$ Hay otras cuatro mediciones de la calidad de la democracia o de aspectos relacionados con ella, para América Latina, que por diversas razones que explicaré más adelante no incluyo en el análisis. Estas son: a) el estudio desarrollado por el Programa de Naciones Unidas para el Desarrollo, especialmente su índice de democracia electoral (PNUD, 2004); b) la serie anual que mantiene la Fundación Konrad Adenauer con el Índice de Desarrollo Democrático, IDD, generado por Polilat (www.idd.lat.org); c) los sondeos de opinión desarrollados por Latinobarómetro, que incluyen algunos aspectos acerca de las percepciones sobre la democracia; d) la serie que mantiene el proyecto Lapop de la Universidad de Vanderbilt, que recoge también percepciones sobre la democracia. Los dos últimos han sido utilizados por varios autores fundamentalmente como fuentes de información para sus respectivos estudios sobre la democracia y su calidad. Así mismo, cabe citar el índice de Freedom House (www.freedomhouse.org) y el de Polity IV (www.systemicpeace.org/polity/polity4.htm).
} 
expresada en la proporción de votantes sobre la población total en edad de votar (Altman y Pérez-Liñán, 2002: 88). La competencia efectiva se manifiesta en el debate -en y entre elecciones-, entendiendo que una democracia más competitiva es una mejor democracia. Para su medición toman el acceso de la oposición al proceso legislativo (y no solamente a los resultados electorales), los mecanismos que limitan la presencia excesiva del partido gobernante en el proceso de formulación de políticas y los límites que existen para evitar la presencia excesiva de la oposición (Altman y Pérez-Liñán, 2002: 89) ${ }^{46}$. Finalmente, con todos estos elementos, los autores construyen un índice de calidad de la democracia que resulta ya sea del producto (de la multiplicación) o del promedio de los valores del índice de Freedom House (normalizado a un rango de 0 a 1), el porcentaje de participación electoral y el índice de competitividad (Altman y Pérez-Liñán, 2002: 92). Se trata, por tanto de una medición que utiliza el análisis de factores y que en esa medida permite valorar el peso de cada uno de los tres (derechos civiles, participación y competencia) que constituyen el índice final.

En mi opinión hay dos problemas que no resuelve esta medición de la calidad de la democracia. El primero se refiere a que los tres factores que confluyen en la construcción del índice no están sujetos a ponderación, de modo que resultan equivalentes. Esto es muy discutible, especialmente si se considera que en la mayor parte de conceptos de democracia -específicamente en el de Dahl que toman como referencia los autores (Altman y Pérez Liñán, 2002: 90)- los derechos civiles tienen un peso que no puede ser equivalente al de la participación y al de la competitividad. Como se ha visto a lo largo de este capítulo, la vigencia de los derechos civiles es una condición fundamental para considerar a las elecciones como libres y limpias. Por tanto, es un elemento previo y determinante de éstas, hasta el punto de que la sola existencia de elecciones sin la vigencia de aquellos derechos lleva a la constitución de algunas de las formas de democracia disminuida revisadas en la segunda sección. Adicionalmente, este problema se profundiza, cuando la participación se mide exclusivamente por la concurrencia a elecciones y la competitividad por la diferencia de votación entre el partido de gobierno y el de oposición, es decir, por aspectos parciales de cada una de las categorías. Así mismo, al no ponderar los factores, el índice final se ve influido de manera determinante por los

\footnotetext{
${ }^{46}$ Para medir la competencia efectiva, los autores construyen un índice de competitividad,basado en la proporción de puestos obtenidos por el partido más grande de la oposición y el partido de gobierno (o el más grande de la coalición gobernante), con lo que esta variable se expresa de manera similar a las otras dos en una cifra que se mueve entre 0 y 1 (Altman y Pérez-Liñán, 2002: 89-90).
} 
cambios que pueda sufrir uno solo de ellos. A manera de ejemplo, una mayor concurrencia de los electores a las urnas se verá reflejada automáticamente en una elevación del índice de calidad, lo que resulta muy dudoso si las otras dimensiones se mantienen estables e incluso si no se conocen las causas que produjeron esa afluencia. Lo mismo se puede decir acerca de los cambios en la dimensión de la competitividad, que se producirá cuando las proporciones de votos de los partidos de gobierno y oposición sean relativamente similares, lo que puede expresar mayores grados de polarización que no expresan necesariamente mejor calidad de la democracia.

El segundo problema es que esta medición no cuenta con un procedimiento que permita identificar a los países democráticos antes de proceder a la medición de su calidad. La aplicación del índice requiere de estudios previos que determinen cuáles regímenes son democráticos para poder proceder a su aplicación exclusivamente en ellos. Por ello, cuando construyen el ranking de los países latinoamericanos, los autores acuden al apoyo de clasificaciones previas -específicamente las de Álvarez et al. (1996) y Mainwaring, Brinks y Pérez-Liñán (2001)- para seleccionar a los países calificados como poliarquías. En sí misma, esta medición no cuenta con un recurso para hacerlo, lo que se deriva de la premisa señalada antes acerca de que la calidad solamente es aplicable a las poliarquías ya constituidas (Altman y Pérez-Liñán, 2002: 87). Pero, el problema es que para saber cuáles son esas poliarquías constituidas se hace necesario contar con las muletas que ofrecen otros estudios. La alternativa a ello podría encontrarse en utilizar para la selección de los casos las mismas dimensiones que sirven para la medición, pero eso produciría un efecto circular o de endogeneidad ${ }^{47}$.

Con estas anotaciones es pertinente observar la aplicación de este índice realizada por los autores al conjunto de países latinoamericanos destacando los resultados con respecto a Bolivia Ecuador y Perú. Así, en una escala en que el máximo es 1 y el mínimo 0, Ecuador ocupa el séptimo lugar de un total de 18 países con un índice de 0,759, mientras Bolivia obtiene un índice de 0,725, con lo que se sitúa en el décimo lugar y Perú, con un índice de 0,620, aparece en el puesto decimotercero. De esta manera, Ecuador y Bolivia se situarían por encima de la media, que es de 0,716 , en tanto que Perú estaría por debajo de

\footnotetext{
${ }^{47}$ El efecto circular de endogeneidad ya se advierte en el aspecto señalado en el punto anterior, esto es, en la agregación de los derechos civiles y las elecciones libres y limpias, dado que éstas últimas dependen en gran medida de aquellos.
} 
ella ${ }^{48}$. Pero, la situación cambia cuando se toma cada uno de los factores por separado. Así, en el índice derechos civiles (la medición de Freedom House), Ecuador se mantiene en el sexto lugar, con un puntaje de 0,781 , Bolivia desciende al noveno puesto con 0,750 y Perú se mantiene en el decimotercero con 0,625. La media en este caso es de 0,717, de manera que nuevamente Perú se sitúa debajo de ella. Por otra parte, cuando se utiliza el índice de participación, Perú es el mejor situado de los tres, en el noveno puesto, con un índice de 0,631, mientras Ecuador y Bolivia se sitúan en el decimoprimero y decimosegundo, con 0,627 y 0,563, respectivamente. La media de este indicador es de 0,633, de modo que los tres están debajo de ella, lo que no deja de llamar la atención si se considera que en todos ellos el voto es obligatorio y este indicador mide básicamente la asistencia a las urnas. Finalmente, de acuerdo al índice de competitividad, Ecuador y Bolivia se sitúan en los puestos sexto y séptimo, con puntajes de 0,870 y 0,862 , respectivamente, mientras que Perú desciende hasta el decimosexto lugar, con un puntaje de 0,681. La media en este caso es de 0,798, con lo que nuevamente Perú está por debajo.

En términos generales, a partir de estos indicadores y considerando que Ecuador y Bolivia se sitúan levemente encima de la media latinoamericana, se podría decir que ambos países tienen una democracia de calidad media, en tanto que Perú tendría una democracia de calidad más baja o deficitaria. La medición no permite extraer más conclusiones al respecto, lo que ciertamente es insuficiente. Es útil, sin duda, para establecer un ranking de países, como lo hacen los autores cuando presentan una tabla de conjunto de los países latinoamericanos (Altman y Pérez Liñán, 2002: 92), o para apreciar las distancias con determinados países, como se observa en el gráfico 8 que compara a los tres países con los que obtienen el mayor y el menor puntaje (Uruguay y Guatemala, respectivamente) y con la media latinoamericana. Sin embargo, no es mucho más lo que se puede extraer del indicador ${ }^{49}$.

\footnotetext{
${ }^{48}$ La puntuación y la ubicación están determinadas por el promedio de los tres factores. Como lo anotan los autores, son mínimos los cambios que se observan cuando se utiliza el producto de los tres y solamente afectan a la posición que ocupan Chile y Costa Rica (Altman y Pérez-Liñán, 2002: 92), por tanto es indiferente cual de las dos formas de agregación se tome para el análisis de los tres países.

${ }^{49}$ Como sostendré más adelante, considero que el problema central se encuentra en la utilización de un índice como expresión de la calidad. La reducción a una cifra puede ser muy útil para construir un ranking o para establecer comparaciones generales (especialmente cuando de trabaja con un $\mathrm{N}$ grande), pero no aporta más que en eso, especialmente cuando es un análisis comparado de pocos casos.
} 
Gráfico $\mathrm{N}^{\circ} 8$

Ubicación de los tres países según el índice de calidad de la democracia de Altman y Pérez-Liñán

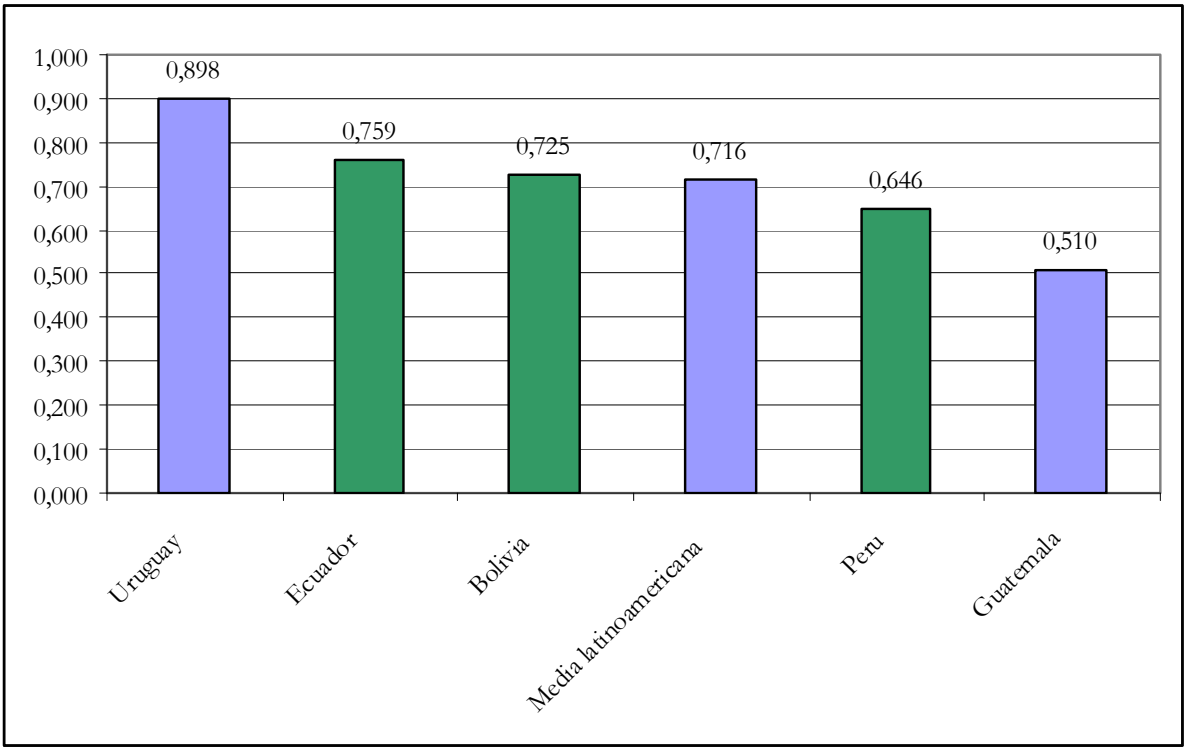

Fuente: Altman y Pérez-Liñán (2002). Elaboración: Simón Pachano

La segunda propuesta, que también ha tenido acogida en América Latina sostiene que "la calidad de la democracia depende del funcionamiento de los procesos mediante los cuales la población selecciona y controla [a] sus gobernantes, no de la eficacia del gobierno en la solución de los problemas del país" (Levine y Molina, 2007: 19). Los ejes centrales de ésta son la legitimidad de la democracia y la exclusión del buen gobierno como criterio de la evaluación de la calidad. Ello queda claro cuando los autores señalan que su “definición [de democracia] y el concepto de calidad que se deriva de ella, determina[n] la legitimidad con base en las condiciones de competitividad, participación política y mecanismos para exigir rendición de cuentas y responsabilidad, y no en el contenido «sustantivo» o el resultado de las políticas que se instrumenten, a menos que éstas violenten o promuevan las primeras" (Levine y Molina, 2007: 20). De este modo, la calidad de la democracia descansa en una legitimidad que no está asentada en los rendimientos del gobierno sino en algunos componentes del régimen democrático. Por ello, su propuesta consiste en "centrar el análisis sobre los procedimientos establecidos para escoger y controlar [a] los gobiernos, y para que los ciudadanos influyan en las decisiones de estos; las reglas del juego y su funcionamiento real (instituciones formales e informales) y los derechos asociados con ellas; lo cual necesariamente conlleva dos elementos adicionales que se requieren para que haya legitimidad democrática: ciudadanía inclusiva (sufragio universal) y derecho efectivo a la organización y participación" (Levine 
y Molina, 2007: 19) ${ }^{50}$. Con estos elementos, los autores identifican "tres áreas interrelacionadas cuyo funcionamiento nos indica los niveles de calidad: la decisión electoral, el proceso de adopción de políticas públicas, y los mecanismos para exigir responsabilidad a los gobernantes" (Levine y Molina, 2007: 23) ${ }^{51}$.

Esas tres áreas se expresan en "cinco dimensiones conceptuales: 1) decisión electoral; 2) participación; 3) respuesta a la voluntad popular [responsiveness]; 4) responsabilidad [accountability]; y 5) soberanía" (Levine y Molina, 2007: 24). En consecuencia, la medición de los grados de calidad de la democracia deberá establecerse por medio de indicadores de cada una de ellas. En términos generales, como indicadores de decisión electoral proponen sufragio universal (incluyendo el derecho al voto en el exterior y de extranjeros residentes en el país), frecuencia de elecciones (a tiempos más cortos mayor control ciudadano), elecciones libres (incluyendo la posibilidad de presentar candidaturas independientes), elecciones imparciales, libertad de prensa y acceso a múltiples fuentes de información (que incluye el nivel de igualdad de la población en recursos cognitivos, evaluado por el acceso a la educación media) y el nivel de tolerancia hacia varios sectores (Levine y Molina, 2007: 30). En participación proponen medir el porcentaje de población en edad de votar que efectivamente lo hace, además del número de oportunidades que la población ha tenido para votar en un período determinado y la participación en organizaciones sociales (Levine y Molina, 2007: 31). En respuesta a la voluntad popular escogen como indicador "el nivel en que la población considera que sus acciones, y en particular el voto, influyen en la orientación de las políticas públicas" (Levine y Molina, 2007: 33). Para responsabilidad seleccionan tres formas de accountability (horizontal, vertical y social), además de la independencia del poder judicial (Levine y Molina, 2007: 32). Para soberanía acuden como indicador al peso de la deuda externa sobre la economía,

\footnotetext{
${ }^{50}$ De la misma manera que la mayor parte de autores que desarrollan el estudio de la calidad de la democracia, Levine y Molina utilizan un concepto mínimo y procedimental de democracia. Retomando a Dahl, consideran a la democracia "como un sistema en el cual los ciudadanos eligen a sus gobernantes y tienen el poder de removerlos e influenciar sus decisiones dentro de las siguientes condiciones: a. El gobierno está efectivamente en manos de los funcionarios elegidos; b. Las elecciones son libres, imparciales y frecuentes; c. Hay libertad de expresión; d. Los ciudadanos tienen acceso efectivo a fuentes alternativas de información; e. Hay libertad de organización y de reunión, y las asociaciones tienen autonomía frente al gobierno; f. La ciudadanía es inclusiva (sufragio universal) y no hay barreras discriminatorias para la participación electoral y política” Levine y Molina, 2007: 22-23)

${ }^{51}$ En cierto sentido, esas “tres áreas” aluden a los niveles de legitimidad que he señalado antes, de origen, de procedimientos y de resultados. También tienen relación con los tres niveles de análisis de la calidad que plantean Diamond y Morlino, 2004: 21), a los que me he referido antes y sobre los que volveré más adelante.
} 
entendiendo que mientras mayor sea el peso de esta "es de suponer que mayor será la necesidad para el país de atender los requerimientos de sus acreedores y de las organizaciones financieras internacionales" (Levine y Molina, 2007: 33). Adicionalmente, en este tema consideran también al grado en que los civiles controlan a los políticos.

Para contar con información de la mayor parte de estos indicadores -así como para construir su índice de calidad de la democracia-, los autores toman "como punto de partida el índice de FH [Freedom House], incorporando nuevos indicadores para cubrir los elementos no incluidos" (Levine y Molina, 2007: 34). Estos "nuevos indicadores" se refieren a "respuesta a la voluntad popular, participación electoral, representatividad de los cuerpos legislativos, nivel de recursos cognitivos, tolerancia o responsabilidad social" (Levine y Molina, 2007: 34). Sin embargo, el mayor peso recae en el índice de Freedom House, que con sus 25 elementos cubre la mayor parte de los temas incluidos en la medición de los autores ${ }^{52}$. Con este conjunto de elementos, construyen un índice agregado, que al ser aplicado -y como lo anotan los mismos autores (Levine y Molina, 2007: 38)- arroja resultados muy similares al de Freedom House.

Al aplicar este índice a 18 países latinoamericanos, Bolivia, Ecuador y Perú aparecen en posiciones que se sitúan debajo de la media, que es de 76,0. Así, Perú se encuentra en el noveno lugar con un puntaje de 75,4 (en una escala máxima de 100), Bolivia en el decimoprimero con 70,3 y Ecuador en el decimoquinto con 68,9. Estos puestos no cambian si se toma como referencia únicamente a los puntajes de Freedom House, pero sí varían cuando se consideran los otros indicadores que utilizan los autores, lo que constituye una expresión de la importancia que tiene aquel componente en el índice final ${ }^{53}$. Como conclusión se puede decir que, según este índice, los tres países tienen democracias de baja calidad o deficitarias. Sin embargo, de la misma manera que se vio con el índice de Altman y Pérez-Liñán, no se puede ir más allá en el análisis.

\footnotetext{
${ }^{52}$ A los 25 temas de Freedom House, los autores añaden 8 propios de ellos y al mismo tiempo introducen algunos correctivos en los primeros, sobre todo en los que tienen un sesgo ideológico que perjudica a los gobiernos de izquierda (Levine y Molina, 2007: 36-37).

${ }^{53}$ A manera de ejemplo, en participación electoral Perú ocupa el tercer lugar, Ecuador el octavo y Bolivia el decimoprimero, en la proporcionalidad de la representación de partidos en la legislatura nacional, Bolivia se sitúa en el octavo lugar, Perú en el noveno y Ecuador en el decimosegundo.
} 
Gráfico No 9

Ubicación de los tres países según el índice de calidad de la democracia de Levine y Molina

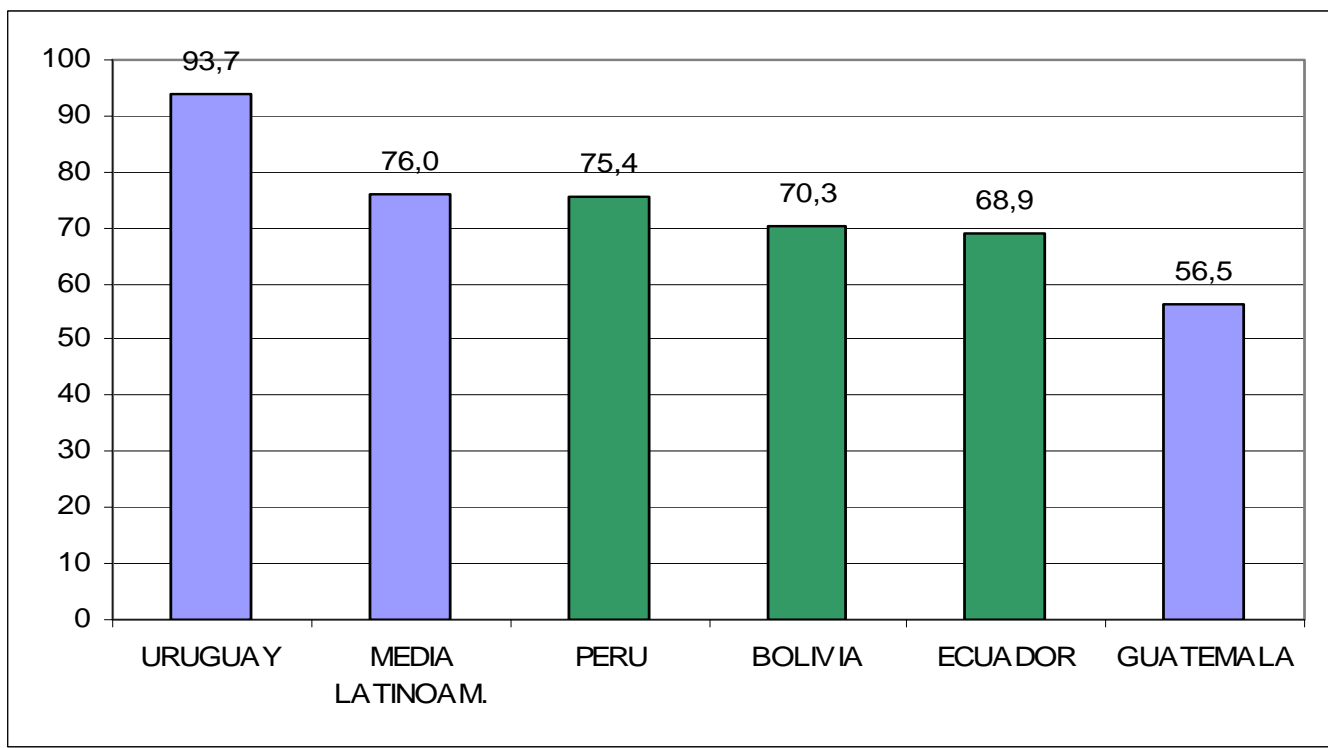

Fuente: Levine y Molina (2007). Elaboración: Simón Pachano

Dentro de una visión comparativa, cada una de estas dos mediciones presenta resultados muy diferentes. Solamente seis de los dieciocho países ocupan los mismos lugares en ambas tablas, y tres de esos seis corresponden a los primeros lugares (Uruguay, Chile y Costa Rica), uno al último lugar (Guatemala) y dos a países que ocupan diversos lugares de la tabla (Argentina en el quinto puesto y Nicaragua en el decimosegundo). Así mismo, la media varía considerablemente, ya que es de 71,6 en Altman y Pérez-Liñán (ajustada a escala de 0 a 100) y de 76,0 en Levine y Molina ${ }^{54}$. Por otra parte, algunos países se mueven más de 10 lugares entre ambas tablas, como es el caso de México, que ocupa el puesto 17 en la medición Altman y Pérez-Liñán y el 6 en la de Levine y Molina, o de Venezuela que se encuentra en los puestos 6 y 16, respectivamente. Casos menos extremos, pero no por ello menos importantes, son los de Ecuador, que ocupa los puestos 7 y 15, Panamá que aparece en los puestos 11 y 4 y Honduras que se sitúa en el 8 y el 14, en las mediciones Altman y Pérez-Liñán y de Levine y Molina, respectivamente en cada caso.

\footnotetext{
${ }^{54}$ La variación interna de los datos no difiere significativamente entre ambas mediciones si se considera que la desviación estándar es de 11,4 y 10,8 en las de Altman y Pérez-Liñán y Levine y Molina, respectivamente.
} 
Es probable que estas diferencias (que se aprecian en el cuadro número 1 y en el gráfico 10) obedezcan en buena medida a que cada una de estas mediciones trabaja con información correspondiente a distintos años, ya que en el un caso las cifras corresponden al período 1978-1996 (Altman y Pérez Liñán, 2002: 92), mientras en el otro son cifras correspondientes aproximadamente a los años 2004-2006 (Levine y Molina, 2007: 39). Pero, también se puede suponer que se deben -seguramente en mayor medida que a las causas temporales señaladas- a las dimensiones seleccionadas para cada medición. Sin embargo, en principio esa no debería ser una razón para obtener resultados tan diferentes ya que se supondría que ambas están midiendo al mismo objeto. Pero, ese supuesto no es válido, ya que es evidente que cada una de ellas mide un objeto diferente y además utiliza unidades de medida sustancialmente distintas. Aunque ambas sostienen que el objeto de su medición es la calidad de la democracia, en realidad cada una ha construido previamente un objeto diferente o específico. Es verdad que las dos toman como punto de partida a un concepto mínimo de democracia, pero de inmediato se distancian, especialmente desde el momento que construyen las dimensiones sobre las que realizarán la medición. Como se vio, Altman y Pérez-Liñán seleccionan solamente tres dimensiones (derechos civiles, participación efectiva y competencia efectiva), en tanto que Levine y Molina establecen seis dimensiones (decisión electoral, participación, representatividad, responsabilidad, respuesta a la voluntad popular, soberanía). Ambos acuden al índice de Freedom House, que adquiere enorme peso proporcional en cada uno, pero no es interpretado de la misma manera (o no está utilizado para el mismo fin). 
Cuadro $\mathrm{N}^{\mathrm{o}} 1$

Ranking de países latinoamericanos según índices de calidad de la democracia de Altman y Pérez-Liñán y Levine y Molina

\begin{tabular}{|l|c|c|}
\hline \multicolumn{1}{|c|}{ País } & Altman y Pérez-Liñán & Levine y Molina \\
\hline URUGUAY & $89,8(1)$ & $93,7(1)$ \\
\hline CHILE & $88,4(2)$ & $92,3(2)$ \\
\hline COSTA RICA & $87,9(3)$ & $92,1(3)$ \\
\hline PANAMA & $69,9(11)$ & $86,2(4)$ \\
\hline ARGENTINA & $80,6(5)$ & $82,9(5)$ \\
\hline MEXICO & $53,7(17)$ & $82,5(6)$ \\
\hline REP. DOMINIACANA & $73,5(9)$ & $82,1(7)$ \\
\hline BRASIL & $81,2(4)$ & $76,4(8)$ \\
\hline PERU & $64,6(13)$ & $75,4(9)$ \\
\hline EL SALVADOR & $62,0(14)$ & $74,4(10)$ \\
\hline BOLIVIA & $72,5(10)$ & $70,3(11)$ \\
\hline NICARAGUA & $66,2(12)$ & $69,0(12)$ \\
\hline PARAGUAY & $60,9(15)$ & $69,3(14)$ \\
\hline HONDURAS & $75,3(8)$ & $68,9(15)$ \\
\hline ECUADOR & $75,9(7)$ & $67,8(16)$ \\
\hline VENEZUELA & $77,4(6)$ & $56,9(17)$ \\
\hline COLOMBIA & $57,4(16)$ & 76,0 \\
\hline GUATEMALA & $51,0(18)$ & 71,6 \\
\hline Media & $2(18)$ \\
\hline
\end{tabular}

Fuente: Altman y Pérez-Liñán (2002), ajustado a escala de 0 a 100; Levine y Molina (2007). Elaboración: Simón Pachano. Los números entre paréntesis indican la posición que ocupa en el ranking correspondiente.

En términos estrictos, cada una de estas mediciones entiende a su propia manera el concepto de calidad de la democracia. Esa comprensión diferente está dada en parte por el número de dimensiones que se someten a la medición, pero sobre todo por el carácter de éstas. Es evidente que un mayor número de dimensiones permitirá mejores mediciones, en tanto incluirá más atributos de la democracia, pero ese criterio tomado de manera aislada no será suficiente para considerar que una medición será mejor que otra. La confiabilidad de una medición se encuentra fundamentalmente en los contenidos de las dimensiones que se utilizan, en la manera de comprender a cada una de ellas y, con mucha importancia también, se asienta en los indicadores que se seleccionan para la 
respectiva medición ${ }^{55}$. Estos aspectos vienen a ser tan importantes como la definición de los atributos de la democracia.

\section{Gráfico $\mathbf{N}^{\circ} 10$}

Ubicación de los países latinoamericanos según mediciones de calidad de la democracia de Altman y Pérez-Liñán y Levine y Molina

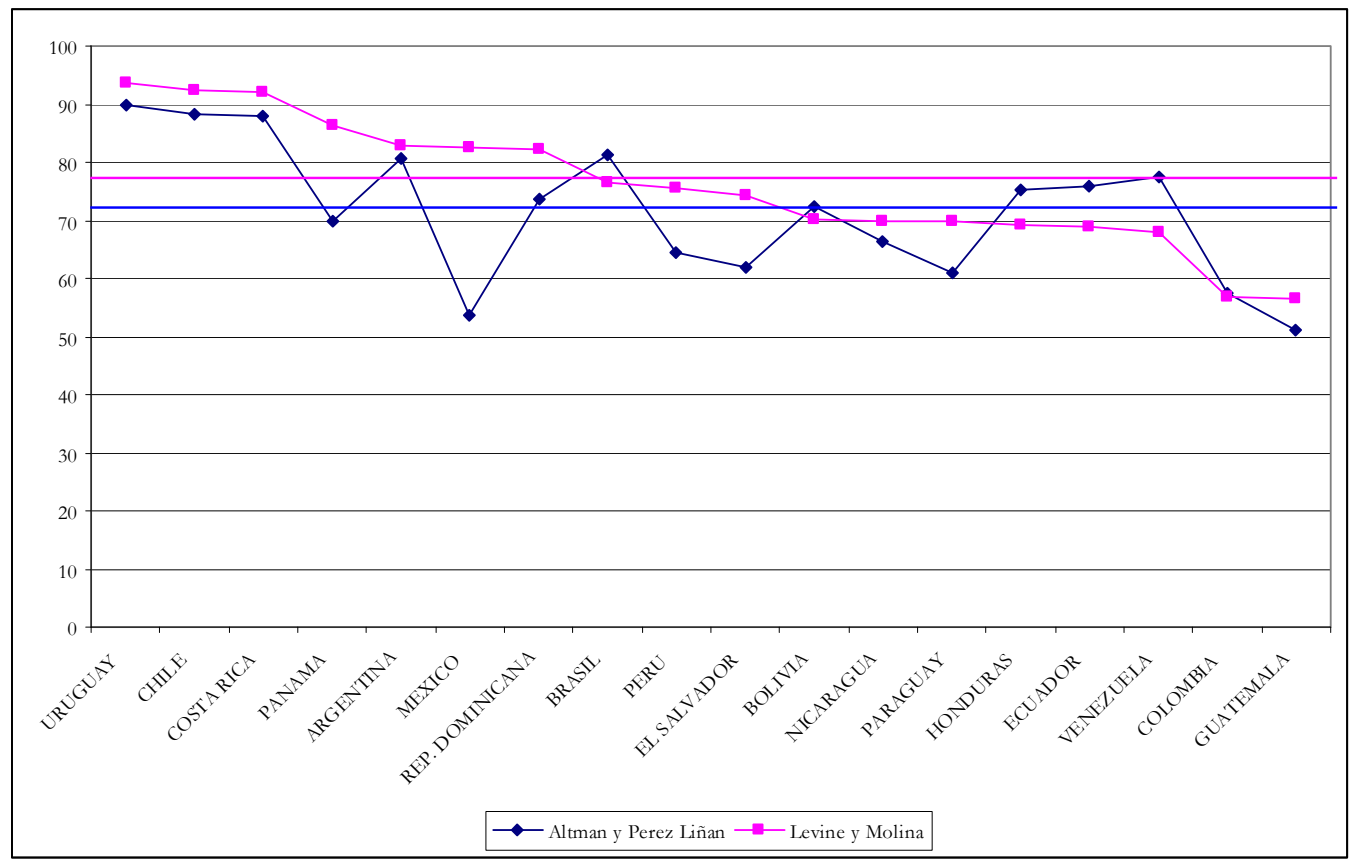

Fuente: Altman y Pérez-Liñán (2002), ajustado a escala de 0 a 100; Levine y Molina (2007). Elaboración: Simón Pachano

En este punto considero necesario regresar al tema de la capacidad explicativa de este tipo de medición, un aspecto al que me he referido brevemente en las páginas anteriores. Es innegable que un índice puede ser muy útil para la construcción de un ranking y, a partir de éste, para conocer las posiciones relativas de los países en un determinado contexto general (en este caso en un conjunto seleccionado de países latinoamericanos). Así mismo, es muy útil para apreciar los cambios a lo largo del tiempo, de manera que se puede hacer el seguimiento del comportamiento de un determinado país o de un conjunto de ellos en un periodo determinado. Finalmente, estos índices permiten hacer un seguimiento y un balance -en caso de que se cuente con series temporales- de la

\footnotetext{
${ }^{55}$ Un ejemplo concreto de esto es que el índice de Levine y Molina aparece como más completo que el de Altman y Pérez-Liñán, ya que al contar con mayor número de dimensiones hace posible la identificación de múltiples factores que determinan la ubicación final de los países en el ranking. Sin embargo, esta ventaja se reduce significativamente por el enorme peso que tiene uno solo de esos factores -la medición de Freedom House- en su índice final, lo que, como he señalado antes, minimiza la incidencia de las otras dimensiones. Por tanto, las ventajas del mayor número se han visto mermadas por el contenido asignado a las dimensiones y por los indicadores utilizados dentro de cada una de estas.
} 
evolución de sus diversos componentes, de manera que se pueda apreciar los efectos que se desprenden de los cambios en cada uno de ellos. Pero, me parece que hasta allí llega la utilidad de un índice y no se puede esperar que entregue más información. Ese es un primer límite de los índices, pero hay tres restricciones adicionales que son más importantes y que no pueden ser pasadas por alto.

Se trata, en primer lugar, de la inconveniencia de reducir toda la complejidad de las múltiples dimensiones que constituyen la calidad de la democracia a una cifra única. Al hacerlo se pierde gran parte de la capacidad explicativa, ya que se diluye el aporte de cada una de esas dimensiones. A pesar de que se puede identificar ese aporte por medio del análisis aislado de cada una de las variables, como lo hacen los autores mencionados (Altman y Pérez-Liñán, 92; Levine y Molina, 2007: 39), el índice final solamente expresa diferencias agregadas que pueden ocultar aspectos muy importantes de cada una de las dimensiones sujetas a medición. La utilización aislada de un índice de esta naturaleza no deja ver los avances y retrocesos en cada una de las dimensiones. El índice en sí mismo no da cuenta de los elementos que determinan la posición de cada país dentro de la escala y tampoco de las causas de las diferencias entre los países ${ }^{56}$.

En segundo lugar, detrás de la utilización de este tipo de índices está siempre presente el riesgo de endogeneidad que ya he señalado. En las dos mediciones reseñadas se encuentran rasgos de ese problema, especialmente por la utilización de índices previos, como el de Freedom House, que incluyen algunas de las dimensiones que después son tratadas como elementos independientes, o de indicadores que aparecen en más de una dimensión, como los que aluden a la participación electoral. Ciertamente, este problema se podría solucionar por medio de la utilización de indicadores menos agregados y con un mejor control al respecto, pero de todas maneras existe el riesgo de llegar a formulaciones de carácter circular.

\footnotetext{
${ }^{56}$ Adicionalmente, el peso de cada uno de los componentes depende de la ponderación asignada, lo que debe ser cuidadosamente observado a la hora de valorar su incidencia sobre el total y, de manera especial, al analizar cada uno de ellos aisladamente. Como ya señalé antes, este es uno de los problemas que se encuentra en la propuesta de Altman y Pérez-Liñán, que asigna similar peso a cada una de las dimensiones. Esta es una observación que se puede hacer extensiva a la propuesta de Levine y Molina, que apenas introduce mínimos elementos de ponderación de sus indicadores y que sobredimensiona el aporte del índice de Freedom House (Levine y Molina, 2007: 34-38)
} 
En tercer lugar, este tipo de medición no recoge la incidencia de otros aspectos que afectan de manera fundamental a la calidad de la democracia, como el desempeño de las instituciones, el tipo de régimen o el papel de los partidos políticos. Obviamente, la solución consistiría en incluir estas dimensiones, pero con ello se elevaría el riesgo de endogeneidad y de establecer relaciones circulares, ya que se trataría de indicadores extremadamente agregados. Además -y por encima de cualquier otra consideración-, son dimensiones que por su gran complejidad no pueden ser reducidas a un solo indicador que a su vez sirva para construir un índice final ${ }^{57}$. Tratar de hacerlo de esa manera significaría sacrificar la profundidad del análisis en aras de la obtención de un instrumento que, como se ha visto, apenas puede ofrecer una información muy limitada del fenómeno que se intenta analizar. Por consiguiente, este tipo de medición termina por sacrificar aspectos que son sustanciales para evaluar la calidad de la democracia ${ }^{58}$.

Como trasfondo de estos problemas propios de la medición de la calidad de la democracia se encuentra el debate acerca de las bondades y las limitaciones de los acercamientos cuantitativos. Es innegable que la calidad de la democracia puede ser abordada por este tipo de estudios, pero siempre es necesario considerar las limitaciones que ellos tienen, especialmente por el carácter complejo de cada una de las dimensiones que deben ser sometidas a evaluación. Son dimensiones que difícilmente pueden ser reducidas a un solo indicador sin sacrificar una gran parte de su complejidad. Aspectos como las libertades civiles, la tolerancia, la vigencia de los derechos ciudadanos e incluso otras que tienen un carácter menos abstracto y por tanto más fáciles de materializar en indicadores, como las relacionadas con los procesos electorales, están conformados por una cantidad de componentes que se pierde cuando son reducidos a un indicador. Además, la cuantificación de esas dimensiones tiene siempre una alta carga de subjetividad e incluso puede tener un sesgo ideológico (como sucede con los indicadores de Freedom House referidos a los aspectos económicos). Finalmente, a esta subjetividad se debe añadir la que se encuentra casi de manera inevitable en la ponderación de cada

\footnotetext{
${ }^{57}$ Los límites para la incorporación de un mayor número de dimensiones y variables en este tipo de estudios han sido destacados por algunos autores, como Morlino (2005: 13) y Beetham (2004: 6-7).

${ }^{58}$ Un llamado de atención en este sentido se encuentra en un texto que se ocupa de la calidad de la democracia desde una perspectiva diferente, cuando advierte que "los indicadores señalan varios aspectos o dimensiones de la democracia, a través de diversos derechos políticos, civiles y sociales. Esta realidad compleja no puede resumirse adecuadamente en un solo índice (...) Aunque en su conjunto pueden pintar un panorama detallado, ofrecen una visión parcial de la realidad y no agotan el significado de los conceptos medidos” (PNUD, 2004: 73)
} 
una de las dimensiones. Por ello, considero que las mediciones cuantitativas de calidad de la democracia pueden considerarse de utilidad limitada y siempre deben tomarse como instrumentos de apoyo para la evaluación cualitativa, que ofrece mejores condiciones para el análisis ${ }^{59}$.

La tercera propuesta que quiero recoger es precisamente una de carácter cualitativo, que no busca construir un índice de calidad de la democracia, sino analizarla en su complejidad. Esta sostiene que "una buena democracia ofrece a sus ciudadanos una amplia libertad, igualdad política y control sobre las políticas públicas y sobre los gestores de las políticas [policy makers], a través del funcionamiento legal y legítimo de instituciones estables" (Diamond y Morlino, 2004: 22) ${ }^{60}$. Su visión reconoce -como se vio antes- a los procedimientos, los contenidos y los resultados como los tres niveles en que se puede evaluar la calidad. Por ello sostienen que un régimen con aquellos atributos podrá satisfacer "las expectativas ciudadanas atendiendo a la gobernabilidad (calidad de los resultados); permitirá a los ciudadanos, asociaciones y comunidades disfrutar de una amplia libertad y de igualdad política (calidad del contenido); y proveerá un contexto en el cual el conjunto de la ciudadanía puede juzgar el desempeño del gobierno a través de mecanismos como las elecciones, mientras que las instituciones gubernamentales y las autoridades se controlan unas a otras (calidad de procedimiento)" (Diamond y Morlino, 2004: 22, cursivas en el original). Por tanto, desde esta perspectiva el estudio de la calidad de la democracia abarcaría no solamente un gran conjunto de sus atributos, sino que se mueve en diversos niveles.

Los autores proponen "ocho dimensiones en las cuales la democracia varía en calidad" (Diamond y Morlino, 2004: 22). Estas son el estado de derecho, participación, competencia, accountability vertical, accountability horizontal, respeto a las libertades civiles y políticas y la progresiva implementación de igualdad política (y subyacentemente, igualdad económica y social). Los autores consideran a las cinco primeras dimensiones

\footnotetext{
${ }^{59}$ Una limitación adicional de los enfoques cuantitativos (que también puede afectar en alguna media a los de carácter cualitativo), y que no constituye un asunto menor, es la escasa disponibilidad de información confiable y apta para conformar series históricas. Los ajustes que deben hacerse, en términos temporales o, más grave aún, la necesidad de adaptar a los propios objetivos indicadores y mediciones que han sido construidos para otros fines, tienden a hacerlos poco confiables.

${ }^{60}$ De manera complementaria a esta defnición, uno de los autores sostiene que "puede decirse que una buena democracia es una que presenta una estructura institucional estable que realiza la libertad y la igualdad de los ciudadanos a través del funcionamiento legítimo y correcto de sus instituciones y mecanismos (Morlino, 2004: 12, cursiva en el original).
} 
como procedimentales o como relacionadas con las reglas y las prácticas, en tanto que a las dos siguientes les atribuyen carácter sustantivo. La última es un puente entre ambos tipos (Diamond y Morlino, 2004: 22) ${ }^{61}$. A su vez, cada una de estas dimensiones puede variar por las formas institucionales y por el grado de desarrollo, manteniendo fuertes lazos e intercambios y tensiones entre ellas, de manera que se configura una propuesta de naturaleza multidimensional (Diamond y Morlino, 2004; 22). Sin embargo, los autores destacan la dimensión de su enfoque -y en general de los diversos acercamientos a este tema- cuando señalan "no hay una vía objetiva para construir un esquema de calidad de la democracia correcto y válido para todas las sociedades" (Diamond y Morlino, 2004; 22).

La dimensión estado de derecho está entendida, en este propuesta, como la igualdad ante la ley, la cual es pública, conocida universalmente, estable, no retroactiva y es aplicada limpia y consistentemente por un sistema judicial independiente. Lo que hace democrático a un estado de derecho es que "el sistema legal defiende los derechos políticos y los procedimientos democráticos, conserva los derechos civiles de los individuos y refuerza la autoridad de otras instituciones de accountability horizontal que aseguran la legalidad de las acciones de las autoridades" (Diamond y Morlino, 2004: 23). A la vez, éste constituye la base sobre la que descansan todas las demás dimensiones, y es lo que marca la diferencia con las democracias iliberales en que se desarrollan elecciones competitivas y existe participación popular, pero con considerable desorden y abuso del poder (Diamond y Morlino, 2004: 23). Por consiguiente, es el elemento que establece el punto de partida para determinar si un régimen es democrático o si se trata de una de las formas disminuidas de democracia (concretamente, de democracia iliberal).

Participación está entendida como la plena vigencia de los derechos políticos de la población adulta, incluido - pero no exclusivamente- el derecho al voto. Para ello, "una buena democracia debe asegurar que todos los ciudadanos tienen en efecto capacidad para hacer uso de esos derechos formales para influir en el proceso de toma de decisiones: votar, organizarse, reunirse, protestar y presionar por sus intereses" (Diamond y Morlino, 2004: 23). Por tanto, esta dimensión incluye no solamente el

\footnotetext{
${ }^{61}$ Creo que es cuestionable calificar como procedimental al estado de derecho, ya que es un elemento sustantivo del régimen. La afirmación de los autores, como se verá de inmediato, se explica porque no lo toman en su totalidad, como el imperio de la ley y la igualdad ciudadana, sino en tanto un conjunto de procedimientos que aseguran la vigencia de los derechos políticos.
} 
derecho al voto y su ejercicio efectivo, sino también el control a los políticos y está íntimamente relacionada con la igualdad política. Por ello, el desigual acceso a los recursos políticos puede significar la reducción e incluso la pérdida de los mismos derechos políticos (Diamond y Morlino, 2004: 23).

Competencia es una dimensión que alude básicamente a la existencia de elecciones libres y limpias, pero también a la apertura para el acceso de nuevas fuerzas a la arena electoral, así como para el acceso de los partidos y las organizaciones políticas a los medios de comunicación y a los recursos para las campañas electorales (Diamond y Morlino, 2004: 23). Se trata, por consiguiente, de la dimensión electoral, en la que desempeñan papeles de primera importancia los arreglos institucionales que hacen viable la competencia entre los diversos actores políticos y sociales (Diamond y Morlino, 2004: 23-24).

Accountability vertical "es la obligación de los líderes políticos elegidos a responder por sus decisiones políticas cuando son interpelados por los votantes o por otros cuerpos constitucionales" (Diamond y Morlino, 2004: 24). Siguiendo a Schedler, los autores destacan como atributos básicos de esta dimensión a la información, la justificación y el castigo o la compensación (Diamond y Morlino, 2004: 24). Por tanto, en esos tres niveles se expresaría la acción de control de los ciudadanos, que requiere de condiciones adecuadas para la competencia política, así como la distribución de los recursos políticos y la consecuente participación ciudadana. De esta manera, se establece una relación estrecha con las dimensiones señaladas antes, configurándose uno de los lazos, intercambios y refuerzos mencionados.

Por Accountability horizontal entienden al control que se realiza entre las instituciones democráticas, sean o no de elección popular. Así, el hecho de "que una autoridad o brazo del gobierno responde a otra, más que formar parte de una pauta regular de 'comando y obediencia', en términos gruesos se denomina accountability horizontal" (Diamond y Morlino, 2004: 24). Las instituciones propias de esta relación incluyen a la oposición legislativa, las comisiones de investigación de hechos específicos, las cortes, los organismos de control, las comisiones anticorrupción, el banco central, la administración electoral independiente, el defensor del pueblo, entre otros cuerpos que tienen la misión de investigar y controlar el poder los gobernantes (Diamond y Morlino, 2004: 25). Esta dimensión descansa en el marco legal que establece el sistema de controles y balances. 
La libertad, entendida por los autores como la primera de las dimensiones sustantivas, es vista como el conjunto de "tres tipos de derechos: políticos, civiles y sociales (o socioeconómicos)" (Diamond y Morlino, 2004: 26). Los primeros hacen posible la participación y la representación y por tanto la accountability horizontal. Los segundos requieren contar con varias de las condiciones apropiadas para la accountability horizontal y vertical y a la vez aseguran la vigencia del estado de derecho. Los últimos están entendidos como los rendimientos del sistema político, de manera que hacen referencia fundamentalmente a la evaluación de la calidad de los resultados (Diamond y Morlino, 2004: 26). Se trata, por tanto, de una de las dos dimensiones que preceden a las demás (la otra es la igualdad) y por tanto que las condicionan.

La otra dimensión sustantiva es igualdad, que también está entendida como un prerrequisito para las otras dimensiones, ya que ellas "implican o requieren (...) la igualdad política y legal de todos los ciudadanos. Una buena democracia asegura a todos los ciudadanos y grupos los mismos derechos y protección legal y, significativamente, acceso ágil a la justicia y al poder" (Diamond y Morlino, 2004: 27). El logro de esa igualdad está condicionado en gran medida por la situación social y económica de las personas, en el sentido de que grandes inequidades en la distribución del ingreso y obstáculos para el acceso a servicios básicos pueden impedir su materialización. Por consiguiente, se establece un lazo con los derechos sociales, plasmados en servicios básicos como los de educación y seguridad (Diamond y Morlino, 2004: 27) ${ }^{62}$. Por consiguiente, la igualdad política -y lo mismo se puede decir para la libertad- está fuertemente condicionada por la situación socioeconómica de los individuos, en la medida en que ésta establece los incentivos o los obstáculos para su ejercicio pleno.

La última dimensión, responsabilidad, "es equivalente a la accountability vertical (y por tanto a la participación y a la competencia), e influye en el grado en que los ciudadanos están satisfechos con el desempeño de la democracia pero también en la percepción de ésta como legítima" (Diamond y Morlino, 2004: 27). Por ello los autores la consideran como un puente entre las dimensiones procedimentales y sustantivas, como he mencionado

\footnotetext{
${ }^{62}$ La igualdad política se sitúa, en esta perspectiva, en el mismo nivel que la libertad. Por ello uno de los objetivos de la investigación empírica es "detectar el grado en el cual ellas [las dimensiones] han alcanzado los dos objetivos principales de una democracia ideal: libertad e igualdad política" (Morlino, 2004: 10)
} 
antes. Esta dimensión hace referencia a la capacidad de los gobiernos -0 en general de las instituciones democráticas- para definir y aplicar las políticas que anhelan los ciudadanos. Las condiciones que la favorecen son las mismas que requiere la accountability vertical, esto es, "una sociedad civil robusta, un sistema de partidos funcional y gobiernos que puedan traducir las preferencias, una vez agregadas, en políticas y programas" (Diamond y Morlino, 2004: 28). Adicionalmente, necesita una burocracia pública eficiente y honrada, ya que buena parte de su materialización se expresa en la capacidad de gestión de los gobiernos. A la vez, ésta tiene por lo menos tres límites. En primer lugar, el interés de los políticos por maximizar su autonomía. En segundo lugar, el carácter limitado de los recursos públicos, lo que puede reducir las opciones en la toma de decisiones. Tercero, las limitaciones a la soberanía, especialmente las que se derivan de la inserción internacional de los países, que también reducen las opciones para los gobiernos (Diamond y Morlino, 2004: 28).

A partir de estas ocho dimensiones se podrían identificar otras tantas calidades de la democracia en caso de que se tomara a cada una de ellas de manera aislada. Pero, como lo reiteran los autores -y en mi opinión ahí se encuentra uno de sus aportes más importantes-, "estas diferentes dimensiones interactúan densamente y se refuerzan unas a otras, convergiendo finalmente en un sistema. Aunque es posible identificar diferentes tipos de baja calidad de la democracia, los cuales son deficientes en diferentes cualidades, las diversas dimensiones están estrechamente ligadas y tienden a moverse juntas, ya sea hacia el mejoramiento y la profundización o hacia el descenso" (Diamond y Morlino, 2004: 2829 , cursiva mía $)^{63}$. Al considerar como un sistema al conjunto de las dimensiones se hace evidente el carácter multidimensional y complejo de la calidad de la democracia y por tanto de su evaluación. La interrelación entre las diversas dimensiones plantea un reto enorme para la investigación, ya que lleva necesariamente a abordar todas ellas y a tratarlas no solamente en conjunto sino en sus múltiples interacciones.

Dos anotaciones son pertinentes acerca de esta propuesta de análisis de la calidad de la democracia que, junto a su visión sistémica, hacen demuestran la imposibilidad de reducirla a un índice. En primer lugar, todas las dimensiones aluden a elementos propios

\footnotetext{
${ }^{63}$ Altman y Pérez-Liñán (2002: 90) abordan el tema de la correlación entre las dimensiones (obviamente sólo sobre las tres que ellos utilizan), para determinar si la calidad de la democracia es un fenómeno multidimensional o si, por el contrario, todas ellas reflejan un solo aspecto subyacente. Su índice se justifica por la correlación existente entre sus las variables analizadas.
} 
del ordenamiento político, esto es, a componentes del régimen y del sistema en los términos planteados en el capítulo I. En ese sentido, son aspectos que tienen que ver directamente con el diseño institucional y con los procedimientos que hacen posible los fines últimos de la poliarquía, esto es, la inclusión y la participación. En segundo lugar, ellos están tomados en su totalidad y no solamente en una de sus manifestaciones (como la proporción de electores, el número de escaños de los partidos o la vigencia de determinado tipo de derechos o un pequeño número de ellos). En este sentido, son variables complejas que no pueden ser reducidas a uno o, en el mejor de los casos, a algunos de sus componentes, ya que constituyen en sí mismas condiciones fundamentales y constitutivas de la democracia. Por ello, resulta muy poco probable que se las pueda reducir a indicadores simples, que expresen con una sola cifra la totalidad de cada una, mucho menos el conjunto que finalmente constituye la calidad de la democracia. De esta manera, se trata de una perspectiva radicalmente diferente a las reseñadas antes, que al buscar la construcción de un índice deben inevitablemente sacrificar esa complejidad y abordar únicamente aspectos parciales de las dimensiones (en realidad de algunas de ellas).

\section{Conclusiones}

La revisión de algunas perspectivas de análisis de la calidad de la democracia y de los dos ámbitos de estudio estrechamente ligados a ella -la medición y la identificación de los subtipos de democracia- permiten arribar a seis conclusiones generales. En primer lugar, como he insistido a lo largo de este capítulo, estos son campos en construcción, en los que se han realizado avances sustanciales pero que aún pueden ser considerados como los primeros pasos o los movimientos tentativos hacia la construcción conceptual y metodológica. Esto se hace evidente de manera especial en el campo de la calidad de la democracia, donde el único acuerdo básico que se puede identificar es el referido a la utilización de un concepto mínimo de democracia. Sin embargo, ese acuerdo alude al tipo de concepto que se debe utilizar, pero no al contenido del concepto en sí mismo. Aunque la mayor parte de autores inician su reflexión en la poliarquía de Dahl, no todos ellos escogen similares atributos ni le otorgan el mismo peso a cada uno de ellos. Este carácter incipiente y tentativo de la construcción conceptual lleva a que bajo la calificación de calidad de la democracia se cobijen múltiples perspectivas. Por ello, mientras no existan acuerdos en torno a los conceptos fundamentales, se deberá aceptar que cualquier 
referencia a la calidad de la democracia será en realidad una alusión a una de las formas bajo las cuales ésta se concibe, no a una concepción única. En ese sentido cabe hablar de teorías de la calidad de la democracia, en plural, antes que de una teoría única y compartida por la comunidad académica.

En segundo lugar, es evidente la indiferencia por el concepto de calidad. La mayor parte de estudios no se preocupan de hacer explícita su noción de calidad, con lo que todo un componente fundamental de la construcción teórico-conceptual queda implícito y, por tanto, sujeto a múltiples interpretaciones. La excepción en este aspecto se encuentra en el enfoque de Diamond y Morlino, que hacen una formulación clara y operativa al respecto, pero en el resto de la literatura se deja todo el peso en la definición de las dimensiones con las que se va a realizar la evaluación. Estas se convierten a la vez en las variables a medir y en los parámetros con los que son medidas, lo que constituye un serio problema de carácter metodológico. Para evitarlo es necesario prestar atención a la calidad en sí misma, a su significado y a su función dentro de la evaluación de la democracia.

En tercer lugar, es posible sostener que las perspectivas cuantitativas presentan grandes limitaciones y que solamente pueden entregar una visión parcial y reducida de una realidad mucho más compleja, como es la calidad de la democracia. Esa complejidad y la densidad de las dimensiones sujetas al análisis hacen poco viable la reducción a indicadores únicos de carácter cuantitativo. Si bien es cierto que éstos -y en general la medición cuantitativa- tienden a hacer operativas las dimensiones, también es verdad que esa operación deja más dudas que confianza. Hay una serie de pasos necesarios para llegar a este ese punto, y en cada uno de ellos se deben tomar decisiones que -por el nivel en que se encuentra la teoría- quedan sujetos a los criterios o a los valores del investigador. Desde la selección de las dimensiones hasta la ponderación de los indicadores, pasando por la definición de las variables que se someterán a la medición, son pasos que por largo tiempo seguirán expresando una búsqueda más que acuerdos teóricos y conceptuales dentro de la comunidad académica. Adicionalmente, los resultados de la medición o de la cuantificación no demuestran ser mejores que los obtenidos por medio del análisis cualitativo. Por el contrario, al reducir las dimensiones a un pequeño número de indicadores y, finalmente, la calidad de la democracia a un índice único, sacrifican la riqueza explicativa. Como he señalado antes, se los debería utilizar siempre como complemento de los estudios cualitativos, mas no como sus sustitutos. 
En cuarto lugar, son significativos los avances logrados en los tres ámbitos de análisis reseñados en este capítulo (subtipos, medición y calidad), pero es necesario buscar mayor integración entre ellos. Aunque existe cierto vínculo entre la medición y los estudios de calidad, éste sigue siendo relativamente débil y reducido a un pequeño número de autores. Una mayor vinculación entre ellos podría ayudar a superar las limitaciones de los estudios cuantitativos y los fortalecería a ambos. Así mismo, es necesario integrar (como lo hacen algunos de los autores revisados) los hallazgos obtenidos en el estudio de los subtipos o de las democracias disminuidas dentro de los estudios de calidad de la democracia. El primer ámbito permite identificar situaciones específicas o -para decirlo en términos de la visión espacial que ofrecen los gráficos presentados- ubicaciones particulares de los regímenes dentro del continuo autoritarismo-democracia. Esa ubicación, y la correspondiente identificación del tipo disminuido, son fundamentales porque permiten identificar las carencias de cada uno de ellos y por tanto los factores que determinan la mayor o menor calidad de la democracia de cada caso en concreto. La identificación de subtipos debe ser un elemento básico para el estudio de la calidad de la democracia, lo que se puede lograr al establecer un diálogo permanente y fluido entre ambos ámbitos de reflexión.

En quinto lugar, los avances logrados en el estudio de la calidad de la democracia no han tenido un correlato en la indagación de las causas que determinan su mayor o menor grado. Ha habido notables avances en la explicación del resultado final, pero muy poco o nada se ha avanzado en la identificación de los orígenes. Se puede decir, en consecuencia, que se ha avanzado mucho en el conocimiento de la variable dependiente, pero se ha dejado de lado las variables independientes. Al aplicar los instrumentos teóricos y conceptuales disponibles en este momento a un caso concreto, se puede sostener que su democracia es de menor calidad porque las elecciones no son libres o porque existen violaciones evidentes al derecho de acceso a la información plural, pero eso no lleva necesariamente a la identificación de los factores institucionales y procedimentales que determinan que así sea. No se conoce, a manera de ejemplos, la incidencia del tipo de régimen, de las relaciones entre las funciones del estado, del sistema de partidos o del sistema electoral sobre la calidad de la democracia. Los estudios de calidad tienen una deuda en ese aspecto. 
En sexto lugar y ligado a lo anterior, es imprescindible bajar el nivel de abstracción de los estudios, desde las dimensiones de la democracia a los componentes del régimen y del sistema político, como las relaciones entre los poderes, los partidos políticos y las prácticas de los actores. El nivel en que se mantienen actualmente los estudios es muy útil para comprender las características generales de la democracia y para profundizar en el análisis de cada una de sus dimensiones, pero no ofrece las mismas facilidades para el estudio de esos aspectos más concretos y que sin duda son determinantes en la determinación del grado de calidad. Es necesario encontrar el puente teórico, conceptual y metodológico que una a la reflexión sobre la calidad con los componentes del régimen y del sistema. Se requiere contar con respuestas acerca de la incidencia de un sistema electoral proporcional, de un régimen presidencial, de un sistema de partido hegemónico, en fin, de las múltiples expresiones concretas de los componentes del régimen y el sistema. Esto abre un campo de investigación poco explorado hasta el momento, pero de enorme valor para la búsqueda de explicaciones. Es un campo que debe conformarse como un espacio de menor nivel de abstracción que la reflexión sobre la calidad de la democracia -que se mueve en las grandes dimensiones-, pero que debe formar parte de ese mismo cuerpo teórico.

Por último, cabe reiterar que los análisis de calidad de la democracia demuestran que existe una relación de interdependencia entre todos los componentes que se someten a evaluación y que constituyen el elemento central del análisis. Aunque cada uno de ellos expresa condiciones específicas y alude a condiciones y atributos particulares, es evidente que entre ellos se produce una relación de mutuo condicionamiento y de interacción. Por ello, cuando uno varía lo hace también el conjunto, no solamente por la incidencia de aquel en términos de elemento constitutivo, sino por las interrelaciones que guarda con los demás. Son relaciones que están determinadas por los componentes básicos de la democracia, y que pueden expresarse por medio de la estrecha relación que existe entre los diversos tipos de derechos (especialmente civiles y políticos). El mutuo condicionamiento es un hecho que aparece en cualquier análisis o evaluación, de manera que resulta poco adecuado el aislamiento de uno de ellos en aras de la simplificación o de cualquier otro objetivo de similar naturaleza. Por el contrario, conviene tener presente que el estudio de la calidad de la democracia será siempre complejo y que la simplificación no se expresará en un mejor resultado final. 
Capítulo V

Una conclusión incierta: la calidad de la democracia en Bolivia, Ecuador y Perú 


\section{Resumen}

En este capítulo presento las conclusiones del estudio. En una breve síntesis intento comprender tres aspectos fundamentales. Primero, el grado alcanzado por la calidad de la democracia en cada uno de los tres países. Segundo, la manera en que los elementos institucionales han incidido sobre la calidad de la democracia. Tercero, la posible incidencia de otros factores, como las relaciones particularistas y la presencia de poderosos actores con poder de veto.

\section{Introducción}

La revisión de los procesos vividos en Bolivia, Ecuador y Perú desde la perspectiva de la calidad de la democracia permite llegar a tres conclusiones básicas. En primer lugar, a lo largo de las últimas tres décadas -con la excepción del período füimorista en Perú-, en los tres países se han conformado regímenes que se encuentran dentro del campo de las democracias políticas o de las poliarquías, pero las carencias o los vacíos en varios de sus atributos obligan a considerarlos como formas disminuidas, como democracias que requieren de algún tipo de adjetivo y que presentan problemas de calidad. En segundo lugar, aún manteniéndose en el campo de las poliarquías, aquellos regímenes han sufrido cambios constantes, han avanzado o han retrocedido en su condición de democracias, lo que significa que existieron elementos determinantes para producir esos cambios. En tercer lugar, la revisión conceptual y su aplicación en el estudio comparado de los tres países demuestran que existen avances significativos en términos teóricos, conceptuales y metodológicos, pero a la vez que lo realizado hasta el momento no entrega todas las herramientas necesarias para el análisis empírico de la calidad de la democracia y que aún falta mucho camino por recorrer en esta materia.

Las dos primeras conclusiones demuestran la necesidad de contar con elementos clasificatorios de los tipos de régimen, no sólo para conocer sus características, sino sobre todo parar comprender los cambios que se producen en ellos. A su vez, esta necesidad se enlaza con otra que surge de la tercera conclusión, y es que el grado de avance de la teoría es muy útil para estudios de un gran conjunto de países (un $\mathrm{N}$ grande), pero no es adecuado para el análisis en profundidad que requiere el estudio comparativo. La construcción teórica y conceptual permite identificar las grandes dimensiones de la calidad de la democracia con sus respectivos atributos, lo que constituye un gran paso en términos de la identificación de los elementos fundamentales. Sin embargo, no cuenta con los elementos suficientes para explicar las causas que producen las diferencias en el 
grado alcanzado en cada una de las dimensiones, y mucho menos para explicar los cambios de régimen e identificar los factores que los provocan. Por ello, se puede sostener que la teoría de la calidad de la democracia tiene, por el momento, dos características que constituyen serias limitaciones. Primera: es una teoría que abarca solamente los aspectos generales, las grandes dimensiones y que, por consiguiente, no puede explicar los factores desencadenantes de los propios fenómenos que estudia. Segunda: es una teoría estática, que puede explicar situaciones o momentos específicos pero no los procesos que van constituyendo esos procesos.

Con estos elementos, el estudio comparado de la calidad de la democracia en los tres países no podría avanzar más allá de lo límites impuestos por el desarrollo teórico y conceptual. Pero, al mismo tiempo, la revisión de los procesos políticos vividos en ellos a lo largo de las últimas tres décadas -así como la contraposición con las perspectivas conceptuales- permite formular algunas propuestas para superar aquellas limitaciones. Básicamente, considero que es conveniente y necesario superar el nivel de generalidad en que se ha mantenido la teoría y buscar los elementos más concretos y operacionales que constituyen los elementos explicativos de los problemas tratados. Ese es el objetivo de estas conclusiones, que inevitablemente tienen un carácter tentativo y no eliminan la incertidumbre.

\section{Instituciones y calidad de la democracia}

Para iniciar ese camino considero necesario repetir la primera conclusión, que no es sino la repetición de lo expresado al inicio del capítulo $V$, en el sentido de que ninguno de sus regímenes -con la anotada excepción peruana- puede ser calificado como autoritario, lo que significa que se sitúan en el espacio de la democracia. Pero, como se vio a lo largo de ese capítulo, ese es un espacio bastante amplio -una larga línea si se piensa en un continuo-, de manera que no se puede suponer una ubicación única o automática. En otras palabras, que un régimen no sea autoritario no significa que deba ser considerado ipso facto como una democracia plena. Las posibilidades de esa ubicación son múltiples y dependen de la combinación de varios factores. Eso es precisamente lo que muestra la realidad de los tres países, ya que cumplen en diversos grados las condiciones de la poliarquía pero no se puede asegurar que lo hacen en su totalidad. En consecuencia, son formas de democracias que deben ser explicadas. 
Esta es, sin duda, una constatación importante, ya que demuestra que la clasificación del tipo de régimen es uno de los problemas centrales que se presentan en las nuevas democracias y en las que han sufrido retrocesos en su institucionalización ${ }^{1}$. El optimismo de buena parte de la literatura de la transición debió ceder espacio a una visión más realista en la medida en que se constataba que las nuevas poliarquías no se dirigían necesariamente en la dirección armónica que se deriva del equilibrio entre los avances en la liberalización y en la participación, como sugiere el esquema de Dahl (1989: 18). La realidad -en especial la latinoamericana- demostró que pueden desviarse no sólo en uno de los dos sentidos que previó este autor (hacia las oligarquías competitivas o hacia las hegemonías representativas), sino hacia cualquiera de las muchas combinaciones que pueden configurarse entre las dos dimensiones básicas². Así mismo, demostró que esas formas pueden ser bastante estables y, de esa manera, tienen capacidad para perdurar a pesar de sus propias debilidades internas.

Sin embargo, esa constatación no es suficiente para comprender a cabalidad las características de esos regímenes. Ella debe estar acompañada de la identificación de las causas que llevan a esa situación. Así, la revisión de las condiciones vigentes en los tres países lleva a concluir que se cumplen varios de los requisitos de la poliarquía, especialmente los que hacen relación a los procedimientos electorales y a las condiciones básicas asociadas a ellas, incluida la vigencia de los derechos políticos. Pero son democracias que muestran gran déficit tanto en la vigencia plena de los derechos civiles como en los procedimientos políticos de toma de decisiones y de procesamiento de los conflictos. En cuanto a lo primero, como se vio en el capítulo I, son democracias con débiles estados de derecho, lo que equivale a decir que en ellas no se ha podido materializar en su plenitud la ciudadanía civil. Por su parte, en lo que respecta a lo segundo, en el capítulo III se pudo apreciar los problemas que han enfrentado los tres países en el procesamiento de los conflictos políticos, cuya expresión más clara ha sido el

\footnotetext{
${ }^{1}$ Como se vio en su momento, la clasificación de los tipos de régimen proviene de otras corrientes teóricas que solo ocasionalmente están vinculadas con la preocupación por la calidad de la democracia. La vinculación entre ambas es un paso necesario y fundamental, que solamente ha sido dado por escasos autores (Diamond, 2002; Morlino, 2004; Munck, 2007a; 2009).

${ }^{2}$ Las diversas perspectivas de análisis sobre las democracias disminuidas o los subtipos de régimen democrático, revisadas en el capítulo IV, constituyen sin duda uno de los aportes más significativos realizados en gran medida a la luz de la experiencia latinoamericana. Todos ellos pueden ser vistos como un desarrollo de la propuesta de Dahl, de la cual parten implícita o explícitamente.
} 
constante irrespeto o desconocimiento de los procedimientos democráticos. En diversos momentos, los gobiernos, los órganos legislativos, las entidades de control y los organismos electorales han entrado en conflicto y, para superarlo, han sobrepasado los límites establecidos constitucional y legalmente para su acción. Adicionalmente, en muchas ocasiones -especialmente frente a problemas económicos y a conflictos socialeslos presidentes tomaron medidas que no correspondían a sus atribuciones.

Se trata, por consiguiente, de dos fuentes de deterioro de la calidad de la democracia. La primera hace referencia fundamentalmente a la debilidad del estado de derecho, en particular a los obstáculos que se presentan para la constitución de la ciudadanía civil, esto es, para la igualdad jurídica de las personas. Por consiguiente, se sitúa fundamentalmente en el nivel del régimen. La segunda alude a la manera en que se desempeñan las instituciones y en que se procesa la política. Por tanto, se sitúa específicamente en el nivel del sistema político. La primera puede explicarse básicamente por causas históricas y estructurales, a las que aludí en la primera sección del capítulo I. La exclusión jurídica - pero también económica y social- de amplios sectores de la población fue una constante desde el inicio de la historia republicana de los tres países y recién comenzó a superarse parcialmente con el inicio de los procesos de democratización hacia el fin de la década de 1970 o al comienzo de la siguiente. Por tanto, en este aspecto se hacen evidentes las causas que inciden en la calidad de sus democracias, y en esa medida no constituyen un problema a resolver por parte de un estudio como el presente. Las formas históricas de exclusión social, económica y política son los elementos explicativos de las deficiencias en la calidad de la democracia en ese campo.

Pero no ocurre lo mismo en el otro aspecto, el de los procedimientos políticos. Aunque pueda caberle un papel a la herencia histórica, no es posible asentar en ella todo el peso de la explicación, ya que varios hechos vividos en estos mismos países demuestran que, como se vio en el capítulo III, bajo ciertas condiciones se logran significativos avances en el respeto a los procedimientos democráticos y en el procesamiento adecuado de los conflictos políticos. Por consiguiente, el paso fundamental en este aspecto es la identificación de las condiciones que hacen posible la plena vigencia de los procedimientos democráticos $-\mathrm{o}$ que, por el contrario, los obstaculizan-, lo que inevitablemente significa descender en la escala de abstracción en un doble sentido. En 
primer lugar, en términos del objeto de análisis, que se desplaza desde los aspectos normativos del régimen político a los aspectos más concretos del sistema político, esto es, a las instituciones y a las prácticas de los actores políticos. En segundo lugar, en términos de la dimensión temporal, que pasa desde la visión histórica de los grandes procesos a la perspectiva más acotada de los hechos políticos de corta duración.

Este descenso en la escala de abstracción o en el nivel de análisis obliga a poner atención en el juego político concreto, en el que intervienen sustancialmente dos elementos: el marco institucional y las decisiones estratégicas de los actores. Como he destacado en el capítulo III, entre ambos existe una interacción permanente y de mutua incidencia, que a la vez tiene efectos sobre las condiciones generales en que se desarrolla la democracia. Por ello, considero que es necesario privilegiar el análisis de los aspectos procedimentales, ya que es allí en donde se encuentran las causas de los problemas de calidad de la democracia que requieren ser explicados (siempre en la que he identificado como la segunda fuente de deterioro de la calidad de la democracia, no de la que alude al estado de derecho). Para entrar en este campo volveré sobre las condiciones institucionales reseñadas y analizadas en los tres primeros capítulos y las vincularé con la reflexión sobre la calidad de la democracia y sobre los tipos de democracias disminuidas realizada en el capítulo IV. El objetivo final es comprender la incidencia de aquellos factores -tanto institucionales como de acción política- sobre la calidad de la democracia. Al mismo tiempo, me interesa evaluar la capacidad explicativa de los diversos acercamientos al estudio de la calidad de la democracia, específicamente en este campo, mas no en todo el conjunto de aspectos que abordan los diversos autores. Sin dejar de reconocer la importancia de esas otras dimensiones -especialmente de las relacionadas al estado de derecho-, considero necesario concentrar el análisis en los de carácter institucional debido a que han recibido menor atención en la construcción conceptual y porque considero que allí se pueden encontrar explicaciones valederas acerca de los tres países.

El análisis de las condiciones institucionales de los tres países, desarrollado en el capítulo III, estuvo guiado por dos premisas que es necesario retomar en estas conclusiones. Por una parte, los arreglos institucionales condicionan las prácticas y las conductas de los actores políticos y sociales (a la vez que están influidas por ellas). Por otra parte, la calidad de la democracia depende en buena medida del diseño institucional tanto en el 
nivel del régimen como del sistema. Ambas premisas se pueden rastrear en los diversos autores que se ocupan del estudio de la calidad de la democracia, que las incluyen de diversas maneras en sus propuestas de medición o de evaluación (Altman y Pérez-Liñán, 2002; Levine y Molina, 2007; Scmitter, 2005; Diamond y Morlino, 2002). Sin embargo, no todos ellos las incorporan en su aplicación práctica o al construir los índices con los que miden la democracia, lo que constituye sin duda un gran vacío en esos acercamientos $^{3}$. Por el contrario, considero que ellos son elementos determinantes de la calidad de la democracia - en un grado de similar importancia al que se atribuye a las otras dimensiones- y por tanto no pueden ser dejados de lado en el análisis. Para sostener esta afirmación es necesario revisar lo ocurrido en los tres países a lo largo del período democrático.

Una primera constatación que cabe destacar -y que se relaciona con la segunda conclusión planteada al inicio de este capítulo- es que a lo largo de este período se produjeron avances y retrocesos en el desempeño de las instituciones en los tres países. En diversos momentos, en cada uno de ellos se fortalecieron las instituciones y los procedimientos democráticos, mientras en otros momentos se debilitaron. Por tanto, es necesario identificar esos momentos, lo que supone establecer una periodización para cada caso en particular. Esta cronología se puede organizar sobre la base de dos variables fundamentales que aluden a elementos institucionales y a las prácticas de los actores, y que fueron revisadas en el capítulo III. La primera de ellas es la representación política, expresada en el sistema de partidos que, con sus características y su desempeño, constituye el elemento fundamental de la participación ciudadana en la democracia representativa. La segunda indaga en la capacidad del sistema político para procesar el conflicto político ${ }^{4}$. Esta se expresa fundamentalmente en la relación entre los poderes del estado, específicamente en el equilibrio entre el ejecutivo y el legislativo Ambas han estado presentes a lo largo de todo el período en los tres países, ya que todos ellos han vivido bajo alguna forma de régimen democrático (siempre con la excepción de período

\footnotetext{
${ }^{3}$ Es muy clara la escasa importancia que ponen en los componentes institucionales autores como Altman y Pérez-Liñán (2002: 88) y Levine y Molina (2007: 39), que únicamente recogen uno de ellos (la dimensión electoral) y sólo de manera parcial cuando toman como indicador a la participación efectiva, entendida únicamente como la proporción de votantes sobre el total de población con derecho a hacerlo

${ }^{4}$ Por conflicto político (en singular) entiendo la agregación de contradicciones y puntos de fricción que debe procesar y resolver el sistema político. El elemento básico que determina si la respuesta es positiva o negativa se encuentra en la capacidad de agregación de intereses, que a su vez está determinada por los arreglos institucionales establecidos para el procesamiento de la diferencias.
} 
autoritario en Perú). Por tanto, para fines de clasificación no es necesario ni conveniente establecer su presencia o su ausencia, sino más bien reconocerles un grado, que por fines operativos puede restringirse a alto o bajo. De este modo, las dos variables se combinan de la manera que se observa en el gráfico $\mathrm{N}^{0} 1$, con lo que se configuran cuatro tipos de capacidades diferentes ${ }^{5}$.

\section{Gráfico $\mathrm{N}^{\mathrm{o}} 1$}

Capacidades del régimen según procesamiento y representación

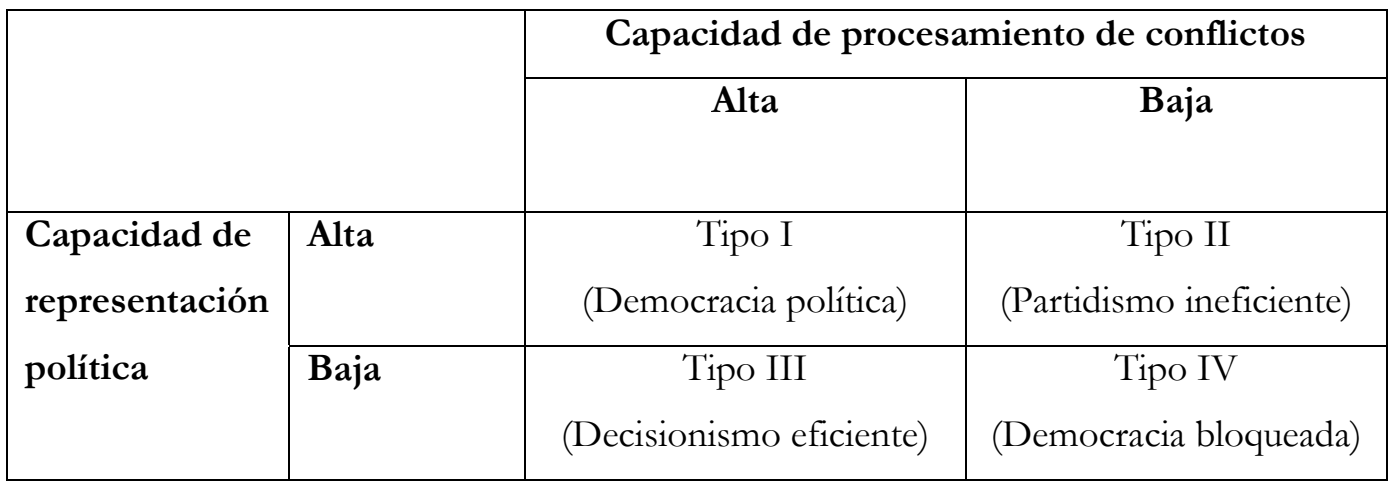

Elaboración: Simón Pachano

La combinación de las dos variables en grados altos daría como resultado un conjunto de capacidades que correspondería a las características que se esperan de una democracia política plena, ya que contaría con todos los atributos de la representación (capacidad de expresar intereses, de agregarlos y de responder a las demandas) y dispondría a la vez de todos los atributos necesarios para procesar los conflictos políticos y evitar que estos erosionen a las instituciones y debiliten al sistema. Por el contrario, en el otro extremo, la combinación de ambas en sus grados bajos daría como resultado no solamente una democracia ineficiente e incapaz de cumplir con los requerimientos de la representación, sino que se encontraría en riesgo de perder su propia condición de democracia. Esta sería característica de las democracias bloqueadas, que no cuentan con los recursos para representar y agregar adecuadamente los intereses y para procesar el conflicto.

\footnotetext{
${ }^{5}$ Considero necesario subrayar que la combinación de ambas variables -o de sus respectivas capacidades- no da como resultado un tipo de régimen, sino un grado de la capacidad de éste para resolver los problemas políticos. El tipo de régimen -como se vio en el capítulo IV- se deriva del grado alcanzado en las dimensiones generales, en tanto que sus capacidades de procesamiento y resolución de los conflictos corresponde a las características y el desempeño de las instituciones y por tanto es un resultado del descenso en el nivel de análisis.
} 
La combinación de alta capacidad de representación política, esto es, de un sistema de partidos estable e institucionalizado, con baja capacidad de procesamiento del conflicto daría como resultado una democracia ineficiente. Dadas sus características centrales, y a falta de un término más afortunado, esta situación puede ser calificada como de partidismo ineficiente ${ }^{6}$. Finalmente, la combinación de alta capacidad de procesamiento de conflictos con baja capacidad de representación política llevaría a formas eficientes de procesamiento del conflicto pero a costa del sacrificio de la representación. Por tanto, al quedar al margen la principal forma de participación ciudadana, concentrarían la capacidad decisoria en el ejecutivo y serían entonces formas de decisionismo eficiente.

Reitero que las cuatro denominaciones mencionadas son útiles para destacar las características de cada una de las combinaciones posibles, pero ellas no califican al tipo de régimen. Más bien, identifican situaciones por las que pueden atravesar los diversos tipos de régimen clasificados de acuerdo a otras consideraciones, como las democracias electorales, las democracias delegativas, las democracias iliberales, los autoritarismos competitivos, entre otros. Por ello y para evitar confusiones, aludiré a ellas en lo posible como tipos de capacidades o como situaciones de los regímenes. Por otra parte, es necesario advertir que en conjunto no conforman una escala continua en términos del grado de calidad. Obviamente, una democracia de alta calidad se encontraría en el primer tipo, en tanto que la peor calidad se encontraría en el tipo IV. Sin embargo, no se puede establecer esa gradación entre el tipo II y III, de manera que allí se rompe la continuidad o ambas se colocan en un mismo grado en términos de bajas capacidades aunque cada una de ellas lo sea por motivos diferentes. Así, lo único que se puede asegurar es que el tipo I es una forma plena de democracia, mientras todos los demás presentan deficiencias de diversa naturaleza, encontrándose las peores condiciones en el tipo IV.

En cada uno de ellos pueden variar en diversos grados las dos variables consideradas, sin que eso signifique que abandone la respectiva casilla. Así, el ideal del tipo II se encontraría en la combinación de un sistema de partidos conformado por un reducido número de integrantes -bajo la forma de pluralismo limitado según la clasificación de Sartori (1992: 168)- con un diseño institucional que no promueve los acuerdos políticos. En éste se

\footnotetext{
${ }^{6}$ Posiblemente sería más apropiado sustituir partidismo por partidocracia, a la manera que lo hace Coppedge (1994) cuando analiza el caso venezolano, pero este término ha sido utilizado en varios países latinoamericanos de una manera peyorativa y diferente a la que propongo aquí y por tanto se prestaría a confusiones.
} 
sacrificaría la eficiencia política por la representación, lo que se traduciría en problemas de gobernabilidad. El Tipo III se derivaría de un diseño institucional apropiado para el procesamiento del conflicto combinado con uno de los sistemas de partidos que bloquean la participación plural (sobre todo uno de partido hegemónico o de bipartidismo, pero también de pluralismo extremo). La característica central de este tipo sería la presencia de líderes fuertes que con su voluntad y su decisión sustituyen a los procedimientos representativos. En éste se tiende a sustituir a la representación por la eficiencia, con lo que se sacrifica uno de los puntales de la democracia. Finalmente, el Tipo IV se originaría en un sistema de partidos que, independientemente de sus características (de partido hegemónico, bipartidista o cualquiera de las formas de multipartidismo), no contaría con capacidad de representación y agregación, combinado con un diseño institucional inadecuado para procesar la relación entre los poderes del estado. Por tanto, en éste estarían ausentes o en vías de extinción las dos variables, lo que se expresaría a través de problemas de gobernabilidad y de representación.

Con estos elementos es posible construir la periodización señalada antes, destacando que un aspecto que llama la atención es que no existe una pauta general para los tres países. Cada uno de ellos sigue su propio camino, aunque en ocasiones coincidan las características en algunos de ellos.

Así, Bolivia inauguró el período democrático, en 1982, con un régimen del Tipo IV, con baja capacidad de representación y de procesamiento de los conflictos. Entre ese año y 1985 se hizo evidente la debilidad de los partidos políticos que, por cierto, recién estaban dando los pasos iniciales en la constitución de un sistema que pudiera reemplazar a las formas corporativas que predominaron desde 1952. Su capacidad de agregación de intereses era prácticamente nula, lo que cerraba la posibilidad de utilización de los procedimientos institucionales de solución de conflictos que tenían a disposición en el marco institucional ${ }^{7}$. La herencia del período inmediatamente anterior es evidente en la conformación de esta situación, ya que se trató de un momento de alta conflictividad social y política que expresaba la ruptura del régimen previamente existente (caracterizado por la representación corporativa que se imponía sobre la política) y de la erosión de las ya de por sí débiles instituciones. En esas condiciones, el régimen que se

\footnotetext{
${ }^{7}$ Cabe recordar que las disposiciones constitucionales a las que se ha atribuido la estabilidad política vivida entre 1985 y 2003 ya estuvieron presentes en el inicio del período democrático, ya que eran parte de la constitución de 1967
} 
instauró con la transición no tuvo la capacidad de representación y de agregación de los intereses sociales y políticos ni contó con la legitimidad de un marco institucional que apenas era visto como un recurso instrumental para superar el momento dictatorial.

Los acuerdos políticos y económicos de 1985 marcaron el fin de ese tipo de régimen y el inicio de uno del tipo I que se extendió hasta octubre de 2003. La denominada democracia pactada-como se conoció a ese período- fue básicamente una democracia de partidos que se alternaban en el gobierno, desarrollaban formas de cooperación política y utilizaban eficientemente los recursos que tenían a disposición en el marco institucional. Esto dio como resultado una relación armónica entre los poderes, así como una gran estabilidad política - desconocida en la historia republicana de Bolivia- y una gran continuidad en las políticas. El papel central para arribar a este resultado les cupo a los partidos políticos que, con gran capacidad de agregación de intereses -y en gran medida impulsados por la crisis económica que les colocaba ante tareas ineludibles e inaplazables- pudieron establecer acuerdos de largo plazo en torno a los temas centrales de la economía, la sociedad y la política.

Sin embargo, en el año 2003 se retornó al tipo IV, cuando los partidos perdieron su capacidad de representación y con ello se volvieron nulos los beneficios institucionales. La conformación de coaliciones gubernamentales multipartidistas, que excluían a la oposición y sobre todo que hacían innecesario cualquier acuerdo con ella, fue erosionando los elementos del diseño institucional que moderaban los aspectos negativos propios del presidencialismo. Con ello se estableció una modalidad política en que los acuerdos dentro del Congreso debían expresarse en beneficios inmediatos para sus integrantes y por tenían altos costos para los gobiernos. Después de por lo menos tres experiencias de este tipo, la desconfianza se trasladó desde el ámbito restringido del gobernante y su partido al amplio conjunto de los partidos. De esta manera, la inestabilidad de los tres años transcurridos entre 2003 y 2006 fue tanto la expresión de la incapacidad de agregación de intereses (no necesariamente de canalización de ellos), como de procesamiento del conflicto. Fue, por tanto, una crisis de representación (en tanto agregación) y de gobernabilidad ${ }^{8}$.

\footnotetext{
${ }^{8}$ Es necesario tener mucho cuidado al hablar de crisis de representación en los tres países y en general en América Latina, ya que en estricto sentido no se puede asegurar que a lo largo del período democrático hubiera existido déficit en este aspecto. Por el contrario, como lo han sostenido diversos autores (Tanaka, 2002b; Mayorga, 2004; Sánchez y Freidenberg, 1998) se
} 
Finalmente, a partir del año 2006 se estableció un situación del tipo III, de decisionismo eficiente, cuando en reemplazo de los partidos se instauró el predominio de un poderoso liderazgo personal y los procedimientos institucionales pasaron a un segundo plano (a pesar de la instalación de una Asamblea Constituyente que expidió una nueva Constitución). El colapso del sistema de partidos y la perdida de vigencia de los procedimientos institucionales por la manera desmedida en que se los había utilizado hicieron que la búsqueda de soluciones se realizara al margen de esos ámbitos y que los elementos institucionales -tanto del procesamiento del conflicto como de la representación- ocuparan un lugar secundario. Por ello, confluyeron en la implantación de un liderazgo personal altamente eficiente para canalizar los intereses de un sector de la sociedad y para hacer innecesario el diálogo político. Este tránsito por las diversas formas está expresado en el gráfico $\mathrm{N}^{\circ} 2$.

\section{Gráfico $\mathbf{N}^{\circ} 2$}

\section{Bolivia: cronología según capacidades}

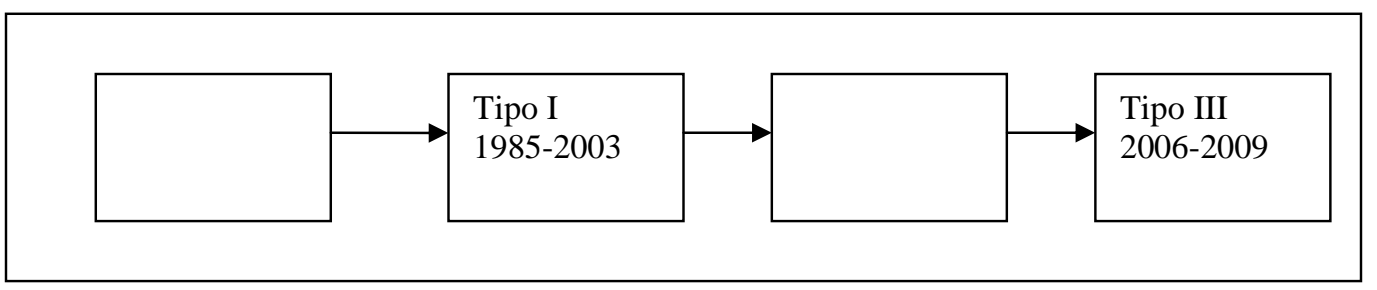

Elaboración: Simón Pachano

Ecuador inauguró su período democrático con una situación de tipo II en el que no estuvieron presentes las condiciones óptimas para el procesamiento del conflicto político, pero el sistema de partidos, que estaba en proceso de conformación, tenía apreciable capacidad de representación y de agregación de intereses ${ }^{9}$. Ésta, que se mantuvo aproximadamente hasta el año 1992, se caracterizó por el predominio del juego político

lograron mayores y mejores niveles de inclusión. El problema, como he sostenido en el capítulo III, se encuentra en la concepción de la representación, entendida como una forma de directa de expresión de los intereses de cada uno de los sectores sociales,

${ }^{9}$ La capacidad de representación y de agregación del sistema de partidos no puede atribuirse a las disposiciones legales vigentes ya que, con excepción de las que establecían el monopolio partidista, constituían en conjunto un bajo aliciente para ello. Se la puede atribuir más bien a la propia dinámica de la transición que, bajo la forma de una coyuntura crítica, definía un camino por el que debían transitar actores políticos sólidamente constituidos. En ese sentido, aquellas capacidades del sistema de partidos se lograron en gran medida a pesar del marco normativo vigente. 
partidista con escaso apego a las normas democráticas y por la evidencia de las limitaciones de las disposiciones institucionales. Los bloqueos políticos fueron constantes a lo largo de esos años en que se sucedieron gobiernos de minoría y resultó imposible definir y mucho menos mantener políticas de largo plazo.

Hacia 1992, cuando surgió el primer gobierno de un candidato independiente se comenzó a transitar hacia una forma de tipo IV que se concretaría a partir de $1995^{10}$. El período de transición entre el tipo II y el IV (vale decir entre un partidismo ineficiente y una democracia bloqueada) se caracterizó por la erosión del sistema de partidos alimentada en gran medida por las reformas constitucionales y legales de apertura indiscriminada del sistema- y por la pérdida de capacidad de las instituciones estatales para procesar el conflicto. Fueron los años en que más se avanzó en la apertura de la economía, con el debilitamiento del estado como contrapartida. Por tanto, se perdió totalmente la débil capacidad de procesamiento del conflicto -congénitamente débil, vale decir- que había producido la denominada pugna de poderes a lo largo de todo el período anterior. Ésta llegó a sus niveles más altos cuando la relación entre los poderes quedó prácticamente congelada o sometida a la presión de grupos corporativos que se expresaban por medio de unos partidos cada vez menos capaces de agregar intereses.

Ante la fragmentación y a la polarización del sistema de partidos, se hicieron más evidentes las deficiencias del diseño institucional. Por ello, terminó de conformarse una situación del tipo IV, con una democracia sujeta a bloqueos permanentes, que se extendió entre 1995 y 2007. La crisis del sistema de partidos -que se hizo evidente sobre todo a partir de 2002, pero que se venía acumulando desde los años anteriores- agudizó los problemas derivados del pésimo diseño institucional. Por esa vía, a partir del año 2007, se llegó finalmente a un régimen de tipo III, caracterizado al igual que en Bolivia, por el predominio de un liderazgo personal, la ausencia de los partidos políticos y el escaso o ningún acatamiento de las normas institucionales (a pesar, al igual que en el caso boliviano, de la promulgación de una nueva Constitución). Es una trayectoria que recoge el gráfico $\mathrm{N}^{\circ} 3$ y que expresa las dificultades para elevar el nivel de la calidad de la democracia en este país.

\footnotetext{
${ }^{10}$ El año 1992 constituyó el primer llamado de alerta a los partidos ecuatoriano, cuando un candidato independiente (desafiliado de uno de ellos) ganó la elección presidencial. Esta pérdida de espacio de los partidos se hizo evidente en tres de las cuatro elecciones presidenciales posteriores (1996, 2002 y 2006) en que triunfaron outsiders o candidatos antisistema (la excepción es la elección de 1998, en que triunfó un candidato partidista).
} 


\section{Gráfico $\mathbf{N}^{\circ} 3$}

\section{Ecuador: cronología según capacidades}

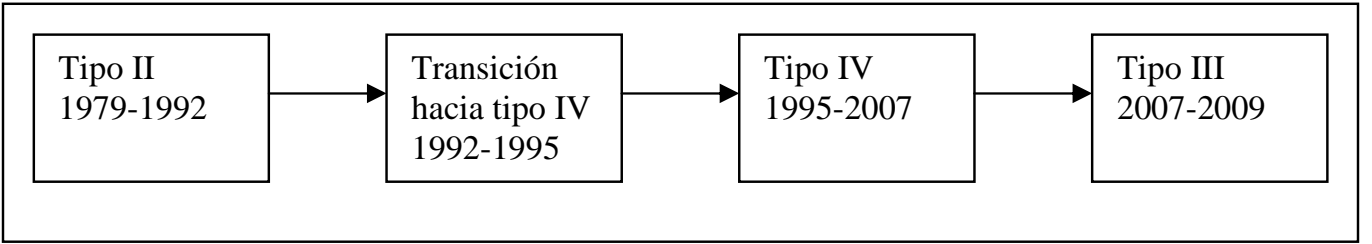

Elaboración: Simón Pachano

Perú inició el período democrático con un régimen de tipo I, conformado por un sistema de partidos con apreciable capacidad de representación (pero menor en términos de agregación de intereses) y por un conjunto de arreglos institucionales que -con muchas dificultades por cierto- permitían algún grado aceptable de procesamiento del conflicto político ${ }^{11}$. Sin embargo, la fragmentación del sistema de partidos llevó a la conformación de gobiernos de minoría y en consecuencia a la constitución de ejecutivos débiles políticamente aunque constitucionalmente fueran relativamente fuertes, lo que fue minando las capacidades en los dos aspectos considerados (representación y procesamiento del conflicto).

A partir de 1985 se abrió una situación de transición, caracterizada por el debilitamiento y la fragmentación del sistema de partidos, que impactó negativamente en la capacidad institucional para procesar los conflictos. Dicho de otra manera, la crisis política, expresada fundamentalmente en el debilitamiento de los partidos, erosionó la capacidad institucional de procesamiento de los conflictos políticos y por tanto redujo al mínimo el aspecto relativamente positivo que existía previamente. Una situación de esa naturaleza podía desembocar en cualquiera de las otras alternativas, y es la que llevó a la instauración de una del tipo III, esto es, a un decisionismo eficiente.

En efecto, a partir de 1990 se estableció una situación caracterizada por la instauración de un gobierno alejado de los partidos, poco ceñido a las normas institucionales y asentado fundamentalmente en la eficacia de la acción gubernamental. Esa forma logró

\footnotetext{
${ }^{11}$ La facultad presidencial de expedir decreto con fuerza de ley encontraban su contrapeso en la calificación de los gabinetes por parte del Congreso, lo que en conjunto obligaba a todos los actores políticos (fundamentalmente al ejecutivo y al legislativo) a buscar acuerdos políticos y e general a actuar con cautela.
} 
mantenerse hasta 1992 debido sobre todo a la crisis del sistema de partidos y a la elasticidad con que se utilizó los procedimientos institucionales. Sin embargo, las limitaciones de ésta eran evidentes, sobre todo porque los recursos institucionales no eran suficientes para contrarrestar las presiones políticas que, por su parte, se amparaban en la debilidad gubernamental.

Esta forma fue sustituida, con el autogolpe de 1992, por un régimen autoritario que, como corresponde a su naturaleza, eliminó los componentes representativos del régimen y dejó el procesamiento del conflicto en la decisión única e inapelable del ejecutivo. Sin embargo, las presiones de diverso tipo -especialmente la de carácter internacionalimpulsaron a buscar una salida que se tradujo, a partir de 1994, en una situación de tipo III que se extendió hasta el año 2000. Esta se asentó no sólo sobre un liderazgo personal, sino también sobre arreglos institucionales diseñados para ese fin, lo que llevaría a considerarla como una versión fortalecida de aquella forma y quizás como una extensión del régimen autoritario. El proceso culminó con una forma disminuida del tipo I (o con una transición hacia ella), con partidos débiles pero con observancia de los procedimientos institucionales. Esta trayectoria se aprecia en el gráfico $\mathrm{N}^{\circ} 4$.

\section{Gráfico $\mathbf{N}^{\circ} 4$}

\section{Perú: cronología según capacidades}

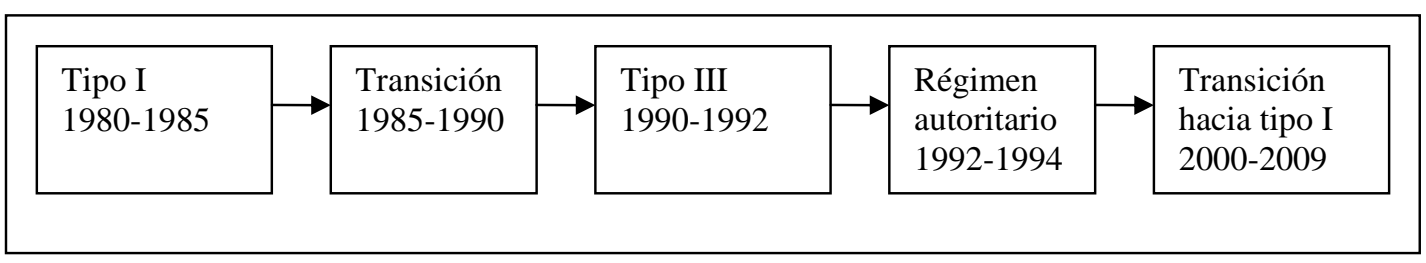

Elaboración: Simón Pachano

A partir de esta breve revisión de los diversos momentos por los que atravesó cada uno de los países se puede sostener que la incorporación de variables operativas -como los sistemas de partidos y la relación entre los poderes del estado- puede ser un buen complemento para la medición de la calidad de la democracia realizada por medio de las dimensiones más densas y abstractas. El análisis hecho a luz de estas dos variables toma como premisa la existencia de aquellas dimensiones, sin buscar sustituirlas. Por tanto, no se trata de una visión alternativa de la calidad de la democracia, sino de la incorporación de elementos que no aparecen en los enfoques que se han construido al respecto. 
Adicionalmente, al situarse en un nivel intermedio entre las dimensiones abstractas y los indicadores que se utilizan para su medición (como la proporción de votantes, el porcentaje de mujeres en cargos públicos y otros similares), estas variables ofrecen un recurso metodológico del que carecen aquellos enfoques generales. Cabe destacar que uno de los problemas de las perspectivas de análisis de la calidad de la democracia -en especial de las mediciones por medio de índices- es la enorme brecha que se abre entre las dimensiones y los indicadores. La necesidad de hacer operativa la medición o la evaluación obliga a pasar directa y abruptamente desde el nivel de la abstracción de las dimensiones hasta los indicadores concretos o tangibles, lo que hace que la relación entre ambos niveles sea extremadamente débil y restringida a determinados aspectos puntuales. Por el contrario, la introducción de estas variables como un nivel intermedio se convierte en un puente entre ambos extremos. En efecto, la distancia entre el carácter extremadamente abstracto de las dimensiones y la condición absolutamente concreta de los indicadores debe ser cerrada o por lo menos reducida con variables operativas que cumplan una función de mediación. Las dos que he destacado aquí cumplen precisamente esa función y de esa manera pueden aportar elementos valiosos para el análisis. La comprensión de los procesos políticos a través de ellas se convierte así en un elemento explicativo fundamental. Desde esta perspectiva, los aspectos tratados en el capítulo III pasan a ser elementos de primera importancia para comprender los altibajos de cada uno de los países en términos de la calidad de la democracia.

En efecto, si se aplican a los tres países los criterios de evaluación de la calidad de la democracia reseñados en el capítulo IV (ya sean las mediciones que buscan construir un índice o las mediciones de carácter cualitativo), se obtiene una idea muy general de los cambios ocurridos en cada uno de ellos. Se podría afirmar que se han producido avances o retrocesos e incluso sería posible comparar la situación de los diversos países en un determinado momento o a lo largo del tiempo. Pero en términos generales no se podría avanzar más allá en cuanto a las explicaciones de los procesos que llevaron a esos resultados. En cambio, al acudir a las variables mencionadas se hace posible identificar las causas que producen los cambios que finalmente se manifiestan como niveles más altos o más bajos de la calidad de la democracia. 
En síntesis, cualquier estudio de la calidad de la democracia -siempre que quiera ir más allá de la comparación de índices generales o de cortes sincrónicos de la situación de un gran conjunto de países- debe incluir el análisis de este tipo de variables intermedias. De manera especial debe preocuparse de los aspectos institucionales, que son los que he destacado en este estudio. Allí se encuentran, sin duda, las principales explicaciones acerca de los cambios que se suceden en la calidad de la democracia, hasta el punto de que se las puede considerar como las variables independientes con respecto a esta última en tanto variable dependiente. Esto maca una diferencia con las dimensiones de análisis de la calidad de la democracia que constituyen los atributos que deben estar presentes para considerar la calidad de la democracia, pero que de ninguna manera pueden ser consideradas como variables independientes. La presencia o ausencia de aquellas dimensiones -o más bien de sus respectivos atributos- depende fundamentalmente de las características de este tipo de variables y de su desempeño a lo largo del tiempo. Por ello la importancia de incluirlas en el estudio, especialmente cuando este busca ser un análisis en profundidad.

\section{Prácticas políticas y calidad de la democracia}

El otro factor que he destacado a lo largo de este estudio es el de las prácticas de los actores políticos, expresadas sobre todo en términos de sus cálculos estratégicos y de las acciones desplegadas para obtener sus objetivos. Así mismo, he puesto atención en otros tipos de prácticas, aquellas que corresponden a formas de relación o intercambio político y que se manifiestan ya sea por medio de los cauces institucionalmente determinados o bien bajo formas particularistas que operan generalmente al margen del marco institucional (pero utilizándolo para sus propios fines). A lo largo de este estudio he buscado identificar esos diversos tipos de prácticas y en este punto corresponde hacer algunas anotaciones acerca de la manera en que ellas inciden sobre la calidad de la democracia.

Para comprender esa relación cabe retomar el principio básico de la acción política, que señala que ésta se desarrolla prácticamente a partir de los cálculos estratégicos que realizan los actores políticos para lograr sus objetivos. Desde esa perspectiva, la acción política es el resultado de las posiciones que asumen y las decisiones que adoptan los actores a partir de evaluaciones permanentes acerca de sus opciones de triunfo y de sus 
riesgos de derrota. La contrapartida de esto, en un ordenamiento democrático, es la dimensión institucional de la política que contiene los arreglos necesarios para canalizar esas acciones. Por tanto, el diseño institucional debe ofrecer las vías y los procedimientos para procesar esas acciones y hacer posible el logro de los objetivos.

Una primera constatación dentro de los procesos vividos en los tres países, a partir de la aceptación de esta perspectiva, es que no siempre los actores políticos ciñeron sus acciones al marco institucional y a los procedimientos establecidos. Por el contrario, la tónica predominante fue el desarrollo de la acción al margen de esos procedimientos, lo que ocurrió bajo tres formas. En primer lugar, muchos de los momentos de crisis o de necesidad de decisiones drásticas e inmediatas fueron enfrentados con acciones que violentaban el ordenamiento vigente. Los derrocamientos de presidentes de la República en Bolivia (2003), en Ecuador (1997, 2000 y 2005) y en Perú (1992) fueron las expresiones más claras de esa orientación, pero también deben sumarse a ellas las acciones de fuerza tomas por los gobiernos cuando debieron enfrentar crisis económicas (como ocurrió en Bolivia en 1985) o cuando intervinieron en los otros poderes del estado (como ocurrió en Ecuador en 1984, 2004 y 2006, y en Bolivia en 2007).

En segundo lugar, muchas de las decisiones políticas adoptadas por los gobiernos y por los órganos legislativos se derivaron de la presión ejercida por actores poderosos que no contaban con representación política. Junto a $-\mathrm{O}$ incluso por encima de- los actores políticos institucionales, en especial de los partidos políticos, incidieron actores con poder de veto que lograron imponer sus intereses o bloquear las iniciativas de los primeros Estos veto players tuvieron enorme incidencia en la toma de decisiones políticas e impidieron que la política se realizara de manera abierta y transparente, con lo que fueron factores de primera importancia en la erosión de legitimidad de los gobiernos y los partidos. Sobre todo en Ecuador y Perú, hicieron que se estrecharan los márgenes de la acción política, con las consecuentes repercusiones negativas que esto podía acarrear especialmente en términos de la pérdida de confianza por parte de la sociedad.

En tercer lugar, en los tres países se generalizaron prácticas particularistas, como el clientelismo, que terminaron por invadir al conjunto de actores. El intercambio de votos por favores, que se consideraba una característica exclusiva de los líderes populistas, se expandió al conjunto de las agrupaciones políticas, incluidas las que nacieron al amparo 
de ideologías claramente definidas. Las prácticas clientelares se convirtieron en una de las principales vías para triunfar o por lo menos para mantenerse en la escena política, con los consecuentes efectos de encerrarle a la política en un horizonte de plazos extremadamente cortos, por un lado y de socavar la condición ciudadana de las poblaciones involucradas, por otro lado. De esta manera, se restringían al mínimo las posibilidades tanto de contar con políticas de largo alcance como de construir una sociedad activa y participativa sobre la base del ejercicio pleno de sus derechos.

En conjunto, estas prácticas políticas afectaron negativamente a las democracias de los tres países. Debilitaron a sus instituciones, sometieron a los políticos a un juego que resultaba insostenible más allá del horizonte inmediato y alimentaba la personalización. Por consiguiente, socavaron las bases de la democracia en uno de sus aspectos fundamentales, como es el de la interrelación entre las instituciones y las elites políticas, por un lado y la sociedad, por el otro lado. La responsabilidad de los políticos y la accountability por parte de la sociedad (e incluso por parte de las propias instituciones) se convertía en algo ajeno a esa lógica de funcionamiento del sistema político.

Con estos elementos es posible volver sobre los análisis de la calidad de la democracia. Al trabajar con las dimensiones más generales y al descender abruptamente a los indicadores de cada una -o más de algunas- de ellas puede perderse de vista la incidencia de estos factores. Por ello, a lo largo de este trabajo he destacado la incidencia de esta variable, de la misma manera que lo he hecho con las dos de carácter institucional tratadas en la sección anterior de estas conclusiones. Su inclusión como variable (independiente) intermedia pasa a ser fundamental en el análisis de la calidad de la democracia.

\section{A manera de conclusión: una agenda de investigación}

Reiteradamente he señalado que la calidad de la democracia es un campo en construcción dentro de la teoría de la democracia. El análisis de los tres países, Bolivia, Ecuador y Perú, ha sido a la vez una puesta a prueba de algunos de los planteamientos centrales de esa perspectiva, pero sobre todo ha sido una demostración de las limitaciones que aún se encuentran en este aspecto. Los procesos vividos en los tres países contienen abundante material para poner a prueba los conceptos y las estrategias de investigación que se han desarrollado dentro de la ciencia política contemporánea. Con el presente trabajo he 
buscado desarrollar un ejercicio exploratorio de aplicación de las perspectivas de análisis dentro de un estudio comparativo que, finalmente, arroja dos conclusiones generales.

La primera es la reiteración de que el estado de avance de la teoría de la calidad de la democracia no permite superar dos límites que se presentan a partir de las propuestas metodológicas al respecto. Uno es el que se establece por la utilización de las grandes dimensiones -esos agregados de alto nivel de abstracción que contienen los atributos de la poliarquía pero que no hacen factible su operación-, que coloca al estudio en un plano de generalidad tan grande que resulta insuficiente para el tratamiento de situaciones concretas como las que he abordado aquí. Otro límite es el que marcan los indicadores siempre restringidos en función de hacerlos operativos- que solamente pueden dar cuenta de aspectos muy parciales de la calidad de la democracia. Por ello, he creído conveniente trabajar con variables de nivel intermedio, que pueden explicar los procesos concretos y que constituyen el núcleo de los estudios comparativos.

La segunda es el reconocimiento de la necesidad de emprender en una agenda de investigación que pueda desplazarse por todos los niveles que se encuentran entre las dimensiones, las variables operativas y los indicadores. La construcción de la teoría de la calidad de la democracia, así como la explicación de los procesos concretos requiere de trabajos de esa naturaleza. El que he presentado aquí ha sido un primer paso en esa dirección. 


\section{Bibliografía}

Abugattás, Luis. 1987. Neoliberalismo y democracia en el Perú. En Cordes (Comp.):

Neoliberalismo y políticas económicas alternativas. Quito. CORDES.

Acosta, Alberto. 2000. Ecuador: del ajuste tortuoso al ajuste dolarizado... (qué he hecho yo para merecer esto). En Ecuador Debate. 50. Páginas 67-104

Adrianzén, Alberto. 1992. Democracia y partidos en el Perú. En Pretextos. 3/4. Páginas 7-19

Aguilera Del Prat, Cesáreo y Rafael Martínez. 2002. Sistemas de gobierno, partidos y territorio. Madrid. Tecnos

Aguinaga, Carlos. 2005. Análisis comparativo de los sistemas electorales andinos. En Vélez, Rubén (Comp.): Sistemas electorales andinos. Bogotá. Parlamento Andino. Páginas 227-264

Alcántara, Manuel. 1995. Gobernabilidad, crisis y cambio. México. Fondo de Cultura Económica

Alcántara, Manuel. 1999. De la reforma y la consolidación del sistema político en el equilibrio entre democracia y mercado en América Latina. En Alcántara, Manuel y Ismael Crespo (Comp.): Los límites de la consolidación democrática en América Latina. Salamanca. Universidad de Salamanca. Páginas 29-45

Alcántara, Manuel. 2004. ¿Instituciones o máquinas ideológicas? Origen, programa y organización de los partidos latinoamericanos. Barcelona. ICPS

Alcántara, Manuel y Flavia Freidenberg (Comp.). 2003. Partidos Políticos de América Latina. Países andinos. México. Fondo de Cultura Económica

Almaraz, Sergio. 1981. Requiem por una república. La Paz. Los amigos del libro

Altman, David y Aníbal Pérez Liñán. 2002. Assessing the Quality of Democracy: Freedom, Competitiveness and Participation in Eighteen Latin American Countries. En Democratization. 9, 2. Páginas 85-100

Alvarez, Michael, José A. Cheibub, Fernando Limongi y Adam Przeworski. 1996. Classifying Political Regimes. En Studies in Comparative International Development. 31, 2. Páginas 3-36

Anckar, Carsten. 2000. Size and Party System Fragmentation. En Party Politics. 6, 3. Páginas 305-328

Anderson, Benedict. 2007. Comunidades imaginadas. México. Fondo de Cultura Económica

Andrews, Josephine T. y Gabriella R. Montinola. 2004. Veto Players and the Rule of Law in Emerging Democracies. En Comparative Political Studies. 37, 1. Páginas 55-87

Ansaldi, Waldo. 1991. Gobernabilidad y seguridad democrática. Santiago. Comisión Sudamericana de Paz

Arat, Zehra. 1991. Democracy and Human Rights in Developing Countries. Boulder. Lynne Rienner

Araujo, Caridad. 1998. Gobernabilidad durante la crisis y políticas de ajuste. Quito. CORDES-KAS

Ardaya, Gloria. 2003. Diputados uninominales. Otra forma de representación. La Paz. Plural-ILDIS

Ardaya, Gloria y Luis Verdesoto. 1994. Racionalidades en construcción. La Paz. ILDIS

Arendt, Hanna. 2004. Sobre la revolución. Madrid. Alianza

Armijos, Ana Lucía y Marco Flores. 1991. Las políticas económicas aplicadas en la década de los ochenta: respuesta a la crisis. En Thorp, Rosemary (Comp.): Las crisis en el 
Ecuador. Los treinta y ochenta. Quito. Corporación Editora Nacional. Páginas 191-223

Ayala, Enrique. 1978. Lucha política y origen de los partidos políticos en Ecuador. Quito. Universidad Católica

Barczak, Mónica. 2001. Squaring Off: Executives and Legislatures in Ecuador. En Elgie, Robert (Comp.): Divided Government in Comparative Perspective. New York. Oxford University Press. Páginas 40-62

Barrios, Raúl. 1994. Hacia una legitimidad renovada de la instituci \{n militar boliviana. En Mayorga, René y Raúl Barrios (Comp.): La cuestión militar en cuestión. La Paz. Cebem. Páginas 113-147

Barry, Brian. 1975. Political Acommodation and Consociotional Democracy. En British Journal of Political Science. 5, 4. Páginas 477-505

Basadre, Jorge. 1980. La multitud, la ciudad y el campo en la historia del Perú. Lima. Mosca Azul

Bauman, Gerd. 2001. El enigma multicultural. Barcelona. Paidós

Beetham, David. 2005. Freedom as the Foundation. En Diamond, Larry y Leonardo Morlino (Comp.): Assessign the Quality of Democracy. Baltimore. Johns Hopkins University Press. Páginas 32-46

Bid. 2002. Informe de progreso económico y social. Washington. BID

Bid. 2006. La política de las políticas públicas. Progreso económico y social en América Latina. Washington. Planeta-Harvard University

Blanes, José. 2001. Mallkus y alcaldes. La Paz. CEBEM

Blanksten, George. 1951. Ecuador: Constitution and Caudillos. Berkeley. University of California Press

Bobbio, Norberto. 1985. El futuro de la democracia. Barcelona. Plaza \& Janes

Bobbio, Norberto. 1987. Estado, gobierno, sociedad. Contribución a una teoría general de la política. Barcelona. Plaza \& Janes

Bobbio, Norberto. 1989. Liberalismo y democracia. México. Fondo de Cultura Económica

Bobbio, Norberto. 1997. Sociedad y Estado en la filosofía política moderna. Bogotá. Fondo de Cultura Económica

Bobbio, Norberto. 2000. La teoría de las formas de gobierno en la historia del pensamiento político. México. Fondo de Cultura Económica

Bohrt, Carlos. 2002. Voto presidencial y voto uninominal en las elecciones de 2002. En Opiniones y Análisis. 58. Páginas 119-186

Bohrt, Carlos y Silvia Chávez. 2002. Elecciones 2002. Resultados y transformaciones. La Paz. Fundemos

Bollen, Keneth. 1980. Issues in the Comparative Measurement of Political Democracy. En American Sociological Review. 44, Páginas 572-587

Bollen, Keneth. 1990. Political Democracy: Conceptual and Measurement Traps. En Studies in Comparative International Development. 25, 1. Páginas 7-24

Bollen, Keneth y Burke Grandjean. 1981. The Dimension(s) of Democracy: Further Issues in the Measurement and Effects of Political Democracy. En American Sociological Review. 46, 5. Páginas 651-659

Bollen, Keneth y Pamela Paxton. 2000. Subjective Measures of Liberal Democracy. En Comparative Political Studies. 33, 1. Páginas 58-86

Bowen, Sally. 2000. El expediente Fujimori. E1 Perú y su presidente 1990-2000. Lima. Perú Monitor S. A.

Bustamante, Fernando. 2000. Los partidos como orientaciones culturales. En Iconos. 9. Páginas

Cais, Jordi. 1997. Metodología del análisis comparativo. Madrid. CIS 
Calderón, Fernando. 1982. La política en las calles. Cochabamba. CERES

Calderón, Fernando. 1988. Cuestionados por la sociedad: los partidos políticos. En Calderón, Fernando (Comp.): Búsquedas y bloqueos. La Paz. Páginas 191-212

Calderón, Fernando. 1995. Movimientos sociales y política. México. Siglo XXI

Calderón, Fernando y Alicia Szmukler. 2000. La política en las calles. La Paz. CERES

Camou, Antonio. 1998. Estudio preliminar. En Camou, Antonio (Comp.): Los desafíos de la gobernabilidad. México. Flacso. Páginas 15-58

Cardoso, Fernando Henrique. 1972. Estado y sociedad (notas preliminares). En Cardoso, Fernando Henrique (Comp.): Estado y sociedad en América Latina. Buenos Aires. Nueva Visión. Páginas 227-247

Cardoso, Fernando Henrique. 1984. La sociedad y el estado. En Pensamiento Iberoamericano. 5. Páginas 25-36

Cardoso, Fernando Henrique. 1985. ¿Transición política en América Latina? En Scartezzini, R., L. Germani y R. Gritti (Comp.): Los límites de la democracia. Buenos Aires. CLACSO. Páginas 129-142

Cardoso, Fernando Henrique y Enzo Faletto. 1971. Dependencia y desarrollo en América Latina. México. Siglo XXI

Carrasquero, José Vicente, Thais Maingon y Friedrich Welsh (Comp.). 2001. Venezuela en transición: elecciones y democracia 1998-2000. Caracas. CDB Publicaciones-RedPol

Carrión, Julio. 1997. La opinión pública bajo el primer gobierno de Fujimori: ¿de identidades a intereses? En Tuesta, Fernando (Comp.): Los enigmas del poder. Fujimori 1990-1996. Lima. Fundación Friedrich Ebert. Páginas 277-302

Collier, David. 1999. El método comparativo: dos décadas de cambios. En Sartori, Giovanni y Leonardo Morlino (Comp.): La comparación en las ciencias sociales. Madrid. Alianza. Páginas 51-79

Collier, David y Steven Levitsky. 1998. Democracia con adjetivos, innovación conceptual en la investigación comparativa. En La política. 4. Páginas 137-160

Collier, David y James E. Mahon Jr. 1993. Conceptual "Stretching" Revisited: Adapting Categories in Comparative Analysis. En The American Political Science Review. 87, 4. Páginas 845-855

Collins, Jennifer. 2001. Opening up Electoral Politics: Political Crisis and the Rise of Pachakutik. (manuscrito)

Colomer, Josep. 2001. Political Institutions. New York. Oxford University Press

Colomer, Josep. 2003. Son los partidos los que eligen los sistemas electorales (o las leyes de Duverger cabeza abajo). En Revista Española de Ciencia Política. 9. Páginas 36-93

Colomer, Josep. 2004. Cómo votamos. Los sistemas electorales del mundo: pasado, presente y futuro. Barcelona. Gedisa

Conaghan, Catherine. 1994. Loose Parties, Floating Politicians and Institutional Stress: Presidentialism in Ecuador, 1979-1988. En Linz, Juan y Arturo Valenzuela (Comp.): The Failure of Presidential Democracy. Baltimore. Johns Hopkins University Press. Páginas

Conaghan, Catherine. 1995. Politician Against Parties: Discord and Disconnection in Ecuador's Party System. En Maiwaring, Scott y Timothy Scully (Comp.): Building Democratic Institutions. Party Systems in Latin America. Stanford. Stanford University Press. Páginas 434-458

Conaghan, Catherine. 1996. A Deficit of Democratic Authenticity: Political Linkage and the Public in Andean Polities. En Studies in Comparative International Development. 31, 3. Páginas 32-55

Conaghan, Catherine. 2005. Fujimori's Perú. Deception in the Public Sphere. Pittsburgh. University of Pittsburg Press 
Conaghan, Catherine. 2008. Ecuador: Correa's Plebiscitary Democracy. En Diamond, Larry, Mark F. Plattner y Diego Abente (Comp.): Latin America's Struggle for

Democracy. Baltimore. The Jonhns Hopkins University Press. Páginas 199-213

Conaghan, Catherine y Rosario Espinal. 1990. Unlikely Transitions to Uncertain Regimes? Democracy without Compromise in The Dominican Republic and Ecuador. En Journal of Latin American Studies. 22, 3. Páginas 553-574

Conaghan, Catherine, James Malloy y Luis Abugattas. 1990. Business and the "Boys": The Politics of Neoliberalism in the Central Andes. En Latin American Research Review. 25, 2. Páginas 3-30

Constant, Benjamin. 1998. De la libertad de los antiguos comparada con la libertad de los modernos. En Del Águila, Rafael y Fernando Vallespín (Comp.): La democracia en sus textos. Madrid. Alianza editorial. Páginas 138-141

Coppedge, Michael. 1996. El concepto de gobernabilidad. Modelos positivos y negativos. En Cordes (Comp.): Ecuador: un problema de gobernabilidad. Quito. CORDES. Páginas 25-61

Coppedge, Michael. 2001. Party Systems, Governability, and the Quality of Democracy in Latin America. Ponencia presentada en el seminario: Representation and Democratic Politics in Latin America. Buenos Aires

Coppedge, Michael. 2002. Democracy and Dimensions. Comments on Munck and Verkuilen. En Comparative Political Studies. 35, 1. Páginas 35-39

Coppedge, Michael y Wolfgang Reinicke. 1990. Meassuring Poliarchy. En Studies in Comparative International Development. 25, 1. Páginas 51-72

Cordero, Sofía. 2008. MAS y Pachakutik: la lucha por la inclusión política en Bolivia y Ecuador. Tesis de Maestría en Ciencia Política. FLACSO, sede Ecuador. Quito

Cotler, Julio. 1978. Clases, estado y nación en el Perú. Lima. Instituto de Estudios Peruanos

Cotler, Julio. 1988. Las intervenciones militares en y la "transferencia del poder a los civiles" en Perú. En O`Donnell, Guillermo y Philippe Schmitter (Comp.): Transiciones desde un gobierno autoritario. Volumen 2, América Latina,. Buenos Aires. Paidós. Páginas 225-259

Cotler, Julio. 2000. La gobernabilidad en el Perú: entre el autoritarismo y la democracia. En Cotler, Julio y Romeo Grompone (Comp.): El fujimorismo: ascenso y caída de un régimen autoritario. Lima. Instituto de Estudios Peruanos. Páginas 13-75

Cotler, Julio y Romeo Grompone (Comp.). 2000. El fujimorismo. Ascenso y caída de un régimen autoritario. Lima. Instituto de Estudios Peruanos

Crabtree, John. 2005. Alan García en el poder. Perú 1985-1990. Lima. Peisa

Crawford, Sue y Elinor Ostrom. 1995. A Grammar of Institutions. En The American Political Science Review. 89, 3. Páginas 582-600

Cuarezma, Sergio y Francisco Cabistán. 2008. Reforma electoral en América Latina: el caso de Nicaragua. En Zovatto, Daniel y Jesús Orozco (Comp.): Reforma política y electoral en América Latina 1978-2007. México. UNAM-IDEA. Páginas 705742

Cueva, Agustín. 1969. Entre la ira y la esperanza. Quito. Casa de la Cultura Ecuatoriana

Cueva, Agustín. 1980. El proceso de dominación política en el Ecuador. Quito. Editorial A. Crespo

Cueva, Agustín. 1988. Las democracias restringidas de América Latina. Quito. Planeta

Dahl, Robert. 1989. La poliarquía. Participación y oposición. Madrid. Tecnos

Dahl, Robert. 1991. La democracia y sus críticos. Buenos Aires. Paidós

De La Torre, Carlos. 1984. La seducción velasquista. Quito. Libri Mundi 
De La Torre, Carlos. 2008a. El regreso del populismo. En De La Torre, Carlos y Enrique Peruzzotti (Comp.): El retorno del pueblo. Populismo y nuevas democracias en América Latina. Quito. Flacso. Páginas 11-19

De La Torre, Carlos. 2008b. Populismo, ciudadanía y Estado de derecho. En De La Torre, Carlos y Enrique Peruzzotti (Comp.): El retorno del pueblo. Populismo y nuevas democracias en América Latina. Quito. Flacso. Páginas 23-53

De Souza, Boaventura. 2004. Reiventar la democracia, reinventar el estado. Quito. Abya-Yala

De Tocqueville, Alexis. 1985. La democracia en América. Madrid. Alianza Editorial

Degregori, Carlos Iván. 1990. Ayacucho 1969-1979: el surgimiento de Sendero

Luminoso. Lima. Instituto de Estudios Peruanos

Degregori, Carlos Iván. 1996. Cosechando tempestades: las rondas campesinas y la derrota Sendero Luminoso en Ayacucho. En Degregori, Carlos Iván (Comp.): Las rondas

campesinas y la derrota de Sendero Luminoso. Lima. Instituto de Estudios Peruanos. Páginas 189-225

Degregori, Carlos Iván. 2000. La década de la antipolítica. Lima. Instituto de Estudios Peruanos

Degregori, Carlos Iván y Carlos Meléndez. 2007. E1 nacimiento de los otorongos. E1 Congreso de la República durante los gobiernos de Alberto Fujimori (19902000). Lima. Instituto de Estudios Peruanos

Demélas, Marie-Danielle. 2003. La invención política. Lima. IEP-IFEA

Diamond, Larry. 2002. Thinking About Hybrid Regimes. En Journal of Democracy. 13, 2. Páginas 21-35

Diamond, Larry y Leonardo Morlino. 2004. The Quality of Democracy. An Overview. En Journal of Democracy. 15, 4. Páginas 20-31

Diamond, Larry y Leonardo Morlino (Comp.). 2005a. Assessing the Quality of Democracy. Baltimore. Johns Hopkins University Press

Diamond, Larry y Leonardo Morlino. 2005b. Introduction. En Diamond, Larry y Leonardo Morlino (Comp.): Assessign the Quality of Democracy. Baltimore. Johns Hopkins University Press. Páginas ix-xliii

Diamond, Larry y Mark F. Plattner (Comp.). 1996a. El resurgimiento global de la democracia. México. UNAM

Diamond, Larry y Mark F. Plattner. 1996b. Introducción. En Diamond, Larry y Mark F. Plattner (Comp.): El resurgimiento global de la democracia. México. UNAM. Páginas IX-XXVI

Dietrich, Wolfram. 1945. Simón Bolívar y las guerras de la Independencia Latinoamericana. Santiago de Chile. Ercilla

Dix, Robert. 1989. Cleavage Structures and Party Systems in Latin America. En Comparative Politics. 22, 1. Páginas 23-37

Downs, Anthony. 1957. An Economic Theory of Democracy. New York. Harper Collins

Duverger, Maurice. 1988. Los partidos políticos. México. Fondo de Cultura Económica [primera edición: 1951]

Easton, David. 1976. Esquema para el análisis político. Buenos Aires. Amorrortu

Easton, David. 1997. Categorías para el análisis sistémico de la política. En Easton, David (Comp.): Enfoques sobre teoría política. Buenos Aires. Amorrortu. Páginas 216-230

Echeverría, Julio. 1997. La democracia bloqueada. Quito. Letras

Elkins, Zachary. 2000. Gradations of Democracy? Empirical Test of Alternative Conceptualizations. En American Journal of Political Science. 44, 2. Páginas 293-300 
Elorza, Antonio. 2005. Tras las huellas de Sabino Arana. Los orígenes totalitarios del nacionalismo vasco. Madrid. Temas de hoy

Elster, Jon. 1998. Regla de mayoría y derechos individuales. En Ágora. 8. Páginas 61-98

Evers, Tilman. 1985. Identidad: la faz oculta de los nuevos movimientos sociales. En Punto de vista. 7, 25. Páginas 31-41

Fitch, Samuel. 1977. The Military Coup D'Etat as a Political Process. Baltimore. The Johns Hopkins University Press

Flisfisch, Ángel. 1983. Gobernabilidad y consolidación democrática. En Revista Mexicana de Sociología. 89, 3. Páginas

Freidenberg, Flavia. 2000a. Las posiciones ideológicas programáticas en los partidos ecuatorianos. Ponencia presentada en el seminario: Political Parties in Latin America. Institute of Latin American Studies (ILAS), Londres

Freidenberg, Flavia. 2000b. Percepciones ciudadanas hacia la democracia y las instituciones politica en los países andinos. En Ecuador Debate. 50. Páginas 205-218

Freidenberg, Flavia. 2006. Irquierda vs. derecha. Polarización ideológica y competencia en el sistema de partidos ecuatoriano. En Política y Gobierno. XIII, 2. Páginas 237-278

Freidenberg, Flavia y Manuel Alcántara. 2001. Cuestión regional y política en Ecuador: partidos de vocación nacional y apoyo regional. En América Latina Hoy. 27. Páginas 123-152

Fundemos. 1998. Datos estadísticos. Elecciones generales 1979-1997. La Paz. Opiniones y análisis

Gaisorowski, Mark. 1996. An Overview of the Political Regime Change Dataset. En Comparative Political Studies. 29, 4. Páginas 469-483

Gamarra, Eduardo. 1992. Presidencialismo híbrido y democratización. En Mayorga, René (Editor) (Comp.): Democracia y gobernabilidad en América Latina. Caracas. Nueva Sociedad. Páginas 21-40

Gamarra, Eduardo y James Malloy. 1995. The Patrimonial Dynamics of Party Politics in Bolivia. En (Comp.): Building Democratic Institutions. Party Systems in Latin America. Stanford. Stanford University Press. Páginas 399-433

García Montero, Mercedes. 2001. Bolivia. En Alcántara, Manuel y Flavia Freidenberg (Comp.): Partidos políticos de América Latina. Países andinos. Salamanca. Universidad de Salamanca. Páginas 33-145

Garnier, Leonardo. 1994. Ajuste estructural e inserción externa: la experiencia en economías pequeñas. En Vargas, Leiner (Comp.): Apertura externa y competitividad. San José. IICA. Páginas 21-54

Garretón, Manuel. 1997. Revisando las transiciones democráticas en América Latina. En Nueva Sociedad. 148. Páginas 20-29

Gellner, Ernest. 1998. El nacionalismo y las dos formas de cohesión en sociedades complejas. En Gellner, Ernest (Comp.): Cultura, identidad y política. Barcelona. Gedisa. Páginas 17-39

Gerlach, Alain. 2003. Indians, Oil and Politics. New Mexico. University of New Mexico

Germani, Gino. 1985. Democracia y autoritarismo en la sociedad moderna. En Scartezzini, R., L. Germani y R. Gritti (Comp.): Los límites de la democracia. Buenos Aires. CLACSO. Páginas 21-58

González De Olarte, Efraín. 1998. E1 neoliberalismo a la Peruana. Lima. Instituto de Estudios Peruanos

Gray, John. 2001. Las dos caras del liberalismo. Una nueva interpretación de la tolerancia liberal. Buenos Aires. Paidós

Griner, Steven y Daniel Zovatto (Comp.). 2004. De las normas a las buenas prácticas. San José. IDEA-OEA 
Grompone, Romeo. 1995. Nuevos tiempos, nueva política. En Grompone, Romeo y Carlos Mejía (Comp.): Nuevos tiempos, nueva política. Lima. Instituto de Estudios Peruanos. Páginas 11-38

Grompone, Romeo y Carlos Mejía. 1995. Los estilos políticos en el final de un ciclo partidario.

En Grompone, Romeo y Carlos Mejía (Comp.): Nuevos tiempos, nueva política. Lima. Instituto de Estudios Peruanos. Páginas 39-110

Guerra, Francois-Xavier. 1994. La metamorfosis de la representación en el siglo XIX. En Couffignal, Georges (Comp.): Democracias posibles. El desafío

latinoamericano. Buenos Aires. Fondo de Cultura Económica. Páginas 39-68

Guerrero, Rafael. 1994. Regionalismo y democracia social en los origenes del CFP. Quito. CAAP

Gunther, Richard, Nikiforos Diamandouros y Hans-Jurgen Puhle. 1996. Las "ilusiones" de O Donnell: una réplica. En La política. 2. Páginas 119-128

Gunther, Richard y Larry Diamond. 2003. Species of Political Parties. A New Tipology. En Party Politics. 9, 2. Páginas 167-199

Gunther, Richard, José Ramón Montero y Juan Linz (Comp.). 2002. Political Parties. Old Concepts and new Challenges. Oxfor. Oxford University Press

Habermas, Jürgen. 1975. Problemas de legitimación en el capitalismo tardío. Buenos Aires. Amorrortu

Halperin Donghi, Tulio. 1970. Historia contemporánea de América Latina. Madrid. Alianza

Haro, Patricio. 1997. La influencia del poder militar en la historia del Ecuador. Quito. Ministerio de Defensa Nacional

Held, David. 2001. Modelos de democracia. Madrid. Alianza

Helliwell, John. 1994. Empirical Linkages Between Democracy and Economic Growth. En British Journal of Political Science. 24, 2. Páginas 225-248

Helmke, Gretchen y Steven Levitsky. 2003. Informal Institutions and Comparative Politics: $A$ Research Agenda. University of California at Berkeley. Working Paper \# 307.

Hobsbawm, Eric. 1991. Naciones y nacionalismo desde 1780. Barcelona. Crítica Huntington, Samuel. 1971. The Change to Change: Modernization, Development, and Politics. En Comparative Politics. 3, 3. Páginas 283-322

Huntington, Samuel. 1980. El orden político en las sociedades en cambio. Buenos Aires. Paidós

Hurtado, Osvaldo. 1979. El poder político en el Ecuador. Quito. Universidad Católica

Hurtado, Osvaldo. 2007. Treinta años después de la primera edición. En Hurtado, Osvaldo (Comp.): El poder político en el Ecuador. Quito. Planeta. Páginas i-li

Ibarra, Hernán. 1992a. El laberinto del mestizaje. En Sánchez Parga, José (Comp.): Identidades y sociedad. Quito. CELA. Páginas

Ibarra, Hernán. 1992b. Indios y cholos en los orígenes de la clase trabajadora ecuatoriana. Quito. El Conejo

Ibarra, Hernán. 2008. El bonapartismo como liderazgo político. En Ecuador Debate. 73. Páginas 41-46

Jácome, Luis. 2003. The Late 1990s Financial Crisis in Ecuador: the Exacerbating Role of Institutional Weaknesses, Fiscal Rigidities, and Financial Dollarization. MIF. Working Paper.

Jones, Mark P. 1994. Presidential Election Laws and Multipartism in Latin America. En Political Research Quarterly. 47, 1. Páginas 41-57

Jones, Mark P. 1999. Electoral Laws and Effective Number of Candidates in Presidential Elections. En The Journal of Politics. 61, 1. Páginas 171-184

Jones, Mark P. 2004. Electoral Institutions, Social Cleavages, and Candidate Competition in Presidential Elections. En Electoral Studies. 23, Páginas 73-106 
Kant, Inmanuel. 1999. Hacia la paz perpetua. Madrid. Biblioteca Nueva

Karl, Terry Lynn. 1990. Dilemmas of Democratization in Latin America. En Comparative Politics. 23, 1. Páginas 1-21

Karl, Terry Lynn. 1995. The Hybrid Regimes of Central America. En Journal of Democracy. 6, 1. Páginas 72-86

Kecskemeti, Pierre. 1994. El pensamiento politico en Norteamerica. En Mayer, J. P. (Comp.): Trayectoria del pensamiento político. México. Páginas 258-303

Kenney, Charles. 1997. ¿Por qué el autogolpe? Fujimori y el Congreso, 1990-1992. En Tuesta, Fernando (Comp.): Los enigmas del poder. Fujimori 1990-1996. Lima. Fundación Friedrich Ebert. Páginas 75- 104

King, Gary, Robert O. Keohane y Sidney Verba. 2005. El diseño de la investigación social. La inferencia científica en los estudios cualitativos. Madrid. Alianza

Klarén, Peter. 2008. Nación y sociedad en la historia del Perú. Lima. IEP

Kornblith, Miriam. 2004. Situación y perspectivas de los partidos en la región andina: caso Venezuela. Ponencia presentada en el seminario: Situación actual de los partidos políticos en la región andina. Lima

Kymlicka, Will. 1996. Ciudadanía multicultural. Barcelona. Paidós

Kymlicka, Will y Wayne Norman. 1997. El retorno del ciudadano. Una revisión de la producción reciente en teoría de la ciudadanía. En La política. 3. Páginas 5-39

Laclau, Ernesto. 2007. La razón populista. Buenos Aires. Fondo de Cultura Económica Landi, Oscar. 1985. El discurso sobre lo posible. Buenos Aires. Cedes

Laserna, Roberto. 1992a. Caudillos, partidos y democracia en Bolivia: informales, gringos-cholos y maxistas en la política. En Laserna, Roberto (Comp.): Productores de democracia. Cochabamba. CERES. Páginas 229-247

Laserna, Roberto. 1992b. Productores de democracia. Cochabamba. CERES

Laserna, Roberto. 1996. Modernización, democracia y participación. En Ildis (Comp.): Democracia y Participación Popular. La Paz. ILDIS. Páginas 101-114

Lavaud, Jean-Pierre. 1998. El embrollo boliviano. La Paz. IFEA-CESU-HISBOL

Lazarte, Jorge. 1992. Partidos políticos e informalización de la política. En Mayorga, René (Comp.): Democracia y gobernabilidad en América Latina. Caracas. Nueva Sociedad. Páginas 63-85

Lazarte, Jorge. 1993a. Bolivia; certezas e incertidumbres de la democracia. La Paz. Los amigos del libro

Lazarte, Jorge. 1993b. Partidos, democracia y problemas de representación e informalización de la política. En Lazarte, Jorge (Comp.): Bolivia: certezas e incertidumbres de la democracia. La Paz. Los amigos del libro. Páginas 173-223

Lechner, Norbert. 1988. La crisis del Estado en América Latina. México. Siglo XXI

Levine, Daniel y José Molina. 2007. La calidad de la democracia en América Latina: una visión comparada. En América Latina Hoy. 45, Páginas 17-46

Levitsky, Steven y Lucan Way. 2002. The Rise of Competitive Autoritarianism. En Journal of Democracy. 13, 2. Páginas 51-65

Lijphart, Arend. 1969. Consociational Democracy. En World Politics. 21, 2. Páginas 207-225

Lijphart, Arend. 1971. Comparative Politics and the Comparative Method. En The American

Political Science Review. 65, 3. Páginas 682-693

Lijphart, Arend. 1989. Democracia en las sociedades plurales. Buenos Aires. Grupo Editor Latinoamericano

Lijphart, Arend. 2000. Modelos de democracia. Barcelona. Ariel

Linke, Lilo. 1962 (1954). Ecuador. Londres. Oxford University Press

Linz, Juan. 1987. La quiebra de las democracias. Madrid. Alianza 
Linz, Juan. 1993. Los peligros del presidencialismo. En Juristas, Comisión Andina De (Comp.): Formas de gobierno: relaciones Ejecutivo-Parlamento. Lima. CAJ. Páginas

Linz, Juan. 1996. Las virtudes del parlamentarismo. En Diamond, Larry y Mark F. Plattner (Comp.): El resurgimiento global de la democracia. México. UNAM. Páginas 133-140

Linz, Juan. 1998. Los problemas de las democracias y la diversidad de las democracias. En Vallespín, Fernando y Rafael Del Águila (Comp.): La democracia en sus textos. Madrid. Alianza. Páginas 225-266

Linz, Juan. 2000. Totalitarian and Authoritarian Regimes. Boulder. Lynne Rienner

Linz, Juan y Alfred Stepan. 1996. Hacia la consolidación democrática. En La política. 2. Páginas 29-49

Linz, Juan y Arturo Valenzuela (Comp.). 1994. The Failure of Presidential Democracy. Baltimore. Johns Hopkins University Press

Lipset, Seymour M. 1959. Some Social Requisites of Democracy: Economic Development and Political Legitimacy. En The American Political Science Review. 53, 1. Páginas 69-105

Lipset, Seymour M. 1980. E1 hombre político. Madrid. Tecnos

Lipset, Seymour M. 1996. Repensando los requisitos sociales de la democracia. En La política. 2. Páginas 51-87

Lipset, Seymour M. y Stein Rokkan. 1967. Cleavage Structures, Party Systems, and Voter Aligments: An Introduction. En Lipset, Seymour M. y Stein Rokkan (Comp.): Party Systems, and Voter Aligments. New York. The Free Press. Páginas 1-64

Lissidini, Alicia. 2008. Democracia directa en Latinoamérica: entre la delegación y la participación. En Pachano, Simón (Comp.): Temas actuales y tendencias en la ciencia política. Quito. Flacso. Páginas 89-147

Locke, John. 1983. Ensayo sobre el gobierno civil. Barcelona. Orbis

Londregan, John B. y Keith T. Poole. 1996. Does High Income Promote Democracy? En World Politics. 49, Páginas 1-30

Lynch, Nicolás. 1999. Una tragedia sin héroes. La derrota de los partidos y el origen de los independientes. Perú 1980-1992. Lima. Universidad de San Marcos

Mahoney, James. 2001. Path Dependence Explanations of Regime Change: Central America in Comparative Perspective. En Studies in Comparative International Development. 36, 1. Páginas 111-141

Maiguashca, Juan. 1991. Los sectores subalternos en los años 30 y el aparecimiento del velasquismo. En Thorp, Rosemary (Comp.): La crisis en el Ecuador: los treinta y ochenta. Quito. Corporación Editora Nacional. Páginas 79-93

Mainwaring, Scott. 1992. Transitions to Democracy and Democratic Consolidation: Theoretical and Comparative Issues. En Mainwaring, Scott, Guillermo O`Donnell y Samuel Valenzuela (Comp.): Issues in Democratic Consolidation: The New South American Democracies. Indiana. Kellogg Institute. Páginas 294-342

Mainwaring, Scott, Ana María Bejarano y Eduardo Pizarro (Comp.). 2006. The Crisis of Democratic Representation in the Andes. Stanford. Stanford University Press

Mainwaring, Scott, Daniel Brinks y Aníbal Pérez Liñán. 2001. Classifying Political Regimes in Latin America, 1945-1999. En Studies in Comparative International

Development. 36, 1. Páginas 37-65

Mainwaring, Scott y Mark P Jones. 2003. The Nationalization of Parties and Party Systems. An Empirical Measure and Application to the Americas. En Party Politics. 9, 2. Páginas 139-166

Mainwaring, Scott y Aníbal Pérez Liñán. 2004. Nivel de desarrollo y democracia: el excepcionalismo latinoamericano. En América Latina Hoy. 36. Páginas 189-248 
Mainwaring, Scott y Aníbal Pérez Liñán. 2008. Latin American Democratization since 1978. En Hagopian, Frances y Scott Mainwaring (Comp.): The Third Wave of Democratization in Latin America. New Yor. Cambridge University Press. Páginas 14-59

Mainwaring, Scott y Timothy Scully. 1995. Introduction: Party Systems in Latin America. En Mainwaring, Scott y Timothy Scully (Comp.): Building Democratic Institutions. Party Systems in Latin America. Stanford. Stanford University Press. Páginas 1-34

Mainwaring, Scott y Matthew Shugart. 1997. Juan Lin₹, Presidentialism, and Democracy: Critical Appraisal. En Comparative Politics. 29, 4. Páginas 449-471

Mainwaring, Scott y Matthew Shugart (Comp.). 2002. Presidencialismo y democracia en América Latina. Buenos Aires. Paidós

Malloy, James. 1992. El problema de la gobernabilidad en Bolivia, Perú y Ecuador. En Mayorga, René (Comp.): Democracia y gobernabilidad en América Latina. Caracas. Nueva Sociedad. Páginas 131-147

Manin, Bernard. 1998. Los principios del gobierno representativo. Madrid. Alianza editorial

Manin, Bernard, Adam Przeworski y Susan Stokes. 1999. Introduction. En Manin, Bernard, Adam Przeworski y Susan Stokes (Comp.): Democracy, Accountability, and

Representation. Cambridge. Cambridge University Press. Páginas 1-26

Maravall, José María. 1999. Accountability and Manipulation. En Przeworski, Adam, Susan Stokes y Bernard Manin (Comp.): Democracy, Accountability, and

Representation. New York. Cambridge University Press. Páginas 154-196

Maravall, José María. 2003. El control de los políticos. Madrid. Taurus

March, James G. y Johann Olsen. 1989. Rediscovering Institutions. The Organizational Basis of Politics. New York. Free Press

March, James G. y Olsen Johan P. 1984. The New Institutionalism: Organizational Factors in Political Life. En The American Political Science Review. 78, 3. Páginas 734749

Marcus-Delgado, Jane. 2001. El fin de Alberto Fujimori: un estudio de legitimidad presidencial. En Tanaka, Martín y Jane Marcus-Delgado (Comp.): Lecciones del final del fujimorismo. Lima. IEP. Páginas 9-55

Mariátegui, José Carlos. 1975. Siete ensayos de interpretación de la realidad peruana. La Habana. Casa de las Américas [primera edición: 1928]

Marshall, Thomas. 2007. Ciudadanía y clase social. En Marshall, Thomas y Tom Bottomore (Comp.): Ciudadanía y clase social. Madrid. Alianza. Páginas 15-82 [primera edición: 1950]

Martí, Salvador. 2008. Elecciones de 2006 en Nicaragua: el regreso del FSLN al poder. En Alcántara, Manuel y Fátima García Díez (Comp.): Elecciones y política en América Latina. México. IEEM. Páginas 293-327

Mayorga, René (Comp.). 1991a. ¿De la anomia política al orden democrático? La Paz. Cebem

Mayorga, René. 1991b. Empate histórico y debilidad constructiva: la crisis del proceso de democratización (1978-1990). En Mayorga, René (Comp.): ¿De la anomia política al orden democrático? La Paz. Cebem. Páginas 19-56

Mayorga, René (Comp.). 1992. Democracia y gobernabilidad en América Latina. Caracas. Nueva Sociedad

Mayorga, René. 1994. Sistema político, Estado y Fuerzas Armadas: consolidación de la democracia y redefinición del rol militar en América Latina. En Mayorga, René y Raúl Barrios

(Comp.): La cuestión militar en cuestión. La Paz. Cebem. Páginas 11-70

Mayorga, René. 1998. Antipolítica y neopopulismo. La Paz. CEBEM 
Mayorga, René. 1999. Los diputados uninominales: problemas y redefinición de su rol parlamentario. La Paz. Ministerio de Desarrllo Sostenible

Mayorga, René. 2003. Presidencialismo parlamentarizado y gobiernos de coalición en Bolivia. En Lanzaro, Jorge (Comp.): Tipos de presidencialismo y coaliciones políticas en América Latina. Buenos Aires. CLACSO. Páginas 101-135

Mayorga, René. 2004. La crisis del sistema de partidos politicos: causas y consecuencias. Caso Bolivia. En Roncagliolo, Rafael (Comp.): Partidos políticos en la Región Andina: entre la crisis y el cambio. Lima. IDEA-Ágora. Páginas 27-49

Mayorga, René. 2005. Bolivia: sistema electoral y transformaciones politicas. En Vélez, Rubén (Comp.): Sistemas electorales andinos. Bogotá. Parlamento Andino. Páginas 141

Mcclintock, Cynthia. 1997. La voluntad politica presidencial y la ruptura constitucional de 1992 en el Perú. En Tuesta, Fernando (Comp.): Los enigmas del poder. Fujimori 19901996. Lima. Fundación Friedrich Ebert. Páginas 53-74

Mcclintock, Cynthia. 2008. An Unlikely Comeback in Peru. En Diamond, Larry, Mark F. Plattner y Diego Abente (Comp.): Latin America's Struggle for Democracy. Baltimore. The Johns Hopkins University Press. Páginas 154-168

Mejía, Andrés. 2002. Gobernabilidad democrática. Quito. Fundación Konrad Adenauer

Mejía, Andrés. 2004. La reelección legislativa en Ecuador: conexión electoral, carreras legislativas y partidos políticos (1979-1998). En Ecuador Debate. 62. Páginas 251-270

Mejía, Andrés, Caridad Araujo, Aníbal Pérez Liñán, Sebastián Saiegh y Simón Pachano. 2004. Political Institutions, Policymaking Processes, and Policy Outcomes in Ecuador. Ponencia presentada en el seminario: Political Institutions, Policymaking Processes, and Policy Outcomes. Boston

Mejía, Andrés, Flavia Freidenberg y Simón Pachano. 2005. La ciencia política en Ecuador: un reflejo de su fragilidad democrática. En Revista de Ciencia Política. 25, 1. Páginas 147-161

Meléndez, Carlos. 2007a. Análisis comparado de las agrupaciones políticas de los Países Andinos. En Roncagliolo, Rafael y Carlos Meléndez (Comp.): La política por dentro. Lima. Ágora Democrática-IDEA-Transparencia. Páginas 41-74

Meléndez, Carlos. 2007b. Partidos y sistema de partidos en el Perú. En Roncagliolo, Rafael y Carlos Meléndez (Comp.): La política por dentro. Lima. Ágora DemocráticaIDEA-Transparencia. Páginas 213-271

Méndez, Juan. 2002. Problemas de violencia ilegal: una introducción. En O`Donnell, Guillermo, Juan Méndez y Paulo Pinheiro (Comp.): La (in)efectividad de la ley y la exclusión en América Latina. Buenos Aires. Paidós. Páginas 31-36

Menéndez, Amparo. 1986. La conquista del voto. Quito. Corporación Editora Nacional

Menéndez, Amparo. 1991. Introducción. En Menéndez, Amparo (Comp.): Ecuador. La democracia esquiva. Quito. Ildis. Páginas 9-29

Mill, John Stuart. 1991. Sobre la libertad. México. Gernika

Mills, Nick. 1984. Crisis, conflicto y consenso. Quito. Corporación Editora Nacional

Molina, José Enrique. 2003a. Izquierda y estabilidad de la democracia en América Latina: la ideología de la Revolución Bolivariana y su repercusión sobre el proceso político en Venezuela y América Latina. En América Latina Hoy. 35. Páginas 169-198

Molina, José Enrique. 2003b. Venezuela. En Alcántara, Manuel y Flavia Freidenberg (Comp.): Partidos políticos de América Latina. Países andinos. México. Fondo de Cultura Económica. Páginas 487-496

Montesquieu, Charles. 1987. Del espíritu de las leyes. Madrid. Tecnos 
Montúfar, César. 2000. La reconstrucción neoliberal. Febres Cordero o la estatización del neoliberalismo en Ecuador 1984-1988. Quito. Abya Yala

Moore, Barrington. 1973. Los orígenes sociales de la dictadura y de la democracia. Barcelona. Península

Morgenstern, Scott y Stephen Swindle. 2005. Are Politics Local? An Analysis of Voting Patterns in 23 Democracies. En Comparative Political Studies. 38, 2. Páginas 143170

Morlino, Leonardo. 1985. Cómo cambian los regímenes políticos. Madrid. Centro de Estudios Políticos y Constitucionales

Morlino, Leonardo. 2004. What is a "Good" Democracy. En Democratization. 11, 5. Páginas 10-32

Morlino, Leonardo. 2007. Explicar la calidad democrática: ¿qué tan relevantes son las tradiciones autoritarias? En Revista de Ciencia Política. 27, 2. Páginas 3-32

Mozaffar, Shaheen, James Scarritt y Glen Galaich. 2003. Electoral Institutions, Ethnopolitical Cleavages, and Party Systems in Africa's Emerging Democracies. En American Political Science Review. 97, 3. Páginas 379-390

Munck, Gerardo. 1996. La democratización en perspectiva comparada. El debate contemporáneo. En Desarrollo Económico. 36, 142. Páginas 661-676

Munck, Gerardo. 2006. Monitoreando la democracia: profundizando un consenso emergente. En Revista de Ciencia Política. 26, 1. Páginas 158-168

Munck, Gerardo (Comp.). 2007a. Regimes and Democracy in Latin America. Theories and Methods. New York. Oxford University Press

Munck, Gerardo. 2007b. The Study of Politics and Democracy: Touchstones of a Research Agenda. En Munck, Gerardo (Comp.): Regimes and Democracy in Latin America. Theories and Methods. New York. Oxford University Press. Páginas 25-37

Munck, Gerardo. 2009. Measurng Democracy. A Bridge Between Scholarship and Politics. Baltimore. The Johns Hopkins University Press

Munck, Gerardo y Jay Verkuilen. 2002. Conceptualizing and Measuring Democracy. Evaluating Alternative Indices. En Comparative Political Studies. 35, 1. Páginas 5-34

Murakami, Yusuke. 2007. Perú en la era del Chino. Lima. IEP-CIAS

Nohlen, Dieter. 1993. Sistemas electorales de América Latina. Lima. Fundación Friedrich Ebert

Nohlen, Dieter. 1995. Elecciones y sistemas electorales. Caracas. Nueva Sociedad

Nohlen, Dieter y Bernhard Thibaut. 1994. La transición en América Latina: enfoques, conceptos, tesis. En Boletín Electoral Latinoamericano. 12. Páginas 101-146

Nun, José. 2002. Democracia ¿Gobierno del pueblo o gobierno de los políticos? Buenos Aires. Fondo de Cultura Económica

O`Donnell, Guillermo. 1979. Notas para el estudio de procesos de democratización politica a partir del estado burocrático autoritario. CEDES, Buenos Aires. Estudios CEDES \# 5.

O`Donnell, Guillermo. 1992. ¿Democracia delegativa? En Cuadernos del CLAEH. 17, 1. Páginas 6-20

O`Donnell, Guillermo. 1993. Estado, democratización y ciudadanía. En Nueva Sociedad. 128. Páginas $62-87$

O`Donnell, Guillermo. 1996a. Ilusiones sobre la consolidación. En Nueva Sociedad. 144. Páginas 70-89

O`Donnell, Guillermo. 1996b. Ilusiones y errores conceptuales. En La política. 2. Páginas 129-139

O`Donnell, Guillermo. 1996c. Otra institucionalización. En La política. 2. Páginas 5-27

O`Donnell, Guillermo. 1999. Democratic Theory and Comparative Politics. Department of Government University of Notre Dame. Working Paper Vol. 99, \# 7. 
O`Donnell, Guillermo. 2000. The Judiciary and the Rule of Law. En Journal of Democracy. 11, 1. Páginas 25-31

O`Donnell, Guillermo y Philippe Schmitter. 1994. Transiciones desde un gobierno autoritario. Volumen 4: Conclusiones tentativas sobre las democracias inciertas. Buenos Aires. Paidós

Oszlak, Oscar. 1978. Formación histórica del estado en América Latina: elementos teóricometodológicos para su estudio. CEDES, Buenos Aires. Estudios CEDES \# 3.

Pachano, Simón. 1993. Imagen, identidad, desigualdad. En Cornejo, Diego (Comp.): Los indios y el Estado-país. Quito. Abya-Yala. Páginas 171-189

Pachano, Simón. 1996. Democracia sin sociedad. Quito. ILDIS

Pachano, Simón. 2000. Representación, clientelismo y corporativismo en Ecuador. En Cañete, Fernanda (Comp.): La crisis ecuatoriana: sus bloqueos económicos, políticos y sociales. Quito. CEDIME. Páginas 131-157

Pachano, Simón. 2001. Partidos y clientelismo en Ecuador. En Quórum. 2. Páginas 21-39

Pachano, Simón. 2003a. El tejido de Penelope. En Hofmeister, Wlhelm (Comp.): Reforma política en América Latina. Río de Janeiro. Fundación Konrad Adenauer. Páginas 207-242

Pachano, Simón. 2003b. Estudio introductorio. Ciudadanía e identidad. En Pachano, Simón (Comp.): Ciudadanía e identidad. Quito. Flacso. Páginas 13-63

Pachano, Simón. 2004a. El territorio de los partidos. En Roncagliolo, Rafael (Comp.): Partidos políticos en la Región Andina: entre la crisis y el cambio. Lima. IDEA. Páginas 71-91

Pachano, Simón. 2004b. Imagen, identidady desigualdad en sociedades multiétnicas. En Salvador, Martí y Josep Sanahuja (Comp.): Etinicidad, autonomías y gobernabilidad en América Latina. Salamanca. Universidad de Salamanca. Páginas 65-78

Pachano, Simón. 2004c. Partidos y representación en la Región Andina. En Roncagliolo, Rafael (Comp.): Partidos políticos en la Región Andina: entre la crisis y el cambio. Lima. IDEA. Páginas 9-25

Pachano, Simón. 2006a. Ecuador: The Provincialization of Representation. En Mainwaring, Scott, Ana María Bejarano y Eduardo Pizarro (Comp.): The Crisis of Democratica Representation in The Andes. Stanford. Stanford University Press. Páginas

Pachano, Simón. 2006b. El peso de lo institucional: ange y caída del modelo boliviano. En América Latina Hoy. 43. Páginas 15-30

Pachano, Simón. 2007. La trama de Penélope. Quito. FLACSO-Ágora DemocráticaIDEA-INMD

Pachano, Simón. 2008. Sistemas subnacionales de partidos en el Ecuador. En Carrión, Fernando y Brigitta Villaronga (Comp.): Descentralizar: un derrotero a seguir. Quito. FLACSO-INWENT-SENPLADES. Páginas 145-162

Pachano, Simón. 2009. Rafael Correa: la revolución ciudadana soy yo. En Tovar, Jesús (Comp.): Liderazgo político en América Latina. México. En prensa. Páginas

Page, Scott E. y Jenna Bednar. 2006. Cultural, Institutional Performance, and Path Dependence. Institute of Governmental Studies. University of California al Berkeley. Working Paper 2006-6.

Panebianco, Angelo. 1990. Modelos de partido. Organización y poder en los partidos políticos. Madrid. Alianza

Paramio, Ludolfo. 1999. Cambios sociales y desconfianza política: el problema de la agregación de preferencias. En Revista Española de Ciencia Política. 1, 1. Páginas 81-95 
Paramio, Ludolfo. 2006. Crisis y cambio del modelo económico. En Alcántara, Manuel, Ludolfo Paramio, Flavia Freidenberg y José Déniz (Comp.): Reformas económicas y consolidación democrática. Madrid. Editorial Síntesis. Páginas 9-44

Park, Myoungho. 2003. Sub-National Sources of Multipartism in Parliamentary Elections. Evidence from Korea. En Party Politics. 9, 4. Páginas 503-522

Parsons, Talcott. 1976. E1 sistema social. Madrid. Revista de Occidente

Payne, Mark, Daniel Zovatto, Fernando Carrillo y Andrés Allamand (Comp.). 2003. La política importa. Washington. BID-IDEA

Paz Y Miño, Juan. 2002. La Revolución Juliana. Nación, ejército y bancocracia. Quito. Abya-Yala

Pease, Henry. 1980. La crisis del Estado oligárquico. Lima. DESCO

Pease, Henry. 1999. Electores, partidos y representantes. Sistema electoral, sistema de partidos y sistema de gobierno en el Perú. Lima. PUCP

Penfold, Michael. 2001. El colapso del sistema de partidos en Venezuela: explicación de una muerte anunciada. En Carrasquero, José Vicente, Thais Maingon y Friedrich Welsh

(Comp.): Venezuela en transición: elecciones y democracia 1998-2000.

Caracas. CDP Publicaciones-RedPol. Páginas 36-51

Pérez Liñán, Aníbal. 2002. La reversión del resultado en la doble vuelta electoral: una evaluación institucional del Balotaje. Ponencia presentada en el seminario: Primer Congreso Latinoamericano de Ciencia Política. Salamanca

Peruzzotti, Enrique. 2001. The Nature of the New Argentine Democracy. The Delegative Democracy Argument Revisited. En Journal of Latin American Studies. 33, 1. Páginas 133-135

Peruzzotti, Enrique y Catalina Smulovitz. 2002. Accountability social: la otra cara del control. En Peruzzotti, Enrique y Catalina Smulovitz (Comp.): Controlando la política. Buenos Aires. Temas. Páginas 23-52

Peters, Guy. 2003. El nuevo institucionalismo. Teoría institucional en ciencia política. Barcelona. Gedisa

Pierson, Paul. 2000. Increasing Returns, Path Dependence, and the Study of Politics. En The American Political Science Review. 94, 2. Páginas 251-267

Pizarro, Eduardo. 1989. Los orígenes del movimiento armado comunista en Colombia (1949-1966). En Análisis Político. 7. Páginas 7-31

Planas, Pedro. 1997. ¿Existe un sistema de partidos en el Perú? En Tuesta, Fernando (Comp.): Los enigmas del poder. Fujimori 1990-1996. Lima. Fundación Friedrich Ebert. Páginas 169-201

Planas, Pedro. 2000a. Hacia una democracia de partidos. Propuestas para institucionalizar la política en el Perú. En Planas, Pedro (Comp.): La democracia volátil. Lima. FES. Páginas 399-415

Planas, Pedro. 2000b. La democracia volátil. Lima. FES

Planas, Pedro. 2000c. Transición democrática y reacomodo político (1978-1980). En Planas, Pedro (Comp.): La democracia volatil. Lima. FES. Páginas 139-183

Pnud. 2004. La democracia en América Latina. New York. PNUD

Portantiero, Juan Carlos. 1984a. La democratización del Estado. En Pensamiento Iberoamericano. 5. Páginas 99-126

Portantiero, Juan Carlos. 1984b. Sociedad civil, estado y sistema politico. En Vega, Juan Enrique (Comp.): Teoría y política en América Latina. México. CIDE. Páginas

Prada, Raúl. 2004. Largo octubre. La Paz. Plural

Prieto, Mercedes. 2004. Liberalismo y temor: imaginando los sujetos indígenas en el Ecuador postcolonial. Quito. Flacso 
Przeworski, Adam. 1995. Democracia y mercado. Cambridge. Cambridge University Press

Przeworski, Adam (Comp.). 1998. Democracia sustentable. Buenos Aires. Paidós

Przeworski, Adam. 1999. Democracia y representación. En Metapolítica. 3, 10. Páginas 227257

Przeworski, Adam. 2002. Accountability social en América Latina y más allá. En Peruzzotti, Enrique y Catalina Smulovitz (Comp.): Controlando la política. Buenos Aires. Temas. Páginas 73-85

Przeworski, Adam, Michael Alvarez, José A. Cheibub y Fernando Limongi. 1996. Las condiciones económicas e institucionales de la durabilidad de las democracias. En La política. 2. Páginas $89-108$

Putnam. 1993. Making Democracy Work. Princeton. Princeton University Press Quintero, Rafael. 1980. El mito del populismo en el Ecuador. Quito. FLACSO Quintero, Rafael. 2002. Entre el hastío y la participación ciudadana. Partidos y elecciones en el Ecuador (2000-2002). Quito. Abya-Yala

Quintero, Rafael. 2005. Electores contra partidos en un sistema político de mandos. Quito. Abya Yala-ILDIS

Quintero, Rafael y Erica Silva. 1990. Ecuador, una nación en ciernes. Quito. FLACSO

Rae, Douglas. 1971. The Political Consequences of Electoral Laws. New Haven. Yale University Press

Ragin, Charles. 1987. The Comparative Method. Los Angeles. University of California Press

Rawls, John. 1996. La justicia como equidad: politica, no metafísica. En La política. 1. Páginas 23-46

Remmer, Karen. 1985. Redemocratization and the Impact of Authoritarian Rule in Latin America. En Comparative Politics. 17, 3. Páginas 253-275

Remmer, Karen. 1990. Democracy and Economic Crisis: The Latin American Experience. En World Politics. 42, 3. Páginas 315-335

Remmer, Karen. 1991. New Wine or Old Bottlenecks? The Study of Latin American Democracy. En Comparative Politics. 23, 4. Páginas 479-495

Renan, Ernest. 2000. ¿Qué es una nación? En Fernández, Álvaro (Comp.): La invención de la nación. Buenos Aires. Manatial. Páginas 53-66

Riker, William. 1982. Liberalism Against Populism. Prospect Heights. Waveland Press Rodríguez, Clara Rocío y Eduardo Pizarro (Comp.). 2005. Los retos de la democracia. Viejas y nuevas formas de la política en Colombia y América Latina. Bogotá. Fundación Foro.IEPRI

Rojas, Gonzalo y Moira Zuazo. 1996. Los problemas de representatividad del sistema democrático boliviano. La Paz. ILDIS

Romero, Salvador. 1998. Las tres generaciones de partidos en el siglo XX. En Opiniones y Análisis. 30. Páginas 9-35

Romero, Salvador. 1999. Reformas, conflictos y consensos. La Paz. Fundemos Romero, Salvador. 2002. Las elecciones uninominales de 1997 a 2002. En Opiniones y Análisis. 58. Páginas 221-255

Romero, Salvador. 2003 (3a). Geografía electoral de Bolivia. La Paz. Fundemos Romero, Salvador. 2005. En la bifurcación del camino. Análisis de resultados de las elecciones municipales 2004. La Paz. Corte Nacional Electoral

Roncagliolo, Rafael y Carlos Meléndez (Comp.). 2007. La política por dentro. Lima. Ágora Democrática-IDEA-Transparencia

Rousseau, Jean Jacques. 1981. El contrato social. Madrid. EDAF 
Rueschemeyer, Dietrich. 2005. Addressing Inequality. En Diamond, Larry y Leonardo Morlino (Comp.): Assessign the Quality of Democracy. Baltimore. Johns Hopkins University Press. Páginas 47-61

Rueschemeyer, Dietrich, Evelyne Huber y John Stephens. 1992. Capitalist Development \& Democracy. Chicago. University of Chicago Press

Saideman, Stephen, David Lanoue, Michael Campenni y Samuel Stanton. 2002. Democratization, Political Institutions, and Ethnic Conflict. En Comparative Political Studies. 35, 1. Páginas 103-129

Salgado, Wilma. 2001. Dolarización: del vértigo devaluador a la pérdida de la competitividad. En Ecuador Debate. 52. Páginas 7-22

Sample, Kristen. 2005. La representación política de las mujeres en la Región Andina. En Sample, Kristen y Daniel Zovatto (Comp.): Democracia en la Región Andina, los telones de fondo. Lima. IDEA-Ágora Democrática. Páginas 119-146

Sample, Kristen y Daniel Zovatto (Comp.). 2005. Democracia en la Región Andina, los telones de fondo. Lima. IDEA

Sánchez, Francisco y Flavia Freidenberg. 1998. El proceso de incorporación de los sectores indígenas en el Ecuador: Pachakutik, un caso de estudio. En América Latina Hoy. 19. Páginas 65-79

Santana, Ciro y Héctor Pérez Brignoli. 1979. Historia económica de América Latina. Barcelona. Crítica

Sartori, Giovanni. 1970. Concept Misformation in Comparative Politics. En The American Political Science Review. 64, 4. Páginas 1033-1053

Sartori, Giovanni. 1988. Teoría de la democracia. Madrid. Alianza Editorial

Sartori, Giovanni. 1992. Partidos y sistemas de partidos. Madrid. Alianza Editorial

Sartori, Giovanni. 1996. Ingeniería Constitucional Comparada. México. Fondo de Cultura Económica

Sartori, Giovanni. 1999a. Comparación y método comparativo. En Sartori, Giovanni y Leonardo Morlino (Comp.): La comparación en las ciencias sociales. Madrid. Alianza. Páginas 29-49

Sartori, Giovanni. 1999b. Representación. En Sartori, Giovanni (Comp.): Elementos de teoría política. Madrid. Alianza. Páginas 257-277

Sartori, Giovanni. 2001. La sociedad multiétnica. Pluralismo, multiculturalismo y extranjeros. Madrid. Taurus

Schedler, Andreas. 2001. Measuring Democratic Consolidation. En Studies in Comparative International Development. 36, 1. Páginas 66-92

Schedler, Andreas. 2002. The Menu of Manuipulation. En Journal of Democracy. 13, 2. Páginas 36-50

Schmitt, Carl. 1984. El concepto de lo político. Buenos Aires. Folios

Schmitter, Philippe. 1985. La transición del gobierno autoritario a la democracia en sociedades en proceso de modernización: ¿puede invertirse la proposición (y el pesimismo) de Gino Germani? En Scartezzini, R., L. Germani y R. Gritti (Comp.): Los límites de la democracia. Buenos Aires. Páginas 143-170

Schmitter, Philippe. 2005. The Ambiguos Virtues of Accountability. En Diamond, Larry y Leonardo Morlino (Comp.): Assessign the Quality of Democracy. Baltimor. Johns Hopkins University Press. Páginas 18-31

Schmitter, Philippe y Terry Lynn Karl. 1996. Qué es... y qué no es democracia. En Diamond, Larry y Mark F. Plattner (Comp.): El resurgimiento global de la democracia. México. UNAM. Páginas 37-49

Schuldt, Jürgen. 1994. Elecciones y política económica en el Ecuador, 1983-1994. Quito. ILDIS

Schumpeter, Joseph A. 1996. Capitalismo, socialismo y democracia. Barcelona. Folio 
Shugart, Matthew y John Carey. 1992. Presidents and Assemblies: Constitutional

Design and Electoral Dinamics. Cambridge. Cambridge University Press

Shugart, Matthew y Rein Taagepera. 1989. Seats and Votes: the Effects and

Determinants of Electoral Systems. New Haven. Yale University Press

Skinner, Quentin. 2003. El nacimiento del Estado. Buenos Aires. Gorla

Smith, Peter. 2005. Democracy in Latin America. New York. Oxford University Press

Snyder, Richard y David Samuels. 2001. Devaluing the Vote in Latin America. En Journal of Democracy. 12, 1. Páginas 146-159

Stokes, Susan. 2002. Mandates and Democracy: Neoliberalism by Surprise in Latin America. Cambridge. Cambridge University Press

Taagepera, Rein y Bernard Grofman. 2003. Mapping the Indices of Seats-Votes Disproportionalty and Inter-Election Volatility. En Party Politics. 9, 6. Páginas 659677

Tamayo, Ana María. 2003. ANFASEP y la lucha por la memoria de sus desaparecidos (19832000). En Degregori, Carlos Iván (Comp.): Jamás tan cerca arremetió lo lejos. Lima. Instituto de Estudios Peruanos. Páginas

Tanaka, Martín. 1998. Los espejismos de la democracia. El colapso del sistema de partidos en el Perú. Lima. IEP

Tanaka, Martín. 2001. ¿Crónica de una muerte anunciada? Determinismo, voluntarismo, actores y poderes estructurales en el Perú, 1980-2000. En Tanaka, Martín y Jane MarcusDelgado (Comp.): Lecciones del final del Fujimorismo. Lima. Instituto de Estudios Peruanos. Páginas 57-112

Tanaka, Martín. 2002a. El asedio a la política. Los partidos latinoamericanos en la era neoliberal. Rosario. Homo Sapiens

Tanaka, Martín. 2002b. La situación de la democracia en Colombia, Perú y Venezuela. Lima. Comisión Andina de Juristas

Tanaka, Martín. 2003. La situación de la democracia en Bolivia, Chile y Ecuador a inicios de siglo. Lima. Comisión Andina de Juristas

Tanaka, Martín. 2005a. Democracia sin partidos. Lima. Instituto de Estudios Peruanos

Tanaka, Martín. 2005b. El colapso de los sistemas de partidos, autoritarismo plebiscitario y los problemas de representación democrática. En Rodríguez, Clara Rocío y Eduardo Pizarro (Comp.): Los retos de la democracia. Viejas y nuevas formas de la política en Colombia y América Latina. Bogotá. Fundación Foro-IEPRI. Páginas 55-86

Tanaka, Martín. 2005c. Los estudios políticos en Perú: ausencias, desconexión de la realidad y la necesidad de la ciencia política como disciplina. En Revista de Ciencia Política. 25, 1. Páginas 222-231

Tanaka, Martín y Jane Marcus-Delgado. 2001. Lecciones del final del fujimorismo. Lima. Instituto de Estudios Peruanos

Tapia, Luis. 2000. Condiciones, problemas y capacidad de proyecto de la representación política. En Tapia, Luis y Carlos Toranzo (Comp.): Retos y dilemas de la representación política. La Paz. PNUD. Páginas 11-50

Taylor, Charles. 2001. El multiculturalismo y 'la política del reconocimiento'. México. Fondo de Cultura Económica

Taylor, Michael y Douglas Rae. 1969. An Analysis of Crosscutting between Political Cleavages. En Comparative Politics. 1, 4. Páginas 534-547

Tenzer, Nicholas. 1991. La sociedad despolitizada. Buenos Aires. Paidós

Thelen, Kathleen. 1999. Historical Institutionalism in Comparative Politics. En Annual Review of Political Science. 2. Páginas 369-404

Thompson, Edwar P. 1979. Tradición, revuelta y conciencia de clase. Barcelona. Crítica 
Thoumi, Francisco y Marilee Grindle. 1992. La política de la economía del ajuste: la actual experiencia ecuatoriana. Quito. FLACSO

Tilly, Charles. 1992. Coersión, capital y los estados europeos, 990-1990. Madrid. Alianza

Todorov, Tzvetan. 1987. La conquista de América. La cuestión del otro. México. Siglo XXI

Toranzo, Carlos. 2000. Lógica corporativa o lógica ciudadana. En Tapia, Luis y Carlos Toranzo (Comp.): Retos y dilemas de la representación política. La Paz. PNUD. Páginas 53-88

Torre, Juan Carlos. 1998. El proceso político de las reformas económicas en América Latina. Buenos Aires. Paidós

Torres Rivas, Edelberto. 1991. Los mecanismos de la ilusión: las elecciones centroamericanas. FLACSO. Documento de trabajo \# 1.

Tsebelis, George. 2000. Veto Players and Institutional Analysis. En Governance. 13, 4. Páginas 441-474

Tsebelis, George. 2002. Veto Players. Princeton. Princeton University Press

Tuesta, Fernando. 1995a. Antecedentes históricos de la democracia y los partidos en el Perú. En Tuesta, Fernando (Comp.): Sistema de partidos políticos en el Perú. Lima. Fundación Friedrich Ebert. Páginas 29-47

Tuesta, Fernando. 1995b. Sistema de partidos políticos en el Perú. Lima. Fundación Friedrich Ebert

Tuesta, Fernando. 1999. Reglas de juego de la competencia política: el Perú y la Región Andina. En Tuesta, Fernando (Comp.): El juego político. Lima. Fundación Friederich Ebert. Páginas 21-41

Tuesta, Fernando. 2005. Sistemas electorales en la región andina. En Sample, Kristen y Daniel Zovatto (Comp.): Democracia en la Región Andina, los telones de fondo. Lima. IDEA. Páginas 171-184

Van Cott, Donna Lee. 2000a. Latin America: Constitutional Reform and Ethnic Right. En Parliamentary Affairs. 53, Páginas 41-54

Van Cott, Donna Lee. 2000b. Party System Development and Indigenous Populations in Latin America. En Party Politics. 6, 2. Páginas 155-174

Van Cott, Donna Lee. 2003. Institutional Change and Ethnic Parties in South America. En Latin American Politics and Society. 45, 2. Páginas 1-40

Van Cott, Donna Lee. 2004. Los movimientos indigenas y sus logros: la representación y el reconocimiento jurídico en los Andes. En América Latina Hoy. 36. Páginas 141-159

Varnoux, Marcelo. 2005. La ciencia política en Bolivia: entre la reforma politica y la crisis de la democracia. En Revista de Ciencia Política. 25, 1. Páginas 92-100

Verdesoto, Luis. 1994. La difícil modernización de los partidos politicos en el Ecuador. En Idis (Comp.): Democracia y desarrollo. Cuenca. IDIS. Páginas

Verdesoto, Luis. 2005. E1 proceso constituyente en Bolivia. La Paz. Plural-ILDIS Vergara, Alberto. 2007. Ni amnésicos ni irracionales. Las elecciones peruanas de 2006 en perspectiva histórica. Lima. Solar

Vich, Víctor. 2003. "Borrachos de amor": las luchas por la ciudadanía en el cancionero popular peruano. The Japan Center for Area Studies. Ocassional Paper \# 15.

Walzer, Michael. 1996. La crítica comunitarista del liberalismo. En La política. 1. Páginas 4764

Ware, Alan. 2004. Partidos políticos y sistemas de partidos. Madrid. Istmo

Weber, Max. 1972. El político y el científico. Madrid. Alianza

Weber, Max. 1977. La ética protestante y el espíritu del capitalismo. Barcelona. Península 
Weber, Max. 1984. Economía y sociedad. México. Fondo de Cultura Económica Weffort, Francisco. 1993. ¿Cuál democracia? San José. FLACSO

Whitehead, Laurence. 1988. La democratización frustrada de Bolivia, 1977-1980. En O`Donnell, Guillermo y Philippe Schmitter (Comp.): Transiciones desde un gobierno autoritario. Volumen 2. América Latina. Buenos Aires. Paidós. Páginas 79-111

Yashar, Deborah J. 2005. Contesting Citinzeship in Latin America. The Rise of Indigenous Movements and the Postliberal Challenge. New York. Cambridge University Press

Young, Oran. 1993. Sistemas de ciencia política. México. Fondo de Cultura Económica

Zakaria, Fareed. 1998. El surgimiento de la democracia iliberal. BID-Gobierno del Ecuador. Publicación ocasional. Programa de Apoyo al Sistema de Gobernabilidad Democrática.

Zavaleta, René. 1990. E1 Estado en América Latina. La Paz. Los Amigos del Libro

Zegada, María Teresa. 1996. Democratización interna de los partidos políticos en Bolivia. La Paz. ILDIS

Zegada, María Teresa. 1998. La representación territorial de los partidos políticos en Bolivia. La Paz. Friedrich Ebert Stiftung

Zielinski, Jakub. 2002. Translating Social Cleavages into Party Systems. The Significance of New Democracies. En World Politics. 54, Páginas 184-211

Zovatto, Daniel. 2005. La participación electoral en la Región Andina, 1978-2004. En Sample, Kristen y Daniel Zovatto (Comp.): Democracia en la Región Andina, los telones de fondo. Lima. Páginas 185-212 